2015-04-27

\title{
Examining Competition in Ontario's Higher Education Market
}

Farhan, Bayan Yousef

Farhan, B. Y. (2015). Examining Competition in Ontario's Higher Education Market (Unpublished doctoral thesis). University of Calgary, Calgary, AB. doi:10.11575/PRISM/26015 http://hdl.handle.net/11023/2168

Downloaded from PRISM Repository, University of Calgary 


\title{
UNIVERSITY OF CALGARY
}

Examining Competition in Ontario's Higher Education Market

\author{
by
}

Bayan Yousef Farhan

\begin{abstract}
A THESIS
SUBMITTED TO THE FACULTY OF GRADUATE STUDIES

IN PARTIAL FULFILMENT OF THE REQUIREMENTS FOR THE DEGREE OF DOCTOR OF EDUCATION
\end{abstract}

GRADUATE DIVISION OF EDUCATIONAL RESEARCH

CALGARY, ALBERTA

April, 2015

(C) Bayan Yousef Farhan 2015 


\begin{abstract}
Financial challenges have forced many publicly funded academic institutions in Ontario to adopt a corporate model and to use market tools to compete in the higher education market and maintain their enrolment and revenue levels. The adoption of costly price and non-price competitive variables creates the need to measure the effect of these variables and to examine whether or not universities have received that for which they have paid. This study has analyzed how competition affects publicly funded universities in Ontario. Competition was examined by relating universities' expenditures on price and non-price competitive variables (awards, marketing, graduates, and professors), as well as population related to the total number of applicants, total number of enrollees, and persistence ratio over the period of 2006 to 2013. The study used quantitative research design and panel data regression method to conduct the research. When examining the whole market, results show that there are positive and significant relationships between awards, marketing, population, and enrolment. Also, positive and significant relationships were observed between awards, professors, population, and total number of applicants. The result shows that awards and marketing have positive and significant effects on persistence ratio. This study also provides empirical evidence on how the effect of the adopted competitive variables varies for each university. This indicates that there are appropriate competitive variables for each publicly funded university, and that what could work for one university might not give the same results for other universities. Results provide relevant information for academic institutions on how to manage their applications and enrolment activities, and how to improve their persistence ratio.
\end{abstract}




\section{Acknowledgements}

I am greatly thankful to my supervisor Dr. Ann Calvert for her valuable guidance and support and for her timely advice and encouragement during my doctoral study. I am grateful that she always offered thoughtful feedback and suggestions. Dr. Calvert is the example that I will follow and the professor I strive to be. I also want to thank my dissertation committee members, Dr. Susan Barker and Dr. James Gaisford, who have provided useful feedback and valuable econometrics expertise. Their feedback and suggestions have helped in strengthening my dissertation. I specially want to thank Dr. James Gaisford, who sacrificed a large amount of his valuable time in reviewing and revising my statistical analysis. Also, I am grateful that I have had the opportunity to work with and learn from Dr. Ian Winchester throughout the last year of my doctoral study.

I am truly thankful to my close friend and dear husband, Dr. Mahmoud Askari, for his ongoing support and encouragement during my doctoral journey. Of course, without his love and his incredible support and encouragement, this would not have been possible. And finally, I extend my thankfulness to my sons, Muhanad Askari and Mohammed Askari who were a source of encouragement. Their inspiration and encouragement throughout the years have provided me with the needed motivation to make this accomplishment possible. 


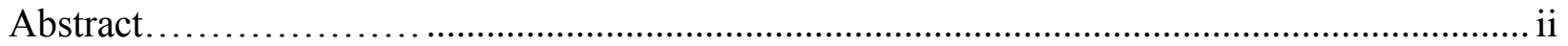

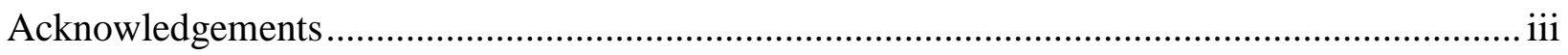

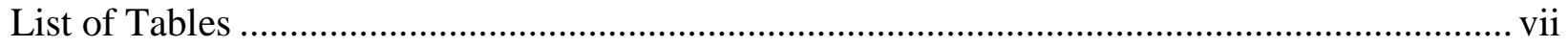

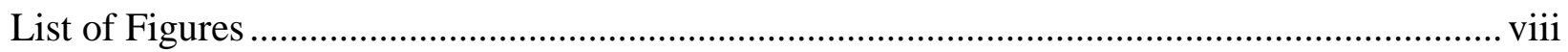

CHAPTER ONE: INTRODUCTION TO THE STUDY .................................................. 1

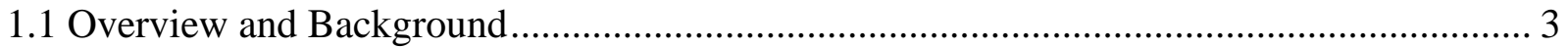

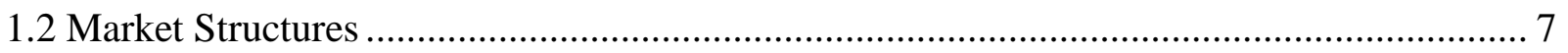

1.3 The Higher Education Market Structure in Ontario .................................................. 9

1.4 Competitive Processes in Higher Education .............................................................. 13

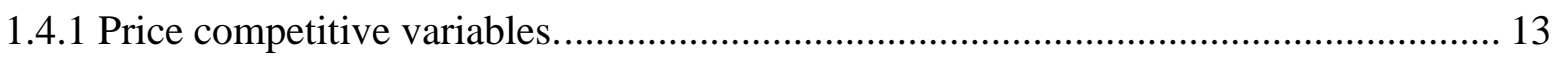

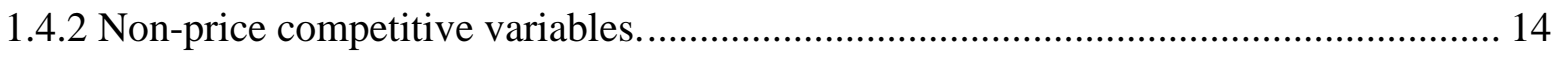

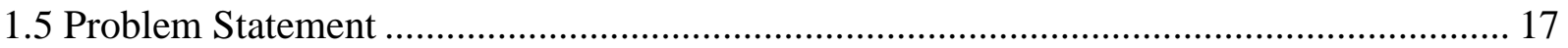

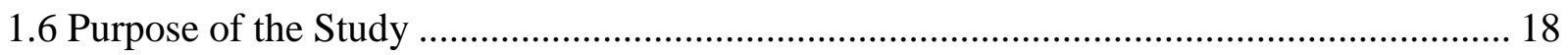

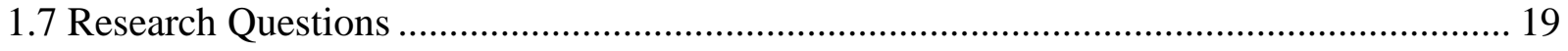

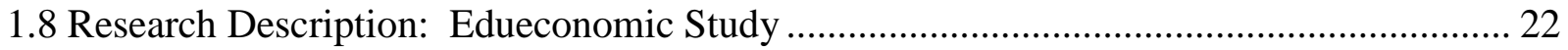

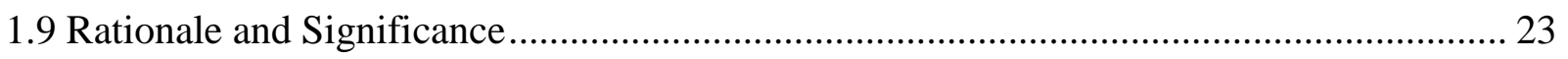

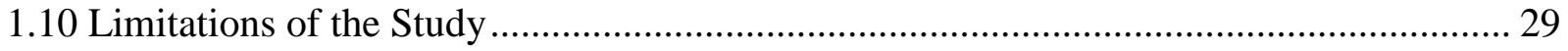

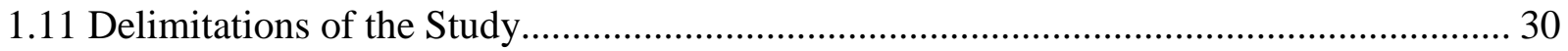

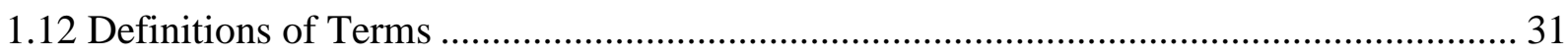

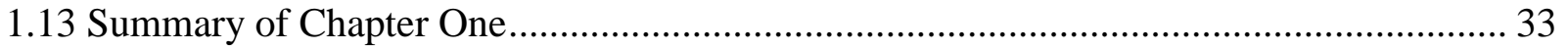

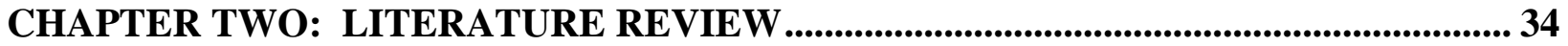

2.1 The Role of Government in Enhancing Competition ................................................. 34

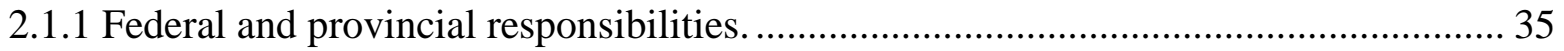

2.1.2 Neoliberal policies and competition in the market of higher education...................... 37

2.1.3 Reforming of higher education and competition............................................... 39

2.1.4 Closing remarks: A new look at publicly funded academic institutions. ................... 42

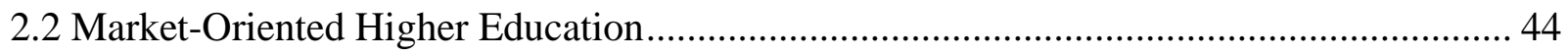

2.3 Market Structure of Higher Education .................................................................. 49

2.4 Proponent Arguments of Competition ..................................................................... 50

2.5 Opposing Arguments to Competition …............................................................ 51 


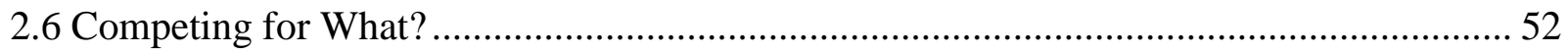

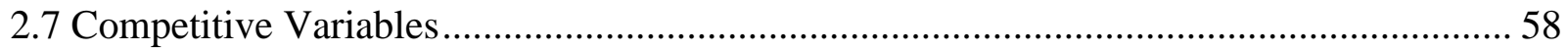

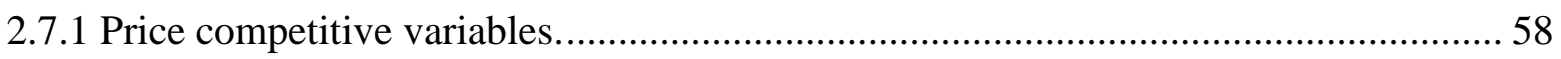

2.7.2 Non-price competitive variables................................................................................ 59

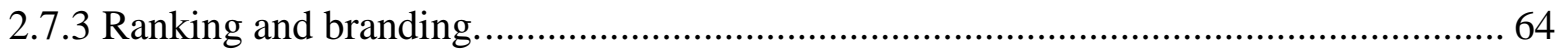

2.7.4 Proponent arguments regarding the adoption of market competitive variables......... 67

2.7.5 Opposing arguments regarding the adoption of market competitive variables. ........... 68

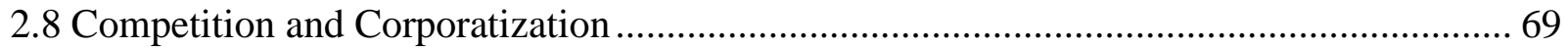

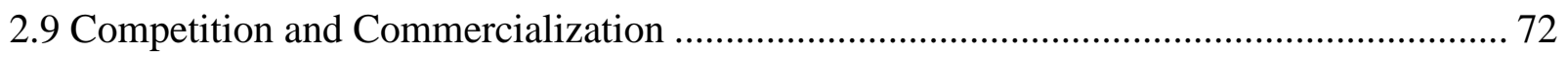

2.10 Competition and Diversity ……………………….................................................... 74

2.11 Competition and Globalization of Higher Education...................................................... 77

2.12 Competition and Autonomy of Higher Education Institutions ....................................... 82

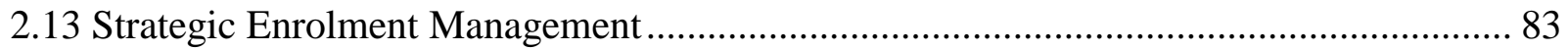

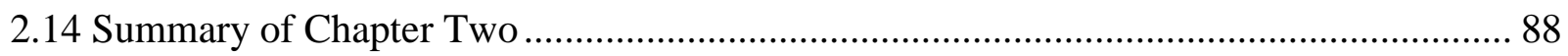

CHAPTER THREE: METHODOLOGY AND METHODS .................................................. 91

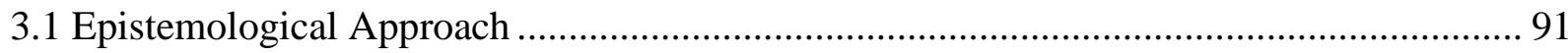

3.2 Research Methodology ............................................................................................... 93

3.3 Research Methods ...................................................................................................... 94

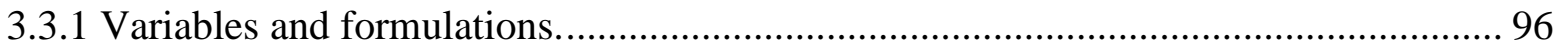

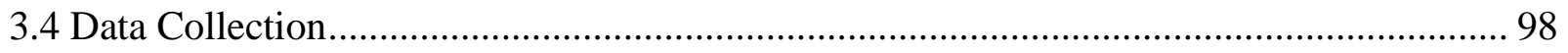

3.4.1 Evaluating the quality of collected data (panel data). ................................................. 99

3.5 Data Analysis .............................................................................................................. 103

3.6 Research Population and Sample …………………….............................................. 107

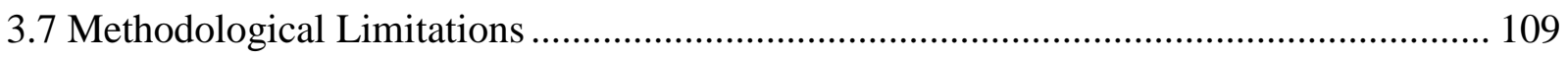

3.8 Trustworthiness, Validity, and Reliability ................................................................. 110

3.9 Ethical Considerations.............................................................................................. 112

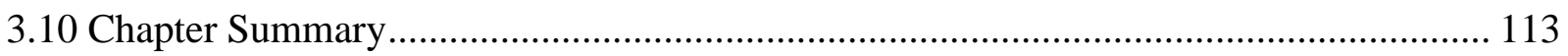

CHAPTER FOUR: DATA ANALYSIS AND FINDINGS.................................................... 114

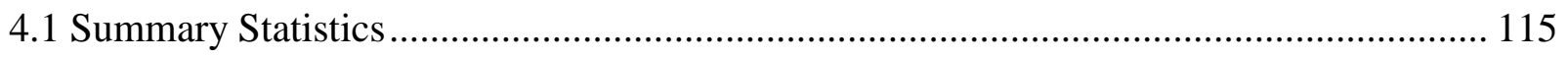

4.2 Regression Result for Sub-Question 1 ………………............................................ 117

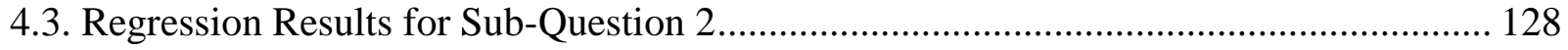


4.4. Regression Results for Sub-Question 3 ............................................................ 139

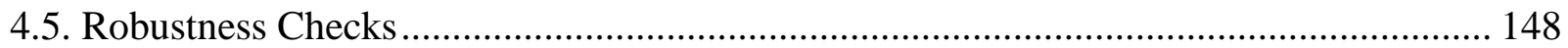

CHAPTER FIVE: DISCUSSION, RECOMMENDATIONS, AND CONCLUSION ........ 151

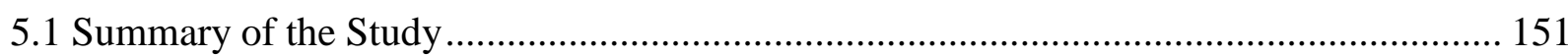

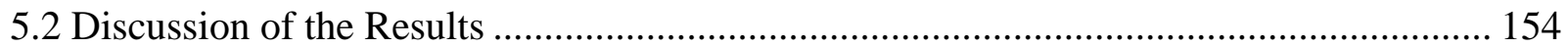

5.3 Implications for Theory, Policy, and Practice ........................................................... 161

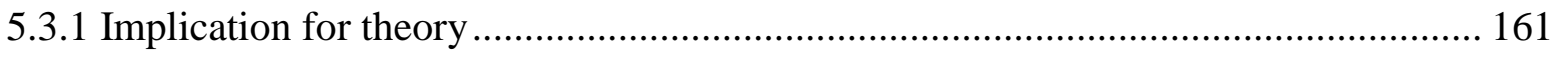

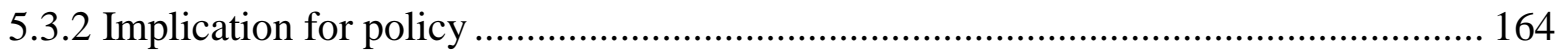

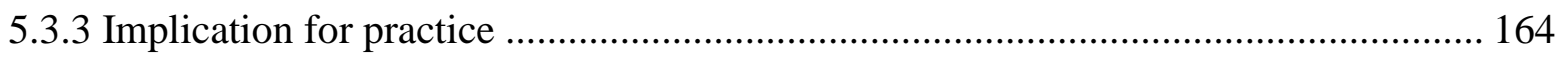

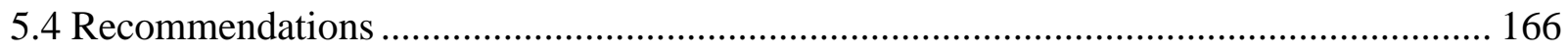

5.5 Opportunities for Future Research ...................................................................... 167

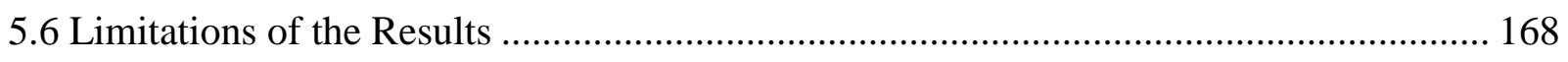

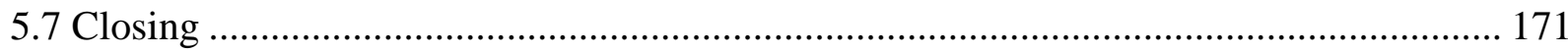

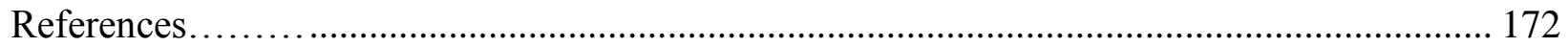

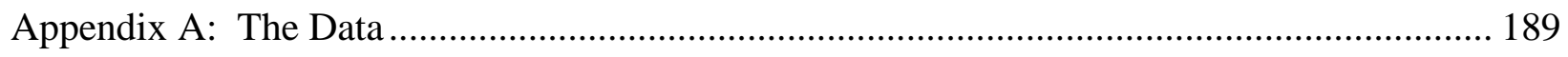

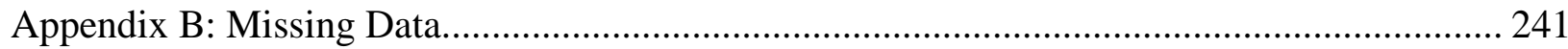

Appendix C: Testing for Heteroskedasticity .............................................................. 242

Appendix D: F-test, Breusch and Pagan LM Test, and Hausman Test ................................ 248

Appendix E: Data Analysis - Total Number of Enrolled Students (All Universities; Lagged

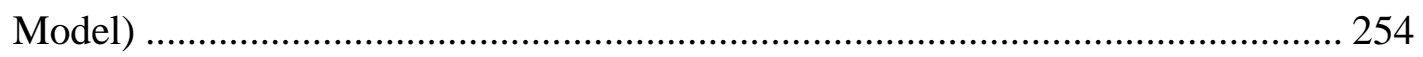

Appendix F: Data Analysis - Total Number of Applications for Admission (All Universities;

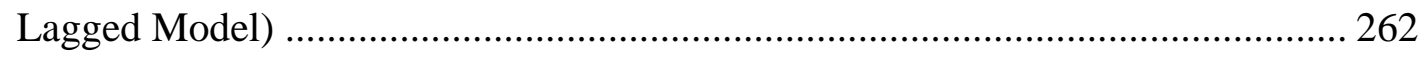

Appendix G: Data Analysis - Persistence Ratio (Lagged Model) ......................................... 270

Appendix H: Data Analysis: Robustness Checks ....................................................... 278

Appendix I: Data Analysis for Each Individual University (Enrollees: Lagged Model) ........... 300

Appendix J: Data Analysis for Each Individual University (Applications: Lagged Model) ...... 327

Appendix K: Data Analysis for Each Individual University (Persistence Ratio: Lagged Model) 


\section{List of Tables}

Table 1. Collected Data and Sources for Dependent Variables.......................................... 101

Table 2. Collected Data and Sources for Independent Variables ........................................ 101

Table 3. Collected Data and Sources for Control Variables ............................................... 102

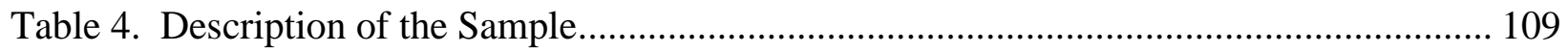

Table 5. Summary of Chapter Three............................................................................ 113

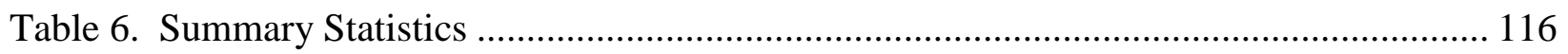

Table 7.1. Summary Results from Panel Data Regression Models for the Dependent Variable of Total Number of Enrolled Students ......................................................... 118

Table 7.2. Additional Effect on Total Number of Enrollees for Each Publicly Funded University

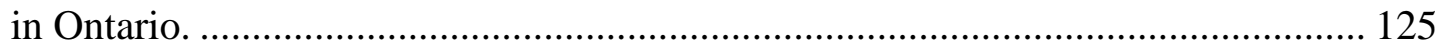

Table 8.1. Summary Results from Panel Data Regression Models for the Dependent Variable of

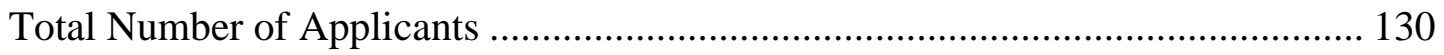

Table 8.2. Additional Effect on Total Number of Applicants for Each Publicly Funded

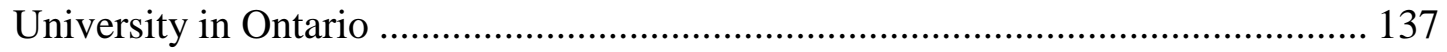

Table 9.1. Summary Results from Panel Data Regression Models for the Dependent Variable of Persistence Ratio 141

Table 9.2. Additional Effect on Persistence Ratio for Each Publicly Funded University in Ontario. 145 


\section{List of Figures}

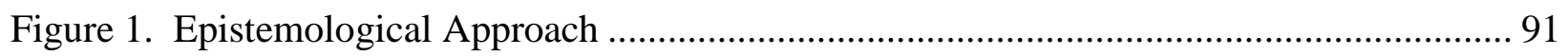

Figure 2. Empirical Results from the Fixed Effect Regression Model (Total Number of........ 122

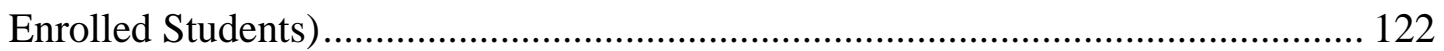

Figure 3.14. Regression Result from Fixed Effect (a modified Fixed Effect) for University of Toronto. The Effect of the Adopted Competitive Variables on Total Number of Enrollees

Figure 4. Empirical Results from Fixed Effect Model (Total Number of Applications for Admission)

Figure 5.14. Regression Result from Fixed Effect (a modified Fixed Effect regression) for University of Toronto. The Effect of the Adopted Competitive Variables on Total Number of Applicants 138

Figure 6. Empirical Results from Fixed Effect Model (Persistence Ratio) 143

Figure 7.14. Regression Result from Fixed Effect (a modified Fixed Effect regression) for University of Toronto. The effect of the Adopted Competitive Variables on Persistence Ratio. 146 


\section{CHAPTER ONE: INTRODUCTION TO THE STUDY}

Similar to many other institutions in a market economy, colleges and universities operate in their own "marketplace." Their industry (higher education) utilizes tools of the market to compete, in order to succeed and progress. Today, changes in the world's economic and political systems are affecting higher education by "making higher education a tradable commodity [and] opening national systems of post-secondary education to international competitors" (Bruneau \& Schuetze, 2004, p. 4). Indeed, these changes have ignited the competitive behaviour of academic institutions and their transformation towards the market, which has enhanced their ability to use market tools. The increasing reliance on the market has become a solution for many publicly funded universities that compensate for the drop in public funding. This market-oriented behaviour has led many academic institutions to adopt corporate and market strategies, which has in turn fuelled competition among traditional public academic institutions.

This study investigated the market of higher education in Ontario and analyzed competition and its effect on enrolment, applications for admission, and persistence ratio. The study examined enrolment levels and the number of applicants as the expected outcome of competition rather than an educational outcome. This study has dealt with competition as a management dimension and has analyzed the administrative side of universities rather than the academic side of knowledge dissemination. The study examined competition within the local market of publicly funded universities in the province of Ontario. Examining Ontario's universities is important due to the large proportion of Canadian institutions represented by Ontario in the Canadian higher education market. Also, a better understanding of the effect of competition will shed light on one of the most dynamic industries in Canada. 
This study has measured a set of competition inputs (competition variables) in relation to a set of competition outputs for each publicly funded university in Ontario's higher education market. Competition input variables are the university resources that can be used to improve its competitiveness in the market; in this study, these are universities' expenditures on price and non-price competitive variables. Competition output variables or, in other words, expected outcomes of competition, are variables for the number of applications for admission and the number of enrolled students. Besides enrollees and applicants, persistence ratio (fill ratio) was examined as a complement work to draw a clear picture regarding competition in Ontario's higher education market. Indeed, these variables are, arguably, the direct output of using market competitive variables, since price and non-price competitive variables are used mainly to attract potential customers for educational programs and services. At the same time, competitive variables can also be used for other purposes (e.g., higher ranking, brand name polishing...), but even these competition targets can be indirectly linked to attracting new applicants.

The study started by analyzing the market structure of higher education in Ontario in order to draw a clear picture of the choices of competitive variables that universities might need to compete successfully and effectively. The study examined whether or not universities' expenditure on implementing competitive variables could improve the competition's targeted outcomes of the number of applications, the number of enrolled students, and persistence ratio. Since applying market competitive variables is not without cost, this study investigated whether or not these universities get what they paid for. This analysis can help universities to explore appropriate competitive variables that fit their goals and enhance their competitiveness. This analysis has the potential to help academic leaders plan for the growth of their institutions by knowing their unique and suitable competitive variables. 
This chapter starts with an overview and background of the study, followed by a full explanation of the market structure of Ontario's higher education, and the suitable competitive variables that might be used in this market. The chapter also includes the problem statement, purpose of the study, research questions, the research description, and the rationale and the significance of the study. Limitations of the study, delimitations, and definitions of some key terms are also included in this chapter.

\subsection{Overview and Background}

Since the early 1980s, social and economic policies have been shifting from a Keynesian approach to neoliberalism (Fanelli \& Meades, 2011). Keynesians support state intervention and the use of fiscal policy as a tool to stimulate the economy and to reduce social inequalities, while neoliberals support a market approach and the importance of competition. Keynesian policies

have reduced and limited the market approach by prohibiting the commodification of health and education (Cudmore, 2005). Commodification of education, according to Cudmore, is the "process of turning education into an article of trade" (p. 44). The pressure towards neoliberalism started to increase when Keynesian policies failed to lift western countries from the deep recession of the 1980s. The Thatcher, Reagan, and Mulroney administrations of the United Kingdom, the United States, and Canada adopted and implemented neoliberal policies before any other countries around the world (Fanelli \& Meades, 2011; Fitzsimons, 2006; Jones, 2004). In reference to this, Joekes (2008) noted:

The wave was triggered in the early 1980s by political and economic shifts in key developed countries, like the United States and the United Kingdom, that favoured private over state control of assets. The wave moved to large parts of the world, as a 
condition on loans from international financial institutions and as a wider shift toward private capital. (p. 8)

It should not be surprising that neoliberalism "has become the dominant ideology and has been embraced by countries all over the world" (Jie, 2010, p. 220). Some of the key neoliberal promoted policies were: encouraging trade liberalization by removing all trade restrictions, reducing government intervention in the economy, privatizing public assets, cutting spending on social services (healthcare and education), and tax reform (Fanelli \& Meades, 2011).

The adoption of neoliberal policies (e.g., the reduction of public funds for social services) has encouraged the corporatization and marketization behaviour of publicly funded institutions such as universities (Jones, 2004). These policies have reduced the role of the state, encouraged the power of the market, and strengthened the market rules of competition, productivity, and efficiency. Strengthening the market rules of competition can be seen as a healthy phenomenon because of the resulting positive effect on price and quality of products (Martineau, 2013). In other words, "governments should not intervene in the economy ... [and a competitive] free market is the best means of inducing rapid and successful development" (Upadhyay, 2009, p. 115). But what is interesting is that encouraging the market rules of productivity, as the Competition Policy Review Panel (2008) described, may "not [be] achieved without risk, stress and cost ... [and], we cannot shy away from taking the tough decisions required to enhance productivity today because the benefits will be realized tomorrow" (p. 4).

In Canada, federal and provincial governments adopted neoliberal policies to solve their continuous budget deficit problems during the 1980s and 1990s (Fanelli \& Meades, 2011). Many federal and provincial policies have been reformed, which in turn has affected many public institutions. "Under the reforms, government policy advocates a minimal level of state 
service provision, corporatization and privatization of state businesses and other services, and a trend towards privatization of services traditionally managed in the public sector" (Fitzsimons, 2006, p. 156). In other words, the implementation of the above-mentioned neoliberal policies has affected the higher education sector and has also enhanced its competitive behaviour in order to increase its efficiency (Marginson, 2006).

Over the years, the movement towards neoliberal-oriented policies in Canada has affected funding policies of higher education. Eastman (2006) noted that public funds for higher education have declined continuously. "Between 1987-2007, the percentage of university operating budgets funded by the federal and provincial governments declined from 81 per cent to 57 per cent" (Fanelli \& Meades, 2011, p. 224). The reduction of government's financial support has created budget shortages for publicly funded universities and pushed them towards the market to create their own revenues in order to balance their budgets. Shifting from the public sphere to the market has forced universities to think about using market strategies to reduce their financial burden. In this regard, it is worthwhile to refer to Eastman (2006), who stated that "[academic] institutions depend for revenue less on the state and more on the market" (p. 59) in order to cover some of the direct and indirect costs of their educational services. Fanelli and Meades (2011) also noted that "today tuition fees [in Ontario universities] accounted for over $50 \%$ of institutional operating budgets" (p. 224). This means that using market competitive strategies to compete for students, private funds, and public funds is critical for long-term financial sustainability. One can note that due to the reduction of public funding, academic institutions find themselves in the market to solve their own urgent financial shortages. They also find themselves in a competitive situation, where they need to sustain their operations and compete to maintain growth and viability. 
In Ontario, reforming the policies of higher education, according to Jones (2004), "falls under four heads: privatization and marketization; blurring boundaries of the binary structure; institutional differentiation; and system expansion" (p. 44). In respect to this, K. Brown (2010) noted that "marketization and privatization meant increasing competition and access. ... marketization, for example, the introduction of fees for all in the public sector, with grants and loans schemes, might mean more competition and substantially more equity" (p. 139). However, in reality, as Jones stated, due to the domination of neoliberalism, Ontario universities as publicly funded institutions have experienced a deregulation of their educational policies and a huge reduction in government funding since 1995. These policies have increased the role of the market and the "university and college sectors became increasingly competitive, and competition came to imply the struggle to maximize both public and private sources of revenue" (Jones, 2004, p. 46). Overall, these neoliberal policies have forced universities towards the market and have created a new competitive environment that requires universities to improve their competitiveness.

Moreover, the recession of 2008 has forced the government of Ontario, which has suffered an approximately $\$ 18.7$ billion budget deficit, to go more towards employing neoliberal policies (e.g. cut spending on social services such as healthcare and education) as a solution to solving its financial problems (Fanelli \& Meades, 2011). It is also worth noting that communication and the technological revolution have played an important role in increasing competition in higher education. This revolution has created non-traditional competitors who are providing non-traditional programs and services (e.g., universities who provide online and distance education) and has also created non-traditional students (continuing education students) (Deschamps, 2013; Douglass, 2005). Moreover, the government of Ontario has passed a new act 
to allow more suppliers of higher education (e.g. private academic institutions) in Ontario's higher education market and that has enhanced competition (Jones, 2004). Increasing the number of providers of higher education through increasing online and distance education and expanding the private higher education institutions has led to more competition.

For any type of industry, competition does not take place in a vacuum. Different market structures exist in different industries, and the higher education industry in Ontario does, indeed, have its own market structure. It is important to explore Ontario's market structure in order to show the features that may affect the performance and the competitiveness of publicly funded universities. It is important to present the following section in this chapter to set the stage for the remaining sections in Chapter One and to connect the key arguments of this chapter. Certainly, this can also help readers to understand how universities may operate and compete successfully in a competitive market.

\subsection{Market Structures}

Understanding the different types of markets is essential in exploring the higher education market in Ontario. This exploration requires a review of the known market models to help associate Ontario's higher education industry with the appropriate model and to shed light on the characteristics of a potential model. A market is a place where buyers (demanders or consumers) and sellers (suppliers or producers) of products and services can interact with each other (James, 1991). Each market, according to Mathis and Koscianski (2002), has a set of characteristics: (a) number of sellers and buyers operating in the market; (b) a degree of product differentiation; (c) a degree of freedom to enter into and exit from the market; and (d) a degree of information available to potential customers (p. 325). Analyzing these characteristics can help in exploring the features of the higher education market in Ontario. 
This study assumes that Ontario's higher education market has some features of a monopolistic competition market. Certainly, there are other market structures (e.g., perfect competition, monopoly, oligopoly, etc.) that do not represent Ontario's higher education market. Reviewing this type of market might help in understanding the market structure of Ontario's post-secondary education and will help in highlighting its features. The target of Ontario's publicly funded universities is, certainly, not to maximize their profits - but they do find an ongoing need to maximize their private and public funds to sustain their operations. Therefore, Ontario's post-secondary market might not be consistent with the profit maximization featured in a monopolistic competition market, but it might be consistent with other features of monopolistic competition. Identifying the market structure in Ontario could also help in understanding which competitive variables could be used by publicly funded institutions to improve their competitiveness. The following paragraph highlights the potential characteristics that might match Ontario's higher education market.

Monopolistic competition "is an industry structure wherein several firms [institutions] produce slightly differentiated products but otherwise have the same characteristics as perfectly competitive firms" (Solberg, 1992, p. 570). In this market, a large number of suppliers are operating and competing. Each supplier provides differentiated products and services and has limited power to affect prices in the market. According to Lipsey and Ragan (2001), product differentiation is the key characteristic and can make this monopolistic competition market different from a perfect competition market. Even though many economists (Frank, Bernanke, Osberg, Cross, \& MacLean, 2005; Lipsey \& Ragan, 2001; Mathis \& Koscianski, 2002) have suggested that it is easy to enter or exit this market, one might argue that it is not that easy. Cauley (1968) provided a different view of this type of market structure and suggested that 
"there are at least some restrictions (mainly in the form of capital needed) upon entry into the industry and some losses connected with departure from it" (p. 248). The last feature of this type of market is related to information which is also available for all stakeholders. Therefore, one can assume that the above characteristics of monopolistic competition market structure, excluding profit maximization, may represent Ontario's higher education market for many reasons. These reasons are explained in the next section and are linked to the higher education market in Ontario.

\subsection{The Higher Education Market Structure in Ontario}

In Ontario, there are 20 publicly funded universities, 24 publicly funded colleges, and 400 private career colleges (Ministry of Training, Colleges and Universities, n.d.a). This large number of academic institutions is consistent with the first criterion of a monopolistic competition market, which is the existence of a large number of providers of products and services. In this market model, providers are located close to each other (Salvatore, 2004). Arguably, this is the case with most higher education institutions in Ontario. For example, University of Toronto, York University, Ryerson University, and some other academic institutions are located in the Greater Toronto Area. Other examples are Wilfrid Laurier University, University of Waterloo, and University of Guelph, which are also very close to each other. Carleton University and University of Ottawa are both in the city of Ottawa. This is also the case with McMaster University and Brock University, in that they are close to each other (Hamilton and St. Catharines). Also, many universities have created satellite locations in other cities. For example, McMaster University has three regional campuses in Burlington, Waterloo, and Niagara. Similarly, University of Toronto has three campuses in Toronto, Mississauga, and Scarborough. Even though some Ontario universities are located close to each other in the same 
city or located in different cities across the province, it is a fact that Ontario has a large number of academic institutions. Based on the above, one can argue that the higher education market in Ontario is consistent with the first feature of a monopolistic competition market, since there are a large number of universities operating in the market.

Program differentiation, in the case of higher education, is another feature of a monopolistic competition market and, according to Salvatore (2004), differentiated services or products "are similar but not identical and satisfy the same basic need" (p. 349). Products and services in this market "are similar enough to be called the same product but dissimilar enough that they can be sold at different prices" (Lipsey \& Ragan, 2001, p. 256). In addition, in a monopolistic competition market, each institution has specific characteristics that allow the institution to act independently and to supply differentiated products and services (Solberg, 1992). Universities in Ontario have different specific features that allow them to differentiate their programs and services. University location, brand name, or programs could be bases for differentiation.

Program differentiation, according to Weingarten and Deller (2010), can be accomplished through brand name, ranking or prestige, size of the academic institution, types of programs and services offered, and by how programs and services are provided (e.g., online or residential university). Solberg (1992) has also suggested that product differentiation can be "caused by advertising, packaging, product design, type of services, geographical location, slight differences in quality, and other attributes that alter consumers' perceptions of the product" (p. 570). Even though Solberg has described the product differentiation of a "tangible product," the same approach can be used in differentiating an academic program. Programs can be advertised, packaged with some attractive features, and designed to be convenient (e.g., online courses, 
part-time study) for customers (students). In addition, each institution, according to James (1991), can distinguish its products by using certain product characteristics of product features, location, the quality of services provided, the institution's employees and, of course, the brand name of the institution. Indeed, the above description of product differentiation processes can be noticed within Ontario's higher education market.

Ontario's market of higher education is consistent with the second feature of a monopolistic competition market. For example, as Weingarten and Deller (2010) described, the University of Ottawa and Laurentian University have differentiated their programs by offering them in both English and French. University of Toronto has differentiated its programs by its academic rank as the top Canadian university (Weingarten \& Deller, 2010). Other examples of differentiation of higher education programs can be seen in various Ontario universities. For example, the University of Waterloo has combined some of its academic programs with on-the-job training. McMaster University has differentiated itself by research excellence in medicine and health programs (Weingarten \& Deller, 2010). Moreover, "geography is a key differentiating factor that has influenced the development of some Ontario postsecondary institutions" (Weingarten \& Deller, 2010, p. 19). In fact, the Greater Toronto Area (GTA) is an "area where considerable university and college differentiation exists already" (Weingarten \& Deller, 2010, p. 19). The previous discussion clearly indicates that the Ontario market of higher education is consistent with the second feature of a monopolistic competition market.

Another feature of monopolistic competition is the nonexistence of barriers to enter or exit the market, although this does not mean the absence of some restrictions such as capital needs. The government of Ontario, as mentioned before, has passed an act to allow more suppliers of higher education (e.g., private academic institutions) in Ontario's higher education 
market (Jones, 2004). At the same time, there are some restrictions to enter into the higher education market, and the capital requirements to establish a new academic institution is one of these restrictions. At the same time, the advancement of technology might reduce physical barriers which make entry and exit into or from the market easy. For example, students can gain their master's or even doctoral degrees online from American or British institutions. Certainly, the revolution of technology and the implementation of advanced communication technology tools to provide e-learning or distance education might make it easy to enter and/or exit the market. But communication technology is still costly, and the restriction of capital needed can still apply in this case. Finally, the monopolistic competition market structure, which is the availability of information to potential customers, can also be seen in all academic institutions in Ontario. Students and parents can find and access any needed academic information by simply visiting the websites of any higher education institutions in Ontario. In addition, published ranking and league tables allow students and parents to get information on different programs and compare different universities (Pringle \& Huisman, 2011).

Based on the above, the combination of competition (many suppliers or institutions) and monopoly (product differentiation) describes the market of higher education in Ontario. Therefore, exploring the market structure in Ontario can be a guide to explaining the major competitive variables that universities may adopt to increase their competitiveness. The following section in this chapter is essential in shedding light on the key argument of competition and competitive variables in a monopolistic competition market highlighted in this study. 


\subsection{Competitive Processes in Higher Education}

The need to compete is not limited to private colleges and universities, but is also one of the normal practices of publicly funded institutions. Colleges and universities compete for many things. Among these things, according to Bradmore and Smyrnios (2009), are reputation and prestige to attract qualified researchers and faculty members, qualified students, public and private funds, and partnerships with professional organizations. Therefore, competing successfully in a higher education market requires the use of price and non-price competitive variables.

Indeed, each academic institution can employ proper competitive variables to match its own needs and its own circumstances in the market. Competing, in this case, does not necessarily mean cutting prices. According to Cauley (1968), "firms [institutions] engaged in monopolistic competition regularly do not compete with each other by cutting prices [price competitive variable]" (p. 250). He added that institutions that are operating in a monopolistic competition market can compete effectively by using non-price competitive variables, such as advertising, product differentiation, and location. The following few paragraphs provide a further explanation of both price and non-price competitive variables.

1.4.1 Price competitive variables. These variables can be used to attract potential customers who are driven by the cost of products. According to Chase, Jacobs, and Aquilano (2004), competitors who use price competitive variables could attract customers who "cannot distinguish the products of one firm from those of another" (p. 25). But some institutions, according to Thompson, Strickland III, and Gamble (2005), have used price (i.e., low price) as the main strategy to compete in the market since they have a lower input cost and have a location advantage. Similar to the competing private institutions in many industries, price competitive 
variables can be used in higher education through charging lower tuition fees or offering grants and subsidies to attract students (Davies \& Hammack, 2005). Furthermore, Davies and Hammack (2005) added that the other application of price competitive variables can be seen through offering attractive salaries to attract highly qualified professors and researchers. Based on the above, it should be clear that the adoption of several forms of price competitive variables could enhance the competitiveness of universities.

1.4.2 Non-price competitive variables. These variables can also be used to compete successfully in the market. Using non-price competitive variables, according to Salvatore (2004), is important in improving any service sector (e.g., higher education services), and also in providing new products (e.g., programs) in order to increase revenues and customer demand. The importance of using non-price competitive variables was highlighted by Cauley (1968), who argued that non-price competitive variables can play a better role than price competitive variables in a monopolistic competition market. Institutions can improve their products over time to compete and, in this case, "there is little or no price cutting in this market situation" (p. 250). However, it is important to provide more details and explanation about the processes of non-price competitive variables of product differentiation, advertising, and location in order to present the key arguments in this study.

1.4.2.1 Product differentiation. Product differentiation explains why students prefer to attend one academic institution over another (Frank et al., 2005). In other words, product differentiation can enhance the demand for a "unique product," even if similar products are offered by other competing institutions at a lower price (Frank et al., 2005). Interestingly, any organization (e.g., academic institution), according to Salvatore (2004), can change (differentiate) its product (programs) characteristics and features in order to make it more 
acceptable to and demanded by customers (students). Each university can differentiate its programs by "offering specializations unavailable at competitor institutions or specializations for which the government will provide additional subsidies" (Pringle \& Huisman, 2011, p. 50). In other words, higher education institutions need to distinguish their programs and services from those of other local and international academic institutions in order to compete in the higher education market. In this regard, K. Brown (2010) argued that the theory of market can be applied to higher education and "institutions go to considerable lengths to differentiate their educational offerings from those of their rivals" (p. 10). This argument was supported by James (1991), who stated that differentiating each product from those of other competitors in the same industry becomes a significant issue in attracting customers.

1.4.2.2 Advertising. Advertising is also an important non-price competitive variable that can be used in a higher education market. Indeed, advertising in national and international media, in newspapers, and through electronic means is a strategy used by higher education institutions. For example, many of Ontario's publicly funded universities are using YouTube to advertise their programs and educational services. Advertising provides students or demanders of academic services with valuable information about program features, locations, and other academic services. According to Frank et al. (2005), using advertising can help the institution protect itself from other competing products, and can also be used to "create product differentiation in the consumer's mind" (p. 248).

The link between advertising as a non-price competitive variable and competition itself was highlighted by many scholars. Franck and Schönfelder (2000) argued that competition can encourage universities to use advertising to show their educational quality and program features to potential demanders. Also, James (1991) suggested that advertising can enhance the 
competition and "make it easier to successfully launch new products that are close substitutes for existing products" (p. 290). In addition, offering experts (administrators and/or faculty members) as speakers in national media can also be considered as a promotion that enhances the quality of university in the public eyes.

1.4.2.3 Location. Location as a significant feature for academic institutions was highlighted in economic literature. Franck and Schönfelder (2000) suggested that while students often prefer to attend a school that is close to home, some prefer universities located in big and attractive cities. Academic institutions that are facing the problem of demand because of location may need to employ proper price and non-price competitive variables to attract more students. According to Pringle and Huisman (2011), smaller academic institutions, often located in less populated areas, have applied other competitive variables of establishing satellite campuses and online and distance education to increase the level of enrolment. In addition, universities located in large cities may have a location competitive advantage, which in turn would enhance their competitive power. The idea of location competitive advantage was explained by Pringle and Huisman, who stated that universities that have convenient public transit routes could have a competitive advantage over those that are isolated with poor transit routes or far locations. Indeed, locations are important competitive tools, and institutions located in less-populated areas may need to adopt different competitive variables from those who are located in high-populated area. For example, Laurentian University can attract both national and international students by offering the Laurentian University Global Opportunities (LUGO) program, which allows both types of students to complete some of their studies inside or outside Canada. 
Using non-price competitive variables can create what is known in the literature as monopoly market power. But this does not mean that this monopoly power is unlimited. Salvatore (2004) explained that the availability of a large number of competitors (institutions) in the monopolistic competition market can reduce their market monopoly power, and thus reduce the institutions' ability to impact the prices of their products. Pringle and Huisman (2011) studied Ontario's higher education market and stated that "the appearance of new higher education institutions erodes the monopoly that traditional institutions have had on the provision of higher education, which can limit the ability of universities and colleges to increase tuition fees" (p. 48). This means that the possibility of losing potential customers (students) to other close competitors can limit institutions' monopoly power. They also added that the amount of Ontario universities' monopoly power may differ between universities, based on the reputation and status of the university. As shown above, it can be argued that some monopoly power might exist in Ontario's higher education market, but it differs based on the institution.

The above explanation has provided detailed information about the availability of market competitive variables that could be used by academic leaders in order to improve their institutional competitiveness. The above explanation is essential, since the focus of this study is on competition in the market of higher education.

\subsection{Problem Statement}

Competition among publicly funded universities in Ontario is affecting the total number of applications for admission, the total number of enrolled students, and the persistence ratio for each individual university.

Competition among academic institutions has grown because of the growing number of academic institutions in national and international higher education markets. In the words of 
Singh (2011): "Traditional higher education institutes are facing many challenges to cope with the new emerging education providers" (p. 7). In other words, the availability of a large number of high quality academic programs with different fee levels has increased the pressure on academic institutions to adopt price and non-price competitive variables to enhance enrolment. Ontario universities, as part of this global academic market, may find themselves needing to deal with this competitive environment to maintain their enrolment and revenue levels.

According to Misra, Grimes, and Rogers (2012), competition among academic institutions might affect them in different ways, "but (will) most importantly affect costs and enrolments" (p. 1179). These affected areas are within the scope of this research, and academic institutions "are expected to do more with the same level of resources" (Marginson, 1991, p. 201), to enhance enrolment and to provide academic programs and services in an efficient way. At the same time, competition has been forcing publicly funded institutions to adopt many competitive variables that are associated with extra costs. In that respect, the adoption of costly competitive variables would create the need to measure the effect of adopting these variables. There is a need to examine how competition and the adoption of a corporate model and competitive variables by publicly funded universities can affect the number of applications for admission, the total number of enrolled students, and persistence ratio.

\subsection{Purpose of the Study}

This study aims to examine competition in Ontario's higher education market by relating universities' expenditures on price and non-price competitive variables to the number of applications for admission, the number of enrolled students, and the persistence ratio over the period of 2006 to 2013. To reach this goal, this study has analyzed the relationship between certain competition inputs (a university's resources that can be used to enhance its 
competitiveness) and their effect on the expected outcome of competition in universities (number of applicants, number of enrolled students, and persistence ratio). This study can help academic leaders make rational decisions in choosing appropriate competitive variables to suit their unique situations and to maximize the benefit of the adopted variables by enhancing the competitiveness of their academic institutions.

Developing a detailed description of competition, of universities' competitive behaviour, and of how Ontario universities can be more competitive in the market is another objective of this study. Analyzing and comparing the competitive variables used by Ontario universities can predict the appropriate competitive variables to use for the purposes of growth, development, and innovation in higher education. Also, this study can help policymakers understand the effect of competition on suppliers of higher education, and thus improve the higher education system in Ontario. In addition, this study can provide relevant information that allows academic leaders to recognize their effective competitive tools. At the same time, this study might be of interest, not solely to Ontario higher education leaders, but also to academic leaders in other provinces.

\subsection{Research Questions}

\section{How does competition affect publicly funded universities in Ontario?}

Three sub-questions were addressed to answer the main question above:

1. How do universities' expenditures on price and non-price competitive variables influence the number of enrolled students in each individual publicly funded university in Ontario?

2. How do universities' expenditures on price and non-price competitive variables influence the number of applications for admission in each individual publicly funded university in Ontario? 
3. How do universities' expenditures on price and non-price competitive variables influence the persistence ratio in each individual publicly funded university in Ontario?

Price competitive variables are examined by measuring university expenditure on scholarships and bursaries (Awards). Non-price competitive variables are examined by measuring university expenditure on communication and on other operational expenditure that includes advertising and marketing (Marketing), university expenditures on research including doctoral fellowships, research assistants, and teaching assistants (Graduates), and university expenditure on ranks including faculty members (Professors).

Choosing the above price and non-price competitive variables can be explained as follows:

1. Awards: University expenditure on scholarships and bursaries (price competitive variable) that is used to attract potential students who are driven by cost.

2. Marketing: University expenditure on communication and marketing (non-price competitive variable) that is used to attract potential students who are driven by the effect of promotion.

3. Graduates: University expenditure on research includes post-doctoral fellowships, research assistants, and teaching assistants (non-price competitive variable). Recruiting qualified researchers can contribute to differentiating the university itself and its educational programs and services from other competitors (academic institutions), and in turn is used to attract potential students.

4. Professors: University expenditure on ranks includes faculty members (non-price competitive variable). Spending on professors and recruiting qualified faculty members can contribute to university's brand name and reputation, and to 
differentiating educational programs and services. This, in turn, is used to attract potential customers (students), who are driven by differentiation of educational programs and services and academic ranks and brand names.

At the same time, this study has controlled for factors that may affect the expected outcome of competition. A control variable, as Misra et al. (2012) explained, is an "outside factor which can affect output" (p. 1180). Therefore, census population in each university location was controlled in this study. This is important, since positive or negative changes in population for a specific university location might affect the total number of enrollees and applicants. However, to answer the research sub-questions, this study has:

i. Examined the relationship between universities' expenditure on awards, marketing, graduates, professors, and the number of enrolled students, with control for population change in each university location.

ii. Examined the relationship between universities' expenditure on awards, marketing, graduates, professors, and the number of applications for admission, with control for population change in each university location.

iii. Examined the relationship between universities' expenditure on awards, marketing, graduates, professors, and the persistence ratio, with control for population change in each university location.

Answering the main research question may describe whether or not competition in Ontario's higher education market can affect the expected outcome of competition (the number of applicants, the number of enrolled students, and the persistence ratio). Indeed, universities compete to fill their capacity through attracting not only highly qualified students, but also those who have the minimum requirements to attend. Hosslar (2004) noted that "recruiting for 
survival, rather than for selectivity, has often been the norm. The struggle for income and students is not something new" (p.2). Finally, answering the main research question can serve the purpose of this study in exploring appropriate competitive variables that allow academic leaders to improve the competitiveness of their institutions in order to compete and progress effectively in the market of higher education. Indeed, academic leaders need to make their choices and take responsibility for these choices, and that could not only affect their academic institutions but also society as a whole.

\subsection{Research Description: Edueconomic Study}

This edueconomic study is based on some important theories borrowed from economics. Edueconomics is the study of education through the use of economic theories. It is the application of economics in the daily processes of higher education and the use of economic rationales to examine and analyze plans and strategies used by academic institutions. Academic leaders in publicly funded universities are dealing with economics, whether they recognize this or not. Publicly funded universities are dealing with neoliberal policies, reduction of public funds, budget shortages, market and market strategies, revenues and their generation, students as demanders for higher education, and enhancing the demand for their programs and services and all of these are economics issues.

Academic leaders have no choice but to utilize economics in managing their complicated organizations. From the suppliers' side (the institution side) of higher education, academic leaders need to master how to manage public and private funds, how and where they may spend these funds, what to do when they have shortages or surpluses of these funds, and how to attract and retain their key providers of funds (students). They also need to attract and retain faculty members and researchers and they need to compete effectively in today's tough global market. 
Certainly, "the application of economic theory of the market to the provision of higher education - seems unstoppable" (K. Brown, 2010, p. 1). In addition, academic leaders also need to make tough decisions and make trade-offs as a result of a scarcity of funding sources. According to Frank et al. (2005), economic theories can be used to examine "how people make choices under conditions of scarcity" (p. 3). Applying theories that are borrowed from economics and are related to competition and competitive behaviour can shed light on the research questions in this study.

Competition started as a result of the transformation of publicly funded universities in adopting a corporate model and using market competitive tools. Because of this transformation, it is logical to utilize economic thoughts and theories in managing higher education institutions. For example, understanding elasticity (percentage change in one variable in response to changes in another variable) is important in higher education when considering enrolment, applications, and persistence ratio. Furthermore, understanding market models, competition theories, and market competitive tools is also important, since many publicly funded universities are looking to enhance their competitiveness. Also, if the adoption of corporate style and competitive variables in higher education is somehow acceptable to academic stakeholders, then applying economic and business thoughts and theories can no longer be separated from the process of managing these institutions.

\subsection{Rationale and Significance}

Since 2005, the phenomenon of competition among Ontario's higher education institutions has surfaced due to declining public funding, which was associated with a growing demand for higher education (Pringle \& Huisman, 2011). The reduction of public funds and the need to find other sources of revenues have forced universities to operate in a new competitive 
environment and to adopt market competitive tools. Mause (2009) noted that many universities have employed marketing processes such as running advertising campaigns, creating information brochures, offering campus tours, investing in infrastructure, offering merit-based tuition discounts, investing in sports, participating in rankings, and recruiting qualified faculty and staff members to compete and to generate other sources of revenues (p. 1108). Indeed, employing these competitive variables is costly; therefore, analyzing their effects is, arguably, important for leaders of academic institutions and for policy makers.

From another point of view, Ontario universities may face another competitive challenge, since distance education has expanded and become more acceptable to students. Online and distance education provided by institutions operating in another higher education market (both national and international competitors) could attract potential students and demanders from Ontario. Indeed, globalization of higher education has increased the global providers of higher education, which could affect Ontario's higher education industry. According to Pringle and Huisman (2011), globalization of higher education has pushed Ontario universities to compete against new suppliers of higher education to protect their market shares. Certainly, increasing their domestic and global market shares is a remarkable challenge for publicly funded universities in Ontario. This can lead one to conclude that publicly funded universities in Ontario have found themselves in a new competitive educational environment that requires that they adopt some competitive variables to succeed.

While competition in the market is based on the idea of freedom (i.e., freedom from government control over quantity and price), the reduction of government funds for higher education has given universities the freedom to fill the funding gap through tuition fees and licensing of new research discoveries (Hemsley-Brown \& Oplatka, 2010). What is even more 
fascinating is that the "existing universities and colleges are becoming more private in the sense that revenue from fees and other private sources has increased substantially relative to revenue from public sources" (Ministry of Training, Colleges and Universities, n.d.b). Consequently, the market has become a solution to cover the reduction of government funding, and universities have moved towards the market to gain more income.

However, it is generally accepted that moving towards the market has increased competition and has created the problem of commercialization. This problem may arise because "increasing costs of running educational institutions and funding educational programs, coupled with decreasing government subsidies to support such costs, have made privatisation and marketization of higher education a common phenomenon throughout the world" (Susanti, 2011, p. 209). Marketization, in the words of K. Brown (2010), is "the application of economic theory of the market to the provision of higher education" (p. 1). This is possible because, as Susanti (2011) observed, moving towards the market allows for marketing higher education programs and services by offering them as products that have a price (tuition fees). This might be the case for Ontario publicly funded universities, since they have experienced the challenge of increasing the cost of providing higher education that has been associated with the reduction of public funding. This situation has forced these academic institutions to adopt market competitive variables to compete in the market to generate their needed revenue.

Another point to be stressed in this explanation is that since the reduction of public funds has become a fact of life, Ontario universities might be finding themselves under pressure to adopt market competitive activities that in turn will lead to corporatization of higher education. Martin (2009) has argued that Canadian universities have adopted a corporate model. Under this model, students become consumers, academic institutions become producers, and faculty 
members become "customer service representatives" (p. 437). The adoption of a corporate model by publicly funded universities can be noticed through recognizing these facets of "CEOstyle executive leadership; goal-driven production, output measurement and performance management ... customer focus and continuous self-evaluation" (Marginson, 2013, p. 355). At the same time, government has also played an important role in encouraging the corporate model in higher education by encouraging competition "using a mix of competitive incentives" (Marginson, 2013, p. 355). Moreover, shifting towards the market has pressured universities to improve their competitiveness and "this new era of competitiveness has created a niche for commercialization to firmly take root and blossom in institutions of higher education, forcing public policy makers to review core missions of public higher education" (Feldman, 2007, p. 14). It is possible that competition as a fact of life has reshaped Ontario universities in the $21^{\text {st }}$ century and has changed their mission to be more competitive.

The rise of competition among publicly funded universities cannot be ignored. Competition to increase market share is critical, since no academic institution can exist without a sufficient demand for its educational services. Increasing the level of enrolment and attracting national and international students have become important aims for academic leaders. Indeed, students represent another source of revenue, and also they have an important role in enhancing the quality and the reputation of academic institutions. According to Noorbakhsh and Culp (2002), competition for students as a source of revenue has increased, and managing the sensitivity of enrolment in a competitive market is essential for academic leaders. At the same time, the aim of attracting both national and international students might create tension regarding access to publicly funded universities. The national versus international student ratio is beyond 
the scope of this study. Investigating an optimal national-international student ratio could be a topic for future research.

Elasticity is a central concept in economics, but it can also be used in the post-secondary context owing to its explanation of how a change in one variable can cause a change in the other variable (Frank et al., 2005; Lipsey \& Ragan, 2001). Elasticity, in this study, can be defined as the responsiveness of enrolment, applications, and persistence ratio to changes in such competitive variables (awards, marketing, graduates, and professors). Fluctuations in applications, enrolment levels, and persistence ratio due to changes in these variables might lead to fluctuations in the revenue of an academic institution. The estimation of how enrolment, applicants, and persistence ratio might respond to changes in competitive variables is within the scope of this study. This prediction can help academic institutions choose appropriate competitive variables, since these adopted variables are not without cost. Indeed, there are other variables (e.g., job market) that might affect enrolment, applications, and persistence ratio, but the focus of this study is on competition and competitive variables that might be adopted by a university to influence enrolment, applications, and persistence ratio (e.g., awards, etc.).

In addition, knowledge of cross elasticity is important for academic leaders, since it is related directly to competitive strategies. For example, enrolment in $\mathrm{X}$ academic institution might change as a result of changes in a competitive variable (e.g., awards) in Y academic institution, if $\mathrm{X}$ and $\mathrm{Y}$ are offering comparable academic programs. Arguably, the competitive behaviour of X University can affect the demand for admission and enrolment level in $\mathrm{Y}$ University and also can affect the demand in X University itself and vice versa. Examining cross elasticity can describe, for example, how a change in Queen's competitive variable (e.g., awards) can affect the enrolment in another rival university. Therefore, academic leaders need to 
recognize the elasticity in order to enhance the competitiveness of their academic institutions and to compete effectively in the market by responding effectively to the competitive behaviour of competing universities. Furthermore, recognizing elasticity could lead to better decisions about where to allocate the universities' expenditures. However, while strategic interaction between universities might not be a situation in the Ontario post-secondary market, it might need to be considered. For example, considering strategic interaction between universities might help in predicting what a rival university might do in reaction to another university. The prediction of strategic interaction across universities in Ontario's higher education market is outside the scope of this study and the study is not going to estimate it. Even so, it is still important to measure this type of elasticity through examining how a change in a university's competitive variables (e.g., awards) might affect the behaviour of some of its rival universities. Investigating this topic is an opportunity for the future.

A final point to be made in this rationale section is that since competition among universities has become the case for all institutions, academic leaders may need to enhance the ability of their institutions to compete nationally and internationally, because competition can create winners and losers (Jones, 2004). At the institutional level (e.g., individual academic institution), "the winners are those who consistently and constantly innovate, invest wisely and adapt quickly to the ever-changing social, demographic, technological, economic and political trends and forces bearing on their industry" (Competition Policy Review Panel, 2008, p. 3). In this regard, this study may help leaders of publicly funded universities to explore strategies of competition that might allow them to succeed and progress, and also allow them to be potential winners. 


\subsection{Limitations of the Study}

The first limitation of this study is that it has only measured the effect of competition in one Canadian province. While the research results are particular to Ontario's higher education market, it is suggestive for universities in other provinces. It may still be possible to generalize the results to universities in other provinces, since whether or not these universities are in the same province or in different provinces, they still compete with each other. Another limitation of this study is its focus on the market side of the "assumed-to-be" public organizations. Analyzing the relationship between the public side and the market side of these organizations to determine if one is dominating the other is beyond the scope of this research. This study has focused only on measuring the competition phenomenon and its effect on individual universities in Ontario without going into further analysis of market versus public powers.

Another obvious limitation is the debate about government regulations and university autonomy. This study has not entered into the discussion around how Ontario universities are subject to government regulations (e.g., regulated directly by universities themselves, or by the Ontario government, or through cooperation between the universities' board members ((board of governors and academic senates)) and the government of Ontario). This study has only focused on examining the effect of competition on applications, enrolment, and persistence ratio, regardless of the government power and autonomy power of publicly funded universities.

The last limitation of this study is that there is an insufficient definition of the educational market of higher education. The debate about the absence of a pure market in higher education, and the existence of a quasi-market (which is controlled by government forces and market forces) is a specific limitation in this study (Bruce, 2006). Therefore, this study has provided an analysis of monopolistic competition markets to help in understanding the shape of Ontario's 
higher education market. Reviewing this type of market structure might be useful in highlighting how Ontario's higher education market is consistent with some characteristics of this type of market.

\subsection{Delimitations of the Study}

While there are many private and public colleges and universities in Ontario, this study has only examined the effect of competition among publicly funded universities. In other words, private and public colleges and private universities were not examined in this study, and the results can only be generalized to publicly funded universities similar to those in Ontario. Moreover, since this study has used individual university level data, the result would be linked to the university as a whole and not to specific individual faculties and departments (e.g., faculty of science or faculty of education). Another point to be made as a delimitation is that this study was mainly concerned with the domestic market of higher education and has only dealt with the effect of competition on domestic universities. Therefore, it does not deal with international markets of higher education or international academic institutions.

In addition, this study has examined competition among suppliers (universities). Studying competition and competitive actions of universities and their impact on applicants and enrollees' behaviour (demanders) is in the scope of this research study. However, this study did not go far in analyzing the effect of using competitive variables on providing equal opportunities to all qualified demanders for higher education. This study has only focused on competition across universities as suppliers of higher education and how that might affect students.

Also, this study did not deal with the quality of learning at publicly funded universities and how it might be affected as a result of adopting competition behaviour and competitive variables. The other point is that this study has not dealt with the internal and external resistance 
that might constrain universities' competitive behaviour and might also influence the choices of adopting competitive variables. Rather, this study has the potential to help academic stakeholders in investigating the effect of competition and the importance of being a competitive institution. Finally, this study did not deal with competition as an educational dimension. Instead, the study is delimited to analyzing competition as a management dimension (applications, enrolment, and persistence ratio). It is delimited to examining the competitive behaviour and the adoption of competitive tools by the administrative side of universities rather than the academic side of knowledge dissemination. This research has only focused on key expected outcomes of competition such as enrolment, applications for admission, and persistence ratio.

\subsection{Definitions of Terms}

1. Competition in higher education market: is competition between universities for gaining monetary (revenues) and non-monetary compensation (reputation and prestige).

2. Competitiveness of an academic institution: refers to the institution's ability to compete in its own market.

3. The market of higher education: the market for educational programs and services that involves potential buyers (students as demanders) and sellers (universities as providers) of higher education.

4. Demand for higher education: educational programs and services are demanded by those who are willing to buy these services and to pay their price (tuition fees).

5. Supply of higher education: all programs and services that are offered by publicly funded universities at different tuition fees. 
6. Customer of higher education: a potential demander for educational programs and services who is willing to pay for these programs and services.

7. Price of educational programs and services: the tuition fees and other fees that are paid for educational programs and services to gain skills and/or educational certification.

8. Higher education industry: a group of academic institutions that provides programs and services for potential demanders (students).

9. Market power: a power to influence prices and the supplied goods and services in a given market.

10. Market share: a university's share of the total number of students in a given academic market.

11. Monopolistic competition market: a market that is characterized by a large number of universities that provide similar but not identical educational programs.

12. Differentiated programs and services: a university differentiates itself by many features and distinguishes its programs and services from those of other universities in order to increase its competitiveness in the market.

13. Service provider (supplier): a university that is willing to offer its educational programs and services at a given price.

14. Substitute: a product or a service that has similar features of an alternative product or service and could replace it.

15. Innovation: the ability to come up with new methods, strategies, ideas, techniques, or features of a product or a service faster than other players in a given market. 


\subsection{Summary of Chapter One}

Examining and analyzing the effect of competition in publicly funded universities has been an under-researched area in higher education leadership. In Chapter One of this study, market structures were analyzed in order to determine the main features and the shape of Ontario's market of higher education. Research problem, purpose, and research questions were also highlighted. This chapter offers a deep explanation of competitive market tools that may help in understanding the competitive behaviour of Ontario universities and the potential price and non-price competitive variables that could be adopted by each institution in the higher education market. In the next chapter, an intensive review of related literature is presented and analyzed. The methods and methodology chapter (the third chapter in this study) includes further discussion of how this study was conducted. A discussion of the findings and presentation of the results are shown in Chapters Four and Five. 


\section{CHAPTER TWO: LITERATURE REVIEW}

This chapter is a review of relevant literature on competition among higher education institutions. Selected books, journal articles, government documents, and internet sources were reviewed to provide the latest and most appropriate scholars' contributions to the topic of this study. This extensive review of literature has adopted a thematic model of review that discusses key ideas and results from studies (Creswell, 2008).

While the notion of "competition" is well represented in economics literature, the subject of competition as it can be linked to higher education has recently gained academic interest. Highlighting the literature that is directly or indirectly related to this research topic is needed to provide the appropriate depth and breadth for this study. To shed light on this study, the literature review: (a) provides a critical review of the historical context of competition in higher education and the role of government in enhancing competition; (b) reviews and critiques competition and the market structure of higher education and the use of competitive variables and consequences such as corporatization, marketization, and diversity, as these topics are treated in the literature; and (c) reviews and critiques the role of other factors such as globalization, autonomy, and strategic enrolment management in higher education.

\subsection{The Role of Government in Enhancing Competition}

Because this study seeks to examine competition and its effect, it is important to start with the role of government in encouraging competition among academic institutions. Three important phases are highlighted and reviewed: federal and provincial responsibilities in relation to higher education; the adoption of neoliberal policies in higher education; and reforming higher education to enhance competition in the market of higher education. 
2.1.1 Federal and provincial responsibilities. After World War II, the Canadian government financially supported many social services (e.g., healthcare and education) in order to enhance the sustainability of these services (Axelrod, 2002). During that period, the Canadian government funded universities to meet the need for more educated people and to meet the growing demand for higher education by using an enrolment-based funding formula: "more students = more funding” (Axelrod, 2002, p. 88).

In the early 1970s, the cost of higher education was covered by public funds with a minimal role for private funds (donors) and low levels of tuition fees (Axelrod, 2002). Since the 1970s, the role of private funding for higher education has increased, and the identity and mission of Canadian universities have been changing as well. According to Axelrod (2002), in the academic year 1970-1971, public to private funding was $76 \%$ to $10 \%$ and the remaining educational cost was covered by tuition fees. In other words, at that time, the lion's share of the budgets of academic institutions was coming from public funding. But during that period, tuition fees were being charged, and these have increased over time (Woodhall, 2007). Imposing tuition fees has changed the classic way of funding to the new way of funding, in which academic institutions generate revenue by encouraging enrolment (Eastman, 2006). This means that the new strategy of tuition fees has enhanced the competition among institutions and it has become normal to see academic institutions compete for students in order to get more revenue through tuition fees (Olssen \& Peters, 2005).

In Canada, higher education is the responsibility of the 13 Canadian provinces and territories (Kirby, 2011). Publicly funded universities in Ontario are the responsibility of the province, and competition among these types of universities has been encouraged by the government of Ontario. According to Young (2002), in 1996, a new funding program was 
announced by the Ontario minister of finance, who stated that "each dollar raised by the colleges and universities within a specified time period would qualify for matching funds from the province" (p. 94). As argued by Young, it seems that the program has enhanced competition among Ontario universities to recruit more students in order to increase their tuition revenue and also to compete for donors and for private funds from businesses and industries to gain more revenue.

At the same time, in 1998, the government of Ontario provided millions of dollars to encourage universities to increase their capacity by $100 \%$ in information technology (IT) and computer science programs (Young, 2002). This new policy offered extra infrastructure funding to serve the purpose of increasing capacity, and raised funding from $\$ 150$ million to $\$ 228$ million in 1998 with some conditions. According to Young:

The \$228 million ATOP [Access to Opportunities Program] fund was allocated among universities using two main criteria: (1) a university's share would be based on its share of IT programs enrolment, and (2) that universities successfully raise the equivalent of their matching dollar share from the private sector before April 1999. (p. 97)

These two criteria describe how the provincial government has fuelled the competition among publicly funded universities in order to fill to the new capacity and to match the conditionality. In this regard, it is worthwhile to refer to the Higher Education Quality Council of Ontario (HEQCO) Performance Indicators Project (2012), where it is noted that increasing capacity has been an important policy over the last ten years. The Ontario government has "set a policy objective of achieving a 70\% postsecondary attainment rate and has established funding incentives to promote higher enrolments" (p. 6). Kirby (2011) also added that "in response to the 2005 review of higher education in Ontario, the province committed to providing universities 
with a total of $\$ 222$ million in additional funds annually to create 15,000 new spaces in doctoral and master degree programs" (p. 271). This financial support was challenged by Teixeira (2006), who suggested this extra money "was supposed to provide institutions with an enhanced capacity to face financial stringencies and new demands" (p.16). In other words, increasing the number of seats available may increase the competition among Ontario universities to fill this excess capacity in each institution.

It could also be argued that filling the capacity by recruiting domestic and foreign students has further value. This value was highlighted by Eastman (2006) who stressed that publicly funded universities have recruited domestic and foreign students for the extra revenues, which has also boosted the competition. In this regard, it is important to mention that in December 20, 2013, the government of Ontario released the "Major Capacity Expansion Policy Framework," which requires each public academic institution to provide its own expansion proposal (Ministry of Training, Colleges and Universities, 2013). Expansion capacity can also serve the same purpose of enhancing competition among publicly funded universities to fill this excess capacity and to gain private revenue that in turn would encourage the "reliance upon private sources of income, namely through tuition" (Metcalfe, 2010, p. 509). Certainly, it is clear from the above discussion that the government of Ontario is responsible for publicly funded universities and has played an important role in enhancing competition among them.

\subsubsection{Neoliberal policies and competition in the market of higher education.}

Neoliberalism affected the economic and political discourse in western countries when a Keynesian demand-driven approach became unable to solve the problem of stagflation in the mid-1970s and the problem of budget deficits in the 1980s (Axelrod, 2002; Olssen \& Peters, 2005). Neoliberal policies have encouraged the idea of the marketization of the public sector and 
have reintroduced the market economy system (Olssen \& Peters, 2005). Neoliberalism and its market economy have promoted the search for efficiencies and the freedom to choose (Bruce, 2006). In addition, neoliberalism has introduced a new perspective regarding the role of the state "in creating the appropriate market by providing the conditions, laws and institutions necessary for its operation" (Olssen \& Peters, 2005, p. 315). In other words, this new role of government has encouraged the market power and autonomy from government control, and that in turn can fuel competition in the market.

In Canada, the first step towards neoliberalism appeared in the 1980s. The change was motivated by both federal and provincial government's budget deficits (Axelrod, 2002). Expenditure pressures have encouraged government's adoption of neoliberal policies and have supported the idea of funding cuts for social services while allowing the private sector to fill the funding gap (Axelrod, 2002). Neoliberal policies are in favour of a market model for higher education and that was, according to Axelrod, a strong reason for the existence of competition among academic institutions. Indeed, the adoption of neoliberal policies, including the reduction of government funding for higher education, created funding shortages that were covered by private sources. This encouraged publicly funded universities to move towards the market for more private funds (e.g., students and donors) (Axelrod, 2002). According to Axelrod, the problem of funding cuts was solved by "the movement by universities toward the market to secure external funds" (p. 92). In other words, each Canadian university became responsible for balancing its own budget by depending on the market to solve its funding problem. However, this new responsibility strengthened the move towards a market system in higher education and also fuelled competition. 
The competition among publicly funded universities is strongly linked to the adoption of neoliberal policies. During periods of budget shortages, governments, according to Feldman (2007), reduce their spending on higher education while maintaining other spending priorities such as spending on primary and secondary education and on healthcare. Feldman suggested that the reduction of public funds for higher education might not come with a political price for governments when compared with the reduction of funds to healthcare or primary education. Most certainly, government's priorities sound like a good excuse to force higher education institutions towards the market in order to generate their need for operational funds. Indeed, this can also explain how competition has been encouraged among publicly funded institutions using the argument that each university should compete to generate its own revenue.

Finally, it is worthwhile to refer to Lolich (2011), who underlined that under a neoliberal umbrella, there is no choice but to agree that education "has become a product in which the student decides to invest ... [and] marketization has become a new universal theme in HE” (p. 280). In other words, students are free to choose and "consume" courses that might increase their utility, enhance their employability, and allow them to enter and meet the needs of the labour market. However, in reality, students are seen as free consumers and also as independent learners (Lolich, 2011). Indeed, neoliberal policies and their effect on both academic institutions and students have enhanced competition in the market of higher education.

2.1.3 Reforming of higher education and competition. This section explains how reforming higher education can enhance competition among post-secondary institutions. It is also important to highlight the vision of the ministry of higher education in Ontario (Ministry of Training, Colleges and Universities), since the first step towards the change began with a new vision. The vision is that "Ontario will have the most educated people and highly skilled 
workforce in the world to build the province's competitive advantage and quality of life" (Ministry of Training, Colleges and Universities, n.d.c). In other words, highly skilled and educated people are the competitive advantage for Ontario, and increasing the competitiveness can be achieved by improving the higher education system to create a highly educated and skilled workforce. Increasing the competitiveness of higher education has been explained by The Council of Ministers of Education (2008):

Canada must increase the number of students pursuing postsecondary education by increasing the quality and accessibility of postsecondary education ... [to] enhance and stabilize the long-term capacity of postsecondary systems to meet the training and learning needs of all Canadians seeking higher education learning opportunities. (p. 10-11).

It should not be surprising that the above-cited educational vision can shed light on the reform of higher education (Axelrod, 2002). In this regard, Ontario universities need to respond to the preferences of their "clients," and also they need to cooperate and collaborate effectively with industry and business sectors. However, to reach the future goal - namely, providing highly skilled and educated people to fit the needs of Ontario's economy - improving the relationship between higher education and the labour market is important (MTCU, n.d.c).

It is important to look in more detail at how higher education policies were reformed in Canada. The idea of who benefits from higher education has guided the reform (Beach, Broadway, \& McInnis, 2005). The argument for change stressed that educated people are taking advantage of their post-secondary education by having higher wages and good job environments and "graduates should be expected to help shoulder the costs of their postsecondary education" (Beach et al., 2005, p. 2). This way of thinking, as Beach et al. (2005) argued, has encouraged 
the reform of higher education by changing government public funding policies and student support policies. In Canada, the largest funding reform was adopted by the government of Ontario in 2005 (Beach et al., 2005).

However, reform is never without consequences since, as Beach et al. (2005) argued, the reform of Canadian public funding policies has affected the higher education market in Canada and boosted competition from American higher education institutions. Beach et al (2005) stated that "Canadian universities face competition from United States schools for top talent and have experienced a considerable brain drain of their best scholars to the United States as they have been hobbled by on-going provincial funding cuts" (p. 3). Indeed, recognizing that Canadian universities may face a large number of competitors, not just from the United States but also from many countries around the world, may explain the need to reform the higher education system.

In 1995, the Ontario provincial government established new policies that enhanced the shift towards the market by reforming some policies in order to increase the competitiveness of Ontario's academic institutions (Young, 2002). The deregulation of higher education policies, as Young argued, has increased competition through:

1. Deregulation of tuition fees policy;

2. Deregulation of "provincial allocations direct to the universities, and the increasing importance of other sources of income" (p. 93);

3. Availability of information related to academic programs and services, since students as customers of higher education should have access to information in order to support their choice and rationality;

4. Increase in the amount of government grants to needy students; 
5. Support for access to high employability programs (e.g., IT);

6. Increased research funding;

7. Establishing “of new private, degree-granting institutions and programs" (p.94).

Indeed, the above policies have changed higher education and have explained how reforming higher education has increased competition. At the same time, the above policies are a good example of the "double" control by both the government and the market (Young, 2002). Also, these polices have strengthened the link between higher education institutions and the organizational model (Young, 2002).

It is important to end this section by noting that reforming higher education can serve the purpose of encouraging academic institutions to be more competitive. The motivation behind this purpose is that competitive institutions can "survive and provide the benefits of competition to their ... employees, customers and host societies" (Competition Policy Review Panel, 2008, p. 4). In addition, competition can provide higher wages for employees, innovation and productivity for institutions, and provide "better products, lower prices, more choice and better service" (Competition Policy Review Panel, 2008, p. 3). On the other hand, the risk of uncertainty and a higher financial cost may appear as a result of competition.

\subsubsection{Closing remarks: A new look at publicly funded academic institutions.}

Reforming higher education was one of the reasons behind the birth of competition among publicly funded academic institutions (Beach et al., 2005). "Recent higher education reforms, therefore, have often been described as managerial reforms ... which have moved the universities' governance regime towards a much more competition-driven and managerial arrangement" (Kosmutzky, 2012, p. 58). This was also noticed by Singh (2011), who stated that "in the 1980s and in the early 1990s this [market approach] was initially carried forward by the 
rise of managerialism in many western education systems" (p. 3). Indeed, the strength of managerialism in higher education has supported the use of market competitive tools by higher education institutions (Kosmutzky, 2012). This has been possible because, in the words of Teixeira (2006), "the goal [of using market mechanism] was to reduce inefficiencies, to generate additional revenues, and to create innovative organisational models" (p. 16). It should be noted that reforming higher education, and strengthening competition and the managerialism approach in higher education played an important role in creating the new look of publicly funded universities.

In this regard, it is worthwhile to refer to some scholars who addressed the new look of publicly funded universities. Feldman (2007) noted that "public universities look more like private universities every year as state funding shrinks and tuition makes up the difference in funding" (p. 31). What is fascinating is that higher education, as Gumport (2001) observed, has been seen as an industry, and universities have been seen as a "sector of the economy" (p. 243). In other words, universities became business institutions producing goods (programs) and services (educational services) to sell them in a competitive market. This argument was supported by Hemsley-Brown and Oplatka (2010) who noted that "decreasing government funding for both research and teaching, and increasing pressure to maximise income is changing the nature and focus of $\mathrm{HE}$ from a process of learning to a product ... which is delivered in the context of consumerism to meet the needs of industry" (p. 125-126).

Other scholars (Gumport, 2011) have described public universities as business institutions that have a role in economic development through producing highly trained and skilled graduates to match labour market needs to enhance economic growth and prosperity. In this regard, Ontario's Proposed Differentiation Policy Framework (2013) suggested that 
"postsecondary education is an important driver of social and economic development. The government recognizes the valuable contributions that colleges and universities make towards job creation, enhanced productivity and the vitality of communities and regions throughout the province" (p. 4).

The role of government in enhancing competition through reforming higher education and adopting neoliberal policies has transformed publicly funded universities and has forced these universities towards the market as a solution. The following section provides more explanation about how shifting towards the market has boosted competition and encouraged the use of competitive variables.

\subsection{Market-Oriented Higher Education}

Market-oriented higher education was supported by many scholars, including Fredrick Hayek and Milton Friedman. Hayek and Friedman described the education market as a "system that provides the freedom for producers and consumers to voluntarily associate with one another, as well as the incentives that encourage families to be diligent consumers and educators to innovate, control costs, and expand their services" (Kaklauskas et al., 2012, p. 417). In this regard, it is worth noting that the question of why higher education institutions might need to adopt a market approach was answered by Sheehy (2010), who suggested that it was "to increase resources, to increase choice for students by increasing diversity in higher education, to improve quality, ... and to increase both overall participation and participation of marginalised groups" (p. 61).

However, the existence and the domination of markets in higher education are still questionable and, as Teixeira (2006) argued, "in most Western countries we are still very far 
from having a higher education market" (p. 19). This argument is supported by the following observations:

1. While price is a key issue in exchanging goods and services in any market, the price of education is regulated by a government, and there is a limited price contribution by students and their families.

2. Older providers of higher education are feeling the pressure of competition due to rising competition from the new providers of higher education.

3. The lack of sufficient information about the quality of programs may affect students' choice regarding programs and institutions (Teixeira, 2006).

Certainly, the above points can be seen as a proof of the existence of a market, since each point (price or tuition fees, competition, and information) can be considered as a pillar of a market structure, regardless of the limitations highlighted above.

Opponents and proponents of a higher education market provide different arguments about markets. Supporters argue that market orientation in higher education allows for the adoption of market strategies of marketing and facilitate the generation of extra revenues (Felgueira \& Rodrigues, 2012). Furthermore, market orientation in higher education could lead to more innovation and development to meet the demanders' needs as well as to respond to the market needs (Felgueira \& Rodrigues, 2012). This has been possible because market theory, as supporters argue, can be applied in higher education to serve the purpose of increasing revenue, efficiency, and diversity (Sheehy, 2010). Supporters of the market approach in higher education, as Sheehy asserted, are motivated by the role of market theories and strategies in providing an opportunity to get what market stakeholders need. He also added that applying market theory to higher education may serve the purpose of improving efficiency through getting new sources of 
revenues or/and reducing their expenses. However, these benefits, as he described, can be seen as a natural result of introducing a market approach in higher education and supporting competition among universities.

In addition, there is an important argument mentioned by Teixeira (2006) who stated that "the adoption of market-based policies in many countries represents the application of a less direct form of regulation" (p. 12). Indeed, advocates for the adoption of market policies in higher education may agree with this argument, since the adoption of a market approach would maximize the autonomy of publicly funded universities and that, in the long run, would improve the quantity and quality of higher education programs and services (Teixeira, 2006). Another supporting argument was noted by Bruce (2006), who stated that a market system can provide more educational opportunities for those who are willing to attain higher education and can improve higher education institutions (Bruce, 2006). Bruce also argued that a market approach can move higher education from public good to private good, and this can support a costeffective approach as a result of using a market mechanism.

At the same time, the movement towards the market by publicly funded universities was criticized. An opposing argument was suggested by R. Brown (2008), who noted that introducing a market approach in higher education can lead to financial inequality among academic institutions. In addition, adopting a market approach in higher education can increase social inequality, reduce accessibility to higher education, and enhance "social stratification" (R. Brown, 2008). Interestingly, "many individuals argue that the application of market forces to higher education is inappropriate because higher education is a public good" (Teixeira, 2006, p.14). The argument that education is not a pure public good due to its return to both individuals and society has been highlighted by other scholars including Goan \& Cunningham (2006). Goan 
and Cunningham argued that the public benefits from higher education arise from the declining reliance on public assistance and social services due to education as well as the increasing participation in volunteerism and voting activities. They also stated that the private benefits can be seen through having higher income and better health. Beach et al. (2005) also stressed that the private benefits of higher education can be seen through having higher wages and good jobs for individuals. The combination of private and public benefits was discussed by Askari (2014) who argued that increasing the level of education can positively influence the employability of educated people which in turn can contribute to higher income for individuals and higher taxes for governments. Further, Hensley, Galilee-Belfer, and Lee (2013) argued that social benefits of higher education can be noticed through job creation, increase in charitable giving, and higher community engagement. Hensley et al. also added that social benefits can be seen through the increased awareness of human rights and democracy, increasing life expectancy, and lowering crime rates. Since the overall social benefits of post-secondary education might exceed the private benefits, there is a justification for a government contribution to higher education as well as tuition fees.

Public good has been defined as non-excludable and non-rival good (Lipsey \& Ragan, 2001; Teixeira, 2006). According to Teixeira, the meaning of non-excludable is that suppliers of products or services cannot prevent or exclude demanders who do not pay for the good from demanding that public good or service. Non-rival means that good can be consumed by more than one demander without reducing the amount available for other potential demanders. In the case of higher education, the existence of tuition fees could prevent potential demanders from consuming educational programs and services. Potential demanders (students) need to cover at least a portion of the cost of higher education even though the cost is proportionally covered by 
government subsidies. Higher education does not reach the level of a public good because it has failed to meet the condition of non-excludable as it is restricted to those who are willing to pay (Lipsey \& Ragan, 2001; Teixeira, 2006). Higher education, as a public good or a public responsibility, has failed to match the definition of a pure public good. In this regard, Teixeira suggested that higher education can be considered as a merit good instead of public good.

Moreover, opponents of the market approach in higher education assume that using a market approach may not improve the quality of education but may improve "polarisation in higher education, with growing inequality between institutions and between socio-economic and ethnic groups" (Teixeira, 2006, p. 15). However, the dangers of adopting a market approach were signalled by Singh (2011), who explained some of these dangerous consequences, such as marketization and commodification (A full explanation about these consequences is shown later in this chapter).

Other challenging arguments asserted that higher education should not be left to the market, since higher education services can be seen as both a public and a private good and cannot be supplied without government subsidies (R. Brown, 2008). R. Brown also added that higher education should not be left to the market, since higher education services might be sold at a high price, and it is hard to get sufficient information about educational programs and courses. Moreover, recognizing the market theory of supply and demand and its effect on the cost of higher education might negatively affect access to higher education. At the same time, as Sheehy (2010) noted, no one can ignore the problem of inequality in the power to purchase (access) goods and services.

Certainly there are strong arguments for and against applying a market approach to higher education, as each side has its own rationale and presents its own valid arguments. These 
different perspectives need further analysis to present the nature of the market structure of higher education and competition within this market.

\subsection{Market Structure of Higher Education}

Since the focus of this study is on competition and on universities' expenditures to adopt a market approach, describing the market structure of higher education becomes essential to understand this study. Potential questions were highlighted by scholars who asked, "What would a market in higher education look like? .... What is it that would be produced and traded?" (K. Brown, 2010, p. 7). Marginson (2006) noted that the higher education market is a positional market and "higher education produces 'positional goods' ... that provide access to social prestige and income-earning" (p. 1). In addition, these questions that were mentioned above were also answered by K. Brown (2010), who suggested eight conditions that should be available to describe the higher education market. Four of these conditions are related to students as consumers, and the other four conditions are related to academic institutions as suppliers. Conditions that are related to higher education institutions as suppliers of higher education are:

- ease of entry to the higher education market and the ability to compete;

- freedom to identify their products of programs and services, curriculum, and assessment;

- freedom to choose and organize inputs such as students, faculty members, and their public and private funds;

- freedom to set the prices (e.g., tuition fees) of their programs and services (K. Brown, 2010, p. 7-8).

The other conditions that are related to students as consumers are:

- Students will be able to choose which academic institution to attend. 
- Students should be able to choose the program they want to study and be able to compare programs that are offered by several institutions.

- Information about academic institutions and their programs and services should be available to all potential students.

- Students should be aware that they are consumers of higher education services when they directly pay and cover the cost of their education (K. Brown, 2010).

The market structure of higher education was also described by Marginson (1997), who argued that the higher education market is a quasi-market:

In a quasi-market in higher education there might be competition between institutions, corporate-style management, and some commercial activity, but the number of student places is affected by factors other than supply and demand - for example public funding of tuition costs. (p. 6)

However, it can be argued that competition is a fact of life that has supporters and challengers. The next section highlights these arguments.

\subsection{Proponent Arguments of Competition}

Some supporters of competition argued that increasing competition among higher education institutions supports education and can also generate benefits for higher education itself (K. Brown, 2010). Berulava (2005) strongly supported competition among publicly funded universities and criticized those who received public funds and refused to respond to student and market demands. In the words of Berulava, "They [publicly funded universities] are aware that their budget funds will continue to come in as they have in the past. But does society gain anything from this? I don't think so" (p. 7). 
Other arguments were suggested by proponent groups regarding competition in the higher education market. K. Brown (2010) explained that while opponents are concerned about equity, proponents believed that equity is a national government responsibility that is not an academic institutions issue. Proponents, as K. Brown noted, advocated that market competition is a healthy environment and would encourage academic institutions to cooperate positively with student needs and would encourage academic institutions to improve the quality of education. Martineau (2013) suggested that strong competition can be seen as a healthy phenomenon due to its positive effect on customers through lower prices of commodities and services, positive effect on the quality of these services, and due to its effect on increasing customers' choice.

\subsection{Opposing Arguments to Competition}

The rising competition among publicly funded universities has been criticized by many scholars. Calhoun and Kamerschen (2010) argued that intervention of governments in the higher education system is better than the adoption of a market approach and competition. They argued that government intervention can reduce the cost of education and that can keep students in the publicly funded universities. Calhoun and Kamerschen also added that public funds can reduce the cost of education by offering lower tuition fees or by offering merit-based financial aid. This outcome can attract domestic students who might be encouraged to stay in their homeland and work in their home labour market after graduation (Calhoun \& Kamerschen, 2010). In this regard, Teixeira (2006) argued that:

Government intervention may ... work to introduce sufficient incentives to ensure that providers reveal the quality of their services and students express clearly their demands and capacities, ... [by] preventing ... monopolies, ... provid[ing] equal opportunities to 
all qualified individuals who wish to participate in a higher education course. (Teixeira, 2006, p. 11)

Furthermore, this intervention, as Calhoun and Kamerschen (2010) argued, can reduce the level of competition for students between local universities. At the same time, the absence of government intervention and their funds will lead to increased competition between universities

"to fill their seats and gain prestige, marketing power, and excellence" (Calhoun \& Kamerschen, 2010, p. 321). In addition, opponents were worried about losing the diversity of higher education institutions and also damaging the quality of higher education. But, as opponents believe, competition may have a negative effect and, in the words of Sheehy (2010), "among these negative effects is an increased discontent and declining morale among members of the academic profession ... [and] reduced quality" (p. 62). In other words, universities might invest their revenue in marketing activities in order to attract students and increase enrolment rather than investing to improve quality (Sheehy, 2010).

Academic institutions compete for many things and the question of what they compete for is discussed in more detail in the following section.

\subsection{Competing for What?}

The motivation behind competition, why publicly funded universities are willing to compete, and for what, should be underlined. Exploring these fundamental questions may provide an opportunity to connect the competition puzzle and to see the big picture clearly. Not surprisingly, competition among publicly funded universities is strongly linked to the reduction of public funds; therefore, academic leaders need the marketplace, not only to generate revenues, but also to survive (Feldman, 2007). Indeed, the need for survival is a new argument, suggested by Rothschild and White (1993), who stated that the problem of reduction of public funds has 
forced publicly funded universities to rely on other sources of revenue to avoid the problem of leaving the market and to survive. Eastman (2006) concurred with the previous argument and added that, in Canada, the reduction of provincial funding for higher education has forced academic institutions towards the market to survive by creating their needs of revenue.

There is general agreement that cutting public funds for higher education has created financial pressure for academic institutions to meet their need for revenue and cover their expenses (Zona, 2005). In other words, universities have to face financial shortages by relying more on private sources of revenue that, in turn, fuel competition among public academic institutions (local and foreign) and among public and private academic institutions (Heidrich \& Chandler, 2011). In this regard, Zona (2005) argued that financial pressure has changed the traditional ethos of the higher education system and has increased competition. Furthermore, Heidrich and Chandler (2011) added that competition in the higher education market has affected the operational ways of publicly funded academic institutions. "The steep declines in governmental support have contributed to higher tuition rates and an increasing dependence on tuition dollars as a revenue source, particularly at public institutions" (Zona, 2005, p. 6). Cost sharing or direct charging (tuition fees) for higher education programs and services, as Teixeira (2006) described, has "contributed to experiments in funding to increase competition between higher education institutions" (p. 15). Based on the above, the first motive for publicly funded universities to compete is the reduction of public funds.

The second motive to compete is that competition among universities may arise as a result of increasing the number of providers of educational services (Deschamps, 2013). A large number of providers who can serve the same pool of students will increase students' choices regarding selection of an academic institution that offers what they are looking for (Deschamps, 
2013). In other words, competition is fueled by increasing the number of providers while reducing public funds, which creates a highly competitive market and increased competition for students who become a source of revenue (Douglass, 2005). In this regard, it is worth noting that in Canada, "demographic analyses indicate that in the coming years the number of high school graduates will decline sharply in a number of provinces and regions" (Kirby, 2011, p. 268). Competition will increase in coming years, as Kirby described, not only to raise the enrolment level as a solution to increase the institutions' revenue, but also to maintain enrolment levels. This argument was supported by the Association of Universities and Colleges of Canada (AUCC) (2011). AUCC announced that population in the age group of 18-21 will decline by about $10 \%$ over the next decade. In addition, the Council of Ontario Universities (COU) released a report in January, 2015 that confirms the demographic decline in university-age population. COU (2015) stated that the number of high school applicants for Ontario's universities for the 2015 academic year has slightly declined; in comparison with last year, it has declined from 89,272 to 87,600 .

Other arguments have described why publicly funded universities are willing to compete. These arguments suggested that government aids for students, which are given directly to them rather than to academic institutions, have enhanced the competition among publicly funded institutions (Deschamps, 2013). In this regard, Teixeira (2006) noted that government subsidies to students themselves will "enhance the competition between higher education institutions and encourage better use of resources" (p. 9). What is even more interesting is that competition between universities is also encouraged by the law of patent and copyright (Deschamps, 2013). This law has reinforced the intellectual property aspect of knowledge that is generated by universities and has encouraged universities to generate some revenue from their research. This 
in turn increases competition for highly intelligent researchers to generate competitive and commercial knowledge (Deschamps, 2013).

To go further, it is worthwhile to focus more on the fundamental question - "competition for what?" - and to investigate what the literature has to say. In general, the decline of public funds for publicly funded universities has enhanced competition for students, research grants, and endowments (Feldman, 2007). Also, it is important to note that in order to avoid falling behind, publicly funded universities need to compete in recruiting the best students, the best faculty members, the best doctoral candidates, and the best researchers to develop their programs and services (Berulava, 2005). Thus far, competition for qualified students and faculty members might be the first answer to the question "competing for what?"

Additionally, academic institutions are also competing for endowments. Zona (2005) argued that academic leaders have faced the challenge of public funding cuts by competing to gain more private funds such as donations to fund their educational programs and services. "Endowment income currently represents a significant portion of college and university annual operating budgets, and at the largest institutions, it accounts for 25 to $40 \%$ of the annual budget in many instances" (Zona, 2005, p. 2). Indeed, competition for endowments is also a part of the answer to the question.

Competition within the higher education sector also exists for research funding from both public and private sources (Marginson, 2004). But it could be argued that competition for public and private research funding was forced by the increasing cost of equipment and researchers in research areas such as science, medicine, and technology (Beach et al., 2005). The growing shift towards these research areas has forced academic institutions to compete in order to cover the cost of their research and training, instead of covering it by reallocating internal funds. The 
motivation behind the competition for research funding is to avoid "the effect of increasing student-faculty ratios and reducing quality of education elsewhere in the universities" (Beach et al., 2005, p. 2). On the other hand, competing for research funding from the private sector was criticized by Holbrook (2004), who warned that allowing private firms to finance academic research would "come to violate academic values by constraining free inquiry, by influencing intellectual priorities, or by distorting research findings" (p. 69).

Competition for revenue and prestige can also be seen as answers to the question “competing for what?" Duane (2002) described how institutions can compete to increase their market share and revenue. Eastman (2006) has another point of view, arguing that Canadian universities not only compete for revenue but also for prestige and reputation by attracting highly qualified faculty members and subsidizing qualified graduate students. Eastman's argument was supported by Sheehy (2010), who noted that universities do not compete to increase their market-share or revenue, but rather they compete to enhance their prestige through increasing the quality of their programs and services. Sheehy explained that "the main elements in the competition for prestige are attractive buildings, doctoral programs, and researchers with international reputations" (p. 64).

Tuition revenue is another area of competition. Marginson (2004) argued that institutions are competing for tuition revenue from domestic and foreign students. From a slightly different point of view, Douglass (2005) stated that publicly funded universities that have limited power to increase the rate of local tuition fees yet have the power to increase international tuition fees are also competing for this same purpose. Increasing enrolment levels of foreign students, as Douglass suggested, is important economically and academically for academic institutions (economically: generate revenue; and academically: increase their highly 
qualified students). Deschamps (2013) also suggested that competition in the market of higher education to recruit international students is driven by the need to generate revenue as a result of the reduction of public funds. But Zona (2005) has highlighted that academic institutions need to find other funding sources, since tuition revenue alone is not enough to cover the rising cost of higher education.

A final point to be made in this section is that academic institutions in developed and developing countries have to compete to attract their customers (students) by offering "what they think that students want, from state-of-the-art recreation centers to highly ranked academic departments" (Deschamps, 2013, p. 30). Attracting potential customers (domestic and foreign) can be achieved through "the quality of the university, the quality of the student body that the university attracts, the location and physical surroundings of the university, and the price (tuition) charged" (Rothschild \& White, 1993, p. 23). From students' perspectives, students may be interested in high quality programs or prestigious universities, or they may prefer foreign universities for the special and unique programs that are not being offered by their local universities. Furthermore, students may prefer to attend foreign universities to discover new cultures and to gain new experiences (Douglass, 2005).

The discussion of whether or not publicly funded universities have no choice but to compete is likely to be ongoing. Therefore, a critical review of literature on the competitive variables that might be used by academic institutions in order to enhance their competitiveness and to succeed in the market is presented in the next section. This is important, as this study has investigated competition by examining universities' expenditure on competitive variables and their effect on applications, enrolments, and persistence ratio. 


\subsection{Competitive Variables}

It is important to examine the use of market competitive variables in higher education since "many universities are now applying marketing theories and concepts that have been successful in the business world to the HE context in an effort to gain a larger share of the international market" (Hemsley-Brown \& Oplatka, 2010, p. 204). Further, it is important because publicly funded academic institutions have been under greater pressure to be financially self-sufficient, and this has forced them to adopt market tools and "strengthen their institutional managements" (Heidrich \& Chandler, 2011, p. 676). In this regard, Kirby (2011) argued that the use of competitive variables by academic institutions is essential in facing the challenge of "funding and maintaining educational institutions" (p. 269). According to this argument, as Holbrook (2004) noted, publicly funded universities have struggled to survive and have been forced to adopt market tools to maximize their "monetary return" (p. 68) while maintaining their not-for-profit identity. In other words, leaders of publicly funded academic institutions are finding themselves under pressure to adopt market tools to handle their institutions' challenges (Gumport, 2001).

These are the main competitive variables used by institutions to compete with other institutions: price competitive variables and non-price competitive variables. The following section briefly highlights these variables.

2.7.1 Price competitive variables. The use of price competitive variables by universities has been discussed by many scholars. Rothschild and White (1993) noted that "price competition among universities is a significant phenomenon. It is supported, however, by many of the studies of student enrolment choices among universities" (p. 23). Under this type of competitive variable, competition between universities can be seen through the offering of 
scholarships and competitive tuition fees (Rothschild \& White, 1993). Clotfelter and Rothschild (1993) also added that "there were increasing signs that colleges were using marketing techniques and non-need-based scholarships often to attract top applicants” (p. 2). Indeed, one could argue that using price (tuition fees and scholarships) as a competitive variable is noticed among publicly funded academic institutions in Canada and, certainly, in Ontario.

It should not be surprising to see publicly funded universities act and behave as private universities do in the marketplace (Clotfelter \& Rothschild, 1993). Marginson (2004) noted that Australian universities, as producers of international education, are using price to compete, have a price advantage, and that their "costs were therefore less than two thirds of those in the UK and the American public universities" (Marginson, 2004, p. 24). He also added that adopting a low tuition fee might not work in the long run and might not be enough to attract bright and talented students. Using price competitive variables alone may not be enough to compete in a tough competitive market. Indeed, to compete effectively, universities have no choice but to use both price and non-price competitive variables.

2.7.2 Non-price competitive variables. Non-price competitive variables are the other option available for publicly funded universities to compete. Non-price competitive variables can be used to increase the competitiveness of academic institutions. Among these variables are:

1. Program differentiation: According to Marginson (1997), differentiation of higher education programs and services can enhance the sustainability and the competitiveness of academic institutions in the national and international markets. The variable of differentiation was explained by the Competition Policy Review Panel (2008), who stated that program differentiation of co-op programs and internship opportunities in appropriate fields that meet the needs of labour market can increase the competitiveness 
of Canadian universities in the market of higher education. Moreover, to serve the purpose of being competitive, several academic institutions have introduced new graduate programs in order to increase their enrolment level (Duane, 2002).

2. Brand name, ranking, and reputation: According to Deschamps (2013), "universities are positioned in direct competition with each other by rankings" (p. 30). (More explanation is provided in the next section).

3. Quality of programs and education services: The Provincial and Territorial Ministers of Education and of Immigration (2011) recommended:

In a highly competitive global market, Canada must match other countries in its efforts to emphasize the high quality of the educational opportunities it offers. Among other things, this requires clear communication about Canada's approach to quality assurance and developments in foreign qualifications recognition. (p. 20)

4. Collaboration with domestic industry: Collaboration with domestic industry can lead to the redesign of academic programs to match the needs of the labour market (Competition Policy Review Panel, 2008).

5. Advertising: Deschamps (2013) stated that publicly funded universities "compete in a marketplace ... [by using] advertising on the beauty of campuses and the availability of recreational opportunities" (p. 3). Provincial and Territorial Ministers of Education and of Immigration (2011) explained that advertising is an important competitive variable for Canadian academic institutions to increase their market share in international markets.

6. "Recruiting star faculty, replacing tenure-line positions with term contracts and parttimers" (Gumport, 2001, p. 241). However, recruiting part-time and contract instructors 
instead of tenured faculty members, as Gumport argued, may have an ambiguous effect on students, academic institutions, and on society as a whole.

7. Outsourcing academic activities (Gumport, 2001).

8. "Creating academic partnerships with industry and other non-academic entities" (Gumport, 2001, p. 241).

9. Expanding distance and on-line learning (Gumport, 2001).

10. Internationalization: This competitive strategy may include most of the benefits of generating revenue, enhancing prestige and reputation, and improving the quality of higher education (Deschamps, 2013).

The adoption of the strategy of internationalization of higher education is motivated by both academic and commercial purposes. Academic motivation can be seen as gaining prestige and branding, and "establish[ing] an international identity" (Deschamps, 2013, p. 25). In other words, adopting an internationalization strategy may allow universities to compete and permit them to attract international students and qualified faculty members who, in turn, would add to their reputation and identity.

Commercial gain is a new motive for an institution to adopt internationalization. According to Deschamps (2013), the new commercial motive is important due to its role in generating revenue for higher education institutions. Generation of revenue can be seen through offering for-profit educational programs that require international students to pay full tuition fees (Deschamps, 2013). Douglass (2005) suggested that universities are willing to attract international students to expand enrolment and also to recruit them as a new source of revenue. What is even more fascinating is that the adoption of an internationalization strategy has given life to the "for-profit" side of publicly funded institutions (Deschamps, 2013). For instance, 
universities in "the United States, Canada, the United Kingdom, New Zealand, Australia, Denmark, The Netherlands, Singapore, Malaysia, and Hong Kong have been the most active in pursuing revenue-generating internationalization" (Deschamps, 2013, p. 36). In these countries, the for-profit side of publicly funded universities can be seen through "tuition based on market rates, franchising their programs abroad, hosting international programs on their home campuses, and opening campuses abroad" (Deschamps, 2013, p. 36).

The adoption of internationalization as a competitive strategy is strongly encouraged by the Canadian federal government. In January 15, 2014, the federal government launched a new international education strategy that aims to double the number of international students to become 450,000 by 2022 (Foreign Affairs, Trade and Development Canada, 2014). At the same time, Provincial and Territorial Ministers of Education and of Immigration (2011) recommended competitive variables to help Canadian academic institutions to compete for international students and to increase their competitiveness in global markets. These recommendations are:

1. Accessing information: information should be easy to find by all academic stakeholders including "information and counselling about educational opportunities, the status and equivalencies of Canadian diplomas and degrees, visas and other regulations, employment opportunities, and immigration" (p. 22);

2. Using market competitive variables such as advertising in other international markets in order to provide additional information;

3. "Providing an enhanced Web presence for the brand that makes effective use of information technologies and social media ... [also] providing prominent conference speakers to communicate directly about educational opportunities in Canada" (p. 23). 
While competitive variables can be used by publicly funded academic institutions, the ability of each of these institutions to benefit from competition is not the same. Five different measures were used by Marginson (1997) to examine the competitive behaviour of Australian public universities. These measures were: enrolment level, share of research spending, fees paid by international students, government research funding, and government-funded student loans. He concluded that academic institutions were affected by competition but at different levels as a result of differences in institutions' locations, ranking and prestige, programs and courses, and also domestic demand. In other words, high-ranking and prestigious academic institutions, with professional and business programs and located in highly populous areas, were not affected by declining enrolment levels and tuition revenue. Marginson (1997) recommended that individual academic institutions should promote their ranking and prestige and should also increase their capacity to compete and to gain more private funding.

Academic institutions are not the same in terms of size, programs and services, and prestige, and their exposure to competition might affect them based on these variables. According to Douglass (2005), in tough competitive markets, older and prestigious universities can survive because of their prestige and reputation. These universities still claim the lion's share of public and private funding due to their brand name, reputation, and quality services and programs (Douglass, 2005). At the same time, other publicly funded universities (less prestigious universities) need to adopt competitive variables for their long term sustainability. They may also need to eliminate some of their unprofitable programs and services (e.g., philosophy) and expand other profitable ones (e.g., business) (Douglass, 2005). Finally, universities that are "too conservative in their internal culture" (Douglass, 2005, p. 10) and are unable to adapt will not be able to survive in the market of higher education. 
2.7.3 Ranking and branding. The movement towards the market and the growing competition among academic institutions have increased their awareness of the importance of improving their competitiveness in the marketplace. Competition requires universities to differentiate themselves from other competitors through many things, including their ranks and brand names. According to Joseph, Mullen, and Spake (2012), ranks and "brands have long been used in marketing to differentiate a company's product offerings in the marketplace" (p. 2). Ranking, as Iqbal, Rasli, and Hassan (2012) argued, can also help a university to differentiate itself in the consumer's mind. Ranking is an important benchmark that has been used by potential demanders to differentiate a university from other competing universities. This has been possible because a university's rank can be seen as "the perception and reputation developed in the minds of the people about the university or institution" (Iqbal et al. 2012, p. 169). A higher rank can be seen as a competitive advantage and a power to effectively compete in the academic marketplace.

Ranking is an important part of the process of brand creation and could be considered as a "key to shaping and maintaining brand identity" (Anctil, 2008, p. 56). Ranking is a key indicator of a university's brand and reputation and it is also a key competitive variable to develop the status of a university (Naidoo, Gosling, Bolden, O'Brien, \& Hawkins, 2014). Naidoo et al. suggested that the practice of using ranking as a competitive variable is borrowed from the business sector and has been employed by higher education institutions. Bunzel (2007) concurred with Naidoo et al. and stated that "various corporate marketing strategies are being employed in the academic world as universities search for ways to improve ranking" (p. 152). On the other hand, while a university rank might not be a true representation of the institution's quality, it has been utilized by potential customers to rationalize their choice (Anctile, 2008). 
Ranking is an important competitive variable to improve a university's brand and image among potential demanders. According to Priporas and Kamenidou (2011), improving institutional rank can create university branding that can help in increasing the market share through its role in polishing the quality and value of the academic products. Ranking helps in creating the reputation of academic institutions that might affect enrolment level, since students are presumably willing to attend institutions with a good brand and reputation (Anctile, 2008). Investing in ranks by spending a considerable sum of money to polish the brand name in the marketplace has become an important issue in attracting the best higher education demanders (Bunzel, 2007). This argument is supported by scholars who argued that good ranks, brands, and reputation can strongly affect the enrolment decisions of potential demanders (Priporas \& Kamenidou, 2011). Anctil (2008) also added that university reputation has played an important role in increasing the applications for admission and in affecting students' choices.

At the same time, ranking and branding can play an important role in shaping the identity of a university itself and play an important role, not only in recruiting potential students, but also in partnerships with industry and business (Lee, Miloch, Kraft, \& Tatum, 2008). According to Joseph et al. (2012), the competitive variable of ranking and branding has been used by most publicly funded universities in Ontario to attract students who are driven by academic ranks and also to attract donors from community and from business and industry. Ranking can be used to target applicants for admission and enrolment, faculty members, donors, business and industry partners, and private and public research funds. It is worthwhile to refer to Naidoo et al. (2014), who stated that ranking and branding can add value to the identity of a university when it seeks research funds from both the public and private sectors. Moreover, branding or ranking, as Joseph et al. noted, can help in "improving student recruitment ... improving the fiscal health of 
the University; creating a more inclusive environment; and improving research and outreach support” (p. 3). These arguments were supported by Anctil (2008), who suggested that rankings can affect the university reputation itself and this might affect the university's enrolment level, public and private funds, and research funding.

The key point in employing ranking as a competitive variable "is to persuade the audience that you have a product that is both different and better than your competitor's similarly designed and marketed product" (Anctil, 2008, p. 49). Indeed, there are many different ranking systems that have different evaluation categories (e.g., citation, research dollars, etc.). But the target of the evaluation was to draw a ranking that potential demanders care about, regardless of the evaluated categories. For that purpose, the challenge of building brand identification in the demander's mind is an important target in several universities, since ranking and branding can provide protection from other competing universities in the academic market (Lee et al., 2008). Lee et al. noted that building a brand image becomes an essential competitive variable because "universities are becoming increasingly more entrepreneurial in nature as schools seek various strategies to generate additional revenues" (p. 178). This has been possible because ranking and branding have been used by many institutions to differentiate their products or services from those who produce similar products (Priporas \& Kamenidou, 2011). Further, Naidoo et al. (2014) suggested that ranking and branding are employed by academic leaders who "have become brand agents responsible for maintaining, developing and, where necessary, changing perceptions of brand image by key stakeholders" (p. 145). Academic leaders deeply understand how ranking and branding can enhance the competitiveness of their academic institutions and also understand the role of ranking in differentiating their academic institutions from other competitors to maintain and increase their market share (Priporas \& Kamenidou, 2011). 
To build an academic brand, a university needs to highlight the employability of its programs and the "diversity of faculty and students, international partnerships and arrangements for overseas student placements and exchanges" (Naidoo et al., 2014, p. 149). Lee et al. (2008) suggested that to build the rank or brand, a university needs to show its competitive advantage, quality, tradition, and its values and goals. In addition, ranking and branding can be built by “providing quality services, creating an emotional link with students, a unique set of communication and service” (Iqbal, Rasli, \& Hassan, 2012, p. 170). Joseph et al. (2012) also argued that brands and ranks can be seen as a signaling the quality of education, and building a good relationship with potential demanders. Ranking and branding, as Finch, McDonald, and Staple, (2013) described, can also be used to judge the quality of academic institutions that in turn can affect an academic institution's revenue and the number of applicants. In the higher education market, ranks and brands add value to academic institutions and thus it is now important, more than ever, to manage institutions' ranks and brands.

\subsubsection{Proponent arguments regarding the adoption of market competitive}

variables. The adoption of market competitive variables by publicly funded academic institutions has been both supported and criticized by some scholars. A supporting argument suggested that the introduction of market competitive activities in higher education and using business tools can help in "institutional development" (Teixeira, 2006, p. 17). The adoption of competitive activities might lead universities to be "more flexible, resilient, and responsive than some observers have acknowledged" (Teixeira, 2006, p.17). In Canada, the growth and development of higher education have been affected by the growing use of market competitive tools (Kirby, 2011). These tools have affected the accessibility of higher education by expanding access to higher education across many Canadian provinces, including Ontario (Kirby, 2011). 
Another supporting argument suggested that the adoption of competitive variables can enhance institutional performance and increase their competitive advantage (Duane, 2002). Performance of higher education can be seen through engaging in "some level of competitive activity ... such as a major increase/decrease in tuition or financial aid (pricing action), new facilities such as dorms, classroom buildings, etc. (capacity action) or new programs or majors (new product action)" (Duane, 2002, p. 6). In addition, the adoption of competitive variables may allow academic institutions to respond effectively to the needs of the market by increasing the diversity of their programs and services (Teixeira, 2006). Finally, the adoption of competitive variables can help academic institutions to be "winners" in their own market (Duane, 2002).

\subsubsection{Opposing arguments regarding the adoption of market competitive variables.}

Opponents suggested that adopting market competitive tools from business may damage publicly funded universities. The damage may appear as a result of ignoring the need for gradual change and ignoring the speciality of higher education institutions (Gumport, 2001). Not surprisingly, opponents suggested that using market competitive tools may damage publicly funded universities as an "intellectual enterprise, to further erode knowledge as an end in itself, and to further stratify the academic offerings for different segments of student population" (Gumport, 2001, p. 242). In addition, applying competitive tools to maximize flexibility may involve unwilling behaviours such as "outsourcing and privatizing as well as increasing the proportion of part-time and temporary personnel" (Gumport, 2001, p. 244). Moreover, adopting competitive tools may lead to the elimination of degree programs and courses, and may also lead to the deletion of some departments (Gumport, 2001). 
In addition, the adoption of competitive variables might promote marketization and corporatization of higher education. As described by Swann (2004), corporatization of higher education has taken institutions far from the goals of academic programs. Dobbie and Robinson (2008) also suggested that corporatization of higher education has negatively affected academic stakeholders. They argued that

Students and their families have seen class sizes increase and the cost of attendance skyrocket at many times the rate of inflation, making substantial student debt the norm for graduates ... [also] workers at these institutions have faced job cuts, stagnant wages, and cutbacks in benefits. (p. 117-118)

The use of competitive tools by publicly funded academic institutions can change the nature and philosophy of these institutions. Marketization, corporatization, and diversity are arguably the major effects that should be explored. It is important to explore whether or not these phenomena are noticeable in higher education. The following section is a review and critique of these phenomena to explore their positive and negative sides.

\subsection{Competition and Corporatization}

One of the most fundamental consequences of competition and of using market competitive tools is the so-called corporatization of higher education. The reduction of public funds and the increase in competition has encouraged publicly funded universities to adopt entrepreneurial or corporatization behaviour (Deschamps, 2013). Corporatization, in the case of higher education, can be seen through the activities of revenue generation and through the way that programs and services are offered (Douglass, 2005). The need to reduce the gap between revenue and expenditure in the operating budgets of publicly funded universities has encouraged the adoption of "revenue-generating activities" (Deschamps, 2013, p. 14). "As revenue 
generating opportunities are found beyond public dollars, universities are engaging in market behaviors that have traditionally existed in the for-profit private sector" (Deschamps, 2013, p. 28). It should not be surprising that entrepreneurial or corporatization behaviour has been adopted and has become a priority for many of publicly funded universities in order to generate and to increase their revenue and to collect private funds (Lolich, 2011). In addition, corporatization of higher education has been encouraged as a result of the change in the higher education sphere and that has forced academic leaders towards business and marketing strategies (Zona, 2005).

The adoption of corporatization behaviour was encouraged by government demand and by publicly funded universities themselves to meet their needs and to succeed in a competitive higher education market (Douglass, 2005). "The traditional college or university has become more business oriented and corporate in nature" (Zona, 2005, p. 44). This corporate nature has become the norm for publicly funded universities and the "corporate metaphors of production in a competitive marketplace are omnipresent" (Gumport, 2001, p. 244). Furthermore, the economic crisis of 2008 and its influence on government budget in many western countries have also forced universities towards corporatization (Deschamps, 2013). According to Deschamps, the 2008 economic crisis has encouraged governments to reduce their spending on higher education, which in turn has forced publicly funded universities to adopt entrepreneurial behaviour to generate more revenues. In addition, the creation of the position of Chief Investment Officer in higher education institutions can explain how the shift towards the market and towards corporatization has soared in recent years (Zona, 2005).

In general, corporatization and the entrepreneurial activities of higher education can be noticed as: 
1. Increasing the power of academic management and implementing organizational theory and ideology (Gumport, 2001).

2. Growing consumerism: the "rise of consumerism ... [has created] economic-consumer interests, particularly the student as buyer" (Gumport, 2001, p. 247);

3. Increasing the value and status of some academic programs at the expense of others, which has led to the downsizing of some programs and courses (Gumport, 2001, p. 247).

4. Corporatization or entrepreneurial activities through selling educational products and services. "Universities have traditionally produced goods and services ... and [are] pursuing the revenue generating potential of selling these goods and services to society" (Deschamps, 2013, p. 33). This means that corporatization activities can be seen through "commercialization of the goods and services produced by universities" (Deschamps, 2013, p. 15).

5. Entrepreneurialism, through universities' cooperation with their industrial partners, which has encouraged applied research to meet the needs of the business partners and to gain public and private research funding (Deschamps, 2013; Lolich, 2011). Indeed, the collaboration between universities and business can be seen as an academic transformation towards entrepreneurialism (Lolich, 2011).

One of the most important arguments for the necessity to move towards corporatization is the need to maintain sustainability; academic institutions' refusal to adapt will "result in a loss of centrality and perhaps ultimately a loss of viability as providers" (Gumport, 2001, p. 246). Another supporting argument has suggested that an entrepreneurship approach can promote innovation in higher education, since innovation is the "tendency to support new ideas, experiences and creative processes earlier than competitors" (Felgueira \& Rodrigues, 2012, 
p. 704).

On the other hand, corporatization of higher education was criticized by supporters of higher education as a social institution (Gumport, 2001). Those challengers argued that the adoption of a corporatization approach will lead to ignoring the social responsibilities of publicly funded institutions and this would threaten "democratizing functions and the long-term public interest" (Gumport, 2001, p. 247). Higher education as a social institution is guided by social functions such as "development of individual learning and human capital, the socialization of citizens and cultivation of political loyalties, the preservation of knowledge; and a social space for the play of ideas" (Gumport, 2001, p. 245). Higher education as a social institution has been changed "to advance knowledge through [applied] research, to contribute to economic development by employing and producing workers, and to accelerate the development of industrial applications" (Gumport, 2001, p. 245-246).

\subsection{Competition and Commercialization}

Commercialization is another consequence of competition and using market tools in higher education. Commercialization or marketization of higher education is the application of marketing theories in managing academic institutions (Holbrook, 2004). Students are seen as customers consuming higher education services and products and academic institutions are seen as producers (Holbrook, 2004). According to Holbrook, the "commodification of teaching and the commercialization of research in our educational institutions" (p. 69) have been motivated by the reduction of public funds and the adoption of business behaviour. Collecting tuition fees and selling higher education in domestic and global markets to increase revenue from national and international students are significant proofs of the commercialization of higher education (Sheehy, 2010). It could also be argued that "education is now a commodity, and is promoted in 
the international market place in competition with other providers" (Hemsley-Brown \& Oplatka, 2010, p. 118). In this regard, the Provincial and Territorial Ministers of Education and of Immigration (2011) explained that marketization of Canadian higher education is an essential pillar to succeed in the international market and essential in competing to be the first choice for international students.

Marketization of higher education is not a criticism-free approach to managing academic institutions. Opponents of marketization have argued that if the main target of marketization of higher education is to generate revenue, then the reputation and collegiality of higher education institutions might be damaged (Susanti, 2011). Other arguments have suggested that "students will become clients (and many already view themselves in this manner), not simply thankful participants under the tutelage of faculty" (Douglass, 2005, p. 8). Also, marketization of higher education might create elite universities and also might change the values and mission of higher education institutions (Bruce, 2006). Further, "marketisation can exacerbate existing differentials between institutions and social groups, reduce or threaten diversity, harm quality and reduce value for money" (R. Brown, 2008, p. 83). In addition, the "aspects of the marketing ethos have tended to infiltrate the halls of academia and thereby to corrupt the process of education in our institutions of higher learning" (Holbrook, 2004, p. 68). Moreover, the problem of equity, inequality, social polarization, and equal access may occur as a negative effect of the marketization of higher education (Hemsley-Brown \& Oplatka, 2010). According to Holbrook (2004), the cost of commercialization could be high and might damage the standards and ethos of higher education. In this regard, Holbrook stated:

If we continue to accept the commercialization of higher learning, if we continue to design educational systems on the basis of customer orientation, if we continue to 
acquiesce in the commodification of teaching and research, if we continue to believe that in the university as elsewhere greed is good, then we have no one to blame but ourselves for the inevitable decline, decay, and perhaps demise of academic values that will surely result. (p.74)

\subsection{Competition and Diversity}

Diversity is another possible consequence of competition in higher education. According to Teixeira (2006), "when resources are scarce, the fight for survival takes place under market co-ordination ... [and] institutions would diversify in search of market niches and new clienteles" (p. 14). Using market tools in higher education could allow publicly funded academic institutions to become similar to the private sector, which is driven by financial incentives, and would allow them to respond very strongly to the market needs and diversify their programs and services (Teixeira, 2006).

Diversity or differentiation of higher education products can be noticed through “ 'types' of higher education institutions (HEIs), 'curricular approaches', 'levels' of programmes and degrees, 'length' of programmes and varied 'reputation' and prestige among formally equal institutions and programmes" (Brennan \& Osborne, 2008, p. 179). In addition, each academic institution can differentiate itself through its location, or its program structure and curriculum, and also through its "culture, mission, [and] size" (Brennan and Osborne, 2008, p. 181). The key point is that academic institutions can differentiate themselves by many features that serve the purpose of increasing their competitiveness in the global market.

Many arguments have supported diversity of academic programs and educational services, and have assessed this diversity as a positive consequence. Marginson (1997) argued that competition among academic institutions should be reinforced "to increase the diversity of 
what is produced and can be market-chosen" (p. 5). Various specialized programs and/or educational services allow students to choose from a great number of educational programs and services to match their priorities and preferences (Weingarten \& Deller, 2010). Furthermore, diversity of programs and educational services can support student needs and labour market demand (Weingarten \& Deller, 2010).

There are many arguments that have criticized competition and diversity. Sheehy (2010) did not find a positive relationship between competition and diversity and noted that competition in higher education does not enhance diversity, but rather may have a negative effect on the diversity of higher education. Diversity may decline, since "the choices offered to students will be those that are most profitable to the university... [and] choices will be further constrained to those courses which are currently popular [or] only those courses that promise immediate entry into lucrative careers" (Sheehy, 2010, p. 62). At the same time, Beach et al. (2005) suggested that "uniformity of product rather than differentiation and specialization of universities into different areas or missions" (p.3) has been reinforced due to competition and due to the reduction of public funds. Moreover, competition might not lead to diversity in higher education, but could just lead to institutions copying what their competitors are doing (Teixeira \& Amaral, 2001).

In Ontario, as Weingarten and Deller (2010) suggested, the system of higher education is already differentiated through:

- the differentiation of academic programs (e.g., research intensive, teaching intensive, or comprehensive);

- the differentiation of services provided (e.g., on-line, on-campus, or co-op);

- the differentiation of academic institution prestige or ranking. 
In this regard, Calhoun and Kamerschen (2010) argued that differentiation among academic institutions that are controlled and regulated by the state or provincial government is noticeable. What is interesting is that the differentiated price or tuition fees and the differentiated subsidies and grants can also be seen in the higher education market (Calhoun \& Kamerschen, 2010).

The benefits of a diversity of programs and educational services can be seen in the long run rather than in the short run, and it may need more time for this to occur and be noticed (Weingarten \& Deller, 2010). These benefits can be seen through improving the quality of higher education programs, increasing student choices, facilitating student transfer from one institution to another, increasing national and international student enrolment, strengthening academic institutions' sustainability, improving university ranking and reputation and, finally, matching graduate skills with the needs of labour market (Weingarten \& Deller, 2010). These positive effects of diversity have the potential to create direct benefits for students, academic institutions, and society. Certainly, the previous benefits of differentiation could enhance the competitiveness of academic institutions in the global market, and also could make academic institutions more attractive to domestic and international students.

Another important context of diversity is that it can be seen through horizontal and vertical forms of differentiation (Brennan \& Osborne, 2008; Weingarten \& Deller, 2010). The horizontal form of differentiation of programs and courses provides various choices for students and "may serve different students in different ways" (Weingarten \& Deller, 2010, p. 8). The vertical form of differentiation is related to different reputations and prestige (vertical ranking) between different universities (Brennan \&Osborne, 2008). For example, vertical differentiation is dominant in many countries around the world, and it should not be surprising that the value of 
"where you studied" is more important, in some cases, than the value of "what you studied" (Brennan \& Osborne, 2008, p. 179).

Competition in higher education, one can argue, is a global phenomenon. But the questions one might ask are: (a) which factors have played an important role in expanding the market of higher education? and (b) how did competition become a global phenomenon? The following sections attempt to provide a review of potential answers to the above-mentioned questions. The globalization and autonomy of higher education institutions are presented next, to highlight how these factors have played an important role in expanding the market of higher education.

\subsection{Competition and Globalization of Higher Education}

Globalization "is not merely the business transactions and military and political agreements-rather it is the shared consciousness of being part of a global family that brings nations, peoples, and societies together" (Singh, 2011, p. 2). In other words, globalization is recognized as a process that allows peoples, organizations, and nations to interact cooperatively faster and cheaper than before (Singh, 2011). International organizations like the International Monetary Fund (IMF) and World Bank (WB) have played an important role in facilitating globalization. The roles of these organizations have significantly affected public services (e.g., healthcare and education) through connecting their loans with conditions for countries around the world to receive their loan payments. These conditions involve policies such as "cuts in government expenditures, market liberalization, currency devaluations, reductions of government subsidies ..., and most importantly the privatization of public services such as health and education" (Singh 2011, p. 7). Implementing these policies by many countries around the 
world has pushed publicly funded sectors, including higher education, towards the global market and competition.

Globalization of higher education has enhanced competition and has expanded the market due to a growth in both the supply and demand sides of higher education. The key argument here is that to serve the purpose of participation in global economic activities, demand for highly skilled labour has increased, and this in turn increases the demand for higher education around the world (Singh, 2011). This economic role of higher education has created the situation of excess demand, which has expanded the market of higher education and encouraged competition. For example, "between 1991 and 2005, the number of students enrolled in institutions of higher education worldwide more than doubled from 68 to 137.9 million students" (Singh, 2011, p. 3). Moreover, globalization of higher education has created excess supply, which has expanded the market and fuelled competition through allowing "foreign higher [education] institutions establishing programs in developing countries under a variety of arrangements ranging from cross-border franchised agreements, twinning arrangements, joint programs, validation programs, subcontracting and distance learning activities" (Singh, 2011, p. 5). In addition, globalization of higher education has its own academic advantage because higher education is not only breaking down barriers and connecting institutions across the world, by making universities more visible, but it is also facilitating knowledge flows, values global learning, by creating new opportunities for advanced graduates and faculty across universities and higher education institutes around the world. (Singh, 2011, p. 4) Globalization of higher education can also translate into economic benefits for the hosting nations. Perhaps this is because globalization of higher education "refers more to competition, pushing the concept of higher education as a tradable commodity, and challenging 
the concept of higher education as a public good" (De Wit, 2011, p. 244). For instance: "In 2008, there were 178,227 international students who stayed in Canada for at least six months (long-term), generating more than $\$ 6.5$ billion for the Canadian economy" (Provincial and Territorial Ministers of Education and of Immigration, 2011, p. 12). In other words, “international students spent over $\$ 6.5$ billion on tuition, accommodations, and discretionary spending in 2008, and generated more than \$291 million in government revenue” (p. 14). Publicly funded academic institutions are motivated by these economic benefits to increase their competitiveness in order to participate in this global competition. Also, in January 2014, the Canadian federal government announced that publicly funded academic institutions should be more competitive in attracting more international students and should double the number of foreign students, since that will provide economic benefits and create at least 86,500 net new jobs for Canadians, bringing the total of jobs sustained by international education in Canada to 173,100 new jobs; see international student expenditures in Canada rise to over $\$ 16.1$ billion, generating economic growth and prosperity in every region of Canada; and provide an approximate $\$ 10$ billion annual boost to the Canadian economy. (Foreign Affairs, Trade and Development Canada, 2014, para, 6)

There are no guarantees that all countries around the world will gain similar benefits from the globalization of higher education. On the one hand, as Marginson (2004) suggested, "losers in the global education market are those developing nations that are too weak to sustain their own national and university identities or provide sufficient opportunities to draw back their foreign-educated graduates" (p. 24). On the other hand, English- speaking countries like Australia, Canada, UK, and USA have a competitive advantage in the global market of higher 
education since "students around the world are moving to the English-speaking countries in order to study English language and seek academic degrees" (Singh, 2011, p. 3). By comparing Australia, Canada, UK, and USA, Canada has a competitive advantage "as a country that offers high-quality education, relative affordability, and a high level of comfort with cultural diversity" (Provincial and Territorial Ministers of Education and of Immigration, 2011, p. 17). However, with respect to these benefits, Canada is still not able to take advantage; it "has 4 percent of the world's market share of international students, compared to 7 percent for Australia, 12 percent for the U.K., and 20 percent for the U.S" (Provincial and Territorial Ministers of Education and of Immigration, 2011, p. 13).

Globalization has fuelled competition by encouraging most countries around the world to open their markets, to deregulate their higher education systems, and to allow for new providers of higher education to participate in their markets (Douglass, 2005). It should not be surprising that competitive pressure has been experienced by Canadian universities since "provinces grouped under the Canadian banner have competed with the US, UK, New Zealand and Australia at student recruitment fairs" (Touhey, 2008, p. 2). In this regard, the Provincial and Territorial Ministers of Education and of Immigration (2011) confirmed that "between 2003 and 2007, Canada's population of international students grew by 6 percent, while Australia saw a 41 percent increase, the U.K. 89 percent, and the U.S. 27 percent" (p. 13). To deal with this matter, Canadian universities "should pursue global excellence through greater specialization, focusing on strategies to cultivate and attract top international talent, especially in the fields of math, science and business" (Competition Policy Review Panel, 2008, p. 68). In addition, Canadian governments allow for off-campus work experience for international students and also allow them to apply for permanent residence after they graduate, to enhance the competitiveness of 
Canadian academic institutions in the global market (Jie, 2010). But opening national universities to international students has been criticized because "the large number of international students muddies the waters of local merit-based competition for places" (Marginson, 2004, p. 20). In light of this viewpoint, one might ask if international students are part of the solution or part of the problem, and if "muddying" the water can be attributed to internal (national) government spending policies on higher education.

Globalization has also been criticized for its role in increasing the market power and reducing the influence of national governments on higher education (Douglass, 2005; Puplampu, 2004). According to Puplampu (2004), globalization of higher education has increased the autonomy of higher education institutions and their independence regarding their policies, their structure, and their research and development. Furthermore, globalization of higher education has made higher education a commodity, and academic institutions have redefined their programs to match the needs of the global market (Heidrich \& Chandler, 2011). Certainly, there is some truth to this, since globalization of higher education has encouraged universities to adopt business culture and that has affected the core culture of higher education (Marginson, 2004). But this is not the case for some American universities that do lead in academic research reputation, have a strong educational culture, and are competing nationally and internationally for talented students without adopting an entrepreneurial marketing approach (Marginson, 2004). These universities not only compete globally without changing their culture, programs, and curriculum, but they also set the standard for quality in higher education.

From the above discussion, one can recognize that globalization of higher education has played an important role in expanding the higher education market and in increasing competition 
around the world. The next section provides a review of literature on the role of autonomy of higher education in enhancing competition and in expanding the market of higher education.

\subsection{Competition and Autonomy of Higher Education Institutions}

Autonomy is another factor that might play an important role in expanding the market of higher education and increasing the competition. Autonomy of publicly funded academic institutions has increased due to the dependence on tuition fees and other private funds instead of public funds (Calhoun \& Kamerschen, 2010). In this regard, it is important to remember that "existing universities and colleges are becoming more private in the sense that revenue from fees and other private sources has increased substantially relative to revenue from public sources" (Cameron, Gorbet, Henderson, Stephenson, \& Smith, 1996, recommendation 18). Indeed, the declining role of government in higher education has increased autonomy power for publicly funded universities to manage and organize their activities (Kaklauskas et al., 2012). This autonomy has allowed publicly funded universities to easily move towards the market and to adopt market strategies that in turn would expand the market and fuel competition. For example, $51 \%$ of the operating budgets for Ontario's publicly funded universities was covered by tuition revenue (Ontario Confederation of University Faculty Associations (OCUFA), 2015a).

Consequently, one can assume that the autonomy of publicly funded universities will increase and the use of competitive activities will be raised across publicly funded universities.

Canadian universities, as Eastman (2006) described, "have been and remain relatively free from government control" (p. 64). According to the Council of Ministers of Education (2008), "publicly funded universities are largely autonomous; they set their own admissions standards and degree requirements and have considerable flexibility in the management of their financial affairs and program offerings" (p. 5). The structure of the Canadian higher education 
system is regulated typically by two board systems: Boards of Governors and Boards of Academic Senate. This type of structure gives more autonomy to academic institutions to "set prices and make program changes" (Calhoun \& Kamerschen, 2010, p. 320). For example, on April 10th, 2014, the University of Guelph (U of G) announced that the board of governors approved the budget for the 2014-2015 academic year.

$\mathrm{U}$ of $\mathrm{G}$ tuition will increase by 2.81 per cent for entering and continuing undergraduate domestic students. Tuition for continuing undergraduates in professional programs will increase by four per cent; students entering professional programs will pay five per cent more. Graduate tuition will increase by two per cent for both entering and continuing students. (University of Guelph, 2014)

Indeed, autonomy can be seen through the duties of the Board of Governors, who have the power to draw the vision and values of institutions, to establish university service fees, and charge tuition based on government regulations. Further, the Academic Senate also has the authority to review academic programs and implement academic standards and curriculum policies (Calhoun \& Kamerschen, 2010). The increasing level of autonomy has allowed universities "to competitively price their educational services and choose what academic programs might best draw student enrolment demand" (Douglass, 2005, p. 6). One can argue that these decision-making bodies have the authority to review and implement price and non-price competitive processes, but their power is limited, since the government still has the power over their decisions.

\subsection{Strategic Enrolment Management}

The pressure towards strategic enrolment management has risen due to demographic changes in the traditional ages of high school students, the change of public priorities, and the 
growing number of academic institutions (Hossler \& Bontrager, 2014). These factors have fuelled competition across institutions and academic leaders have started to recognize the importance of strategic enrolment management. Strategic enrolment management, as Vander Schee (2009) described, is the adoption of competitive activities by academic institutions to reach institutional goals of attracting and retaining students. Hossler and Bontrager added that it is a combination of a university's programs, plans, policies, and activities that influence students' decisions to enrol. While strategic enrolment management focuses mainly on attracting potential students through the use of market tools, it also focuses on admission, retention and attrition (Vander Schee, 2009).

To reach the goal of recruiting an optimal number of new students and keeping current enrollees, Hossler and Bontrager (2014) suggested that strategic enrolment planning should be based on data analytics and institutional research. Further, understanding both a university’s internal situation and a university's external environment is essential to conducting a successful strategic enrolment plan (Wilkinson, Taylor, Peterson, \& Machado-Taylor, 2007). A university needs to highlight its strengths and weaknesses and its competitive advantage, and to understand its external challenges and threats, in order to make a good strategic enrolment plan. Wilkinson et.al noted that strategic enrolment planning is a continuous process and subject to change, since each academic institution has its own changeable circumstances that require adopting different strategic enrolment plans to fit its situation.

The effectiveness of strategic enrolment management can be monitored through setting activities "to stabilize enrollments; focus on quality and retention; engage in long-term revenue planning; [and] to reduce vulnerability to environmental forces" (Johnson, 2000, p.6). Johnson added that successful enrolment management should be supported by institutional research, and 
also has to utilize financial and demographic data in order to adopt proper competitive strategies. At the same time, enrolment managers need to handle many things, including “examining what factors influence students’ persistence, developing appropriate marketing, pricing, and financial aid strategies, matching student demand with curricular offerings that are consistent with an institutional mission, and paying attention to academic, social, and institutional factors that can affect student success and graduation”. (Hosslar, 2004, p. 3)

There are few published studies that have examined factors that might affect enrolment and applications across Canadian publicly funded universities in the Canadian higher education market. There have been some studies focussing on enrolment trends and on specific factors such as tuition fees, gender, age, socio-economic status, and parental education. Other studies have also focused on enrolment in specific academic institutions, or in specific programs such as medical or engineering. For example, Austin and Wanzel (2015) analyzed the trends of application to Canadian surgical training programs. Another report (Brown, 2014) highlighted enrolment trends and suggested that enrolment has declined by about $2.9 \%$ among high school graduates. The report explained the reduction in enrolment for specific universities in Ontario and highlighted the importance of population growth on enrolment.

Finnie, Childs, and Qiu (2012) examined persistence ratio in Ontario in comparison with the rest of Canadian provinces. Finnie at al. discussed persistence determinants from two viewpoints: pre-entry features such as age, gender, parental education, high school preparation, students' abilities; and post-entry experiences such as finance, and peer effects. They found that dropout rate is high across first year students in comparison with other years. For college students, the dropout rate (the rate of students leaving post-secondary education completely 
without graduation) among first year students is about $14.9 \%$ compared to $13.3 \%$ for the rest of Canadian provinces. Most colleges offer one-year programs (certificate), two-year programs, and three-year programs. The graduation rates (the rate of students staying at an academic institution until graduation) for first, second, and third year students are about 12.6\%, 49.2\%, and $67.9 \%$ respectively. These rates are higher in Ontario compared to other Canadian provinces. For university students, first year dropout rate is about 3\% compared to $9.7 \%$ for the rest of Canadian provinces. While many universities provide four-year programs, the graduation rate in the first three years of university programs is less than $5 \%$ for both Ontario and the rest of Canadian provinces. The graduation rate in fourth-year is, as Finnie et al suggested, $41.4 \%$ in Ontario compared to $28.6 \%$ for the rest of Canadian provinces. Finnie et al. concluded that students from single-parent families are more likely to dropout, while, first generation and second generation immigrants are less likely to dropout. Good high school preparation also had a significant effect on reducing dropout rate.

Factors that might affect the enrolment and persistence ratios were examined by Canadian Council on Learning (CCL) who reported that tuition fees might affect students' enrolment decisions negatively. Student Financial aid, as CCL suggested, does not have a strong effect like tuition fees, but it still has a positive effect on enrolment and persistence. Other factors like unemployment rates, wages for high school students, socio-economic status, and parental education were also examined by the CCL. The report suggested that high unemployment rates might increase enrolment in post-secondary education. High wages for high school graduates can decrease enrolment, while high wages for post-secondary graduates can increase enrolment at universities and colleges. Also, the CCL stated that enrolment has declined among students who have low socio-economic status and among students of uneducated 
parents. According to the CCL, examining the factors that might affect enrolment and persistence ratio facilitates the prediction of change in enrolment.

Snowdon (2004) investigated the demand for higher education by examining applications for admission. He highlighted the significance of demographic changes in the university-age population across Canadian provinces and its effect on demand for higher education. The focus of his study was on the applications trend for high school traditional students in each province over the period of 1998-2003. For Ontario, Snowdon found that the percentage of qualified applicants who did not get an offer of admission has increased from 3.8 to 5.3\%. Qualified applicants were defined as applicants who have the minimum requirements to attend. He added that Ontario universities were fully prepared to the double cohort of high school graduates in 2003. At the same time, offers for qualified students had increased by $1 \%$ only (from $95 \%$ to 96\%) for fall 2003.

The effect of scholarships on enrolment in the US higher education market was examined extensively by Cornwell, Mustard, and Sridhar (2003). They found that enrolment was positively affected by scholarships and grants. This argument was examined by Hung (2003) who studied the effect of scholarships on students' enrolment decisions for both low-income and high-income groups. Hung examined high tuition/high aid strategy and found that low income students did not respond positively to this strategy. High tuition had a negative effect on enrolment for the low-income group and financial aid had no significant effect in this case. He argued that the availability of information regarding scholarship and grants might help in increasing the effectiveness of this strategy. Hung found that there was a positive relationship between enrolment and scholarships, but surprisingly, the high income-group responded more strongly to scholarship than the low income-group. The likely reason, as Hung explained, is that 
the high-income group knew more about their state's scholarship programs and generally had more information compared to the low income group.

Other factors like age, gender, ethnicity, family characteristics, ability, and job-market, were examined by Stratton, O'Toole, and WetZel's (2004). They examined part-time and fulltime enrolment decisions and suggested that enrollment of part-time students is affected positively by job opportunities and lower employment rate. Bergh and Fink (2006) examined the relationship between public spending on higher education and enrolment in 132 countries. They suggested that there is insignificant relationship between public expenditure on higher education and enrolment. Bergh and Fink suggested that because there is a positive relationship between public spending on primary and secondary education and graduation rates, more spending on this educational system might improve enrolment in higher education due to higher graduation rates. Fredriksson (1997) examined the effect of awards, after-tax wage for post-secondary graduates, and unemployment rate on demanders of higher education in Sweden and found that there is a significant relationship between the tested independent variables and demand for higher education.

The above discussion sheds light on some factors that might affect students' decision to enroll and apply. This study aims to build on this literature and examine other factors (awards, marketing, graduates, professors, and population) that might affect the behaviour of demanders of higher education.

\subsection{Summary of Chapter Two}

Publicly funded universities exist not only to serve the public welfare and spread knowledge, but also are concerned with making revenue. This is because academic institutions can be seen as market organizations and as non-market organizations. "Market organizations 
derive their revenues from prices charged for output ... [and] non-market organizations derive them from taxes, donations or other non-priced sources" (K. Brown, 2010, p. 12). Collecting tuition fees and seeking private funds have encouraged academic institutions to be involved effectively in the market to sell their products and services, and make them market organizations (K. Brown, 2010; Sheehy, 2010). At the same time, they can also be seen as non-market organizations, since they still generate part of their revenue from donations and other public sources.

There is a large volume of literature that is focused on the economics of education, but there is a need for a specific study to examine Ontario's higher education market, since most previous studies have focused on competition in the whole market in one individual country. There is a noticeable gap in literature that does not deal extensively with using market tools by publicly funded universities and there is not enough information about the use of price and nonprice competitive variables in Ontario's higher education market. The need for a specific study to fill that gap and examine the effect of movement towards the market by examining the relationship between input-output variables of competition is important for Ontario's field of higher education. Furthermore, using a market approach in higher education is not a new phenomenon, but examining university expenditure on price and non-price competitive variables and their effects on applications, enrolment, and persistence ratio in publicly funded universities is new. Certainly, the topic of the higher education market, how universities compete, and the adoption of competitive variables to increase competitiveness is an interesting topic to be explored objectively. This study cannot answer all competition-related questions, but it proposes to deal with one important question of how competition can affect publicly funded universities in Ontario. Answering this question and analyzing the phenomenon of competition among Ontario 
universities serves the purpose of this study, and has the potential to assist academic leaders in making good spending decisions and in managing enrolment. 


\section{CHAPTER THREE: METHODOLOGY AND METHODS}

This chapter provides a detailed explanation of the epistemological approach, the methodology, and the methods selected to address the main and subordinate research questions. This chapter also describes the research population and sample, the data collection method, data analysis, trustworthiness, validity and reliability of the research findings, limitations of the selected methodology, and a brief summary of ethical considerations.

\subsection{Epistemological Approach}

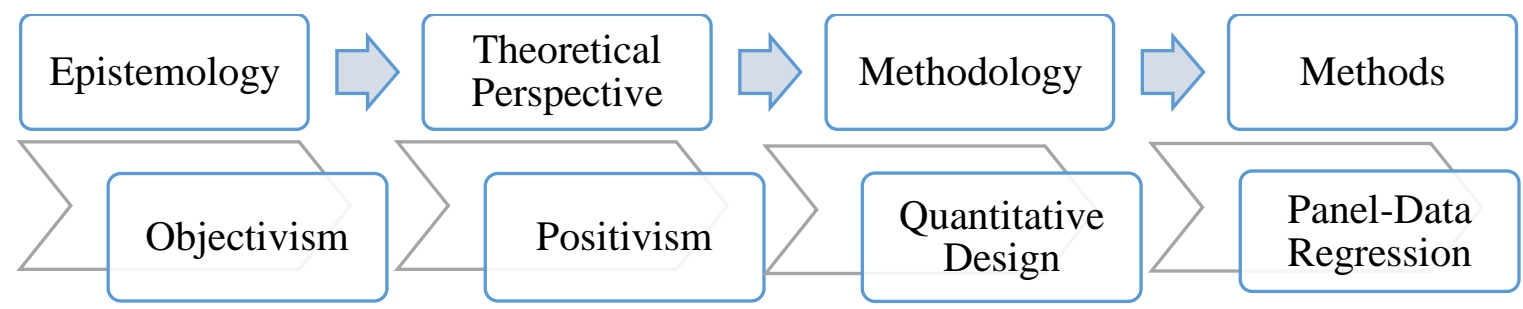

Figure 1. Epistemological Approach

Note: The sequence of the above epistemological approach figure is based on Crotty (1998).

Objectivism was defined by Crotty as "the epistemological view that things exist as meaningful entities independently of consciousness and experience ... [and] research can attain that objective truth and meaning" (p. 5). This approach will be essential to uncover existing realities in the academic market of Ontario, since this study is not building or constructing the researcher's own realities. At the same time, positivism is linked to objectivist epistemological stances. According to Scott and Usher (2010), realities do exist on their own.

The world is 'real', that it exists around us 'out there' indifferent to our hopes, beliefs and desires at any particular moment. This independent 'objective' world is the yardstick against which we must measure our hopes, beliefs, etc. to assess and establish their truth and reality. (p. 15) 
Scott and Usher argued that positivism "still remains a dominant philosophy in practice, and of course is particularly alive and well in the practices of technical rationality, itself still influential in educational research, practice and policy-making" (p. 14). According to positivism, realities exist independently and they can be discovered by the research process. Positivism was adopted to uncover the existing realities regarding the effect of competition on enrolment, applications, and persistence ratio in publicly funded universities in Ontario's higher education market. The epistemological view in this study is based on knowledge that exists independently and can be discovered by using empirical data and unambiguous quantitative measurement tools (Crotty, 1998; Hinchey, 2005). According to Crotty, positivism, which is based on observation, experiments, and comparison methods, has been used to describe the relationship between variables. At the same time, positivism, as a way of doing research, "involves accepting the position that there is a set of logical rules of explanation, independent of the world and its social practices, that can distinguish between and judge all knowledge claims" (Scott \& Usher, 2010, p.13).

The choice of this epistemological view was guided by the nature of the research questions and purposes. Other epistemological approaches can be used for different research purposes but, in this case, objectivism and positivism is the right fit, since these can serve the research purpose of measuring and uncovering the existing reality of the effect of competitive variables on enrolment, applications, and persistence ratio. Other epistemological stances like constructionism or subjectivism might be irrelevant here. Approaches based on individuals' beliefs, opinions, feelings, experiences, and hopes could not serve the research purpose and could not be accepted easily, owing to human bias. In this case, it is unacceptable to draw a conclusion based on people's understanding of the effect of awards, marketing, graduates, 
professors, and population on enrolment, applications, and persistence ratio in publicly funded universities. The purpose of this study is not to understand an individual perception of realities, but rather to discover and report the existing reality and draw a conclusion based on objective data and not on individual perspectives.

Adopting a positivism without any personal subjective effect on constructing a reality (e.g., researchers' own experiences and beliefs) can, certainly, work to produce "generalizable" results. Matusitz and Kramer (2011) suggested that "positivism demands that there can be only one true picture of reality, only one best solution for each problem" (p. 299). According to Crotty (1998), positivism is interested in reaching an estimated truth. The use of any other epistemology might not be appropriate, due to the large number of academic institutions in the study. Indeed, using statistical techniques and numerical data can combine well with the 'handsoff' approach of positivism.

\subsection{Research Methodology}

In this research, a quantitative research methodology was the right fit. Quantitative design is "research in which the researcher decides what to study; asks specific, narrow questions; collects quantifiable data ...; analyze(s) these numbers using statistics; and conduct(s) the inquiry in an unbiased, objective manner" (Creswell, 2008, p. 46). This quantitative design is an appropriate choice for this study, since it allows statistical analysis to measure the relationship between two or more variables and examine how they impact each other. This design can be used when researchers "seek to relate two or more variables to see if they influence each other" (Creswell, 2008, p. 356). Employing this methodology has the potential to answer the research main and sub-questions by estimating the effect of competition through examining the relationship between universities' expenditures on price and non-price 
competitive variables and the number of applicants, the number of enrollees, and persistence ratio in Ontario publicly funded universities. This methodology can be used to explain how independent variables can influence dependent variables (Creswell, 2008).

The nature of the research questions, the research purpose, and the epistemological approach in this research have played an important role in choosing quantitative research methodology. This methodology can yield "conclusions made with reasonable certainty" (Jha, 2008, p. 23). It can also be argued that this methodology might enhance the credibility of the research results by reducing the possibility of human bias. In addition, this methodology allows the researcher to generalize the research results to a similar population of higher education institutions, such as those in other provinces.

\subsection{Research Methods}

This research has used panel regression analysis method to measure the relationship between dependent and independent variables (Creswell, 2008). Panel regression analysis method can be used when researchers need to determine the change of variables in the same specific organization over time (Creswell, 2008). Panel regression analysis is an appropriate choice for this study, as this study has examined 19 universities over eight years. According to Cooper, Glaesser, and Hammersley (2012), regression analysis is valued for its scientific and legitimate quantitative approach. This "analysis involve[s] inferences that are clearly more mechanistic (i.e., nonjudgmental or 'objective') and more precise” (Howe, 2003, p. 33). In addition, this statistical method (panel regression analysis) can reduce the bias by controlling for observed and unobserved or unmeasured variables that might be correlated with $\mathrm{X}$ variables that, in turn, would affect the regression outcomes of $\mathrm{Y}$. 
Therefore, Pooled, Random, and Fixed Effects regression analysis models were used to predict competition outcomes by examining a set of competition variables and analyzing the relationship among them. Pooled regression is the easiest estimation method. Pooled estimation was used and the panel structure of the data was ignored (Johnston \& DiNardo, 1997). A Random Effect model was used by assuming that there are outside or unobserved variables but that are uncorrelated with $\mathrm{X}$ independent variables. A Fixed Effects model was also used, based on the assumption that there are other factors (observed and/or unobserved variables) that are correlated with independent variables and might affect the regression outcomes.

While regression analysis has been employed to describe the relationship between variables (e.g., positive or negative), the advanced statistical method of panel data regression analysis was used to predict and describe the degree of association between variables. The natural logarithm for both dependent and independent variables (log-log regression) was conducted to predict the direction and magnitude of the responsiveness of dependent variables with respect to change in adopted independent variables. To find out the similarities and differences across Ontario universities, regression analysis using university level data was conducted for each dependent variable separately for publicly funded universities in Ontario. According to Salvatore (2004), regression analysis can provide useful information about how the variation in one variable would affect the other variable. Therefore, regression analysis was used to determine:

1. The statistical significance of each independent and control variables' effect on dependent variables ( $\rho$ value or probability value: is the exact level of significance) (Gujarati, 2003). 
2. The size of each independent and control variables' effect on the dependent variable (parameter coefficient $(\beta)$.

3. R-Squared: "is a measure of the degree of association between two variables" (Gujarati, 2003, p. 85).

4. A standard error of estimation: is about the variability of the statistic (e.g., mean and variance) (Norusis, 2004). Standard error might be positive or negative, but a smaller value of standard error is better (Gujarati, 2003). Gujarati (2003) noted that a standard error of estimation "is simply the standard deviation of the $\mathrm{Y}$ values ... and is often used as a summary measure of the 'goodness of fit' of the estimated regression line" (p. 78). The produced regression equation was used to predict the effect of competition and the use of competitive variables for each analyzed university. This prediction can help academic leaders to choose the proper competitive variables that fit their mission and vision and that will work with their institutional needs. This prediction can also help in exploring the effect of competition in Ontario's higher education market and whether it is a "healthy" phenomenon for academic institutions or not.

3.3.1 Variables and formulations. In this study, panel data formulation was employed to estimate the effect of competition on applications, enrolments, and persistence ratio in each individual university over eight years. A panel data regression model has used the following regression prediction equation:

$\log Y(\mathrm{t})=\alpha+\beta 1 \log X l(\mathrm{t}-1)+\beta 2 \log X 2(\mathrm{t}-1)+\beta 3 \log X 3(\mathrm{t}-1)+\beta 4 \log X 4(\mathrm{t}-1)+\beta 5 \log X 5(\mathrm{t})+u$

Where:

$Y$ is the dependent variable. 
$\alpha$ is an individual effect or heterogeneity that includes a constant term and a set of individual specific variables that may be observed or not observed.

$\beta$ is the slope coefficient (responsiveness of the target variables: the estimation of the percentage change in $\mathrm{Y}$ when $\mathrm{X}$ is changed by one percent).

$X$ are the independent and control variables.

$u$ is the error term.

The dependent variables are:

1. Enrollees $=$ natural logarithm of the number of enrolments.

2. Applicants $=$ natural logarithm of the number of applications.

3. Persistence Ratio = natural logarithm of persistence ratio (total number of enrollees to total number of applicants).

The independent and control variables are:

1. Awards $=$ natural logarithm of the expenditure on scholarships and bursaries.

2. Marketing $=$ natural logarithm of the expenditure on communications and other operational expenditure, which includes advertising and marketing.

3. Graduates $=$ natural logarithm of the expenditure on research, which includes doctoral fellowships, research assistants, and teaching assistants.

4. Professors $=$ natural logarithm of the expenditure on ranks, which includes full, associate, and assistant professors.

5. Population $=$ natural logarithm of the city/metropolitan population (control variable). 


\subsection{Data Collection}

In this study, quantitative data was collected and derived from the main data sources of Statistics Canada, the Ontario Universities' Application Centre (OUAC), and from the Council of Ontario Universities (COU): Common University Data Ontario (CUDO). Panel data was collected at the university level for 19 Ontario publicly funded universities (the target population). Using panel data can give "more informative data, more variability, less collinearity among variables" (Gujarati, 2003, p. 637). By repeating observation of several variables for the same publicly funded universities (19 universities over 8 years), useful information regarding competition behaviour would be collected. In this research, numerical values of all variables were collected for the academic years 2006 to 2013. These quantitative data already exist and were collected directly from Statistics Canada, OUAC, and the COU website.

Universities' expenditure data (awards, marketing, graduates, and professors) collected directly from COU. While the data for the number of applications for admission were collected from OUAC, the data of number of enrolled students were collected from COU. All data were collected at one time. For example, data of the number of applications for admission and data of the number of enrolled students (headcount) were collected annually for the Fall term, (e.g., $2006,2007 \ldots$. . regardless of if the process of application for admission and the process of enrolment had been delivered in September, February, or July. The control variable data (population in each university location) were collected from Statistics Canada. Finally, the accuracy of the data was addressed by collecting the data of each variable from reliable sources to enhance the validity and reliability of the research result. Appendix A includes all collected data for each publicly funded university. 
3.4.1 Evaluating the quality of collected data (panel data). The panel data set covers 19 publicly funded universities in Ontario over eight years. The same 19 universities were observed for each period of time (yearly from 2006 to 2013) and the total number of observations is 152 (19 Universities*8 years). During the time of data collection, panel data was collected carefully in two steps. First, it was collected and prepared for analysis by organizing it in tables. Data were organized in tables to show the variables' information for 19 publicly funded universities in Ontario (Appendix A). Second, the data set was organized in a long-shape format that is compatible with and easily read by Stata software. Prior to analyzing the data, I matched the values of all variables in tables and in long format to check for data entry errors and to check for missing data. In addition, I manually checked for the quality of panel data by examining if panel data were well organized or not (cross-sectional and time-series). This manual check confirmed that data were well arranged (both cross-sectional and time series), and panel data regression models were appropriate. In addition, the panel data set was also checked by Stata software to show the characteristics of the data and to make sure the data were well-structured. Stata is a statistical software package that is used to analyze many types of data including panel data. For this study, Stata 13 was employed to explore, summarize, and analyze variables.

In reviewing data, a small proportion of it was missing for some variables in some universities (Appendix B, Table $12.1 \&$ Table 12.2). Missing data represents less than six percent of total data, and there were no patterns of missing values. Therefore, this study has used a statistically appropriate approach to handle missing data by adopting the List-wise deletion method, the most commonly used approach in dealing with missing data. This is because of the existence of a small percentage of random missing data. List-wise deletion eliminates any 
observation with missing values by dropping it completely from the analysis, which allows for the use of all available information for each university.

However, Stata software automatically analyzed the data by implementing the List-wise deletion method. Stata software ignores all observations that have a missing value for the dependent and independent variables. Because there is a small proportion of random data missing, the List-wise deletion method, also called complete case analysis, can produce unbiased coefficients, regardless of how it reduces the number of observations. In this study, a small proportion of observations were dropped, and that does not affect the accuracy of results. Therefore, due to the existence of missing data, this study analyzed the data by adopting the List-wise deletion method.

In this study, a Lagged model was used to analyze the effect of adopted competitive variables on enrolment, applications, and persistence ratio. In the Lagged model, the total number of enrollees, total number of applicants, and persistence ratio in the current year (t) were linked to various categories of expenditure in the previous year ( $\mathrm{t}-1)$, as well as the population in the current year $(\mathrm{t})$. A model was used to estimate the responsiveness of enrollees, applicants, and persistence ratio in the current year $(\mathrm{t})$ to university expenditure on adopted competitive variables in the last year (t-1). For detailed information about data collection, Tables 2, 3, and 4 provide full explanations regarding data sources and a measurement summary for all dependent, independent, and control variables. 
Table 1. Collected Data and Sources for Dependent Variables

Collected Data

Sources

Total Number of Enrolled Students

Total number of Enrolled Students includes both domestic and international and full and part-time students who enrolled in BA,

$\mathrm{MA}$, and $\mathrm{PhD}$ programs in a Fall term.

Council of Ontario Universities: Common

University Data Ontario

Total enrolment was collected annually and includes those who

enrolled for Fall term. For example, total enrolment in 2006

(academic year of 2005-2006) is the total enrolment in Fall 2005.

Total Number of Applications for Admission

Total number of applications includes all choices (1st, 2nd, 3rd,

$\ldots>3$ ), for all domestic and international applicants.

Ontario Universities' Application Centre, Common University Data Ontario

Total number of applications for admissions was collected annually. For example, total number of applications for the year of 2006 (academic year 2005-2006) is the total number of applications for admission for Fall 2005.

Persistence Ratio

Persitence ratio was calculated by dividing total number of enrolled students by total number of applications for admission,

Table 2. Collected Data and Sources for Independent Variables

Collected Data $\quad$ Sources

Awards, Marketing, Graduates, and Professors.

University expenses for fiscal year ending April 30, 2005 was reported under the year of 2006 (academic year 2005-2006). The adoption of fiscal year ending April, 30, 2005 for 2006 allows for examining its effect on enrolment for Fall 2005 (academic year 2005-2006), and also examining its effect on number of applicantions for admission for Fall 2005 (academic year 2005-2006). The same logic applies for the other years.
Council of Ontario Universities: Common University Data Ontario 
Table 3. Collected Data and Sources for Control Variables

\begin{tabular}{l}
\hline Collected Data \\
\hline Census Population for Each University Location in Ontario \\
Estimated census population for 18 out of 19 universities location \\
area was availale at annual population estimates by census \\
metropolitan area, Canada - Population at July 1. \\
Estimated census population in North Bay area was not included in \\
annual population estimation by census metropolitan area, canada - \\
population July 1. \\
To estimate census population for North Bay area for the years \\
2006 to 2013, the researcher has used percentage change of \\
population between two census years (census 2006 and census \\
2011) in North Bay area. These percentages are obtained from \\
Census metropolitan areas (CMAs) or census agglomerations \\
(CAs) in Ontario. \\
Census population in both North Bay over the years was \\
estimated as follows: estimated population in 2007 was: census \\
population in 2006 + (census population in $2006 * \%$ of change \\
with respect to compound rate). Same mathmatical process was \\
used to estimate census population for the rest of the years.
\end{tabular}

In the process of managing the data and prior to running the regression analysis, testing

for heteroskedasticity was conducted. The Breusch and Pagan test for heteroskedasticity (heteroskedasticity across variables) and the Wald test (heteroskedasticity across universities) were performed (Appendix C, Table $13.1 \&$ 13.2). Heteroskedasticity might occur when the variance of the error term is not constant (Gujarati, 2003). In this study, a greater variability in expenditure among universities might create the problem of heteroskedasticity. In other words, the variance of the error term might be affected when university expenditure is extremely high in larger universities and/or extremely low in smaller universities. The result is found in Appendix $\mathrm{C}$ and the presence of heteroskedasticity is shown. Due to heteroskedasticity, standard errors become biased, which affects the significance (too high or too low), and this can lead one to draw the wrong conclusion. However, the presence of heteroskedasticity suggests that the 
relationship between the dependent variables and the independent variables is not linear. In this case, the transformation of the variables by using natural logarithm of the dependent and independent variables was conducted to provide accurate standard error, p-values, and accurate estimates. In addition, robust standard error was conducted to correct heteroskedasticity and to avoid the biased standard errors. Stata software offers a technique to handle the problem by running the regression with robust standard error through adding the option of robust or cluster. Correcting heteroskedasticity leads to consistent standard error and provides accurate p-values and accurate estimates.

\subsection{Data Analysis}

This study was guided by one main research question: How does competition affect publicly funded universities in Ontario? Three research sub-questions were examined to address the main research question. Examination of these questions was guided using panel data regression models (Pooled OLS, Fixed Effect, and Random Effect). The objective of conducting these models was to provide unbiased and accurate estimates through choosing a proper model. The study began with the simplest case, assuming that unobserved heterogeneity across universities does not exist. A Pooled OLS model can provide consistent and efficient estimates if individual specific effect (heterogeneity) does not exist. But if heterogeneity or individual university effect is not zero and correlated with the included variables, Pooled OLS can no longer provide unbiased estimations. This is to say that the Pooled OLS regression model might produce biased estimates as a result of ignoring the panel structure of data and as a result of treating all universities equally and ignoring any differences across universities.

In this study, the analysis also incorporated the complicated case of assuming that heterogeneity does exist, but it is unobserved and cannot be included in the regression equation 
as an explanatory variable due to the unavailability of its data. For example, it is hard to include university reputation or university program differentiation as an explanatory variable, since these are hard to measure. To capture this dimension, Fixed Effect and Random Effect models were used. A Fixed Effect model can provide consistent and efficient estimation if university specific effect (heterogeneity) does exist and has a correlation with explanatory variables. A Random Effect model can also provide consistent and efficient estimation if university specific effect (heterogeneity) might exist, but it does not correlate with the included explanatory variables. In this study, Fixed Effect (Least-Square Dummy Variable (LSDV)) was conducted to handle the possibility of the correlation between unobserved heterogeneity and explanatory variables. The Fixed Effect (LSDV) model is useful for this study since universities are different from one another and each individual university has its own set of omitted variables that might be observed or not observed and might be correlated, positively or negatively, with explanatory variables. With the Fixed Effect (LSDV) model, the study used one set of dummy variables (Brock_U, Carleton_U... and York_U) to control for any differences across universities and to capture any specific effect in that university.

The analysis further conducted a modified Fixed Effect regression for each individual university due to the assumption that not only the intercepts but also the coefficients vary for each individual university. A modified Fixed Effect regression is about extending Fixed Effect (LSDV) to include not only university dummies but also their interactions with explanatory variables that provide differential slop coefficients (differential effect of explanatory variables for each university). The interaction term or the additional effect is the effect coefficient that measures how enrolment, applications, and persistence ratio respond to any change in university expenditure on price and non-price competitive variables for each individual university. In this 
study, a persistence ratio was examined to complement the analysis of enrolment and applications. The persistence ratio (total enrollees to applicants) was investigated, since it might be an important target from the adoption of competitive variables. However, conducting this model provides an opportunity to gain new insights regarding the relationship among the variables and to explore the responsiveness of enrolment, applications, and persistence ratio to changes in the adopted competitive variables for each individual university.

In this study, three sub-questions were addressed to answer the main research question. For the first-sub question, panel regression models were used to examine the relationship between competition in Ontario's higher education market and the number of enrolled students in each university for the years 2006 to 2013. The effect of competition can be estimated by examining the effect of using price and non-price competitive variables on enrolment in publicly funded universities. This estimation can measure the degree of association between variables, and also can examine how $\mathrm{Y}(\mathrm{t})$ (dependent variables: the number of enrolled students) at publicly funded universities might be affected by changes in $\mathrm{X}_{\mathrm{t}-1}$ (independent variables: universities' expenditure on price and non-price competitive variables; control variable: population). The notation "t- 1 " indicates that a variable is lagged by one year. Lagged variables associated with expenditure in the previous year (t-1) were used to predict the responsiveness of the dependent or "Y" variables in current year $(\mathrm{t})$;

The first research sub-question was answered by estimating the percentage change in the number of enrolled students in a publicly funded university, due to:

- a one percent change in a university's expenditures on awards $\left(\mathrm{X}_{1}(\mathrm{t}-1)\right)$;

- a one percent change in a university's expenditures on marketing $\left(\mathrm{X}_{2}(\mathrm{t}-1)\right)$; 
- a one percent change in a university's expenditures on graduates $\left(\mathrm{X}_{3}(\mathrm{t}-\mathrm{l})\right)$;

- a one percent change in a university's expenditures on professors $\left(\mathrm{X}_{4}(\mathrm{t}-1)\right)$;

- a one percent change in the census population of a university location $\left(\mathrm{X}_{5}(\mathrm{t})\right)$;

The second research sub-question was answered by estimating how much $Y(t)$ (dependent variables: the number of applications for admission) at publicly funded universities might be affected by changes in $\mathrm{Xt}_{\mathrm{t}-1}$ (independent variables: universities' expenditure on price and nonprice competitive variables; control variable: population). Panel data regression models were used to estimate the effect of competition by examining the percentage change in the number of applications for admission in publicly funded universities due to:

- a one percent change in a university's expenditures on awards ( $\left.\mathrm{X}_{1}(\mathrm{t}-1)\right)$;

- a one percent change in a university's expenditures on marketing $\left(\mathrm{X}_{2}(\mathrm{t}-1)\right)$;

- a one percent change in a university's expenditures on graduates $\left(\mathrm{X}_{3}(\mathrm{t}-1)\right)$;

- a one percent change in a university's expenditures on professors $\left(\mathrm{X}_{4}(\mathrm{t}-1)\right)$;

- a one percent change in the census population of a university location $\left(\mathrm{X}_{5}(\mathrm{t})\right)$;

The third research sub-question was answered by estimating how much $Y_{(t)}$ (dependent variables: persistence ratio) at publicly funded universities might be affected by changes in $\mathrm{Xt}_{\mathrm{t}-1}$ (independent variables: universities' expenditure on price and non-price competitive variables; control variable: population). Panel data regression models were used to estimate the effect of 
competition by examining the percentage change in the persistence ratio in publicly funded universities due to:

- a one percent change in a university's expenditures on awards $\left(\mathrm{X}_{1}(\mathrm{t}-1)\right)$;

- a one percent change in a university's expenditures on marketing $\left(\mathrm{X}_{2}(\mathrm{t}-1)\right)$;

- a one percent change in a university's expenditures on graduates $\left(\mathrm{X}_{3}(\mathrm{t}-1)\right)$;

- a one percent change in a university's expenditures on professors $\left(\mathrm{X}_{4}(\mathrm{t}-1)\right)$;

- a one percent change in the census population of a university location $\left(\mathrm{X}_{5}(\mathrm{t})\right)$;

Examining a university's expenditure on price and non-price competitive variables (i.e., awards, marketing, ...) and other control variables (i.e., census population of university location) at each academic institution can reveal how these universities compete by using these competitive variables in the market of higher education. Answering the above sub-questions is important in understanding the competitive behaviour and its effect for each university in Ontario and can make it easier to compare the effect of their competitive behaviour. In addition, it can help in predicting the effect of using these variables and can help in identifying the proper variable/(s) that could be utilized to enhance the competition outcome in each institution. This process also can explore how Ontario publicly funded universities are using price and non-price competitive variables to compete and can help to show the big picture of competition in Ontario’s higher education market.

\subsection{Research Population and Sample}

A research study population has been defined by Creswell (2008) as a group that has the same characteristics (e.g., publicly funded universities). This study has analyzed the competitive 
behaviour within publicly funded universities operating in Ontario. Choosing Ontario's higher education market and Ontario's publicly funded universities as a population in this study is based on the fact that Ontario has a large number of publicly funded universities compared to other Canadian provinces. Ontario has a large market share of higher education compared to other provinces. Ontario publicly funded universities were the first, compared to other provinces, to adopt corporatization and marketization activities to compete for public and private sources of income (Cameron, 2005). According to the Rae report in 2005, Ontario's publicly funded universities have experienced a huge shortage of public funds compared to other Canadian provinces (Cameron, 2005). In Ontario, the "postsecondary system as a whole, including colleges, provincial support fell from over fifty per cent of total revenue to less than forty per cent between 1993-94 and 2002-03" (Cameron p. 281). The report stated that this shortage has fuelled the competition among publicly funded universities for other sources of income. Beach et al. (2005) added that, in Ontario, public funding for higher education became the lowest compared to other Canadian provinces as a result of the reduction of provincial funding for higher education by $36 \%$ between $1992-1993$ and 2002-2003. This means that competition for other sources of income has encouraged publicly funded universities in Ontario to adopt a corporate style and to adopt market competitive tools as solutions to survive. Therefore, the transformation towards the market and the adoption of corporatization and marketization activities by Ontario's publicly funded universities are not new, and they have encouraged the researcher to examine Ontario's higher education market and competition among these publicly funded universities.

In this study, 19 publicly funded universities in Ontario were analyzed as part of the study population, which means that the sample consists of $95 \%$ of the population. The province 
of Ontario has 20 publicly funded universities; Algoma University was excluded from the sample because there was only one observation for Algoma (Table 4).

Table 4. Description of the Sample

\begin{tabular}{ll}
\hline University Name & Location \\
\hline Brock University & St. Catharines, Ontario \\
Carleton University & Ottawa, Ontario \\
Lakehead University & Thunder Bay, Ontario \\
Laurentian University & Sudbury, Ontario \\
McMaster University & Hamilton, Ontario \\
Nipissing University & North Bay, Ontario \\
Ontario College for Art and Design (OCAD) & Toronto, Ontario \\
Queen's University & Kingston, Ontario \\
Ryerson University & Toronto, Ontario \\
Trent University & Peterborough, Ontario \\
University of Guelph & Guelph, Ontario \\
University of Ontario Institute of Technology (UOIT) & Oshawa, Ontario \\
University of Ottawa & Ottawa, Ontario \\
University of Toronto & Toronto, Ontario \\
University of Waterloo & Waterloo, Ontario \\
University of Windsor & Windser, Ontario \\
Western University: & London, Ontario \\
Wilfrid Laurier University & Waterloo, Ontario \\
York University & Toronto, Ontario \\
\hline Source: Ming
\end{tabular}

Source: Ministry of Training, Colleges and Universities, 2015

\subsection{Methodological Limitations}

Among the limitations associated with quantitative studies is the inability to provide human perspectives and opinions regarding the phenomenon under study. While quantitative data in the case of this study might provide comprehensive answers in relation to the study population (Ontario publicly funded universities), a deeper understanding of each university might not be reached. Indeed, numbers can tell many stories when one tries to understand organizations, but one will also be left with many unanswered questions. Utilizing a positivist epistemological approach can also contribute to some limitations. According to Howe (2003), 
"social life cannot be understood, or even accurately described, without 'meanings' that humans pervasively interpret.” (p. 102). At the same time, the purpose of this study was not to construct a personal understanding of competition in Ontario's higher education market but to measure and investigate the effect of competition based on universities' existing realities. This research approach has the potential to free the research study from human bias and will improve the reliability of the research results. At the same time, maturation bias might occur as a result of the change within the publicly funded university itself, owing to a change in its admission policies or as a result of the change in government policies. Another limitation can be linked to the use of historical data collected from existing databases, as history might not be a perfect indication for the future. Finally, since some universities accept applications for admission three times a year (e.g., summer, fall, and winter), this study has collected the data annually (e.g., 2006, 2007 ...) instead of collecting the data in each academic term.

\subsection{Trustworthiness, Validity, and Reliability}

Evaluating the validity and reliability of the research methodology and method enhances the trustworthiness of a research study. According to Easterby-Smith, Thorpe, and Lowe (2004), validity can be shown if "the instruments are accurate measures of reality" (p. 53), and reliability can be presented if "the research design is capable of eliminating bias and the effect of extraneous variables" (p. 53). To start, one can argue that the adoption of positivism is one way to strengthen the legitimacy of the research results. According to Howe (2003), trustworthiness

can be enhanced through the use of positivism that is "based on neutral observation ... [and] free of the interests, values, purposes, and psychological schemata of individuals" (p. 35). The targeted knowledge of the research is believed to exist independently and will not need to be 
built or constructed by the researcher (Scott \& Usher, 2010). The researcher's "hands-off strategy" during the research processes will enhance the trustworthiness of the results.

The internal and external validity of the research results can be shown through using appropriate research methodology and data collection methods, reliable data sources, and appropriate data analysis methods. For this study, the use of quantitative analysis methodology and a panel data regression method helped to boost internal validity by limiting the researcher's ability to influence the results (Fink, 2005; Norusis, 2004). According to Fink (2005), using an appropriate statistical analysis method to answer the research question can enhance the validity and reliability of research results. In this study, applying an appropriate data analysis method that clearly states the research question, clearly defines both dependent and independent variables, clearly explains the type of data, and sufficiently describes the statistical method and the statistical program to analyze the data supports the internal validity (Fink, 2005).

According to Fink (2005), "data collection is the soul of a study. The validity or 'truth' of all research depends on accurate data" (p. 106). Indeed, accurate data can strengthen the internal validity of this study because data was obtained from reliable sources: Statistics Canada, the Council of Ontario Universities (COU), and the Ontario Universities' Application Centre (OUAC). Finally, internal validity is assured in this study through preventing non-random sample bias, since the sample of population includes $95 \%$ of the research population (19 Ontario publicly funded universities out of 20).

Moreover, the external validity of the research results was addressed through the ability to generalize the results to other populations of publicly funded universities. In addition, collecting and analyzing empirical quantitative data will facilitate the replication of the same results through the process of testing and retesting and will enhance the generalizability of the 
results. Also, the use of quantitative analysis will allow other researchers to examine the validity of the result by repeating the measurement to validate the same research results. The validity and generalizability of the result to other situations can occur when the same result has been obtained by other researchers, who may repeat the experiment at different times using the same method (McNiff \& Whitehead, 2001).

Because most of the population of Ontario's publicly funded universities was included, this sample (19 universities out of 20) can help in generalizing the research result to the population under study. According to Scott and Usher (2010), "generalization from the sample to the population is therefore more difficult, except in those cases in which the researcher is confident that the whole population is included in their sample" (p. 79). At the same time, involving $95 \%$ of the population in the sample reduces the sampling error. Sampling error, according to Creswell (2008), may occur if the sample is very small and then the estimation result will not represent the study population.

\subsection{Ethical Considerations}

Formal ethics approval to collect the data is a requirement for both quantitative and qualitative research studies from academic ethics review boards. In general, permission from the researcher's academic institution is required before collecting the data (Creswell, 2008). According to The Conjoint Faculties Research Ethics Board (CFREB) at the University of Calgary, any potential studies that may interact with human subjects have to get ethics approval before the research is conducted (University of Calgary, n.d). In this study, quantitative methods were used and numerical data was collected from Statistics Canada, OUAC, and from COU: no human participants were involved in the study. The secondary data studied here is available to the public and can be downloaded from the government websites by anyone. At the same time, 
approval from the University of Calgary research ethics review board was sought; but for this study, ethics approval was not required, since no human participants were involved and all the secondary data was obtained from publicly available sources.

\subsection{Chapter Summary}

Table 5. Summary of Chapter Three

\begin{tabular}{ll}
\hline Title & Summary \\
\hline Sector & Higher Education \\
Population of Study & Publicly Funded Universities in Ontario \\
Sample Size & 19 Universities \\
Unit Analysis & Individual/Institutional Level \\
& Examining competition in higher education market by relating universities \\
& expenditure on using price and non-price competitive variables to \\
Study Purpose & enrolment, applications, and persistence ratio in Ontario over the period of \\
& Secondary data from Statistics Canada, Ontario University Application \\
Data Collection Methods & Centre (OUAC), and from Council of Ontario Universities (COU) \\
Methodology and Data Analysis Methods & Quantitative Research Methodology and Panel Data Regression Models \\
\hline
\end{tabular}




\section{CHAPTER FOUR: DATA ANALYSIS AND FINDINGS}

The aim of this chapter is to analyze data and to present the findings of this research

study. The study collected data to explore competition in Ontario's higher education market by examining the relationship between university expenditure on price and non-price competitive variables and enrolments, applications, and persistence ratio. Panel regression models (Pooled OLS, Fixed Effect, and Random Effect) were conducted for each research sub-question. The use of these models was motivated by whether or not estimates of parameter coefficients are statistically significant and whether or not there is a relationship between the variables under consideration. Panel data regression models were run with and without robust standard errors. The research results were reported from panel regressions with robust standard errors to get accurate standard error, p-values, and accurate estimates. These panel regression models were tested by using the F-test, the LM test, and the Hausman test to decide which model would provide consistent and efficient estimates to draw a correct conclusion.

In this statistical analysis, lagged explanatory variables are used to predict the percentage change in dependent variable in the year $(\mathrm{t})$ based on the previous year value (last year's) of explanatory variables ( $\mathrm{t}-1)$. A Lagged model was used to estimate the responsiveness of enrolments, applications, and persistence ratio in year (t) to university expenditure on adopted competitive variables in last year (t-1), as well as to the population in the same year $(\mathrm{t})$. The Lagged model was used because the potential enrollees and applicants and persistence ratio might not be affected immediately by the current year's expenditure. It is not uncommon to assume that enrolment in the current year $(\mathrm{t})$ depends on university expenditure of the previous year ( $\mathrm{t}-1)$. Indeed, the use of competitive activities by universities in the previous year has the potential to affect demanders' behaviour in the current year. In fact, if potential students who are 
convinced by the promotional activities of a university apply for admission, it will take them almost a year to get admitted and enrolled in a program. Thus, using lagged variables would be the right choice because of the "lagged" effect of the variables. Furthermore, this study identified five key research predictions about the regression results:

1. An increase in expenditure on awards is expected to increase enrolments, applications, and persistence ratio.

2. An increase in expenditure on marketing is expected to increase enrolments, applications, and persistence ratio.

3. An increase in expenditure on graduates could increase enrolments, applications, and persistence ratio (if research and teaching are complementary) or decrease enrolments, applications, and persistence ratio (if research and teaching are substitutes).

4. An increase in expenditure on professors could increase enrolments, applications, and persistence ratio (if research and teaching are complementary) or decrease enrolments, applications, and persistence ratio (if research and teaching are substitutes).

5. An increase in census area population is expected to increase enrolments, applications, and persistence ratio.

This chapter starts by presenting a summary of statistics to explore and review each variable's mean, standard deviation, minimum, and maximum. This is followed by presentation of the results for each research sub-question. Finally, the chapter presents the robustness checks through exploring the robustness of the research findings.

\subsection{Summary Statistics}

Summary statistics shows information about each variable's mean, standard deviation, and minimum and maximum. The table shows overall, between, and within statistics for each 
variable. The overall statistics provide information that is based on 152 observations (19 universities $* 8$ years). Between statistics provide information that is based on 19 universities regardless of time periods ( 8 years). Within statistics provide information that is based on 8 years regardless of universities.

Table 6. Summary Statistics

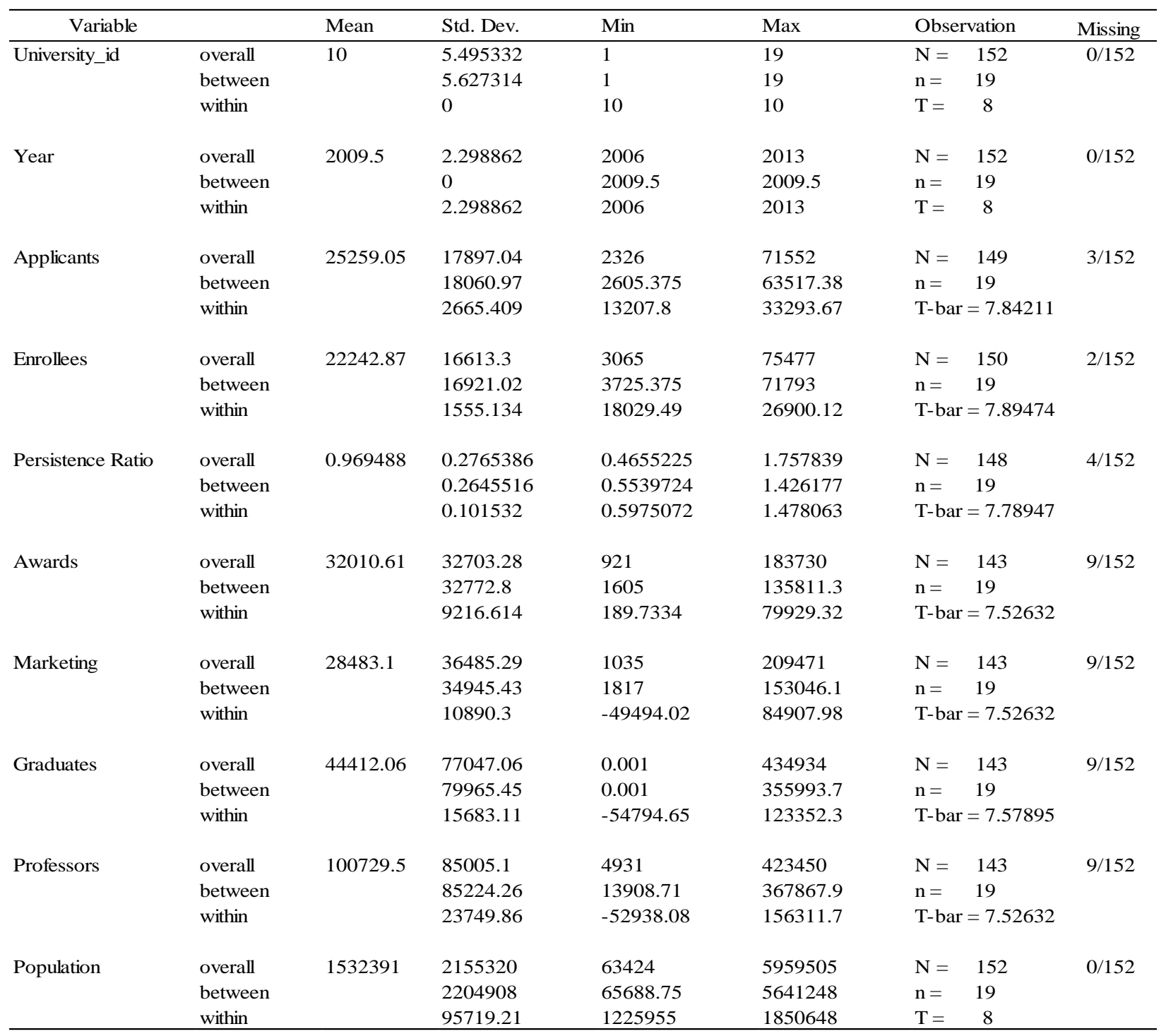

Table 6 provides summary information for each variable in the data set. The table shows that the between variations across universities vary and differ to that observed within each individual university over time. This is due to the existence of a larger variation from one 
university to the next (between) than the within variation. For example, Table 6 shows that there are more variations from one individual university to the next in their expenditure on awards (between variation: 32772.8 dollars in thousands) than the variation of the university itself over time (within variation: 9216.614 dollars in thousands). However, the between and within that is shown in Table 6 indicated that mostly all of the variation is between (from one university to the next) but not within.

The following section presents the results of panel data regression models.

\subsection{Regression Result for Sub-Question 1}

The first research sub-question guiding this study examined the relationship between university expenditure on price and non-price competitive variables and enrolment in publicly funded universities in Ontario, controlling for population growth of the university location and other unobserved omitted variables. The focus of the analysis was to find out if there is a significant relationship between university expenditure on awards, marketing, graduates, professors, and enrolment. The analysis aimed to predict the direction and magnitude of the responsiveness of enrolment with respect to the adopted competitive variables. Examining the responsiveness of enrolment facilitates the measurement of the percentage change in enrolment due to a one percent change in university expenditure on competitive variables. The aim of the analysis is to explicitly test the research assumptions and to demonstrate if these assumptions are correct. Panel data regression models were used as the main statistical analysis to address this relationship. Table 7.1 presents a summary result of Pooled OLS, Fixed Effect (LSDV), and Random Effect regression models for publicly funded universities in Ontario. Detailed results from panel regressions models are shown in Appendix E. 
Table 7.1. Summary Results from Panel Data Regression Models for the Dependent Variable of Total Number of Enrolled Students

\begin{tabular}{|c|c|c|c|}
\hline \multirow[b]{3}{*}{ Independent Variable } & \multicolumn{3}{|c|}{ Dependent Variable: Log Enrollees } \\
\hline & Pooled OLS & Fixed Effect LSDV & Random Effect \\
\hline & Coef./ Robust & Coef./ Robust & $\begin{array}{c}\text { Coef./ Robust } \\
\text { Std } \sim \mathrm{s}\end{array}$ \\
\hline Log Awards (t-1) & $\begin{array}{l}0.410237 * * * \\
(0.061250)\end{array}$ & $\begin{array}{l}0.327466 * * * \\
(0.062180)\end{array}$ & $\begin{array}{c}0.396848 * * * \\
(0.062812)\end{array}$ \\
\hline Log Marketing (t-1) & $\begin{array}{r}0.051935 * * \\
(0.023585)\end{array}$ & $\begin{array}{c}0.060010 * * * \\
(0.020093)\end{array}$ & $\begin{array}{r}0.062229 * * \\
(0.026419)\end{array}$ \\
\hline Log Graduates (t-1) & $\begin{array}{l}-0.015324 * * * \\
\quad(0.003936)\end{array}$ & $\begin{array}{l}0.009142 \\
(0.011295)\end{array}$ & $\begin{array}{c}0.006093 \\
(0.011269)\end{array}$ \\
\hline Log Professors (t-1) & $\begin{array}{c}0.217524 * * * \\
(0.078868)\end{array}$ & $\begin{array}{c}0.047106 \\
(0.048203)\end{array}$ & $\begin{array}{c}0.053431 \\
(0.060730)\end{array}$ \\
\hline Log Population (t) & $\begin{array}{l}0.121574 * * * \\
(0.016646)\end{array}$ & $\begin{array}{c}1.080964 * * * \\
(0.324187)\end{array}$ & $\begin{array}{r}0.142460 * * \\
(0.060569)\end{array}$ \\
\hline Trend & $\begin{array}{l}-0.028550 * * * \\
(0.006965)\end{array}$ & $\begin{array}{l}-0.017898 * * * \\
\quad(0.006348)\end{array}$ & $\begin{array}{l}-0.015451 * * * \\
\quad(0.005755)\end{array}$ \\
\hline Constant & $\begin{array}{c}1.443172 * * * * \\
(0.289572)\end{array}$ & $\begin{array}{c}-10.771064 * * \\
(4.916223)\end{array}$ & $\begin{array}{c}2.778940 * * * \\
(0.710176)\end{array}$ \\
\hline U_Toronto & & (omitted) & \\
\hline Brock_U & & $\begin{array}{c}2.376803 * * * \\
(0.83)\end{array}$ & \\
\hline Carleton_U & & $\begin{array}{c}1.143378 * * \\
(0.48)\end{array}$ & \\
\hline Lakehead_U & & $\begin{array}{c}3.107288 * * \\
(1.20)\end{array}$ & \\
\hline Laurentian_U & & $\begin{array}{c}2.888898 * * * \\
(1.11)\end{array}$ & \\
\hline McMaster_U & & $\begin{array}{c}1.577523 * * \\
(0.64)\end{array}$ & \\
\hline Nipissing_U & & $\begin{array}{c}3.999261 * * * \\
(1.38)\end{array}$ & \\
\hline OCAD_U & & $\begin{array}{c}-1.112785 * * * \\
(0.33)\end{array}$ & \\
\hline Queens_U & & $\begin{array}{c}2.957848 * * \\
(1.13)\end{array}$ & \\
\hline Ryerson_U & & $\begin{array}{c}-0.123931 \\
(0.16)\end{array}$ & \\
\hline Trent_U & & $\begin{array}{c}3.108048 * * \\
(1.21)\end{array}$ & \\
\hline U_Guelph & & $\begin{array}{c}3.440905 * * * \\
(1.16)\end{array}$ & \\
\hline UOIT_U & & $\begin{array}{c}2.045683 * * * \\
(0.87)\end{array}$ & \\
\hline U_Ottawa & & $\begin{array}{c}1.285741 * * * \\
(0.48)\end{array}$ & \\
\hline U_Waterloo & & $\begin{array}{c}2.084566 * * * \\
(0.78)\end{array}$ & \\
\hline U_Windsor & & $\begin{array}{c}2.456484 * * * \\
(0.90)\end{array}$ & \\
\hline Western_U & & $\begin{array}{c}1.988012 * * \\
(0.78)\end{array}$ & \\
\hline Wilfrid_U & & $\begin{array}{c}2.097024 * * * * \\
(0.77)\end{array}$ & \\
\hline York_U & & $\begin{array}{c}0.055148 \\
\quad(0.08)\end{array}$ & \\
\hline $\begin{array}{l}\text { No. of Obs. } \\
\text { R-Squared }\end{array}$ & $\begin{array}{r}142 \\
0.95\end{array}$ & $\begin{array}{c}142 \\
0.9961\end{array}$ & $\begin{array}{r}142 \\
0.93\end{array}$ \\
\hline
\end{tabular}

Note. Robust Standard errors are in parentheses.

Uuniversity of Toronto is the base.

Independent variables are lagged by one year (t-1). Population is an unlagged variable (t).

$* \mathrm{p}<.10, * * \mathrm{p}<.05, * * * \mathrm{p}<.01$ 
Table 7.1 presents a summary result from panel data regression models where determining the magnitude and direction of the total effect, and the significance is the aim of the analysis. As shown in Table 7.1, all panel regression models report different slope coefficients of the included variables and different standard errors and R-squared. Column 1 presents a Pooled OLS regression result without controlling for unobserved heterogeneity. The Pooled OLS model allows no difference in intercepts and in coefficient estimates across universities. The result of the Pooled OLS regression suggests that the sign of the total effect of university expenditure on adopted competitive variables is statistically significant at 1, 5, 1, 1, and $1 \%$, respectively $(\rho<.01, \rho<.05, \rho<.01, \rho<.01 \& \rho<.01)$. This would imply that the total number of enrolled students is positively and significantly related to awards, marketing, professors, and population for all publicly funded universities in Ontario. This suggests that the total number of enrollees is expected to increase, on average, by about $0.41,0.05,0.22$, and $0.12 \%$, respectively, due to a one percent increase in awards, marketing, professors, and population. A negative and significant relationship was shown for graduates. This suggests that enrolment is expected to decrease, on average, by about $0.02 \%$ due to a one percent increase in graduates.

Table 7.1, column 2 present results from Fixed Effect (LSDV) models. The Fixed Effect (LSDV) regression model created dummy variables for each university, which allows for the recognition of differences between universities and for capturing the unobserved heterogeneity as part of the intercept. The result from the Fixed Effect model suggests that the total number of enrolled students is positively and significantly related to awards, marketing, and population. This suggests that the total number of enrollees is expected to increase, on average, by about $0.33,0.06$, and $1.08 \%$, respectively, due to a one percent increase in awards, marketing, and population. Column 3 summarizes the results from the Random Effect regression model. The 
results from the Random Effect model show that the total number of enrolled students is positively and significantly related to awards, marketing, and population. This suggests that the total number of enrollees is expected to increase, on average, by about $0.40,0.06$, and $0.14 \%$, respectively, due to a one percent increase in awards, marketing, and population. Across all these regression models, one can observe that the parameter estimates are slightly different for both Fixed and Random Effect from those in the Pooled OLS regression model for the included variables. This would suggest that unobserved or unmeasured heterogeneity could be affecting the outcome. This leads one to conclude that the coefficients in the Pooled OLS estimation might be overestimated or underestimated owing to unobserved heterogeneity (omitted variables bias).

While the aim of conducting a panel regression framework is to present the right model that provides consistent and efficient estimates, testing for unobserved heterogeneity is an essential step to make sure which model is the correct (significant) one. An F-test, a Breusch and Pagan LM test, and a Hausman test were conducted to choose the regression model that could produce consistent and efficient estimation. The F-test was conducted to decide between Pooled OLS and Fixed Effect regression models. The Breusch and Pagan LM test was also conducted to choose between Pooled OLS and Random Effect models. The tests results are found in Appendix D, Table 14.1.1 and 14.1.2. The Breusch and Pagan LM test and the F-test suggested that Fixed and Random Effect models are favoured over Pooled OLS model, which provides evidence that unobserved heterogeneity across universities does exist. This means that the Fixed and Random Effect models deal with heterogeneity better than the Pooled OLS model, since Pooled OLS produces inconsistent and inefficient estimates. 
To decide between Fixed and Random Effect models, a Hausman test was conducted. The main difference between Fixed and Random Effect models is whether unobserved heterogeneity is correlated with explanatory variables. Conducting the Hausman test to decide between them is important, since the Random Effect model might provide biased estimates if unobserved heterogeneity were correlated with independent variables. However, the result of the Hausman test suggested that the Fixed Effect model is favoured over the Random Effect Model. The result of the Hausman test indicated that there is a correlation between unobserved heterogeneity and independent variables (Appendix D, Table 14.1.3). In other words, each individual university has its own characteristics that might influence the explanatory variables. Unmeasured or unobserved characteristics (heterogeneity) that vary across universities might impact or bias the pooled ordinary least squares regression outcomes, but the Fixed Effect model controls for such bias. Consequently, fixed effects models are predicted to win out over pooled or random effects models because of omitted variables such as perceived quality. To answer the first research sub-question, the Fixed Effect model is the proper model to provide consistent and efficient estimations. Presenting the regression result from a significant model leads to accurate results that are shown in the following section.

4.2.1 Significant results. Table 7.1, column 2 presents significant results from the Fixed Effect regression model. As shown in Table 7.1, Fixed Effect (LSDV) shows different intercepts across universities. Figure 2 shows the estimated results from the Fixed Effect regression model, which provide the same slope coefficients of included variables across universities. Figure 2 shows the expected percentage change in the total number of enrolled students in response to a one percent change in university expenditure on price and non-price competitive variables for all universities. 
Figure 2. The Expected Percentage Change in Enrolment Due to a $1 \%$ Change in the Adopted Competitive Variables

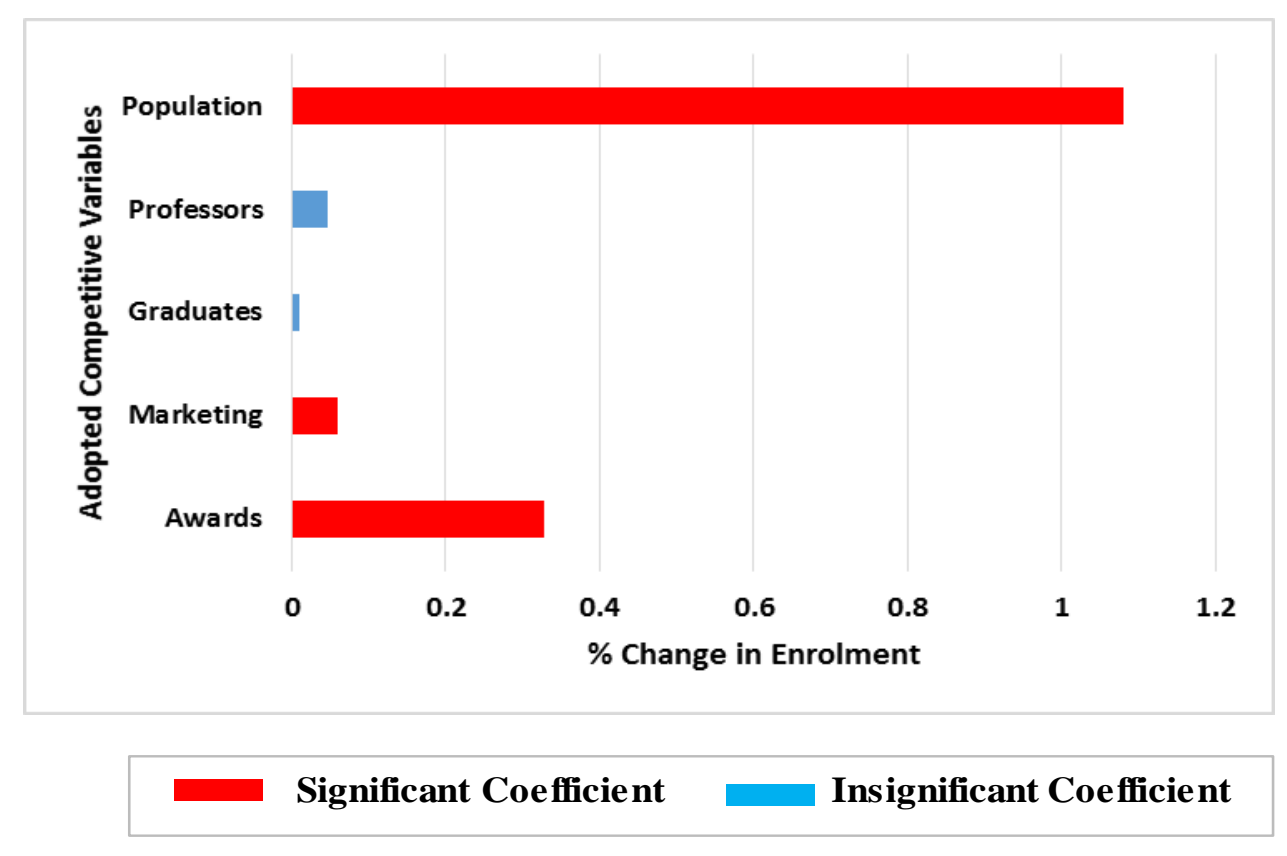

Figure 2. Empirical Results from the Fixed Effect Regression Model (Total Number of Enrolled Students)

Figure 2 presents the regression results that show the relationship between the expected change in the number of enrolled students and a one percent change in the competitive variables used and the control variable (population). The result suggests that the total number of enrolled students is significantly related to awards, marketing, and population. Not surprisingly, awards, marketing, and population have a positive and significant effect on enrolment. The estimated coefficients matched expectations that enrolment would be affected positively by these competitive variables. These variables are statistically significant at $1 \%$, respectively $(\rho<.01)$. Indeed, enrolment could be affected by other variables (e.g., government grants) and a single research study cannot cover all important variables. The focus of this study is only on examining some of these competitive variables that are adopted by universities in order to attract potential students and retain current enrollees. Turning to the effect of graduates and professors, the 
estimated coefficient is insignificant. The lack of statistical significance in these competitive variables might not provide strong support for the assumption that enrolment would be affected significantly by university expenditure on graduates and professors.

Positive and significant relationships suggest that for a one percent increase in awards, the total number of enrollees is expected to increase, on average, by about $0.33 \%$ across publicly funded universities in Ontario, with standard error of plus or minus $0.06 \%$. Not surprisingly, positive and significant effects were also found for university expenditure on marketing. This significance suggests that if university expenditure on marketing goes up by one percent, enrolment is estimated to go up by about $0.06 \%$ with standard error of plus or minus $0.02 \%$. A one percent increase in expenditure on marketing is estimated to result in about $0.06 \%$ increase in enrolment.

The regression results also show that population has a positive and significant effect. This result suggests that population growth is likely to affect enrolment for all publicly funded universities in Ontario. A one percent increase in population is expected to increase enrolment by about $1.08 \%$, with plus or minus $0.32 \%$. To summarize, the existence of significant coefficients suggests that the competitiveness of universities could be affected when adopting competitive variables such as awards and marketing. Also, the positive effect of population suggests that population growth can play an important role in increasing enrolment in publicly funded universities.

Table 7.1, column 2 presents the result from the Fixed Effect (LSDV) where university dummies were added and the individuality of each university was considered through providing a specific intercept for each university. The Fixed Effect (LSDV) regression result suggests that there are variations in the intercepts across universities, which indicates that unobserved 
heterogeneity was captured and considered as part of the intercept. However, the Fixed Effect (LSDV) regression result suggests that the intercepts of all universities, excluding Ryerson University and York University, are statistically significant. The significance of the Fixed Effect provides evidence that universities are not the same, which leads one to speculate that not only the intercepts, but also the coefficients of the explanatory variables might vary for all individual universities. This is to say, it is useful to investigate whether changes in expenditure on price and non-price competitive variables have differing effects on enrolment across universities. To explore this variation, a modified Fixed Effect regression was conducted for each individual university. As well as the baseline effects (coefficients) for awards, marketing, graduates, professors, and population, which are applicable to all universities, each regression introduced an additional effect (coefficient) for each of the variables applicable to the individual university in question. These additional effects capture whether a variable has a weaker or stronger effect for the particular university relative to other universities. In Table 7.2., each row corresponds to the regression for a particular university and reports the key coefficients for the additional effects that were estimated. Detailed regression outcomes are found in Appendix E, Table 7.2.1. 
Table 7.2. Additional Effect on Total Number of Enrollees for Each Publicly Funded University in Ontario.

\begin{tabular}{|c|c|c|c|c|c|}
\hline Universities & Awards & Marketing & Graduates & Professors & Population \\
\hline Brock University & $-0.301436 * *$ & $-0.187899 * *$ & -0.021967 & $0.228352 *$ & $14.024738 * * *$ \\
\hline Carleton University & $-0.497753 * * *$ & -0.011092 & $-0.147147 * *$ & $-0.780108^{*}$ & $5.740965^{* * *}$ \\
\hline Lakehead University & $-0.673856^{* * *}$ & $0.272045^{* * *}$ & $0.371863 * * *$ & 0.059207 & -0.635705 \\
\hline Laurentian Univeristy & $0.624055^{* * *}$ & $0.487951 * * *$ & $-0.095051 * * *$ & $-1.371854 * * *$ & 0 \\
\hline McMaster University & -0.177671 & $-0.107369 * * *$ & $-0.237429 * * *$ & 0.014535 & $4.566495^{* * *}$ \\
\hline Nipissing University & $-0.162725^{*}$ & $1.098854 * * *$ & (omitted) & $-3.178117 * * *$ & 21.271785 *** \\
\hline OCAD University & $-0.147812^{*}$ & -0.096567 & 0.11024 & 0.228063 & 0.792687 \\
\hline Queen's University & $-0.383554 * * *$ & $-0.061525^{* * *}$ & -0.007898 & 0.017381 & $4.262499 * * *$ \\
\hline Ryerson Univ & $-0.218917 * * *$ & & & 0.13 & 0 \\
\hline Trent University & -0.856369 & -0.13 & -0.082766 & 0.211869 & 0 \\
\hline University of & $-1.457145^{* * *}$ & & $0.812901 * * *$ & $0.479283^{* *}$ & $3.027466^{* *}$ \\
\hline UOIT University & 0.17751 & $-0.119009 * *$ & -0.0646 & $0.401083 * * *$ & -0.403719 \\
\hline University Ottawa & $-0.194183^{* * *}$ & $-0.083918 * * *$ & -0.015463 & $0.135746^{* *}$ & 0 \\
\hline University of Toronto & $-0.420940 * * *$ & $-0.068266^{* * *}$ & $-0.384366 * * *$ & $0.744732 * * *$ & 0 \\
\hline University Waterloo & $-0.328239 * * *$ & $-0.103622 * * *$ & $-0.045067 * * *$ & $0.119075 * * *$ & $3.703593 * * *$ \\
\hline University Windsor & 0.120712 & $-0.361003 * * *$ & -0.031907 & -0.203534 & -0.595697 \\
\hline Western University & -0.226363 & 0.019831 & $0.417748 * *$ & $-0.323064 * * *$ & $2.047397 * * *$ \\
\hline Wilfrid Laurier University & $-0.804555^{* * *}$ & $0.217482 * * *$ & $-0.962835 * * *$ & $2.478139 * * *$ & 0 \\
\hline York University & $-0.289628 * * *$ & $-0.102628 * * *$ & $-0.061127 * * *$ & -0.095153 & 0.828227 \\
\hline
\end{tabular}

Note. Expenditure on Graduates at Nipissing University remains constant over time and is thus perfectly co-linear with the dummy variable.

Additional Effects were reported in the table.

$* \mathrm{p}<0.10, * * \mathrm{p}<0.05, * * * \mathrm{p}<0.01$

The results shown in each row of Table 7.2 indicate which variables have stronger effects (denoted by positive additional effect) in the particular university relative to the baseline for all other universities, and which variables have weaker effects (denoted by negative additional effects). Thus, the coefficients show the expected additional percentage changes in enrolment for a given university relative to the baseline for all universities stemming from a one percent change in its variables. Detailed regression results (baseline, additional, and overall effects) for each individual university are shown in Appendix E.

The positive and significant additional effects suggest that a competitive variable has a larger effect on enrollees, while a negative and significant sign suggests that the competitive 
variable has a smaller effect on enrollees for a specific university relative to all other Ontario universities. Positive and negative signs for overall effects were discussed in Appendix E. However, the following paragraphs present the regression result of how enrolment for University of Toronto responds to changes in awards, marketing, graduates, professors, and population. University of Toronto is used as an example, but a full analysis for the other eighteen universities is found in Appendix I.

University of Toronto. Figure 3.14 illustrates the difference in the effect of the adopted competitive variables on enrolment for University of Toronto relative to all other Ontario universities.

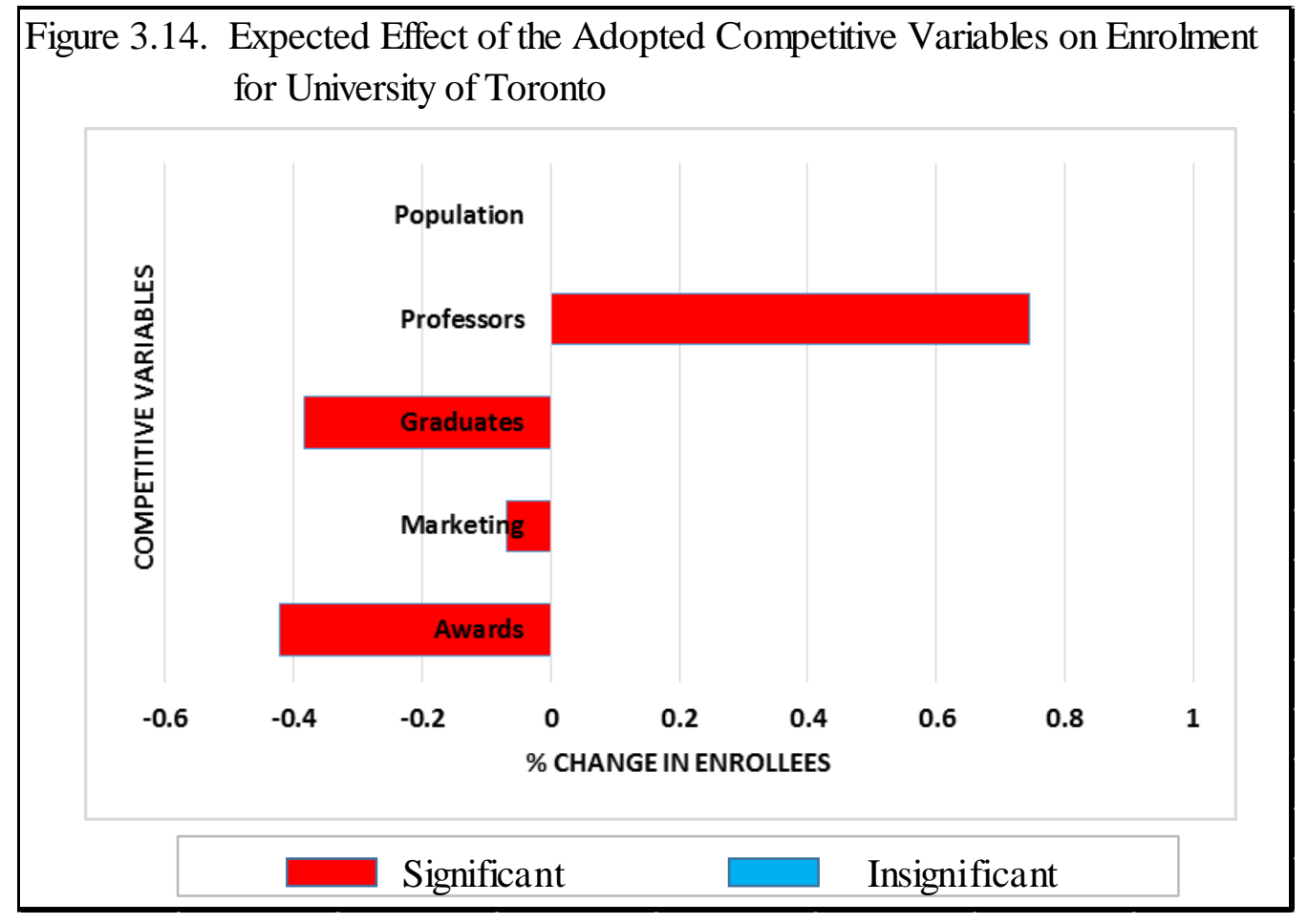

Figure 3.14. Regression Result from Fixed Effect (a modified Fixed Effect) for University of Toronto. The Effect of the Adopted Competitive Variables on Total Number of Enrollees.

Figure 3.14 shows the result from Fixed Effects (a modified Fixed Effect) that explains which variables have larger effects (positive additional effects) in the University of Toronto relative to the baseline for all other universities, and which variables have smaller effects 
(negative additional effects). Thus, the coefficients show the expected additional percentage changes in enrolment for University of Toronto relative to the baseline for all universities, stemming from a one percent change in its variables. The regression result shows a strong relationship between enrolment and the adopted competitive variables ( $\mathrm{R}$-Squared=0.99). R-Squared indicates that approximately $99 \%$ of the change in enrolment can be explained by the change in university expenditure on awards, marketing, graduates, and professors. The result suggests that the responsiveness of enrolment with respect to awards, marketing, graduates, and professors is about $-0.42,-0.07,-0.38$, and $0.74 \%$, respectively. These additional effect coefficients are statistically at $1 \%(\rho<.01)$. Overall effects also estimate negative and positive significant signs and these are explained in Appendix E.

The positive and significant additional effects suggest that expenditure on professors has a larger effect on enrollees, while a negative and significant sign suggests that awards, marketing, and graduates have a smaller effect on enrollees. A one percent increase in expenditure on professors has a greater effect, while a one percent increase in expenditure on awards, marketing, and graduates has a smaller effect for University of Toronto relative to all other Ontario Universities.

A larger effect suggests that a one percent increase in investing in faculty members (professors) is expected to produce a greater effect on enrolment by about $0.74 \%$. A smaller effect suggests that a one percent increase in expenditure on awards, marketing, and graduates is expected to produce a smaller effect on enrolment by about $0.42,0.07$, and $0.38 \%$, respectively, for University of Toronto relative to all other Ontario universities.

However, the existence of significant responsiveness leads one to infer that the changes in university expenditure on awards, marketing, graduates, and professors are likely to affect the 
total number of enrolled students for University of Toronto. Evaluating the effect of adopted competitive variables can shed light on the importance of resource allocation in order to enhance the competitiveness of publicly funded universities. Fund allocations and the shift from variables with smaller effects to variables with greater effects can help publicly funded university compete effectively and increase their market share. University of Toronto might need these responsiveness estimates in order to determine the most effective competitive variables to makes good managerial decisions in the short run, and to plan for its enrolment growth in the long run. Full explanation of the other eighteen publicly funded universities is provided in Appendix I.

\subsection{Regression Results for Sub-Question 2}

The second research sub-question examined the relationship between universities' expenditure on price and non-price competitive variables and the total number of applications for admission in publicly funded universities in Ontario, controlling for population growth of university location and other unobserved omitted variables. The focus of the analysis was to determine if there is a significant relationship between university expenditure on awards, marketing, graduates, and professors and the total number of applications. The analysis aimed to predict the direction and magnitude of the responsiveness of applications with respect to the adopted competitive variables. Examining the responsiveness of applications facilitated the measurement of the percentage change in applications due to a one percent change in university expenditure on competitive variables. The aim of the analysis was to explicitly test the research assumptions and to demonstrate if these assumptions were correct. Panel data regression models were used as the main statistical analysis to address this relationship. Table 8.1 presents a summary result of Pooled OLS, Fixed Effect (LSDV), and Random Effect regression models for 
publicly funded universities in Ontario. Detailed results from panel regressions models are shown in Appendix F. 
Table 8.1. Summary Results from Panel Data Regression Models for the Dependent Variable of Total Number of Applicants

\begin{tabular}{|c|c|c|c|}
\hline \multirow[b]{3}{*}{ Independent Variable } & \multicolumn{3}{|c|}{ Dependent Variable: Log Applicants } \\
\hline & Pooled OLS & Fixed Effect LSDV & Random Effect \\
\hline & Coef./ Robust Std. s & Coef./ Robust Std. $\sim$ s & Coef./ Robust Std. s \\
\hline \multirow{2}{*}{ Log Awards (t-1) } & $0.419232 * * *$ & $0.124130 * *$ & $0.237833 * * *$ \\
\hline & (0.0599700) & $(0.0537960)$ & $(0.0557920)$ \\
\hline \multirow[t]{2}{*}{ Log Marketing (t-1) } & $0.208789 * * *$ & 0.008169 & 0.023726 \\
\hline & $(0.0380210)$ & $(0.0199380)$ & $(0.0311710)$ \\
\hline \multirow[t]{2}{*}{ Log Graduates (t-1) } & -0.005429 & 0.041178 & $0.047817 * * *$ \\
\hline & $(0.0055520)$ & $(0.0395140)$ & $(0.0096530)$ \\
\hline \multirow{2}{*}{ Log Professors (t-1) } & 0.095063 & $0.045456 * * *$ & $0.055735 * *$ \\
\hline & $(0.0724120)$ & $(0.0163450)$ & $(0.0227190)$ \\
\hline \multirow[t]{2}{*}{ Log Population (t) } & $0.136485 * * *$ & $1.386017 * * *$ & 0.176181 \\
\hline & $(0.0310110)$ & $(0.4743600)$ & $(0.1317610)$ \\
\hline \multirow[t]{2}{*}{ Trend } & $-0.038970 * * *$ & $-0.010071 *$ & -0.010346 \\
\hline & $(0.0125280)$ & $(0.0058190)$ & $(0.0064600)$ \\
\hline \multirow{2}{*}{ Constant } & $1.043072 * *$ & $-13.099941 *$ & $3.902504 * * *$ \\
\hline & $(0.4480690)$ & $(7.1586020)$ & $(1.2588210)$ \\
\hline U_Toronto & & (omitted) & \\
\hline \multirow[t]{2}{*}{ Brock_U } & & $3.012437 * *$ & \\
\hline & & $(1.2082250)$ & \\
\hline \multirow[t]{2}{*}{ Carleton_U } & & $1.565802 * *$ & \\
\hline & & $(0.6905940)$ & \\
\hline \multirow[t]{2}{*}{ Lakehead_U } & & $3.459473 *$ & \\
\hline & & $(1.7506610)$ & \\
\hline \multirow[t]{2}{*}{ Laurentian_U } & & $3.401784 * *$ & \\
\hline & & $(1.6165780)$ & \\
\hline \multirow{2}{*}{ McMaster_U } & & $2.556261 * * *$ & \\
\hline & & $(0.9448960)$ & \\
\hline \multirow[t]{2}{*}{ Nipissing_U } & & $4.804562 * *$ & \\
\hline & & $(2.0372780)$ & \\
\hline \multirow[t]{2}{*}{ OCAD_U } & & $-2.244777 * * *$ & \\
\hline & & $(0.2344870)$ & \\
\hline \multirow[t]{2}{*}{ Queens_U } & & $4.259583 * *$ & \\
\hline & & $(1.6605550)$ & \\
\hline \multirow[t]{2}{*}{ Ryerson_U } & & 0.162613 & \\
\hline & & $(0.1040260)$ & \\
\hline Trent_U & & $3.920495 * *$ & \\
\hline & & $(1.7633700)$ & \\
\hline U_Guelph & & $4.408670^{* *}$ & \\
\hline & & $(1.6950040)$ & \\
\hline UOIT_U & & $2.617377 * *$ & \\
\hline & & $(1.2428850)$ & \\
\hline U_Ottawa & & $1.594833 * *$ & \\
\hline & & $(0.7038110)$ & \\
\hline U_Waterloo & & $3.052462 * * *$ & \\
\hline & & $(1.1445890)$ & \\
\hline U_Windsor & & $2.856232 * *$ & \\
\hline & & $(1.3110080)$ & \\
\hline Western_U & & $3.126047 * * *$ & \\
\hline & & $(1.1452600)$ & \\
\hline Wilfrid_U & & $2.884926 * *$ & \\
\hline & & $(1.1124500)$ & \\
\hline York_U & & 0.094592 & \\
\hline & & $(0.0943270)$ & \\
\hline No. of Obs. & 143 & 143 & 143 \\
\hline R-Squared & 0.87 & 0.99 & 0.76 \\
\hline
\end{tabular}

Note. Robust Standard errors are in parentheses.

Uuniversity of Toronto is the base.

Independent variables are lagged by one year (t-1). Population is an unlagged variable (t).

$* \mathrm{p}<.10, * * \mathrm{p}<.05, * * * \mathrm{p}<.01$ 
Table 8.1 presents a summary result from the panel data regressions models. The aim of the analysis was to determine the magnitude and direction of the total effect and the significance. As shown in Table 8.1, all panel regression models have different slope coefficients of the included variables and different standard errors and R-squared. Column 1 presents a Pooled OLS regression model without controlling for unobserved heterogeneity. The Pooled OLS model allows no difference in intercepts and in coefficient estimates across universities. The result from the Pooled OLS regression model shows that the total number of applications for admission is significantly related to awards, marketing, and population at $1 \%(\rho<.01)$. This suggests that the total number of applicants is expected to increase, on average, by about $0.42,0.21$, and $0.14 \%$, respectively, due to a one percent increase in awards, marketing, and population.

Table 8.1, column 2 provides results from the Fixed Effect (LSDV) models. The Fixed Effect (LSDV) regression model created dummy variables for each university, which allow for the recognition of differences between universities and the capturing unobserved heterogeneity as part of the intercept. The result from the Fixed Effect regression shows that there are positive and significant relationships between awards, professors, and population and the total number of applications at 5,1 , and $1 \%$, respectively $(\rho<.05, \rho<.01, \& \rho<.01)$. This suggests that the total number of applications is expected to increase, on average, by about $0.12,0.05$, and $1.39 \%$, respectively, due to a one percent increase in awards, professors, and population.

Column 3 summarizes the statistical results from the Random Effect regression model. The result from Random Effect regression shows that there are positive and significant relationships between awards, graduates, and professors and the total number of applications at 1,1 , and $5 \%$, respectively $(\rho<.01, \rho<.01, \& \rho<.05)$. This suggests that the total number of applications is expected to increase, on average, by about $0.24,0.05$, and $0.06 \%$, respectively, 
due to a one percent increase in expenditure on awards, graduates, and professors. Across all these regression models, one can observe that the parameter estimates are different for both Fixed and Random Effect models from those of the Pooled OLS model. This would imply that the estimated coefficients are not the same when using the Pooled OLS, the Fixed, and the Random Effect models, and indicates that unobserved heterogeneity could be affecting the outcome. This leads one to conclude that the coefficients in the Pooled OLS estimation might be overestimated or underestimated, due to unobserved heterogeneity (omitted variables bias).

While the aim of conducting panel regression framework is to present the right model that provides consistent and efficient estimates, testing for unobserved heterogeneity is an essential step in choosing the correct (significant) model. An F-test, a Breusch and Pagan LM test, and a Hausman test were conducted to choose the regression model that could produce consistent and efficient estimation. The results of the three tests (found in Appendix D, Tables 14.2.1 - 14.2.3) suggest that the Fixed and the Random Effect models are favoured over the Pooled OLS model but the Fixed Effect is favoured over the Random Effect model. This result indicates that unobserved heterogeneity across universities does exist and there is a correlation between unobserved heterogeneity and independent variables. This means that the Fixed Effect models are dealing with heterogeneity better than the Pooled OLS and the Random Effect models. To answer the second research sub-question, the Fixed Effect model is the proper model that can provide consistent and efficient estimations. The regression results from a significant model are shown in the following section.

4.3.1 Significant results. Table 8.1 , column 2 presents the significant results from the Fixed Effect regression models. As shown in Table 8.1, the Fixed Effect (LSDV) regression results show different intercepts across universities. Figure 4 shows the estimated results from 
the Fixed Effect regression model that provides the same slope coefficients of the included variables across universities. Figure 4 shows the expected percentage change in the total number of applicants in response to a one percent change in university expenditure on price and nonprice competitive variables for all publicly funded universities.

Figure 4. Empirical Results from Fixed Effect Model (Total Number of Applications for Admission)

\section{Figure 4. The Expected Percentage Change in Applications for Admission Due to $1 \%$} Change in the Adopted Competitive Variables

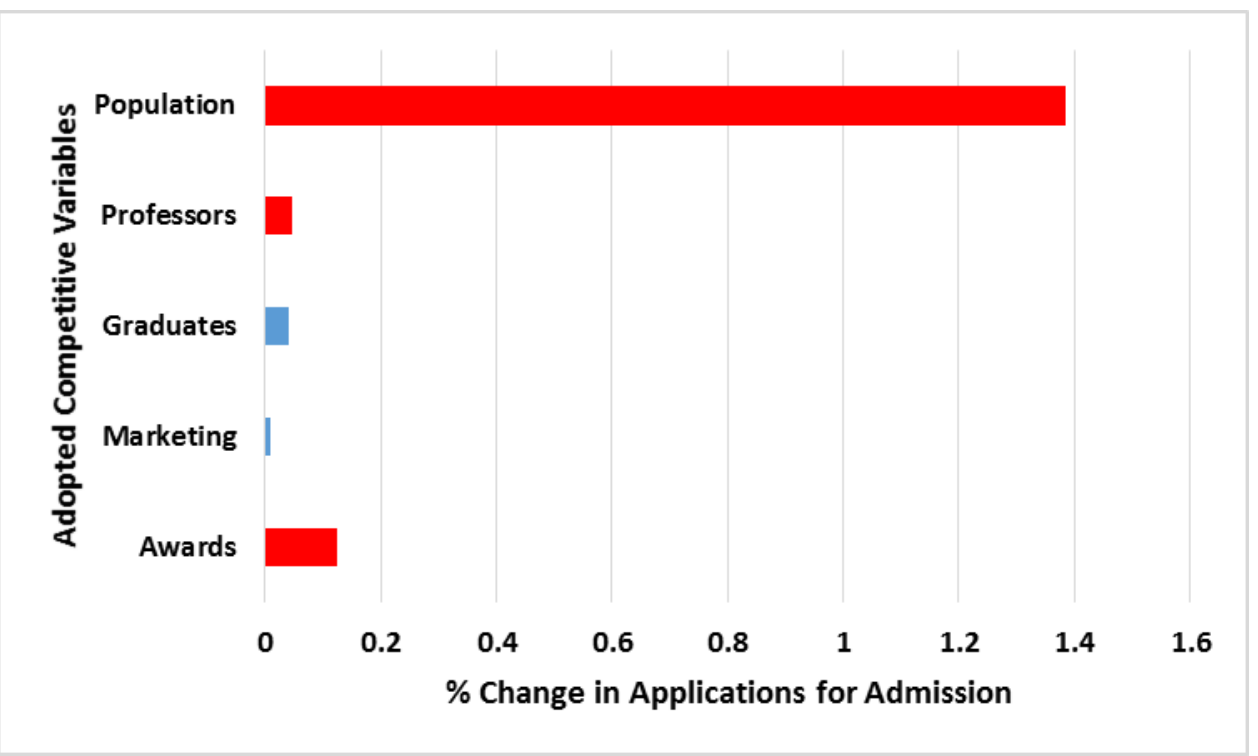

Significant

Insignificant

Figure 4 presents the regression results from the Fixed Effect model and shows the expected percentage change in the number of applications for admission in response to a one percent change in the used competitive variables and the control variable (population). The estimated coefficients have the expected sign that support the research assumption that applications for admission would be affected positively by the adopted competitive variables. The result suggests that the total number of applicants is significantly related to awards, 
professors, and population. These coefficients are statistically significant at 5, 1 , and $1 \%(\rho<.05$, $\rho<.01, \& \rho<.01)$. The regression result shows a strong relationship between applications and the significant competitive variables ( $\mathrm{R}$-Squared=0.99). R-Squared indicates that approximately 99\% of the change in applications can be explained by the change in university expenditure on awards and professors, and also by the change in population. This result provides support for the research assumption that there is a relationship between awards, professors, population and applications. Turning to the effect of marketing and graduates, the coefficients for these two variables are positive but, surprisingly, insignificant. The lack of statistical significance in these competitive variables does not support the assumption that applicants would be affected by university expenditure on marketing and graduates. It was somewhat surprising to see that marketing did not significantly affect applications even though it does affect enrolment. This result might arise due to the nature of the student application process in Ontario. Students can apply to five or even more different universities but they only end up enrolling in one of them at most. Consequently, the process of applying to many universities at the same time might diminish the apparent effect of marketing. It is not clear why marketing and graduates might have an insignificant effect on applications. In order to explore this relationship, the study conducted a modified Fixed Effect regression to find out the effect of these variables for each university (the result is shown later in this chapter).

The results would imply that for a one percent increase in awards, the total number of applications is expected to increase, on average, by about $0.12 \%$ across publicly funded universities in Ontario, with standard error of plus or minus $0.05 \%$. For a one percent increase in investing in faculty members (professors), the total number of applications for admission is expected to increase, on average, by about $0.05 \%$, with standard errors of plus or minus $0.02 \%$. 
This coefficient is significant at $1 \%(\rho<.01)$. This suggests that a one percent change in expenditure on professors is estimated to result in about a $0.05 \%$ change in applications. A positive and significant effect was also found for population. A one percent increase in population is expected to increase applicants by about $1.4 \%$, with plus or minus $0.5 \%$. At the same time, other variables were found to be insignificant. This suggests that changes in university expenditure on marketing and graduates are likely to have an insignificant effect on applications for all publicly funded universities.

To summarize, awards, professors, and population are likely to have a significant effect on the total number of applications for admission. This finding leads one to infer that the existence of significant coefficients suggests that the competitiveness of universities could be affected when adopting competitive variables such as awards and professors. Also, the positive and significant effect of population on the total number of applications for admission suggests that population growth can play an important role in increasing the total number of applications in publicly funded universities. The result of a positive and significant relationship between awards and applicants can lead one to argue that awards (scholarship and bursaries) are common in publicly funded universities and have become an important part of the higher education system. Accordingly, future applicants are recognizing this common fact and they are seeing awards as a tuition discount. This perspective can encourage them to apply even though they do not know the amount of the offered awards. In addition, the positive and significant relationship between professors and applications can also lead one to argue that investing in faculty members (professors) through recruiting qualified professors can add to a university's reputation and brand name, which would have a significant role in affecting the decisions of future applicants. These 
predicted results can help publicly funded universities to plan for applications growth as a first step in planning for enrolment growth.

Table 8.1, column 2 presents the result from Fixed effect (LSDV) where university dummies were added, and the individuality of each university was considered by providing a specific intercept for each university. The Fixed Effect (LSDV) regression result suggests that there are variations in the intercepts across universities, which indicates that unobserved heterogeneity was captured and considered as part of the intercept. Differential intercepts across universities suggest that the intercepts of all universities, excluding Ryerson and York University, are statistically significant. The significance of the Fixed Effect provides evidence that universities are not the same, which leads one to speculate that not only the intercepts, but also the coefficients of explanatory variables, might vary for all individual universities. This is to say that it is useful to investigate whether or not changes in expenditure on price and non-price competitive variables have differing effects on applications for admission across universities.

To explore this variation, a modified Fixed Effect regression was conducted for each individual university. As well as the baseline effects (coefficients) for awards, marketing, graduates, professors, and population, which are applicable to all universities, each regression introduced an additional effect (coefficient) for each of the variables applicable to the individual university in question. These additional effects capture whether a variable has a weaker or stronger effect for the particular university relative to other universities. In Table 8.2., each row corresponds to the regression for a particular university and reports the key coefficients for the additional effects that were estimated. Detailed regression outcomes are found in Appendix F, Table 8.2.1. 
Table 8.2. Additional Effect on Total Number of Applicants for Each Publicly Funded University in Ontario

\begin{tabular}{|c|c|c|c|c|c|}
\hline Universities & Awards & Marketing & Graduates & Professors & Population \\
\hline Brock University & -0.034626 & 0.110508 & -0.19442 & $-0.385573^{*}$ & -3.773687 \\
\hline Carleton University & $-1.593475 * * *$ & $-0.250586 * * *$ & $-0.364884 * *$ & $4.029948 * * *$ & $-5.324053 * * *$ \\
\hline Lakehead University & $-0.355307 * *$ & $0.504009 * * *$ & -0.304301 & $0.960299 *$ & $15.003800 * * *$ \\
\hline Laurentian Univeristy & $5.054362 * * *$ & 0.144435 & 0.005498 & $-3.869711 * * *$ & 0 \\
\hline McMaster University & $-0.395528 * *$ & $-0.058320 *$ & $-0.190704^{* *}$ & $0.089276^{*}$ & $4.080589 * * *$ \\
\hline Nipissing University & -0.20472 & $1.091727 * * *$ & (omitted) & $-1.337545^{* * *}$ & $4.953131 * * *$ \\
\hline OCAD University & $-0.209351 * * *$ & $0.245555^{* *}$ & $-0.527586 * * *$ & $0.614829 * * *$ & $-3.179458 * *$ \\
\hline Queen's University & $0.245557 * *$ & $-0.179715 * * *$ & $-0.189851^{*}$ & $0.811403 * * *$ & -2.241591 \\
\hline Ryerson University & $-0.295196 * * *$ & $-0.278732 * * *$ & $-0.198776^{* *}$ & 0.989 & 0 \\
\hline Trent University & $1.273899 * * *$ & $0.204238 * * *$ & -0.36 & $4 * * *$ & 0 \\
\hline University of Guelph & $-7.089486 * * *$ & $1.845483 * * *$ & $4.438921 * * *$ & $4.087661 * * *$ & -3.707585 \\
\hline UOIT University & -0.063585 & $-0.186816 * * *$ & 0.001957 & -0.092944 & $6.305469^{* *}$ \\
\hline University Ottawa & 0.11224 & -0.036552 & -0.16381 & -0.011654 & 0 \\
\hline University of Toronto & 0.110133 & 0.038635 & -0.097892 & 416 & 0 \\
\hline University Waterloo & $-0.244771 * * *$ & 0.140907 & $0.195653 * *$ & $0.771994 * * *$ & -1.144378 \\
\hline University Windsor & $-0.966383 * * *$ & $0.816167 * * *$ & -0.536262 & $0.957065^{* *}$ & $10.264450 * * *$ \\
\hline Western University & $1.710157 * * *$ & $-0.373120 * * *$ & $-2.250168 * * *$ & -0.045437 & $7.561819 * * *$ \\
\hline Wilfrid Laurier University & $0.296836 * * *$ & $-0.181063 * * *$ & $0.571076 * * *$ & $-0.937799 * * *$ & 0 \\
\hline York University & -1.495413 & $2.259015^{*}$ & 0.300967 & 0.375818 & -0.991769 \\
\hline
\end{tabular}

Note. Expenditure on Graduates at Nipissing University remains constant over time and is thus perfectly co-linear with the dummy variable.

Additional Effects were reported in the table.

$* \mathrm{p}<0.10, * * \mathrm{p}<0.05, * * * \mathrm{p}<0.01$

The results shown in each row of Table 8.2 indicate which variables have stronger effects (denoted by positive additional effects) in the particular university relative to the baseline for all other universities and which variables have weaker effects (denoted by negative additional effects). Thus, the coefficients show the expected additional percentage changes in applications for admission for a given university relative to the baseline for all universities stemming from a one percent change in its variables. Detailed regression results (baseline, additional, and overall effects) for each individual university are shown in Appendix F.

The positive and significant additional effects suggest that a competitive variable has a larger effect on applications, while a negative and significant sign suggests that the competitive 
variable has a smaller effect on applications for a specific university relative to all other Ontario universities. Positive and negative signs for overall effects are discussed in Appendix F. However, the following paragraphs present the regression result of how the total number of applicants for University of Toronto responds to changes in awards, marketing, graduates, professors, and population. University of Toronto is used as an example, but full analysis for the other eighteen universities is found in Appendix $\mathrm{J}$.

University of Toronto. Figure 5.14 illustrates the difference in the effect of the adopted competitive variables on the total number of applicants for University of Toronto relative to all other Ontario universities.

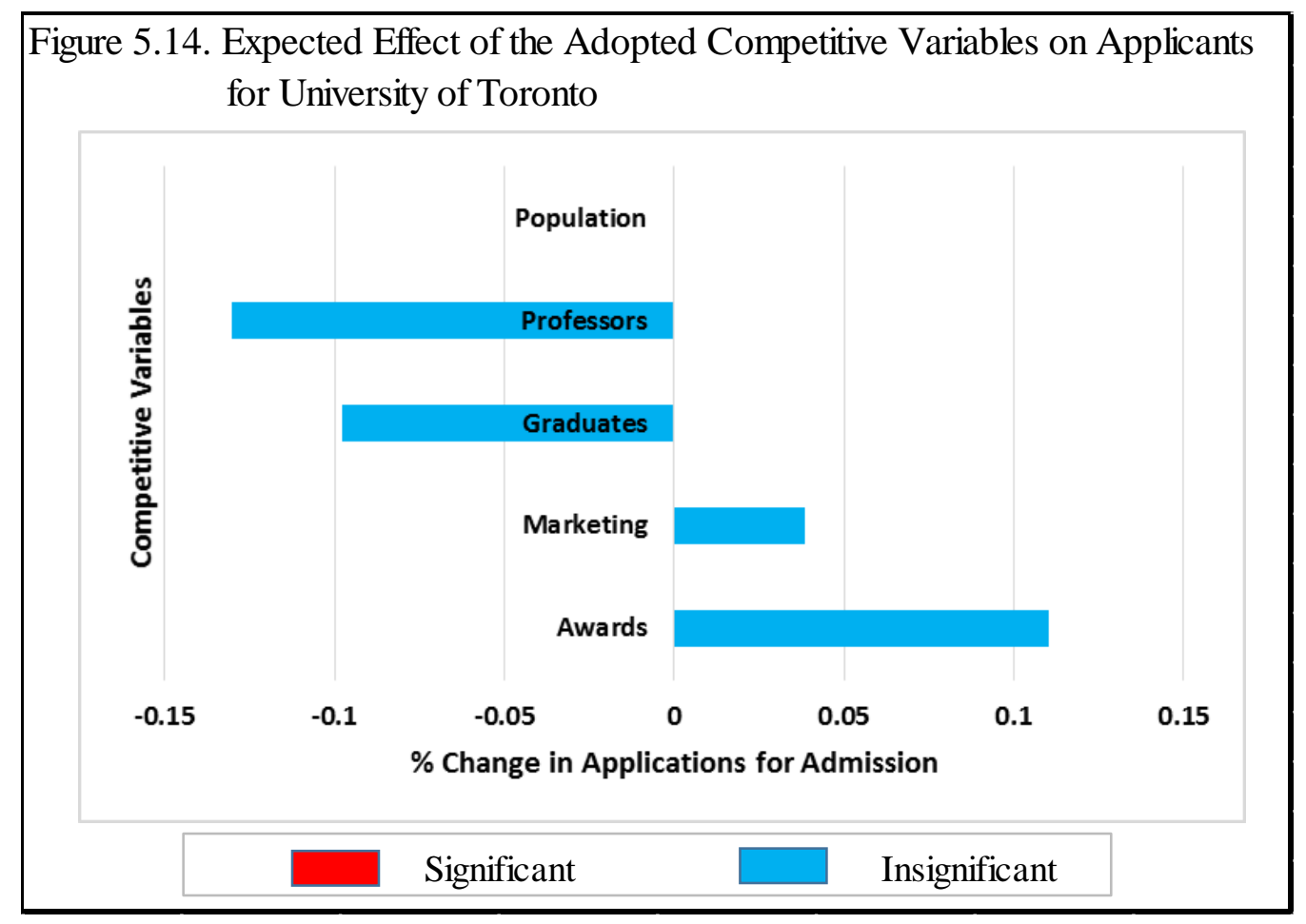

Figure 5.14. Regression Result from Fixed Effect (a modified Fixed Effect regression) for University of Toronto. The Effect of the Adopted Competitive Variables on Total Number of Applicants.

Figure 5.14 shows the result from Fixed Effects (a modified Fixed Effect regression) that explains which variables have larger effects (positive additional effects) in the University of 
Toronto relative to the baseline for all other universities and which variables have smaller effects (negative additional effects). Thus, the coefficients show the expected additional percentage changes in applications for University of Toronto relative to the baseline for all universities stemming from a one percent change in its variables. The regression result shows an insignificant relationship between the adopted competitive variables and applicants for University of Toronto. Insignificant additional effects suggest that awards, marketing, graduates, and professors are unlikely to affect the total number of applicants for University of Toronto relative to all other Ontario universities. Full explanation of the other eighteen publicly funded universities is provided in Appendix J.

\subsection{Regression Results for Sub-Question 3}

This study has examined persistence ratio to complement the analysis of enrollees and applicants. Persistence ratio of total enrolees to applicants is included due to its potential implications for both conversion and retention. The conversion rate is generally defined as the percentage of applicants that go on to enrol while a retention rate is the percentage of nongraduating enrolees who complete academic year $\mathrm{x}$ who go on to enrol in academic year $\mathrm{x}+1$. Conversion and retention are related to the loyalty of future and current demanders (student) through their decisions to apply, enrol and continue to enrol. Improving conversion and retention rates is an important goal and could be driven by various economic variables (e.g., awards, marketing, etc.). At the same time, the persistence ratio is also related to gaining more demanders since universities need to attract new applicants and new enrollees to fill the available seats to compensate for the reduction of enrolment due to graduation in each year. Persistence ratio is important for academic institutions due to its significant academic and monetary implications. Universities need to fill their capacity to maintain their educational institutions and 
to keep their key source of funds (tuition revenue). The examination of awards, marketing, graduates, professors, population, and persistence ratio facilitated the measurement of the percentage change in persistence ratio in current year ( $t$ ) due to a one percent change in university expenditure on competitive variables in the previous year (t-1), as well as population in year (t). Panel data regression models were used as the main statistical analysis to address this relationship. Table 9.1 presents a summary result of Pooled OLS, Fixed Effect (LSDV), and Random Effect regressions models for publicly funded universities in Ontario. Detailed results from the panel regression models are shown in Appendix G. 
Table 9.1. Summary Results from Panel Data Regression Models for the Dependent Variable of Persistence Ratio

\begin{tabular}{|c|c|c|c|}
\hline \multirow{4}{*}{ Independent Variable } & \multicolumn{3}{|c|}{ Dependent Variable: Log Persistence Ratio } \\
\hline & Pooled OLS & Fixed Effect LSDV & Random Effect \\
\hline & Coef./ Robust & Coef./ Robust & Coef./ Robust \\
\hline & Std. $\sim \mathrm{s}$ & Std. $\sim \mathrm{s}$ & Std. $\sim \mathrm{s}$ \\
\hline \multirow[t]{2}{*}{ Log Awards (t-1) } & -0.008266 & $0.204885 * * *$ & 0.104161 \\
\hline & $(0.0576880)$ & $(0.075988)$ & $(0.0756760)$ \\
\hline \multirow[t]{2}{*}{ Log Marketing (t-1) } & $-0.156722 * * *$ & $0.052310 * *$ & 0.022443 \\
\hline & $(0.0279760)$ & $(0.025995)$ & $(0.0334620)$ \\
\hline \multirow[t]{2}{*}{ Log Graduates (t-1) } & $-0.010630 *$ & -0.032043 & $-0.038860 * * *$ \\
\hline & $(0.0053850)$ & $(0.038992)$ & $(0.0094500)$ \\
\hline \multirow[t]{2}{*}{ Log Professors (t-1) } & 0.122407 & 0.001486 & -0.012865 \\
\hline & $(0.0829130)$ & $(0.053750)$ & $(0.0504890)$ \\
\hline \multirow[t]{2}{*}{ Log Population (t) } & -0.014835 & -0.310831 & -0.01148 \\
\hline & $(0.0207030)$ & $(0.445756)$ & $(0.0731230)$ \\
\hline \multirow[t]{2}{*}{ Trend } & 0.010311 & -0.007994 & 0.000981 \\
\hline & $(0.0091930)$ & $(0.007384)$ & $(0.0081170)$ \\
\hline \multirow[t]{2}{*}{ Constant } & 0.40 & 2.398298 & -0.66 \\
\hline & $(0.4144730)$ & $(6.650201)$ & $(1.0280610)$ \\
\hline U_Toronto & & (omitted) & \\
\hline \multirow[t]{2}{*}{ Brock_U } & & -0.646967 & \\
\hline & & $(1.1135310)$ & \\
\hline \multirow[t]{2}{*}{ Carleton_U } & & -0.428737 & \\
\hline & & $(0.6352340)$ & \\
\hline \multirow[t]{2}{*}{ Lakehead_U } & & -0.369131 & \\
\hline & & $(1.6222880)$ & \\
\hline \multirow[t]{2}{*}{ Laurentian_U } & & -0.528373 & \\
\hline & & $(1.4935900)$ & \\
\hline \multirow[t]{2}{*}{ McMaster_U } & & -0.989289 & \\
\hline & & $(0.8684870)$ & \\
\hline \multirow[t]{2}{*}{ Nipissing $U$} & & -0.812375 & \\
\hline & & $(1.8692770)$ & \\
\hline \multirow[t]{2}{*}{ OCAD_U } & & $1.139862 * * *$ & \\
\hline & & $(0.3917410)$ & \\
\hline \multirow[t]{2}{*}{ Queens_U } & & -1.320614 & \\
\hline & & $(1.5456530)$ & \\
\hline \multirow[t]{2}{*}{ Ryerson_U } & & -0.282914 & \\
\hline & & $(0.1805240)$ & \\
\hline Trent_U & & -0.82969 & \\
\hline & & $(1.6309740)$ & \\
\hline U_Guelph & & -0.98609 & \\
\hline & & $(1.5744240)$ & \\
\hline UOIT_U & & -0.581171 & \\
\hline & & $(1.1445020)$ & \\
\hline U_Ottawa & & -0.316410 & \\
\hline & & $(0.6502580)$ & \\
\hline U_Waterloo & & -0.98 & \\
\hline & & $(1.0631780)$ & \\
\hline U_Windsor & & -0.412404 & \\
\hline & & $(1.2049100)$ & \\
\hline Western_U & & -1.151144 & \\
\hline & & $(1.0612180)$ & \\
\hline Wilfrid_U & & -0.798233 & \\
\hline & & $(1.0227780)$ & \\
\hline York_U & & -0.037771 & \\
\hline & & $(0.1174750)$ & \\
\hline No. of Obs. & 142 & 142 & 142 \\
\hline R-Squared & 0.28 & 0.92 & 0.004 \\
\hline
\end{tabular}

Note. Robust and Non-Robust Standard errors are in parentheses.

Uuniversity of Toronto is the base.

Independent variables are lagged by one year ( $t-1)$. Population is an unlagged variable (t).

$* \mathrm{p}<.10, * * \mathrm{p}<.05, * * * \mathrm{p}<.01$ 
As shown in Table 9.1, all panel regression models report different slope coefficients of the included variables and different standard errors and R-squared. Column 1 presents a Pooled OLS regression result without controlling for unobserved heterogeneity. The result from Pooled OLS regression shows that there are negative and significant relationships between marketing, graduates, and persistence ratio at 1 and $10 \%$, respectively $(\rho<.01 \& \rho<.10)$. This suggests that persistence ratio is expected to decrease, on average, by about 0.16 and $0.01 \%$, respectively, due to a one percent increase in expenditure on marketing and graduates.

Table 9.1, column 2 provides results from Fixed Effect (LSDV) models. The Fixed Effect (LSDV) regression model created dummy variables for each university, which allowed for the recognition of differences between universities and capturing the unobserved heterogeneity as part of the intercept. The result from Fixed Effect regression shows that there are positive and significant relationships between awards, marketing, and persistence ratio at 1 and 5\%, respectively $(\rho<.01 \& \rho<.05)$. This suggests that persistence ratio is expected to increase, on average, by about 0.20 and $0.05 \%$, respectively, due to a one percent increase in awards and marketing. Column 3 summarizes the statistical result from the Random Effect regression model. The result from Random Effect regression shows that there is a negative and significant relationship between graduates and persistence ratio at one percent $(\rho<.01)$. This suggests that persistence ratio is expected to decrease, on average, by about $0.04 \%$ due to a one percent increase in expenditure on graduates.

Across all these regression models, one can observe that the parameter estimates are different for both the Fixed and Random Effect models from those in the Pooled OLS model. This would imply that the estimated coefficients are not the same when using Pooled OLS, Fixed, and Random Effect models and indicates that unobserved heterogeneity could be affecting 
the outcome. However, to choose the regression model that can produce consistent and efficient estimation, the F-test, the Breusch and Pagan LM test, and the Hausman test were conducted. The results from conducting the F-test, the Breusch and Pagan LM test, and the Hausman test suggest that Fixed Effect is favoured over the Pooled OLS and the Random Effect models (Appendix D, Table 14.3.1 - 14.3.3). The following section provides an explanation of the result from the Fixed Effect model as the proper model that can provide consistent and efficient estimations.

4.4.1. Significant results. Figure 4 shows the estimated results from the Fixed Effect regression model that provides the expected percentage change in persistence ratio in response to a one percent change in university expenditure on price and non-price competitive variables for publicly funded universities.

Figure 6. Empirical Results from Fixed Effect Model (Persistence Ratio)

\section{Figure 6. The Expected Percentage Change in Persistence Ratio Due to a $1 \%$ Change in the Adopted Competitive Variables}

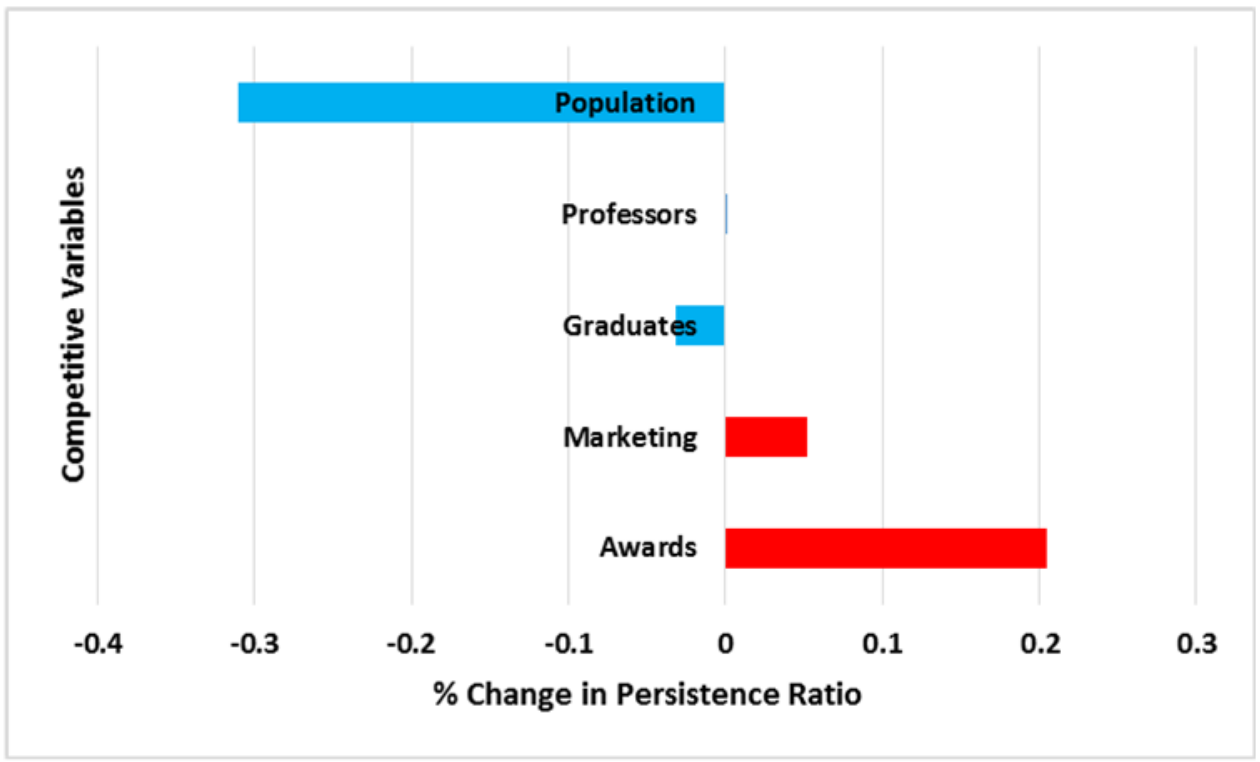

Significant Coefficient

Insignificant Coefficient 
The estimated result from the Fixed Effect (LSDV) model suggests that persistence ratio is significantly related to awards and marketing. Not surprisingly, awards and marketing have a positive and significant effect on persistence ratio. These variables are statistically significant at 1 and $5 \%$, respectively $(\rho<.01 \& \rho<.05)$. A positive and significant relationship suggests that for a one percent increase in awards, the persistence ratio is expected to improve, on average, by about $0.20 \%$ across publicly funded universities in Ontario, with standard error of plus or minus $0.08 \%$. Not surprisingly, a positive and significant effect was also found for university expenditure on marketing. This significance suggests that if university expenditure on marketing goes up by one percent, persistence ratio is estimated to improve by about $0.05 \%$ with standard error of plus or minus $0.03 \%$. To summarize, the existence of significant coefficients suggests that the competitiveness of universities could be affected when adopting competitive variables such as awards and marketing.

To examine the relationship among the variables for each individual university, a modified Fixed Effect regression was conducted for each individual university. As well as the baseline effects (coefficients) for awards, marketing, graduates, professors, and population, which are applicable to all universities, each regression introduced an additional effect (coefficient) for each of the variables applicable to the individual university in question. These additional effects capture whether a variable has a weaker or stronger effect for the particular university relative to other universities. In Table 9.2., each row corresponds to the regression for a particular university and reports the key coefficients for the additional effects that were estimated. Detailed regression outcomes are found in Appendix G, Table 9.2.1. 
Table 9.2. Additional Effect on Persistence Ratio for Each Publicly Funded University in Ontario.

\begin{tabular}{|c|c|c|c|c|c|}
\hline Universities & Awards & Marketing & Graduates & Professors & Population \\
\hline Brock University & -0.268491 & -0.2987 & 0.173349 & $0.616426^{* *}$ & $17.830479 *$ \\
\hline Carleton University & $1.093909 * *$ & $0.238926^{* * *}$ & 0.217638 & $-4.810081 * * *$ & $11.085624 * * *$ \\
\hline Lakehead University & $-0.320172 * * *$ & $-0.232115^{* *}$ & $0.676330 * * *$ & $-0.898599 * * *$ & $-15.626661 * * *$ \\
\hline Laurentian Univeristy & $-4.428640 * * *$ & $0.345699 * *$ & $-0.100704 * * *$ & $2.493777 * * *$ & 0 \\
\hline McMaster University & 0.215975 & -0.049611 & -0.047356 & -0.074193 & 0.514361 \\
\hline Nipissing University & 0.044388 & 0.024266 & (omitted) & $-1.869339 * * *$ & $16.461924 * * *$ \\
\hline OCAD University & 0.05984 & -0.342533 & $0.637766 * *$ & -0.386457 & 3.989136 \\
\hline Queen's University & $-0.630642 * * *$ & $0.117776^{* *}$ & 0.182112 & $-0.793643 * * *$ & $6.531155^{* * *}$ \\
\hline Ryerson University & 0.075543 & $0.301741 * * *$ & $0.282750 * * *$ & $-0.850045 * * *$ & 0 \\
\hline Trent University & $-2.132704 * * *$ & $-0.339147 * * *$ & 0.281481 & $0.749499 * *$ & 0 \\
\hline University of Guelph & $5.630557 * * *$ & $-1.938717 * * *$ & $-3.624703 * * *$ & $-3.606779 * * *$ & 6.744564 \\
\hline UOIT University & 0.237727 & 0.066937 & -0.066713 & $0.494217 * *$ & -6.680447 \\
\hline University Ottawa & $-0.306824 *$ & -0.04816 & 0.148606 & 0.149219 & 0 \\
\hline University of Toronto & $-0.531233 * * *$ & $-0.107264 * * *$ & $-0.285220 * *$ & $0.877068 * * *$ & 0 \\
\hline University Waterloo & -0.085259 & -0.24486 & $-0.240697 * *$ & $-0.652254 * * *$ & $4.866339 * * *$ \\
\hline University Windsor & $1.085143 * * *$ & $-1.177745^{* * * *}$ & 0.509665 & $-1.161811 * *$ & $-10.837952 * * *$ \\
\hline Western University & $-1.937673 * * *$ & $0.392268 * * *$ & $2.667628 * * *$ & $-0.275946 * * *$ & $-5.498478 * * *$ \\
\hline Wilfrid Laurier University & $-1.103367 * * *$ & $0.398665^{* * *}$ & $-1.535377 * * *$ & $3.421503 * * *$ & 0 \\
\hline York University & 1.204152 & $-2.362078^{*}$ & $-0.362119^{*}$ & -0.470961 & 1.840568 \\
\hline
\end{tabular}

Note. Expenditure on Graduates at Nipissing University remains constant over time and is thus perfectly co-linear with the dummy variable.

Additional Effects were reported in the table.

$* \mathrm{p}<0.10, * * \mathrm{p}<0.05, * * * \mathrm{p}<0.01$

The results shown in each row of Table 9.2 indicate which variables have stronger effects (denoted by positive additional effects) in the particular university relative to the baseline for all other universities and which variables have weaker effects (denoted by negative additional effects). Thus, the coefficients show the expected additional percentage changes in persistence ratio for a given university relative to the baseline for all universities stemming from a one percent change in its variables. Detailed regression results (baseline, additional, and overall effects) for each individual university are shown in Appendix G.

The positive and significant additional effects suggest that a competitive variable has a larger effect on persistence ratio, while a negative and significant sign suggests that the competitive variable has a smaller effect on persistence ratio for specific university relative to all 
other Ontario universities. Positive and negative signs for overall effects are discussed in Appendix G. However, the following paragraphs present the regression result of how persistence ratio for University of Toronto responds to changes in awards, marketing, graduates, professors, and population. University of Toronto is used as an example, but full analysis for the other eighteen universities is found in Appendix K.

University of Toronto. Figure 7.14 illustrates the difference in the effect of the adopted competitive variables on persistence ratio for University of Toronto relative to all other Ontario universities.

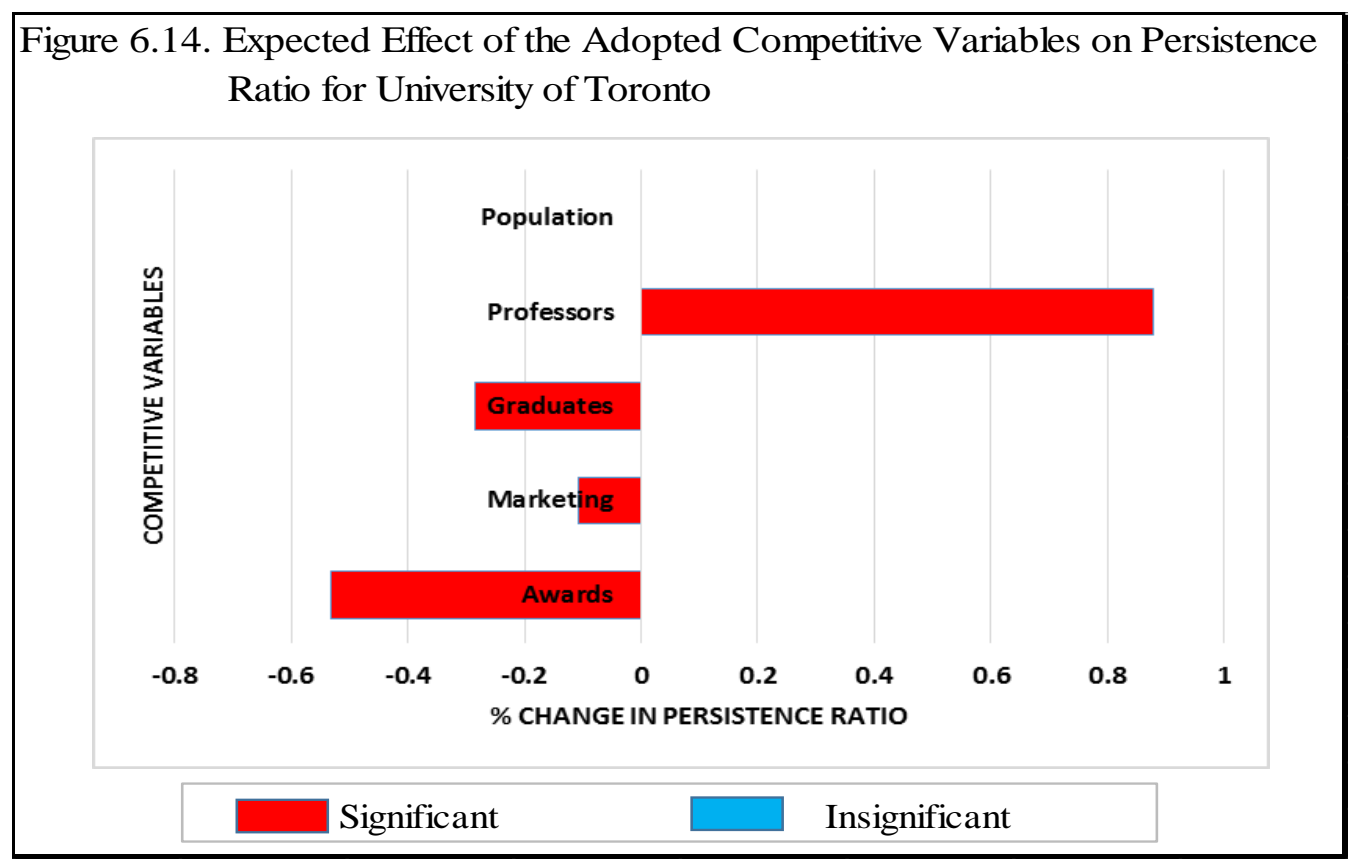

Figure 7.14. Regression Result from Fixed Effect (a modified Fixed Effect regression) for University of Toronto. The effect of the Adopted Competitive Variables on Persistence Ratio.

The result from Fixed Effects (a modified Fixed Effect regression) explains which variables have stronger effects (positive additional effects) in the University of Toronto relative to the baseline for all other universities and which variables have weaker effects (negative additional effects). Thus, the coefficients show the expected additional percentage changes in persistence ratio for University of Toronto relative to the baseline for all universities stemming 
from a one percent change in its variables. The regression result shows a strong relationship between persistence ratio and the adopted competitive variables ( $R$-Squared=0.92). R-Squared indicates that approximately $92 \%$ of the change in persistence ratio can be explained by the change in university expenditure on awards, marketing, graduates, and professors. The result suggests that the responsiveness of persistence ratio with respect to awards, marketing, graduates, and professors is about $-0.53,-0.11,-0.29$, and $0.88 \%$, respectively. These additional effect coefficients are statistically significant at $1,1,5$, and $1 \%(\rho<.01, \rho<.01, \rho<.05, \& \rho<.01)$. Overall effects also estimate negative and positive significant signs; they are explained in Appendix G.

The positive and significant additional effects suggest that expenditure on professors has a larger effect on persistence ratio, while a negative and significant sign suggests that expenditure on awards, marketing, and graduates has a smaller effect on persistence ratio. A one percent increase in expenditure on professors has a greater effect, while a one percent increase in expenditure on awards, marketing, and graduates has a smaller effect for University of Toronto relative to all other Ontario universities. Larger effect suggests that a one percent increase in investing in faculty members (professors) is expected to produce a greater effect on persistence ratio by about $0.88 \%$. A smaller effect suggests that a one percent increase in expenditure on awards, marketing, and graduates is expected to produce a smaller effect on persistence ratio by about $0.53,0.11$, and $0.29 \%$, respectively, for University of Toronto relative to all other Ontario universities.

However, the existence of significant responsiveness leads one to infer that the changes in university expenditure on awards, marketing, graduates, and professors are likely to affect the persistence ratio for University of Toronto. Evaluating the effect of adopted competitive 
variables can shed light on the importance of fund allocations. Fund allocations and the shift from variables with smaller effects to variables with greater effects can help publicly funded universities compete effectively and increase their market share. However, University of Toronto might need these responsiveness estimates in order to determine the most effective competitive variables to makes good managerial decisions in the short run and in the long run. A full explanation of the other eighteen publicly funded universities is provided in Appendix K.

\subsection{Robustness Checks}

This study has conducted a robustness check of the relationship between dependent variables (total number of enrolled students, total number of applications for admission, and persistence ratio) and explanatory variables (awards, marketing, graduates, professors, and population). Tests of the sensitivity of the results were performed by conducting additional tests: first, linking enrolment, applications, and persistence ratio in the current year with the expenditure ratio in the previous year (the ratio university expenditure on a particular variable to total university expenditure); and second, linking enrolment, applications, and persistence ratio in the current year (t) with university expenditure on competitive variables in the current year (Unlagged model). Panel regression models were used to examine both expenditure ratios and the Unlagged model. Regressions results are provided in Appendix H.

The research results and findings were tested by examining the effect of expenditure ratio on enrollees, applicants, and persistence ratio. Lagged expenditure ratios were calculated by dividing expenditure on awards, marketing, graduates, and professors in the previous year ( $\mathrm{t}-1)$ by total expenditure in the year ( $\mathrm{t}-1)$. The total number of enrollees, total number of applicants, and persistence ratio in the current year $(\mathrm{t})$ is linked with the various expenditure ratios (awards, marketing ...) in the previous year ( $\mathrm{t}-1)$, as well as the population in the current year $(\mathrm{t})$. These 
expenditure ratios were used to estimate the percentage change of enrollees, applicants, and persistence ratio due to a $1 \%$ change in these expenditure ratio values. This examination was used as a first robustness check for the research results and findings. The results from using expenditure ratios are similar to the original finding and positive and a significant relationship between awards, marketing, population and enrollees was found. Also, a positive and significant relationship between awards, professors, population and applications was found (Appendix $\mathrm{H}$ ). For persistence ratio, the result was similar to the original finding and positive and significant relationships between awards, marketing and persistence ratio were found. The standard errors are considerably similar to the errors in the panel regression models in the original finding. All of the significant coefficients are similar to the original finding. This robustness check strengthens the research original findings.

The second robustness check of the research results was conducted to examine the Unlagged model. The Unlagged model was used to estimate the responsiveness of enrollees, applicants, and persistence ratio in year (t) to expenditure on awards, marketing, graduates, and professors in year $(\mathrm{t})$, as well as to the population in the same year $(\mathrm{t})$. The results continue to show a positive and significant relationship between awards, marketing, population and enrollees, which strengthen the research findings (Appendix H). For the result of applications as a dependent variable, a positive and significant relationship between population and applications was found, which supports the original finding. Also, the insignificant effect for awards and professors, which does not match the original finding, does not qualitatively change the result. Using an Unlagged model with persistence ratio as the dependent variable shows that the standard errors for awards and marketing are similar to the errors in the Lagged model, but the 
coefficients become insignificant and with a lower magnitude. However, the above results support the robustness of my original findings. 


\section{CHAPTER FIVE: DISCUSSION, RECOMMENDATIONS, AND CONCLUSION}

This chapter presents a summary of the study and a discussion of the results, and highlights the implications for theory, policy, and practice. The chapter offers recommendations that have the potential to help academic institutions in Ontario in crafting appropriate managerial policies related to applications, enrolments, and persistence ratio. It also suggests opportunities for future research, discusses limitations of the result, and wraps up with a closing statement.

\subsection{Summary of the Study}

The culture of competition has become part of Ontario's higher education market. The government of Ontario has encouraged publicly funded universities to increase their capacity to absorb more students, which has fuelled competition to fill this excess capacity. Competition has also been encouraged through reforming higher education policies (e.g., deregulation of public funds and deregulation of tuition fees) that have encouraged publicly funded universities to rely more on and to compete for private sources of income. Based on these policies, the nature of higher education has changed and the competitive behaviour across universities has grown. This is to say that changes in the nature of higher education, because of the reduction of the government's financial support, have pushed publicly funded universities towards the market in order to generate their needed revenues. The market has become a solution for publicly funded universities to compensate for the drop in public funds, which has encouraged the use of market tools and the adoption of competitive variables.

Certainly, the challenge of financial self-sufficiency has forced many academic institutions to adopt a corporate model and to use market competitive tools to cover some of the costs of their educational programs and services to avoid the problem of closure and leaving the market. This means that publicly funded universities are seeing themselves in the market and in a 
competitive situation where they need to improve their competitiveness to sustain their operations and to maintain growth and viability.

The managerial style of leading publicly funded academic institutions has become acceptable due to the movement towards the market. Academic leaders find themselves under pressure to overcome their institutional competition challenges by utilizing the tools of the market to compete in order to succeed and progress. However, competing successfully in the market of higher education requires the use of price and non-price competitive variables. It should not be surprising to see publicly funded universities act and behave as private institutions do in the marketplace. The adoption of several forms of competitive activities borrowed from the business sector has become a significant issue for these universities to increase their market share and to enhance their competitiveness. Ontario universities, as part of this competitive academic market, may find themselves needing to deal with this competitive environment to maintain their enrolment and revenue levels by adopting price competitive variables (e.g., awards) or non-price competitive variables (e.g., marketing, graduates, and professors).

The adoption of these competitive variables could enhance institutional performance and increase their competitive advantage but, importantly, employing these variables is associated with extra costs. The adoption of costly competitive variables creates the need to measure the effect of these variables and to examine whether universities are getting what they have paid for. Theoretically, competition and the adoption of competitive variables can affect enrolment and cost (Misra et al., 2012). Analyzing the effects of these costly variables is important for academic leaders who are concerned with enhancing the competitiveness of their institutions. Therefore, this study has been conducted to examine how competition and the adoption of 
competitive variables by publicly funded universities can affect the total number of applications for admission, total number of enrolled students, and persistence ratio.

This study was guided by one research question: How does competition affect publicly funded universities in Ontario? This primary question was addressed by the use of three subquestions that are related to enrolment, applications for admission, and persistence ratio. In particular, this study has dealt with competition as a management dimension and has analyzed competition from the administrative side of universities rather than the academic side. The study analyzed competition and the use of competitive variables that are adopted mainly to attract potential customers for educational programs and services. Indeed, competitive variables can also be used for other purposes (e.g., higher ranking, brand name polishing...), but even these competition targets can be indirectly linked to attracting new applicants. Therefore, this study has explored competition by examining competitive variables such as university expenditure on awards, marketing, graduates, and professors, and their effects on enrolment, applications, and persistence ratio and controlled for population change in university location.

There are a few studies that have attempted to analyze competition among Canadian universities, but no one has analyzed all publicly funded universities in Ontario. Therefore, it should be noted that it may be hard to compare the results from this research with other studies, since most previous studies have focused on competition in the whole market in one individual country. Also, there has not been any published study that has dealt extensively with using price and non-price competitive variables in Ontario's higher education market and their effects on applications, enrolment, and persistence ratio. Consequently, results can only be compared with studies that explain, in general, the effect of some competitive variables on enrolment and applications, but not exactly for Ontario's publicly funded universities. Further insights and 
discussion on the relationship between the adopted competitive variables and enrolment, applications for admission, and persistence ratio is shown below.

\subsection{Discussion of the Results}

5.2.1 Research sub-question 1. The aim of examining how universities' expenditures on price and non-price competitive variables influence the number of enrolled students in each individual publicly funded university in Ontario is to answer the main research question regarding competition and its effect. The use of competitive variables to enhance competitiveness has forced universities to invest in variables such as awards, marketing, graduates, and professors. This investment in competitive variables can be seen as an effort to sustain the university's competitive position in the market to increase its market share (enrolment). Indeed, increasing the level of enrolment is important, not only for revenue generation but also for enhancing enrolment itself, since no academic institution can exist without sufficient demand for its educational services. Indeed, investment in competitive variables has the potential to maintain and to generate additional enrolled students.

Analysis of the relationship between the adopted competitive variables and enrolment for all Ontario publicly funded universities (the whole market) shows that the total number of enrolled students in all universities is significantly related to awards, marketing, and population. Not surprisingly, increasing university expenditure on awards and marketing, as well as increasing the population in the university's location has a significant effect on enrolment across publicly funded universities. The results show that awards and marketing as competitive tools have a significant effect on enrollees. This means that the positive and significant relationship between awards, marketing, and enrolment makes them proper competitive variables that could be adopted to enhance the competitiveness of publicly funded universities in Ontario. In general, 
this result is consistent with Rothschild and White (1993) and with Clotfelter and Rothschild (1993), who explained that the use of awards can affect student enrolment choices and can also attract top applicants. Also the result is consistent with the report of the Provincial and Territorial Ministers of Education and of Immigration (2011) who explained that communication and advertising have become important competitive tools for Canadian academic institutions to increase their market share, not only in national markets, but also in international markets. Moreover, results show that there is a positive and significant relationship between population and enrolment. This would encourage universities to propose recommendations for the government of Ontario to implement proper policies to enhance population growth.

However, the results also show that universities are not the same and that each university has its own demanders who prefer its programs and services even if other universities offer similar programs. This means that universities might compete in respect to some features but each also has some power due to its unique characteristics (e.g., program differentiation) that are preferred by some students. This finding suggests that each individual university has slight differences in its educational programs and services and has some features that alter students' perceptions to prefer it over other universities. The existence of variations across universities suggests that the effect of university expenditure on awards, marketing, graduates, and professors, as well as population, is different for publicly funded universities.

The result from examining the effect of the adopted competitive variables on enrolment for each individual university indicates that awards, marketing, graduates, professors, and population have a different effect for each individual university. For example, awards and marketing have a greater effect, while graduates and professors have a smaller effect on enrolment for Laurentian University relative to all other Ontario Universities. Another example 
is that graduates, professors, and population have a greater effect, while awards has a smaller effect on enrolment for University of Guelph relative to all other Ontario universities.

Furthermore, the result shows that enrolment is highly responsive to the change in population for most universities. This result facilitates the comparison of the effect of the adopted competitive variables and could help in justifying the shift from variables with smaller impact to variables with greater impact to enhance the competitiveness of publicly funded universities.

Results show that awards, marketing, graduates, professors, and population have a different effect on enrolment for each individual university. For example, the use of awards or marketing might be effective competitive variables for some universities in attracting students, while graduates or professors might be highly effective variables for other universities. Awards could be used to attract students, while social media, advertising, and web technology could also be used as tools and to provide information about universities' educational opportunities nationally and internationally. At the same time, professors (faculty members) and graduates (doctoral fellows, research assistants, and teaching assistants) have the potential to differentiate higher education institutions and their educational programs and services. This differentiation could affect the competitiveness of academic institutions in both national and international markets that can help them gain more enrolled students and increase their market share. The result is consistent with Duane (2002), who explained that differentiation can serve the purpose of being competitive in order to increase enrolment levels. Moreover, on March 10, 2015, Alan Wildeman, the president of University of Windsor, explained his vision regarding investing in faculty members as an important factor in managing enrolment. Wildeman announced that "University [of Windsor] will allocate its resources to permit the hiring of up to 50 new full-time 
faculty members to ... build on the University's academic strengths and opportunities" (uWindsor News, 2015).

5.2.2 Research sub-question 2. The aim of examining how universities' expenditures on price and non-price competitive variables influence the number of applications for admission in each individual publicly funded university in Ontario is to answer the main research question regarding competition and its effect. Competition across publicly funded universities can be measured by examining the number of applications for admission, since it represents the first indicator for the competitiveness of academic institutions. In addition, examining the competitive variables that might affect the number of applications for admission is important, since no one can enroll in an academic institution without applying. This is to say that a university needs to know the competitive variables that might affect the number of applications for admission, since a specific percentage of those applicants will accept the offer and enroll in the university. Therefore, a university needs to enhance its competitiveness to increase the number of applicants in order to increase its percentage of enrolled students. The regression results of the relationship between the adopted competitive variables (awards, marketing, graduates, professors, and population) and the total number of applicants for all publicly funded universities in Ontario are summarized below.

When examining all publicly funded universities in Ontario as one market, results show that the total number of applications for admission is significantly responsive to awards, professors, and population. These competitive variables are significant for publicly funded universities to influence students' preferences. A positive and significant effect of awards on applicants might raise an argument that students do not know the amount of the scholarships or awards that a university offers when they apply for admission. Indeed, this might not be the full 
story, since publicly funded universities do participate in promotional activities that take place in each secondary school across the province and/or overseas as part of their recruitment activities. Representatives of universities provide future applicants with all information, including the availability of scholarships, to influence their application decisions. They also provide potential applicants with brochures (or books) that include valuable information about scholarships to capture their attention. Scholarships and bursaries (awards) are usually considered by potential applicants as a tuition discount, and that can encourage students to apply. The target of these recruitment activities is to bring future demanders to the campuses by encouraging them to fill out applications for admission, an important step in the recruiting process. In addition, the power of "word of mouth" from previous applicants regarding grants and bursaries as a tuition discount can also influence the decision of new demanders.

The result from this study shows a positive and significant effect of professors on applications. This means that the adoption of investing in faculty members (professors) as a competitive variable has the potential to affect students' choices and affect the total number of applications for admission. This result is consistent with the recommendations that were released by the Ontario Confederation of University Faculty Associations (OCUFA) on February 4, 2015. OCUFA $(2015, \mathrm{~b})$ recommended that "universities should receive adequate funding to support good jobs on their campuses. ... and hire sufficient numbers of tenure stream faculty to maintain high academic standards and fair workloads." (para. 2, point 4). Indeed, investing in recruiting qualified professors can contribute to program differentiation and university reputation. A university reputation can be used to differentiate a university from other competitor universities to attract future applicants. This result is also consistent with Anctil 
(2008), who explained that university reputation has been utilized by potential demanders to rationalize their choices.

Results from this study also indicate that there are significant differences between universities that make the effect of awards, marketing, graduates, professors, and population not the same for publicly funded universities. This means that the competitive behaviour of publicly funded universities and the use of competitive tools can affect future applicants differently for each individual university. For example, expenditure on professors and graduates has a greater effect, while expenditure on awards has a smaller effect, on the total number of applicants for University of Waterloo relative to all other Ontario Universities. Another example was that awards and marketing have a greater effect, while professors and graduates have a smaller effect on applicants for Trent University. This result indicates that each university has its own significant competitive variables. This means that the competitiveness of publicly funded universities can be improved by adopting effective competitive variables. This result is consistent with Davies and Hammack (2005), who explained that price competitive variables can be used in higher education by offering grants and subsidies to attract students. This result is also consistent with Franck and Schönfelder (2000), who explained that competition can encourage universities to use marketing and advertising to show their educational quality and the features of their programs in order to attract potential demanders. In addition, investing in faculty members (professors) and graduates (doctoral fellows and research assistants) can play an important role in shaping the identity of university itself, which plays a significant role in targeting applicants for admission and affecting their choices. Certainly, the reputation of a university might be the key factor in driving students' decisions to apply for their programs. 
5.2.3. Research sub-question 3 . The aim of examining how universities' expenditures on price and non-price competitive variables influence the persistence ratio in each individual publicly funded university in Ontario is to answer the main research question regarding competition and its effect. It was important to consider analyzing the relationship between the adopted competitive variables and persistence ratio in this study. The persistence ratio of total enrollees to applicants is analyzed because of its potential implications for both conversion and retention. It was interesting to find out from this research that persistence ratio is significantly related to awards and marketing when examining all publicly funded universities in Ontario as one market. This result indicates that the use of awards and marketing can improve persistence ratio, and that publicly funded universities could enhance their competitiveness when using these competitive tools. Indeed, a university needs to fill its capacity by recruiting new students and retain current students, not only for academic purposes, but also for the stability of its tuition revenue.

Results also show that the effect of awards, marketing, graduates, professors, and population on persistence ratio are not the same for each individual publicly funded university. For example, marketing and graduates have a greater effect, while expenditure on professors has a smaller effect on persistence ratio for Ryerson University relative to all other Ontario universities. Also, awards, marketing, and population have a larger effect on persistence ratio, while expenditure on professors has a smaller effect on persistence ratio for Carleton University relative to all other Ontario universities. The research results show that competitive variables are different in their effect for individual universities, which suggests that each university has its own significant competitive variables for improving its persistence ratio. This result is consistent with Kirby (20011), who explained that competition will increase in coming years and the use of 
competitive variables by academic institutions is essential, not only to increase enrolment level as a solution to increase institutions' revenue, but also to maintain enrolment level. Indeed, each university can enhance its competitiveness to improve its persistence ratio based on its own significant competitive variables.

\subsection{Implications for Theory, Policy, and Practice}

The results of this study have implications for theory, policy, and practice and a discussion of these implications is provided below.

5.3.1 Implication for theory. The results of this study have several theory implications. While the focus of this study is on competition in publicly funded universities, the study can add empirical support to the importance of Porter's Five Forces model, since these forces can affect the competitiveness of academic institutions in the higher education market. These forces can also be considered as a structural framework for academic leaders to manage enrolment in their academic institutions. This structural framework can guide academic leaders in choosing appropriate competitive variables to influence students' decisions to apply and enroll. Porter's Five Forces analysis is an important tool to evaluate the potential success of academic institutions in the higher education market. In the case of universities, Porter's Five Forces can be identified as:

1. Supplier power (Union power).

2. Buyer power (Student power).

3. Competitive rivalry (Competitive universities in the market).

4. The threat of substitutions (Programs and services that are provided by other universities in the market). 
5. The threat of the new entry (The ease to enter into the market by a new competitor) (Thompson Jr. et al. 2005).

Recognizing these forces and how they might affect academic institutions is critical in evaluating the ability of publicly funded universities to compete in the market. Indeed, each academic institution has its own features, characteristics, and circumstances and there is a need to incorporate these forces with the university's own situation in order to adopt the right competitive variables.

The competitiveness of each university could be affected first by the power of suppliers. In the case of a university, it could be argued that the main suppliers are the faculty members and other employees in each university, who are usually members of a labour union. Indeed, this is the case for all publicly funded universities in Ontario. The cost of instruction and the production of research, as an example, are directly linked to faculty members (suppliers in this case) who are unionized and hold a reasonable amount of power that might affect all processes in a university. On the other hand, the input of professors and researchers in achieving the goals of higher rank or better reputation for an institution could be the main factor of success for a university. This power of suppliers is assumed to have an effect on all publicly funded universities, and universities need to find the right approach to deal with the power of their suppliers.

Student power (buyer power) can be recognized by highlighting the number of demanders and their sensitivity to tuition fees, scholarship and bursaries, program differentiation, university location, and so forth, and the ability of students to substitute one university program for another. This recognition is an important issue in enhancing the competitiveness of academic institutions. Similarly, knowing which university can be seen as a competitor (competitive rivalry) and 
knowing the number of competitor universities in the market are important in choosing suitable competitive variables. In addition, knowing the demanders' favourability and recognizing the students' ability to find similar programs (the threat of substitutions) are also crucial in choosing a proper competitive variable. Finally, recognizing the ability of other universities to enter the market (threat of new entry), or if there are strong barriers to entry and to competing effectively can also be considered important issues for success (Thompson Jr. et al., 2005).

This study focuses on the managerial side of a higher education institution. Using generic competitive strategies can improve the competitiveness of universities. These generic strategies are: low-cost provider strategy, differentiation strategy, best-cost provider strategy, and focused strategy (low-cost or differentiation) (Thompson Jr. et al., 2005). The adoption of one specific strategy from these generic competitive strategies can help in establishing a competitive advantage for universities to get the attention of potential students. Indeed, the complicated nature of managing publicly funded universities is well-known, due to the existing challenges of competition and the limited ability to adopt more business-like organizational processes. But one could argue that the role of leaders should be unlimited when dealing with administrationrelated issues.

This study is the first study to suggest that Ontario's post-secondary market is consistent with some features of monopolistic competition (excluding the feature of profit maximization) in a monopolistic competition market. In this type of market structure, universities vary slightly through differentiating themselves and that can contribute to the importance of contingency theory. This means that the adoption of a specific competitive variable is contingent on, for example, university size, type, reputation, brand name, or location. There might not be a single competitive variable that is purely effective for all universities and in all circumstances. 
Therefore, competitive variables are contingent on the university's own situation and the adoption of appropriate variables can contribute to a university's success.

5.3.2 Implication for policy. The result of examining all Ontario publicly funded universities together has several policy implications. The result suggests that enrolment is significantly and positively related to awards, marketing, and population, while application for admission is significantly and positively related to awards, professors, and population. Policy makers can use the results of this study to encourage investment in strategies that could support public purposes. The results from this study give an explanation regarding the appropriate competitive variables that could be used for the purpose of growth and efficiency in higher education. This study might help policymakers to underline the importance of competitive strategies when they aim to target the efficiency and competitiveness of higher education institutions.

5.3.3 Implication for practice. Results of this study have implications for the practice of leadership in academic institutions. Academic leaders who are willing to adopt a business-like approach when managing viable, sustainable, and efficient publicly funded universities might benefit from this study. Results from this study are directed towards academic leaders, since the study provides an empirical analysis of the effect of adopted competitive variables. Research results indicate that there are optimal or sub-optimal competitive variables for each individual university that might have a significant effect on enrolment, applications, and persistence ratio. The results have the potential to help academic leaders in planning to improve competitiveness by knowing universities' unique and suitable competitive variables that might help them compete in the academic marketplace. 
In addition, since academic leaders need to make rational decisions and make trade-offs as a result of the scarcity of their funding sources, this study provides relevant information that might help academic leaders manage their spending processes. Since academic leaders have to make choices and take all the responsibility of adopting these choices, this study serves the purpose of assisting academic leaders in making good spending decisions and in managing enrolment.

The other implication of this study is that it sheds light on the importance of determining the optimum competitive variables that could maximize the benefit of adopting these variables. In this study, the benefit of adopting the competitive variables is to maximize enrolment that will in turn maximize tuition revenue. The benefits of adopting an optimum competitive variable have the potential to outweigh the cost of implementing that variable. Indeed, optimization can occur when the change in tuition revenue equals the change in university expenditure on adopted competitive variables. However, for some universities, extra enrollees might be seen as an extra liability. Except for some cost-recovery programs in some Ontario universities, regular tuition revenue could only cover a portion of the variable cost per student (e.g., \$2000 tuition out of a $\$ 5000$ cost). When transferred grants are less than what should be covered by government, the benefit of recruiting extra enrollees (tuition revenue) will be covered by other university funding sources and, consequently, become a university liability rather than extra revenue. In fact, some universities might have a limitation on their endowment and that might reduce their ability to adopt optimum competitive variables and maximize their enrolment. To reduce the constrained optimization problem, universities might use these research results in order to make good managerial decisions regarding funds allocation. This suggests that universities need to shift their expenditure away from less effective competitive variables and devote themselves to 
getting closer to the optimum competitive variables in order to sustain educational services within a balanced budget.

\subsection{Recommendations}

Perhaps the most significant recommendation for academic leaders who lead universities with scarce funding sources, and/or who lead universities that have enough funds to do what is needed, is that they need to give attention to how the university's resources can be allocated to enhance competitiveness. Academic leaders need to do an effective job in steering resources into highly-effective competitive variables that could help them reach their objectives. They need to shift away from ineffective competitive variables into highly-effective competitive variables and invest in variables that can strengthen the long term competitiveness and growth of their institutions. For example, this study shows that a non-price competitive variable like marketing is an appropriate competitive variable for universities such as Lakehead, since marketing is expected to have a greater effect on both enrolment and applications relative to all other Ontario universities. Another example is the use of graduates and professors (non-price competitive variable), which turned out to be appropriate competitive variables for University of Guelph since they have a greater effect on both enrolment and application.

However, this study recommends that academic leaders need to allocate enough funds towards the optimal or sub-optimal competitive variables to reach their goals and they need to reduce their investment (spending) in low-effect variables.

To prepare for increased competition, the results of this study recommend that publicly funded universities need to create a specific enrolment committee, other than an enrolment management division. The focus of the committee would be to propose an enrolment strategic plan based on changes in the competitive environment of higher education. The committee 
members need to discuss the results of an internal and external data analysis for factors that might affect applications for admission, enrolment, and attrition and retention in order to recommend appropriate competitive activities. The suggested competitive factors should be subject to regular evaluation and should be adjusted by the committee in order to succeed in the higher education market. Committee members should come from different offices across the university, including faculty members. Shared information and collaboration across the committee members could help in proposing rational recommendations regarding appropriate competitive behaviour and resource allocation for current competitive activities, in order to influence future and current students and stabilize the university's revenue. Indeed, each university has a limited capacity, so proposing a proper strategic enrolment plan should be within the context of a university's enrolment capacity and budget constraints.

\subsection{Opportunities for Future Research}

Tremendous opportunities for future research can be derived from the results of this study. This study shows that each individual university is expected to have a specific percentage of enrolled students and a specific percentage of applications for admission based on its own observed and unobserved characteristics. Future research may choose to highlight some of these observed and unobserved characteristics. An additional line of research could be adopted and use other research methodologies that might provide a deeper understanding of these effective characteristics. In addition, this study has controlled for local population over time and its effect on enrolment, applications, and persistence ratio. An additional line of research could be adopted and could examine regional competition through controlling for the travel zone between universities. For example, Lakehead University is located in Thunder Bay, which is far from Toronto, and it might have its own market for those who are willing to stay home. Looking at 
how far universities are from one another and examining the relationship between distance and student choice might reflect the competitiveness of universities.

This study suggests that in Ontario's higher education market, each university can differentiate itself by some features; and analyzing the relationship between the degree of program differentiation and tuition revenue is strongly recommended for future research. This area of study is important for both policy makers and academic leaders, since it allows for the understanding of which competitive variables could be used to improve the competitiveness of higher education institutions.

In addition, since the nature of higher education is complex, Ontario's publicly funded universities are seen as mixed-institutions in terms of public versus private orientation. This means that publicly funded universities rely on both public and private funds and they have to use market tools and take on a responsibility to compete for public and private funds. They are dealing with both academically related issues and administratively needed processes. Managing an "assumed" public institution, while having to deal with its real, and mostly hidden, businesslike nature, could certainly make publicly funded university complex institutions. This "hidden" face of academia can, indeed, benefit from additional research to investigate the managerial segment in higher education.

\subsection{Limitations of the Results}

It could be argued that the existence of limitations in social science research go hand in hand with almost every study, regardless of the methodology and methods used. Indeed, this quantitative study does have its own limitations and this section highlights the limitations of the results. The first limitation is the use of secondary data that was historically collected for purposes other than the use of this study. Even though data sources might be trusted sources, 
their quality could be questioned because of the data collection methods used or because the data has become outdated and might not be useful for future use. However, in this study, secondary data was collected from reliable official institutions that have collected the data by using the same criteria for all universities under study. These official institutions have collected the data for the same purpose of accountability, and it was published for the purpose of transparency. Furthermore, the collected data (e.g., total expenditure) was audited by an independent auditor group and based on Canadian auditing standards.

While the use of historical data might be problematic in some cases, it is in fact necessary for this research study. The use of secondary data allows for examining the effect over a long period of time (2006-2013), and using data that was collected over many years was a must for this study. Collecting primary data would not have served the purpose of examining the historical relationship that should be understood to properly evaluate the competitive variables used. This study has used the data of eight years, and certainly results could be improved if more years were analyzed. At the same time, the quantity of data that was needed to conduct this research study is very large, and it is beyond the ability of any researcher to collect it as primary data. Collecting data for 19 publicly funded universities in the largest Canadian province could not be done through the use of primary data. In this study, collecting primary data would not be efficient, since the needed data (universities expenditure on competitive variables over the years 2006 to 2013 and census population) was already collected, audited, and published for the public.

Another limitation is related to the way the missing data was handled. The use of the List-wise deletion method (complete case analysis) in dealing with missing data has some limitations, since this method deals with missing data by dropping all observations that have 
missing values. Because this study has a small proportion of missing data (less than six percent), the use of the List-wise deletion method did not affect the quality of this research results.

Moreover, the limitations of using panel data regression models cannot be ignored, even though these models control for variables that cannot be observed across universities. The advantage of using Fixed Effect regression models can be seen through controlling for unique characteristics that cannot be measured and might affect the regression outcome and bias the estimation results. However, the potential limitation for these models is that omitted variable bias cannot be eliminated if unobserved heterogeneity is time-variant. In other words, if unobserved factors change over the years and are correlated with included explanatory variables in regressions, fixed effect regression outcomes can be affected by omitted variable bias. To avoid this bias, time trend was used to control for any unobserved variables that varied over time and might affect the research results.

The last potential limitation is the generalizability of the research result since the research utilized only publicly funded universities that operate in Ontario's higher education market. The research results are still applicable to other higher education markets in other Canadian provinces, since they are probably not much different from Ontario. Competitive behaviour and the use of market tools can be recognized across universities in different provinces, which might facilitate generalizing the results to other publicly funded universities that operate in different provinces. Therefore, the research result might not be perfectly applied to other universities outside Ontario, but the results remain suggestive for some other universities in other provinces. In addition, the results cannot be generalized to other private universities or colleges, since this study examined only publicly funded universities 


\subsection{Closing}

Competition across universities is a healthy phenomenon that might improve the higher education system through differentiation and efficiency. The creativity of universities in providing competitive academic programs and services is encouraged by competition. The race is not only to gain market share (enrolment) and to improve the quality of educational programs and services, but also to provide them in an efficient way. Examining how well a university's adopted competitive variables are working can help the academic institution in understanding its competitive advantage and in recognizing its effective strategies. Evaluating the effectiveness of competitive variables should be seen as an ongoing process that is undertaken at regular intervals. Certainly, the internal and external factors that affect an institution are always changing and the ability of the institution to adapt to new changes could be a major factor in its existence and continuity.

Indeed, the higher education market is getting tougher for Ontario-based universities due to competition from provincial, national, and international academic institutions. Evaluating the competitive variables used provides an opportunity for feedback on appropriate variables for rational and informed decision making. Evaluation can highlight the importance of resource allocation and how an institution might spend its money to achieve its desired objectives. Evaluation also provides opportunities to avoid competitive variables that perform poorly and might put a university at a disadvantage in the marketplace. There is no room for poor performance in today's higher education market and, certainly, the ongoing battle of competition will make the room even more crowded. 


\section{References}

Anctil, E. J. (2008). Market differentiation. ASHE Higher Education Report, 34(2), 49-88.

Askari, M. (2014). A partnership approach to public finance for higher education funding in Canada (Doctoral Dissertation). Retrieved from Dissertations and Theses database, University of Calgary http://hdl.handle.net/11023/1383.

Association of Universities and Colleges of Canada (AUCC), (2011). Retrieved from http://www.aucc.ca/wp-content/uploads/2011/05/trends-2011-vol1-enrolment-e.pdf

Austin, R. E., \& Wanzel, K. R. (2015). Supply versus demand: a review of application trends to Canadian surgical training programs. Canadian Journal of Surgery, 58(2), 143-144. doi:10.1503/cjs.006614

Axelrod, P. (2002). Values in conflict: The university, the marketplace, and the trials of liberal education. McGill-Queen's University Press, Montréal, QC, CAN http://site.ebrary.com/lib/ucalgary/Doc?id=10135894

Beach, C., Broadway, R., \& McInnis, R.M. (2005). Introduction. Higher Education in Canada. Kingston, Canada: Queen's University.

Bergh, A., \& Fink, G. (2006). Higher education: Does public expenditure increase enrollment? Retrieved from http://www.academia.edu/3568444/Higher_Education_Does_Public_Expenditure_Increa se_Enrollment

Berulava, M. N. (2005). Higher education in Russia in the light of market reforms. Russian Education and Society, 47(8), 6-13.

Bradmore, D. J., \& Smyrnios, K. X. (2009). The writing on the wall: Responses of Australian public universities to competition in global higher education. Higher Education Research and Development, 28(5), 495-508. 
Brennan, J., \& Osborne, M. (2008). Higher education's many diversities of students, institutions and experiences; and outcomes? Research Papers in Education, 23(2), 179-190.

Brown, K. (2010). Higher education and the market. Routledge: Florence, KY, USA. Retrieved from http://site.ebrary.com/lib/ucalgary/Doc?id=10416535

Brown, R. (2008). Higher education and the market. Perspectives: Policy and Practice in Higher Education, 12(3), 78-83.

Bruce, V. (2006). Markets and higher education: A regime of truth? Irish Educational Studies, 25(2), 141-154.

Bruneau, W., \& Schuetze, H. G. (2004). Less state, more market: University reform in Canada and abroad. Canadian Journal of Higher Education, 34(3): 1-12.

Bunzel, D. L. (2007). Universities sell their brands. The Journal of Product and Brand Management, 16(2), 152-153. doi:http://dx.doi.org/10.1108/10610420710740034

Calhoun, J., \& Kamerschen, D. R. (2010). The impact of governing structure on the pricing behavior and market structure of public institutions of higher education in the U.S. International Review of Economics, 57(3), 317-333. doi:http://dx.doi.org/10.1007/s12232-010-0089-2

Cameron, D. M. (2005). Ontario's Rae Report: Investing in growth. Canadian Public Administration, 48 (2), 280-287. doi: 10.1111/j.1754-7121.2005.tb02193.x

Cameron, D. M., Gorbet, F., Henderson, C., Stephenson, B. M., \& Smith, D. C. (1996). Report of the advisory panel on future directions for postsecondary education. Retrieved from Ontario, Ministry of Training, Colleges and Universities website. http://www.tcu.gov.on.ca/eng/document/reports/futuree.html 
Canadian Council on Learning (2006). Factors influencing post-secondary enrolment increases and decreases. Ottawa, ON, CAN. Retrieved from: http://www.ccl-cca.ca/pdfs/SystematicReviews/EnrolmentinPSE.pdf.

Cauley, T. J. (2 Ed). (1968). Economics: Principles and institutions. International Textbook Company: Scranton, Pennsylvania.

Chase, R. B., Jacobs, F. R., \& Aquilano, N. J. (10 ${ }^{\text {th }}$ Ed). (2004). Operations management for competitive advantage. New York: McGraw-Hill//rwin.

Clotfelter, C. T. \& Rothschild, M. (1993). Introduction. In Studies of supply and demand in higher education. NBER Chapters, National Bureau of Economic Research, Inc. University of Chicago Press. 1- 8, ISBN: 0-226-11054-0

Common University Data Ontario (CUDO), (2013). Retrieved from http://cou.on.ca/statistics/cudo.

Competition Policy Review Panel (2008). Compete to win: Final report June 2008. Ottawa, ON, Canada: Competition Policy Review Panel. Retrieved form http://site.ebrary.com/lib/ucalgary/Doc?id=10232104.

Cooper, B., Glaesser, J., Hammersley, M. (2012). Challenging the qualitative-quantitative divide: Explorations in case-focused causal analysis. London: Continuum International. Retrieved from http://site.ebrary.com.ezproxy.lib.ucalgary.ca/lib/ucalgary/docDetail.action?docID=1055 4611.

Cornwell, C., Mustard, D. B., \& Sridhar D. J. (2006). The enrollment effects of merit-based financial aid: Evidence from Georgia's HOPE program. Journal of Labor Economics, 24 (4), 761-786. 
Council of Ministers of Education, Canada in collaboration with The Canadian Commission for UNESCO, (2008). The Development of Education Reports for Canada. Canada: The Council of Ministers of Education. ISBN 978-0-88987-184-7.

Council of Ontario Universities (COU), 2015. Retrieved from http://www.cou.on.ca/news/media-releases/cou/applications-still-pouring-in-to-ontariouniversit.

Creswell, J. W. (2008). Educational research: Planning, conducting, and evaluating quantitative and qualitative research. Pearson Education: Upper Saddle River, New Jersey 07458.

Crotty, M. (1998). The foundations of social research: Meaning and perspective in the research process. London: SAGE.

Cudmore, G. (2005). Globalization, internationalization, and the recruitment of international students in higher education, and in the Ontario colleges of applied arts and technology. The Canadian Journal of Higher Education, 35(1), 37-60.

Davies, S., \& Hammack, F. M. (2005). The channeling of student competition in higher education: Comparing Canada and the U.S. Journal of Higher Education, 76(1), 89.

Deschamps, E. (2013). Entrepreneurialism's influence on the international strategies and activities of public U.S. universities. (Order No. 3560788, The University of Arizona). ProQuest Dissertations and Theses. Retrieved from http://ezproxy.lib.ucalgary.ca/login?url=http://search.proquest.com/docview/1362251701 ?accountid=9838. (1362251701).

De Wit, H. (2011). Globalisation and internationalisation of higher education. RUSC: Revista De Universidad Y Sociedad Del Conocimiento, 8(2), 241-248. 
Dobbie, D., \& Robinson, I. (2008). Reorganizing higher education in the United States and Canada. Labor Studies Journal, 33(2), 117-140.

Douglass, J. (2005). All globalization is local: Countervailing forces and the influence on higher education markets. Higher Education Policy, 18(4), 445-473.

doi:10.1057/palgrave.hep.8300096. Retrieved from http://www.eric.ed.gov/contentdelivery/servlet/ERICServlet?accno=ED492331

Duane, K. L. Jr. (2002). The influence of institutional pressure on competitive activity: An empirical test in the higher education industry. (Order No. 3039687, University of Kentucky). ProQuest Dissertations and Theses. Retrieved from http://ezproxy.lib.ucalgary.ca/login?url=http://search.proquest.com/docview/305559484? accountid=9838. $(305559484)$.

Easterby-Smith, M., Thorpe, R., \& Lowe, A. (2Ed.). (2004). Management research: An introduction. London: SAGE.

Eastman, J. (2006). Revenue generation and organisational change in higher education: Insights from Canada. Higher Education Management and Policy, 18(3), 48-75.

Ekelund, R. B., \& Ault, R. (1995). Intermediate microeconomics: Price theory and applications. Lexington, MA 02173: D. C. Heath.

Fanelli, C., \& Meades, J. (2011). Austerity, Ontario and post-secondary education: The case of “Canada's capital university”. Journal for Critical Education Policy Studies, 9(2), 216240.

Feldman, K. S. (2007). The commercialization of public higher education: Balancing academic, fiscal and market values. (Order No. 3268520, The University of New Mexico). ProQuest Dissertations and Theses. Retrieved from 
http://ezproxy.lib.ucalgary.ca/login?url=http://search.proquest.com/docview/304829090? accountid=9838 (304829090).

Felgueira, T., \& Rodrigues, R. (2012). Entrepreneurial orientation, market orientation and performance of teachers and researchers in public higher education institutions. Viesoji Politika Ir Administravimas, 11(4), 703-718.

Finch, D., McDonald, S., \& Staple, J. (2013). Reputational interdependence: An examination of category reputation in higher education. Journal of Marketing for Higher Education, 3461. doi:10.1080/08841241.2013.810184.

Fink, A. (2Ed). (2005). Conducting research literature reviews: From the internet to paper. Thousand Oaks, CA: Sage.

Finnie, R., Childs, S., \& Qiu, H. (2012). Patterns of persistence in postsecondary education: New evidence for Ontario. Higher Education Quality Council of Ontario.

Fitzsimons, P. (2006). Third way: Values for education. Theory and Research in Education, 4 (151). DOI: $10.1177 / 1477878506064541$. Retrieved from http://tre.sagepub.com/content/4/2/151.

Foreign Affairs, Trade and Development Canada, (2014). Retrieved from http://www.international.gc.ca/media/comm/news-communiques/2014/01/15a.aspx? lang=eng

Frank, R.H., Bernanke, B.S., Osberg, L., Cross, M.L., \& MacLean, B.K. (2Ed). (2005). Principles of microeconomics. Toronto: McGraw-Hill Ryerson.

Franck, E. P., \& Schönfelder, B. (2000). On the role of competition in higher education - uses and abuses of the economic metaphor. Schmalenbach Business Review (SBR), 52(3), 214-237. 
Fredriksson, P. (1997). Economic incentives and the demand for higher education. Scandinavian Journal of Economics, 99(1), 129-42.

Goan, S. K., \& Cunningham, A. F. (2006). The investment payoff: A 50-state analysis of the public and private benefits of higher education. American Academic, 23-38.

Gujarati, D. N. (2003). Basic econometrics (4 ${ }^{\text {th }}$ Ed). New York.: McGraw-Hill Higher Education.

Gumport, P. J. (2001). Restructuring: Imperatives and opportunities for academic leaders. Innovative Higher Education, 25(4), 239 - 251.

Heidrich, B., \& Chandler, N. (2011). The effect of market-oriented subcultures on post-merger higher education institutions. Online Submission, US-China Education Review, A5, 666681. http://www.eric.ed.gov/contentdelivery/servlet/ERICServlet?accno=ED527687

Hemsley-Brown, J., \& Oplatka, I. (2010). Market orientation in universities. The International Journal of Educational Management, 24(3), 204-220. doi:http://dx.doi.org/10.1108/09513541011031565

Hensley, B., Galilee-Belfer, M., \& Lee, J. J. (2013). What is the greater good? The discourse on public and private roles of higher education in the new economy. Journal of Higher Education Policy and Management, 35(5), 553-567.

HEQCO, Performance Indicators Project (2012). Performance indicators for the public postsecondary system in Ontario. A consultation paper prepared by the Higher Education Quality Council of Ontario (HEQCO).

Hinchey, P. H. (2008). Action research primer. New York: Peter Lang. Retrieved from http://web.ebscohost.com.ezproxy.lib.ucalgary.ca/ehost/detail 
Holbrook, M. B. (2004). Universities in the marketplace: The commercialization of higher education. Journal of Macromarketing, 24, 68-74, DOI: 10.1177/0276146704264011.

Hosslar, D. R. (2004). How enrollment management has transformed-or ruined- higher education. Chronicle of Higher Education, 40(34).

Hossler, D., \& Bontrager, B. (2014). Handbook of strategic enrollment management. Wiley. Howe, K. R. (2003). Closing methodological divides: Toward democratic educational research. Secaucus, NJ, USA: Kluwer Academic. Retrieved from http://site.ebrary.com.ezproxy.lib.ucalgary.ca/lib/ucalgary/docDetail.action?docID=1006 7525.

Hung, C. (2003). College enrollment and state financial policies: Low-tuition/low-aid vs. hightuition/high-aid. (Doctoral Dissertation, University of Virginia, 2003).

James, E. M. (1991). Economics: A problem-solving approach (2 ${ }^{\text {nd }}$ ed.) Scarborough, ON: Prentice-Hall.

Jha, N.K. (2008). Research methodology. Global Media. Chandigarh, IND. Retrieved from http://site.ebrary.com.ezproxy.lib.ucalgary.ca/lib/ucalgary/docDetail.action?docID=1041 6498.

Jie, Z. (2010). Neoliberal globalization, higher education policies and international student flows: An exploratory case study of Chinese graduate student flows to Canada. Journal of Alternative Perspectives in the Social Sciences, 2(1), 216-244.

Joekes, S. (2008). Competition and development: The power of competitive markets (in focus collection). Ottawa, ON, CAN: IDRC Books / Les Éditions du CRDI. Retrieved from http://site.ebrary.com/lib/ucalgary/Doc?id=10239196.

Johnson, A. L. (2000). The evolution of strategic enrollment management: a historical perspective. Journal of College Admission, (166), 4-11. 
Johnston, J. \& DiNardo, J. (1997). Econometric methods. (4 ${ }^{\text {th }}$ ed), USA: McGraw-Hill.

Jones, G. A. (2004). Ontario higher education reform, 1995-2003: From modest modifications to policy reform. The Canadian Journal of Higher Education, 34(3) 39-54.

Joseph, M., Mullen, E. W., \& Spake, D. (2012). University branding: Understanding students' choice of an educational institution. Journal of Brand Management, 20(1), 1-12. doi:http://dx.doi.org/10.1057/bm.2012.13

Kaklauskas, A., Daniūnas, A., Amaratunga, D., Urbonas, V., Lill, I., Gudauskas, R., D’Amato, M., Trinkunas, V., \& Jackutè, I. (2012). Life cycle process model of a market-oriented and student centered higher education. International Journal of Strategic Property Management, 16(4), 414-430. doi:10.3846/1648715X.2012.750631

Kirby, D. (2011). Strategies for widening access in a quasi-market higher education environment: Recent developments in Canada. Higher Education: The International Journal of Higher Education and Educational Planning, 62(3), 267-278.

Kosmutzky, A. (2012). Between mission and market position: Empirical findings on mission statements of German higher education institutions. Tertiary Education and Management, 18(1), 57-77.

Iqbal, M., Rasli, A. d., \& Hassan, I. (2012). University branding: A myth or a reality. Pakistan Journal of Commerce \& Social Sciences, 6(1), 168-184.

Lee, J. W., Miloch, K. S., Kraft, P., \& Tatum, L. (2008). Building the brand: A case study of Troy University. Sport Marketing Quarterly, 17(3), 178-182.

Lipsey, R. G., \& Ragan, C. T. S. (10 ${ }^{\text {th }}$ Ed). (2001). Economics. Toronto, Ontario: Pearson. 
Lolich, L. (2011)....And the market created the student to its image and likening. Neo-liberal governmentality and its effects on higher education in Ireland. Irish Educational Studies, 30(2), 271-284.

Brown, L. (2014, September 23). Ontario university enrolment down. Toronto Star (Canada). Marginson, S. (1991). Productivity and efficiency in education. Australian Journal of Education, 35(2), 201-14.

Marginson, S. (1997). Competition and contestability in Australian higher education, 19871997. Australian Universities’ Review 40(1), 5-14.

Marginson, S. (2004). National and global competition in higher education. Australian Educational Researcher, 31(2), 1-28.

Marginson, S. (2006). Dynamics of national and global competition in higher education. Higher Education: The International Journal of Higher Education and Educational Planning, 52(1), 1-39.

Marginson, S. (2013). The impossibility of capitalist markets in higher education. Journal of Education Policy, 28(3), 353-370, DOI: 10.1080/02680939.2012.747109 http://dx.doi.org/10.1080/02680939.2012.747109

Martin, R. (2009). University legal education in Canada is corrupt beyond repair. Interchange, 40(4): 437- 448. doi:10.1007/s10780-009-9100-9

Martineau, M. D. (2013). The competitive effects of charter schools in Utah. (Order No. 3561293, The University of Utah). ProQuest Dissertations and Theses. Retrieved from http://ezproxy.lib.ucalgary.ca/login?url=http://search.proquest.com/docview/1369011617 accountid=9838. $(1369011617)$ 
Mathis, S. A., \& Koscianski, J. (2002). Microeconomic theory: An integrated approach. Upper Saddle River, New Jersey 07458: Prentice Hall.

Matusitz, J. \& Kramer, E. (2011). A critique of Bernstein's beyond objectivism and relativism: Science, hermeneutics, and praxis. Poiesis \& Praxis, 7(4), 291-303. doi: 10.1007/s10202-011-0089-7.

Mause, K. (2009). Too much competition in higher education? Some conceptual remarks on the excessive-signaling hypothesis. American Journal of Economics and Sociology, 68(5), 1107-1133.

McNiff, J. \& Whitehead, J. (2001). Action research: Principles and practice (2 ${ }^{\text {nd }}$ ed.) Falmer Press. Retrieved from http://site.ebrary.com.ezproxy.lib.ucalgary.ca/lib/ucalgary/docDetail.action?docID=1009 6251.

Metcalfe, A. S. (2010). Revisiting academic capitalism in Canada: No longer the exception. The Journal of Higher Education, 81(4), 489-514. DOI: 10.1353/jhe.0.0098.

Ministry of Training, Colleges and Universities (n.d.a). Retrieved from http://www.ontario.ca/education-and-training/go-college-or-university-ontario.

Ministry of Training, Colleges and Universities (n.d.b). Report of the Advisory Panel on Future Directions for Postsecondary Education, 1996. Retrieved from http://www.tcu.gov.on.ca/eng/document/reports/futuree.html

Ministry of Training, Colleges and Universities (n.d.c). Published result-based plan 2012-13. ISSN \# 1718-7095. Retrieved from http://www.tcu.gov.on.ca/eng/about/annualreport/2013RbP_En.pdf. 
Ministry of Training, Colleges and Universities, (2013). Major capacity expansion policy framework. Retrieved from http://news.ontario.ca/tcu/en/2013/12/guiding-growth-in-ontarios-postsecondaryeducation-system.html?utm_source=ondemand\&utm_medium=email\&utm_campaign=p.

Misra, K., Grimes, P. W., \& Rogers, K. E. (2012). Does competition improve public school efficiency? A Spatial Analysis. Economics of Education Review, 31(6), 1177-1190. doi:http://dx.doi.org.ezproxy.lib.ucalgary.ca/10.1016/j.econedurev.2012.08.001

Naidoo, R., Gosling, J., Bolden, R., O'Brien, A., \& Hawkins, B. (2014). Leadership and branding in business schools: A Bourdieusian analysis. Higher Education Research \& Development, 33(1), 144-156. doi:10.1080/07294360.2013.864612

Noorbakhsh, A., \& Culp, D. (2002). The demand for higher education: Pennsylvania's nonresident tuition experience. Economics of Education Review, 21(3), 277-286.

Norusis, M. J. (2004). SPSS 12.0 Guide to data analysis. Upper Saddle River, NJ 07458: Prentice Hall.

Olssen, M., \& Peters, M.A. (2005). Neoliberalism, higher education, and the knowledge economy: From the free market to knowledge capitalism. Journal of Educational Policy, 20 (3), 313-345. DOI: 10.1080/02680930500108718

Ontario Confederation of University Faculty Associations (OCUFA), (2015. a). Retrieved from http://ocufa.on.ca/blog-posts/universities-blog-posts/university-funding-in-ontario-hitsworrisome-milestone

OCUFA, (2015b). Retrieved from http://ocufa.on.ca/blog-posts/universities-blog-posts/ocufa-releases-principles-for-theontario-university-funding-formula-review. 
Ontario's Proposed Differentiation Policy Framework, (September, 2013). Ontario's differentiation policy framework for post-secondary education. Retrieved from Ministry of Training, Colleges and Universities http://www.tcu.gov.on.ca/pepg/publications/PolicyFramework_PostSec.pdf

Ontario Universities' Application Centre (OUAC) (n.d.). Retrieved from http://www.ouac.on.ca/about/about-background/; http://www.ouac.on.ca/statistics/. http://www.ouac.on.ca/about/about-background/.

Pringle, J., \& Huisman, J. (2011). Understanding universities in Ontario, Canada: An industry analysis using porter's five forces framework. Canadian Journal of Higher Education, $41(3): 36-58$.

Priporas, C., \& Kamenidou, I. (2011). Perceptions of potential postgraduate Greek business students towards UK universities, brand and brand reputation. Journal of Brand Management, 18(4/5), 264-273. doi:10.1057/bm.2010.40

Provincial and Territorial Ministers of Education and of Immigration (2011). Bringing education in Canada to the world, bringing the world to Canada: An international education marketing action plan for provinces and territories. Council of the Federation. Ottawa, ON, Canada. Retrieved from http://site.ebrary.com/lib/ucalgary/Doc?id=10490992.

Puplampu, K. P. (2004). The restructuring of higher education and part-time instructors: A theoretical and political analysis of undergraduate teaching in Canada. Teaching in Higher Education, 9(2), 171-182. 
Rothschild, M., White, L.J. (1993). The university in the marketplace: Some insights and some puzzles. In: Clotfelter CT, Rothschild M (Eds.). Studies of supply and demand in higher education. University of Chicago Press for the NBER, Chicago, 11-37.

Salvatore, D. (2004). Managerial economics in a global economy ( $5^{\text {th }}$ ed.). United States of America: South-Western, Thomson Learning.

Scott, D. \& Usher, R. (2010). Researching education: Data, methods and theory in educational enquiry (2 Ed). London, GBR: Continuum International. Retrieved from http://site.ebrary.com.ezproxy.lib.ucalgary.ca/lib/ucalgary/docDetail.action?docID=1043 8515.

Sheehy, B. (2010). Regulation by markets and the Bradley review of Australian higher education. Australian Universities' Review, 52(1), 60-68.

Singh, N. (2011). Higher education in the global market: Opportunities and threats. International Journal of Educational Leadership Preparation, 6(2), 1-15.

Snowdon,K. (2004). Applicant data in Canada: Another perspective on access. The Canada Millennium Scholarship Foundation, Ottawa, ON, CAN. ProQuest ebrary. Web. 23 April 2015.

Solberg, E.J. (1992). Microeconomics for business decisions. Lexington, Massachusetts, Toronto: D. C. Heath and Company.

Stratton, L. S., O’Toole, D. M., \& Wetzel, J. N. (2004). Factors affecting initial enrollment intensity: Part-time versus full-time enrollment. Economics of Education Review, 23(2), $167-75$. 
Susanti, D. (2011). Privatisation and marketisation of higher education in Indonesia: The challenge for equal access and academic values. Higher Education: The International Journal of Higher Education and Educational Planning, 61(2), 209-218.

Swann, J. (2004). Educational research in practice. London: Continuum International. Retrieved from http://site.ebrary.com.ezproxy.lib.ucalgary.ca/lib/ucalgary/docDetail.action?docID=1025 0726.

Teixeira, p. (2006). Markets in higher education: Can we still learn from economics' founding fathers? Research \& Occasional Paper Series: CSHE.4.06. Center for Studies in Higher Education.

http://www.eric.ed.gov/contentdelivery/servlet/ERICServlet?accno=ED492164

Teixeira, P., \& Amaral, A. (2001). Private higher education and diversity: An exploratory survey. Higher Education Quarterly, 55(4): 359-395.

Thompson, A. A., Strickland III, A. J., \& Gamble, J. E. (14 ${ }^{\text {th }}$ Ed) (2005). Crafting and executing strategy: The quest for competitive advantage, concepts and cases. New York: McGraw-Hill/Irwin.

Touhey, R. (2008). A perspective on Canada-India higher educational partnerships: Prospects and obstacles. Asia Pacific Foundation of Canada: Vancouver, BC, Canada.

University of Calgary (n.d.). Research Ethics Approval. Retrieved from http://www.ucalgary.ca/research/researchers/ethics-compliance/cfreb http://grad.ucalgary.ca/current/managing-my-program/academic-integrity http://arts.ucalgary.ca/research/research-integrity-ethics/research-requiring-ethicsapproval. 
University of Guelph, 2014. Retrieved from

http://www.uoguelph.ca/news/2014/04/board_of_govern_2.html

Upadhyay, M.M. (2009). Research in economics: Areas, method and guidelines. Delhi, IND:

Global Media. Retrieved from

http://site.ebrary.com.ezproxy.lib.ucalgary.ca/lib/ucalgary/docDetail.action?docID=1041 7676.

uWindsor News, 2015. Retrieved from

http://www.uwindsor.ca/dailynews/2015-03-09/presidential-address-lays-out-agendarenewal

Vander Schee, B. A. (2009). Embracing enrollment management: A comprehensive approach to college student marketing. Academy of Marketing Studies Journal, 13(1), 1+.

Weingarten, H. \& Deller, F. (2010). The benefits of greater differentiation of Ontario's university sector. Higher Education Quality Council of Ontario.

Wilkinson, R.B., Taylor, J. S., Peterson, A., Machado-Taylor, M. L. (2007).

A practical guide to strategic enrollment management planning in higher education. Educational Policy Institute.

Woodhall, M. (2007). Funding higher education: The contribution of economic thinking to debate and policy development. The World Bank. Washington, D.C. - USA.

Young, S. J. (2002). The use of market mechanisms in higher education finance and state control: Ontario considered. Canadian Journal of Higher Education, 32(2), 79-101.

Zona, J. J. (2005). Competitive strategy: Understanding investment decision-making in higher education. (Order No. 3207012, Boston College). ProQuest Dissertations and Theses, 248-248 p. Retrieved from 
http://ezproxy.lib.ucalgary.ca/login?url=http://search.proquest.com/docview/305028154? accountid=9838. $(305028154)$ 


\section{Appendix A: The Data}

Data were collected and are explained in the following sections:

\section{Section 1: Data of Enrolled Students}

\section{Brock University: Total Number of Enrolled Students (Headcount)}

\begin{tabular}{|c|c|c|c|c|c|c|c|}
\hline \multirow[b]{3}{*}{ Year } & \multicolumn{6}{|c|}{ Enrolment } & \multirow[b]{3}{*}{ Total Enrolment } \\
\hline & \multirow{2}{*}{$\begin{array}{l}\text { Bachelor's } \\
\text { Full-Time }\end{array}$} & \multirow{2}{*}{$\frac{\text { Degree }}{\text { Part-Time }}$} & \multicolumn{2}{|c|}{$\underline{\text { Master's Degree }}$} & \multicolumn{2}{|c|}{$\underline{\text { Doctoral Degree }}$} & \\
\hline & & & Full-Time & Part-Time & Full-Time & Part-Time & \\
\hline 2006 & & & & & & & 17077 \\
\hline Total Domestic Enrolment & 12693 & 2595 & 310 & 467 & 35 & 21 & 16121 \\
\hline Total International Enrolment & 591 & 150 & 204 & 1 & 10 & 0 & 956 \\
\hline 2007 & & & & & & & 17145 \\
\hline Total Domestic Enrolment & 12798 & 2542 & 335 & 499 & 42 & 18 & 16234 \\
\hline Total International Enrolment & 512 & 126 & 258 & 6 & 9 & 0 & 911 \\
\hline 2008 & & & & & & & 16690 \\
\hline Total Domestic Enrolment & 12342 & 2535 & 433 & 484 & 41 & 30 & 15865 \\
\hline Total International Enrolment & 454 & 107 & 245 & 4 & 15 & 0 & 825 \\
\hline 2009 & & & & & & & 16084 \\
\hline Total Domestic Enrolment & 12339 & 1782 & 477 & 585 & 48 & 27 & 15258 \\
\hline Total International Enrolment & 459 & 90 & 259 & 4 & 14 & 0 & 826 \\
\hline 2010 & & & & & & & 16757 \\
\hline Total Domestic Enrolment & 12841 & 1731 & 524 & 581 & 69 & 23 & 15769 \\
\hline Total International Enrolment & 566 & 80 & 323 & 4 & 15 & 0 & 988 \\
\hline 2011 & & & & & & & 17,218 \\
\hline Total Domestic Enrolment & 13,288 & 1,686 & 487 & 568 & 78 & 31 & 16,138 \\
\hline Total International Enrolment & 621 & 96 & 345 & 2 & 16 & 0 & 1,080 \\
\hline 2012 & & & & & & & 17650 \\
\hline Total Domestic Enrolment & 13608 & 1720 & 487 & 462 & 84 & 35 & 16396 \\
\hline Total International Enrolment & 699 & 109 & 418 & 3 & 25 & 0 & 1254 \\
\hline 2013 & & & & & & & 17930 \\
\hline Total Domestic Enrolment & 13763 & 1677 & 531 & 414 & 104 & 27 & 16516 \\
\hline Total International Enrolment & 741 & 132 & 511 & 2 & 28 & 0 & 1414 \\
\hline
\end{tabular}

Source: Council of Ontario Universities: Common University Data Ontario, Brock University, General Information: Total Enrolment by

Rrgaram.) The year of 2006 represents the academic year of 2005-2006, the year of 2007 represents the academic year of 2006-2007, the year of 2008 represents the academic year of $2007-2008, \ldots$, and so on.

2) Total enrolment is collected annually and includes those who enrolled for Fall term. For example, total enrolment in 2006 (academic year of 2005-2006) is the total enrolment in Fall 2005. Total enrolment in 2007 (academic year of 2006-2007) is the total enrolment in Fall 2006, total enrolment in 2008 (academic year 2007-2008) is the total enrolment in Fall 2007, ... and so on.

3) Total enrolment does not include co-op enrolment and work-term enrolment. 


\section{Carleton University: Total Number of Enrolled Students (Headcount)}

\begin{tabular}{|c|c|c|c|c|c|c|c|}
\hline \multirow[b]{3}{*}{ Year } & \multicolumn{6}{|c|}{ Enrolment } & \\
\hline & \multicolumn{2}{|c|}{$\underline{\text { Bachelors Degree }}$} & \multicolumn{2}{|c|}{$\underline{\text { Master's Degree }}$} & \multicolumn{2}{|c|}{$\underline{\text { Doctoral Degree }}$} & \multirow[b]{2}{*}{ Total Enrolment } \\
\hline & Full-Time & Part-Time & Full-Time & Part-Time & Full-Time & Part-Time & \\
\hline 2006 & & & & & & & 21,917 \\
\hline Total Domestic Enrolment & 15,026 & 2,284 & 1,181 & 581 & 559 & 180 & 19,811 \\
\hline Total International Enrolment & 1,321 & 382 & 249 & 30 & 115 & 9 & 2,106 \\
\hline 2007 & & & & & & & 22,064 \\
\hline Total Domestic Enrolment & 15,251 & 2,194 & 1,244 & 506 & 589 & 188 & 19,972 \\
\hline Total International Enrolment & 1,284 & 354 & 307 & 20 & 118 & 9 & 2,092 \\
\hline 2008 & & & & & & & 22,247 \\
\hline Total Domestic Enrolment & 14,821 & 2,462 & 1,596 & 467 & 629 & 181 & 20,156 \\
\hline Total International Enrolment & 1,342 & 331 & 281 & 17 & 108 & 12 & 2,091 \\
\hline 2009 & & & & & & & 22,321 \\
\hline Total Domestic Enrolment & 14,916 & 2,267 & 1,634 & 544 & 629 & 186 & 20,176 \\
\hline Total International Enrolment & 1,418 & 316 & 279 & 18 & 108 & 6 & 2,145 \\
\hline 2010 & & & & & & & 23,206 \\
\hline Total Domestic Enrolment & 15,587 & 2,276 & 1,607 & 582 & 635 & 190 & 20,877 \\
\hline Total International Enrolment & 1,566 & 316 & 307 & 21 & 107 & 12 & 2,329 \\
\hline 2011 & & & & & & & 23,983 \\
\hline Total Domestic Enrolment & 16,081 & 2,319 & 1,704 & 557 & 651 & 210 & 21,522 \\
\hline Total International Enrolment & 1,717 & 324 & 271 & 22 & 113 & 14 & 2,461 \\
\hline 2012 & & & & & & & 24893 \\
\hline Total Domestic Enrolment & 16917 & 2403 & 1661 & 522 & 705 & 180 & 22388 \\
\hline Total International Enrolment & 1776 & 319 & 266 & 19 & 113 & 12 & 2505 \\
\hline 2013 & & & & & & & 25,585 \\
\hline Total Domestic Enrolment & 17,286 & 2,586 & 1,710 & 482 & 757 & 161 & 22,982 \\
\hline Total International Enrolment & 1,766 & 345 & 351 & 17 & 118 & 6 & 2,603 \\
\hline
\end{tabular}

Source: Council of Ontario Universities: Common University Data Ontario, Carleton University, General Information: Total Enrolment by Program. Note. 1) The year of 2006 represents the academic year of 2005-2006, the year of 2007 represents the academic year of 2006-2007, the year of 2008 represents the academic year of $2007-2008, \ldots$, and so on.

2) Total enrolment is collected annually and includes those who enrolled for Fall term. For example, total enrolment in 2006 (academic year of 2005-2006) is the total enrolment in Fall 2005. Total enrolment in 2007 (academic year of 2006-2007) is the total enrolment in Fall 2006, total enrolment in 2008 (academic year 2007-2008) is the total enrolment in Fall 2007, ... and so on.

3) Total enrolment does not include co-op enrolment and work-term enrolment. 


\section{Lakehead University: Total Number of Enrolled Students (Headcount)}

\begin{tabular}{|c|c|c|c|c|c|c|c|}
\hline \multirow[b]{3}{*}{ Year } & \multicolumn{6}{|c|}{ Enrolment } & \\
\hline & \multicolumn{2}{|c|}{ Bachelors Degree } & \multicolumn{2}{|c|}{$\underline{\text { Master's Degree }}$} & \multicolumn{2}{|c|}{$\underline{\text { Doctoral Degree }}$} & \multirow[b]{2}{*}{ Total Enrolment } \\
\hline & Full-Time & Part-Time & Full-Time & Part-Time & Full-Time & Part-Time & \\
\hline 2006 & 5630 & 1123 & 352 & 153 & 32 & 5 & 7,295 \\
\hline Total Domestic Enrolment & N/A & N/A & N/A & N/A & N/A & N/A & N/A \\
\hline Total International Enrolment & N/A & N/A & N/A & N/A & N/A & N/A & N/A \\
\hline 2007 & & & & & & & 7,342 \\
\hline Total Domestic Enrolment & 5471 & 1237 & 348 & 97 & 44 & 0 & 7,197 \\
\hline Total International Enrolment & 67 & 16 & 57 & 0 & 5 & 0 & 145 \\
\hline 2008 & & & & & & & 7,631 \\
\hline Total Domestic Enrolment & 5607 & 1233 & 574 & 26 & 60 & 0 & 7,500 \\
\hline Total International Enrolment & 67 & 10 & 48 & 0 & 6 & 0 & 131 \\
\hline 2009 & & & & & & & 7,409 \\
\hline Total Domestic Enrolment & 5569 & 1145 & 488 & 16 & 69 & 0 & 7,287 \\
\hline Total International Enrolment & 56 & 14 & 44 & 0 & 8 & 0 & 122 \\
\hline 2010 & & & & & & & 8,015 \\
\hline Total Domestic Enrolment & 6000 & 1312 & 466 & 18 & 82 & 0 & 7,878 \\
\hline Total International Enrolment & 80 & 8 & 41 & 0 & 8 & 0 & 137 \\
\hline 2011 & & & & & & & 8,406 \\
\hline Total Domestic Enrolment & 6316 & 1417 & 437 & 23 & 88 & 0 & 8,281 \\
\hline Total International Enrolment & 67 & 5 & 42 & 0 & 11 & 0 & 125 \\
\hline 2012 & & & & & & & 8481 \\
\hline Total Domestic Enrolment & 6242 & 1443 & 516 & 26 & 96 & 0 & 8323 \\
\hline Total International Enrolment & 79 & 13 & 50 & 0 & 16 & 0 & 158 \\
\hline 2013 & & & & & & & 8,465 \\
\hline Total Domestic Enrolment & 6208 & 1394 & 559 & 18 & 89 & 0 & 8,268 \\
\hline Total International Enrolment & 86 & 7 & 88 & 0 & 16 & 0 & 197 \\
\hline
\end{tabular}

Source: Council of Ontario Universities: Common University Data Ontario (CUDO), Lakehead University, General Information: Total Enrolment by Program.

Note. 1) The year of 2006 represents the academic year of 2005-2006, the year of 2007 represents the academic year of 2006-2007, the year of 2008 represents the academic year of $2007-2008, \ldots$, and so on.

2) Total enrolment is collected annually and includes those who enrolled for Fall term. For example, total enrolment in 2006 (academic year of 2005-2006) is the total enrolment in Fall 2005. Total enrolment in 2007 (academic year of 2006-2007) is the total enrolment in Fall 2006, total enrolment in 2008 (academic year 2007-2008) is the total enrolment in Fall 2007, ... and so on.

3) Total enrolment does not include co-op enrolment and work-term enrolment.

4) In 2006, CUDO reported only total enrolment by program. 


\section{4) Laurentian University: Total Number of Enrolled Students (Headcount)}

\begin{tabular}{|c|c|c|c|c|c|c|c|c|}
\hline \multirow[b]{3}{*}{ Year } & \multicolumn{6}{|c|}{ Enrolment } & & \\
\hline & \multicolumn{2}{|c|}{$\underline{\text { Bachelors Degree }}$} & \multicolumn{2}{|c|}{$\underline{\text { Master's Degree }}$} & \multicolumn{2}{|c|}{$\underline{\text { Doctoral Degree }}$} & \multirow{2}{*}{\multicolumn{2}{|c|}{ Total Enrolment }} \\
\hline & Full-Time & Part-Time & Full-Time & Part-Time & Full-Time & Part-Time & & \\
\hline 2006 & & & & & & & & N/A \\
\hline Total Domestic Enrolment & N/A & N/A & N/A & N/A & N/A & N/A & & N/A \\
\hline Total International Enrolment & N/A & N/A & N/A & N/A & N/A & N/A & & N/A \\
\hline 2007 & & & & & & & & 8,726 \\
\hline Total Domestic Enrolment & 5887 & 2026 & 199 & 279 & 29 & 2 & & 8,422 \\
\hline Total International Enrolment & 226 & 41 & 24 & 4 & 9 & 0 & & 304 \\
\hline 2008 & & & & & & & $r$ & 8,454 \\
\hline Total Domestic Enrolment & 5589 & 2004 & 221 & 307 & 52 & 12 & & 8,185 \\
\hline Total International Enrolment & 181 & 44 & 24 & 3 & 17 & 0 & & 269 \\
\hline 2009 & & & & & & & $F$ & 8,409 \\
\hline Total Domestic Enrolment & 5469 & 2021 & 222 & 349 & 69 & 14 & & 8,144 \\
\hline Total International Enrolment & 173 & 46 & 27 & 4 & 15 & 0 & & 265 \\
\hline 2010 & & & & & & & $F$ & 8,689 \\
\hline Total Domestic Enrolment & 5730 & 1971 & 231 & 324 & 78 & 22 & & 8,356 \\
\hline Total International Enrolment & 241 & 37 & 39 & 3 & 13 & 0 & & 333 \\
\hline 2011 & & & & & & & $r$ & 9,006 \\
\hline Total Domestic Enrolment & 5929 & 2000 & 222 & 318 & 82 & 40 & & 8,591 \\
\hline Total International Enrolment & 276 & 48 & 75 & 3 & 13 & 0 & & 415 \\
\hline 2012 & & & & & & & $r$ & 9164 \\
\hline Total Domestic Enrolment & 6030 & 1973 & 223 & 340 & 84 & 50 & & 8700 \\
\hline Total International Enrolment & 298 & 54 & 91 & 6 & 15 & 0 & & 464 \\
\hline 2013 & & & & & & & & 9,058 \\
\hline Total Domestic Enrolment & 5902 & 1925 & 211 & 366 & 71 & 57 & & 8,532 \\
\hline Total International Enrolment & 340 & 70 & 94 & 5 & 17 & 0 & & 526 \\
\hline
\end{tabular}

Source: Council of Ontario Universities: Common University Data Ontario, Laurentian University, General Information: Total Enrolment by Program. Note. 1) The year of 2006 represents the academic year of 2005-2006, the year of 2007 represents the academic year of 2006-2007, the year of 2008 represents the academic year of 2007-2008, .., and so on.

2) Total enrolment is collected annually and includes those who enrolled for Fall term. For example, total enrolment in 2006 (academic year of 2005-2006) is the total enrolment in Fall 2005. Total enrolment in 2007 (academic year of 2006-2007) is the total enrolment in Fall 2006, total enrolment in 2008 (academic year 2007-2008) is the total enrolment in Fall 2007, ... and so on.

3) Total enrolment does not include co-op enrolment and work-term enrolment. 


\section{5) McMaster University: Total Number of Enrolled Students (Headcount)}

\begin{tabular}{|c|c|c|c|c|c|c|c|}
\hline \multirow[b]{3}{*}{ Year } & \multicolumn{6}{|c|}{ Enrolment } & \multirow[b]{3}{*}{ Total Enrolment } \\
\hline & \multicolumn{2}{|c|}{$\underline{\text { Bachelors Degree }}$} & \multicolumn{2}{|c|}{$\underline{\text { Master's Degree }}$} & \multicolumn{2}{|c|}{$\underline{\text { Doctoral Degree }}$} & \\
\hline & Full-Time & Part-Time & Full-Time & Part-Time & Full-Time & Part-Time & \\
\hline 2006 & & & & & & & 23,528 \\
\hline Total Domestic Enrolment & 17073 & 2465 & 1092 & 320 & 711 & 83 & 21,744 \\
\hline Total International Enrolment & 1071 & 203 & 217 & 7 & 285 & 1 & 1,784 \\
\hline 2007 & & & & & & & 24,265 \\
\hline Total Domestic Enrolment & 17776 & 2552 & 1183 & 329 & 793 & 82 & 22,715 \\
\hline Total International Enrolment & 838 & 209 & 239 & 5 & 257 & 2 & 1,550 \\
\hline 2008 & & & & & & & 24,935 \\
\hline Total Domestic Enrolment & 18052 & 2628 & 1383 & 381 & 853 & 86 & 23,383 \\
\hline Total International Enrolment & 906 & 154 & 247 & 7 & 236 & 2 & 1,552 \\
\hline 2009 & & & & & & & 25,554 \\
\hline Total Domestic Enrolment & 18551 & 2556 & 1425 & 406 & 918 & 107 & 23,963 \\
\hline Total International Enrolment & 987 & 146 & 242 & 6 & 206 & 4 & 1,591 \\
\hline 2010 & & & & & & & 26,440 \\
\hline Total Domestic Enrolment & 19291 & 2445 & 1530 & 466 & 989 & 101 & 24,822 \\
\hline Total International Enrolment & 994 & 122 & 269 & 3 & 227 & 3 & 1,618 \\
\hline 2011 & & & & & & & 27,499 \\
\hline Total Domestic Enrolment & 19379 & 2881 & 1751 & 520 & 1031 & 101 & 25,663 \\
\hline Total International Enrolment & 1083 & 186 & 307 & 8 & 250 & 2 & 1,836 \\
\hline 2012 & & & & & & & 27989 \\
\hline Total Domestic Enrolment & 19726 & 2873 & 1766 & 544 & 1048 & 97 & 26054 \\
\hline Total International Enrolment & 1147 & 138 & 360 & 5 & 281 & 4 & 1935 \\
\hline 2013 & & & & & & & 28,415 \\
\hline Total Domestic Enrolment & 20050 & 2762 & 1769 & 606 & 1033 & 98 & 26,318 \\
\hline Total International Enrolment & 1220 & 141 & 398 & 9 & 328 & 1 & 2,097 \\
\hline Source: Council of Ontario Univers & nmon Un & ty Data $\mathrm{O}$ & rio, $\mathrm{McN}$ & r Unive & General I & tion: To & nrolment by Program. \\
\hline $\begin{array}{l}\text { Note. 1) The year of } 2006 \text { repres } \\
\text { of } 2008 \text { represents the a } \\
\text { 2) Total enrolment is colle } \\
\text { year of 2005-2006) is } \\
\text { enrolment in Fall 2006, } \\
\text { 3) Total enrolment does }\end{array}$ & $\begin{array}{l}\text { academic } \\
\text { ic year of } 2 \\
\text { nually and i } \\
\text { lenrolment } \\
\text { arolment in } \\
\text { Ide co-op e }\end{array}$ & $\begin{array}{l}\text { ar of } 2005-2 \\
-2008, \ldots, \\
\text { des those w } \\
\text { fall } 2005 . \mathrm{T} \\
8 \text { (academic }\end{array}$ & $\begin{array}{l}06, \text { the yea } \\
\text { nd so on. } \\
\text { o enrolled } \mathrm{f} \\
\text { tal enrolme } \\
\text { year } 2007-\text { ? }\end{array}$ & $\begin{array}{l}\text { of } 2007 \text { repr } \\
\text { Fall term. } \\
\text { in } 2007 \text { (act } \\
008 \text { ) is the to }\end{array}$ & $\begin{array}{l}\text { sents the aca } \\
\text { or example, } \\
\text { demic year o } \\
\text { al enrolment }\end{array}$ & $\begin{array}{l}\text { mic year of } 2 \\
\text { al enrolment } \\
\text { 006-2007) i } \\
\text { Fall 2007, .. }\end{array}$ & $\begin{array}{l}\text { 006-2007, the year } \\
2006 \text { (academic } \\
\text { the total } \\
\text { and so on. }\end{array}$ \\
\hline
\end{tabular}




\section{6) Nipissing University: Total Number of Enrolled Students (Headcount)}

\begin{tabular}{|c|c|c|c|c|c|c|c|}
\hline \multirow[b]{3}{*}{ Year } & \multicolumn{6}{|c|}{ Enrolment } & \\
\hline & \multicolumn{2}{|c|}{$\underline{\text { Bachelors Degree }}$} & \multicolumn{2}{|c|}{$\underline{\text { Master's Degree }}$} & \multicolumn{2}{|c|}{$\underline{\text { Doctoral Degree }}$} & \multirow[b]{2}{*}{ Total Enrolment } \\
\hline & Full-Time & Part-Time & Full-Time & Part-Time & Full-Time & Part-Time & \\
\hline 2006 & 3658 & 885 & 0 & 368 & 0 & 0 & 4,911 \\
\hline Total Domestic Enrolment & N/A & N/A & N/A & N/A & N/A & N/A & $\mathrm{N} / \mathrm{A}$ \\
\hline Total International Enrolment & N/A & N/A & N/A & N/A & N/A & N/A & $\mathrm{N} / \mathrm{A}$ \\
\hline 2007 & & & & & & & 5,177 \\
\hline Total Domestic Enrolment & 3788 & 1000 & 0 & 327 & 0 & 0 & 5,115 \\
\hline Total International Enrolment & 25 & 37 & 0 & 0 & 0 & 0 & 62 \\
\hline 2008 & & & & & & & 4,886 \\
\hline Total Domestic Enrolment & 3,592 & 916 & 25 & 295 & 0 & 0 & 4,828 \\
\hline Total International Enrolment & 19 & 39 & 0 & 0 & 0 & 0 & 58 \\
\hline 2009 & & & & & & & N/A \\
\hline Total Domestic Enrolment & N/A & N/A & N/A & N/A & N/A & N/A & N/A \\
\hline Total International Enrolment & N/A & N/A & N/A & N/A & N/A & N/A & $\mathrm{N} / \mathrm{A}$ \\
\hline 2010 & & & & & & & 4,483 \\
\hline Total Domestic Enrolment & 3700 & 395 & 71 & 268 & 0 & 0 & 4,434 \\
\hline Total International Enrolment & 19 & 30 & 0 & 0 & 0 & 0 & 49 \\
\hline 2011 & & & & & & & 5,505 \\
\hline Total Domestic Enrolment & 3846 & 1285 & 59 & 267 & 0 & 0 & 5,457 \\
\hline Total International Enrolment & 18 & 29 & 0 & 1 & 0 & 0 & 48 \\
\hline 2012 & & & & & & & 5662 \\
\hline Total Domestic Enrolment & 3840 & 1461 & 53 & 266 & 0 & 0 & 5620 \\
\hline Total International Enrolment & 15 & 25 & 2 & 0 & 0 & 0 & 42 \\
\hline 2013 & & & & & & & 5,591 \\
\hline Total Domestic Enrolment & 3642 & 1552 & 83 & 262 & 10 & 0 & 5,549 \\
\hline Total International Enrolment & 21 & 20 & 1 & 0 & 0 & 0 & 42 \\
\hline
\end{tabular}

Source: Council of Ontario Universities: Common University Data Ontario, Nipissing University, General Information: Total Enrolment by Program.

Note. 1) The year of 2006 represents the academic year of 2005-2006, the year of 2007 represents the academic year of 2006-2007, the year of 2008 represents the academic year of $2007-2008, \ldots$, and so on.

2) Total enrolment is collected annually and includes those who enrolled for Fall term. For example, total enrolment in 2006 (academic year of 2005-2006) is the total enrolment in Fall 2005. Total enrolment in 2007 (academic year of 2006-2007) is the total enrolment in Fall 2006, total enrolment in 2008 (academic year 2007-2008) is the total enrolment in Fall 2007, ... and so on.

3) Total enrolment does not include co-op enrolment and work-term enrolment.

4) In 2006, CUDO reported only total enrolment by program. 
7) Ontario College for Art and Design (OCAD) University: Total Number of Enrolled Students (Headcount)

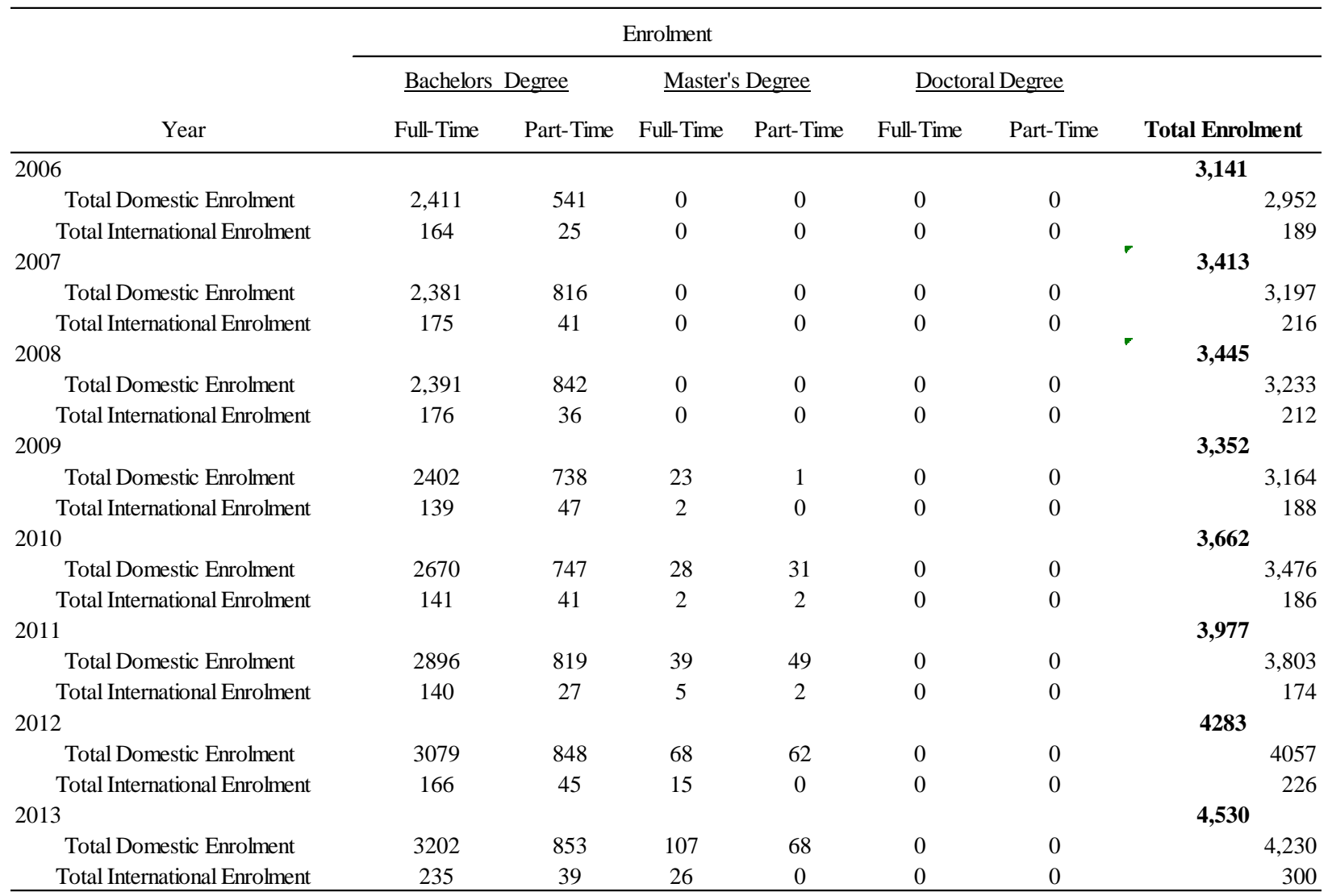

Source: Council of Ontario Universities: Common University Data Ontario, OCAD University, General Information: Total Enrolment by Program. Note. 1) The year of 2006 represents the academic year of 2005-2006, the year of 2007 represents the academic year of 2006-2007, the year of 2008 represents the academic year of $2007-2008, \ldots$, and so on.

2) Total enrolment is collected annually and includes those who enrolled for Fall term. For example, total enrolment in 2006 (academic year of 2005-2006) is the total enrolment in Fall 2005. Total enrolment in 2007 (academic year of 2006-2007) is the total enrolment in Fall 2006, total enrolment in 2008 (academic year 2007-2008) is the total enrolment in Fall 2007, ... and so on.

3) Total enrolment does not include co-op enrolment and work-term enrolment. 


\section{8) Queen's University: Total Number of Enrolled Students (Headcount)}

\begin{tabular}{|c|c|c|c|c|c|c|c|}
\hline \multirow[b]{3}{*}{ Year } & \multicolumn{6}{|c|}{ Enrolment } & \\
\hline & \multicolumn{2}{|c|}{$\underline{\text { Bachelors Degree }}$} & \multicolumn{2}{|c|}{$\underline{\text { Master's Degree }}$} & \multicolumn{2}{|c|}{$\underline{\text { Doctoral Degree }}$} & \multirow[b]{2}{*}{ Total Enrolment } \\
\hline & Full-Time & Part-Time & Full-Time & Part-Time & Full-Time & Part-Time & \\
\hline 2006 & & & & & & & 18,393 \\
\hline Total Domestic Enrolment & 13330 & 1582 & 1595 & 275 & 754 & 66 & 17,602 \\
\hline Total International Enrolment & 394 & 44 & 178 & 3 & 167 & 5 & 791 \\
\hline 2007 & & & & & & & 18,249 \\
\hline Total Domestic Enrolment & 13073 & 1514 & 1701 & 255 & 796 & 54 & 17,393 \\
\hline Total International Enrolment & 404 & 44 & 213 & 3 & 188 & 4 & 856 \\
\hline 2008 & & & & & & & 18,295 \\
\hline Total Domestic Enrolment & 12882 & 1530 & 1767 & 268 & 844 & 65 & 17,356 \\
\hline Total International Enrolment & 413 & 25 & 302 & 4 & 191 & 4 & 939 \\
\hline 2009 & & & & & & & 19,021 \\
\hline Total Domestic Enrolment & 13458 & 1541 & 1823 & 245 & 895 & 62 & 18,024 \\
\hline Total International Enrolment & 451 & 39 & 292 & 1 & 213 & 1 & 997 \\
\hline 2010 & & & & & & & 19661 \\
\hline Total Domestic Enrolment & 13837 & 1525 & 2007 & 248 & 927 & 67 & 18611 \\
\hline Total International Enrolment & 449 & 32 & 332 & 1 & 235 & 1 & 1050 \\
\hline 2011 & & & & & & & 20187 \\
\hline Total Domestic Enrolment & 14347 & 1505 & 2019 & 275 & 926 & 68 & 19140 \\
\hline Total International Enrolment & 399 & 55 & 345 & 3 & 243 & 2 & 1047 \\
\hline 2012 & & & & & & & 20879 \\
\hline Total Domestic Enrolment & 15521 & 933 & 2010 & 270 & 930 & 75 & 19739 \\
\hline Total International Enrolment & 431 & 15 & 436 & 8 & 248 & 2 & 1140 \\
\hline 2013 & & & & & & & 21176 \\
\hline Total Domestic Enrolment & 15814 & 874 & 1997 & 286 & 975 & 92 & 20038 \\
\hline Total International Enrolment & 425 & 16 & 455 & 4 & 235 & 3 & 1138 \\
\hline
\end{tabular}

Source: Council of Ontario Universities: Common University Data Ontario, Queen's University, General Information: Total Enrolment by Program.

Note. 1) The year of 2006 represents the academic year of 2005-2006, the year of 2007 represents the academic year of 2006-2007, the year of 2008 represents the academic year of 2007-2008, ..., and so on.

2) Total enrolment is collected annually and includes those who enrolled for Fall term. For example, total enrolment in 2006 (academic year of 2005-2006) is the total enrolment in Fall 2005. Total enrolment in 2007 (academic year of 2006-2007) is the total enrolment in Fall 2006, total enrolment in 2008 (academic year 2007-2008) is the total enrolment in Fall 2007, ... and so on.

3) Total enrolment does not include co-op enrolment and work-term enrolment. 
9) Ryerson University: Total Number of Enrolled Students (Headcount)

\begin{tabular}{|c|c|c|c|c|c|c|c|}
\hline \multirow[b]{3}{*}{ Year } & \multicolumn{6}{|c|}{ Enrolment } & \multirow[b]{3}{*}{ Total Enrolment } \\
\hline & \multicolumn{2}{|c|}{$\underline{\text { Bachelors Degree }}$} & \multicolumn{2}{|c|}{$\underline{\text { Master's Degree }}$} & \multicolumn{2}{|c|}{$\underline{\text { Doctoral Degree }}$} & \\
\hline & Full-Time & Part-Time & Full-Time & Part-Time & Full-Time & Part-Time & \\
\hline 2006 & & & & & & & 22,927 \\
\hline Total Domestic Enrolment & 14,983 & 6,315 & 436 & 205 & 63 & 1 & 22,003 \\
\hline Total International Enrolment & 552 & 294 & 65 & 2 & 11 & 0 & 924 \\
\hline 2007 & & & & & & & 23,947 \\
\hline Total Domestic Enrolment & 15,363 & 6,768 & 585 & 325 & 83 & 2 & 23,126 \\
\hline Total International Enrolment & 557 & 174 & 71 & 3 & 16 & 0 & 821 \\
\hline 2008 & & & & & & & 25,181 \\
\hline Total Domestic Enrolment & 15,439 & 7,393 & 1,033 & 374 & 104 & 2 & 24,345 \\
\hline Total International Enrolment & 535 & 175 & 92 & 4 & 30 & 0 & 836 \\
\hline 2009 & & & & & & & 26,452 \\
\hline Total Domestic Enrolment & 16,328 & 7,400 & 1,228 & 420 & 147 & 2 & 25,525 \\
\hline Total International Enrolment & 556 & 202 & 118 & 2 & 49 & 0 & 927 \\
\hline 2010 & & & & & & & 27,693 \\
\hline Total Domestic Enrolment & 17,045 & 7,825 & 1278 & 445 & 216 & 2 & 26,811 \\
\hline Total International Enrolment & 516 & 187 & 127 & 2 & 50 & 0 & 882 \\
\hline 2011 & & & & & & & 29,029 \\
\hline Total Domestic Enrolment & 17,629 & 8,356 & 1,435 & 349 & 261 & 4 & 28,034 \\
\hline Total International Enrolment & 492 & 306 & 148 & 0 & 49 & 0 & 995 \\
\hline 2012 & & & & & & & 30,343 \\
\hline Total Domestic Enrolment & 18,321 & 8,838 & 1,410 & 361 & 301 & 4 & 29,235 \\
\hline Total International Enrolment & 498 & 364 & 183 & 1 & 62 & 0 & 1,108 \\
\hline 2013 & & & & & & & 31551 \\
\hline Total Domestic Enrolment & 19704 & 8757 & 1403 & 343 & 349 & 7 & 30563 \\
\hline Total International Enrolment & 493 & 248 & 163 & 2 & 82 & 0 & 988 \\
\hline Source: Council of Ontario Univer & mmon Uni & ty Data Or & tario, Ryers & University & neral Info & on: Tota & olment by Program. \\
\hline $\begin{array}{l}\text { Note. 1) The year of } 2006 \text { repre } \\
\text { of } 2008 \text { represents the } \\
\text { 2) Total enrolment is colle } \\
\text { year of 2005-2006) is } \\
\text { enrolment in Fall 2006, }\end{array}$ & $\begin{array}{l}\text { academic y } \\
\text { ic year of } 20 \\
\text { mually and in } \\
\text { lenrolment il } \\
\text { arolment in } 2\end{array}$ & $\begin{array}{l}\text { of of } 2005-2 \\
-2008, \ldots, \\
\text { ides those w } \\
8 \text { (academic } 2005 . \mathrm{T}\end{array}$ & $\begin{array}{l}06, \text { the year } \\
\text { ind so on. } \\
\text { no enrolled fo } \\
\text { tal enrolmen } \\
\text { year } 2007-2\end{array}$ & $\begin{array}{l}\text { of } 2007 \text { rep } \\
\text { Fall term. } \\
\text { in } 2007 \text { (ac }\end{array}$ & $\begin{array}{l}\text { sents the ac: } \\
\text { or example, } \\
\text { demic year } 0\end{array}$ & al enrolment & $\begin{array}{l}06-2007, \text { the year } \\
2006 \text { (academic } \\
\text { the total } \\
\text { and so on. }\end{array}$ \\
\hline
\end{tabular}


10) Trent University: Total Number of Enrolled Students (Headcount)

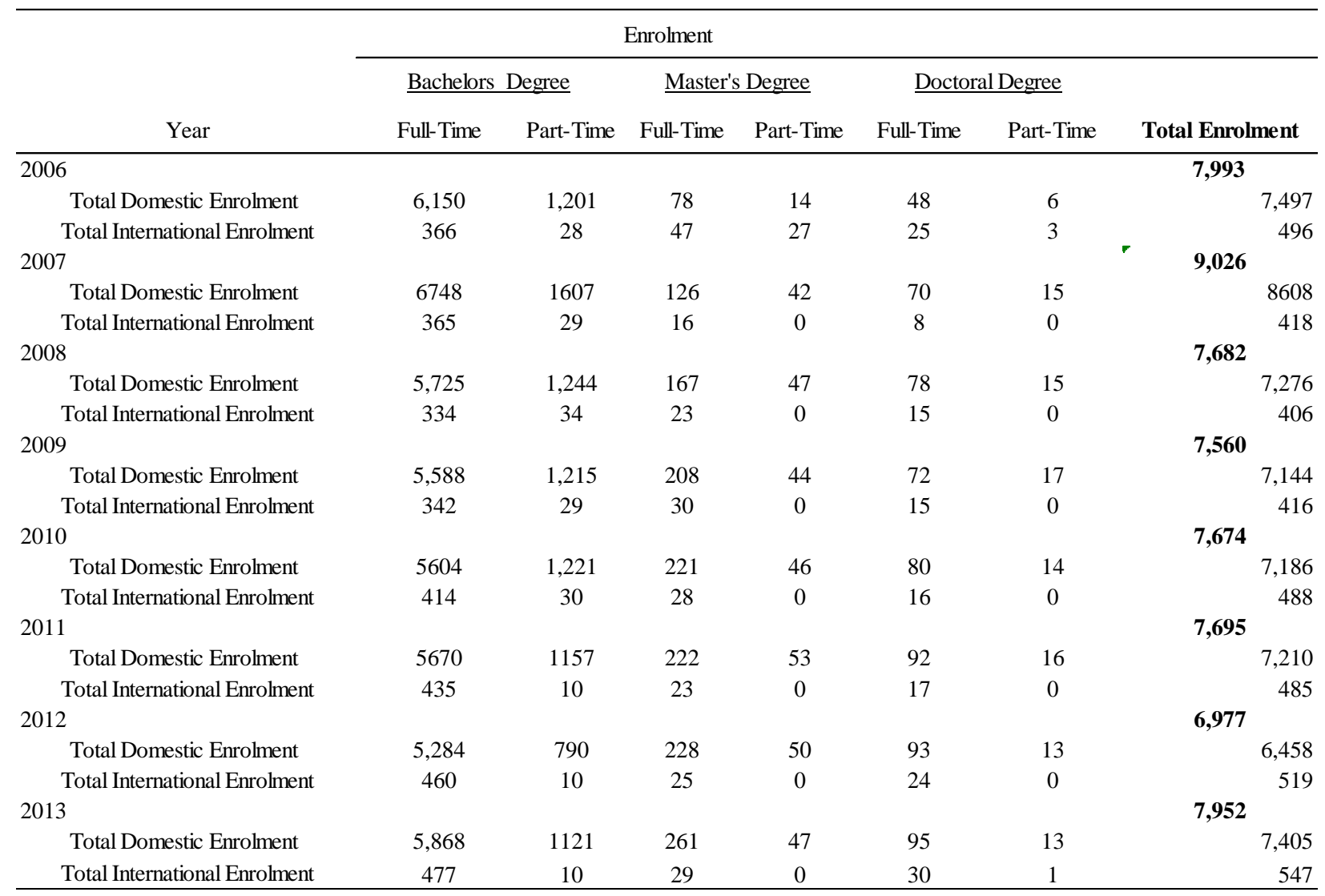

Source: Council of Ontario Universities: Common University Data Ontario, Trent University, General Information: Total Enrolment by Program.

Note. 1) The year of 2006 represents the academic year of 2005-2006, the year of 2007 represents the academic year of 2006-2007, the year of 2008 represents the academic year of $2007-2008, \ldots$, and so on.

2) Total enrolment is collected annually and includes those who enrolled for Fall term. For example, total enrolment in 2006 (academic year of 2005-2006) is the total enrolment in Fall 2005. Total enrolment in 2007 (academic year of 2006-2007) is the total enrolment in Fall 2006, total enrolment in 2008 (academic year 2007-2008) is the total enrolment in Fall 2007, ... and so on.

3) Total enrolment does not include co-op enrolment and work-term enrolment.

4) Total enrolment data for 2007 was collected from CUDO by adding both total enrolment of Trent @ Peterborough Campus and total enrolment of Trent @ UOIT Campus.

5) Total enrolment data for 2009 was collcted from CUDO by adding both total enrolment of Trent @ Peterborough Campus and total enrolment of Trent @ Oshawa Campus. 


\section{1) University of Guelph: Total Number of Enrolled Students (Headcount)}

\begin{tabular}{|c|c|c|c|c|c|c|c|}
\hline \multirow[b]{3}{*}{ Year } & \multicolumn{6}{|c|}{ Enrolment } & \multirow[b]{3}{*}{ Total Enrolment } \\
\hline & \multicolumn{2}{|c|}{$\underline{\text { Bachelors Degree }}$} & \multicolumn{2}{|c|}{$\underline{\text { Master's Degree }}$} & \multicolumn{2}{|c|}{$\underline{\text { Doctoral Degree }}$} & \\
\hline & Full-Time & Part-Time & Full-Time & Part-Time & Full-Time & Part-Time & \\
\hline 2006 & & & & & & & 20,369 \\
\hline Total Domestic Enrolment & 16,551 & 1,494 & 1073 & 98 & 497 & 44 & 19,757 \\
\hline Total International Enrolment & 246 & 34 & 156 & 0 & 175 & 1 & 612 \\
\hline 2007 & & & & & & & 21,656 \\
\hline Total Domestic Enrolment & 17,616 & 1,638 & 1,073 & 126 & 497 & 57 & 21,007 \\
\hline Total International Enrolment & 300 & 39 & 144 & 0 & 164 & 2 & 649 \\
\hline 2008 & & & & & & & 22,060 \\
\hline Total Domestic Enrolment & 17,528 & 1,919 & 1,280 & 125 & 576 & 58 & 21,486 \\
\hline Total International Enrolment & 273 & 19 & 128 & 0 & 151 & 3 & 574 \\
\hline 2009 & & & & & & & 19,865 \\
\hline Total Domestic Enrolment & 15,349 & 1,898 & 1,292 & 130 & 592 & 66 & 19,327 \\
\hline Total International Enrolment & 255 & 15 & 122 & 1 & 141 & 4 & 538 \\
\hline 2010 & & & & & & & 20,756 \\
\hline Total Domestic Enrolment & 16,479 & 1,549 & 1,301 & 150 & 613 & 78 & 20,170 \\
\hline Total International Enrolment & 304 & 32 & 106 & 2 & 136 & 6 & 586 \\
\hline 2011 & & & & & & & 21,698 \\
\hline Total Domestic Enrolment & 17,229 & 1,638 & 1,355 & 141 & 640 & 81 & 21,084 \\
\hline Total International Enrolment & 313 & 38 & 112 & 1 & 146 & 4 & 614 \\
\hline 2012 & & & & & & & 22,705 \\
\hline Total Domestic Enrolment & 18,008 & 1,681 & 1,396 & 143 & 673 & 100 & 22,001 \\
\hline Total International Enrolment & 370 & 45 & 129 & 2 & 154 & 4 & 704 \\
\hline 2013 & & & & & & & 22,916 \\
\hline Total Domestic Enrolment & 17,898 & 1,930 & 1,395 & 140 & 677 & 96 & 22,136 \\
\hline Total International Enrolment & 418 & 48 & 150 & 2 & 154 & 8 & 780 \\
\hline
\end{tabular}

Source: Council of Ontario Universities: Common University Data Ontario, University of Guelph, General Information: Total Enrolment by Program.

Note. 1) The year of 2006 represents the academic year of 2005-2006, the year of 2007 represents the academic year of 2006-2007, the year of 2008 represents the academic year of $2007-2008, \ldots$, and so on.

2) Total enrolment is collected annually and includes those who enrolled for Fall term. For example, total enrolment in 2006 (academic year of 2005-2006) is the total enrolment in Fall 2005. Total enrolment in 2007 (academic year of 2006-2007) is the total enrolment in Fall 2006, total enrolment in 2008 (academic year 2007-2008) is the total enrolment in Fall 2007, ... and so on.

3) Total enrolment does not include co-op enrolment and work-term enrolment. 


\section{2) University of Ontario Institute of Technology (UOIT): Total Number of Enrolled}

Students (Headcount)

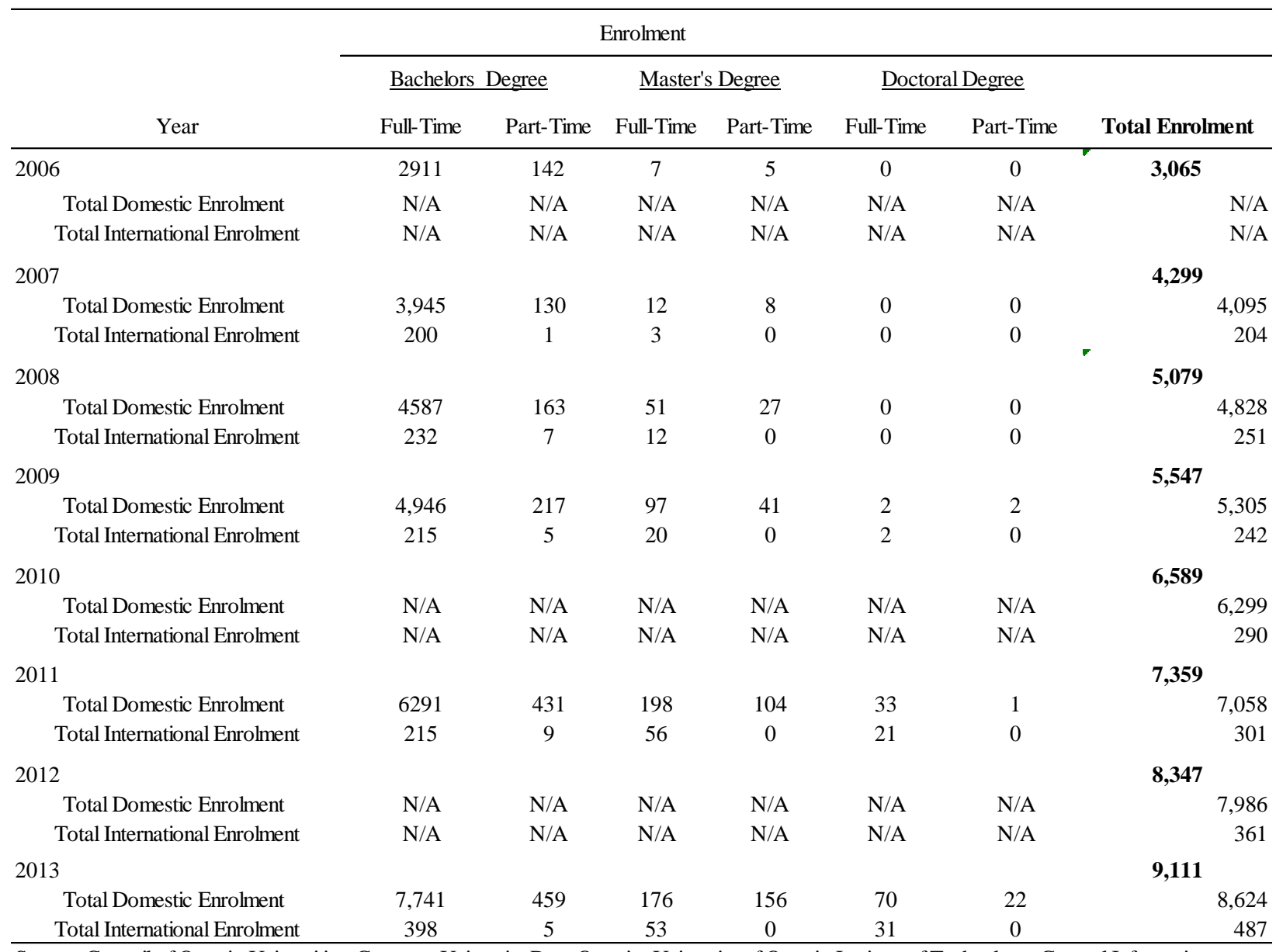

Source: Council of Ontario Universities: Common University Data Ontario, University of Ontario Institute of Technology, General Information:

Total Enrolment by Program.

Note. 1) The year of 2006 represents the academic year of 2005-2006, the year of 2007 represents the academic year of 2006-2007, the year of 2008 represents the academic year of $2007-2008, \ldots$, and so on.

2) Total enrolment is collected annually and includes those who enrolled for Fall term. For example, total enrolment in 2006 (academic year of 2005-2006) is the total enrolment in Fall 2005. Total enrolment in 2007 (academic year of 2006-2007) is the total enrolment in Fall 2006, total enrolment in 2008 (academic year 2007-2008) is the total enrolment in Fall 2007, ... and so on.

3) Total enrolment does not include co-op enrolment and work-term enrolment.

4) In 2006, CUDO reported only total enrolment by program.

5) Enrolment data for 2010 and 2012 is not available at CUDO. Therefore, total enrolment for 2010 and 2012 was obtained from Fact Book 2009-2010 \& Fact Book 2011-2012 (http://uoit.ca/sites/oira/fact_book/). 


\section{3) University of Ottawa: Total Number of Enrolled Students (Headcount)}

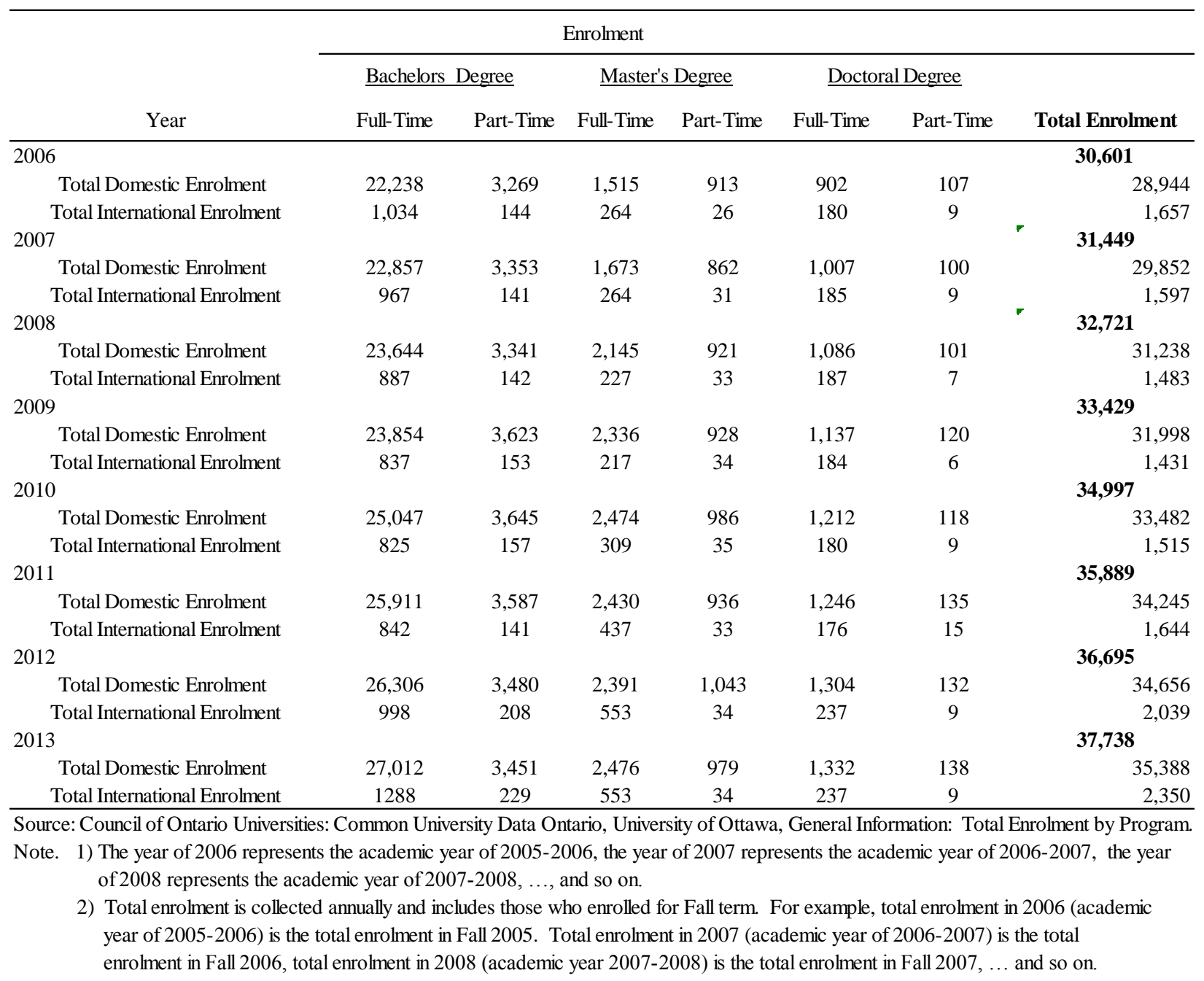




\section{4) University of Toronto: Total Number of Enrolled Students (Headcount)}

\begin{tabular}{|c|c|c|c|c|c|c|c|}
\hline \multirow[b]{3}{*}{ Year } & \multicolumn{6}{|c|}{ Enrolment } & \multirow[b]{3}{*}{ Total Enrolment } \\
\hline & \multicolumn{2}{|c|}{$\underline{\text { Bachelors Degree }}$} & \multicolumn{2}{|c|}{$\underline{\text { Master's Degree }}$} & \multicolumn{2}{|c|}{$\underline{\text { Doctoral Degree }}$} & \\
\hline & Full-Time & Part-Time & Full-Time & Part-Time & Full-Time & Part-Time & \\
\hline 2006 & & & & & & & 71,399 \\
\hline Total Domestic Enrolment & 47,682 & 6,356 & 4,553 & 1,953 & 3,951 & 84 & 64,579 \\
\hline Total International Enrolment & 4,767 & 296 & 768 & 32 & 951 & 6 & 6,820 \\
\hline 2007 & & & & & & & 72,098 \\
\hline Total Domestic Enrolment & 47,930 & 6,227 & 4,753 & 1754 & 4,139 & 66 & 64,869 \\
\hline Total International Enrolment & 5102 & 289 & 819 & 18 & 999 & 2 & 7,229 \\
\hline 2008 & & & & & & & 69,147 \\
\hline Total Domestic Enrolment & 45,872 & 5,023 & 5,675 & 1,753 & 4,379 & 80 & 62,782 \\
\hline Total International Enrolment & 4,318 & 297 & 707 & 13 & 1,028 & 2 & 6,365 \\
\hline 2009 & & & & & & & 69,054 \\
\hline Total Domestic Enrolment & 45,609 & 4,561 & 5,989 & 1,649 & 4,414 & 71 & 62,293 \\
\hline Total International Enrolment & 4,836 & 346 & 643 & 17 & 919 & 0 & 6,761 \\
\hline 2010 & & & & & & & 71,196 \\
\hline Total Domestic Enrolment & 46,703 & 4,505 & 6,296 & 1738 & 4,578 & 72 & 63,892 \\
\hline Total International Enrolment & 5375 & 330 & 668 & 15 & 916 & 0 & 7,304 \\
\hline 2011 & & & & & & & 72,156 \\
\hline Total Domestic Enrolment & 46,923 & 4,469 & 6,426 & 1579 & 4,747 & 73 & 64,217 \\
\hline Total International Enrolment & 5911 & 410 & 694 & 17 & 907 & 0 & 7,939 \\
\hline 2012 & & & & & & & $\mathbf{7 3 , 8 1 7}$ \\
\hline Total Domestic Enrolment & 47,514 & 4,402 & 6,652 & 1,500 & 4,746 & 112 & 64,926 \\
\hline Total International Enrolment & 6604 & 509 & 799 & 23 & 956 & 0 & 8,891 \\
\hline 2013 & & & & & & & $\mathbf{7 5 , 4 7 7}$ \\
\hline Total Domestic Enrolment & 48,223 & 4,358 & 6,802 & 1393 & 4,714 & 117 & 65,607 \\
\hline Total International Enrolment & 7380 & 508 & 955 & 20 & 1007 & 0 & 9,870 \\
\hline
\end{tabular}

Source: Council of Ontario Universities: Common University Data Ontario, University of Toronto, General Information: Total Enrolment by Program. Note. 1) The year of 2006 represents the academic year of 2005-2006, the year of 2007 represents the academic year of 2006-2007, the year of 2008 represents the academic year of $2007-2008, \ldots$, and so on.

2) Total enrolment is collected annually and includes those who enrolled for Fall term. For example, total enrolment in 2006 (academic year of 2005-2006) is the total enrolment in Fall 2005. Total enrolment in 2007 (academic year of 2006-2007) is the total enrolment in Fall 2006, total enrolment in 2008 (academic year 2007-2008) is the total enrolment in Fall 2007, ... and so on.

3) Total enrolment does not include co-op enrolment and work-term enrolment.

4) Erolment data includes all enrolled students in three campuses (St. George, Mississauga (UTM), and Scarborough (UTSC)).

5) In 2008, enrolment data does not include 308 undergraduate and 103 graduate students enrolled in diploma or certificate programs.

6) In 2009, enrolment data does not include 321 diploma or certificate program students, 1,717 special students, and 2,593 residents.

7) In 2009, enrolment data does not include 916 Toronto School of Technology students.

8) In years (2010, 2011, 2012, and 2013), enrolment data does not include special students, students in diploma, certificate and residence program, and students in Toronto School of Technology. 
15) University of Waterloo: Total Number of Enrolled Students (Headcount)

\begin{tabular}{|c|c|c|c|c|c|c|c|}
\hline \multirow[b]{3}{*}{ Year } & \multicolumn{6}{|c|}{ Enrolment } & \multirow[b]{3}{*}{ Total Enrolment } \\
\hline & \multicolumn{2}{|c|}{$\underline{\text { Bachelors Degree }}$} & \multicolumn{2}{|c|}{$\underline{\text { Master's Degree }}$} & \multicolumn{2}{|c|}{$\underline{\text { Doctoral Degree }}$} & \\
\hline & Full-Time & Part-Time & Full-Time & Part-Time & Full-Time & Part-Time & \\
\hline 2006 & & & & & & & 25,150 \\
\hline Total Domestic Enrolment & 19,777 & 1,334 & 960 & 380 & 709 & 121 & 23,281 \\
\hline Total International Enrolment & 1,144 & 49 & 298 & 13 & 363 & 2 & 1,869 \\
\hline 2007 & & & & & & & 25,890 \\
\hline Total Domestic Enrolment & 20,142 & 1,281 & 1,016 & 442 & 758 & 124 & 23,763 \\
\hline Total International Enrolment & 1347 & 30 & 300 & 16 & 427 & 7 & 2,127 \\
\hline 2008 & & & & & & & 26,812 \\
\hline Total Domestic Enrolment & 20,505 & 1,180 & 1,337 & 469 & 883 & 132 & 24,506 \\
\hline Total International Enrolment & 1,457 & 67 & 297 & 14 & 462 & 9 & 2,306 \\
\hline 2009 & & & & & & & 27,768 \\
\hline Total Domestic Enrolment & 21,131 & 1,081 & 1,471 & 523 & 941 & 137 & 25,284 \\
\hline Total International Enrolment & 1,567 & 59 & 362 & 18 & 472 & 6 & 2,484 \\
\hline 2010 & & & & & & & 29,629 \\
\hline Total Domestic Enrolment & 22,534 & 978 & 1,447 & 622 & 982 & 167 & 26,730 \\
\hline Total International Enrolment & 1843 & 68 & 443 & 23 & 516 & 6 & 2,899 \\
\hline 2011 & & & & & & & 31,362 \\
\hline Total Domestic Enrolment & 23,805 & 965 & 1,313 & 721 & 1,028 & 165 & 27,997 \\
\hline Total International Enrolment & 2141 & 76 & 561 & 27 & 547 & 13 & 3,365 \\
\hline 2012 & & & & & & & 32,598 \\
\hline Total Domestic Enrolment & 24,412 & 910 & 1,314 & 902 & 1,017 & 169 & 28,724 \\
\hline Total International Enrolment & 2472 & 68 & 610 & 33 & 676 & 15 & 3,874 \\
\hline 2013 & & & & & & & 33,601 \\
\hline Total Domestic Enrolment & 24,793 & 853 & 1,410 & 991 & 941 & 197 & 29,185 \\
\hline Total International Enrolment & 2818 & 75 & 734 & 43 & 735 & 11 & 4,416 \\
\hline
\end{tabular}

Source: Council of Ontario Universities: Common University Data Ontario, University of Waterloo, General Information: Total Enrolment by Program.

Note. 1) The year of 2006 represents the academic year of 2005-2006, the year of 2007 represents the academic year of 2006-2007, the year of 2008 represents the academic year of $2007-2008, \ldots$, and so on.

2) Total enrolment is collected annually and includes those who enrolled for Fall term. For example, total enrolment in 2006 (academic year of 2005-2006) is the total enrolment in Fall 2005. Total enrolment in 2007 (academic year of 2006-2007) is the total enrolment in Fall 2006, total enrolment in 2008 (academic year 2007-2008) is the total enrolment in Fall 2007, ... and so on. 
16) University of Windsor: Total Number of Enrolled Students (Headcount)

\begin{tabular}{|c|c|c|c|c|c|c|c|}
\hline \multirow[b]{3}{*}{ Year } & \multicolumn{6}{|c|}{ Enrolment } & \multirow[b]{3}{*}{ Total Enrolment } \\
\hline & \multicolumn{2}{|c|}{$\underline{\text { Bachelors Degree }}$} & \multicolumn{2}{|c|}{$\underline{\text { Master's Degree }}$} & \multicolumn{2}{|c|}{$\underline{\text { Doctoral Degree }}$} & \\
\hline & Full-Time & Part-Time & Full-Time & Part-Time & Full-Time & Part-Time & \\
\hline 2006 & & & & & & & 16,300 \\
\hline Total Domestic Enrolment & 11,246 & 2,415 & 704 & 178 & 207 & 17 & \multirow{3}{*}{$\quad 16,640$} \\
\hline Total International Enrolment & 955 & 346 & 168 & 2 & 60 & 2 & \\
\hline 2007 & & & & & & & \\
\hline Total Domestic Enrolment & 11,206 & 2,764 & 694 & 157 & 207 & 16 & 15,044 \\
\hline Total International Enrolment & 981 & 293 & 241 & 1 & 79 & 1 & 1,596 \\
\hline 2008 & & & & & & & 15,643 \\
\hline Total Domestic Enrolment & 10,434 & 2,417 & 728 & 142 & 217 & 21 & 13,959 \\
\hline Total International Enrolment & 1,006 & 307 & 274 & 4 & 93 & 0 & \multirow[b]{2}{*}{15,318} \\
\hline 2009 & & & & & & & \\
\hline Total Domestic Enrolment & 10,399 & 2,016 & 836 & 139 & 235 & 20 & 13,645 \\
\hline Total International Enrolment & 1,015 & 251 & 301 & 2 & 104 & 0 & 1,673 \\
\hline 2010 & & & & & & & 15,231 \\
\hline Total Domestic Enrolment & 10,438 & 1,988 & 867 & 123 & 262 & 21 & 13,699 \\
\hline Total International Enrolment & 846 & 270 & 321 & 2 & 93 & 0 & \multirow[b]{2}{*}{15,508} \\
\hline 2011 & & & & & & & \\
\hline Total Domestic Enrolment & 10730 & 1947 & 891 & 105 & 283 & 24 & 13,980 \\
\hline Total International Enrolment & 803 & 239 & 388 & 2 & 95 & 1 & \multirow{2}{*}{$\mathbf{1 5 , 5 3 8}{ }^{1,528}$} \\
\hline 2012 & & & & & & & \\
\hline Total Domestic Enrolment & 10,756 & 1,971 & 863 & 88 & 260 & 22 & 13,960 \\
\hline Total International Enrolment & 751 & 271 & 448 & 2 & 103 & 3 & \multirow{2}{*}{15,718} \\
\hline 2013 & & & & & & & \\
\hline Total Domestic Enrolment & 10,855 & 1,800 & 860 & 69 & 260 & 18 & 13,862 \\
\hline Total International Enrolment & 797 & 272 & 672 & 2 & 113 & 0 & 1,856 \\
\hline \multicolumn{8}{|c|}{$\begin{array}{l}\text { Source: Council of Ontario Universities: Common University Data Ontario, University of Windsor, General Information: Total Enrolment by } \\
\text { Program. }\end{array}$} \\
\hline \multicolumn{8}{|c|}{$\begin{array}{l}\text { Note. 1) The year of } 2006 \text { represents the academic year of 2005-2006, the year of } 2007 \text { represents the academic year of 2006-2007, the year } \\
\text { of } 2008 \text { represents the academic year of } 2007-2008, \ldots \text {, and so on. } \\
\text { 2) Total enrolment is collected annually and includes those who enrolled for Fall term. For example, total enrolment in } 2006 \text { (academic } \\
\text { year of 2005-2006) is the total enrolment in Fall 2005. Total enrolment in } 2007 \text { (academic year of 2006-2007) is the total } \\
\text { enrolment in Fall 2006, total enrolment in } 2008 \text { (academic year 2007-2008) is the total enrolment in Fall 2007, ... and so on. } \\
\text { 3) Total enrolment does not include co-op enrolment and work-term enrolment. }\end{array}$} \\
\hline
\end{tabular}


17) Western University: Total Number of Enrolled Students (Headcount)

\begin{tabular}{|c|c|c|c|c|c|c|c|}
\hline \multirow[b]{3}{*}{ Year } & \multicolumn{6}{|c|}{ Enrolment } & \multirow[b]{3}{*}{ Total Enrolment } \\
\hline & \multicolumn{2}{|c|}{$\underline{\text { Bachelors Degree }}$} & \multicolumn{2}{|c|}{$\underline{\text { Master's Degree }}$} & \multicolumn{2}{|c|}{$\underline{\text { Doctoral Degree }}$} & \\
\hline & Full-Time & Part-Time & Full-Time & Part-Time & Full-Time & Part-Time & \\
\hline 2006 & & & & & & & 25,537 \\
\hline Total Domestic Enrolment & 19,389 & 1,333 & 2,009 & 334 & 955 & 56 & 24,076 \\
\hline Total International Enrolment & 794 & 88 & 289 & 9 & 280 & 1 & 1,461 \\
\hline 2007 & & & & & & & 25,923 \\
\hline Total Domestic Enrolment & 19,698 & 1,368 & 1,980 & 343 & 1,079 & 39 & 24,507 \\
\hline Total International Enrolment & 686 & 55 & 331 & 11 & 332 & 1 & 1,416 \\
\hline 2008 & & & & & & & 25,825 \\
\hline Total Domestic Enrolment & 19,147 & 1,476 & 2,239 & 367 & 1,166 & 62 & 24,457 \\
\hline Total International Enrolment & 611 & 68 & 323 & 22 & 341 & 3 & 1,368 \\
\hline 2009 & & & & & & & 25,922 \\
\hline Total Domestic Enrolment & 19,318 & 1,226 & 2,293 & 419 & 1,228 & 94 & 24,578 \\
\hline Total International Enrolment & 568 & 60 & 353 & 8 & 354 & 1 & 1,344 \\
\hline 2010 & & & & & & & 26,567 \\
\hline Total Domestic Enrolment & 19,736 & 1,227 & 2,270 & 415 & 1,330 & 77 & 25,055 \\
\hline Total International Enrolment & 626 & 41 & 411 & 7 & 423 & 4 & 1,512 \\
\hline 2011 & & & & & & & 27,445 \\
\hline Total Domestic Enrolment & 20304 & 1168 & 2340 & 433 & 1433 & 68 & 25,746 \\
\hline Total International Enrolment & 687 & 54 & 488 & 7 & 460 & 3 & 1,699 \\
\hline 2012 & & & & & & & 28,126 \\
\hline Total Domestic Enrolment & 20,795 & 1,047 & 2,310 & 449 & 1,435 & 81 & 26,117 \\
\hline Total International Enrolment & 899 & 61 & 531 & 8 & 505 & 5 & 2,009 \\
\hline 2013 & & & & & & & 28,476 \\
\hline Total Domestic Enrolment & 20,747 & 1,028 & 2,264 & 565 & 1,511 & 69 & 26,184 \\
\hline Total International Enrolment & 1220 & 53 & 512 & 9 & 494 & 4 & 2,292 \\
\hline
\end{tabular}

Source: Council of Ontario Universities: Common University Data Ontario, Western University, General Information: Total Enrolment by Program. Note. 1) The year of 2006 represents the academic year of 2005-2006, the year of 2007 represents the academic year of 2006-2007, the year of 2008 represents the academic year of $2007-2008, \ldots$, and so on.

2) Total enrolment is collected annually and includes those who enrolled for Fall term. For example, total enrolment in 2006 (academic year of 2005-2006) is the total enrolment in Fall 2005. Total enrolment in 2007 (academic year of 2006-2007) is the total enrolment in Fall 2006, total enrolment in 2008 (academic year 2007-2008) is the total enrolment in Fall 2007, ... and so on.

3) Total enrolment does not include co-op enrolment and work-term enrolment. 
18) Wilfrid Laurier University: Total Number of Enrolled Students (Headcount)

\begin{tabular}{|c|c|c|c|c|c|c|c|}
\hline \multirow[b]{3}{*}{ Year } & \multicolumn{6}{|c|}{ Enrolment } & \multirow[b]{3}{*}{ Total Enrolment } \\
\hline & \multicolumn{2}{|c|}{$\underline{\text { Bachelors Degree }}$} & \multicolumn{2}{|c|}{$\underline{\text { Master's Degree }}$} & \multicolumn{2}{|c|}{$\underline{\text { Doctoral Degree }}$} & \\
\hline & Full-Time & Part-Time & Full-Time & Part-Time & Full-Time & Part-Time & \\
\hline 2006 & & & & & & & 13,094 \\
\hline Total Domestic Enrolment & 10605 & 1182 & 419 & 494 & 96 & 6 & 12802 \\
\hline Total International Enrolment & 206 & 52 & 27 & 0 & 7 & 0 & 292 \\
\hline 2007 & & & & & & & 14,275 \\
\hline Total Domestic Enrolment & 11576 & 1323 & 463 & 509 & 120 & 5 & 13,996 \\
\hline Total International Enrolment & 210 & 34 & 20 & 2 & 13 & 0 & 279 \\
\hline 2008 & & & & & & & 14,418 \\
\hline Total Domestic Enrolment & 11528 & 1515 & 522 & 473 & 132 & 10 & 14,180 \\
\hline Total International Enrolment & 182 & 26 & 15 & 2 & 13 & 0 & 238 \\
\hline 2009 & & & & & & & 15,105 \\
\hline Total Domestic Enrolment & 12014 & 1536 & 622 & 533 & 133 & 14 & 14,852 \\
\hline Total International Enrolment & 160 & 44 & 29 & 4 & 16 & 0 & 253 \\
\hline 2010 & & & & & & & 16,588 \\
\hline Total Domestic Enrolment & N/A & N/A & N/A & N/A & N/A & N/A & N/A \\
\hline Total International Enrolment & N/A & N/A & N/A & N/A & N/A & N/A & N/A \\
\hline 2011 & & & & & & & 16,963 \\
\hline Total Domestic Enrolment & 13702 & 1536 & 709 & 571 & 132 & 20 & 16,670 \\
\hline Total International Enrolment & 195 & 37 & 38 & 5 & 18 & 0 & 293 \\
\hline 2012 & & & & & & & 17,746 \\
\hline Total Domestic Enrolment & 14210 & 1688 & 691 & 612 & 150 & 23 & 17,374 \\
\hline Total International Enrolment & 267 & 38 & 39 & 3 & 25 & 0 & 372 \\
\hline 2013 & & & & & & & 18,515 \\
\hline Total Domestic Enrolment & 14666 & 1825 & 667 & 597 & 179 & 21 & 17,955 \\
\hline Total International Enrolment & 397 & 86 & 50 & 2 & 25 & 0 & 560 \\
\hline
\end{tabular}

Source: Council of Ontario Universities: Common University Data Ontario, Wilfrid Laurier University, General Information: Total Enrolment by Program.

Note. 1) The year of 2006 represents the academic year of 2005-2006, the year of 2007 represents the academic year of 2006-2007, the year of 2008 represents the academic year of $2007-2008, \ldots$, and so on.

2) Total enrolment is collected annually and includes those who enrolled for Fall term. For example, total enrolment in 2006 (academic year of 2005-2006) is the total enrolment in Fall 2005. Total enrolment in 2007 (academic year of 2006-2007) is the total enrolment in Fall 2006, total enrolment in 2008 (academic year 2007-2008) is the total enrolment in Fall 2007, ... and so on.

3) Total enrolment does not include co-op enrolment and work-term enrolment.

4) Enrolment data for 2010 is not available at CUDO. The enrolment data for 2010 (academic year 2009-2010) was obtained from: WLU Enrolment for Fall 2009. ( https://www.wlu.ca/documents/38918/Fall_2009_Registration_Senate_Dec_7_09.pdf) 


\begin{tabular}{|c|c|c|c|c|c|c|c|}
\hline \multirow[b]{3}{*}{ Year } & \multicolumn{6}{|c|}{ Enrolment } & \multirow[b]{3}{*}{ Total Enrolment } \\
\hline & \multicolumn{2}{|c|}{$\underline{\text { Bachelors Degree }}$} & \multicolumn{2}{|c|}{ Master's Degree } & \multicolumn{2}{|c|}{$\underline{\text { Doctoral Degree }}$} & \\
\hline & Full-Time & Part-Time & Full-Time & Part-Time & Full-Time & Part-Time & \\
\hline 2006 & & & & & & & 49,450 \\
\hline Total Domestic Enrolment & 36150 & 6072 & 1714 & 1439 & 1028 & 148 & 46551 \\
\hline Total International Enrolment & 2241 & 339 & 153 & 29 & 135 & 2 & 2899 \\
\hline 2007 & & & & & & & 50,056 \\
\hline Total Domestic Enrolment & 36526 & 6156 & 1818 & 1603 & 1118 & 160 & 47,381 \\
\hline Total International Enrolment & 2049 & 289 & 170 & 20 & 136 & 11 & 2,675 \\
\hline 2008 & & & & & & & 50,291 \\
\hline Total Domestic Enrolment & 36023 & 6389 & 2095 & 1780 & 1240 & 174 & 47,701 \\
\hline Total International Enrolment & 1955 & 325 & 156 & 21 & 125 & 8 & 2,590 \\
\hline 2009 & & & & & & & 50,464 \\
\hline Total Domestic Enrolment & 36333 & 6063 & 2124 & 1753 & 1353 & 187 & 47,813 \\
\hline Total International Enrolment & 1993 & 298 & 180 & 32 & 139 & 9 & 2,651 \\
\hline 2010 & & & & & & & 51,630 \\
\hline Total Domestic Enrolment & 37019 & 6183 & 2022 & 1907 & 1435 & 193 & 48,759 \\
\hline Total International Enrolment & 2108 & 329 & 242 & 28 & 151 & 13 & 2,871 \\
\hline 2011 & & & & & & & 52,602 \\
\hline Total Domestic Enrolment & 37795 & 6015 & 1808 & 1871 & 1467 & 217 & 49,173 \\
\hline Total International Enrolment & 2569 & 322 & 344 & 30 & 155 & 9 & 3,429 \\
\hline 2012 & & & & & & & 52,744 \\
\hline Total Domestic Enrolment & 37721 & 6009 & 1780 & 1761 & 1430 & 236 & 48,937 \\
\hline Total International Enrolment & 2850 & 373 & 368 & 32 & 176 & 8 & 3,807 \\
\hline 2013 & & & & & & & 53,022 \\
\hline Total Domestic Enrolment & 37548 & 6030 & 1863 & 1708 & 1430 & 246 & 48,825 \\
\hline Total International Enrolment & 3089 & 497 & 385 & 38 & 177 & 11 & 4,197 \\
\hline Source: Council of Ontario Univers & nmon $\mathrm{Ul}_{\mathrm{r}}$ & Data & o, Yor & ersity, & 1 Infor & Total I & nt by Program. \\
\hline $\begin{array}{l}\text { Note. 1) The year of } 2006 \text { repres } \\
\text { of } 2008 \text { represents the a } \\
\text { 2) Total enrolment is collec } \\
\text { year of 2005-2006) is t } \\
\text { enrolment in Fall 2006, }\end{array}$ & $\begin{array}{l}\text { ic year of } 20 \\
\text { nually and in } \\
\text { lenrolment }\end{array}$ & $\begin{array}{l}\text { Ir of } 2005-2 \\
-2008, \ldots, \\
\text { ides those w } \\
\text { all } 2005 . \mathrm{T}\end{array}$ & $\begin{array}{l}\text { in, the year } \\
\text { ind so on. } \\
\text { no enrolled fo } \\
\text { tal enrolmen }\end{array}$ & $\begin{array}{l}\text { of } 2007 \text { rep } \\
\text { Fall term. } \\
\text { in } 2007 \text { (ac }\end{array}$ & $\begin{array}{l}\text { sents the ac: } \\
\text { or example, }\end{array}$ & al enrolmen & 2006 (academic \\
\hline
\end{tabular}




\section{Section 2: Number of Applications for Admission Data}

\section{1) Brock University: Total Number of Applications for Admission}

\begin{tabular}{|c|c|c|c|c|c|c|c|c|}
\hline \multirow[b]{2}{*}{ Program } & \multicolumn{8}{|c|}{ Total Number of Applications for Admission } \\
\hline & 2006 & 2007 & 2008 & 2009 & 2010 & 2011 & 2012 & 2013 \\
\hline Arts/Humanities/Social Science & 8233 & 7,567 & 8165 & 9716 & 9349 & 8,885 & 8313 & 8393 \\
\hline Science & 2,100 & 1,920 & 2059 & 2063 & 2209 & 2,167 & 2245 & 2475 \\
\hline Commerce/Mgmt/Business Admin & 3,610 & 3,577 & 3150 & 3502 & 3169 & 3,102 & 3271 & 3577 \\
\hline Phys/Health Ed/Recreation & 5,503 & 4,442 & 4150 & 3423 & 3303 & 3,220 & 3274 & 3399 \\
\hline Fine \& Applied Arts & 890 & 725 & 705 & 742 & 717 & 662 & 673 & 619 \\
\hline Music & N/A & 87 & 68 & 77 & 79 & 67 & 57 & 65 \\
\hline Nursing & 330 & 439 & 690 & 766 & 741 & 838 & 867 & 918 \\
\hline Diploma Program & 2 & 0 & 0 & 8 & 7 & 0 & 0 & 0 \\
\hline Education & 1,020 & 725 & 916 & N/A & N/A & N.A & N/A & N/A \\
\hline Total Number of Applications for Admission & 21688 & 19482 & 19903 & 20297 & 19574 & 18941 & 18700 & 19446 \\
\hline \multicolumn{9}{|c|}{$\begin{array}{l}\text { Source: Ontario Universities' Application Centre, Common University Data Ontario, Brock University, Admission: Applicants by type } \\
\text { and program. }\end{array}$} \\
\hline \multicolumn{9}{|c|}{ Note. 1) Total number of applicantions includes all choices (1st, 2nd, 3rd, ... $>3$ ). } \\
\hline \multicolumn{9}{|c|}{ 2) Total number of applications includes all domestic and international applicants. } \\
\hline \multicolumn{9}{|c|}{$\begin{array}{l}\text { 3) The year of } 2006 \text { represents the academic year of } 2005-2006 \text {, the year of } 2007 \text { represents the academic year of } 2006-2007 \text {, } \\
\text { the year of } 2008 \text { represents the academic year of } 2007-2008, \ldots \text {, and so on. }\end{array}$} \\
\hline $\begin{array}{l}\text { 4) Total number of applications for the ye } \\
\text { admission for fall } 2005 \text {. }\end{array}$ & $2006(\mathrm{a}$ & demic ye & $2005-2$ & 6) for ex & mple, is $\mathrm{t}$ & total nu & ber of ap & cations for \\
\hline
\end{tabular}


2) Carleton University: Total Number of Applications for Admission

\begin{tabular}{|c|c|c|c|c|c|c|c|c|}
\hline \multirow[b]{2}{*}{ Program } & \multicolumn{8}{|c|}{ Total Number of Applications for Admission } \\
\hline & 2006 & 2007 & 2008 & 2009 & 2010 & 2011 & 2012 & 2013 \\
\hline Architecture & 1,048 & 1,035 & 1,166 & 1,283 & 1314 & 1,262 & 1266 & 1,277 \\
\hline Arts/Humanities/Social Science & 10,493 & 9,533 & 9,769 & 10,948 & 10785 & 9,921 & 9342 & 9,719 \\
\hline Science & 3,270 & 3,176 & 3,475 & 3,615 & 3943 & 3,943 & 4149 & 4,759 \\
\hline Commerce/Mgmt/Business Admin & 4,668 & 4,831 & 5,372 & 5,842 & 5350 & 4,173 & 3998 & 4,340 \\
\hline Engineering \& Applied Science & 2,637 & 2,682 & 2,970 & 3,351 & 3596 & 3469 & 3710 & 3,986 \\
\hline Journalism & 1,442 & 1,571 & 1,595 & 1,524 & 1426 & 1231 & 1177 & 1,112 \\
\hline Music & 99 & 104 & 120 & 113 & 115 & 125 & 146 & 139 \\
\hline Social Work & 469 & 499 & 511 & 507 & 555 & 511 & 603 & 642 \\
\hline Other Administration & N/A & N/A & N/A & N/A & N/A & N/A & 870 & 1,009 \\
\hline Diploma Program & 14 & 23 & 22 & 6 & 3 & 3 & 1 & 3 \\
\hline Total Number of Applications for Admission & 24,140 & 23,454 & 25,000 & 27,189 & 27,087 & 24,638 & 25,262 & 26,986 \\
\hline
\end{tabular}

Source: Ontario Universities' Application Centre, Common University Data Ontario, Carleton University, Admission: Applicants by type and program.

Note. 1) Total number of applicantions includes all choices (1st, 2nd, 3rd, $\ldots>3$ ).

2) Total number of applications includes all domestic and international applicants.

3) The year of 2006 represents the academic year of 2005-2006, the year of 2007 represents the academic year of 2006-2007, the year of 2008 represents the academic year of $2007-2008, \ldots$, and so on.

4) Total number of applications for the year of 2006 (academic year 2005-2006) for example, is the total number of applications for admission for fall 2005. 


\section{3) Lakehead University: Total Number of Applications for Admission}

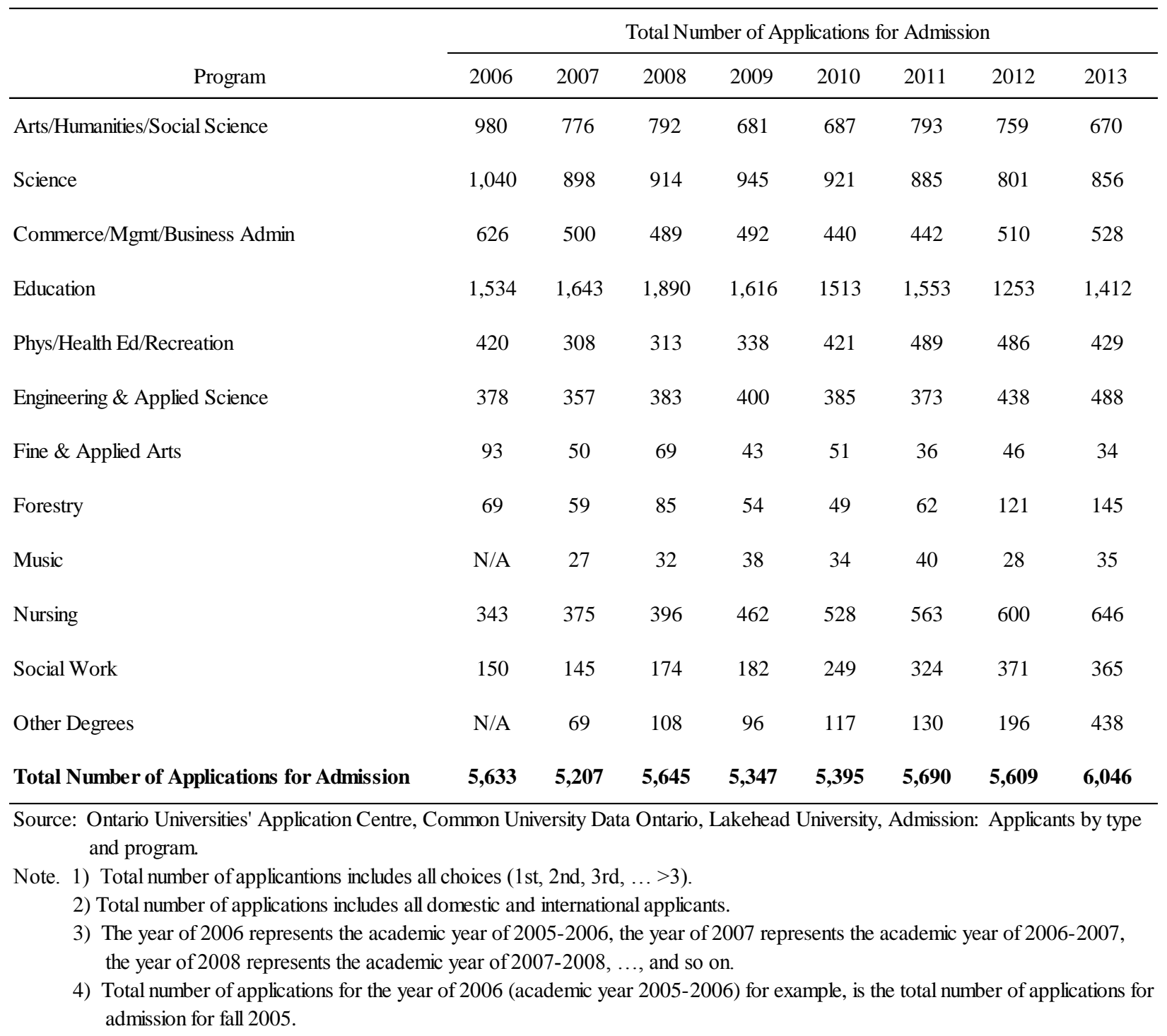




\section{4) Laurentian University: Total Number of Applications for Admission}

\begin{tabular}{lcccccccc}
\hline & \multicolumn{7}{c}{ Total Number of Applications for Admission } \\
\cline { 2 - 8 } \multicolumn{1}{c}{ Program } & 2006 & 2007 & 2008 & 2009 & 2010 & 2011 & 2012 & 2013 \\
\hline Arts/Humanities/Social Science & N/A & 2,668 & 2,153 & 2,402 & 1,625 & 2,502 & 1,907 & 1,709 \\
Science & N/A & 1,171 & 1,123 & 1,171 & 870 & 1,503 & 1,337 & 1,398 \\
Commerce/Mgmt/Business Admin & N/A & 629 & 486 & 608 & 415 & 558 & 500 & 499 \\
Education & N/A & 1,530 & 1,520 & 1,359 & 813 & 1,538 & 1,162 & 1,032 \\
Phys/Health Ed/Recreation & N/A & 540 & 476 & 475 & 173 & 500 & 319 & 510 \\
Engineering \& Applied Science & N/A & 168 & 261 & 306 & 240 & 328 & 319 & 485 \\
Fine \& Applied Arts & N/A & 74 & 38 & 51 & 19 & 45 & 43 & 9 \\
Music & N/A & 52 & 44 & 51 & 26 & 31 & 47 & 33 \\
Nursing & N/A & 330 & 384 & 446 & 324 & 639 & 625 & 696 \\
Social Work & N/A & 387 & 371 & 397 & 257 & 453 & 473 & 500 \\
Other Administration & N/A & 176 & 197 & 223 & 133 & 222 & 277 & 249 \\
Other Degrees & N/A & 133 & 139 & 141 & 48 & 124 & 115 & 150 \\
Total Number of Applications for Admission & N/A & $\mathbf{7 , 8 5 8}$ & $\mathbf{7 , 1 9 2}$ & $\mathbf{7 , 6 3 0}$ & $\mathbf{4 , 9 4 3}$ & $\mathbf{8 , 4 4 3}$ & $\mathbf{7 , 1 2 4}$ & $\mathbf{7 , 2 7 0}$ \\
\hline Solnyyyyyyyyy
\end{tabular}

Source: Ontario Universities' Application Centre, Common University Data Ontario, Laurentian University, Admission: Applicants by type and program.

Note. 1) Total number of applicantions includes all choices (1st, 2nd, 3rd, $\ldots>3$ ).

2) Total number of applications includes all domestic and international applicants.

3) The year of 2006 represents the academic year of 2005-2006, the year of 2007 represents the academic year of 2006-2007, the year of 2008 represents the academic year of $2007-2008, \ldots$, and so on.

4) Total number of applications for the year of 2006 (academic year 2005-2006) for example, is the total number of applications for admission for fall 2005 .

5) Total number of applications includes applications for admission in the federated universities (Thorneloe, Huntington, University of Sudbury, and Laurentian University) as well as the collaboration with Georgian College and St-Lawrence College (BBA only).

6) Total number of applications for admission does not include applications for admission in Algoma, Hearst, the Northern Ontario School of medicine, and collaboration with Sault, Northern, Cambrian, and St-Lawrence College (Nursing program). 
5) McMaster University: Total Number of Applications for Admission

\begin{tabular}{lcccccccc}
\hline & \multicolumn{7}{c}{ Total Number of Applications for Admission } \\
\cline { 2 - 9 } \multicolumn{1}{c}{ Program } & 2006 & 2007 & 2008 & 2009 & 2010 & 2011 & 2012 & 2013 \\
\hline Arts/Humanities/Social Science & 9,190 & 9,119 & 9,927 & 9,338 & 9,018 & 9,011 & 9,306 & 9,189 \\
Science & 8,002 & 8,207 & 8,686 & 10,672 & 11381 & 11,648 & 12,209 & 11,987 \\
Commerce/Mgmt/Business Admin & 5,637 & 5,925 & 6,264 & 6,289 & 6586 & 6,341 & 6,687 & 7,183 \\
Engineering \& Applied Science & 4,224 & 4,553 & 5,047 & 6,077 & 6296 & 6220 & 6,712 & 7,571 \\
Music & 431 & 438 & 201 & 207 & 222 & 182 & 179 & 182 \\
Nursing & 1,307 & 1,164 & 1293 & 1423 & 1408 & 1407 & 1,536 & 1,547 \\
Other Degrees & 3,030 & 3,702 & 3695 & 3448 & 3112 & 3378 & 3,576 & 3,600 \\
Kinesiology/Physical Education & 1,615 & 1,691 & 1927 & N/A & N/A & N/A & N/A & N/A \\
Total Number of Applications for Admission & $\mathbf{3 3 , 4 3 6}$ & $\mathbf{3 4 , 7 9 9}$ & $\mathbf{3 7 , 0 4 0}$ & $\mathbf{3 7 , 4 5 4}$ & $\mathbf{3 8 , 0 2 3}$ & $\mathbf{3 8 , 1 8 7}$ & $\mathbf{4 0 , 2 0 5}$ & $\mathbf{4 1 , 2 5 9}$ \\
\hline Soryyyyyyyyyyyy
\end{tabular}

Source: Ontario Universities' Application Centre, Common University Data Ontario, McMaster University, Admission: Applicants by type and program.

Note. 1) Total number of applicantions includes all choices (1st, $2 \mathrm{nd}, 3 \mathrm{rd}, \ldots>3)$.

2) Total number of applications includes all domestic and international applicants.

3) The year of 2006 represents the academic year of 2005-2006, the year of 2007 represents the academic year of 2006-2007, the year of 2008 represents the academic year of $2007-2008, \ldots$, and so on.

4) Total number of applications for the year of 2006 (academic year 2005-2006) for example, is the total number of applications for admission for fall 2005. 
6) Nipissing University: Total Number of Applications for Admission

\begin{tabular}{lcccccccc}
\hline & \multicolumn{7}{c}{ Total Number of Applications for Admission } \\
\cline { 2 - 8 } \multicolumn{1}{c}{ Program } & 2006 & 2007 & 2008 & 2009 & 2010 & 2011 & 2012 & 2013 \\
\hline Arts/Humanities/Social Science & 1,947 & 1,616 & 1,721 & N/A & 1,403 & 1,557 & 1,260 & 1,214 \\
Science & 485 & 376 & 426 & N/A & 240 & 281 & 263 & 302 \\
Commerce/Mgmt/Business Admin & 401 & 495 & 590 & N/A & 475 & 443 & 365 & 461 \\
Education & 548 & 1,452 & 1,756 & N/A & 840 & 830 & 680 & 654 \\
Phys/Health Ed/Recreation & N/A & N/A & 275 & N/A & 337 & 341 & 295 & 279 \\
Fine \& Applied Arts & N/A & N/A & N/A & N/A & 69 & 90 & 80 & 76 \\
Nursing & 162 & 209 & 259 & N/A & 429 & 442 & 488 & 536 \\
Total Number of Applications for Admission & $\mathbf{3 , 5 4 3}$ & $\mathbf{4 , 1 4 8}$ & $\mathbf{5 , 0 2 7}$ & $\mathbf{4 , 0 1 6}$ & $\mathbf{3 , 7 9 3}$ & $\mathbf{3 , 9 8 4}$ & $\mathbf{3 , 4 3 1}$ & $\mathbf{3 , 5 2 2}$ \\
\hline
\end{tabular}

Source: Ontario Universities' Application Centre, Common University Data Ontario, Nipissing University, Admission: Applicants by type and program.

Note. 1) Total number of applicantions includes all choices (1st, 2nd, 3rd, .. $>3$ ).

2) Total number of applications includes all domestic and international applicants.

3) The year of 2006 represents the academic year of 2005-2006, the year of 2007 represents the academic year of 2006-2007, the year of 2008 represents the academic year of 2007-2008, .., and so on.

4) Total number of applications for the year of 2006 (academic year 2005-2006) for example, is the total number of applications for admission for fall 2005 .

5) Total number of applications for 2009 (academic year 2008-2009) is not available at CUDO. Application data for 2009 is obtained from "2012-2013 Multi-Year Accountability Agreement (MYAA) Report Back", page 10. 2009 application data includes only those who applied for admission for Fall term as full-time students. 
7) Ontario College for Art and Design (OCAD) University: Total Number of Applications for

\section{Admission}

\begin{tabular}{|c|c|c|c|c|c|c|c|c|}
\hline \multirow[b]{2}{*}{ Program } & \multicolumn{8}{|c|}{ Total Number of Applications for Admission } \\
\hline & 2006 & 2007 & 2008 & 2009 & 2010 & 2011 & 2012 & 2013 \\
\hline Fine \& Applied Arts & 2,326 & 2,372 & 2,505 & 2,585 & 2692 & 2795 & 2,742 & 2,826 \\
\hline Total Number of Applications for Admission & 2,326 & 2,372 & 2,505 & 2,585 & 2692 & 2795 & 2,742 & 2,826 \\
\hline \multicolumn{9}{|c|}{$\begin{array}{l}\text { Source: Ontario Universities' Application Centre, Common University Data Ontario, OCAD University, Admission: Applicants by type } \\
\text { and program. }\end{array}$} \\
\hline \multicolumn{9}{|c|}{ Note. 1) Total number of applicantions includes all choices (1st, $2 \mathrm{nd}, 3 \mathrm{rd}, \ldots>3$ ). } \\
\hline \multicolumn{9}{|c|}{ 2) Total number of applications includes all domestic and international applicants. } \\
\hline \multicolumn{9}{|c|}{$\begin{array}{l}\text { 3) The year of } 2006 \text { represents the academic year of } 2005-2006 \text {, the year of } 2007 \text { represents the academic year of 2006-2007, } \\
\text { the year of } 2008 \text { represents the academic year of } 2007-2008, \ldots \text {, and so on. }\end{array}$} \\
\hline 4) Total number of applications for the ye & $2006(\mathrm{a}$ & demic ye & $2005-2$ & 6) for $\mathrm{e}$ & nple, i & total & er of ap & cations $\mathrm{f}$ \\
\hline
\end{tabular}




\section{8) Queen's University: Total Number of Applications for Admission}

\begin{tabular}{|c|c|c|c|c|c|c|c|c|}
\hline \multirow[b]{2}{*}{ Program } & \multicolumn{8}{|c|}{ Total Number of Applications for Admission } \\
\hline & 2006 & 2007 & 2008 & 2009 & 2010 & 2011 & 2012 & 2013 \\
\hline Arts/Humanities/Social Science & 7205 & 7915 & 7861 & 8414 & 8162 & 7922 & 8005 & 7801 \\
\hline Science & 6395 & 6317 & 6869 & 6906 & 6393 & 6602 & 6940 & 6886 \\
\hline Commerce/Management/Business Administration & 3551 & 4139 & 4458 & 4768 & 4274 & 4234 & 4549 & 4877 \\
\hline Education & 1672 & 1913 & 1843 & 1478 & 1528 & 1419 & 1408 & 1352 \\
\hline Physical/Health Education/Recreation & 776 & 850 & 601 & 482 & 491 & 486 & 484 & 458 \\
\hline Engineering and Applied Science & 3035 & 2859 & 3145 & 3413 & 3490 & 3428 & 3754 & 4051 \\
\hline Fine and Applied Arts & 455 & 316 & 301 & 320 & 315 & 295 & 240 & 3 \\
\hline Music & N/A & 224 & 220 & 248 & 248 & 222 & 217 & 188 \\
\hline Nursing & 558 & 577 & 605 & 658 & 748 & 845 & 777 & 794 \\
\hline Total Number of Applications for Admission & 23,647 & 25,110 & 24,396 & 26,687 & 25,649 & 25,453 & 26,374 & 26,410 \\
\hline
\end{tabular}

Source: Ontario Universities' Application Centre, Common University Data Ontario, Queen's University, Admission: Applicants by type and program.

Note. 1) Total number of applicantions includes all choices (1st, $2 \mathrm{nd}, 3 \mathrm{rd}, \ldots>3$ ).

2) Total number of applications includes all domestic and international applicants.

3) The year of 2006 represents the academic year of 2005-2006, the year of 2007 represents the academic year of 2006-2007, the year of 2008 represents the academic year of $2007-2008, \ldots$, and so on.

4) Total number of applications for the year of 2006 (academic year 2005-2006) for example, is the total number of applications for admission for fall 2005. 
9) Ryerson University: Total Number of Applications for Admission

\begin{tabular}{|c|c|c|c|c|c|c|c|c|}
\hline \multirow[b]{2}{*}{ Program } & \multicolumn{8}{|c|}{ Total Number of Applications for Admission } \\
\hline & 2006 & 2007 & 2008 & 2009 & 2010 & 2011 & 2012 & 2013 \\
\hline Architecture & 1055 & 1,050 & 1,094 & 1,150 & 1,179 & 1,116 & 1,197 & 1,187 \\
\hline Arts/Humanities/Social Science & 8,312 & 11,810 & 12,133 & 12,453 & 12,453 & 12,997 & 13,284 & 15,497 \\
\hline Commerce/Management/Business Administration & 9,742 & 10,108 & 11,308 & 12,163 & 12,265 & 11,739 & 12,194 & 12,751 \\
\hline Education & 1,134 & 1,029 & 1,200 & 1,232 & 1,232 & 1,218 & 1,084 & 1,028 \\
\hline Engineering & 4,248 & 4,296 & 4,508 & 5,540 & 5,462 & 5,451 & 5,742 & 5,819 \\
\hline Fine \& Applied Arts & 4,630 & 5,751 & 6,169 & 6,228 & 6,228 & 5,885 & 5,546 & 5,336 \\
\hline Geographic Analysis / Urban Planning & 1,016 & 618 & 812 & 828 & 909 & N/A & N/A & N/A \\
\hline Environmental Studies & N/A & N/A & N/A & N/A & N/A & 1,691 & 1,781 & 1,427 \\
\hline Household Sciences & 613 & 642 & 682 & 706 & 706 & 805 & 827 & 897 \\
\hline Journalism / Radio \& Television Arts & 2,684 & 2,763 & 2,861 & 2,902 & 2,981 & 2,639 & 2,460 & 2,345 \\
\hline Nursing & 1,533 & 1,508 & 1,607 & 1,742 & 1,742 & 2,109 & 2,239 & 2,388 \\
\hline Public Health & 332 & 346 & 400 & 613 & 443 & N/A & N/A & N/A \\
\hline Physical Sciences & 3,043 & 3,177 & 3,282 & 3,616 & 3,616 & 3,812 & 4,129 & 4,440 \\
\hline Social Work & 1,298 & 1,064 & 1,110 & 1,094 & 1,192 & 1,257 & 1,580 & 897 \\
\hline Other - Degree & 1,342 & 130 & 125 & 154 & 181 & 237 & 276 & 250 \\
\hline Other - Diploma & 196 & 86 & N/A & N/A & N/A & N/A & N/A & N/A \\
\hline Total Number of Applications for Admission & 41,178 & 44,378 & 47,291 & 50,421 & $\mathbf{5 0 , 5 8 9}$ & $\mathbf{5 0 , 9 5 6}$ & 52,339 & 54,262 \\
\hline
\end{tabular}

Source: Ontario Universities' Application Centre, Common University Data Ontario, Ryerson University, Admission: Applicants by type and program.

Note. 1) Total number of applicantions includes all choices (1st, 2nd, 3rd, .. $>3$ ).

2) Total number of applications includes all domestic and international applicants.

3) The year of 2006 represents the academic year of 2005-2006, the year of 2007 represents the academic year of 2006-2007, the year of 2008 represents the academic year of $2007-2008, \ldots$, and so on.

4) Total number of applications for the year of 2006 (academic year 2005-2006) for example, is the total number of applications for admission for fall 2005. 
10) Trent University: Total Number of Applications for Admission

\begin{tabular}{lcccccccc}
\hline & \multicolumn{7}{c}{ Total Number of Applications for Admission } \\
\cline { 2 - 9 } \multicolumn{1}{c}{ Program } & 2006 & 2007 & 2008 & 2009 & 2010 & 2011 & 2012 & 2013 \\
\hline Agriculture & N/A & N/A & N/A & N/A & 0 & 0 & 3 & 54 \\
Arts/Humanities/Social Science & 3,261 & 3,102 & 3,094 & 3,302 & 3,109 & 3,831 & 3,845 & 3,727 \\
Science & 1,546 & 1,491 & 1,453 & 1,356 & 1,362 & 1,779 & 1,977 & 2,024 \\
Commerce/Mgmt/Business Admin & 1,146 & 1,046 & 1,131 & 1,214 & 912 & 774 & 883 & 998 \\
Education & 1,679 & 1,832 & 1,740 & 1,586 & 1,447 & 1,479 & 1,415 & 1,354 \\
Nursing & 405 & 401 & 653 & 676 & 847 & 868 & 943 & 1,258 \\
Other Degrees & 439 & 528 & 552 & 3 & 4 & 6 & 11 & 7 \\
Diploma Program & 36 & 25 & 34 & 29 & 30 & 13 & 14 & 17 \\
Ineligible Program & N/A & N/A & N/A & N/A & N/A & 13 & 29 & 36 \\
Total Number of Applications for Admission & $\mathbf{8 , 5 1 2}$ & $\mathbf{8 , 4 2 5}$ & $\mathbf{8 , 6 5 7}$ & $\mathbf{8 , 1 6 6}$ & $\mathbf{7 , 7 1 1}$ & $\mathbf{8 , 7 6 3}$ & $\mathbf{9 , 1 2 0}$ & $\mathbf{9 , 4 7 5}$ \\
\hline
\end{tabular}

Source: Ontario Universities' Application Centre, Common University Data Ontario, Trent University, Admission: Applicants by type and program.

Note. 1) Total number of applicantions includes all choices (1st, 2nd, 3rd, .. $>3$ ).

2) Total number of applications includes all domestic and international applicants.

3) The year of 2006 represents the academic year of 2005-2006, the year of 2007 represents the academic year of 2006-2007, the year of 2008 represents the academic year of $2007-2008, \ldots$, and so on.

4) Total number of applications for the year of 2006 (academic year 2005-2006) for example, is the total number of applications for admission for fall 2005 . 


\section{1) University of Guelph: Total Number of Applications for Admission}

\begin{tabular}{|c|c|c|c|c|c|c|c|c|}
\hline \multirow[b]{2}{*}{ Program } & \multicolumn{8}{|c|}{ Total Number of Applications for Admission } \\
\hline & 2006 & 2007 & 2008 & 2009 & 2010 & 2011 & 2012 & 2013 \\
\hline Agriculture and Biological Science & 2,626 & N/A & 368 & $1,, 944$ & 331 & 331 & 324 & 347 \\
\hline Architecture & 97 & 61 & N/A & 63 & N/A & N/A & $\mathrm{N} / \mathrm{A}$ & N/A \\
\hline Arts/Humanities/Social Science & N/A & N/A & 9,197 & N/A & 8,677 & 9,476 & 8,331 & 7,928 \\
\hline Science & N/A & N/A & 6,717 & N/A & 6,245 & 6,663 & 7,110 & 7,857 \\
\hline Commerce/Mgmt/Business Admin & 3,388 & 2,626 & 4,178 & 3,059 & 4,270 & 4,437 & 4,206 & 4,426 \\
\hline Phys/Health Ed/Recreation & N/A & 1,194 & N/A & N/A & N/A & 580 & N/A & N/A \\
\hline Computer Science & 402 & 267 & N/A & 164 & N/A & N/A & N/A & N/A \\
\hline Engineering and Applied Science & 541 & 407 & 825 & 492 & 1,452 & 1,742 & 1,917 & 2,073 \\
\hline Fine \& Applied Arts & 635 & 587 & N/A & 586 & N/A & N/A & N/A & N/A \\
\hline Food Science and Nutrition & 930 & 1,006 & N/A & 1,633 & N/A & N/A & N/A & N/A \\
\hline Humanities & 2,390 & 1,978 & N/A & 1,963 & N/A & N/A & N/A & N/A \\
\hline Kinesiology & 1,200 & N/A & N/A & 1,570 & N/A & N/A & N/A & N/A \\
\hline Mathematics & 120 & 110 & N/A & 68 & N/A & N/A & N/A & N/A \\
\hline General Arts and Science & 1,550 & 1,059 & N/A & 1,133 & N/A & N/A & N/A & N/A \\
\hline Biological Science & N/A & 2,180 & N/A & N/A & N/A & N/A & N/A & N/A \\
\hline Physical Science & 720 & 531 & N/A & 323 & N/A & N/A & $\mathrm{N} / \mathrm{A}$ & $\mathrm{N} / \mathrm{A}$ \\
\hline Social Science & 5,192 & 3,982 & N/A & 4,121 & N/A & N/A & N/A & N/A \\
\hline Health Science & 73 & 61 & N/A & 64 & N/A & N/A & N/A & N/A \\
\hline Household Science & N/A & N/A & 933 & N/A & 969 & 1,028 & 1,037 & 1,139 \\
\hline Journalism & N/A & N/A & N/A & N/A & N/A & 903 & N/A & N/A \\
\hline Landscape Architecture & N/A & N/A & 135 & N/A & 465 & 477 & 457 & 447 \\
\hline Social Work & N/A & N/A & N/A & N/A & N/A & 765 & N/A & N/A \\
\hline Other Administration & N/A & N/A & N/A & N/A & N/A & 1,453 & N/A & N/A \\
\hline Other Degrees & N/A & N/A & 751 & N/A & 623 & 698 & 665 & 669 \\
\hline Diploma Program & N/A & N/A & 125 & N/A & N/A & N/A & N/A & N/A \\
\hline Total Number of Applications for Admission & 19,864 & 16,049 & 23,229 & 15,239 & 23,032 & 28,553 & 24,047 & 24,886 \\
\hline
\end{tabular}

Source: Ontario Universities' Application Centre, Common University Data Ontario, University of Guelph, Admission: Applicants by type and program.

Note. 1) Total number of applicantions includes all choices (1st, 2nd, 3rd, . $>3$ ).

2) Total number of applications includes all domestic and international applicants.

3) The year of 2006 represents the academic year of 2005-2006, the year of 2007 represents the academic year of 2006-2007, the year of 2008 represents the academic year of $2007-2008, \ldots$, and so on.

4) Total number of applications for the year of 2006 (academic year 2005-2006) for example, is the total number of applications for admission for fall 2005 . 
12) University of Ontario Institute of Technology (UOIT): Total Number of Applications for

\section{Admission}

\begin{tabular}{lcccccccc}
\hline & \multicolumn{7}{c}{ Total Number of Applications for Admission } \\
\cline { 2 - 8 } \multicolumn{1}{c}{ Program } & 2006 & 2007 & 2008 & 2009 & 2010 & 2011 & 2012 & 2013 \\
\hline Arts/Humanities/Social Science & 915 & 884 & 871 & 1,297 & 1,472 & 1,441 & N/A & 2,532 \\
Science & 1,688 & 1,797 & 1,819 & 2,005 & 2,003 & 1,768 & N/A & 2,656 \\
Commerce/Mgmt/Business Admin & 1,872 & 2,367 & 2,207 & 2,392 & 2,164 & 2,086 & N/A & 2,351 \\
Education & 170 & 156 & 149 & 119 & 119 & 127 & N/A & 156 \\
Phys/Health Ed/Recreation & N/A & N/A & N/A & N/A & 283 & 464 & N/A & 533 \\
Engineering and Applied Science & 1,537 & 1,630 & 1,828 & 1,838 & 1,873 & 1,686 & N/A & 2,325 \\
Nursing & 402 & 372 & 453 & 570 & 616 & 735 & N/A & 842 \\
Total Number of Applications for Admission & $\mathbf{6 , 5 8 4}$ & $\mathbf{7 , 2 0 6}$ & $\mathbf{7 , 3 2 7}$ & $\mathbf{8 , 2 2 1}$ & $\mathbf{8 , 5 3 0}$ & $\mathbf{8 , 3 0 7}$ & N/A & $\mathbf{1 1 , 3 9 5}$ \\
\hline
\end{tabular}

Source: Ontario Universities' Application Centre, Common University Data Ontario, University of Ontario Institute of Technology, Admission: Applicants by type and program.

Note. 1) Total number of applicantions includes all choices (1st, 2nd, 3rd, .. $>3$ ).

2) Total number of applications includes all domestic and international applicants.

3) The year of 2006 represents the academic year of 2005-2006, the year of 2007 represents the academic year of 2006-2007, the year of 2008 represents the academic year of $2007-2008, \ldots$, and so on.

4) Total number of applications for the year of 2006 (academic year 2005-2006) for example, is the total number of applications for admission for fall 2005. 


\section{3) University of Ottawa: Total Number of Applications for Admission}

\begin{tabular}{|c|c|c|c|c|c|c|c|c|}
\hline \multirow[b]{2}{*}{ Program } & \multicolumn{8}{|c|}{ Total Number of Applications for Admission } \\
\hline & 2006 & 2007 & 2008 & 2009 & 2010 & 2011 & 2012 & 2013 \\
\hline Arts/Humanities/Social Science & 11,833 & 12,214 & 12,856 & 12,699 & 13,465 & 13,269 & 13,639 & 13,802 \\
\hline Science & 4,789 & 4,381 & 4,742 & 4,550 & 4,764 & 4,951 & 5,437 & 5,662 \\
\hline Business \& Commerce & 3,676 & 3,648 & 4,022 & 3,782 & 4,250 & 3,960 & 4,347 & 5,312 \\
\hline Education & 57 & N/A & N/A & N/A & N/A & N/A & N/A & N/A \\
\hline Physical \& Health Education & 2,031 & 2,560 & 3,006 & 2,653 & 3,085 & 3,105 & 140 & 3,481 \\
\hline Engineering & 2,253 & 2,256 & 2,396 & 2,556 & 2,911 & 2,632 & 2,843 & 3,118 \\
\hline Fine Arts & N/A & 291 & 353 & 305 & 271 & 312 & 273 & 264 \\
\hline Fine \& Applied Arts (incl Music) & 449 & N/A & N/A & N/A & N/A & N/A & N/A & N/A \\
\hline Journalism & 503 & 586 & 615 & 535 & 541 & 454 & 435 & 389 \\
\hline Music & N/A & 198 & 215 & 201 & 214 & 213 & 218 & 228 \\
\hline Rehabilitation & 391 & N/A & N/A & N/A & N/A & N/A & N/A & N/A \\
\hline Nursing & 1,404 & 1,348 & 1,685 & 1,884 & 2,085 & 2,366 & 2,522 & 2,506 \\
\hline Other Degrees & 393 & 378 & 612 & 654 & 766 & 886 & 910 & 887 \\
\hline Total Number of Applications for Admission & 27,779 & 27,860 & 30,502 & 29,819 & 32,352 & 32,148 & 30,764 & 35,649 \\
\hline
\end{tabular}

Source: Ontario Universities' Application Centre, Common University Data Ontario, University of Ottawa, Admission: Applicants by type and program.

Note. 1) Total number of applicantions includes all choices (1st, 2nd, 3rd, .. $>3$ ).

2) Total number of applications includes all domestic and international applicants.

3) The year of 2006 represents the academic year of 2005-2006, the year of 2007 represents the academic year of 2006-2007, the year of 2008 represents the academic year of $2007-2008, \ldots$, and so on.

4) Total number of applications for the year of 2006 (academic year 2005-2006) for example, is the total number of applications for admission for fall 2005 . 
14) University of Toronto: Total Number of Applications for Admission

\begin{tabular}{|c|c|c|c|c|c|c|c|c|}
\hline \multirow[b]{2}{*}{ Program } & \multicolumn{8}{|c|}{ Total Number of Applications for Admission } \\
\hline & 2006 & 2007 & 2008 & 2009 & 2010 & 2011 & 2012 & 2013 \\
\hline Architecture & N/A & N/A & N/A & N/A & 0 & 0 & 0 & 1678 \\
\hline Arts/Humanities/Social Science & 19,143 & 18,017 & 18,769 & 18,748 & 19,634 & 20,362 & 21,263 & 20,990 \\
\hline Science & 18,869 & 18,306 & 17,932 & 16,855 & 17,036 & 17,651 & 18,869 & 20,423 \\
\hline Commerce/Mgmt/Business Admin & 10,562 & 10,598 & 12,789 & 13,147 & 13,403 & 13,188 & 14,054 & 14,587 \\
\hline Education & N/A & N/A & 822 & 794 & 965 & 1,425 & 1,331 & 1,207 \\
\hline Physical / Health Educ / Recreation & 876 & 1,125 & 952 & 861 & 845 & 1,002 & 1099 & 1,187 \\
\hline Engineering \& Applied Science & 5,783 & 5,955 & 6,376 & 6,705 & 6,999 & 7,386 & 8,267 & 8,679 \\
\hline Fine \& Applied Arts & 1,523 & 923 & 953 & 953 & 832 & 791 & 310 & 294 \\
\hline Journalism & 555 & 538 & 509 & 503 & 542 & 415 & 489 & 469 \\
\hline Music & N/A & 716 & 517 & 597 & 600 & 637 & 577 & 571 \\
\hline Nursing & 361 & N/A & N/A & N/A & N/A & N/A & N/A & N/A \\
\hline Other Administration & 2,335 & 2,674 & 2,029 & 1,857 & 1,684 & 1,626 & 1,444 & 1,467 \\
\hline Other Degrees & 162 & 172 & N/A & N/A & N/A & N/A & N/A & N/A \\
\hline Total Number of Applications for Admission & 60,169 & 59,024 & 61,648 & 61,020 & 62,540 & 64,483 & 67,703 & $\mathbf{7 1 , 5 5 2}$ \\
\hline
\end{tabular}

Source: Ontario Universities' Application Centre, Common University Data Ontario, University of Toronto, Admission: Applicants by type and program.

Note. 1) Total number of applicantions includes all choices (1st, 2nd, 3rd, ... $>3$ ).

2) Total number of applications includes all domestic and international applicants.

3) The year of 2006 represents the academic year of 2005-2006, the year of 2007 represents the academic year of 2006-2007, the year of 2008 represents the academic year of 2007-2008, ..., and so on.

4) Total number of applications for the year of 2006 (academic year 2005-2006) for example, is the total number of applications for admission for fall 2005.

5) Total number of applications for admission includes all three campuses (St. George, Mississauga (UTM), and Scarborough (UTSC)).

6) "Other Administration" includes Management, Arts Management, Arts Management Co-op program.

7) "Other Degrees" includes Paramedicine Co-op program. 
15) University of Waterloo: Total Number of Applications for Admission

\begin{tabular}{lcccccccc}
\hline & \multicolumn{7}{c}{ Total Number of Applications for Admission } \\
\cline { 2 - 8 } \multicolumn{1}{c}{ Program } & 2006 & 2007 & 2008 & 2009 & 2010 & 2011 & 2012 & 2013 \\
\hline Architecture & 780 & 872 & 988 & 1,115 & 1,147 & 1,096 & 1,086 & 1,106 \\
Arts/Humanities/Social Science & 8,766 & 9,563 & 10,035 & 11,483 & 10,583 & 9,799 & 9,926 & 10,046 \\
Science & 5,400 & 6,023 & 7,275 & 7,153 & 6,837 & 7,017 & 7,341 & 7,384 \\
Physical/ Health Educ / Recreation & 2,611 & 2,493 & 2,697 & 2,790 & 2,739 & 2,596 & 2,861 & 2,804 \\
Engineering \& Applied Science & 5,094 & 6,285 & 6,249 & 6,687 & 6,791 & 6,675 & 7,586 & 8,490 \\
Environmental Studies & 1,133 & 1,123 & 1,637 & 2,443 & 2,473 & 2,308 & 2,468 & 2,191 \\
Mathematics & 4,424 & 5,052 & 5,290 & 7,280 & 6,889 & 7,162 & 8,058 & 8,160 \\
Other Degrees & 61 & 47 & N/A & N/A & N/A & N/A & N/A & N/A \\
Total Number of Applications for Admission & $\mathbf{2 8 , 2 6 9}$ & $\mathbf{3 1 , 4 5 8}$ & $\mathbf{3 4 , 1 7 1}$ & $\mathbf{3 8 , 9 5 1}$ & $\mathbf{3 7 , 4 5 9}$ & $\mathbf{3 6 , 6 5 3}$ & $\mathbf{3 9 , 3 2 6}$ & $\mathbf{4 0 , 1 8 1}$ \\
\hline
\end{tabular}

Source: Ontario Universities' Application Centre, Common University Data Ontario, University of Waterloo, Admission: Applicants by type and program.

Note. 1) Total number of applicantions includes all choices (1st, 2nd, $3 \mathrm{rd}, \ldots>3$ ).

2) Total number of applications includes all domestic and international applicants.

3) The year of 2006 represents the academic year of 2005-2006, the year of 2007 represents the academic year of 2006-2007, the year of 2008 represents the academic year of $2007-2008, \ldots$, and so on.

4) Total number of applications for the year of 2006 (academic year 2005-2006) for example, is the total number of applications for admission for fall 2005 . 
16) University of Windsor: Total Number of Applications for Admission

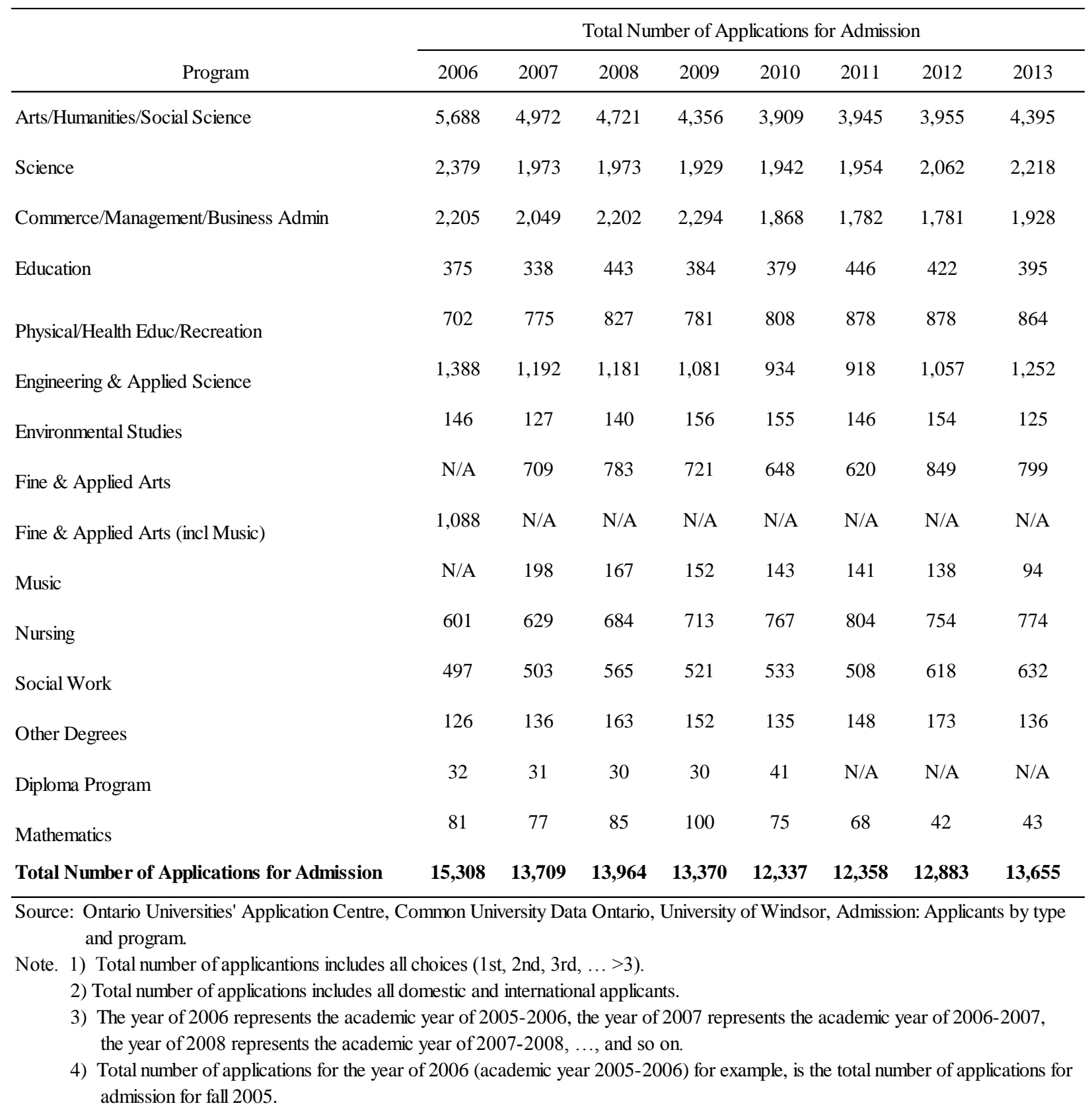


17) Western University: Total Number of Applications for Admission

\begin{tabular}{lcccccccc}
\hline & \multicolumn{7}{c}{ Total Number of Applications for Admission } \\
\cline { 2 - 8 } \multicolumn{1}{c}{ Program } & 2006 & 2007 & 2008 & 2009 & 2010 & 2011 & 2012 & 2013 \\
\hline Arts/Humanities/Social Science & 11,957 & 10,920 & 10,880 & 10,863 & 10,897 & 10,989 & 10,800 & 10,707 \\
Science & 8,267 & 8,407 & 8,683 & 8,820 & 9,171 & 9,737 & 9,848 & 10,084 \\
Commerce/Management/Business Admin & 4,956 & 5,269 & 6,094 & 6,492 & 6,664 & 6,361 & 6,487 & 7,082 \\
Physica/Health Educ/Recreation & 2,142 & 2,165 & 2,365 & 2,431 & 2,477 & 2,960 & 3,026 & 2,834 \\
Education & N/A & N/A & N/A & N/A & 3,633 & N/A & N/A & N/A \\
Engineering \& Applied Science & 2,539 & 2,631 & 2,960 & 3,131 & 3,085 & 3,030 & 3,508 & 3,827 \\
Household Science & N/A & N/A & N/A & 236 & N/A & N/A & N/A & N/A \\
Music & 600 & 730 & 806 & 771 & 769 & 778 & 751 & 640 \\
Nursing & 889 & 1,098 & 1,269 & 1,465 & 1,533 & 1,699 & 1,683 & 2,608 \\
Other Degrees & & & & & & & & \\
Total Number of Applications for Admission & $\mathbf{3 3 , 5 5 0}$ & $\mathbf{3 5 , 2 0 6}$ & $\mathbf{3 7 , 4 9 4}$ & $\mathbf{3 8 , 7 0 3}$ & $\mathbf{4 2 , 8 0 8}$ & $\mathbf{4 0 , 1 3 3}$ & $\mathbf{4 1 , 0 0 0}$ & $\mathbf{4 2 , 6 3 3}$ \\
\hline
\end{tabular}

Source: Ontario Universities' Application Centre, Common University Data Ontario, Western University, Admission: Applicants by type and program.

Note. 1) Total number of applicantions includes all choices (1st, 2nd, $3 \mathrm{rd}, \ldots>3$ ).

2) Total number of applications includes all domestic and international applicants.

3) The year of 2006 represents the academic year of 2005-2006, the year of 2007 represents the academic year of 2006-2007, the year of 2008 represents the academic year of 2007-2008, ..., and so on.

4) Total number of applications for the year of 2006 (academic year 2005-2006) for example, is the total number of applications for admission for fall 2005.

5) "Other Degrees" includes programs in Health Science and Information and Media Studies.

6) Number of applications for admission data does not include the number of applicants for affiliate campuses. 
18) Wilfrid Laurier University: Total Number of Applications for Admission

\begin{tabular}{lccccccccc}
\hline & \multicolumn{7}{c}{ Total Number of Applications for Admission } \\
\cline { 2 - 9 } \multicolumn{1}{c}{ Program } & 2006 & 2007 & 2008 & 2009 & 2010 & 2011 & 2012 & 2013 \\
\hline Arts/Humanities/Social Science & 9,903 & 9,903 & 10,377 & 11,606 & N/A & 10,960 & 10,909 & 11,028 \\
Science & 2,061 & 2,035 & 1,973 & 1,997 & N/A & 2,823 & 2,931 & 3,129 \\
Commerce/Management/Business Admin & 5,118 & 5,522 & 6,388 & 6,889 & N/A & 6,628 & 7,359 & 7,740 \\
Physica/Health Educ/Recreation & 1,462 & 1,472 & 1,747 & 1,792 & N/A & 1,456 & 1,515 & 1,371 \\
Music & 397 & 474 & 487 & 465 & N/A & 506 & 524 & 496 \\
Diploma Program & 29 & 38 & 45 & 38 & N/A & 33 & 39 & 29 \\
Total Number of Applications for Admission & $\mathbf{1 8 , 9 7 0}$ & $\mathbf{1 9 , 4 4 4}$ & $\mathbf{2 1 , 0 1 7}$ & $\mathbf{2 2 , 7 8 7}$ & N/A & $\mathbf{2 2 , 4 0 6}$ & $\mathbf{2 3 , 2 7 7}$ & $\mathbf{2 3 , 7 9 3}$ \\
\hline
\end{tabular}

Source: Ontario Universities' Application Centre, Common University Data Ontario, Wilfrid Laurier University, Admission: Applicants by type and program.

Note. 1) Total number of applicantions includes all choices (1st, $2 \mathrm{nd}, 3 \mathrm{rd}, \ldots>3$ ).

2) Total number of applications includes all domestic and international applicants.

3) The year of 2006 represents the academic year of 2005-2006, the year of 2007 represents the academic year of 2006-2007, the year of 2008 represents the academic year of $2007-2008, \ldots$, and so on.

4) Total number of applications for the year of 2006 (academic year 2005-2006) for example, is the total number of applications for admission for fall 2005 . 


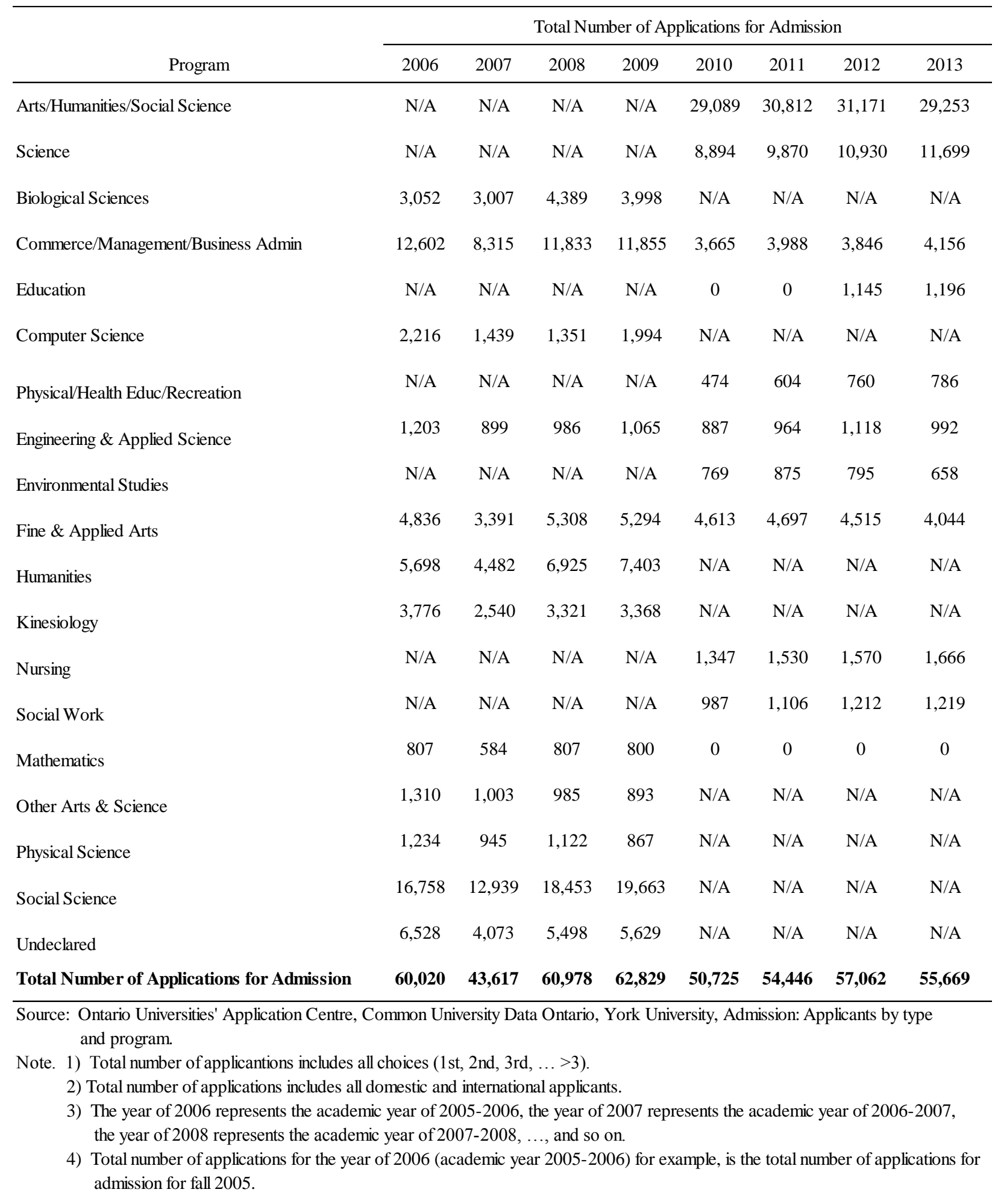




\section{Section 3: University Expenditure Data}

\section{A) Total Expenditure (000's)}

\begin{tabular}{lcccccccc}
\hline & \multicolumn{7}{c}{ Total Expenditure } \\
\cline { 2 - 8 } University & 2006 & 2007 & 2008 & 2009 & 2010 & 2011 & 2012 & 2013 \\
\hline Brock University & 186130 & 197802 & 217068 & 222128 & 245364 & 252863 & 263348 & 272367 \\
Carleton University & 341524 & 353967 & 382592 & 397099 & 415215 & 418630 & 430378 & 437148 \\
Lakehead University & 107939 & 117305 & 124011 & 134610 & 140771 & 143301 & 158971 & 162206 \\
Laurentian University & N/A & 127024 & 131075 & 152546 & 152385 & 152320 & 165076 & 170675 \\
McMaster University & 631095 & 685155 & 707304 & 745508 & 785772 & 816723 & 837556 & 868748 \\
Nipissing University & 47128 & 52600 & 57622 & 59085 & 65738 & 69954 & 72210 & 75560 \\
OCAD University & N/A & 37666 & 39615 & 41952 & 47849 & 51135 & 59758 & 66353 \\
Queens University & 614390 & 636866 & 694802 & 779261 & 800139 & 739770 & 751154 & 773715 \\
Ryerson University & 282219 & 324607 & 348541 & 388278 & 415110 & 433833 & 467727 & 517224 \\
Trent University & N/A & 110289 & 120489 & 129320 & 131256 & 134802 & 139244 & 146342 \\
University of Guelph & 516893 & 521694 & 569944 & 581441 & 627917 & 636624 & 652553 & 669227 \\
UOIT & 126704 & 83817 & 94515 & 108157 & 152630 & 174827 & N/A & 150622 \\
University of Ottawa & 527640 & 549369 & 577530 & 640226 & 702870 & 759490 & 810051 & 843752 \\
University of Toronto & 1612600 & 1709300 & 1807500 & 1898300 & 2068700 & 2165500 & 2313900 & 2437900 \\
University of Waterloo & 504048 & 539831 & 562111 & 604950 & 649963 & 668368 & 712803 & 763129 \\
University of Windsor & 230337 & 248820 & 272421 & 286689 & 290870 & 297697 & 310151 & 319574 \\
Western University & 668903 & 721930 & 762251 & 844913 & 905280 & 915262 & 952204 & 975732 \\
Wilfrid University & 178895 & 188538 & 207409 & 218342 & 240477 & 243956 & 264973 & 291305 \\
York University & 689200 & 738833 & 783901 & 847099 & 858416 & 894803 & 926551 & 959371 \\
\hline
\end{tabular}

Source: Council of Ontario Universities (COU), University Financial Statements: Statement of Operations.

Note. Total expenditure for UOIT is obtained from COU-Common University Data Ontario-University Revenue and Expenses: University Expenses.

Total expenditure for fiscal year ended April 30, 2005 is reported under the year of 2006 (academic year 2005-2006). 


\section{B) University Expenditure on Competitive Variables}

\section{1) Brock University: University Expenditure on Price and Non-Price Competitive Variables}

\begin{tabular}{|c|c|c|c|c|c|c|c|c|}
\hline \multirow[b]{2}{*}{ University Expenditure in Thousands (000's) } & \multicolumn{7}{|c|}{ Year } & \multirow[b]{2}{*}{2013} \\
\hline & 2006 & 2007 & 2008 & 2009 & 2010 & 2011 & 2012 & \\
\hline $\begin{array}{l}\text { University Expenditure on Scholarship, Bursaries } \\
(000 \text { 's })\end{array}$ & 9,621 & 10198 & 9602 & 11504 & 14256 & 14,134 & 14,469 & 16,143 \\
\hline $\begin{array}{l}\text { University Expenditure on Communication \& on } \\
\text { other Operational Expenditures ( } 000 \text { 's) }\end{array}$ & 15,033 & 10463 & 13827 & 15113 & 14810 & 18221 & 20,117 & 20,243 \\
\hline $\begin{array}{l}\text { University Expenditure on Instruction and } \\
\text { Research ( } 000 \text { 's) }\end{array}$ & 12,328 & 15392 & 9952 & 11762 & 11717 & 10,734 & 10,569 & 10,795 \\
\hline $\begin{array}{l}\text { University Expenditure on Academic Ranks } \\
\left(000^{\prime} \text { s }\right)\end{array}$ & 45,235 & 47629 & 61261 & 62595 & 67477 & 70,821 & 74,883 & 77,580 \\
\hline
\end{tabular}

Source: Council of Ontario Universities: Common University Data Ontario, Brock University, University Revenue and Expenses: University Expenses.

Note. 1) The year of 2006 represents the academic year of 2005-2006, the year of 2007 represents the academic year of 2006-2007, ..., and so on.

2) University expenses for fiscal year ended April 30, 2005 is reported under the year of 2006 (academic year 2005-2006). The adoption of fiscal year ended April, 30, 2005 for 2006 allows for examining its effect on enrolment for Fall 2005 ( academic year 2005-2006), and also examining its effect on number of applicantions for Fall 2005 (academic year 2005-2006).

3) Expenses for fiscal year ended April 30, 2006 is reported under 2007 (academic year 2006-2007) allows for examining its effect on enrolment and on number of applications for Fall 2006 (academic year 2006-2007). The same logic applies for the other years.

\section{2) Carleton University: University Expenditure on Price and Non-Price Competitive Variables}

\begin{tabular}{|c|c|c|c|c|c|c|c|c|}
\hline \multirow[b]{2}{*}{ University Expenditure in Thousands ( 000 's) } & \multicolumn{7}{|c|}{ Year } & \multirow[b]{2}{*}{2013} \\
\hline & 2006 & 2007 & 2008 & 2009 & 2010 & 2011 & 2012 & \\
\hline $\begin{array}{l}\text { University Expenditure on Scholarship, Bursaries } \\
\left(000^{\prime} \text { s }\right)\end{array}$ & 22,152 & 25363 & 27,828 & 28,393 & 30423 & 37,324 & 36,979 & 37,886 \\
\hline $\begin{array}{l}\text { University Expenditure on Communication \& on } \\
\text { other Operational Expenditures ( } 000 \text { 's) }\end{array}$ & 16,535 & 15831 & 17,366 & 17,062 & 26079 & 23046 & 25,777 & 23,479 \\
\hline $\begin{array}{l}\text { University Expenditure on Instruction and } \\
\text { Research (000's) }\end{array}$ & 12,409 & 12209 & 13,585 & 18,929 & 21270 & 18,892 & 21,982 & 23,107 \\
\hline $\begin{array}{l}\text { University Expenditure on Academic Ranks } \\
(000 \text { 's })\end{array}$ & 67,179 & 70272 & 76,325 & 82,197 & 88450 & 93,543 & 97,200 & 100,513 \\
\hline $\begin{array}{l}\text { University Expenditure on other Operational } \\
\text { Expenditures }(000 \text { 's) }\end{array}$ & 14,915 & 14,225 & 15,288 & 15,153 & 24,263 & 20,719 & 24,300 & 21,954 \\
\hline \multicolumn{9}{|c|}{$\begin{array}{l}\text { Source: Council of Ontario Universities: Common University Data Ontario, Carleton University, University Revenue and Expenses: University Expenses. } \\
\text { Note. 1) The year of } 2006 \text { represents the academic year of 2005-2006, the year of } 2007 \text { represents the academic year of 2006-2007, ..., and so on. } \\
\text { 2) University expenses for fiscal year ended April 30, } 2005 \text { is reported under the year of } 2006 \text { (academic year 2005-2006). The adoption of } \\
\text { fiscal year ended April, } 30,2005 \text { for } 2006 \text { allows for examining its effect on enrolment for Fall } 2005 \text { ( academic year 2005-2006), and also } \\
\text { examining its effect on number of applicantions for Fall } 2005 \text { (academic year 2005-2006). } \\
\text { 3) Expenses for fiscal year ended April 30, } 2006 \text { is reported under } 2007 \text { (academic year 2006-2007) allows for examining its effect on enrolment }\end{array}$} \\
\hline
\end{tabular}




\section{3) Lakehead University: University Expenditure on Price and Non-Price Competitive Variables}

\begin{tabular}{|c|c|c|c|c|c|c|c|c|}
\hline \multirow[b]{2}{*}{ University Expenditure in Thousands ( 000 's) } & \multicolumn{7}{|c|}{ Year } & \multirow[b]{2}{*}{2013} \\
\hline & 2006 & 2007 & 2008 & 2009 & 2010 & 2011 & 2012 & \\
\hline $\begin{array}{l}\text { University Expenditure on Scholarship, Bursaries } \\
(000 \text { 's })\end{array}$ & 6,198 & 6,631 & 6,827 & 8,132 & 8,609 & 7,992 & 8,898 & 9,901 \\
\hline $\begin{array}{l}\text { University Expenditure on Communication \& on } \\
\text { other Operational Expenditures ( } 000 \text { 's) }\end{array}$ & 4,039 & 4,164 & 4,859 & 5,268 & 5,371 & 5,837 & 5,535 & 6,057 \\
\hline $\begin{array}{l}\text { University Expenditure on Instruction and } \\
\text { Research }(000 \text { 's) }\end{array}$ & 7,289 & 7,926 & 8,080 & 9,176 & 11,790 & 12,454 & 15,362 & 15,484 \\
\hline $\begin{array}{l}\text { University Expenditure on Academic Ranks } \\
\left(000^{\prime} \mathrm{s}\right)\end{array}$ & 26,638 & 28,524 & 31,073 & 34,031 & 36,256 & 38,036 & 41,539 & 42,763 \\
\hline
\end{tabular}

Source: Council of Ontario Universities: Common University Data Ontario, Lakehead University, University Revenue and Expenses: University Expenses.

Note. 1) The year of 2006 represents the academic year of 2005-2006, the year of 2007 represents the academic year of 2006-2007, ..., and so on.

2) University expenses for fiscal year ended April 30, 2005 is reported under the year of 2006 (academic year 2005-2006). The adoption of fiscal year ended April, 30, 2005 for 2006 allows for examining its effect on enrolment for Fall 2005 ( academic year 2005-2006), and also examining its effect on number of applicantions for Fall 2005 (academic year 2005-2006).

3) Expenses for fiscal year ended April 30, 2006 is reported under 2007 (academic year 2006-2007) allows for examining its effect on enrolment and on number of applications for Fall 2006 (academic year 2006-2007). The same logic applies for the other years.

\section{4) Laurentian University: University Expenditure on Price and Non-Price Competitive}

\section{Variables}

\begin{tabular}{|c|c|c|c|c|c|c|c|c|}
\hline \multirow[b]{2}{*}{ University Expenditure in Thousands (000's) } & \multicolumn{7}{|c|}{ Year } & \multirow[b]{2}{*}{2013} \\
\hline & 2006 & 2007 & 2008 & 2009 & 2010 & 2011 & 2012 & \\
\hline $\begin{array}{l}\text { University Expenditure on Scholarship, Bursaries } \\
(000 \text { 's })\end{array}$ & N/A & 7,823 & 8,238 & 8,238 & 8,830 & 9,980 & N/A & 9,978 \\
\hline $\begin{array}{l}\text { University Expenditure on Communication \& on } \\
\text { other Operational Expenditures ( } 000 \text { 's) }\end{array}$ & N/A & 3561 & 4,718 & 4,718 & 5612 & 5402 & N/A & 6,814 \\
\hline $\begin{array}{l}\text { University Expenditure on Instruction and } \\
\text { Research }(000 \text { 's })\end{array}$ & N/A & 994 & 6,070 & 6,070 & 181 & 223 & N/A & 402 \\
\hline $\begin{array}{l}\text { University Expenditure on Academic Ranks } \\
(000 \text { 's })\end{array}$ & N/A & 35,104 & 39,608 & 39,608 & 46,054 & 47,168 & N/A & 49,684 \\
\hline
\end{tabular}

Source: Council of Ontario Universities: Common University Data Ontario, Laurentian University, University Revenue and Expenses: University Expenses.

Note. 1) The year of 2006 represents the academic year of 2005-2006, the year of 2007 represents the academic year of 2006-2007, ..., and so on.

2) University expenses for fiscal year ended April 30, 2005 is reported under the year of 2006 (academic year 2005-2006). The adoption of fiscal year ended April, 30, 2005 for 2006 allows for examining its effect on enrolment for Fall 2005 ( academic year 2005-2006), and also examining its effect on number of applicantions for Fall 2005 (academic year 2005-2006).

3) Expenses for fiscal year ended April 30, 2006 is reported under 2007 (academic year 2006-2007) allows for examining its effect on enrolment and on number of applications for Fall 2006 (academic year 2006-2007). The same logic applies for the other years. 


\section{5) McMaster University: University Expenditure on Price and Non-Price Competitive}

\section{Variables}

\begin{tabular}{|c|c|c|c|c|c|c|c|c|}
\hline \multirow[b]{2}{*}{ University Expenditure in Thousands (000's) } & \multicolumn{7}{|c|}{ Year } & \multirow[b]{2}{*}{2013} \\
\hline & 2006 & 2007 & 2008 & 2009 & 2010 & 2011 & 2012 & \\
\hline $\begin{array}{l}\text { University Expenditure on Scholarship, Bursaries } \\
\left(000^{\prime} \text { 's }\right)\end{array}$ & 35,310 & 34,476 & 35,521 & 38,130 & 39,891 & 43,397 & 44,147 & 43,891 \\
\hline $\begin{array}{l}\text { University Expenditure on Communication \& on } \\
\text { other Operational Expenditures ( } 000 \text { 's) }\end{array}$ & 164,901 & 145,602 & 75,069 & 151,546 & 170561 & 209,471 & 149,001 & 158,218 \\
\hline $\begin{array}{l}\text { University Expenditure on Instruction and } \\
\text { Research ( } 000 \text { 's) }\end{array}$ & 47,945 & 45,392 & 50,543 & 47,597 & 43588 & 46,643 & 55,235 & 60,148 \\
\hline $\begin{array}{l}\text { University Expenditure on Academic Ranks } \\
(000 \text { 's })\end{array}$ & 103,074 & 96,124 & 151,813 & 171,490 & 172,782 & 181,503 & 187,086 & 207,953 \\
\hline
\end{tabular}

Source: Council of Ontario Universities: Common University Data Ontario, McMaster University, University Revenue and Expenses: University Expenses.

Note. 1) The year of 2006 represents the academic year of 2005-2006, the year of 2007 represents the academic year of 2006-2007, ..., and so on.

2) University expenses for fiscal year ended April 30, 2005 is reported under the year of 2006 (academic year 2005-2006). The adoption of fiscal year ended April, 30, 2005 for 2006 allows for examining its effect on enrolment for Fall 2005 ( academic year 2005-2006), and also examining its effect on number of applicantions for Fall 2005 (academic year 2005-2006).

3) Expenses for fiscal year ended April 30, 2006 is reported under 2007 (academic year 2006-2007) allows for examining its effect on enrolment and on number of applications for Fall 2006 (academic year 2006-2007). The same logic applies for the other years. 


\section{6) Nipissing University: University Expenditure on Price and Non-Price Competitive Variables}

\begin{tabular}{|c|c|c|c|c|c|c|c|c|}
\hline \multirow[b]{2}{*}{ University Expenditure in Thousands (000's) } & \multicolumn{7}{|c|}{ Year } & \multirow[b]{2}{*}{2013} \\
\hline & 2006 & 2007 & 2008 & 2009 & 2010 & 2011 & 2012 & \\
\hline $\begin{array}{l}\text { University Expenditure on Scholarship, Bursaries } \\
(000 \text { 's })\end{array}$ & 2122 & 2,466 & N/A & 2,536 & 2,388 & 2,388 & 3,018 & 3,061 \\
\hline $\begin{array}{l}\text { University Expenditure on Communication \& on } \\
\text { other Operational Expenditures ( } 000 \text { 's) }\end{array}$ & 1429 & 1,757 & N/A & 1,868 & 1,998 & 1,998 & 1,921 & 1,748 \\
\hline $\begin{array}{l}\text { University Expenditure on Instruction and } \\
\text { Research ( } 000 \text { 's })\end{array}$ & 0 & 0 & N/A & 0 & 0 & 0 & 0 & 0 \\
\hline $\begin{array}{l}\text { University Expenditure on Academic Ranks } \\
(000 \text { 's })\end{array}$ & 14338 & 16,301 & N/A & 18,716 & 21,778 & 21,778 & 23,102 & 23,719 \\
\hline
\end{tabular}

Source: Council of Ontario Universities: Common University Data Ontario, Nipissing University, University Revenue and Expenses: University Expenses.

Note. 1) The year of 2006 represents the academic year of 2005-2006, the year of 2007 represents the academic year of 2006-2007, ..., and so on.

2) University expenses for fiscal year ended April 30, 2005 is reported under the year of 2006 (academic year 2005-2006). The adoption of fiscal year ended April, 30, 2005 for 2006 allows for examining its effect on enrolment for Fall 2005 ( academic year 2005-2006), and also examining its effect on number of applicantions for Fall 2005 (academic year 2005-2006).

3) Expenses for fiscal year ended April 30, 2006 is reported under 2007 (academic year 2006-2007) allows for examining its effect on enrolment and on number of applications for Fall 2006 (academic year 2006-2007). The same logic applies for the other years. 


\section{7) Ontario College for Art and Design (OCAD) University: University Expenditure on Price}

\section{and Non-Price Competitive Variables}

\begin{tabular}{|c|c|c|c|c|c|c|c|c|}
\hline \multirow[b]{2}{*}{ University Expenditure in Thousands (000's) } & \multicolumn{7}{|c|}{ Year } & \multirow[b]{2}{*}{2013} \\
\hline & 2006 & 2007 & 2008 & 2009 & 2010 & 2011 & 2012 & \\
\hline $\begin{array}{l}\text { University Expenditure on Scholarship, Bursaries } \\
(000 \text { 's })\end{array}$ & 1,356 & 1,266 & 1247 & 1,294 & 1,640 & 1,951 & 1,957 & 2,118 \\
\hline $\begin{array}{l}\text { University Expenditure on Communication \& on } \\
\text { other Operational Expenditures ( } 000 \text { 's) }\end{array}$ & 1035 & 1,248 & 1541 & 1,574 & 2,015 & 1,890 & 2,688 & 2,886 \\
\hline $\begin{array}{l}\text { University Expenditure on Instruction and } \\
\text { Research }(000 \text { 's })\end{array}$ & 1,063 & 1,419 & 1345 & 1,151 & 1,344 & 1,174 & 1,547 & 1,812 \\
\hline $\begin{array}{l}\text { University Expenditure on Academic Ranks } \\
(000 \text { 's })\end{array}$ & 10,408 & 12,781 & 13283 & 12,937 & 15,081 & 16,338 & 18,255 & 22,117 \\
\hline \multicolumn{9}{|c|}{$\begin{array}{l}\text { Source: Council of Ontario Universities: Common University Data Ontario, OCAD University, University Revenue and Expenses: University Expenses. } \\
\text { Note. 1) The year of } 2006 \text { represents the academic year of 2005-2006, the year of } 2007 \text { represents the academic year of 2006-2007, ..., and so on. } \\
\text { 2) University expenses for fiscal year ended April 30, } 2005 \text { is reported under the year of } 2006 \text { (academic year 2005-2006). The adoption of } \\
\text { fiscal year ended April, 30, } 2005 \text { for } 2006 \text { allows for examining its effect on enrolment for Fall } 2005 \text { (academic year 2005-2006), and also } \\
\text { examining its effect on number of applicantions for Fall } 2005 \text { (academic year 2005-2006). } \\
\text { 3) Expenses for fiscal year ended April 30, } 2006 \text { is reported under } 2007 \text { (academic year 2006-2007) allows for examining its effect on enrolment }\end{array}$} \\
\hline
\end{tabular}

8) Queen's University: University Expenditure on Price and Non-Price Competitive Variables

\begin{tabular}{|c|c|c|c|c|c|c|c|c|}
\hline \multirow[b]{2}{*}{ University Expenditure in Thousands (000's) } & \multicolumn{7}{|c|}{ Year } & \multirow[b]{2}{*}{2013} \\
\hline & 2006 & 2007 & 2008 & 2009 & 2010 & 2011 & 2012 & \\
\hline $\begin{array}{l}\text { University Expenditure on Scholarship, Bursaries } \\
(000 \text { 's })\end{array}$ & 39,244 & 39,339 & 48174 & 52,225 & 57,475 & 54,099 & 53,266 & 55,238 \\
\hline $\begin{array}{l}\text { University Expenditure on Communication \& on } \\
\text { other Operational Expenditures ( } 000 \text { 's) }\end{array}$ & 19,948 & 20,316 & 21813 & 22,276 & 26,961 & 40,823 & 31,151 & 38,572 \\
\hline $\begin{array}{l}\text { University Expenditure on Instruction and } \\
\text { Research }(000 \text { 's) }\end{array}$ & 56,327 & 58,511 & 59690 & 55,237 & 58,713 & 39,111 & 37,094 & 37,865 \\
\hline $\begin{array}{l}\text { University Expenditure on Academic Ranks } \\
(000 \text { 's })\end{array}$ & 111,844 & 120,626 & 110024 & 119,648 & 121,308 & 125,786 & 127,957 & 131,477 \\
\hline
\end{tabular}

Source: Council of Ontario Universities: Common University Data Ontario, Queen's University, University Revenue and Expenses: University Expenses. Note. 1) The year of 2006 represents the academic year of 2005-2006, the year of 2007 represents the academic year of 2006-2007, ..., and so on.

2) University expenses for fiscal year ended April 30, 2005 is reported under the year of 2006 (academic year 2005-2006). The adoption of fiscal year ended April, 30, 2005 for 2006 allows for examining its effect on enrolment for Fall 2005 ( academic year 2005-2006), and also examining its effect on number of applicantions for Fall 2005 (academic year 2005-2006).

3) Expenses for fiscal year ended April 30, 2006 is reported under 2007 (academic year 2006-2007) allows for examining its effect on enrolment and on number of applications for Fall 2006 (academic year 2006-2007). The same logic applies for the other years. 


\section{9) Ryerson University: University Expenditure on Price and Non-Price Competitive Variables}

\begin{tabular}{|c|c|c|c|c|c|c|c|c|}
\hline \multirow[b]{2}{*}{ University Expenditure in Thousands ( 000 's) } & \multicolumn{7}{|c|}{ Year } & \multirow[b]{2}{*}{2013} \\
\hline & 2006 & 2007 & 2008 & 2009 & 2010 & 2011 & 2012 & \\
\hline $\begin{array}{l}\text { University Expenditure on Scholarship, Bursaries } \\
(000 \text { 's })\end{array}$ & 12,163 & 13,631 & 14,455 & 14,185 & 16,265 & 18,915 & 26,671 & 30,910 \\
\hline $\begin{array}{l}\text { University Expenditure on Communication \& on } \\
\text { other Operational Expenditures ( } 000 \text { 's) }\end{array}$ & 6,933 & 6,980 & 8,344 & 9,847 & 11,171 & 11,665 & 12,047 & 12,721 \\
\hline $\begin{array}{l}\text { University Expenditure on Instruction and } \\
\text { Research ( } 000 \text { 's) }\end{array}$ & 25,463 & 28,464 & 31,001 & 39,015 & 44,418 & 45,035 & 43,636 & 45,988 \\
\hline $\begin{array}{l}\text { University Expenditure on Academic Ranks } \\
(000 \text { 's })\end{array}$ & 54,834 & 60,686 & 68,220 & 76,914 & 82,849 & 86,630 & 93,099 & 96,995 \\
\hline
\end{tabular}

Source: Council of Ontario Universities: Common University Data Ontario, Ryerson University, University Revenue and Expenses: University Expenses. Note. 1) The year of 2006 represents the academic year of 2005-2006, the year of 2007 represents the academic year of 2006-2007, ..., and so on.

2) University expenses for fiscal year ended April 30, 2005 is reported under the year of 2006 (academic year 2005-2006). The adoption of fiscal year ended April, 30, 2005 for 2006 allows for examining its effect on enrolment for Fall 2005 ( academic year 2005-2006), and also examining its effect on number of applicantions for Fall 2005 (academic year 2005-2006).

3) Expenses for fiscal year ended April 30, 2006 is reported under 2007 (academic year 2006-2007) allows for examining its effect on enrolment and on number of applications for Fall 2006 (academic year 2006-2007). The same logic applies for the other years.

\section{0) Trent University: University Expenditure on Price and Non-Price Competitive Variables}

\begin{tabular}{|c|c|c|c|c|c|c|c|c|}
\hline \multirow[b]{2}{*}{ University Expenditure in Thousands (000's) } & \multicolumn{7}{|c|}{ Year } & \multirow[b]{2}{*}{2013} \\
\hline & 2006 & 2007 & 2008 & 2009 & 2010 & 2011 & 2012 & \\
\hline $\begin{array}{l}\text { University Expenditure on Scholarship, Bursaries } \\
(000 \text { 's })\end{array}$ & 7,710 & 7,745 & 8,515 & 8,843 & 8,856 & 9,987 & 10,078 & N/A \\
\hline $\begin{array}{l}\text { University Expenditure on Communication \& on } \\
\text { other Operational Expenditures }(000 \text { 's) }\end{array}$ & 3,828 & 4,114 & 4,209 & 3,440 & 3,079 & 2,964 & 3,979 & N/A \\
\hline $\begin{array}{l}\text { University Expenditure on Instruction and } \\
\text { Research }(000 \text { 's) }\end{array}$ & 6,340 & 6,500 & 7,083 & 7,825 & 8,395 & 9,255 & 9,774 & N/A \\
\hline $\begin{array}{l}\text { University Expenditure on Academic Ranks } \\
(000 \text { 's })\end{array}$ & 28,223 & 31,064 & 33,884 & 36,117 & 37,026 & 38,262 & 38,173 & N/A \\
\hline
\end{tabular}

Source: Council of Ontario Universities: Common University Data Ontario, Trent University, University Revenue and Expenses: University Expenses.

Note. 1) The year of 2006 represents the academic year of 2005-2006, the year of 2007 represents the academic year of 2006-2007, ..., and so on.

2) University expenses for fiscal year ended April 30, 2005 is reported under the year of 2006 (academic year 2005-2006). The adoption of fiscal year ended April, 30, 2005 for 2006 allows for examining its effect on enrolment for Fall 2005 ( academic year 2005-2006), and also examining its effect on number of applicantions for Fall 2005 (academic year 2005-2006).

3) Expenses for fiscal year ended April 30, 2006 is reported under 2007 (academic year 2006-2007) allows for examining its effect on enrolment and on number of applications for Fall 2006 (academic year 2006-2007). The same logic applies for the other years. 


\section{1) University of Guelph: University Expenditure on Price and Non-Price Competitive}

\section{Variables}

\begin{tabular}{|c|c|c|c|c|c|c|c|c|}
\hline \multirow[b]{2}{*}{ University Expenditure in Thousands (000's) } & \multicolumn{7}{|c|}{ Year } & \multirow[b]{2}{*}{2013} \\
\hline & 2006 & 2007 & 2008 & 2009 & 2010 & 2011 & 2012 & \\
\hline $\begin{array}{l}\text { University Expenditure on Scholarship, Bursaries } \\
(000 \text { 's })\end{array}$ & 19,426 & N/A & 21,830 & 24,356 & 26,658 & 26,461 & 28,921 & 31,261 \\
\hline $\begin{array}{l}\text { University Expenditure on Communication \& on } \\
\text { other Operational Expenditures }(000 \text { 's })\end{array}$ & 15,784 & N/A & 14,986 & 17,365 & 20,591 & 21,526 & 20,683 & 24,297 \\
\hline $\begin{array}{l}\text { University Expenditure on Instruction and } \\
\text { Research ( } 000 \text { 's })\end{array}$ & 24,006 & N/A & 27,995 & 28,610 & 29,870 & 31,033 & 33,230 & 35,567 \\
\hline $\begin{array}{l}\text { University Expenditure on Academic Ranks } \\
(000 \text { 's })\end{array}$ & 83,852 & N/A & 91,881 & 96,800 & 104,073 & 107,584 & 112,393 & 113,280 \\
\hline
\end{tabular}

Source: Council of Ontario Universities: Common University Data Ontario, University of Guelph, University Revenue and Expenses: University Expenses.

Note. 1) The year of 2006 represents the academic year of 2005-2006, the year of 2007 represents the academic year of 2006-2007, .., and so on.

2) University expenses for fiscal year ended April 30, 2005 is reported under the year of 2006 (academic year 2005-2006). The adoption of fiscal year ended April, 30, 2005 for 2006 allows for examining its effect on enrolment for Fall 2005 ( academic year 2005-2006), and also examining its effect on number of applicantions for Fall 2005 (academic year 2005-2006).

3) Expenses for fiscal year ended April 30, 2006 is reported under 2007 (academic year 2006-2007) allows for examining its effect on enrolment and on number of applications for Fall 2006 (academic year 2006-2007). The same logic applies for the other years.

\section{2) University of Ontario Institute of Technology (UOIT): University Expenditure on Price and}

\section{Non-Price Competitive Variables}

\begin{tabular}{|c|c|c|c|c|c|c|c|c|}
\hline \multirow[b]{2}{*}{ University Expenditure in Thousands (000's) } & \multicolumn{7}{|c|}{ Year } & \multirow[b]{2}{*}{2013} \\
\hline & 2006 & 2007 & 2008 & 2009 & 2010 & 2011 & 2012 & \\
\hline $\begin{array}{l}\text { University Expenditure on Scholarship, Bursaries } \\
(000 \text { 's })\end{array}$ & 921 & 1,200 & 1,766 & 2,150 & 3,060 & 3,771 & N/A & 6,442 \\
\hline $\begin{array}{l}\text { University Expenditure on Communication \& on } \\
\text { other Operational Expenditures ( } 000 \text { 's) }\end{array}$ & 4,355 & 3,605 & 6,944 & 7,363 & 13,804 & 23,047 & N/A & 22,133 \\
\hline $\begin{array}{l}\text { University Expenditure on Instruction and } \\
\text { Research (000's) }\end{array}$ & 1,281 & 1,210 & 2,471 & 6,195 & 5,666 & 5,047 & N/A & 8,717 \\
\hline $\begin{array}{l}\text { University Expenditure on Academic Ranks } \\
(000 \text { 's })\end{array}$ & 4,931 & 7,909 & 10,908 & 13,022 & 19,016 & 18,909 & N/A & 22,666 \\
\hline
\end{tabular}

Source: Council of Ontario Universities: Common University Data Ontario, University of Ontario Institute of Technology, University Revenue and Expenses: University Expenses.

Note. 1) The year of 2006 represents the academic year of 2005-2006, the year of 2007 represents the academic year of 2006-2007, ..., and so on.

2) University expenses for fiscal year ended April 30, 2005 is reported under the year of 2006 (academic year 2005-2006). The adoption of fiscal year ended April, 30, 2005 for 2006 allows for examining its effect on enrolment for Fall 2005 ( academic year 2005-2006), and also examining its effect on number of applicantions for Fall 2005 (academic year 2005-2006).

3) Expenses for fiscal year ended April 30, 2006 is reported under 2007 (academic year 2006-2007) allows for examining its effect on enrolment and on number of applications for Fall 2006 (academic year 2006-2007). The same logic applies for the other years. 


\section{3) University of Ottawa: University Expenditure on Price and Non-Price Competitive}

\section{Variables}

\begin{tabular}{|c|c|c|c|c|c|c|c|c|}
\hline \multirow[b]{2}{*}{ University Expenditure in Thousands (000's) } & \multicolumn{7}{|c|}{ Year } & \multirow[b]{2}{*}{2013} \\
\hline & 2006 & 2007 & 2008 & 2009 & 2010 & 2011 & 2012 & \\
\hline $\begin{array}{l}\text { University Expenditure on Scholarship, Bursaries } \\
(000 \text { 's })\end{array}$ & 32,993 & 38,213 & 44,419 & 51,619 & 49,059 & 54,566 & 58,639 & 67,198 \\
\hline $\begin{array}{l}\text { University Expenditure on Communication \& on } \\
\text { other Operational Expenditures ( } 000 \text { 's })\end{array}$ & 55,285 & 46,039 & 40,659 & 59,638 & 67,058 & 33,202 & 34,522 & 31,843 \\
\hline $\begin{array}{l}\text { University Expenditure on Instruction and } \\
\text { Research (000's) }\end{array}$ & 81,835 & 90,972 & 90,839 & 101,391 & 83,096 & 105,124 & 140,030 & 158,193 \\
\hline $\begin{array}{l}\text { University Expenditure on Academic Ranks } \\
(000 \text { 's })\end{array}$ & 101,579 & 103,216 & 111,704 & 126,287 & 157,119 & 168,359 & 179,066 & 187,300 \\
\hline $\begin{array}{l}\text { University Expenditure on other Operational } \\
\text { Expenditures }(000 \text { 's) }\end{array}$ & 52,574 & 43,171 & 37,641 & 56,742 & 62,386 & 28,300 & 29,638 & 27,122 \\
\hline
\end{tabular}

Source: Council of Ontario Universities: Common University Data Ontario, University of Ottawa, University Revenue and Expenses: University Expenses.

Note. 1) The year of 2006 represents the academic year of 2005-2006, the year of 2007 represents the academic year of 2006-2007, ..., and so on.

2) University expenses for fiscal year ended April 30, 2005 is reported under the year of 2006 (academic year 2005-2006). The adoption of fiscal year ended April, 30, 2005 for 2006 allows for examining its effect on enrolment for Fall 2005 ( academic year 2005-2006), and also examining its effect on number of applicantions for Fall 2005 (academic year 2005-2006).

3) Expenses for fiscal year ended April 30, 2006 is reported under 2007 (academic year 2006-2007) allows for examining its effect on enrolment and on number of applications for Fall 2006 (academic year 2006-2007). The same logic applies for the other years. 


\section{4) University of Toronto: University Expenditure on Price and Non-Price Competitive}

\section{Variables}

\begin{tabular}{|c|c|c|c|c|c|c|c|c|}
\hline \multirow[b]{2}{*}{ University Expenditure in Thousands (000's) } & \multicolumn{7}{|c|}{ Year } & \multirow[b]{2}{*}{2013} \\
\hline & 2006 & 2007 & 2008 & 2009 & 2010 & 2011 & 2012 & \\
\hline $\begin{array}{l}\text { University Expenditure on Scholarship, Bursaries } \\
(000 \text { 's })\end{array}$ & 110,905 & 107,096 & 116,384 & N/A & 149,577 & 136,681 & 146,306 & 183,730 \\
\hline $\begin{array}{l}\text { University Expenditure on Communication \& on } \\
\text { other Operational Expenditures ( } 000 \text { 's) }\end{array}$ & 39,228 & 47,921 & 53,416 & N/A & 16,987 & 72,928 & 75,954 & 86,474 \\
\hline $\begin{array}{l}\text { University Expenditure on Instruction and } \\
\text { Research }(000 \text { 's })\end{array}$ & 256,787 & 291,206 & 323,258 & N/A & 372,324 & 413,303 & 434,934 & 400,144 \\
\hline $\begin{array}{l}\text { University Expenditure on Academic Ranks } \\
(000 \text { 's })\end{array}$ & 306,767 & 328,641 & 331,341 & N/A & 378,730 & 389,383 & 416,763 & 423,450 \\
\hline
\end{tabular}

Source: Council of Ontario Universities: Common University Data Ontario, University of Toronto, University Revenue and Expenses: University Expenses.

Note. 1) "University Expenditure" data includes all three campuses (St. George, Mississauga (UTM), and Scarborough (UTSC)).

2) The year of 2006 represents the academic year of 2005-2006, the year of 2007 represents the academic year of 2006-2007, ..., and so on

3) University expenses for fiscal year ended April 30, 2005 is reported under the year of 2006 (academic year 2005-2006). The adoption of fiscal year ended April, 30, 2005 for 2006 allows for examining its effect on enrolment for Fall 2005 ( academic year 2005-2006), and also examining its effect on number of applicantions for Fall 2005 (academic year 2005-2006).

4) Expenses for fiscal year ended April 30, 2006 is reported under 2007 (academic year 2006-2007) allows for examining its effect on enrolment and on number of applications for Fall 2006 (academic year 2006-2007). The same logic applies for the other years.

\section{5) University of Waterloo: University Expenditure on Price and Non-Price Competitive Variables}

\begin{tabular}{|c|c|c|c|c|c|c|c|c|}
\hline \multirow[b]{2}{*}{ University Expenditure in Thousands ( 000 's) } & \multicolumn{7}{|c|}{ Year } & \multirow[b]{2}{*}{2013} \\
\hline & 2006 & 2007 & 2008 & 2009 & 2010 & 2011 & 2012 & \\
\hline $\begin{array}{l}\text { University Expenditure on Scholarship, Bursaries } \\
(000 \text { 's })\end{array}$ & 33,810 & 40,630 & 43,340 & 51,411 & 68,028 & 81,594 & 88,945 & 97,677 \\
\hline $\begin{array}{l}\text { University Expenditure on Communication \& on } \\
\text { other Operational Expenditures ( } 000 \text { 's) }\end{array}$ & 24,188 & 27,131 & 33,150 & 38,061 & 39,334 & 38,524 & 44,572 & 50,327 \\
\hline $\begin{array}{l}\text { University Expenditure on Instruction and } \\
\text { Research (000's) }\end{array}$ & 40,397 & 42,196 & 43,880 & 51,217 & 46,195 & 34,393 & 36,046 & 37,399 \\
\hline $\begin{array}{l}\text { University Expenditure on Academic Ranks } \\
(000 \text { 's })\end{array}$ & 89,364 & 98,652 & 108,503 & 124,014 & 134,231 & 143,217 & 149,488 & 156,379 \\
\hline
\end{tabular}

Source: Council of Ontario Universities: Common University Data Ontario, University of Waterloo, University Revenue and Expenses: University Expenses.

Note. 1) The year of 2006 represents the academic year of 2005-2006, the year of 2007 represents the academic year of 2006-2007, ..., and so on.

2) University expenses for fiscal year ended April 30, 2005 is reported under the year of 2006 (academic year 2005-2006). The adoption of fiscal year ended April, 30, 2005 for 2006 allows for examining its effect on enrolment for Fall 2005 ( academic year 2005-2006), and also examining its effect on number of applicantions for Fall 2005 (academic year 2005-2006).

3) Expenses for fiscal year ended April 30, 2006 is reported under 2007 (academic year 2006-2007) allows for examining its effect on enrolment and on number of applications for Fall 2006 (academic year 2006-2007). The same logic applies for the other years. 


\section{6) University of Windsor: University Expenditure on Price and Non-Price Competitive}

\section{Variables}

\begin{tabular}{|c|c|c|c|c|c|c|c|c|}
\hline \multirow[b]{2}{*}{ University Expenditure in Thousands ( 000 's) } & \multicolumn{7}{|c|}{ Year } & \multirow[b]{2}{*}{2013} \\
\hline & 2006 & 2007 & 2008 & 2009 & 2010 & 2011 & 2012 & \\
\hline $\begin{array}{l}\text { University Expenditure on Scholarship, Bursaries } \\
(000 \text { 's })\end{array}$ & 10,926 & 13,342 & 14,202 & 14,271 & 14,590 & 15,143 & 16,601 & 17,613 \\
\hline $\begin{array}{l}\text { University Expenditure on Communication \& on } \\
\text { other Operational Expenditures ( } 000 \text { 's) }\end{array}$ & 10,718 & 12,641 & 15,148 & 15,196 & 14,607 & 13,875 & 13,812 & 14,402 \\
\hline $\begin{array}{l}\text { University Expenditure on Instruction and } \\
\text { Research }(000 \text { 's })\end{array}$ & 15,696 & 17,228 & 18,820 & 20,382 & 21,115 & 22,527 & 23,092 & 23,749 \\
\hline $\begin{array}{l}\text { University Expenditure on Academic Ranks } \\
(000 \text { 's })\end{array}$ & 51,123 & 54,283 & 57,206 & 62,670 & 63,151 & 68,278 & 72,539 & 74,378 \\
\hline
\end{tabular}

Source: Council of Ontario Universities: Common University Data Ontario, University of Windsor, University Revenue and Expenses: University Expenses.

Note. 1) The year of 2006 represents the academic year of 2005-2006, the year of 2007 represents the academic year of 2006-2007, ..., and so on.

2) University expenses for fiscal year ended April 30, 2005 is reported under the year of 2006 (academic year 2005-2006). The adoption of fiscal year ended April, 30, 2005 for 2006 allows for examining its effect on enrolment for Fall 2005 ( academic year 2005-2006), and also examining its effect on number of applicantions for Fall 2005 (academic year 2005-2006).

3) Expenses for fiscal year ended April 30, 2006 is reported under 2007 (academic year 2006-2007) allows for examining its effect on enrolment and on number of applications for Fall 2006 (academic year 2006-2007). The same logic applies for the other years. 


\section{7) Western University: University Expenditure on Price and Non-Price Competitive Variables}

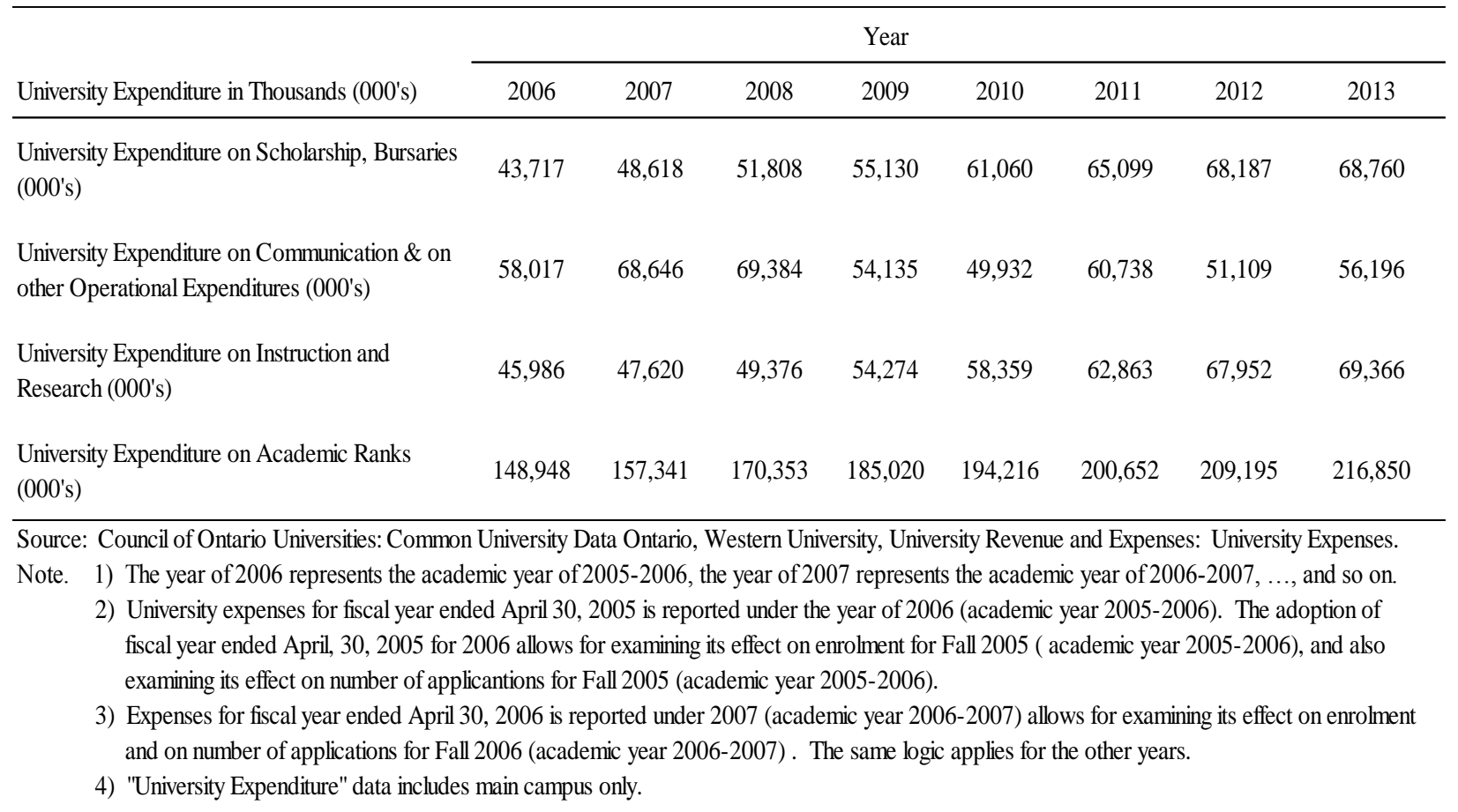

\section{8) Wilfrid Laurier University: University Expenditure on Price and Non-Price Competitive}

\section{Variables}

\begin{tabular}{|c|c|c|c|c|c|c|c|c|}
\hline \multirow[b]{2}{*}{ University Expenditure in Thousands (000's) } & \multicolumn{7}{|c|}{ Year } & \multirow[b]{2}{*}{2013} \\
\hline & 2006 & 2007 & 2008 & 2009 & 2010 & 2011 & 2012 & \\
\hline $\begin{array}{l}\text { University Expenditure on Scholarship, Bursaries } \\
(000 \text { 's })\end{array}$ & 8,655 & 9,851 & 10,800 & N/A & N/A & 12,525 & 15,473 & 19,443 \\
\hline $\begin{array}{l}\text { University Expenditure on Communication \& on } \\
\text { other Operational Expenditures ( } 000 \text { 's) }\end{array}$ & 28,070 & 13,041 & 14,154 & N/A & N/A & 15,105 & 18,138 & 21,859 \\
\hline $\begin{array}{l}\text { University Expenditure on Instruction and } \\
\text { Research ( } 000 \text { 's) }\end{array}$ & 2,634 & 2,462 & 3,072 & N/A & N/A & 4,390 & 4,189 & 4,452 \\
\hline $\begin{array}{l}\text { University Expenditure on Academic Ranks } \\
(000 \text { 's })\end{array}$ & 42,036 & 47,738 & 52,689 & N/A & N/A & 66,456 & 67,650 & 72,553 \\
\hline
\end{tabular}

Source: Council of Ontario Universities: Common University Data Ontario, Wilfrid Laurier University, University Revenue and Expenses: University Expenses.

Note. 1) The year of 2006 represents the academic year of 2005-2006, the year of 2007 represents the academic year of 2006-2007, ..., and so on.

2) University expenses for fiscal year ended April 30, 2005 is reported under the year of 2006 (academic year 2005-2006). The adoption of fiscal year ended April, 30, 2005 for 2006 allows for examining its effect on enrolment for Fall 2005 ( academic year 2005-2006), and also examining its effect on number of applicantions for Fall 2005 (academic year 2005-2006).

3) Expenses for fiscal year ended April 30, 2006 is reported under 2007 (academic year 2006-2007) allows for examining its effect on enrolment and on number of applications for Fall 2006 (academic year 2006-2007). The same logic applies for the other years. 


\section{9) York University: University Expenditure on Price and Non-Price Competitive Variables}

\begin{tabular}{|c|c|c|c|c|c|c|c|c|}
\hline \multirow[b]{2}{*}{ University Expenditure in Thousands (000's) } & \multicolumn{7}{|c|}{ Year } & \multirow[b]{2}{*}{2013} \\
\hline & 2006 & 2007 & 2008 & 2009 & 2010 & 2011 & 2012 & \\
\hline $\begin{array}{l}\text { University Expenditure on Scholarship, Bursaries } \\
(000 \text { 's })\end{array}$ & 45,448 & 49,542 & 52,457 & 54,980 & 54,369 & 58,815 & 58,024 & 61,292 \\
\hline $\begin{array}{l}\text { University Expenditure on Communication \& on } \\
\text { other Operational Expenditures ( } 000 \text { 's) }\end{array}$ & 20070 & 19164 & 21101 & 21472 & 21432 & 21849 & 20325 & 21721 \\
\hline $\begin{array}{l}\text { University Expenditure on Instruction and } \\
\text { Research }(000 \text { 's })\end{array}$ & 37,259 & 40,734 & 44,492 & 45,956 & 42,781 & 33,305 & 44,746 & 44,584 \\
\hline $\begin{array}{l}\text { University Expenditure on Academic Ranks } \\
(000 \text { 's })\end{array}$ & 156,208 & 168,043 & 175,397 & 200,646 & 203,778 & 223,957 & 229,240 & 241,355 \\
\hline
\end{tabular}

Source: Council of Ontario Universities: Common University Data Ontario, York University, University Revenue and Expenses: University Expenses.

Note. 1) The year of 2006 represents the academic year of 2005-2006, the year of 2007 represents the academic year of 2006-2007, ..., and so on.

2) University expenses for fiscal year ended April 30, 2005 is reported under the year of 2006 (academic year 2005-2006). The adoption of fiscal year ended April, 30, 2005 for 2006 allows for examining its effect on enrolment for Fall 2005 ( academic year 2005-2006), and also examining its effect on number of applicantions for Fall 2005 (academic year 2005-2006).

3) Expenses for fiscal year ended April 30, 2006 is reported under 2007 (academic year 2006-2007) allows for examining its effect on enrolment and on number of applications for Fall 2006 (academic year 2006-2007). The same logic applies for the other years. 


\section{Section 4: Data for University Location}

\section{Census Population for Each University Location in Ontario}

\begin{tabular}{|c|c|c|c|c|c|c|c|c|c|}
\hline University & Location & 2006 & 2007 & 2008 & 2009 & 2010 & 2011 & 2012 & 2013 \\
\hline Nipissing University & North Bay, Ontario & 63424 & 63547 & 63671 & 63794 & 63918 & 64043 & 64167 & 64292 \\
\hline Trent University & Peterborough, Ontario & 120,610 & 120,560 & 120,895 & 120,988 & 121,865 & 122,197 & 122,738 & 123,105 \\
\hline Lakehead University & Thunder Bay, Ontario & 127,066 & 126,024 & 125,463 & 125,087 & 125,098 & 124,952 & 125,132 & 125,093 \\
\hline University of Guelph & Guelph, Ontario & 139,329 & 140,035 & 141,399 & 142,587 & 144,204 & 145,637 & 148,060 & 150,305 \\
\hline Queen's University & Kingston, Ontario & 158,117 & 158,664 & 159,838 & 161,375 & 162,913 & 164,492 & 165,987 & 167,151 \\
\hline Laurentian University & Sudbury, Ontario & 164,214 & 164,808 & 165,515 & 165,684 & 165,200 & 165,253 & 165,508 & 165,534 \\
\hline University of Windsor & Windser, Ontario & 336,009 & 333,507 & 330,475 & 328,335 & 328,173 & 328,321 & 330,954 & 333,082 \\
\hline $\begin{array}{l}\text { University of Ontario Institute } \\
\text { of Technology }\end{array}$ & Oshawa, Ontario & 344,262 & 348,280 & 352,630 & 357,061 & 362,255 & 367,266 & 373,818 & 379,995 \\
\hline Brock University & St. Catharines, Ontario & 403,959 & 402,581 & 401,456 & 401,337 & 401,957 & 402,563 & 404,073 & 404,971 \\
\hline Western University: & London, Ontario & 475,903 & 478,492 & 481,249 & 483,045 & 486,129 & 489,461 & 494,511 & 498,623 \\
\hline University of Waterloo & Kitchener - Cambridge - Waterloo & 470,597 & 474,219 & 478,759 & 482,586 & 487,186 & 492,961 & 498,978 & 504,258 \\
\hline Wilfrid Laurier University & Kitchener - Cambridge - Waterloo & 470,597 & 474,219 & 478,759 & 482,586 & 487,186 & 492,961 & 498,978 & 504,258 \\
\hline McMaster University & Hamilton, Ontario & 719,434 & 722,102 & 725,297 & 729,247 & 736,141 & 742,498 & 750,802 & 758,073 \\
\hline Carleton University & Ottawa, Ontario & $1,172,106$ & $1,188,073$ & $1,207,376$ & $1,228,635$ & $1,250,553$ & $1,270,232$ & $1,288,720$ & $1,305,210$ \\
\hline University of Ottawa & Ottawa, Ontario & $1,172,106$ & $1,188,073$ & $1,207,376$ & $1,228,635$ & $1,250,553$ & $1,270,232$ & $1,288,720$ & $1,305,210$ \\
\hline OCAD University & Toronto, Ontario & $5,334,812$ & $5,418,207$ & $5,504,836$ & $5,591,195$ & $5,681,721$ & $5,769,759$ & $5,869,950$ & $5,959,505$ \\
\hline Ryerson University & Toronto, Ontario & $5,334,812$ & $5,418,207$ & $5,504,836$ & $5,591,195$ & $5,681,721$ & $5,769,759$ & $5,869,950$ & $5,959,505$ \\
\hline University of Toronto & Toronto, Ontario & $5,334,812$ & $5,418,207$ & $5,504,836$ & $5,591,195$ & $5,681,721$ & $5,769,759$ & $5,869,950$ & $5,959,505$ \\
\hline York University & Toronto, Ontario & $5,334,812$ & $5,418,207$ & $5,504,836$ & $5,591,195$ & $5,681,721$ & $5,769,759$ & $5,869,950$ & $5,959,505$ \\
\hline
\end{tabular}

Source: Statistics Canada:

1) Annual population estimates by census metropolitan area, Canada — Population at July 1 , "http://www.statcan.gc.ca/pub/91-214-x/2012000/t001-eng.pdf"

2) Census metropolitan areas (CMAs) or census aggoloeration (CAs) in Ontario.

Note. 1) Estimated census population in North Bay area is not included in annual population estimation by census metropolitan area, canada population July 1.

2) To estimate census population for North Bay area for the years from 2006 to 2013, the researcher has used percentage change of population among two census years (census 2006 and census 2011) in North Bay area. Percentage change of population in North Bay is 1\% over five years This percentages is obtained from Census metropolitan areas (CMAs) or census agglomerations (CAs) in Ontario.

Annual population growth rate, with respect to compound rate, is $0.1943 \%$ for North Bay. Census population in both North Bay over the years is estimated as follows: estimated population in 2007 is: censusn population in $2006+$ (census population in $2006 * \%$ of change $(0.1943 \%)$ ), estimated population in 2008 is: estimated population in $2007+$ (estimated population in $2007 * \%$ of change $(0.1943 \%)$ ). Same mathmatical procees was used to estimate census population for the rest of the years.

\section{Percentage Change of Population in North Bay and in Sault Ste. Marie}

\begin{tabular}{lcccc}
\hline & & \multicolumn{2}{c}{ Census Population } & \\
\cline { 3 - 4 } CMA or CA name & Type & 2011 & 2006 & \% of Change \\
\hline North Bay & CA & 64,043 & 63,424 & 1 \\
\hline Sounn
\end{tabular}

Source: Statistics Canada: Ontario - Metropolitan areas, population rank and population change, 2006 to 2011 http://www.statcan.gc.ca/pub/91-214-x/2012000/tablelist-listetableaux1-eng.htm 


\section{Appendix B: Missing Data}

Table 12.1. Missing Values

\begin{tabular}{lccccc}
\hline & & & & \multicolumn{2}{c}{ Obs. Not Missing } \\
\cline { 5 - 6 } \multicolumn{1}{c}{ Variable } & Obs=missing & Missing \% & Obs. Not Missing & Min & Max \\
\hline Applicants & $3 / 152$ & $1.97 \%$ & 149 & 2326 & 71552 \\
Enrollees & $2 / 152$ & $1.32 \%$ & 150 & 3065 & 75477 \\
Persistence Ratio & $4 / 152$ & $3 \%$ & 148 & 0.4655225 & 1.757839 \\
Awards & $9 / 152$ & $6 \%$ & 143 & 921 & 183730 \\
Marketing & $9 / 152$ & $6 \%$ & 143 & 1035 & 209471 \\
Graduates & $9 / 152$ & $6 \%$ & 143 & 0.001 & 434934 \\
Professors & $9 / 152$ & $6 \%$ & 143 & 4931 & 423450 \\
\hline
\end{tabular}

Table 12.2.

Missing Variables for Each Individual University

\begin{tabular}{lcccccc}
\hline \multicolumn{1}{c}{ University } & Applicants & Enrollees & Awards & Marketing & Graduates & Professors \\
\hline Brock_U & 0 & 0 & 0 & 0 & 0 & 0 \\
Carleton_U & 0 & 0 & 0 & 0 & 0 & 0 \\
Lakehead_U & 0 & 0 & 0 & 0 & 0 & 0 \\
Laurentian_U & 1 & 1 & 2 & 2 & 2 & 2 \\
McMaster_U & 0 & 0 & 0 & 0 & 0 & 0 \\
Nipissing_U & 0 & 1 & 1 & 1 & 1 & 1 \\
OCAD_U & 0 & 0 & 0 & 0 & 0 & 0 \\
Queen's_U & 0 & 0 & 0 & 0 & 0 & 0 \\
Ryerson_U & 0 & 0 & 0 & 0 & 0 & 0 \\
Trent_U & 0 & 0 & 1 & 1 & 1 & 1 \\
U_Guelph & 0 & 0 & 1 & 1 & 1 & 1 \\
UOIT & 1 & 0 & 1 & 1 & 1 & 1 \\
U_Ottawa & 0 & 0 & 0 & 0 & 0 & 0 \\
U_Toronto & 0 & 0 & 1 & 1 & 1 & 1 \\
U_Waterloo & 0 & 0 & 0 & 0 & 0 & 0 \\
U_Windsor & 0 & 0 & 0 & 0 & 0 & 0 \\
Western_U & 0 & 0 & 0 & 0 & 0 & 0 \\
Wilfrid Laurier_U & 1 & 0 & 2 & 2 & 2 & 2 \\
York_U & 0 & 0 & 0 & 0 & 0 & 0 \\
\hline
\end{tabular}

Note. Algoma was excluded from the sample because there was only one observation. 


\section{Appendix C: Testing for Heteroskedasticity}

Table 13.1.1.

Heteroskedasticity across Variables (Total Number of Enrolled Students)

\begin{tabular}{|c|c|c|c|c|c|}
\hline & & & & & $\begin{array}{l}\text { Number of obs }=142 \\
F(5,136)=250.17\end{array}$ \\
\hline Source & SS & df & MS & & $=0.0000$ \\
\hline Model & $3.43 \mathrm{E}+10$ & 5 & $6.85 \mathrm{E}+09$ & & R-squared \\
\hline$\underline{\text { Residual }}$ & $3.72 \mathrm{E}+09$ & 136 & 27382335 & & Adj R-squared $=0.8983$ \\
\hline Total & $3.80 \mathrm{E}+10$ & 141 & 269330609 & & Root MSE \\
\hline Enrolment & Coef. & Std. Err. & $\mathrm{t}$ & $\mathrm{P}>\mathrm{t}$ & [95\% Conf. \\
\hline Awards & 0.0928921 & 0.043041 & 2.16 & 0.033 & $0.0077759 \quad 0.1780083$ \\
\hline Marketing & -0.0249701 & 0.0151898 & -1.64 & 0.103 & -0.05500890 .0050687 \\
\hline Graduates & -0.0097987 & 0.0120724 & -0.81 & 0.418 & $-0.0336726 \quad 0.0140751$ \\
\hline Professors & 0.1439661 & 0.0177773 & 8.1 & 0.000 & $0.1088104 \quad 0.1791217$ \\
\hline Population & 0.0014628 & 0.0002404 & 6.09 & 0.000 & $0.0009875 \quad 0.0019381$ \\
\hline _cons & 3679.301 & 803.7896 & 4.58 & 0.000 & 5268.844 \\
\hline
\end{tabular}

Breusch-Pagan / Cook-Weisberg test for heteroskedasticity

Ho: Constant variance

Variables:Awards, Marketing, Graduates, Professors, Population

$\operatorname{chi} 2(5)=43.78$

Prob $>$ chi2 $=0.0000$

Note. The null hypothesis is the presence of homoscedasticity (constant variance), while the alternative is the presence of heteroskedasticity. Significance $(<0.05)$ allowed rejecting the null hypothesis and proved the presence of heteroskedasticity. 


\section{Table 13.1.2.}

Heteroskedasticity across Universities

Fixed-effects (within) regression

Group variable: University d

R-sq: within $=0.6436$

between $=0.5487$

overall $=0.5203$

$\operatorname{corr}\left(\mathrm{u} \_\mathrm{i}, \mathrm{Xb}\right)=0.1341$
Number of obs $=142$

Number of groups $=19$

Obs per group: $\min =\quad 6$

avg $=7.5$

$\max =8$

$\mathrm{F}(5,118)=42.62$

Prob $>\mathrm{F} \quad=0.0000$

\begin{tabular}{lcccccc}
\hline Enrolment & Coef. & Std. Err. & $\mathrm{t}$ & $\mathrm{P}>\mathrm{t}$ & [95\% Conf. & Interval] \\
\hline Awards & 0.0858044 & 0.013565 & 6.33 & 0.000 & 0.0589414 & 0.1126675 \\
Marketing & 0.0081541 & 0.00819 & 1 & 0.321 & -0.0080636 & 0.0243718 \\
Graduates & -0.0254113 & 0.006952 & -3.66 & 0.000 & -0.0391772 & -0.0116453 \\
Professors & 0.0197806 & 0.005247 & 3.77 & 0.000 & 0.00939 & 0.0301713 \\
Population & 0.0041871 & 0.001081 & 3.88 & 0.000 & 0.0020473 & 0.0063268 \\
_cons & 11920.31 & 1502.308 & 7.93 & 0.000 & 8945.33 & 14895.29 \\
\hline sigma_u & 11612.831 & & & & \\
sigma_e & 1020.754 & & & & \\
rho & 0.99233304 & (fraction of variance due to universities number) &
\end{tabular}

F test that all $\mathrm{u} \_\mathrm{i}=0: \quad \mathrm{F}(18,118)=192.01 \quad$ Prob $>\mathrm{F}=0.0000$

Modified Wald test for groupwise heteroskedasticity

in fixed effect regression model

H0: sigma(i $)^{\wedge} 2=\operatorname{sigma}^{\wedge} 2$ for all $\mathrm{i}$

chi2 $(19)=12430.77$

Prob $>$ chi2 $=0.0000$

Note. The null hypothesis is the presence of homoscedasticity (constant variance), while the alternative is the presence of heteroskedasticity. Significance $(<0.05)$ allowed rejecting the null hypothesis and proved the presence of heteroskedasticity. 
Table 13.2.1.

Heteroskedasticity across Variables: Total Number of Applications for Admission

\begin{tabular}{|c|c|c|c|c|c|}
\hline Source & SS & df & MS & & $\begin{array}{l}\text { Number of obs }=143 \\
F(5,137)=122.58\end{array}$ \\
\hline Model & $3.68 \mathrm{E}+10$ & 5 & $7.36 \mathrm{E}+09$ & & $=0.0000$ \\
\hline Residual & $8.23 \mathrm{E}+09$ & 137 & 60062023 & & R-squared \\
\hline \multirow[t]{2}{*}{ Total } & \multirow[t]{2}{*}{$4.50 \mathrm{E}+10$} & \multirow[t]{2}{*}{142} & \multirow[t]{2}{*}{317194000} & & Adj R-squared $=0.8106$ \\
\hline & & & & & Root MSE $=7750$ \\
\hline Applications & Coef. & Std. Err. & $\mathrm{t}$ & $\mathrm{P}>\mathrm{t}$ & [95\% Conf. \\
\hline Awards & 0.1675855 & 0.0637278 & 2.63 & 0.01 & 0.0415681 \\
\hline Marketing & 0.0475738 & 0.0224878 & 2.12 & 0.036 & 0.0031057 \\
\hline Graduates & -0.0921819 & 0.0178616 & -5.16 & 0.000 & $\begin{array}{ll}-0.1275019 & -0.0568619\end{array}$ \\
\hline Professors & 0.1519962 & 0.0263255 & 5.77 & 0.000 & $0.0999392 \quad 0.2040531$ \\
\hline Population & 0.0026155 & 0.0003556 & 7.36 & 0.000 & $0.0019124 \quad 0.0033187$ \\
\hline cons & 3440.458 & 1180.832 & 2.91 & 0.004 & 5775.473 \\
\hline
\end{tabular}

Breusch-Pagan / Cook-Weisberg test for heteroskedasticity

Ho: Constant variance

Variables: Awards, Marketing, Graduates, Professors, Populationa

$\operatorname{chi} 2(5)=202.77$

Prob $>$ chi2 $=0.0000$

Note. The null hypothesis is the presence of homoscedasticity (constant variance), while the alternative is the presence of heteroskedasticity. Significance $(<0.05)$ allowed rejecting the null hypothesis and proved the presence of heteroskedasticity. 


\section{Table 13.2.2. Heteroskedasticity across Universities}

Fixed-effects (within) regression

Group variable: University $\sim$

R-sq: within $=0.4059$

between $=0.7542$

overall $=0.7312$

$\operatorname{corr}\left(\mathrm{u} \_\mathrm{i}, \mathrm{Xb}\right)=0.5814$

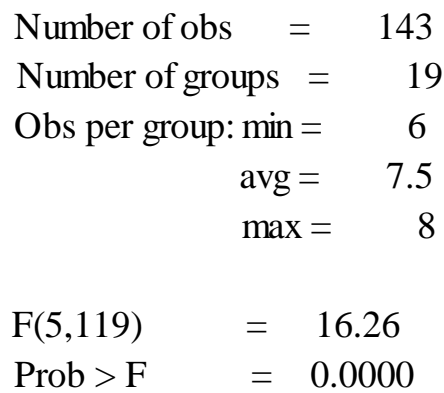

Number of obs $=143$

Prob $>\mathrm{F} \quad=0.0000$

\begin{tabular}{lcccccc}
\hline Applications & Coef. & Std. Err. & $\mathrm{t}$ & $\mathrm{P}>\mathrm{t}$ & [95\% Conf. & Interval] \\
\hline Awards & 0.0947335 & 0.0297244 & 3.19 & 0.002 & 0.0358761 & 0.1535908 \\
Marketing & 0.0087796 & 0.0179453 & 0.49 & 0.626 & -0.0267539 & 0.044313 \\
Graduates & 0.0059259 & 0.0152323 & 0.39 & 0.698 & -0.0242356 & 0.0360873 \\
Professors & 0.0318332 & 0.0114972 & 2.77 & 0.007 & 0.0090675 & 0.0545989 \\
Population & 0.0019723 & 0.0023677 & 0.83 & 0.406 & -0.0027159 & 0.0066605 \\
_cons & 15607.36 & 3269.811 & 4.77 & 0.000 & 9132.806 & 22081.91 \\
\hline sigma_u & 11199.035 & & & & \\
sigma_e & 2236.6939 & & & & \\
rho & 0.9616412 & (fraction of variance due to universities number) &
\end{tabular}

F test that all $u_{-} i=0: \quad F(18,119)=84.77 \quad$ Prob $>F=0.0000$

Modified Wald test for groupwise heteroskedasticity

in fixed effect regression model

$\mathrm{H} 0: \operatorname{sigma}(\mathrm{i})^{\wedge} 2=\operatorname{sigma}^{\wedge} 2$ for all $\mathrm{i}$

chi2 $(19)=34656.85$

Prob $>$ chi2 $=0.0000$

Note. The null hypothesis is the presence of homoscedasticity (constant variance), while the alternative is the presence of heteroskedasticity. Significance $(<0.05)$ allowed rejecting the null hypothesis and proved the presence of heteroskedasticity. 
Table 13.3.1.

Heteroskedasticity across Variables: Persistence Ratio

\begin{tabular}{|c|c|c|c|c|c|c|}
\hline Source & SS & df & MS & & \multicolumn{2}{|c|}{$\begin{array}{l}\text { Number of obs }=142 \\
F(5,136)=6.62\end{array}$} \\
\hline Model & 2.12494172 & 5 & 0.4249883 & & R-squared & $=0.1957$ \\
\hline Residual & 8.73341896 & 136 & 0.0642163 & & Adj R-square & $d=0.1661$ \\
\hline Total & 10.8583607 & 141 & 0.0770097 & & Root MSE & $=.25341$ \\
\hline Persistence Ratio & Coef. & Std. Err. & $\mathrm{t}$ & $\mathrm{P}>\mathrm{t}$ & [95\% Conf. & Interval] \\
\hline Awards & $-2.89 \mathrm{E}-06$ & $2.08 \mathrm{E}-06$ & -1.39 & 0.168 & $-7.01 \mathrm{E}-06$ & $1.23 \mathrm{E}-06$ \\
\hline Marketing & $-1.96 \mathrm{E}-06$ & $7.36 \mathrm{E}-07$ & -2.66 & 0.009 & $-3.41 \mathrm{E}-06$ & $-5.04 \mathrm{E}-07$ \\
\hline Graduates & $2.20 \mathrm{E}-06$ & $5.85 \mathrm{E}-07$ & 3.76 & 0.000 & $1.04 \mathrm{E}-06$ & $3.36 \mathrm{E}-06$ \\
\hline Professors & $-8.04 \mathrm{E}-07$ & 8.61E-07 & -0.93 & 0.352 & $-2.51 \mathrm{E}-06$ & 8.98E-07 \\
\hline Population & $-7.57 \mathrm{E}-10$ & $1.16 \mathrm{E}-08$ & -0.07 & 0.948 & $-2.38 \mathrm{E}-08$ & $2.23 \mathrm{E}-08$ \\
\hline ccons & 1.099344 & 0.0389251 & 28.24 & 0.000 & 1.022368 & 1.176321 \\
\hline
\end{tabular}

Breusch-Pagan / Cook-Weisberg test for heteroskedasticity

Ho: Constant variance

Variables: Awards, Marketing, Graduates, Professors, Population

$\operatorname{chi} 2(5)=46.83$

Prob $>$ chi2 $=0.0000$

Note. The null hypothesis is the presence of homoscedasticity (constant variance), while the alternative is the presence of heteroskedasticity. Significance $(<0.05)$ allowed rejecting the null hypothesis and proved the presence of heteroskedasticity. 


\section{Table 13.3.2.}

Heteroskedasticity across Universities

Fixed-effects (within) regression

Group variable: University d

R-sq: within $=0.0376$

between $=0.0011$

overall $=0.0020$

$\operatorname{corr}\left(u_{-}\right.$i, Xb) $=-0.7925$
Number of obs $=142$

Number of groups $=19$

Obs per group: $\min =\quad 6$

$\operatorname{avg}=7.5$

$\max =8$

$\mathrm{F}(5,118)=0.92$

Prob $>\mathrm{F} \quad=0.4693$

\begin{tabular}{lcccccc}
\hline Persistence Ratio & Coef. & Std. Err. & $\mathrm{t}$ & $\mathrm{P}>\mathrm{t}$ & [95\% Conf. & Interval] \\
\hline Awards & $-2.85 \mathrm{E}-07$ & $1.32 \mathrm{E}-06$ & -0.22 & 0.83 & $-2.91 \mathrm{E}-06$ & $2.34 \mathrm{E}-06$ \\
Marketing & $3.32 \mathrm{E}-07$ & $7.99 \mathrm{E}-07$ & 0.42 & 0.678 & $-1.25 \mathrm{E}-06$ & $1.92 \mathrm{E}-06$ \\
Graduates & $-1.11 \mathrm{E}-06$ & $6.79 \mathrm{E}-07$ & -1.63 & 0.105 & $-2.45 \mathrm{E}-06$ & $2.36 \mathrm{E}-07$ \\
Professors & $-1.24 \mathrm{E}-08$ & $5.12 \mathrm{E}-07$ & -0.02 & 0.981 & $-1.03 \mathrm{E}-06$ & $1.00 \mathrm{E}-06$ \\
Population & $1.76 \mathrm{E}-07$ & $1.05 \mathrm{E}-07$ & 1.66 & 0.099 & $-3.33 \mathrm{E}-08$ & $3.84 \mathrm{E}-07$ \\
_cons & 0.7388523 & 0.1466433 & 5.04 & 0.000 & 0.4484586 & 1.029246 \\
\hline sigma_u & 0.43640245 & & & & \\
sigma_e & 0.09963787 & & & & \\
rho & 0.95045432 & (fraction of variance due to universities number) & \\
\hline
\end{tabular}

F test that all $u \_i=0: \quad F(18,118)=42.32 \quad$ Prob $>F=0.0000$

Modified Wald test for groupwise heteroskedasticity

in fixed effect regression model

H0: $\operatorname{sigma}(i)^{\wedge} 2=\operatorname{sigma}^{\wedge} 2$ for all $\mathrm{i}$

$\operatorname{chi} 2(19)=1.3 \mathrm{e}+05$

Prob $>$ chi2 $=0.0000$

Note. The null hypothesis is the presence of homoscedasticity (constant variance), while the alternative is the presence of heteroskedasticity. Significance $(<0.05)$ allowed rejecting the null hypothesis and proved the presence of heteroskedasticity. 


\section{Appendix D: F-test, Breusch and Pagan LM Test, and Hausman Test}

\section{1a) F-test: Compares a Fixed Effect Model and a Pooled OLS Model (Total Number of Enrolled Students).}

Table 14.1.1. F-test: Compares a Fixed Effect Model and a Pooled OLS Model (Total Number of Enrolled Students)

\begin{tabular}{lccc}
\hline Source & SS & df & MS \\
\hline Model & $3.79 \mathrm{E}+10$ & 23 & $1.65 \mathrm{E}+09$ \\
Residual & 122948776 & 118 & 1041938.8 \\
\hline Total & $3.80 \mathrm{E}+10$ & 141 & 269330609
\end{tabular}

Number of obs $=142$

$\mathrm{F}(23,118)=1579.52$

Prob $>\mathrm{F}=0.0000$

R-squared $=0.9968$

Adj R-squared $=0.9961$

Root MSE $=1020.8$

\begin{tabular}{|c|c|c|c|c|c|c|}
\hline Total Number of Enrolled Students & Coef. & Std. Err. & $\mathrm{t}$ & $\mathrm{P}>|\mathrm{t}|$ & [95\% Conf. & Interval] \\
\hline Awards & 0.0858044 & 0.0135653 & 6.33 & 0.000 & 0.0589414 & 0.1126675 \\
\hline Marketing & 0.0081541 & 0.0081896 & 1 & 0.321 & -0.0080636 & 0.0243718 \\
\hline Graduates & -0.0254113 & 0.0069515 & -3.66 & 0.000 & -0.0391772 & -0.0116453 \\
\hline Professors & 0.0197806 & 0.0052471 & 3.77 & 0.000 & 0.00939 & 0.0301713 \\
\hline Population & 0.0041871 & 0.0010805 & 3.88 & 0.000 & 0.0020473 & 0.0063268 \\
\hline \multicolumn{7}{|l|}{ University_id } \\
\hline 2 & 839.4124 & 996.4283 & 0.84 & 0.401 & -1133.787 & 2812.612 \\
\hline 3 & -6997.371 & 587.8616 & -11.9 & 0.000 & -8161.497 & -5833.244 \\
\hline 4 & -6780.058 & 598.1488 & -11.34 & 0.000 & -7964.555 & -5595.56 \\
\hline 5 & 3266.645 & 1215.514 & 2.69 & 0.008 & 859.597 & 5673.693 \\
\hline 6 & -8910.445 & 640.0877 & -13.92 & 0.000 & -10177.99 & -7642.897 \\
\hline 7 & -33534.36 & 5783.624 & -5.8 & 0.000 & -44987.51 & -22081.21 \\
\hline 8 & -41.15077 & 778.7665 & -0.05 & 0.958 & -1583.32 & 1501.019 \\
\hline 9 & -11932.32 & 5610.352 & -2.13 & 0.036 & -23042.34 & -822.2936 \\
\hline 10 & -7200.992 & 604.2904 & -11.92 & 0.000 & -8397.651 & -6004.332 \\
\hline 11 & 4061.758 & 666.5589 & 6.09 & 0.000 & 2741.789 & 5381.726 \\
\hline 12 & -9355.111 & 563.2319 & -16.61 & 0.000 & -10470.46 & -8239.759 \\
\hline 13 & 11050.22 & 925.0565 & 11.95 & 0.000 & 9218.358 & 12882.09 \\
\hline 14 & 24971.39 & 4817.949 & 5.18 & 0.000 & 15430.54 & 34512.24 \\
\hline 15 & 6505.802 & 745.0286 & 8.73 & 0.000 & 5030.442 & 7981.161 \\
\hline 16 & -963.597 & 523.3139 & -1.84 & 0.068 & -1999.901 & 72.70696 \\
\hline 17 & 4148.617 & 743.1239 & 5.58 & 0.000 & 2677.03 & 5620.205 \\
\hline 18 & -1732.515 & 565.3047 & -3.06 & 0.003 & -2851.972 & -613.0577 \\
\hline 19 & 6713.276 & 5436.7 & 1.23 & 0.219 & -4052.87 & 17479.42 \\
\hline constant & 13221.42 & 545.2774 & 24.25 & 0.000 & 12141.62 & 14301.22 \\
\hline
\end{tabular}

( 1) 2. University_id $=0$
( 2) 3.University_id $=0$
( 3) 4.University_id $=0$
( 4) 5.University_id $=0$
( 5) 6.University_id $=0$
(6) 7.University_id $=0$
( 7) 8.University_id $=0$
( 8) 9.University_id $=0$
(9) 10.University_id $=0$
(10) 11.University_id $=0$
(11) 12.University_id $=0$
(12) 13.University_id $=0$
(13) 14.University_id $=0$
(14) 15.University_id $=0$
(15) 16.University_id $=0$
(16) 17.University_id $=0$
(17) 18.University_id $=0$
(18) 19.University_id $=0$

$\mathrm{F}(18,118)=192.01$

Prob $>\mathrm{F}=0.0000$

Note. Significant level (0.000) allows rejecting the null hypothesis of no Fixed effect. Therefore, Fixed Effect model is significant and is favorable over Pooled OLS model. 


\section{1b) Breusch and Pagan LM-Test: Compares Random Effect Model with Pooled OLS Model (Total Number of Enrolled Students)}

Table 14.1.2. LM-Test: Compares Random Effect Model with Pooled OLS Model (Total Number of Enrolled Students)

Breusch and Pagan Lagrangian multiplier test for random effects

Enrollement[University_id,t] $=\mathrm{Xb}+\mathrm{u}[$ University_id $]+\mathrm{e}[$ University_id,t]

Estimated results:

\begin{tabular}{lcc}
\hline & Var & sd = sqrt(Var) \\
\hline Enrolle $\mathrm{t}$ & $2.69 \mathrm{E}+08$ & 16411.3 \\
$\mathrm{e}$ & 1041939 & 1020.754 \\
$\mathrm{u}$ & $1.83 \mathrm{E}+07$ & 4276.351 \\
\hline
\end{tabular}

Test: $\operatorname{Var}(\mathrm{u})=0$

chibar2 $2(01)=175.63$

Prob $>$ chibar2 $=0.0000$

Note. Significant level (0.000) allows rejecting the null hypthesis that differences across universities do not exist. Significance $(<0.05)$ provides evidence that there are significant differences across universities. This makes the Random Effect model favourable over Pooled OLS model.

\section{1c) Hausman Test: Compares Fixed Effect Model with Random Effect Model (Total Number of Enrolled Students)}

Table 14.1.3. Hausman Test: Compares Fixed Effect Model with Random Effect Model (Total Number of Enrolled Student)

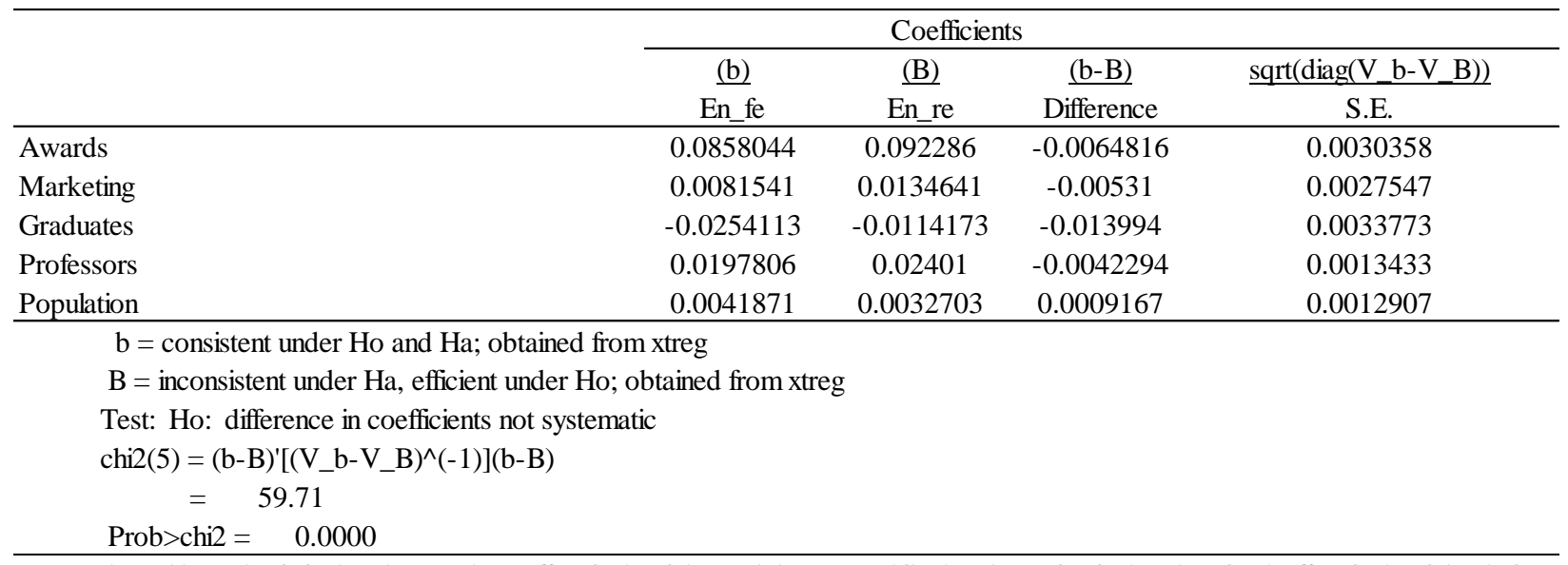

Note. The nul hypothesis is that the Random Effect is the right model to use, while the alternative is that the Fixed Effect is the right choice. Significant $(<0.05)$ allows rejecting the null hypothesis and suggests that Fixed Effect is the favourable model. 


\section{2.a) F-test: Compares a Fixed Effect model and a Pooled OLS (Total Number of Applications for Admission)}

Table 14.2.1. F-test: Compares a Fixed Effect model and a Pooled OLS (Total Number of Applications for Admission)

\begin{tabular}{|c|c|c|c|c|c|c|}
\hline Source & SS & df & MS & & \multicolumn{2}{|c|}{ Prob $>F=0.0000$} \\
\hline Model & $4.44 \mathrm{E}+10$ & 23 & $1.93 \mathrm{E}+09$ & & \multicolumn{2}{|c|}{$\mathrm{R}$-squared $=0.9868$} \\
\hline Residual & 595333174 & 119 & 5002799.8 & & \multicolumn{2}{|c|}{ Adj R-squared $=0.9842$} \\
\hline Total & $4.50 \mathrm{E}+10$ & 142 & 317194000 & & Root MSE & $=2236.7$ \\
\hline $\begin{array}{l}\text { Total Number of Applications for } \\
\text { Admission }\end{array}$ & Coef. & Std. Err. & $\mathrm{t}$ & $P>|t|$ & [95\% Conf. & Interval] \\
\hline Awards & 0.0947335 & 0.0297244 & 3.19 & 0.002 & 0.0358761 & 0.1535908 \\
\hline Marketing & 0.0087796 & 0.0179453 & 0.49 & 0.626 & -0.0267539 & 0.044313 \\
\hline Graduates & 0.0059259 & 0.0152323 & 0.39 & 0.698 & -0.0242356 & 0.0360873 \\
\hline Professors & 0.0318332 & 0.0114972 & 2.77 & 0.007 & 0.0090675 & 0.0545989 \\
\hline Population & 0.0019723 & 0.0023677 & 0.83 & 0.406 & -0.0027159 & 0.0066605 \\
\hline \multicolumn{7}{|l|}{ University_id } \\
\hline 2 & 1586.221 & 2183.39 & 0.73 & 0.469 & -2737.11 & 5909.552 \\
\hline 3 & -12191.18 & 1288.132 & -9.46 & 0.000 & -14741.81 & -9640.548 \\
\hline 4 & -10912.5 & 1310.674 & -8.33 & 0.000 & -13507.76 & -8317.234 \\
\hline 5 & 10126.61 & 2663.454 & 3.8 & 0 & 4852.704 & 15400.51 \\
\hline 6 & -12795.13 & 1359.776 & -9.41 & 0.000 & -15487.63 & -10102.64 \\
\hline 7 & -24726.98 & 12673.17 & -1.95 & 0.053 & -49821.13 & 367.1704 \\
\hline 8 & 476.6237 & 1706.447 & 0.28 & 0.78 & -2902.311 & 3855.559 \\
\hline 9 & 17730.14 & 12293.5 & 1.44 & 0.152 & -6612.215 & 42072.49 \\
\hline 10 & -9325.833 & 1324.131 & -7.04 & 0.000 & -11947.75 & -6703.921 \\
\hline 11 & 863.4358 & 1460.574 & 0.59 & 0.556 & -2028.647 & 3755.519 \\
\hline 12 & -8862.611 & 1234.161 & -7.18 & 0.000 & -11306.37 & -6418.849 \\
\hline 13 & 2621.007 & 2026.999 & 1.29 & 0.198 & -1392.654 & 6634.668 \\
\hline 14 & 10007.72 & 10557.17 & 0.95 & 0.345 & -10896.54 & 30911.97 \\
\hline 15 & 8520.583 & 1632.519 & 5.22 & 0.000 & 5288.032 & 11753.13 \\
\hline 16 & -6379.748 & 1146.694 & -5.56 & 0.000 & -8650.318 & -4109.179 \\
\hline 17 & 10742.44 & 1628.345 & 6.6 & 0.000 & 7518.154 & 13966.72 \\
\hline 18 & 1730.95 & 1238.705 & 1.4 & 0.165 & -721.8099 & 4183.711 \\
\hline 19 & 17052.43 & 11912.99 & 1.43 & 0.155 & -6536.482 & 40641.34 \\
\hline Constant & 15547.3 & 1194.819 & 13.01 & 0.000 & 13181.44 & 17913.16 \\
\hline
\end{tabular}

\footnotetext{
( 1) 2.University_id $=0$

(2) 3.University_id $=0$

(3) 4.University_id $=0$

(4) 5.University_id $=0$

(5) 6.University_id $=0$

(6) 7.University_id $=0$

(7) 8.University_id $=0$

(8) 9.University_id $=0$

(9) 10.University_id $=0$

(10) 11.University_id $=0$

(11) 12.University_id $=0$

(12) 13.University_id $=0$

(13) 14.University_id $=0$

(14) 15.University_id $=0$

(15) 16.University_id $=0$

(16) 17.University_id $=0$

(17) 18.University_id $=0$

(18) 19.University_id $=0$
}

$\mathrm{F}(18,119)=84.77$

Prob $>\mathrm{F}=0.0000$

Note. Significant level (0.000) allows rejecting the null hypothesis of no Fixed effect. Therefore, Fixed Effect model is significant and is favorable over Pooled OLS model. 


\section{2b) Breusch and Pagan LM-Test: Compares a Random Effect Model with Pooled OLS Model (Total Number of Applications for Admission)}

Table 14.2.2. LM-Test: Compares a Random Effect Model with Pooled OLS Model (Total Number of Applications for Admission)

Breusch and Pagan Lagrangian multiplier test for random effects

Application[University_id,t] $=\mathrm{Xb}+\mathrm{u}[$ University_id $]+\mathrm{e}[$ University_id,t $]$

Estimated results:

\begin{tabular}{lrr}
\hline & \multicolumn{1}{c}{ Var } & sd $=$ sqrt(Var) \\
\hline Applica n & $3.17 \mathrm{E}+08$ & 17809.94 \\
$\mathrm{e}$ & 5002800 & 2236.694 \\
$\mathrm{u}$ & $5.83 \mathrm{E}+07$ & 7633.017 \\
\hline
\end{tabular}

Test: $\operatorname{Var}(\mathrm{u})=0$

chibar2 $(01)=285.74$

Prob $>$ chibar2 $=0.0000$

Note. Significant level (0.000) allows rejecting the null hypthesis that differences across universities do not exist. Significance $(<0.05)$ provides evidence that there are significant differences across universities. This makes the Random Effect model favourable over Pooled OLS model.

\section{2c) Hausman Test: Compares Fixed Effect Model with Random Effect Model (Total Number of Applications for Admission)}

Table 14.2.3. Hausman Test: Compares Fixed Effect Model with Random Effect Model (Total Number of Applications for Admission)

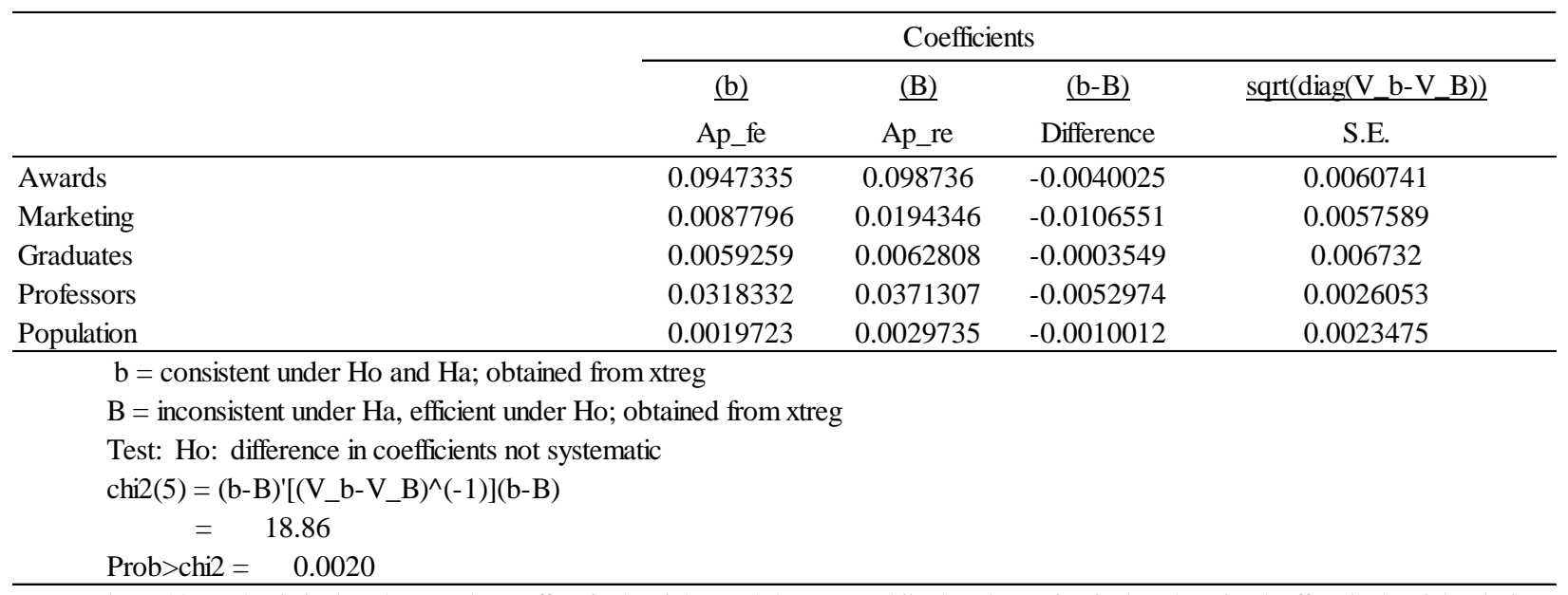

Note. The nul hypothesis is that the Random Effect is the right model to use, while the alternative is that the Fixed Effect is the right choice. Significant $(<0.05)$ allows rejecting the null hypothesis and suggests that Fixed Effect is the favourable model. 
3a) F-test: Compares a Fixed Effect Model and a Pooled OLS Model (Persistence Ratio).

Table 14.3.1. F-test: Compares a Fixed Effect Model and a Pooled OLS Model (Persistence)

\begin{tabular}{lccc} 
Source & SS & df & MS \\
\hline Model & 10.4863971 & 23 & 0.4559303 \\
Residual & 0.924007031 & 118 & 0.0078306 \\
\hline Total & 11.4104042 & 141 & 0.0809249
\end{tabular}

Number of obs $=142$

$\mathrm{F}(23,118)=58.22$

Prob $>\mathrm{F}=0.0000$

R-squared $=0.9190$

Adj R-squared $=0.9032$

Root MSE $=.08849$

\begin{tabular}{|c|c|c|c|c|c|c|c|}
\hline log Persistence Ratio & & Coef. & Std. Err. & $\mathrm{t}$ & $\mathrm{P}>\mathrm{t}$ & [95\% Conf. & Interval] \\
\hline $\log$ Award & & 0.1782645 & 0.0595883 & 2.99 & 0.003 & 0.0602634 & 0.2962656 \\
\hline log Marketing & & 0.0526387 & 0.034115 & 1.54 & 0.126 & -0.0149183 & 0.1201958 \\
\hline log Research & & -0.0275735 & 0.0212176 & -1.3 & 0.196 & -0.0695902 & 0.0144432 \\
\hline $\log$ Professors & & -0.012317 & 0.0365499 & -0.34 & 0.737 & -0.0846957 & 0.0600617 \\
\hline log Population & & -0.6501324 & 0.4458768 & -1.46 & 0.147 & -1.53309 & 0.2328251 \\
\hline \multicolumn{8}{|l|}{ University_id } \\
\hline & 2 & 0.6253967 & 0.473691 & 1.32 & 0.189 & -0.3126405 & 1.563434 \\
\hline & 3 & -0.1373423 & 0.5042296 & -0.27 & 0.786 & -1.135854 & 0.8611695 \\
\hline & 4 & -0.1873127 & 0.3871905 & -0.48 & 0.629 & -0.9540552 & 0.5794299 \\
\hline & 5 & -0.1019983 & 0.2353804 & -0.43 & 0.666 & -0.5681156 & 0.3641191 \\
\hline & 6 & -0.7666311 & 0.7995529 & -0.96 & 0.34 & -2.349963 & 0.8167012 \\
\hline & 7 & 2.617881 & 1.256548 & 2.08 & 0.039 & 0.1295734 & 5.106189 \\
\hline & 8 & -0.9425717 & 0.459681 & -2.05 & 0.043 & -1.852865 & -0.0322782 \\
\hline & 9 & 1.266455 & 1.164923 & 1.09 & 0.279 & -1.040411 & 3.57332 \\
\hline & 10 & -0.600537 & 0.5226037 & -1.15 & 0.253 & -1.635435 & 0.4343606 \\
\hline & 11 & -0.6683707 & 0.486682 & -1.37 & 0.172 & -1.632134 & 0.2953922 \\
\hline & 12 & -0.0324045 & 0.0749201 & -0.43 & 0.666 & -0.1807668 & 0.1159578 \\
\hline & 13 & 0.7488997 & 0.4547654 & 1.65 & 0.102 & -0.1516597 & 1.649459 \\
\hline & 14 & 1.614435 & 1.092106 & 1.48 & 0.142 & -0.5482333 & 3.777103 \\
\hline & 15 & -0.2240801 & 0.0771824 & -2.9 & 0.004 & -0.3769223 & -0.0712379 \\
\hline & 16 & 0.1699671 & 0.1041823 & 1.63 & 0.105 & -0.0363422 & 0.3762763 \\
\hline & 17 & -0.3962094 & 0.0750857 & -5.28 & 0 & -0.5448995 & -0.2475193 \\
\hline & 18 & -0.0830319 & 0.101782 & -0.82 & 0.416 & -0.284588 & 0.1185241 \\
\hline & 19 & 1.554132 & 1.124668 & 1.38 & 0.17 & -0.6730164 & 3.781281 \\
\hline _cons & & 6.452522 & 5.390279 & 1.2 & 0.234 & -4.221698 & 17.12674 \\
\hline
\end{tabular}

(1) 2.University_id $=0$

(2) 3.University_id $=0$

(3) 4.University_id $=0$

(4) 5.University_id $=0$

(5) 6.University_id $=0$

(6) 7.University_id $=0$

(7) 8.University_id $=0$

(8) 9.University_id $=0$

(9) 10.University_id $=0$

(10) 11.University_id $=0$

(11) 12.University_id $=0$

(12) 13.University_id $=0$

(13) 14.University_id $=0$

(14) 15.University_id $=0$

(15) 16 .University_id $=0$

(16) 17.University_id $=0$

(17) 18.University_id $=0$

(18) 19.University_id $=0$

$\mathrm{F}(18,118)=52.49$

Prob $>$ F $=0.0000$

Note. Significant level (0.000) allows rejecting the null hypothesis of no Fixed effect. Therefore, Fixed Effect model is significant and is favorable over Pooled OLS model. 


\section{3b) Breusch and Pagan LM-Test: Compares a Random Effect Model with Pooled OLS Model (Persistence)}

Table 14.3.2.

\section{LM-Test: Compares a Random Effect Model with Pooled OLS Model (Persistence Ratio)}

Breusch and Pagan Lagrangian multiplier test for random effects

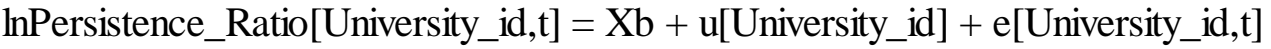

Estimated results:

\begin{tabular}{lcc}
\hline & Var & sd = sqrt(Var) \\
\hline Enrolle $\sim \mathrm{t}$ & $8.09 \mathrm{E}-02$ & 0.2844729 \\
$\mathrm{e}$ & 0.0078306 & 0.884905 \\
$\mathrm{u}$ & $6.18 \mathrm{E}-02$ & 0.2485885 \\
\hline
\end{tabular}

Test: $\operatorname{Var}(\mathrm{u})=0$

chibar2 $(01)=299.99$

Prob $>$ chibar $2=0.0000$

Note. Significant level $(0.000)$ allows rejecting the null hypthesis that differences across universities do not exist. Significance $(<0.05)$ provides evidence that there are significant differences across universities. This makes the Random Effect model favourable over Pooled OLS model.

3c) Hausman Test: Compares Fixed Effect Model with Random Effect Model (Persistence Ratio)

Table 14.3.3.

Hausman Test: Compares Fixed Effect Model with Random Effect Model (Persistence Ratio)

\begin{tabular}{|c|c|c|c|c|}
\hline & \multicolumn{4}{|c|}{ Coefficients } \\
\hline & (b) & (B) & $\underline{(b-B)}$ & $\underline{\operatorname{sqrt}\left(\operatorname{diag}\left(\mathrm{V} \_b-V \_B\right)\right)}$ \\
\hline & Ap_fe & Ap_re & Difference & S.E. \\
\hline log Award & 0.1782645 & 0.1082913 & 0.0699732 & 0.0378003 \\
\hline log Marketing & 0.0526387 & 0.0221083 & 0.0305305 & 0.0121502 \\
\hline $\log$ Research & -0.0275735 & -0.0396369 & 0.0120634 & 0.0167949 \\
\hline $\log$ Professors & -0.012317 & -0.0103631 & -0.0019539 & 0.0072772 \\
\hline log Population & -0.6501324 & -0.0114043 & -0.6387281 & 0.4624053 \\
\hline \multicolumn{5}{|c|}{$\mathrm{b}=$ consistent under $\mathrm{Ho}$ and $\mathrm{Ha}$; obtained from $\mathrm{xtreg}$} \\
\hline \multicolumn{5}{|c|}{$\mathrm{B}=$ inconsistent under $\mathrm{Ha}$, efficient under Ho; obtained from xtreg } \\
\hline \multicolumn{5}{|c|}{ Test: Ho: difference in coefficients not systematic } \\
\hline \multicolumn{5}{|c|}{$\operatorname{chi} 2(5)=(b-B)^{\prime}\left[\left(V \_b-V \_B\right)^{\wedge}(-1)\right](b-B)$} \\
\hline \multicolumn{5}{|l|}{$=15.38$} \\
\hline Prob $>$ chi $2=0.0089$ & & & & \\
\hline
\end{tabular}

Note. The nul hypothesis is that the Random Effect is the right model to use, while the alternative is that the Fixed Effect is the right choice. Significant $(<0.05)$ allows rejecting the null hypothesis and suggests that Fixed Effect is the favourable model. 


\section{Appendix E: Data Analysis - Total Number of Enrolled Students (All Universities; Lagged}

\section{Model)}

In the Lagged models that follow, the (natural logarithm of the) total number of enrollees in the current year $(\mathrm{t})$ is linked with the (natural logarithms of the) various categories of expenditure in the previous year (t-1) as well as the (natural logarithm of the) population in the current year $(\mathrm{t})$. The Lagged model was used because potential enrollees might not fully anticipate current year expenditures and might not be able to respond immediately. It is not uncommon to assume that enrolment in the current year $(\mathrm{t})$ depends on categories of expenditure of the previous year $(\mathrm{t}-1)$. Indeed, the use of competitive activities by universities in the previous year has the potential to affect demanders' behaviour in the current year. In fact, if potential students who are convinced by promotional activities of a university apply for admission, it would take them almost a year to get admitted and enroll in a program. Thus, using lagged variables would be the right choice due to the "lagged" effect of the variables. Models without lags generated similar results as reported in the section on robustness checks later in the Appendix.

Table 7 1.1.

Pooled OLS Model for Total Number of Enrolled Students

Linear regression $\quad$ Number of obs $=142$

$\mathrm{F}(6,135)=712.88$

Prob $>\mathrm{F}=0.0000$

R-squared $=0.9455$

Root MSE $=.18595$

\begin{tabular}{lcccccc}
\hline \multicolumn{1}{c}{ Log Enrollees } & Coef. & Robust Std. Err. & $\mathrm{t}$ & $\mathrm{P}>|\mathrm{t}|$ & [95\% Conf. & Interval] \\
\hline Log Awards (t-1) & 0.410237 & 0.061250 & 6.7 & 0.000 & 0.2891038 & 0.531370 \\
Log Marketing (t-1) & 0.051935 & 0.023585 & 2.2 & 0.029 & 0.0052908 & 0.098579 \\
Log Graduates (t-1) & -0.015324 & 0.003936 & -3.89 & 0.000 & -0.0231075 & -0.0075396 \\
Log Professors (t-1) & 0.217524 & 0.078869 & 2.76 & 0.007 & 0.0615466 & 0.373502 \\
Log Population (t) & 0.121574 & 0.016646 & 7.3 & 0.000 & 0.0886535 & 0.154495 \\
Trend & -0.02855 & 0.0069647 & -4.1 & 0.000 & -0.0423241 & -0.0147759 \\
Constant & 1.443172 & 0.2895723 & 4.98 & 0.000 & 0.8704876 & 2.015857 \\
\hline
\end{tabular}

Note. Independent variables are lagged by one year $(\mathrm{t}-1)$. Population is an unlagged variable $(\mathrm{t})$.

Robust standard errors are reported in the table. 
Table 7.1.2.

Fixed Effect (LSDV) Model for Total Number of Enrolled Students

Linear regression

Number of obs $=142$
$F(24, \quad 117)=2160.09$
Prob $>F=0.0000$
R-squared $=0.9961$
Root MSE $=.05329$

\begin{tabular}{lcccccc}
\hline \multicolumn{1}{c}{ Log Enrollees } & Coef. & Robust Std. Err. & $\mathrm{t}$ & $\mathrm{P}>|\mathrm{t}|$ & {$[95 \%$ Conf. } & Interval] \\
\hline Log Awards (t-1) & 0.3274664 & 0.0621802 & 5.27 & 0.000 & 0.2043218 & 0.4506111 \\
Log Marketing (t-1) & 0.0600104 & 0.020093 & 2.99 & 0.003 & 0.0202172 & 0.0998036 \\
Log Graduates (t-1) & 0.0091418 & 0.011295 & 0.81 & 0.42 & -0.0132274 & 0.0315109 \\
Log Professors (t-1) & 0.0471064 & 0.0482035 & 0.98 & 0.33 & -0.048358 & 0.1425709 \\
Log Population(t) & 1.080964 & 0.3241873 & 3.33 & 0.001 & 0.4389277 & 1.723 \\
U_Toronto & (omitted) & & & & & \\
Brock_U & 2.376803 & 0.8303431 & 2.86 & 0.005 & 0.7323521 & 4.021254 \\
Carleton_U & 1.143378 & 0.4755144 & 2.4 & 0.018 & 0.2016464 & 2.085109 \\
Lakehead_U & 3.107288 & 1.200543 & 2.59 & 0.011 & 0.7296753 & 5.4849 \\
Laurentian_U & 2.888898 & 1.108875 & 2.61 & 0.010 & 0.6928285 & 5.084967 \\
McMaster_U & 1.577523 & 0.6408204 & 2.46 & 0.015 & 0.3084114 & 2.846634 \\
Nipissing_U & 3.999261 & 1.378749 & 2.9 & 0.004 & 1.268721 & 6.729802 \\
OCAD_U & -1.112785 & 0.3327942 & -3.34 & 0.001 & -1.771867 & -0.4537038 \\
Queens_U & 2.957848 & 1.132946 & 2.61 & 0.01 & 0.7141066 & 5.201589 \\
Ryerson_U & -0.1239312 & 0.1552894 & -0.8 & 0.426 & -0.4314737 & 0.1836113 \\
Trent_U & 3.108048 & 1.213758 & 2.56 & 0.012 & 0.7042633 & 5.511832 \\
U_Guelph & 3.440905 & 1.16311 & 2.96 & 0.004 & 1.137426 & 5.744384 \\
UOIT_U & 2.045683 & 0.8675314 & 2.36 & 0.020 & 0.3275829 & 3.763784 \\
U_Ottawa & 1.285741 & 0.4786867 & 2.69 & 0.008 & 0.3377269 & 2.233755 \\
U_Waterloo & 2.084566 & 0.778846 & 2.68 & 0.009 & 0.5421024 & 3.62703 \\
U_Windsor & 2.456484 & 0.8989581 & 2.73 & 0.007 & 0.6761447 & 4.236823 \\
Western_U & 1.988012 & 0.7789403 & 2.55 & 0.012 & 0.4453618 & 3.530663 \\
Wilfrid_U & 2.097024 & 0.7665694 & 2.74 & 0.007 & 0.5788732 & 3.615174 \\
York_U & 0.0551483 & 0.0760114 & 0.73 & 0.47 & -0.0953883 & 0.2056849 \\
Trend & -0.0178979 & 0.0063481 & -2.82 & 0.006 & -0.03047 & -0.0053257 \\
Constant & -10.77106 & 4.916223 & -2.19 & 0.030 & -20.50739 & -1.034741 \\
\hline Not.Uwnst & & & & &
\end{tabular}

Note. Uuniversity of Toronto is the base.

Independent variables are lagged by one year $(\mathrm{t}-1)$. Population is an unlagged variable $(\mathrm{t})$.

Robust standard errors are reported in the table. 
Table 7.1.3.

Random Effect Model for Total Number of Enrolled Students

Random-effects GLS regression
Group variable: University $\sim$ d

R-sq: within $=0.7527$

between $=0.9347$

overall $=0.9295$

corr(u_i, X) $=0$ (assumed) $\begin{array}{rc}\text { Number of obs }= & 142 \\ \text { Number of groups }= & 19 \\ \text { Obs per group: } \min = & 6 \\ \text { avg }= & 7.5 \\ \max = & 8\end{array}$

Wald chi2(6) $=367.25$

Prob $>$ chi $2=0.0000$

(Std. Err. adjusted for 19 clusters in University_id)

\begin{tabular}{lcccccc}
\hline \multicolumn{1}{c}{ Log Enrollees } & Coef. & Robust Std. Err. & $\mathrm{z}$ & $\mathrm{P}>|\mathrm{z}|$ & {$[95 \%$ Conf. } & Interval] \\
\hline Log Awards (t-1) & 0.396849 & 0.062812 & 6.32 & 0.000 & 0.273739 & 0.519958 \\
Log Marketing (t-1) & 0.062229 & 0.026419 & 2.36 & 0.018 & 0.010449 & 0.114010 \\
Log Graduates (t-1) & 0.006093 & 0.011269 & 0.54 & 0.589 & -0.0159931 & 0.028179 \\
Log Professors (t-1) & 0.053432 & 0.060730 & 0.88 & 0.379 & -0.065597 & 0.172460 \\
Log Population (t) & 0.142460 & 0.060569 & 2.35 & 0.019 & 0.023748 & 0.261173 \\
Trend & -0.015451 & 0.005755 & -2.68 & 0.007 & -0.026730 & -0.004172 \\
Constant & 2.77894 & 0.7101763 & 3.91 & 0.000 & 1.38702 & 4.170861 \\
\hline sigma_u & 0.20335841 & & & & & \\
sigma_e & 0.05328827 & & & & \\
rho & 0.93574644 & (fraction of variance due to universities number) & & \\
\hline
\end{tabular}

Note. Independent variables are lagged by one year $(\mathrm{t}-1)$. Population is an unlagged variable $(\mathrm{t})$.

Robust standard errors are reported in the table.

Note. Each of the above regressions was run with robust standard effects because of the heteroskedasticity (Appendix C). Consequently, results reported throughout the thesis arise from running regressions with robust standard errors. Regressions with robust standard errors and without robust standard errors are summarized in Table 7.1.4. 
Table 7.1.4.

Summary Results from Pooled OLS, Fixed Effect (OLDV), and Random Effect Regressions with Robust Standard Errors and without Robust Standard Errors for Total Number of Enrolled Students.

\begin{tabular}{|c|c|c|c|c|c|c|c|c|c|}
\hline \multirow[b]{3}{*}{ Independent Variable } & \multicolumn{8}{|c|}{ Dependent Variable: Log Enrollees } & \\
\hline & \multicolumn{3}{|c|}{ Pooled OLS } & \multicolumn{3}{|c|}{ Fixed Effect LSDV } & \multicolumn{3}{|c|}{ Random Effect } \\
\hline & Coef. & $\begin{array}{c}\text { Non_Robust } \\
\text { Std. s } \\
\end{array}$ & $\begin{array}{l}\text { Robust } \\
\text { Std. s }\end{array}$ & Coef. & $\begin{array}{c}\text { Non_Robust } \\
\text { Std. s } \\
\end{array}$ & $\begin{array}{l}\text { Robust } \\
\text { Std. s } \\
\end{array}$ & Coef. & $\begin{array}{c}\text { Non_Robust } \\
\text { Std. s }\end{array}$ & $\begin{array}{c}\text { Robust } \\
\text { Std. s } \\
\end{array}$ \\
\hline Log Awards (t-1) & 0.410237 & $(0.050764)$ & $(0.061250)$ & 0.327466 & $(0.038711)$ & $(0.062180)$ & 0.396848 & $(0.035142)$ & $(0.062812)$ \\
\hline Log Marketing (t-1) & 0.051935 & $(0.025054)$ & $(0.023585)$ & 0.06001 & $(0.020545)$ & $(0.020093)$ & 0.062229 & $(0.020734)$ & $(0.026419)$ \\
\hline Log Graduates (t-1) & -0.015324 & $(0.006115)$ & $(0.003936)$ & 0.009142 & $(0.013008)$ & $(0.011295)$ & 0.006093 & $(0.010361)$ & $(0.011269)$ \\
\hline Log Professors (t-1) & 0.217524 & $(0.063584)$ & $(0.078868)$ & 0.047106 & $(0.023262)$ & $(0.048203)$ & 0.053431 & $(0.023987)$ & $(0.060730)$ \\
\hline Log Population (t) & 0.121574 & $(0.013142)$ & $(0.016646)$ & 1.080964 & $(0.326117)$ & $(0.324187)$ & 0.142460 & $(0.036989)$ & $(0.060569)$ \\
\hline Trend & -0.028550 & $(0.007174)$ & $(0.006965)$ & -0.017898 & $(0.004361)$ & $(0.006348)$ & -0.015451 & $(0.003266)$ & $(0.005755)$ \\
\hline Constant & 1.443172 & $(0.290031)$ & $(0.289572)$ & -10.771064 & (4.978948) & (4.916223) & 2.77894 & $(0.529729)$ & $(0.710176)$ \\
\hline U_Toronto & & & & (omitted) & & & & & \\
\hline Brock_U & & & & 2.376803 & $(0.84)$ & $(0.83)$ & & & \\
\hline Carleton_U & & & & 1.143378 & $(0.48)$ & $(0.48)$ & & & \\
\hline Lakehead_U & & & & 3.107288 & $(1.22)$ & $(1.20)$ & & & \\
\hline Laurentian_U & & & & 2.888898 & (1.13) & (1.11) & & & \\
\hline McMaster_U & & & & 1.577523 & $(0.66)$ & $(0.64)$ & & & \\
\hline Nipissing_U & & & & 3.999261 & (1.41) & (1.38) & & & \\
\hline OCAD_U & & & & -1.112785 & $(0.16)$ & $(0.33)$ & & & \\
\hline Queens_U & & & & 2.957848 & (1.15) & (1.13) & & & \\
\hline Ryerson_U & & & & -0.123931 & $(0.08)$ & $(0.16)$ & & & \\
\hline Trent_U & & & & 3.108048 & (1.23) & $(1.21)$ & & & \\
\hline U_Guelph & & & & 3.440905 & (1.18) & (1.16) & & & \\
\hline UOIT_U & & & & 2.045683 & $(0.88)$ & $(0.87)$ & & & \\
\hline U_Ottawa & & & & 1.285741 & $(0.49)$ & $(0.48)$ & & & \\
\hline U_Waterloo & & & & 2.084566 & $(0.79)$ & $(0.78)$ & & & \\
\hline U_Windsor & & & & 2.456484 & $(0.91)$ & $(0.90)$ & & & \\
\hline Western_U & & & & 1.988012 & $(0.79)$ & $(0.78)$ & & & \\
\hline Wilfrid_U & & & & 2.097024 & $(0.78)$ & $(0.77)$ & & & \\
\hline York_U & & & & 0.055148 & $(0.05)$ & $(0.08)$ & & & \\
\hline No. of Obs. & 142 & & & 142 & & & 142 & & \\
\hline R-Squared & 0.95 & & & 0.996 & & & 0.93 & & \\
\hline
\end{tabular}

Note. Robust and Non-Robust Standard errors are in parentheses.

Uuniversity of Toronto is the base.

Independent variables are lagged by one year $(\mathrm{t}-1)$. Population is an unlagged variable $(\mathrm{t})$. 


\section{Table 7.2.1.}

Fixed Effect (a modified Fixed Effect regression): Enrollees

To explore the variation across universities, a modified Fixed Effect regression was conducted for each individual university. As well as the baseline effects (coefficients) for awards, marketing, graduates, professors, and population, which are applicable to all universities, each regression introduced an additional effect (coefficient) for each of the variables. These additional effects capture whether a variable has a weaker or stronger effect for the particular university relative to other universities.

Fixed Effect (a modified Fixed Effect) regressions were initially run with robust standard errors

\begin{tabular}{|c|c|c|c|c|c|c|}
\hline \multirow[b]{2}{*}{ Variables } & \multicolumn{6}{|c|}{ Fixed Effect (a modified Fixed Effect regression ) : Enrollees } \\
\hline & Brock_U & Carleton_U & Lakehead_U & Laurentian_U & McMaster_U & Nipissing_U \\
\hline \multicolumn{7}{|l|}{ Awards } \\
\hline Baseline Effect (Estimated) & $0.335455^{* * *}$ & $0.324813^{* * *}$ & $0.337030 * * *$ & $0.294901 * * *$ & $0.341047 * * *$ & $0.326548 * * *$ \\
\hline Additional Effect (Estimated) & $-0.301436 * *$ & $-0.497753 * * *$ & $-0.673856 * * *$ & $0.624055^{* * *}$ & -0.177671 & $-0.162725^{*}$ \\
\hline Overall Effect (Calculated) & 0.0340144 & -0.1729838 & $-0.336829 * * *$ & $0.918959 * * *$ & 0.1633442 & $0.163848 * * *$ \\
\hline \multicolumn{7}{|l|}{ Marketing } \\
\hline Baseline Effect (Estimated) & $0.060780 * * *$ & $0.061210 * * *$ & $0.055985^{* * *}$ & $0.058814^{* * *}$ & $0.065237 * * *$ & $0.062560 * * *$ \\
\hline Additional Effect (Estimated) & $-0.187899 * *$ & -0.011092 & $0.272045^{* * *}$ & $0.487951 * * *$ & $-0.107369 * * *$ & $1.098854^{* * *}$ \\
\hline Overall Effect (Calculated) & -0.1271273 & $0.050119 * * *$ & $0.328030 * * *$ & $0.546770 * * *$ & $-0.042130 * *$ & $1.161355^{* * *}$ \\
\hline \multicolumn{7}{|l|}{ Graduates } \\
\hline Baseline Effect (Estimated) & 0.007922 & 0.010291 & 0.000077 & $0.065873 * *$ & 0.008261 & 0.009477 \\
\hline Additional Effect (Estimated) & -0.021967 & $-0.147147 * *$ & $0.371863 * * *$ & $-0.095051 * * *$ & $-0.237429 * * *$ & omitted \\
\hline Overall Effect (Calculated) & -0.0140514 & $-0.136876 *$ & $0.371939 * * *$ & $-0.029179 * * *$ & $-0.229164 * *$ & $\ldots$ \\
\hline \multicolumn{7}{|l|}{ Professors } \\
\hline Baseline Effect (Estimated) & 0.046192 & 0.045497 & 0.050877 & 0.03894 & 0.040817 & 0.049633 \\
\hline Additional Effect (Estimated) & $0.228352^{*}$ & $-0.780108^{*}$ & 0.059207 & $-1.371854^{* * *}$ & 0.014535 & $-3.178117^{* * *}$ \\
\hline Overall Effect (Calculated) & $0.274550 * *$ & $-0.734527^{*}$ & 0.1100858 & $-1.332927^{* * *}$ & 0.0553536 & $-3.128422 * * *$ \\
\hline \multicolumn{7}{|l|}{ Population } \\
\hline Baseline Effect (Estimated) & $0.904969 * *$ & $1.190718^{* * *}$ & $1.487049 * * *$ & $1.125959 * * *$ & $1.095043^{* * *}$ & $1.070435^{* * *}$ \\
\hline Additional Effect (Estimated) & $14.024738 * * *$ & $5.740965^{* * *}$ & -0.635705 & 0 & $4.566495 * * *$ & $21.271785^{* * *}$ \\
\hline Overall Effect (Calculated) & $14.930688 * * *$ & $6.931670 * * *$ & 0.8513048 & 1.125959 & $5.661661 * * *$ & $22.341874 * * *$ \\
\hline $\mathrm{N}$ & 142 & 142 & 142 & 142 & 142 & 142 \\
\hline $\mathrm{R} 2$ & 0.9963 & 0.9962 & 0.9964 & 0.9964 & 0.9963 & 0.9964 \\
\hline
\end{tabular}

Note: Constant, trend and fixed-effect coefficients omitted for brevity.

Expenditure on Graduates at Nipissing University remains constant over time and is thus perfectly co-linear with the dummy variable $* \mathrm{p}<0.10, * * \mathrm{p}<0.05, * * * \mathrm{p}<0.01$ 


\begin{tabular}{|c|c|c|c|c|c|c|}
\hline \multirow[b]{2}{*}{ Variables } & \multicolumn{6}{|c|}{ Fixed Effect (a modified Fixed Effect regression ) : Enrollees } \\
\hline & OCAD_U & Queen's_U & Ryerson_U & Trent_U & U_Guelph & UOIT \\
\hline \multicolumn{7}{|l|}{ Awards } \\
\hline Baseline Effect (Estimated) & $0.343090 * * *$ & $0.342363 * * *$ & $0.349987^{* * *}$ & $0.325350 * * *$ & $0.327723 * * *$ & $0.178261 * * *$ \\
\hline Additional Effect (Estimated) & $-0.147812^{*}$ & $-0.383554 * * *$ & $-0.218917 * * *$ & -0.856369 & $-1.457145^{* * *}$ & 0.17751 \\
\hline Overall Effect (Calculated) & $0.195278 * * *$ & $-0.041189 *$ & $0.131070 * * *$ & -0.5310373 & $-1.129462 * * *$ & 0.3558453 \\
\hline \multicolumn{7}{|l|}{ Marketing } \\
\hline Baseline Effect (Estimated) & $0.051518^{* *}$ & $0.053759 * *$ & $0.054695 * * *$ & $0.053117 * * *$ & $0.061694 * * *$ & 0.024597 \\
\hline Additional Effect (Estimated) & -0.096567 & $-0.061525 * * *$ & 0.023159 & -0.134688 & -0.09295 & $-0.119009 * *$ \\
\hline Overall Effect (Calculated) & -0.0450194 & -0.007765 & $0.077852 * * *$ & -0.0815685 & -0.0312508 & $-0.094418^{*}$ \\
\hline \multicolumn{7}{|l|}{ Graduates } \\
\hline Baseline Effect (Estimated) & 0.008069 & 0.011804 & 0.006633 & 0.013811 & 0.009217 & -0.007465 \\
\hline Additional Effect (Estimated) & 0.11024 & -0.007898 & 0.083372 & -0.082766 & $0.812901 * * *$ & $-0.064613 * *$ \\
\hline Overall Effect (Calculated) & 0.118276 & 0.003908 & $0.090005^{*}$ & -0.0689424 & $0.822125^{* * *}$ & $-0.072080 * *$ \\
\hline \multicolumn{7}{|l|}{ Professors } \\
\hline Baseline Effect (Estimated) & 0.043079 & 0.048441 & 0.042452 & 0.040743 & 0.045575 & 0.012912 \\
\hline Additional Effect (Estimated) & 0.228063 & 0.017381 & $0.138587 *$ & 0.211869 & $0.479283 * *$ & $0.401083^{* * *}$ \\
\hline Overall Effect (Calculated) & 0.2712008 & 0.0658439 & $0.181042 * *$ & 0.2526089 & $0.524922 * *$ & $0.413973 * * *$ \\
\hline \multicolumn{7}{|l|}{ Population } \\
\hline Baseline Effect (Estimated) & $0.946251^{* * *}$ & $1.050321 * * *$ & $1.121988^{* * *}$ & $0.883597 * * *$ & $1.077743^{* * *}$ & $1.223039 * * *$ \\
\hline Additional Effect (Estimated) & 0.792687 & $4.262499 * * *$ & 0 & 0 & $3.027466^{* *}$ & -0.403719 \\
\hline Overall Effect (Calculated) & 1.7384305 & $5.312754 * * *$ & 1.121988 & 0.883597 & $4.105126^{* *}$ & 0.8183144 \\
\hline $\mathrm{N}$ & 142 & 142 & 142 & 142 & 142 & 142 \\
\hline $\mathrm{R} 2$ & 0.9963 & 0.9963 & 0.9962 & 0.9965 & 0.9963 & 0.9973 \\
\hline
\end{tabular}

Note: Constant, trend and fixed-effect coefficients omitted for brevity.

$* p<0.10, * * p<0.05, * * * p<0.01$

\begin{tabular}{|c|c|c|c|c|c|c|c|}
\hline \multirow[b]{2}{*}{ Variables } & \multicolumn{7}{|c|}{ Fixed Effect (a modified Fixed Effect regression ) : Enrollees } \\
\hline & U_Ottawa & U_Toronto & U_Waterloo & U_Windsor & Western_U & Wilfrid_U & York_U \\
\hline \multicolumn{8}{|l|}{ Awards } \\
\hline Baseline Effect (Estimated) & $0.328619 * * *$ & $0.304623^{* * *}$ & $0.373406 * * *$ & $0.328682 * * *$ & $0.230030 * * *$ & $0.317212^{* * *}$ & $0.323067^{* * *}$ \\
\hline Additional Effect (Estimated) & $-0.194183^{* * *}$ & $-0.420940 * * *$ & $-0.328239 * * *$ & 0.120712 & -0.226363 & $-0.804555 * * *$ & $-0.289628 * * *$ \\
\hline Overall Effect (Calculated) & $0.134435^{* * *}$ & $-0.116314^{* * *}$ & $0.045165^{* * *}$ & $0.449412 * * *$ & 0.0036891 & $-0.487344 * * *$ & 0.0334491 \\
\hline \multicolumn{8}{|l|}{ Marketing } \\
\hline Baseline Effect (Estimated) & $0.063617^{* *}$ & $0.074688 * * *$ & $0.054612 * * *$ & $0.061760 * * *$ & $0.047924^{* *}$ & $0.075430^{* * *}$ & $0.059298 * * *$ \\
\hline Additional Effect (Estimated) & $-0.083918^{* * *}$ & $-0.068266 * * *$ & $-0.103622 * * *$ & $-0.361003 * * *$ & 0.019831 & $0.217482 * * *$ & $-0.102628 * * *$ \\
\hline Overall Effect (Calculated) & -0.0203 & 0.0064219 & $-0.049001^{* *}$ & $-0.299249 * * *$ & $0.067748 * * *$ & $0.292911^{* * *}$ & $-0.043336 *$ \\
\hline \multicolumn{8}{|l|}{ Graduates } \\
\hline Baseline Effect (Estimated) & 0.008837 & 0.010739 & 0.003955 & 0.012722 & -0.002669 & 0.007104 & 0.008919 \\
\hline Additional Effect (Estimated) & -0.015463 & $-0.384366 * * *$ & $-0.045067 * * *$ & -0.031907 & $0.417748^{* *}$ & $-0.962835^{* * *}$ & $-0.061127^{* * *}$ \\
\hline Overall Effect (Calculated) & -0.0066249 & $-0.373637 * * *$ & $-0.041127 * * *$ & -0.0192906 & $0.415039 * *$ & $-0.955723^{* * *}$ & $-0.052208 * * *$ \\
\hline \multicolumn{8}{|l|}{ Professors } \\
\hline Baseline Effect (Estimated) & 0.046086 & 0.04126 & 0.041485 & 0.042768 & $0.321098 * * *$ & 0.048625 & 0.047281 \\
\hline Additional Effect (Estimated) & $0.135746^{* *}$ & $0.744732^{* * *}$ & $0.119075^{* * *}$ & -0.203534 & $-0.323064 * * *$ & $2.478139 * * *$ & -0.095153 \\
\hline Overall Effect (Calculated) & $0.181832^{* * *}$ & $0.786003^{* * *}$ & $0.160574 * * *$ & -0.1606787 & -0.001966 & $2.526757^{* * *}$ & -0.0478782 \\
\hline \multicolumn{8}{|l|}{ Population } \\
\hline Baseline Effect (Estimated) & $1.067402^{* * *}$ & $1.342683^{* * *}$ & $1.011892^{* * *}$ & $0.780750^{* *}$ & $1.058181^{* * *}$ & $1.074835 * * *$ & $1.146708^{* * *}$ \\
\hline Additional Effect (Estimated) & 0 & 0 & $3.703593^{* * *}$ & -0.595697 & $2.047397^{* * *}$ & 0 & 0.828227 \\
\hline Overall Effect (Calculated) & 1.067402 & 1.342682 & $4.715247^{* * *}$ & 0.1846899 & $3.105743^{* * *}$ & 1.074834 & $1.974939 * * *$ \\
\hline $\mathrm{N}$ & 142 & 142 & 142 & 142 & 142 & 142 & 142 \\
\hline $\mathrm{R} 2$ & 0.9962 & 0.9965 & 0.9964 & 0.9963 & 0.9971 & 0.9964 & 0.9961 \\
\hline
\end{tabular}

Note: Constant, trend and fixed-effect coefficients omitted for brevity.

${ }^{*} p<0.10,{ }^{* *} p<0.05,{ }^{* * *} p<0.01$ 


\section{General Discussion on the above Fixed Effect Tables}

This study has extended the LSDV model to estimate how the effect of expenditure on awards, marketing, graduates, and professors differs for each individual university. In this regression, the additional effects can estimate the difference in the effect of variables for different universities. The positive and significant additional effects suggest that a competitive variable (e.g., awards) has a larger effect on enrollees, while a negative and significant sign suggests that the competitive variable (e.g., graduates) has a smaller effect on enrollees for a specific university relative to all other Ontario universities. In this type of regression, overall effects were calculated by adding baseline effects and additional effects. The negative and significant overall effects for awards and marketing are paradoxical and counter-intuitive, while negative and significant signs on the overall effects for graduates and professors suggest that students see instruction and research as substitutes rather than complements. At the same time, positive and significant signs on the overall effects for graduates and professors suggest that students see instruction and research as complements rather than substitutes.

By examining the effect of awards and marketing on enrollees, negative and significant paradoxical overall effects for awards were shown for five universities. For example, enrollees are expected to change by about $-0.34 \%$ due to a $1 \%$ change in awards for Lakehead University. A negative and significant overall effect for marketing was also shown for five universities. For example, enrollees are expected to change by about $-0.04 \%$ due to a $1 \%$ change in marketing for York University.

Negative and significant signs on the overall effects for graduates suggest that students see instruction and research as substitutes rather than complementary. Positive and significant signs on the overall effects for graduates suggest that students see instruction and research as complements rather than substitutes. The effect of graduates on enrollees was examined and a 
negative and significant overall effect for graduates was shown for eight universities. Similarly, a positive and significant overall effect for graduates was shown for four universities. For example, enrollees are expected to change by about $-0.03 \%$ due to a $1 \%$ change in graduates for Laurentian. On the other hand, enrollees are expected to change by about $0.42 \%$ due to a $1 \%$ change in graduates for Western University.

Negative and significant signs on the overall effects for professors suggest that students see instruction and research as substitutes rather than complementary. Positive and significant signs on the overall effects for professors suggest that students see instruction and research as complements rather than substitutes. Estimation of the effect of professors on enrollees shows negative and significant overall effects for three universities and positive and significant overall effects for eight universities. For example, enrollees are expected to change by about $-0.73 \%$ due to a $1 \%$ change in expenditure on professors for Carleton University. Enrollees are expected to change by about $0.79 \%$ due to a $1 \%$ change in expenditure on professors for University of Toronto. 


\section{Appendix F: Data Analysis - Total Number of Applications for Admission (All Universities; Lagged Model)}

A Lagged model was used to estimate the responsiveness of applicants in year ( $t$ ) to university expenditure on adopted competitive variables in the last year (t-1). Detailed explanation of the Lagged model is available in Appendix E.

\section{Table 8.1.1.}

Pooled OLS Model for Total Number of Applications for Admission

Linear regression

$$
\begin{aligned}
& \text { Number of obs }=143 \\
& F(6, \quad 136)=338.31 \\
& \text { Prob }>F=0.0000 \\
& \text { R-squared }=0.8726 \\
& \text { Root MSE }=.33576
\end{aligned}
$$

\begin{tabular}{lcccccc}
\hline \multicolumn{1}{c}{ Log Applicants } & Coef. & Robust Std. Err. & $\mathrm{t}$ & $\mathrm{P}\rangle|\mathrm{t}|$ & {$[95 \%$ Conf. } & Interval] \\
\hline Log Awards (t-1) & 0.4192322 & 0.0599697 & 6.99 & 0.000 & 0.3006384 & 0.537826 \\
Log Marketing (t-1) & 0.2087887 & 0.0380211 & 5.49 & 0.000 & 0.1335997 & 0.2839778 \\
Log Graduates (t-1) & -0.0054285 & 0.0055517 & -0.98 & 0.330 & -0.0164073 & 0.0055503 \\
Log Professors (t-1) & 0.0950632 & 0.0724121 & 1.31 & 0.191 & -0.0481361 & 0.2382626 \\
Log Population (t) & 0.1364846 & 0.0310113 & 4.4 & 0.000 & 0.0751578 & 0.1978114 \\
Trend & -0.0389704 & 0.0125281 & -3.11 & 0.002 & -0.0637455 & -0.0141954 \\
Constant & 1.043072 & 0.4480689 & 2.33 & 0.021 & 0.156988 & 1.929155 \\
\hline
\end{tabular}

Note. Independent variables are lagged by one year $(\mathrm{t}-1)$. Population is an unlagged variable $(\mathrm{t})$.

Robust standard errors are reported in the table. 
Table 8.1.2.

Fixed Effect (LSDV) Model for Total Number of Applications for Admission

Linear regression

Number of obs $=143$

$\mathrm{F}(24,118)=3569.82$

Prob $>\mathrm{F}=0.0000$

R-squared $=0.9938$

Root MSE $=.07966$

\begin{tabular}{lcccccc}
\hline \multicolumn{1}{c}{ Log Applicants } & Coef. & Robust Std. Err. & $\mathrm{t}$ & $\mathrm{P}>|\mathrm{t}|$ & {$[95 \%$ Conf. } & Interval] \\
\hline Log Awards (t-1) & 0.1241301 & 0.0537958 & 2.31 & 0.023 & 0.0175997 & 0.2306605 \\
Log Marketing (t-1) & 0.0081694 & 0.0199375 & 0.41 & 0.683 & -0.0313123 & 0.047651 \\
Log Graduates (t-1) & 0.0411777 & 0.039514 & 1.04 & 0.299 & -0.0370709 & 0.1194262 \\
Log Professors (t-1) & 0.0454563 & 0.0163451 & 2.78 & 0.006 & 0.0130886 & 0.077824 \\
Log Population (t) & 1.386017 & 0.4743599 & 2.92 & 0.004 & 0.446655 & 2.325379 \\
& & & & & & \\
U_Toronto & (omitted) & & & & & \\
Brock_U & 3.012437 & 1.208225 & 2.49 & 0.014 & 0.6198218 & 5.405052 \\
Carleton_U & 1.565802 & 0.6905945 & 2.27 & 0.025 & 0.1982374 & 2.933368 \\
Lakehead_U & 3.459473 & 1.750661 & 1.98 & 0.05 & -0.0073123 & 6.926259 \\
Laurentian_U & 3.401784 & 1.616578 & 2.1 & 0.037 & 0.2005199 & 6.603049 \\
McMaster_U & 2.556261 & 0.9448963 & 2.71 & 0.008 & 0.6851092 & 4.427413 \\
Nipissing_U & 4.804562 & 2.037278 & 2.36 & 0.020 & 0.7701962 & 8.838928 \\
OCAD_U & -2.244777 & 0.2344869 & -9.57 & 0.000 & -2.709125 & -1.780429 \\
Queens_U & 4.259583 & 1.660555 & 2.57 & 0.012 & 0.9712322 & 7.547934 \\
Ryerson_U & 0.1626133 & 0.1040255 & 1.56 & 0.121 & -0.0433855 & 0.3686122 \\
Trent_U & 3.920495 & 1.76337 & 2.22 & 0.028 & 0.4285429 & 7.412447 \\
U_Guelph & 4.40867 & 1.695004 & 2.6 & 0.010 & 1.0521 & 7.76524 \\
UOIT_U & 2.617377 & 1.242885 & 2.11 & 0.037 & 0.1561253 & 5.078628 \\
U_Ottawa & 1.594833 & 0.7038107 & 2.27 & 0.025 & 0.2010964 & 2.98857 \\
U_Waterloo & 3.052462 & 1.144589 & 2.67 & 0.009 & 0.7858647 & 5.31906 \\
U_Windsor & 2.856232 & 1.311008 & 2.18 & 0.031 & 0.2600788 & 5.452385 \\
Western_U & 3.126047 & 1.14526 & 2.73 & 0.007 & 0.8581216 & 5.393973 \\
Wilfrid_U & 2.884926 & 1.11245 & 2.59 & 0.011 & 0.6819715 & 5.087881 \\
York_U & 0.0945919 & 0.094327 & 1 & 0.318 & -0.0922012 & 0.2813851 \\
Trend & -0.010071 & 0.0058188 & -1.73 & 0.086 & -0.0215937 & 0.0014517 \\
Constant & -13.09994 & 7.158602 & -1.83 & 0.07 & -27.27592 & 1.07604 \\
\hline Nre.Uw & & & & &
\end{tabular}

Note. Uuniversity of Toronto is the base.

Independent variables are lagged by one year $(\mathrm{t}-1)$. Population is an unlagged variable $(\mathrm{t})$.

Robust standard errors are reported in the table. 


\section{Table 8.1.3.}

Random Effect Model for Total Number of Applications for Admission

Random-effects GLS regression

Group variable: University d

R-sq: within $=0.3623$

between $=0.7752$

overall $=0.7648$

corr(u_i, X) $=0$ (assumed)

(Std. Err. adjusted for 19 clusters in University_id)

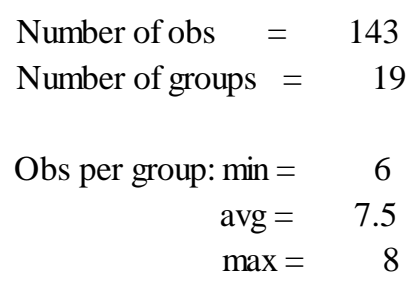

Wald chi2(6) $=221.17$

Prob $>$ chi2 $=0.0000$

\begin{tabular}{lcccccc}
\hline \multicolumn{1}{c}{ Log Applicants } & Coef. & Robust Std. Err. & $\mathrm{z}$ & $\mathrm{P}>|\mathrm{z}|$ & {$[95 \%$ Conf. } & Interval] \\
\hline Log Awards (t-1) & 0.237833 & 0.055792 & 4.26 & 0.000 & 0.128482 & 0.347184 \\
Log Marketing (t-1) & 0.0237263 & 0.031171 & 0.76 & 0.447 & -0.037367 & 0.084819 \\
Log Graduates (t-1) & 0.047817 & 0.009653 & 4.95 & 0 & 0.028897 & 0.066736 \\
Log Professors (t-1) & 0.055735 & 0.022719 & 2.45 & 0.014 & 0.011207 & 0.100263 \\
Log Population (t) & 0.176181 & 0.131761 & 1.34 & 0.181 & -0.082066 & 0.434428 \\
Trend & -0.010346 & 0.006461 & -1.6 & 0.109 & -0.023008 & 0.002316 \\
Constant & 3.902504 & 1.258821 & 3.1 & 0.002 & 1.43526 & 6.369749 \\
\hline sigma_u & 0.37743 & & & & & \\
sigma_e & 0.07966 & & & & \\
rho & 0.9573548 & (fraction of variance due to universities number) &
\end{tabular}

Note. Independent variables are lagged by one year $(\mathrm{t}-1)$. Population is an unlagged variable $(\mathrm{t})$.

Robust standard errors are reported in the table.

Note. The results reported throughout the thesis arise from running panel data regression models with robust standard errors. Regressions with robust standard errors and without robust standard errors are summarized in Table 8.1.4. 
Table 8.1.4.

Summary Results from Pooled OLS, Fixed (LSDV), and Random Effect Regressions with Robust Standard Errors and without Robust Standard Errors for Total Number of Applicants.

\begin{tabular}{|c|c|c|c|c|c|c|c|c|c|}
\hline \multirow[b]{3}{*}{ Independent Variable } & \multicolumn{9}{|c|}{ Dependent Variable: Log Applicants } \\
\hline & \multicolumn{3}{|c|}{ Pooled OLS } & \multicolumn{3}{|c|}{ Fixed Effect LSDV } & \multicolumn{3}{|c|}{ Random Effect } \\
\hline & Coef. & $\begin{array}{c}\text { Non_Robust } \\
\text { Std. s } \\
\end{array}$ & $\begin{array}{l}\text { Robust } \\
\text { Std. s } \\
\end{array}$ & Coef. & $\begin{array}{c}\text { Non_Robust } \\
\text { Std. } \mathrm{S} \\
\end{array}$ & Robust Std. $\sim \mathrm{S}$ & Coef. & $\begin{array}{c}\text { Non_Robust } \\
\text { Std. s } \\
\end{array}$ & Robust Std. s \\
\hline Log Awards (t-1) & 0.419232 & $(0.0915940)$ & $(0.0599700)$ & 0.12413 & $(0.057844)$ & $(0.0537960)$ & 0.237833 & $(0.0559990)$ & $(0.0557920)$ \\
\hline Log Marketing (t-1) & 0.208789 & $(0.0452330)$ & $(0.0380210)$ & 0.008169 & $(0.030708)$ & $(0.0199380)$ & 0.023726 & $(0.0322160)$ & $(0.0311710)$ \\
\hline Log Graduates (t-1) & -0.005429 & $(0.0104830)$ & $(0.0055520)$ & 0.041178 & $(0.019445)$ & $(0.0395140)$ & 0.047817 & $(0.0171430)$ & $(0.0096530)$ \\
\hline Log Professors (t-1) & 0.095063 & $(0.1148060)$ & $(0.0724120)$ & 0.045456 & $(0.034774)$ & $(0.0163450)$ & 0.055735 & $(0.0369680)$ & $(0.0227190)$ \\
\hline Log Population (t) & 0.136485 & $(0.0237260)$ & $(0.0310110)$ & 1.386017 & $(0.487468)$ & $(0.4743600)$ & 0.176181 & $(0.0695050)$ & $(0.1317610)$ \\
\hline Trend & -0.038970 & $(0.0129430)$ & $(0.0125280)$ & -0.010071 & $(0.006516)$ & $(0.0058190)$ & -0.010346 & $(0.0052090)$ & $(0.0064600)$ \\
\hline Constant & 1.04 & $(0.5236460)$ & $(0.4480690)$ & -13.099941 & (7.442578) & (7.1586020) & 3.903 & $(0.9708640)$ & (1.2588210) \\
\hline U_Toronto & & & & (omitted) & & & & & \\
\hline Brock_U & & & & 3.012437 & $(1.26)$ & $(1.21)$ & & & \\
\hline Carleton_U & & & & 1.565802 & $(0.72)$ & $(0.69)$ & & & \\
\hline Lakehead_U & & & & 3.459473 & $(1.82)$ & $(1.75)$ & & & \\
\hline Laurentian_U & & & & 3.401784 & (1.68) & (1.62) & & & \\
\hline McMaster_U & & & & 2.556261 & $(0.98)$ & $(0.94)$ & & & \\
\hline Nipissing_U & & & & 4.804562 & (2.10) & $(2.04)$ & & & \\
\hline OCAD_U & & & & -2.244777 & $(0.24)$ & $(0.23)$ & & & \\
\hline Queens_U & & & & 4.259583 & $(1.72)$ & (1.66) & & & \\
\hline Ryerson_U & & & & 0.162613 & $(0.11)$ & $(0.10)$ & & & \\
\hline Trent_U & & & & 3.920495 & (1.84) & (1.76) & & & \\
\hline U_Guelph & & & & 4.40867 & (1.77) & (1.70) & & & \\
\hline UOIT_U & & & & 2.617377 & $(1.31)$ & $(1.24)$ & & & \\
\hline U_Ottawa & & & & 1.594833 & $(0.73)$ & $(0.70)$ & & & \\
\hline U_Waterloo & & & & 3.052462 & (1.18) & (1.14) & & & \\
\hline U_Windsor & & & & 2.856232 & $(1.36)$ & $(1.31)$ & & & \\
\hline Western_U & & & & 3.126047 & (1.19) & $(1.15)$ & & & \\
\hline Wilfrid_U & & & & 2.884926 & (1.17) & (1.11) & & & \\
\hline York_U & & & & 0.094592 & $(0.07)$ & $(0.09)$ & & & \\
\hline No. of Obs. & 143 & & & 143 & & & 143 & & \\
\hline R-Squared & 0.87 & & & 0.99 & & & 0.76 & & \\
\hline
\end{tabular}

Note. Robust and Non-Robust Standard errors are in parentheses.

Uuniversity of Toronto is the base.

Independent variables are lagged by one year $(\mathrm{t}-1)$. Population is an unlagged variable $(\mathrm{t})$. 


\section{Table 8.2.1.}

Fixed Effect (a modified Fixed Effect regression): Applicants

To explore the variation across universities, a modified Fixed Effect regression was conducted for each individual university. As well as the baseline effects (coefficients) for awards, marketing, graduates, professors, and population, which are applicable to all universities, each regression introduced an additional effect (coefficient) for each of the variables. These additional effects capture whether a variable has a weaker or stronger effect for the particular university relative to other universities.

Fixed Effects (A Modified Fixed Effect) Regressions Were Initially Run With Robust Standard Errors.

\begin{tabular}{|c|c|c|c|c|c|c|}
\hline \multirow[b]{2}{*}{ Variables } & \multicolumn{6}{|c|}{ Fixed Effect (a modified Fixed Effect regression ) : Applicants } \\
\hline & Brock_U & Carleton_U & Lakehead_U & Laurentian_U & McMaster_U & Nipissing_U \\
\hline \multicolumn{7}{|l|}{ Awards } \\
\hline Baseline Effect (Estimated) & $0.134174 * *$ & $0.123225^{* *}$ & $0.128981^{* *}$ & $0.106141^{* *}$ & $0.137078 * *$ & $0.116343^{* *}$ \\
\hline Additional Effect (Estimated) & -0.034626 & $-1.593475 * * *$ & $-0.355307^{* *}$ & $5.054362 * * *$ & $-0.395528 * *$ & -0.20472 \\
\hline Overall Effect (Calculated) & 0.0995533 & $-1.470218 * * *$ & -0.2263209 & $5.160501^{* * *}$ & -0.2584734 & -0.0883677 \\
\hline \multicolumn{7}{|l|}{ Marketing } \\
\hline Baseline Effect (Estimated) & 0.007538 & 0.008966 & 0.006174 & 0.014948 & 0.012345 & 0.002105 \\
\hline Additional Effect (Estimated) & 0.110508 & $-0.250586 * * *$ & $0.504009 * * *$ & 0.144435 & $-0.058320^{*}$ & $1.091727^{* * *}$ \\
\hline Overall Effect (Calculated) & 0.1180594 & $-0.241622 * * *$ & $0.510188^{* * *}$ & 0.1593717 & $-0.045974 *$ & $1.093820 * * *$ \\
\hline \multicolumn{7}{|l|}{ Graduates } \\
\hline Baseline Effect (Estimated) & 0.040159 & 0.041228 & 0.038016 & $0.049789 *$ & 0.040492 & 0.039804 \\
\hline Additional Effect (Estimated) & -0.19442 & $-0.364884 * *$ & -0.304301 & 0.005498 & $-0.190704 * *$ & omitted \\
\hline Overall Effect (Calculated) & -0.1542526 & $-0.323640 *$ & -0.266295 & $0.055288 * * *$ & $-0.150208 *$ & $\ldots$ \\
\hline \multicolumn{7}{|l|}{ Professors } \\
\hline Baseline Effect (Estimated) & $0.042788 * *$ & $0.041802 * *$ & $0.046851^{* *}$ & $0.049991 * * *$ & $0.038834 *$ & $0.043942 * * *$ \\
\hline Additional Effect (Estimated) & $-0.385573 *$ & $4.029948 * * *$ & $0.960299 *$ & $-3.869711 * * *$ & $0.089276^{*}$ & $-1.337545 * * *$ \\
\hline Overall Effect (Calculated) & $-0.342795 *$ & $4.071643 * * *$ & $1.007196 * *$ & $-3.819705^{* * *}$ & $0.128112^{* *}$ & $-1.293584 * * *$ \\
\hline \multicolumn{7}{|l|}{ Population } \\
\hline Baseline Effect (Estimated) & $1.101580 * *$ & $1.554881 * * *$ & $1.524728 * *$ & $1.482703^{* * *}$ & $1.401857^{* * *}$ & $1.445719 * * *$ \\
\hline Additional Effect (Estimated) & -3.773687 & $-5.324053 * * *$ & $15.003800 * * *$ & 0 & $4.080589 * * *$ & $4.953131 * * *$ \\
\hline Overall Effect (Calculated) & -2.673012 & $-3.769002^{* *}$ & $16.529759 * * *$ & 1.482703 & $5.482532 * * *$ & $6.398713^{* * *}$ \\
\hline $\mathrm{N}$ & 143 & 143 & 143 & 143 & 143 & 143 \\
\hline $\mathrm{R} 2$ & 0.9939 & 0.994 & 0.9939 & 0.9951 & 0.9939 & 0.9942 \\
\hline
\end{tabular}

Note: Constant, trend and fixed-effect coefficients omitted for brevity.

Expenditure on Graduates at Nipissing University remains constant over time and is thus perfectly co-linear with the dummy variable.

${ }^{*} p<0.10, * * p<0.05, * * * p<0.01$ 


\begin{tabular}{|c|c|c|c|c|c|c|}
\hline \multirow[b]{2}{*}{ Variables } & \multicolumn{6}{|c|}{ Fixed Effect (a modified Fixed Effect regression ) : Applicants } \\
\hline & OCAD_U & Queen's_U & Ryerson_U & Trent_U & U_Guelph & UOIT \\
\hline \multicolumn{7}{|l|}{ Awards } \\
\hline Baseline Effect (Estimated) & $0.126548 * *$ & $0.128216^{* *}$ & $0.141097 * *$ & $0.124172^{* *}$ & $0.142185^{* * *}$ & $0.123044^{*}$ \\
\hline Additional Effect (Estimated) & $-0.209351 * * *$ & $0.245557^{* *}$ & $-0.295196 * * *$ & $1.273899 * * *$ & $-7.089486 * * *$ & -0.063585 \\
\hline Overall Effect (Calculated) & $-0.082805 * * *$ & $0.373754 * * *$ & $-0.154104 * * *$ & $1.398075 * * *$ & $-6.947560 * * *$ & 0.0593791 \\
\hline \multicolumn{7}{|l|}{ Marketing } \\
\hline Baseline Effect (Estimated) & 0.008086 & 0.006696 & 0.003705 & 0.004912 & 0.002441 & 0.022149 \\
\hline Additional Effect (Estimated) & $0.245555^{* *}$ & $-0.179715^{* * *}$ & $-0.278732 * * *$ & $0.204238 * * *$ & $1.845483 * * *$ & $-0.186816^{* * *}$ \\
\hline Overall Effect (Calculated) & $0.253649 * *$ & $-0.173016 * * *$ & $-0.275030 * * *$ & $0.209150 * * *$ & $1.847974 * * *$ & $-0.164660 * * *$ \\
\hline \multicolumn{7}{|l|}{ Graduates } \\
\hline Baseline Effect (Estimated) & 0.041861 & 0.042527 & 0.039105 & 0.041188 & 0.039286 & 0.043912 \\
\hline Additional Effect (Estimated) & $-0.527586 * * *$ & $-0.189851^{*}$ & $-0.198776 * *$ & $-0.361358^{* *}$ & $4.438921 * * *$ & 0.001957 \\
\hline Overall Effect (Calculated) & $-0.485737 * * *$ & -0.1473137 & $-0.159678^{* *}$ & $-0.320169 * *$ & $4.478196 * * *$ & $0.045874 * * *$ \\
\hline \multicolumn{7}{|l|}{ Professors } \\
\hline Baseline Effect (Estimated) & $0.046239 * * *$ & $0.046994 * * *$ & $0.041751^{* *}$ & $0.046860 * * *$ & $0.049859 * * *$ & $0.053760 * * *$ \\
\hline Additional Effect (Estimated) & $0.614829 * * *$ & $0.811403 * * *$ & $0.989663 * * *$ & $-0.536904 * * *$ & $4.087661^{* * *}$ & -0.092944 \\
\hline Overall Effect (Calculated) & $0.661083^{* * *}$ & $0.858367 * * *$ & $1.031432 * * *$ & $-0.490047 * * *$ & $4.137931^{* * *}$ & -0.0391687 \\
\hline \multicolumn{7}{|l|}{ Population } \\
\hline Baseline Effect (Estimated) & $1.379389 * * *$ & $1.380790 * * *$ & $1.380778^{* * *}$ & $1.387335 * * *$ & $1.325910 * * *$ & $1.333587 * * *$ \\
\hline Additional Effect (Estimated) & $-3.179458 * *$ & -2.241591 & 0 & 0 & -3.707585 & $6.305469 * *$ \\
\hline Overall Effect (Calculated) & -1.800181 & -0.860516 & 1.380777 & 1.387334 & -2.382131 & $7.640152 * * *$ \\
\hline $\mathrm{N}$ & 143 & 143 & 143 & 143 & 143 & 143 \\
\hline $\mathrm{R} 2$ & 0.9938 & 0.9938 & 0.9939 & 0.9939 & 0.9951 & 0.994 \\
\hline
\end{tabular}

Note: Constant, trend and fixed-effect coefficients omitted for brevity.

$* \mathrm{p}<0.10, * * \mathrm{p}<0.05, * * * \mathrm{p}<0.01$

\begin{tabular}{|c|c|c|c|c|c|c|c|}
\hline \multirow[b]{2}{*}{ Variables } & \multicolumn{6}{|c|}{ Fixed Effect (a modified Fixed Effect regression ) : Applicants } & \multirow[b]{2}{*}{ York_U } \\
\hline & U_Ottawa & U_Toronto & U_Waterloo & U_Windsor & Western_U & Wilfrid_U & \\
\hline \multicolumn{8}{|l|}{ Awards } \\
\hline Baseline Effect (Estimated) & $0.124820^{* *}$ & $0.127331 * *$ & 0.099083 & $0.125294^{* *}$ & $0.128023^{* *}$ & $0.118602 * *$ & $0.107541 *$ \\
\hline Additional Effect (Estimated) & 0.11224 & 0.110133 & $-0.244771 * * *$ & $-0.966383^{* * *}$ & $1.710157^{* * *}$ & $0.296836^{* * *}$ & -1.495413 \\
\hline Overall Effect (Calculated) & 0.2370588 & $0.237467^{* * *}$ & $-0.145689 * * *$ & $-0.841096 * * *$ & $1.838172^{* * *}$ & $0.415435^{* * *}$ & -1.3879188 \\
\hline \multicolumn{8}{|l|}{ Marketing } \\
\hline Baseline Effect (Estimated) & 0.005519 & 0.001233 & 0.006436 & 0.009274 & 0.018032 & 0.014734 & 0.002892 \\
\hline Additional Effect (Estimated) & -0.036552 & 0.038635 & 0.140907 & $0.816167^{* * *}$ & $-0.373120^{* * *}$ & $-0.181063 * * *$ & $2.259015^{*}$ \\
\hline Overall Effect (Calculated) & -0.0310321 & $0.039868 * * *$ & 0.1473104 & $0.825429 * * *$ & $-0.355061^{* * *}$ & $-0.166326 * * *$ & $2.261916^{*}$ \\
\hline \multicolumn{8}{|l|}{ Graduates } \\
\hline Baseline Effect (Estimated) & 0.042056 & 0.041474 & 0.044466 & 0.047468 & 0.040753 & 0.040122 & 0.038842 \\
\hline Additional Effect (Estimated) & -0.16381 & -0.097892 & $0.195653^{* *}$ & -0.536262 & $-2.250168^{* * *}$ & $0.571076 * * *$ & 0.300967 \\
\hline Overall Effect (Calculated) & -0.1217503 & -0.0564137 & $0.240141^{* * *}$ & -0.4886808 & $-2.209340^{* * *}$ & $0.611189^{* * *}$ & $0.339810^{*}$ \\
\hline \multicolumn{8}{|l|}{ Professors } \\
\hline Baseline Effect (Estimated) & $0.045159^{* * *}$ & $0.045102^{* * *}$ & $0.048487^{* * *}$ & $0.038257^{* *}$ & 0.025073 & $0.046439 * * *$ & $0.045835 * * *$ \\
\hline Additional Effect (Estimated) & -0.011654 & -0.130416 & $0.771994^{* * *}$ & $0.957065^{* *}$ & -0.045437 & $-0.937799 * * *$ & 0.375818 \\
\hline Overall Effect (Calculated) & 0.0335047 & -0.0853253 & $0.820491^{* * *}$ & $0.995214^{* *}$ & $-0.020368^{* *}$ & $-0.891345^{* * *}$ & 0.4216602 \\
\hline \multicolumn{8}{|l|}{ Population } \\
\hline Baseline Effect (Estimated) & $1.400678^{* * *}$ & $1.410722^{* * *}$ & $1.428925^{* * *}$ & $0.872727^{*}$ & $1.438089^{* * *}$ & $1.385766^{* * *}$ & $1.643928 * * *$ \\
\hline Additional Effect (Estimated) & 0 & 0 & -1.144378 & $10.264450 * * *$ & $7.561819^{* * *}$ & 0 & -0.991769 \\
\hline Overall Effect (Calculated) & 1.400678 & 1.410721 & 0.284856 & $11.137367^{* * *}$ & $8.999536 * * *$ & 1.385766 & 0.6522349 \\
\hline $\mathrm{N}$ & 143 & 143 & 143 & 143 & 143 & 143 & 143 \\
\hline R2 & 0.9938 & 0.9938 & 0.9941 & 0.9941 & 0.9939 & 0.9938 & 0.9942 \\
\hline
\end{tabular}

Note: Constant, trend and fixed-effect coefficients omitted for brevity.

${ }^{*} p<0.10,{ }^{* *} p<0.05, * * * p<0.01$ 


\section{General Discussion on the above Fixed Effect Tables}

This study has extended the LSDV model to estimate how the effect of expenditure on awards, marketing, graduates, and professors differs for each individual university. In this regression, the additional effects can estimate the difference in the effect of variables for different universities. The positive and significant additional effects suggest that a competitive variable (e.g., awards) has a larger effect on applications for admission, while a negative and significant sign suggests that the competitive variable (e.g., graduates) has a smaller effect on total number of applications for admission for a specific university relative to all other Ontario universities. In this type of regression, overall effects were calculated by adding baseline effects and additional effects. The negative and significant overall effects for awards and marketing are paradoxical and counter-intuitive, while negative and significant signs on the overall effects for graduates and professors suggest that students see instruction and research as substitutes rather than complements.

Counter-intuitive results were shown when examining the effect of awards and marketing on applications. Negative and significant overall effects for awards were shown for six universities. Also, negative and significant overall effects have shown for marketing in six universities. For example, applications are expected to change by about $-0.15 \%$ due to a $1 \%$ change in awards for Ryerson, while applications are expected to change by about $-0.17 \%$ due to a $1 \%$ change in marketing for Queen's University.

Negative and significant signs on the overall effects for graduates suggest that students see instruction and research as substitutes rather than complementary. Positive and significant signs on the overall effects for graduates suggest that students see instruction and research as complements rather than substitutes. The effect of graduates on total number of applications for admission was examined and a negative and significant overall effects for graduates were shown 
for six universities, while positive and significant overall effects were shown for six universities. For example, applications are expected to change by about $-0.15 \%$ due to a $1 \%$ change in graduates for McMaster, while applications are expected to change by about $0.24 \%$ for Waterloo.

Negative and significant signs on the overall effects for professors suggest that students see instruction and research as substitutes rather than complementary. Positive and significant signs on the overall effects for professors suggest that students see instruction and research as complements rather than substitutes. The result of examining the effect of professors on applicants predicts that negative and significant overall effects were shown for six universities, while positive and significant overall effects were shown for nine universities. For example, applicants are expected to change by about $-0.49 \%$ due to a $1 \%$ change in expenditure on professors for Trent University. Applicants are expected to change by about $0.42 \%$ due to a $1 \%$ change in expenditure on professors for York University. 


\section{Appendix G: Data Analysis - Persistence Ratio (Lagged Model)}

A Lagged model was used to estimate the responsiveness of persistence ratio in year $(t)$ to university expenditure on awards, marketing, graduates, and professors in the last year (t-1). Detailed explanation of the Lagged model is available in Appendix E.

Table 9.1.1. Pooled OLS Model for Persistence Ratio

Linear regression

$$
\begin{aligned}
& \text { Number of obs }=142 \\
& F(6,135)=20.68 \\
& \text { Prob }>F=0.0000 \\
& \text { R-squared }=0.2769 \\
& \text { Root MSE }=.24721
\end{aligned}
$$

\begin{tabular}{lcccccc}
\hline Log Persistence Ratio & Coef. & Robust Std. Err. & $\mathrm{t}$ & $\mathrm{P}>|\mathrm{t}|$ & {$[95 \%$ Conf. } & Interval] \\
\hline Log Awards (t-1) & -0.0082659 & 0.0576881 & -0.14 & 0.886 & -0.1223552 & 0.1058234 \\
Log Marketing (t-1) & -0.1567222 & 0.0279764 & -5.6 & 0.000 & -0.2120509 & -0.1013935 \\
Log Graduates (t-1) & -0.0106299 & 0.0053849 & -1.97 & 0.050 & -0.0212796 & 0.0000199 \\
Log Professors (t-1) & 0.1224066 & 0.0829135 & 1.48 & 0.142 & -0.0415707 & 0.286384 \\
Log Population (t) & -0.0148347 & 0.0207027 & -0.72 & 0.475 & -0.0557782 & 0.0261089 \\
Trend & 0.0103113 & 0.0091934 & 1.12 & 0.264 & -0.0078704 & 0.0284931 \\
Constant & 0.3989628 & 0.4144725 & 0.96 & 0.337 & -0.4207364 & 1.218662 \\
\hline
\end{tabular}

Note. Independent variables are lagged by one year $(\mathrm{t}-1)$. Population is an unlagged variable $(\mathrm{t})$.

Robust standard errors are reported in the table. 
Table 9.1.2.

Fixed Effect (LSDV) Model for Persistence Ratio

Linear regression

Number of obs $=142$

$\mathrm{F}(24,117)=244.21$

Prob $>\mathrm{F}=0.0000$

$\mathrm{R}$-squared $=0.9199$

Root MSE $=.08841$

\begin{tabular}{lcccccc}
\hline Log Persistence Ratio & Coef. & Robust Std. Err. & $\mathrm{t}$ & $\mathrm{P}>|\mathrm{t}|$ & {$[95 \%$ Conf. } & Interval] \\
\hline Log Awards (t-1) & 0.2048851 & 0.0759879 & 2.7 & 0.008 & 0.0543951 & 0.355375 \\
Log Marketing (t-1) & 0.0523101 & 0.025995 & 2.01 & 0.046 & 0.0008284 & 0.1037918 \\
Log Graduates (t-1) & -0.0320426 & 0.0389925 & -0.82 & 0.413 & -0.1092651 & 0.04518 \\
Log Professors (t-1) & 0.0014861 & 0.0537498 & 0.03 & 0.978 & -0.1049626 & 0.1079348 \\
Log Population (t) & -0.3108312 & 0.445756 & -0.7 & 0.487 & -1.193628 & 0.5719652 \\
& & & & & & \\
U_Toronto & (omitted) & & & & & \\
Brock_U & -0.6469667 & 1.113531 & -0.58 & 0.562 & -2.852257 & 1.558324 \\
Carleton_U & -0.4287374 & 0.6352336 & -0.67 & 0.501 & -1.686784 & 0.8293093 \\
Lakehead_U & -0.3691308 & 1.622288 & -0.23 & 0.82 & -3.581987 & 2.843725 \\
Laurentian_U & -0.5283728 & 1.49359 & -0.35 & 0.724 & -3.486349 & 2.429603 \\
McMaster_U & -0.9892888 & 0.8684871 & -1.14 & 0.257 & -2.709282 & 0.7307044 \\
Nipissing_U & -0.8123754 & 1.869277 & -0.43 & 0.665 & -4.514381 & 2.88963 \\
OCAD_U & 1.139862 & 0.3917414 & 2.91 & 0.004 & 0.3640389 & 1.915686 \\
Queens_U & -1.320614 & 1.545653 & -0.85 & 0.395 & -4.381699 & 1.740471 \\
Ryerson_U & -0.2829144 & 0.1805241 & -1.57 & 0.120 & -0.6404329 & 0.0746041 \\
Trent_U & -0.8296898 & 1.630974 & -0.51 & 0.612 & -4.059749 & 2.40037 \\
U_Guelph & -0.9860899 & 1.574424 & -0.63 & 0.532 & -4.104155 & 2.131975 \\
UOIT_U & -0.5811706 & 1.144502 & -0.51 & 0.613 & -2.847797 & 1.685456 \\
U_Ottawa & -0.3164102 & 0.650258 & -0.49 & 0.627 & -1.604212 & 0.9713916 \\
U_Waterloo & -0.9808971 & 1.063178 & -0.92 & 0.358 & -3.086466 & 1.124672 \\
U_Windsor & -0.412404 & 1.20491 & -0.34 & 0.733 & -2.798665 & 1.973857 \\
Western_U & -1.151144 & 1.061218 & -1.08 & 0.280 & -3.25283 & 0.9505419 \\
Wilfrid_U & -0.7982325 & 1.022778 & -0.78 & 0.437 & -2.82379 & 1.227325 \\
York_U & -0.0377714 & 0.1174753 & -0.32 & 0.748 & -0.2704252 & 0.1948823 \\
Trend & -0.0079936 & 0.0073842 & -1.08 & 0.281 & -0.0226176 & 0.0066305 \\
Constant & 2.398298 & 6.650201 & 0.36 & 0.719 & -10.77208 & 15.56867 \\
\hline Note_Uwide & & & & &
\end{tabular}

Note. Uuniversity of Toronto is the base.

Independent variables are lagged by one year $(\mathrm{t}-1)$. Population is an unlagged variable $(\mathrm{t})$.

Robust standard errors are reported in the table. 


\section{Table 9.1.3.}

\section{Random Effect Model for Persistence Ratio}

Random-effects GLS regression

Group variable: University d

R-sq: within $=0.1471$

between $=0.0134$

overall $=0.0044$

corr(u_i, X) $=0$ (assumed)

$$
\begin{aligned}
& \text { Number of obs }=142 \\
& \text { Number of groups }=19 \\
& \text { Obs per group: } \min =6 \\
& \text { avg }=7.5 \\
& \max =8 \\
& \text { Wald chi2(6) }=43.49 \\
& \text { Prob }>\text { chi2 }=0.0000
\end{aligned}
$$

(Std. Err. adjusted for 19 clusters in University_id)

\begin{tabular}{lcccccc}
\hline \multicolumn{1}{c}{ Log Persistence Ratio } & Coef. & Robust Std. Err. & $\mathrm{z}$ & $\mathrm{P}>|\mathrm{z}|$ & {$[95 \%$ Conf. } & Interval] \\
\hline Log Awards (t-1) & 0.104161 & 0.075676 & 1.38 & 0.169 & -0.044160 & 0.252483 \\
Log Marketing (t-1) & 0.0224434 & 0.033462 & 0.67 & 0.502 & -0.043141 & 0.088028 \\
Log Graduates (t-1) & -0.038860 & 0.0094496 & -4.11 & 0 & -0.057381 & -0.020339 \\
Log Professors (t-1) & -0.012865 & 0.050489 & -0.25 & 0.799 & -0.111822 & 0.086091 \\
Log Population (t) & -0.011480 & 0.073123 & -0.16 & 0.875 & -0.154798 & 0.131838 \\
Trend & 0.000981 & 0.008117 & 0.12 & 0.904 & -0.014928 & 0.016890 \\
Constant & -0.6634204 & 1.028061 & -0.65 & 0.519 & -2.678383 & 1.351542 \\
\hline sigma_u & 0.250072 & & & & \\
sigma_e & 0.088408 & & & & \\
rho & 0.8889020 & (fraction of variance due to universities number) &
\end{tabular}

Note. Independent variables are lagged by one year $(\mathrm{t}-1)$. Population is an unlagged variable $(\mathrm{t})$.

Robust standard errors are reported in the table.

Note. The results reported throughout the thesis arise from running panel regression models with robust standard errors. Regressions results are summarized in Table 9.1.4. 
Table 9.1.4.

Summary Results from Pooled OLS, Fixed (LSDV), and Random Effect Regressions with Robust Standard Errors and without Robust Standard Errors for Persistence Ratio.

\begin{tabular}{|c|c|c|c|c|c|c|c|c|c|}
\hline \multirow[b]{3}{*}{ Independent Variable } & \multicolumn{8}{|c|}{ Dependent Variable: Log Persistence Ratio } & \\
\hline & \multicolumn{3}{|c|}{ Pooled OLS } & \multicolumn{3}{|c|}{ Fixed Effect LSDV } & \multicolumn{3}{|c|}{ RandomEffect } \\
\hline & Coef. & $\begin{array}{c}\text { Non_Robust } \\
\text { Std. } \sim \mathrm{S}\end{array}$ & $\begin{array}{l}\text { Robust } \\
\text { Std. s }\end{array}$ & Coef. & $\begin{array}{c}\text { Non_Robust } \\
\text { Std. s }\end{array}$ & $\begin{array}{l}\text { Robust } \\
\text { Std. s }\end{array}$ & Coef. & $\begin{array}{c}\text { Non_Robust } \\
\text { Std. } \sim\end{array}$ & $\begin{array}{l}\text { Robust } \\
\text { Std. } \sim \mathrm{s}\end{array}$ \\
\hline Log Awards (t-1) & -0.008266 & $(0.0674870)$ & $(0.0576880)$ & 0.204885 & $(0.064223)$ & $(0.075988)$ & 0.104161 & $(0.0544250)$ & $(0.0756760)$ \\
\hline Log Marketing (t-1) & -0.156722 & $(0.0333080)$ & $(0.0279760)$ & 0.05231 & $(0.034084)$ & $(0.025995)$ & 0.022443 & $(0.0335190)$ & $(0.0334620)$ \\
\hline Log Graduates (t-1) & -0.01063 & $(0.0081300)$ & $(0.0053850)$ & -0.03204 & $(0.021580)$ & $(0.038992)$ & -0.03886 & $(0.0150090)$ & $(0.0094500)$ \\
\hline Log Professors (t-1) & 0.122407 & $(0.0845300)$ & $(0.0829130)$ & 0.001486 & $(0.038593)$ & $(0.053750)$ & -0.012865 & $(0.0395150)$ & $(0.0504890)$ \\
\hline Log Population (t) & -0.014835 & $(0.0174710)$ & $(0.0207030)$ & -0.31083 & $(0.541044)$ & $(0.445756)$ & -0.01148 & $(0.0463740)$ & $(0.0731230)$ \\
\hline Trend & 0.010311 & $(0.0095380)$ & $(0.0091930)$ & -0.007994 & $(0.007234)$ & $(0.007384)$ & 0.000981 & $(0.0050710)$ & $(0.0081170)$ \\
\hline Constant & 0.399 & $(0.3855760)$ & $(0.4144730)$ & 2.398298 & $(8.260313)$ & $(6.650201)$ & -0.663 & $(0.6929750)$ & (1.0280610) \\
\hline U_Toronto & & & & (omitted) & & & & & \\
\hline Brock_U & & & & -0.64697 & $(1.40)$ & $(1.11)$ & & & \\
\hline Carleton_U & & & & -0.42874 & $(0.80)$ & $(0.64)$ & & & \\
\hline Lakehead_U & & & & -0.36913 & (2.02) & (1.62) & & & \\
\hline Laurentian_U & & & & -0.52837 & $(1.87)$ & (1.49) & & & \\
\hline McMaster_U & & & & -0.98929 & (1.09) & $(0.87)$ & & & \\
\hline Nipissing_U & & & & -0.81238 & (2.33) & $(1.87)$ & & & \\
\hline OCAD_U & & & & 1.139862 & $(0.26)$ & $(0.39)$ & & & \\
\hline Queens_U & & & & -1.32061 & $(1.91)$ & $(1.55)$ & & & \\
\hline Ryerson_U & & & & -0.28291 & $(0.13)$ & $(0.18)$ & & & \\
\hline Trent_U & & & & -0.82969 & (2.04) & (1.63) & & & \\
\hline U_Guelph & & & & -0.98609 & (1.96) & (1.57) & & & \\
\hline UOIT_U & & & & -0.58117 & (1.45) & (1.14) & & & \\
\hline U_Ottawa & & & & -0.31641 & $(0.81)$ & $(0.65)$ & & & \\
\hline U_Waterloo & & & & -0.9809 & (1.31) & (1.06) & & & \\
\hline U_Windsor & & & & -0.4124 & $(1.51)$ & $(1.20)$ & & & \\
\hline Western_U & & & & -1.15114 & (1.32) & (1.06) & & & \\
\hline Wilfrid_U & & & & -0.79823 & (1.29) & $(1.02)$ & & & \\
\hline York_U & & & & -0.03777 & $(0.08)$ & $(0.12)$ & & & \\
\hline No. of Obs. & 142 & & & 142 & & & 142 & & \\
\hline R-Squared & 0.28 & & & 0.92 & & & 0.004 & & \\
\hline
\end{tabular}

Note. Robust and Non-Robust Standard errors are in parentheses.

Uuniversity of Toronto is the base.

Independent variables are lagged by one year $(\mathrm{t}-1)$. Population is an unlagged variable $(\mathrm{t})$. 


\section{Table 9.2.1.}

Fixed Effect (a modified Fixed Effect regression): Persistence Ratio

To explore the variation across universities, a modified Fixed Effect regression was conducted

for each individual university. As well as the baseline effects (coefficients) for awards,

marketing, graduates, professors, and population, which are applicable to all universities, each

regression introduced an additional effect (coefficient) for each of the variables applicable to the

individual university in question. These additional effects capture whether a variable has a

weaker or stronger effect for the particular university relative to other universities.

Fixed Effects (a modified Fixed Effect) regressions were initially run with robust standard errors.

\begin{tabular}{|c|c|c|c|c|c|c|}
\hline \multirow[b]{2}{*}{ Variables } & \multicolumn{6}{|c|}{ Fixed Effect (a modified Fixed Effect regression ): Persistence Ratio } \\
\hline & Brock_U & Carleton_U & Lakehead_U & Laurentian_U & McMaster_U & Nipissing_U \\
\hline \multicolumn{7}{|l|}{ Awards } \\
\hline Baseline Effect (Estimated) & $0.202848 * *$ & $0.203219 * *$ & $0.209613^{* * *}$ & $0.190267 * * *$ & $0.205599 * *$ & $0.210205^{* * *}$ \\
\hline Additional Effect (Estimated) & -0.268491 & $1.093909 * *$ & $-0.320172 * * *$ & $-4.428640 * * *$ & 0.215975 & 0.044388 \\
\hline Overall Effect (Calculated) & -0.0656428 & $1.297128 * * *$ & -0.1105593 & $-4.238373 * * *$ & $0.421574 * * *$ & 0.2545922 \\
\hline \multicolumn{7}{|l|}{ Marketing } \\
\hline Baseline Effect (Estimated) & $0.053709 * *$ & $0.052710^{*}$ & $0.050270^{*}$ & $0.044317^{*}$ & $0.053392^{*}$ & $0.060457^{* *}$ \\
\hline Additional Effect (Estimated) & -0.2987 & $0.238926 * * *$ & $-0.232115^{* *}$ & $0.345699 * *$ & -0.049611 & 0.024266 \\
\hline Overall Effect (Calculated) & -0.2449907 & $0.291636 * * *$ & $-0.181845^{* *}$ & $0.390016 * * *$ & 0.0037812 & 0.0847227 \\
\hline \multicolumn{7}{|l|}{ Graduates } \\
\hline Baseline Effect (Estimated) & -0.032242 & -0.030959 & -0.037969 & 0.016179 & -0.032246 & -0.030327 \\
\hline Additional Effect (Estimated) & 0.173349 & 0.217638 & $0.676330 * * *$ & $-0.100704 * * *$ & -0.047356 & omitted \\
\hline Overall Effect (Calculated) & 0.1411075 & 0.1866792 & $0.638362 * * *$ & $-0.084525^{* * *}$ & $-0.079602 * *$ & $\ldots$ \\
\hline \multicolumn{7}{|l|}{ Professors } \\
\hline Baseline Effect (Estimated) & 0.003235 & 0.003549 & 0.003874 & -0.011226 & 0.001766 & 0.005689 \\
\hline Additional Effect (Estimated) & $0.616426^{* *}$ & $-4.810081 * * *$ & $-0.898599 * * *$ & $2.493777^{* * *}$ & -0.074193 & $-1.869339 * * *$ \\
\hline Overall Effect (Calculated) & $0.619662 * *$ & $-4.806532 * * *$ & $-0.894725 * * *$ & $2.482551 * * *$ & $-0.072427 * * *$ & $-1.863650 * * *$ \\
\hline \multicolumn{7}{|l|}{ Population } \\
\hline Baseline Effect (Estimated) & -0.202063 & -0.371251 & -0.042424 & -0.362125 & -0.312349 & -0.375282 \\
\hline Additional Effect (Estimated) & $17.830479 *$ & $11.085624^{* * *}$ & $-15.626661^{* * *}$ & 0 & 0.514361 & $16.461924 * * *$ \\
\hline Overall Effect (Calculated) & $17.628417^{*}$ & $10.714369 * * *$ & $-15.669084^{* * *}$ & -0.3621245 & 0.202012 & $16.086638 * * *$ \\
\hline \multicolumn{7}{|l|}{ Overall Effect (Calculated) } \\
\hline $\mathrm{N}$ & 142 & 142 & 142 & 142 & 142 & 142 \\
\hline R2 & 0.9209 & 0.9215 & 0.9214 & 0.9331 & 0.9199 & 0.9263 \\
\hline
\end{tabular}

Note: Constant, trend and fixed-effect coefficients omitted for brevity.

Expenditure on Graduates at Nipissing University remains constant over time and is thus perfectly co-linear with the dummy variable. ${ }^{*} \mathrm{p}<0.10,{ }^{* *} \mathrm{p}<0.05,{ }^{* * *} \mathrm{p}<0.01$ 


\begin{tabular}{|c|c|c|c|c|c|c|}
\hline \multirow[b]{2}{*}{ Variables } & \multicolumn{6}{|c|}{ Fixed Effect (a modified Fixed Effect regression ) : Persistence Ratio } \\
\hline & OCAD_U & Queen's_U & Ryerson_U & Trent_U & U_Guelph & UOIT \\
\hline \multicolumn{7}{|l|}{ Awards } \\
\hline Baseline Effect (Estimated) & $0.218206 * * *$ & $0.215770 * * *$ & $0.210491 * *$ & $0.202742^{* *}$ & $0.187086 * *$ & 0.058234 \\
\hline Additional Effect (Estimated) & 0.05984 & $-0.630642 * * *$ & 0.075543 & $-2.132704^{* * *}$ & $5.630557 * * *$ & 0.237727 \\
\hline Overall Effect (Calculated) & $0.278047 * * *$ & $-0.414872 * * *$ & $0.286034^{* * *}$ & $-1.929962 * * *$ & $5.817643 * * *$ & 0.2959609 \\
\hline \multicolumn{7}{|l|}{ Marketing } \\
\hline Baseline Effect (Estimated) & 0.043839 & $0.047484 *$ & $0.051433^{*}$ & $0.048721^{*}$ & $0.059704 * *$ & 0.003386 \\
\hline Additional Effect (Estimated) & -0.342533 & $0.117776^{* *}$ & $0.301741^{* * *}$ & $-0.339147^{* * *}$ & $-1.938717^{* * *}$ & 0.066937 \\
\hline Overall Effect (Calculated) & -0.2986941 & $0.165260 * * *$ & $0.353174^{* * *}$ & $-0.290426^{* * *}$ & $-1.879013^{* * *}$ & 0.070323 \\
\hline \multicolumn{7}{|l|}{ Graduates } \\
\hline Baseline Effect (Estimated) & -0.0338 & -0.030708 & -0.032489 & -0.027405 & -0.030081 & -0.051199 \\
\hline Additional Effect (Estimated) & $0.637766^{* *}$ & 0.182112 & $0.282750 * * *$ & 0.281481 & $-3.624703 * * *$ & -0.066713 \\
\hline Overall Effect (Calculated) & $0.603966^{* *}$ & 0.1514035 & $0.250261 * * *$ & 0.2540757 & $-3.654784 * * *$ & $-0.117912 * * *$ \\
\hline \multicolumn{7}{|l|}{ Professors } \\
\hline Baseline Effect (Estimated) & -0.003343 & 0.001311 & 0.000526 & -0.006257 & -0.004421 & $-0.040741 *$ \\
\hline Additional Effect (Estimated) & -0.386457 & $-0.793643 * * *$ & $-0.850045^{* * *}$ & $0.749499 * *$ & $-3.606779 * * *$ & $0.494217^{* *}$ \\
\hline Overall Effect (Calculated) & -0.3897998 & $-0.792332 * * *$ & $-0.849519 * * *$ & $0.743242 * * *$ & $-3.611200 * * *$ & $0.453477^{* *}$ \\
\hline \multicolumn{7}{|l|}{ Population } \\
\hline Baseline Effect (Estimated) & -0.439948 & -0.336333 & -0.264835 & -0.50865 & -0.25406 & -0.117714 \\
\hline Additional Effect (Estimated) & 3.989136 & $6.531155^{* * *}$ & 0 & 0 & 6.744564 & -6.680447 \\
\hline Overall Effect (Calculated) & 3.5491876 & $6.194822 * * *$ & -0.2648352 & -0.5086499 & 6.4905044 & -6.7981605 \\
\hline $\mathrm{N}$ & 142 & 142 & 142 & 142 & 142 & 142 \\
\hline $\mathrm{R} 2$ & 0.9217 & 0.9207 & 0.9202 & 0.9255 & 0.9319 & 0.9311 \\
\hline
\end{tabular}

Note: Constant, trend and fixed-effect coefficients omitted for brevity.

${ }^{*} \mathrm{p}<0.10,{ }^{* *} \mathrm{p}<0.05,{ }^{* * *} \mathrm{p}<0.01$

\begin{tabular}{|c|c|c|c|c|c|c|c|}
\hline \multirow[b]{2}{*}{ Variables } & \multicolumn{7}{|c|}{ Fixed Effect (a modified Fixed Effect regression ) : Persistence Ratio } \\
\hline & U_Ottawa & U_Toronto & U_Waterloo & U_Windsor & Western_U & Wilfrid_U & York_U \\
\hline \multicolumn{8}{|l|}{ Awards } \\
\hline Baseline Effect (Estimated) & $0.205259 * * *$ & $0.178868 * *$ & $0.276139 * * *$ & $0.204969 * * *$ & 0.104067 & $0.200100 * *$ & $0.217362^{* * *}$ \\
\hline Additional Effect (Estimated) & $-0.306824^{*}$ & $-0.531233 * * *$ & -0.085259 & $1.085143^{* * *}$ & $-1.937673 * * *$ & $-1.103367 * * *$ & 1.204152 \\
\hline Overall Effect (Calculated) & -0.1015644 & $-0.352364 * * *$ & $0.190880 * * *$ & $1.290112^{* * *}$ & $-1.833606^{* * *}$ & $-0.903267^{* * *}$ & 1.4215142 \\
\hline \multicolumn{8}{|l|}{ Marketing } \\
\hline Baseline Effect (Estimated) & $0.058796 *$ & $0.073987^{* *}$ & $0.048616^{* *}$ & $0.052972 *$ & 0.030487 & $0.061234^{* *}$ & $0.056928^{* *}$ \\
\hline Additional Effect (Estimated) & -0.04816 & $-0.107264 * * *$ & -0.24486 & $-1.177745^{* * *}$ & $0.392268 * * *$ & $0.398665^{* * *}$ & $-2.362078^{*}$ \\
\hline Overall Effect (Calculated) & 0.0106358 & $-0.033277^{* * *}$ & -0.1962442 & $-1.124773^{* * *}$ & $0.422755^{* * *}$ & $0.459900 * * *$ & $-2.305150^{*}$ \\
\hline \multicolumn{8}{|l|}{ Graduates } \\
\hline Baseline Effect (Estimated) & -0.033231 & -0.03075 & -0.040549 & -0.03477 & -0.043377 & -0.033034 & -0.029912 \\
\hline Additional Effect (Estimated) & 0.148606 & $-0.285220^{* *}$ & $-0.240697^{* *}$ & 0.509665 & $2.667628^{* * *}$ & $-1.535377^{* * *}$ & $-0.362119 *$ \\
\hline Overall Effect (Calculated) & 0.1153751 & $-0.315970 * * *$ & $-0.281246 * * *$ & 0.474895 & $2.624251^{* * *}$ & $-1.568411^{* * *}$ & $-0.392031^{* *}$ \\
\hline \multicolumn{8}{|l|}{ Professors } \\
\hline Baseline Effect (Estimated) & 0.000736 & -0.003977 & -0.0072 & 0.004366 & $0.294341 * * *$ & 0.002029 & 0.00127 \\
\hline Additional Effect (Estimated) & 0.149219 & $0.877068^{* * *}$ & $-0.652254 * * *$ & $-1.161811^{* *}$ & $-0.275946 * * *$ & $3.421503^{* * *}$ & -0.470961 \\
\hline Overall Effect (Calculated) & 0.149955 & $0.873091^{* * *}$ & $-0.659454 * * *$ & $-1.157445 * *$ & 0.0183949 & $3.423532^{* * *}$ & -0.4696906 \\
\hline \multicolumn{8}{|l|}{ Population } \\
\hline Baseline Effect (Estimated) & -0.341371 & -0.075238 & -0.423207 & -0.096549 & -0.38504 & -0.316686 & -0.506345 \\
\hline Additional Effect (Estimated) & 0 & 0 & $4.866339 * * *$ & $-10.837952 * * *$ & $-5.498478 * * *$ & 0 & 1.840568 \\
\hline Overall Effect (Calculated) & -0.3413707 & -0.0752378 & $4.443132^{* * *}$ & $-10.934499 * * *$ & $-5.883518 * * *$ & -0.3166863 & 1.3342235 \\
\hline $\mathrm{N}$ & 142 & 142 & 142 & 142 & 142 & 142 & 142 \\
\hline R2 & 0.9204 & 0.9225 & 0.9267 & 0.9215 & 0.9294 & 0.9209 & 0.9247 \\
\hline
\end{tabular}

Note: Constant, trend and fixed-effect coefficients omitted for brevity.

${ }^{*} p<0.10,{ }^{* *} p<0.05,{ }^{* * *} p<0.01$ 


\section{General Discussion on the above Fixed Effect Tables}

This study has extended the LSDV model to estimate how the effect of expenditure on awards, marketing, graduates, and professors differs for each individual university. In this regression, the additional effects can estimate the difference in the effect of variables for different universities. The positive and significant additional effects suggest that a competitive variable (e.g., awards) has a larger effect on persistence ratio, while a negative and significant sign suggests that the competitive variable (e.g., graduates) has a smaller effect on persistence ratio for a specific university relative to all other Ontario universities. In this type of regression, overall effects were calculated by adding baseline effects and additional effects. The negative and significant overall effects for awards and marketing are paradoxical and counter-intuitive, while negative and significant signs on the overall effects for graduates and professors suggest that students see instruction and research as substitutes rather than complements.

By examining the effect of awards and marketing on persistence ratio, negative and significant overall effects for awards were shown for six universities and, similarly, for marketing in six universities. For example, persistence ratio is expected to change by about $-0.35 \%$ due to a $1 \%$ change in awards for University of Toronto, while persistence ratio is expected to change by about $-0.29 \%$ due to a $1 \%$ change in marketing for Trent University.

Negative and significant signs on the overall effects for graduates suggest that students see instruction and research as substitutes rather than complementary. Positive and significant signs on the overall effects for graduates suggest that students see instruction and research as complements rather than substitutes. The effect of graduates on persistence ratio was examined and a negative and significant overall effects were shown for eight universities, while positive and significant overall effects were shown for four universities. Negative and significant signs on the overall effects for professors suggest that students see instruction and research as 
substitutes rather than complementary. Positive and significant signs on the overall effects for professors suggest that students see instruction and research as complements rather than substitutes. The result of examining the effect of professors on persistence ratio shows negative and significant overall effects for nine universities, while positive and significant overall effects were shown for six universities. For example, persistence ratio is expected to change by about $-0.89 \%$ due to a $1 \%$ change in expenditure on professors for Lakehead University. Persistence ratio is expected to change by about $0.15 \%$ due to a $1 \%$ change in expenditure on professors for University of Ottawa. 


\section{Appendix H: Data Analysis: Robustness Checks}

\section{1) Robustness Check: Expenditure Ratio (Lagged Model)}

Lagged Expenditure Ratios were calculated by dividing expenditure on awards, marketing, graduates, and professors in previous year $(\mathrm{t}-1)$ by total expenditure in year $(\mathrm{t}-1)$. These expenditure ratios were used to estimate the percentage change of enrollees, applicants, and persistence ratio due to a $1 \%$ change in these ratio values. Expenditure ratio was used as a robustness check of the research results and findings. Detailed explanation of the Lagged Model is available in Appendix E.

\section{Table 10.1.}

Robustness Checks of the Relationship between Universities Expenditure on Price and NonPrice competitive variables (Expenditure Ratio) and Enrolment in Publicly Funded Universities in Ontario

\section{Table 10.1.1.}

Pooled OLS for Expenditure Ratio: Enrollees

\begin{tabular}{|c|c|c|c|c|c|c|}
\hline Linear regression & & $\begin{array}{l}\text { Number of ob } \\
\text { F( 6, 133) } \\
\text { Prob > F } \\
\text { R-squared } \\
\text { Root MSE }\end{array}$ & $\begin{array}{l}\text { os }=\quad 140 \\
=81.91 \\
=0.0000 \\
=0.6739 \\
=.44875\end{array}$ & & & \\
\hline Log Enrollees & Coef. & Robust Std. Err. & $\mathrm{t}$ & $\mathrm{P}>|\mathrm{t}|$ & [95\% Conf. & Interval] \\
\hline log Award_Ratio (t-1) & 1.313054 & 0.1712324 & 7.67 & 0.000 & 0.9743629 & 1.651745 \\
\hline log Marketing_Ratio(t-1) & 0.0249958 & 0.0627913 & 0.4 & 0.691 & -0.0992029 & 0.1491945 \\
\hline log Graduates_Ratio(t-1) & 0.0034549 & 0.0154258 & 0.22 & 0.823 & -0.0270568 & 0.0339666 \\
\hline log Professors_Ratio (t-1) & -0.8257814 & 0.3233938 & -2.55 & 0.012 & -1.465442 & -0.1861211 \\
\hline $\log$ Population (t) & 0.2493409 & 0.0374872 & 6.65 & 0.000 & 0.1751928 & 0.323489 \\
\hline Trend & 0.0105733 & 0.0153973 & 0.69 & 0.493 & -0.019882 & 0.0410286 \\
\hline Constant & 9.018452 & 0.62005 & 14.54 & 0.000 & 7.792017 & 10.24489 \\
\hline
\end{tabular}

Note. Independent variables are lagged by one year $(\mathrm{t}-1)$. Population is an unlagged variable $(\mathrm{t})$.

Robust standard errors are reported in the table. 
Table 10.1.2.

Fixed Effect (LSDV) for Expenditure Ratio: Enrollees

Linear regression
Number of obs $=\quad 140$
$F(24, \quad 115)=1404.57$
Prob $>F=0.0000$
R-squared $=0.9955$
Root MSE $=.05656$

\begin{tabular}{|c|c|c|c|c|c|c|}
\hline Log Enrollees & Coef. & Robust Std. Err. & $\mathrm{t}$ & $\mathrm{P}>|\mathrm{t}|$ & [95\% Conf. & Interval] \\
\hline log Award_Ratio (t-1) & 0.3246209 & 0.0559179 & 5.81 & 0.000 & 0.2138582 & 0.4353836 \\
\hline log Marketing_Ratio(t-1) & 0.0595272 & 0.0261781 & 2.27 & 0.025 & 0.0076735 & 0.1113809 \\
\hline log Graduates_Ratio(t-1) & 0.013413 & 0.0125259 & 1.07 & 0.286 & -0.0113984 & 0.0382244 \\
\hline log Professors_Ratio (t-1) & 0.0414263 & 0.0380083 & 1.09 & 0.278 & -0.0338608 & 0.1167134 \\
\hline $\log$ Population $(\mathrm{t})$ & 1.311034 & 0.3676903 & 3.57 & 0.001 & 0.5827103 & 2.039358 \\
\hline Trend & 0.0051715 & 0.0043362 & 1.19 & 0.235 & -0.0034177 & 0.0137607 \\
\hline Constant & -8.028103 & 5.715289 & -1.4 & 0.163 & -19.34899 & 3.292784 \\
\hline U_Toronto & (omitted) & & & & & \\
\hline Brock_U & 2.035021 & 0.9591473 & 2.12 & 0.036 & 0.1351344 & 3.934907 \\
\hline Carleton_U & 0.783603 & 0.5500768 & 1.42 & 0.157 & -0.3059932 & 1.873199 \\
\hline Lakehead_U & 2.794492 & 1.391609 & 2.01 & 0.047 & 0.0379813 & 5.551002 \\
\hline Laurentian_U & 2.558144 & 1.284708 & 1.99 & 0.049 & 0.0133839 & 5.102904 \\
\hline McMaster_U & 1.622393 & 0.7351059 & 2.21 & 0.029 & 0.16629 & 3.078497 \\
\hline Nipissing_U & 3.554469 & 1.59307 & 2.23 & 0.028 & 0.3989039 & 6.710035 \\
\hline OCAD_U & -2.757147 & 0.0636657 & -43.31 & 0.000 & -2.883256 & -2.631037 \\
\hline Queens_U & 3.328015 & 1.30034 & 2.56 & 0.012 & 0.7522911 & 5.903739 \\
\hline Ryerson_U & -0.8440043 & 0.0381243 & -22.14 & 0 & -0.9195212 & -0.7684875 \\
\hline Trent_U & 2.773066 & 1.409495 & 1.97 & 0.052 & -0.0188733 & 5.565005 \\
\hline U_Guelph & 3.752255 & 1.338349 & 2.8 & 0.006 & 1.101243 & 6.403267 \\
\hline UOIT_U & 1.456086 & 0.9932686 & 1.47 & 0.145 & -0.5113878 & 3.42356 \\
\hline U_Ottawa & 1.152032 & 0.5538554 & 2.08 & 0.040 & 0.0549513 & 2.249113 \\
\hline U_Waterloo & 2.137911 & 0.8979604 & 2.38 & 0.019 & 0.3592238 & 3.916597 \\
\hline U_Windsor & 2.244667 & 1.035796 & 2.17 & 0.032 & 0.1929555 & 4.296379 \\
\hline Western_U & 2.172122 & 0.8941028 & 2.43 & 0.017 & 0.4010762 & 3.943167 \\
\hline Wilfrid_U & 1.70759 & 0.8856193 & 1.93 & 0.056 & -0.0466516 & 3.461831 \\
\hline York_U & -0.3239942 & 0.0334221 & -9.69 & 0 & -0.390197 & -0.2577914 \\
\hline
\end{tabular}

Note. University of Toronto is the base.

Independent variables are lagged by one year $(\mathrm{t}-1)$. Population is an unlagged variable $(\mathrm{t})$.

Robust standard errors are reported in the table. 


\section{Table 10.1.3.}

Random Effect for Expenditure Ratio: Enrollees

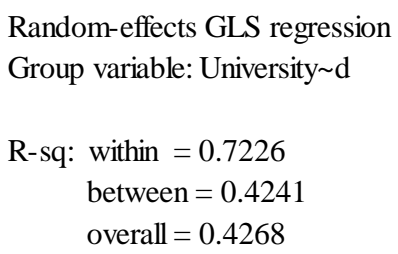

corr $\left(\mathrm{u} \_\mathrm{i}, \mathrm{X}\right)=0$ (assumed)

(Std. Err. adjusted for 19 clusters in University_id)

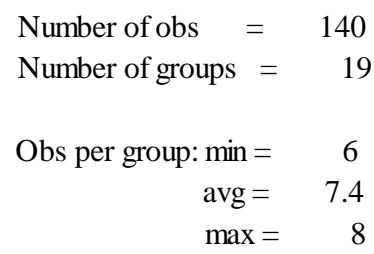

\begin{tabular}{lcccccc}
\hline Log Enrollees & Coef. & Robust Std. Err. & $\mathrm{z}$ & $\mathrm{P}>|\mathrm{z}|$ & [95\% Conf. & Interval] \\
\hline $\log$ Award_Ratio (t-1) & 0.3585452 & 0.0695682 & 5.15 & 0.000 & 0.2221941 & 0.4948963 \\
$\log$ Marketing_Ratio(t-1) & 0.0566845 & 0.0380598 & 1.49 & 0.136 & -0.0179115 & 0.1312804 \\
$\log$ Graduates_Ratio(t-1) & 0.0232579 & 0.0181628 & 1.28 & 0.2 & -0.0123406 & 0.0588564 \\
$\log$ Professors_Ratio (t-1) & 0.0273843 & 0.0355766 & 0.77 & 0.441 & -0.0423446 & 0.0971132 \\
$\log$ Population (t) & 0.2895063 & 0.1379367 & 2.1 & 0.036 & 0.0191554 & 0.5598572 \\
Trend & 0.0143203 & 0.0052188 & 2.74 & 0.006 & 0.0040917 & 0.0245489 \\
Constant & 7.164566 & 1.734869 & 4.13 & 0.000 & 3.764285 & 10.56485 \\
\hline sigma_u & 0.45702478 & & & & \\
sigma_e & 0.05655674 & & & & \\
rho & 0.98491696 & (fraction of variance due to u_i) & & & \\
\hline
\end{tabular}

Note. Independent variables are lagged by one year $(\mathrm{t}-1)$. Population is an unlagged variable $(\mathrm{t})$.

Robust standard errors are reported in the table.

Note. The results reported throughout the thesis arise from running these regressions with robust standard errors. Regression results are summarized in Table 10.1.4. 
Table 10.1.4.

Summary Results from Pooled OLS, Fixed (LSDV), and Random Effect Regressions with Robust

Standard Errors and without Robust Standard Errors for Expenditure Ratio: Enrollees.

\begin{tabular}{|c|c|c|c|c|c|c|c|c|c|}
\hline \multirow[b]{3}{*}{ Independent Variable } & \multicolumn{9}{|c|}{ Dependent Variable: Log Enrollees } \\
\hline & \multicolumn{3}{|c|}{ Pooled OLS } & \multicolumn{3}{|c|}{ Fixed Effect LSDV } & \multicolumn{3}{|c|}{ RandomEffect } \\
\hline & Coef. & $\begin{array}{c}\text { Non_Robust } \\
\text { Std. } \sim \mathrm{s} \\
\end{array}$ & $\begin{array}{c}\text { Robust } \\
\text { Std. S } \\
\end{array}$ & Coef. & $\begin{array}{c}\text { Non_Robust } \\
\text { Std. s } \\
\end{array}$ & $\begin{array}{l}\text { Robust } \\
\text { Std. S } \\
\end{array}$ & Coef. & $\begin{array}{c}\text { Non_Robust } \\
\text { Std. } \sim \mathrm{s} \\
\end{array}$ & $\begin{array}{l}\text { Robust } \\
\text { Std. } \sim \mathrm{S} \\
\end{array}$ \\
\hline log Award_Ratio (t-1) & 1.313053 & $(0.110516)$ & $(0.171232)$ & 0.324622 & $(0.042109)$ & $(0.055918)$ & 0.358546 & $(0.044402)$ & $(0.069568)$ \\
\hline log Marketing_Ratio (t-1) & 0.024996 & $(0.068960)$ & $(0.062791)$ & 0.059527 & $(0.022328)$ & $(0.026178)$ & 0.056684 & $(0.023939)$ & $(0.038060)$ \\
\hline log Graduates_Ratio (t-1) & 0.003455 & $(0.014746)$ & $(0.015426)$ & 0.013413 & $(0.013883)$ & $(0.012526)$ & 0.023258 & $(0.013799)$ & $(0.018163)$ \\
\hline log Professors_Ratio (t-1) & -0.82578 & $(0.127950)$ & $(0.323394)$ & 0.041424 & $(0.024808)$ & $(0.038008)$ & 0.027382 & $(0.026583)$ & $(0.035577)$ \\
\hline Log Population (t) & 0.249341 & $(0.030464)$ & $(0.037487)$ & 1.311035 & $(0.348814)$ & $(0.367690)$ & 0.289506 & $(0.080624)$ & $(0.137937)$ \\
\hline Trend & 0.010573 & $(0.017232)$ & $(0.015397)$ & 0.005172 & $(0.004035)$ & $(0.004336)$ & 0.01432 & $(0.002783)$ & $(0.005219)$ \\
\hline Constant & 9.01845 & $(0.550611)$ & $(0.620050)$ & -8.028117 & $(5.426333)$ & $(5.715289)$ & 7.164567 & (1.087299) & $(1.734869)$ \\
\hline U_Toronto & & & & (omitted) & & & & & \\
\hline Brock_U & & & & 2.035023 & $(0.916095)$ & $(0.959147)$ & & & \\
\hline Carleton_U & & & & 0.783605 & $(0.527624)$ & $(0.550077)$ & & & \\
\hline Lakehead_U & & & & 2.794495 & (1.324116) & $(1.391609)$ & & & \\
\hline Laurentian_U & & & & 2.558147 & $(1.223522)$ & $(1.284708)$ & & & \\
\hline McMaster_U & & & & 1.622396 & $(0.708698)$ & $(0.735106)$ & & & \\
\hline Nipissing_U & & & & 3.554473 & (1.527837) & $(1.593070)$ & & & \\
\hline OCAD_U & & & & -2.757145 & $(0.054016)$ & $(0.063666)$ & & & \\
\hline Queens_U & & & & 3.328017 & (1.236378) & $(1.300340)$ & & & \\
\hline Ryerson_U & & & & -0.844006 & $(0.034246)$ & $(0.038124)$ & & & \\
\hline Trent_U & & & & 2.773069 & (1.335933) & $(1.409495)$ & & & \\
\hline U_Guelph & & & & 3.752258 & $(1.274242)$ & $(1.338349)$ & & & \\
\hline UOIT_U & & & & 1.456088 & $(0.951367)$ & $(0.993269)$ & & & \\
\hline U_Ottawa & & & & 1.152032 & $(0.530013)$ & $(0.553855)$ & & & \\
\hline U_Waterloo & & & & 2.137913 & $(0.855985)$ & $(0.897960)$ & & & \\
\hline U_Windsor & & & & 2.24467 & $(0.985355)$ & $(1.035796)$ & & & \\
\hline Western_U & & & & 2.172122 & $(0.854231)$ & $(0.894103)$ & & & \\
\hline Wilfrid_U & & & & 1.707592 & $(0.848605)$ & $(0.885619)$ & & & \\
\hline York_U & & & & -0.323996 & $(0.034943)$ & $(0.033422)$ & & & \\
\hline No. of Obs. & 140 & & & 140 & & & 140 & & \\
\hline R-Squared & 0.67 & & & 0.9955 & & & 0.4268 & & \\
\hline
\end{tabular}

Note. Robust and Non-Robust Standard errors are in parentheses.

University of Toronto is the base.

Independent variables are lagged by one year (t-1). Population is an unlagged variable (t). 


\section{Table 10.2.}

Robustness Checks of the Relationship between Universities Expenditure on Price and Non-

Price Competitive Variables (Expenditure Ratio) and Total Number of Applicants

Table 10.2.1. Pooled OLS for Expenditure Ratio: Applicants

Linear regression

$$
\begin{aligned}
& \text { Number of obs }=141 \\
& \mathrm{~F}(6, \quad 134)=123.39 \\
& \text { Prob }>\mathrm{F}=0.0000 \\
& \text { R-squared }=0.6333 \\
& \text { Root MSE }=.56215
\end{aligned}
$$

\begin{tabular}{lcccccc}
\hline \multicolumn{1}{c}{ Log Applicants } & Coef. & Robust Std. Err. & $\mathrm{t}$ & $\mathrm{P}>|\mathrm{t}|$ & {$[95 \%$ Conf. } & Interval] \\
\hline $\log$ Award_Ratio (t-1) & 1.322012 & 0.220599 & 5.99 & 0.000 & 0.8857054 & 1.758318 \\
$\log$ Marketing_Ratio(t-1) & 0.1264367 & 0.0745171 & 1.7 & 0.092 & -0.0209452 & 0.2738186 \\
$\log$ Graduates_Ratio(t-1) & 0.0132582 & 0.0193322 & 0.69 & 0.494 & -0.0249775 & 0.0514939 \\
$\log$ Professors_Ratio (t-1) & -1.154481 & 0.4389029 & -2.63 & 0.010 & -2.022555 & -0.2864078 \\
log Population(t) & 0.275162 & 0.0456424 & 6.03 & 0.000 & 0.1848893 & 0.3654346 \\
Trend & 0.0088967 & 0.0190416 & 0.47 & 0.641 & -0.0287642 & 0.0465577 \\
Constant & 8.624344 & 0.8156426 & 10.57 & 0.000 & 7.011145 & 10.23754 \\
\hline
\end{tabular}

Note. Independent variables are lagged by one year $(\mathrm{t}-1)$. Population is an unlagged variable $(\mathrm{t})$.

Robust standard errors are reported in the table. 
Table 10.2.2.

Fixed Effect (LSDV) for Expenditure Ratio: Applicants

Linear regression

Number of obs $=141$
$F(24, \quad 116)=3865.01$
Prob $>F=0.0000$
R-squared $=0.9935$
Root MSE $=.08042$

\begin{tabular}{|c|c|c|c|c|c|c|}
\hline Log Applicants & Coef. & Robust Std. Err. & $\mathrm{t}$ & $\mathrm{P}>|\mathrm{t}|$ & [95\% Conf. & Interval] \\
\hline log Award_Ratio (t-1) & 0.1265015 & 0.0565236 & 2.24 & 0.027 & 0.0145494 & 0.2384535 \\
\hline log Marketing_Ratio(t-1) & 0.0098096 & 0.0191144 & 0.51 & 0.609 & -0.0280488 & 0.047668 \\
\hline log Graduates_Ratio(t-1) & 0.0437443 & 0.039398 & 1.11 & 0.269 & -0.0342884 & 0.121777 \\
\hline log Professors_Ratio (t-1) & 0.0450012 & 0.0182832 & 2.46 & 0.015 & 0.0087891 & 0.0812133 \\
\hline $\log$ Population $(\mathrm{t})$ & 1.499056 & 0.4785484 & 3.13 & 0.002 & 0.551231 & 2.446882 \\
\hline Trend & 0.001218 & 0.0053067 & 0.23 & 0.819 & -0.0092925 & 0.0117286 \\
\hline Constant & -11.71682 & 7.461855 & -1.57 & 0.119 & -26.49597 & 3.062321 \\
\hline U_Toronto & (omitted) & & & & & \\
\hline Brock_U & 2.841194 & 1.252422 & 2.27 & 0.025 & 0.3606148 & 5.321773 \\
\hline Carleton_U & 1.386029 & 0.7223835 & 1.92 & 0.057 & -0.0447427 & 2.8168 \\
\hline Lakehead_U & 3.302707 & 1.811291 & 1.82 & 0.071 & -0.2847825 & 6.890197 \\
\hline Laurentian_U & 3.237213 & 1.674512 & 1.93 & 0.056 & -0.0793695 & 6.553795 \\
\hline McMaster_U & 2.574744 & 0.9663991 & 2.66 & 0.009 & 0.6606691 & 4.488819 \\
\hline Nipissing_U & 4.590274 & 2.105296 & 2.18 & 0.031 & 0.4204698 & 8.760078 \\
\hline OCAD_U & -3.056404 & 0.077022 & -39.68 & 0.000 & -3.208956 & -2.903853 \\
\hline Queens_U & 4.440351 & 1.69315 & 2.62 & 0.010 & 1.086854 & 7.793847 \\
\hline Ryerson_U & -0.190992 & 0.0319408 & -5.98 & 0.000 & -0.2542548 & -0.1277293 \\
\hline Trent_U & 3.752109 & 1.827992 & 2.05 & 0.042 & 0.1315395 & 7.372678 \\
\hline U_Guelph & 4.562744 & 1.731411 & 2.64 & 0.010 & 1.133467 & 7.992021 \\
\hline UOIT_U & 2.330204 & 1.293453 & 1.8 & 0.074 & -0.2316418 & 4.89205 \\
\hline U_Ottawa & 1.525767 & 0.7272016 & 2.1 & 0.038 & 0.0854529 & 2.966082 \\
\hline U_Waterloo & 3.074847 & 1.174114 & 2.62 & 0.010 & 0.7493667 & 5.400327 \\
\hline U_Windsor & 2.750061 & 1.35377 & 2.03 & 0.044 & 0.0687483 & 5.431373 \\
\hline Western_U & 3.214419 & 1.16948 & 2.75 & 0.007 & 0.8981168 & 5.530721 \\
\hline Wilfrid_U & 2.690608 & 1.155633 & 2.33 & 0.022 & 0.4017315 & 4.979485 \\
\hline York_U & -0.0923941 & 0.0710064 & -1.3 & 0.196 & -0.2330312 & 0.048243 \\
\hline
\end{tabular}

Note. University of Toronto is the base.

Independent variables are lagged by one year ( $\mathrm{t}-1)$. Population is an unlagged variable $(\mathrm{t})$.

Robust standard errors are reported in the table. 


\section{Table 10.2.3.}

Random Effect for Expenditure Ratio: Applicants

Random-effects GLS regression

Group variable: University d

R-sq: within $=0.3666$

between $=0.3498$

overall $=0.3563$

$\operatorname{corr}\left(\mathrm{u} \_\mathrm{i}, \mathrm{X}\right)=0$ (assumed)

(Std. Err. adjusted for 19 clusters in University_id)

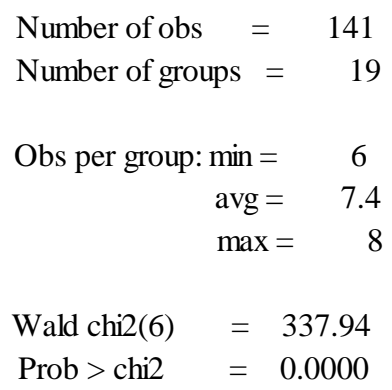

\begin{tabular}{lcccccc}
\hline \multicolumn{1}{c}{ Log Applicants } & Coef. & Robust Std. Err. & $\mathrm{z}$ & $\mathrm{P}>|\mathrm{z}|$ & [95\% Conf. & Interval] \\
\hline log Award_Ratio (t-1) & 0.1712228 & 0.0419158 & 4.08 & 0.000 & 0.0890693 & 0.2533763 \\
log Marketing_Ratio(t-1) & 0.0084418 & 0.0213878 & 0.39 & 0.693 & -0.0334776 & 0.0503612 \\
log Graduates_Ratio(t-1) & 0.0567938 & 0.0108568 & 5.23 & 0.000 & 0.0355149 & 0.0780728 \\
log Professors_Ratio (t-1) & 0.0243378 & 0.0250888 & 0.97 & 0.332 & -0.0248353 & 0.073511 \\
log Population(t) & 0.2786626 & 0.178717 & 1.56 & 0.119 & -0.0716162 & 0.6289414 \\
Trend & 0.0121462 & 0.0050035 & 2.43 & 0.015 & 0.0023395 & 0.0219528 \\
Constant & 6.814892 & 2.287859 & 2.98 & 0.003 & 2.330772 & 11.29901 \\
\hline sigma_u & 0.54243795 & & & & & \\
sigma_e & 0.08042456 & & & & & \\
rho & 0.97849033 & (fraction of variance due to u_i) & & & \\
\hline
\end{tabular}

Note. Independent variables are lagged by one year $(\mathrm{t}-1)$. Population is an unlagged variable $(\mathrm{t})$.

Robust standard errors are reported in the table.

Note. The results reported throughout the thesis arise from running panel regression models with robust standard errors. Regression results are summarized in Table 10.2.4. 
Table 10.2.4.

Summary Results from Pooled OLS, Fixed (LSDV), and Random Effect Regressions with Robust

Standard Errors and without Robust Standard Errors for Expenditure Ratio: Applicants.

\begin{tabular}{|c|c|c|c|c|c|c|c|c|c|}
\hline \multirow[b]{3}{*}{ Independent Variable } & \multicolumn{8}{|c|}{ Dependent Variable: Log Applicants } & \\
\hline & \multicolumn{3}{|c|}{ Pooled OLS } & \multicolumn{3}{|c|}{ Fixed Effect LSDV } & \multicolumn{3}{|c|}{ Random Effect } \\
\hline & Coef. & $\begin{array}{c}\text { Non_Robust } \\
\text { Std. s } \\
\end{array}$ & $\begin{array}{l}\text { Robust } \\
\text { Std. S }\end{array}$ & Coef. & $\begin{array}{c}\text { Non_Robust } \\
\text { Std. } \sim \mathrm{S}\end{array}$ & $\begin{array}{l}\text { Robust } \\
\text { Std. } \sim \text { S }\end{array}$ & Coef. & $\begin{array}{c}\text { Non_Robust } \\
\text { Std. } \sim \mathrm{S} \\
\end{array}$ & $\begin{array}{l}\text { Robust } \\
\text { Std. s }\end{array}$ \\
\hline log Award_Ratio (t-1) & 1.322011 & $(0.138311)$ & $(0.220599)$ & 0.126502 & $(0.059838)$ & $(0.056524)$ & 0.171224 & $(0.062894)$ & $(0.041916)$ \\
\hline log Marketing_Ratio (t-1) & 0.126437 & $(0.086385)$ & $(0.074517)$ & 0.009808 & $(0.031745)$ & $(0.019114)$ & 0.00844 & $(0.033979)$ & $(0.021388)$ \\
\hline log Graduates_Ratio (t-1) & 0.013258 & $(0.017543)$ & $(0.019332)$ & 0.043744 & $(0.019741)$ & $(0.039398)$ & 0.056794 & $(0.019077)$ & $(0.010857)$ \\
\hline log Professors_Ratio (t-1) & -1.154481 & $(0.160272)$ & $(0.438903)$ & 0.045001 & $(0.035277)$ & $(0.018283)$ & 0.024337 & $(0.037816)$ & $(0.025089)$ \\
\hline Log Population (t) & 0.275162 & $(0.038155)$ & $(0.045642)$ & 1.499059 & $(0.495983)$ & $(0.478548)$ & 0.278662 & $(0.096992)$ & $(0.178717)$ \\
\hline Trend & 0.008897 & $(0.021571)$ & $(0.019042)$ & 0.001218 & $(0.005737)$ & $(0.005307)$ & 0.012146 & $(0.003912)$ & $(0.005004)$ \\
\hline Constant & 8.624342 & $(0.69)$ & $(0.82)$ & -11.716871 & (7.715665) & (7.461855) & 6.814891 & $(1.31)$ & $(2.29)$ \\
\hline U_Toronto & & & & (omitted) & & (omitted) & & & \\
\hline Brock_U & & & & 2.841204 & $(1.30)$ & $(1.25)$ & & & \\
\hline Carleton_U & & & & 1.386033 & $(0.75)$ & $(0.72)$ & & & \\
\hline Lakehead_U & & & & 3.30272 & $(1.88)$ & $(1.81)$ & & & \\
\hline Laurentian_U & & & & 3.237225 & $(1.74)$ & $(1.67)$ & & & \\
\hline McMaster_U & & & & 2.574755 & $(1.01)$ & $(0.97)$ & & & \\
\hline Nipissing_U & & & & 4.590291 & $(2.17)$ & $(2.11)$ & & & \\
\hline OCAD_U & & & & -3.056401 & $(0.08)$ & $(0.08)$ & & & \\
\hline Queens_U & & & & 4.440363 & $(1.76)$ & (1.69) & & & \\
\hline Ryerson_U & & & & -0.190992 & $(0.05)$ & $(0.03)$ & & & \\
\hline Trent_U & & & & 3.752121 & $(1.90)$ & (1.83) & & & \\
\hline U_Guelph & & & & 4.562755 & $(1.81)$ & (1.73) & & & \\
\hline UOIT_U & & & & 2.330215 & $(1.35)$ & (1.29) & & & \\
\hline U_Ottawa & & & & 1.525772 & $(0.75)$ & $(0.73)$ & & & \\
\hline U_Waterloo & & & & 3.074856 & $(1.22)$ & $(1.17)$ & & & \\
\hline U_Windsor & & & & 2.750071 & $(1.40)$ & $(1.35)$ & & & \\
\hline Western_U & & & & 3.21443 & $(1.21)$ & (1.17) & & & \\
\hline Wilfrid_U & & & & 2.690619 & $(1.21)$ & (1.16) & & & \\
\hline York_U & & & & -0.092391 & $(0.05)$ & $(0.07)$ & & & \\
\hline No. of Obs. & 141 & & & 141 & & & 141 & & \\
\hline R-Squared & 0.63 & & & 0.99 & & & 0.36 & & \\
\hline
\end{tabular}

Note. Robust and Non-Robust Standard errors are in parentheses.

University of Toronto is the base.

Independent variables are lagged by one year $(\mathrm{t}-1)$. Population is an unlagged variable $(\mathrm{t})$.

Note. The results from the above regressions were compared with Lagged Models. The results are broadly similar. 


\section{Table 10.3.}

Robustness Checks of the Relationship between Universities Expenditure on Price and Non-

Price Competitive Variables (Expenditure Ratio) and Persistence Ratio

\section{Table 10.3.1. Pooled OLS for Expenditure Ratio: Persistence Ratio}

Linear regression

$$
\begin{aligned}
& \text { Number of obs }=140 \\
& F(6, \quad 133)=14.70 \\
& \text { Prob }>F=0.0000 \\
& \text { R-squared }=0.2910 \\
& \text { Root MSE }=.2451
\end{aligned}
$$

\begin{tabular}{lcccccc}
\hline \multicolumn{1}{c}{ Log Persistence Ratio } & Coef. & Robust Std. Err. & $\mathrm{t}$ & $\mathrm{P}>|\mathrm{t}|$ & {$[95 \%$ Conf. } & Interval] \\
\hline $\log$ Award_Ratio (t-1) & -0.0078417 & 0.0678628 & -0.12 & 0.908 & -0.1420717 & 0.1263884 \\
$\log$ Marketing_Ratio(t-1) & -0.101321 & 0.0325501 & -3.11 & 0.002 & -0.1657038 & -0.0369383 \\
$\log$ Graduates_Ratio(t-1) & -0.0108702 & 0.0069062 & -1.57 & 0.118 & -0.0245303 & 0.00279 \\
$\log$ Professors_Ratio (t-1) & 0.3283439 & 0.1240088 & 2.65 & 0.009 & 0.0830593 & 0.5736285 \\
$\log$ Population (t) & -0.0256906 & 0.0191388 & -1.34 & 0.182 & -0.0635464 & 0.0121652 \\
Trend & 0.0015251 & 0.0087596 & 0.17 & 0.862 & -0.0158011 & 0.0188513 \\
Constant & 0.3930083 & 0.3647935 & 1.08 & 0.283 & -0.3285391 & 1.114556 \\
\hline
\end{tabular}

Note. Independent variables are lagged by one year $(\mathrm{t}-1)$. Population is an unlagged variable $(\mathrm{t})$.

Robust standard errors are reported in the table. 
Table 10.3.2.

Fixed Effect (LSDV) for Expenditure Ratio: Persistence Ratio

Linear regression

Number of obs $=140$

$\mathrm{F}(24,115)=259.98$

Prob $>\mathrm{F}=0.0000$

R-squared $=0.9175$

Root MSE $=.08992$

\begin{tabular}{|c|c|c|c|c|c|c|}
\hline Log Persistence Ratio & Coef. & Robust Std. Err. & $\mathrm{t}$ & $\mathrm{P}>|\mathrm{t}|$ & {$[95 \%$ Conf. } & Interval] \\
\hline log Award_Ratio (t-1) & 0.2000821 & 0.0813458 & 2.46 & 0.015 & 0.0389517 & 0.3612124 \\
\hline log Marketing_Ratio(t-1) & 0.0502423 & 0.0300471 & 1.67 & 0.097 & -0.0092752 & 0.1097598 \\
\hline log Graduates_Ratio(t-1) & -0.0303038 & 0.0402737 & -0.75 & 0.453 & -0.1100784 & 0.0494707 \\
\hline log Professors_Ratio (t-1) & -0.0036002 & 0.0484757 & -0.07 & 0.941 & -0.0996213 & 0.0924209 \\
\hline $\log$ Population $(\mathrm{t})$ & -0.1932845 & 0.4624069 & -0.42 & 0.677 & -1.109224 & 0.7226545 \\
\hline Trend & 0.0038703 & 0.0053851 & 0.72 & 0.474 & -0.0067966 & 0.0145372 \\
\hline Constant & 3.77815 & 7.22584 & 0.52 & 0.602 & -10.53485 & 18.09115 \\
\hline U_Toronto & (omitted) & & & & & \\
\hline Brock_U & -0.8200984 & 1.199263 & -0.68 & 0.495 & -3.195608 & 1.555411 \\
\hline Carleton_U & -0.6110054 & 0.6888225 & -0.89 & 0.377 & -1.97543 & 0.7534194 \\
\hline Lakehead_U & -0.5281465 & 1.744428 & -0.3 & 0.763 & -3.983522 & 2.927229 \\
\hline Laurentian_U & -0.6974804 & 1.605969 & -0.43 & 0.665 & -3.878597 & 2.483636 \\
\hline McMaster_U & -0.9636256 & 0.9197671 & -1.05 & 0.297 & -2.785507 & 0.858256 \\
\hline Nipissing_U & -1.046877 & 1.991525 & -0.53 & 0.600 & -4.991706 & 2.897951 \\
\hline OCAD_U & 0.3005309 & 0.0988732 & 3.04 & 0.003 & 0.1046822 & 0.4963797 \\
\hline Queens_U & -1.131245 & 1.630094 & -0.69 & 0.489 & -4.360148 & 2.097657 \\
\hline Ryerson_U & -0.6522085 & 0.0464866 & -14.03 & 0.000 & -0.7442894 & -0.5601275 \\
\hline Trent_U & -0.9993696 & 1.759284 & -0.57 & 0.571 & -4.484172 & 2.485433 \\
\hline U_Guelph & -0.8289086 & 1.665108 & -0.5 & 0.620 & -4.127168 & 2.469351 \\
\hline UOIT_U & -0.8866576 & 1.233143 & -0.72 & 0.474 & -3.329277 & 1.555962 \\
\hline U_Ottawa & -0.3823891 & 0.699062 & -0.55 & 0.585 & -1.767096 & 1.002318 \\
\hline U_Waterloo & -0.9510077 & 1.130878 & -0.84 & 0.402 & -3.191059 & 1.289043 \\
\hline U_Windsor & -0.5201281 & 1.292924 & -0.4 & 0.688 & -3.081162 & 2.040905 \\
\hline Western_U & -1.055758 & 1.12091 & -0.94 & 0.348 & -3.276066 & 1.164549 \\
\hline Wilfrid_U & -0.996044 & 1.102107 & -0.9 & 0.368 & -3.179107 & 1.187019 \\
\hline York_U & -0.2315164 & 0.0760963 & -3.04 & 0.003 & -0.3822485 & -0.0807843 \\
\hline
\end{tabular}

Note. University of Toronto is the base.

Independent variables are lagged by one year $(\mathrm{t}-1)$. Population is an unlagged variable $(\mathrm{t})$.

Robust standard errors are reported in the table. 


\section{Table 10.3.3.}

Random Effect for Expenditure Ratio: Persistence Ratio

Random-effects GLS regression

Group variable: University $\sim$

R-sq: within $=0.1662$

between $=0.1032$

overall $=0.0898$

corr $\left(\mathrm{u} \_\mathrm{i}, \mathrm{X}\right)=0$ (assumed)

(Std. Err. adjusted for 19 clusters in University_id)

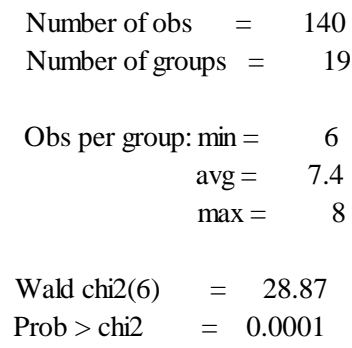

\begin{tabular}{|c|c|c|c|c|c|c|}
\hline Log Persistence Ratio & Coef. & Robust Std. Err. & $\mathrm{Z}$ & $\mathrm{P}>|\mathrm{z}|$ & [95\% Conf. & Interval] \\
\hline log Award_Ratio (t-1) & 0.1880053 & 0.0843454 & 2.23 & 0.026 & 0.0226915 & 0.3533192 \\
\hline log Marketing_Ratio(t-1) & 0.0349931 & 0.0397606 & 0.88 & 0.379 & -0.0429364 & 0.1129225 \\
\hline log Graduates_Ratio(t-1) & -0.0328101 & 0.0100248 & -3.27 & 0.001 & -0.0524584 & -0.0131618 \\
\hline log Professors_Ratio (t-1) & 0.0127114 & 0.0599461 & 0.21 & 0.832 & -0.1047808 & 0.1302036 \\
\hline $\log$ Population (t) & 0.0002787 & 0.0576548 & 0 & 0.996 & -0.1127226 & 0.1132801 \\
\hline Trend & 0.0020079 & 0.0043684 & 0.46 & 0.646 & -0.0065539 & 0.0105698 \\
\hline Constant & 0.4697276 & 0.8538463 & 0.55 & 0.582 & -1.20378 & 2.143235 \\
\hline sigma_u & 0.23975363 & & & & & \\
\hline sigma_e & 0.0899232 & & & & & \\
\hline rho & 0.87667483 & (fraction of variance & & & & \\
\hline
\end{tabular}

Note. Independent variables are lagged by one year $(\mathrm{t}-1)$. Population is an unlagged variable $(\mathrm{t})$.

Robust standard errors are reported in the table.

Note. The results from the above regressions were compared with Lagged models. The results are considerably similar. 


\section{2) Robustness Check - Unlagged Model}

An Unlagged model was used to estimate the responsiveness of enrollees, applicants, and persistence ratio in a year $(\mathrm{t})$ to expenditure on the adopted competitive variables in the same year (t). An Unlagged model was used as a robustness check of the research results and findings.

\section{Table 11.1.}

Robustness Checks of the Relationship between Universities Expenditure on Price and Non-

Price Competitive Variables (Unlagged Variables) and Enrolment in Publicly Funded

Universities in Ontario

Table 11.1.1. Pooled OLS for Unlagged Model: Enrollees

\begin{tabular}{|c|c|c|c|c|c|c|}
\hline Linear regression & & $\begin{array}{l}\text { Numb } \\
\text { F( 6, } \\
\text { Prob } \\
\text { R-squ } \\
\text { Root }\end{array}$ & 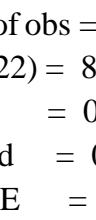 & & & \\
\hline Log Enrollees & Coef. & Robust Std. Err. & $\mathrm{t}$ & $\mathrm{P}>|\mathrm{t}|$ & [95\% Conf. & Interval] \\
\hline $\log$ Award (t) & 0.3643721 & 0.068219 & 5.34 & 0.000 & 0.2293258 & 0.4994184 \\
\hline log Marketing (t) & 0.0075898 & 0.0204749 & 0.37 & 0.712 & -0.0329423 & 0.048122 \\
\hline log Graduates (t) & -0.0094128 & 0.0026588 & -3.54 & 0.001 & -0.0146762 & -0.0041495 \\
\hline $\log$ Professors (t) & 0.3215305 & 0.0892773 & 3.6 & 0.000 & 0.1447971 & 0.4982639 \\
\hline $\log$ Population $(\mathrm{t})$ & 0.1207009 & 0.0154578 & 7.81 & 0.000 & 0.0901006 & 0.1513013 \\
\hline Trend & -0.0205452 & 0.0074402 & -2.76 & 0.007 & -0.0352739 & -0.0058166 \\
\hline Constant & -3.692766 & 0.4961102 & -7.44 & 0.000 & -4.674866 & -2.710666 \\
\hline
\end{tabular}

Note. Variables are unlagged ( $\mathrm{t}$ ).

Robust standard errors are reported in the table. 
Table 11.1.2.

Fixed Effect (LSDV) for Unlagged Model: Enrollees

Linear regression

$$
\begin{aligned}
& \text { Number of obs }=129 \\
& F(24, \quad 104)=2233.48 \\
& \text { Prob }>\mathrm{F}=0.0000 \\
& \text { R-squared }=0.9971 \\
& \text { Root MSE }=.04589
\end{aligned}
$$

\begin{tabular}{|c|c|c|c|c|c|c|}
\hline Log Enrollees & Coef. & Robust Std. Err. & $\mathrm{t}$ & $\mathrm{P}>|\mathrm{t}|$ & {$[95 \%$ Conf. } & Interval] \\
\hline $\log$ Award (t) & 0.2839754 & 0.049156 & 5.78 & 0.000 & 0.1864973 & 0.3814535 \\
\hline $\log$ Marketing (t) & 0.0679181 & 0.0192387 & 3.53 & 0.001 & 0.0297669 & 0.1060692 \\
\hline log Graduates (t) & 0.019759 & 0.0090534 & 2.18 & 0.031 & 0.0018058 & 0.0377121 \\
\hline $\log$ Professors $(t)$ & 0.2202066 & 0.0666655 & 3.3 & 0.001 & 0.0880065 & 0.3524068 \\
\hline $\log$ Population (t) & 0.5298473 & 0.2996654 & 1.77 & 0.080 & -0.0644004 & 1.124095 \\
\hline Trend & -0.0177845 & 0.0053278 & -3.34 & 0.001 & -0.0283497 & -0.0072193 \\
\hline Constant & -8.233118 & 4.125773 & -2 & 0.049 & -16.41468 & -0.0515552 \\
\hline U_Toronto & (omitted) & & & & & \\
\hline Brock_U & 1.180761 & 0.7283137 & 1.62 & 0.108 & -0.263512 & 2.625035 \\
\hline Carleton_U & 0.5184641 & 0.4097918 & 1.27 & 0.209 & -0.2941685 & 1.331097 \\
\hline Lakehead_U & 1.327921 & 1.048402 & 1.27 & 0.208 & -0.7510987 & 3.406941 \\
\hline Laurentian_U & 1.251177 & 0.9735882 & 1.29 & 0.202 & -0.6794851 & 3.181839 \\
\hline McMaster_U & 0.543688 & 0.5789252 & 0.94 & 0.350 & -0.6043425 & 1.691718 \\
\hline Nipissing_U & 2.225004 & 1.21669 & 1.83 & 0.070 & -0.1877384 & 4.637746 \\
\hline OCAD_U & -0.6288543 & 0.3334605 & -1.89 & 0.062 & -1.290119 & 0.0324103 \\
\hline Queens_U & 1.169146 & 1.023675 & 1.14 & 0.256 & -0.8608404 & 3.199133 \\
\hline Ryerson_U & 0.0473364 & 0.1492997 & 0.32 & 0.752 & -0.2487306 & 0.3434033 \\
\hline Trent_U & 1.378504 & 1.062874 & 1.3 & 0.198 & -0.7292145 & 3.486222 \\
\hline U_Guelph & 1.594633 & 1.044835 & 1.53 & 0.130 & -0.4773135 & 3.666579 \\
\hline UOIT_U & 0.8588788 & 0.7333122 & 1.17 & 0.244 & -0.5953068 & 2.313064 \\
\hline U_Ottawa & 0.5603675 & 0.423814 & 1.32 & 0.189 & -0.2800715 & 1.400807 \\
\hline U_Waterloo & 0.8741505 & 0.7015054 & 1.25 & 0.216 & -0.5169611 & 2.265262 \\
\hline U_Windsor & 1.099531 & 0.7870651 & 1.4 & 0.165 & -0.4612487 & 2.660311 \\
\hline Western_U & 0.7015641 & 0.7080001 & 0.99 & 0.324 & -0.7024267 & 2.105555 \\
\hline Wilfrid_U & 1.012526 & 0.6674085 & 1.52 & 0.132 & -0.31097 & 2.336022 \\
\hline York $\bar{U}$ & 0.1422755 & 0.0705325 & 2.02 & 0.046 & 0.0024069 & 0.2821441 \\
\hline
\end{tabular}

Note. University of Toronto is the base.

Variables are unlagged $(\mathrm{t})$.

Robust standard errors are reported in the table. 


\section{Table 11.1.3.}

Random Effect for Unlagged Model: Enrollees

Random-effects GLS regression

Group variable: University $\sim$

R-sq: within $=0.7956$

between $=0.9511$

overall $=0.9453$

corr(u_i, X) $=0$ (assumed)

(Std. Err. adjusted for 19 clusters in University_id)

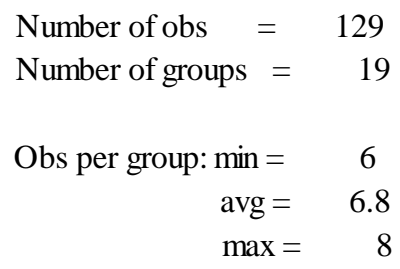

Number of obs $=129$

Number of groups $=19$

Obs per group: $\min =\quad 6$

$\operatorname{avg}=\quad 6.8$

$\max =8$

Wald chi2(6) $=442.79$

Prob $>$ chi2 $=0.0000$

\begin{tabular}{lcccccc}
\hline Log Enrollees & Coef. & Robust Std. Err. & $\mathrm{z}$ & $\mathrm{P}>|\mathrm{z}|$ & {$[95 \%$ Conf. } & Interval] \\
\hline $\log$ Award $(\mathrm{t})$ & 0.3160363 & 0.0504644 & 6.26 & 0.000 & 0.217128 & 0.4149447 \\
$\log$ Marketing ( $\mathrm{t})$ & 0.0621588 & 0.0198918 & 3.12 & 0.002 & 0.0231715 & 0.1011461 \\
$\log$ Graduates $(\mathrm{t})$ & 0.0040421 & 0.0083308 & 0.49 & 0.628 & -0.012286 & 0.0203702 \\
$\log$ Professors $(\mathrm{t})$ & 0.2579208 & 0.0621296 & 4.15 & 0.000 & 0.1361491 & 0.3796926 \\
$\log$ Population $(\mathrm{t})$ & 0.1144221 & 0.0440469 & 2.6 & 0.009 & 0.0280917 & 0.2007524 \\
Trend & -0.0181735 & 0.0047603 & -3.82 & 0.000 & -0.0275036 & -0.0088434 \\
Constant & -2.770976 & 0.7930913 & -3.49 & 0.000 & -4.325406 & -1.216545 \\
\hline sigma_u & 0.1918451 & & & & \\
sigma_e & 0.0458936 & & & & \\
rho & 0.94587045 & (fraction of variance due to u_i) & & & \\
\hline
\end{tabular}

Note. Variables are unlagged (t).

Robust standard errors are reported in the table.

Note. The results reported throughout the thesis arise from running panel data regression models with robust standard errors. Regression results are summarized in Table 11.1.4. 
Table 11.1.4.

Summary Results from Pooled OLS, Fixed (LSDV), and Random Effect Regressions with Robust Standard Errors and without Robust Standard Errors for Unlagged Model: Enrollees

\begin{tabular}{|c|c|c|c|c|c|c|c|c|c|}
\hline \multirow[b]{3}{*}{ Independent Variable } & \multicolumn{8}{|c|}{ Dependent Variable: Log Enrollees } & \\
\hline & \multicolumn{3}{|c|}{ Pooled OLS } & \multicolumn{3}{|c|}{ Fixed Effect LSDV } & \multicolumn{3}{|c|}{ RandomEffect } \\
\hline & Coef. & $\begin{array}{c}\text { Non_Robust } \\
\text { Std. } \sim S\end{array}$ & $\begin{array}{l}\text { Robust } \\
\text { Std. } \sim \mathrm{s}\end{array}$ & Coef. & $\begin{array}{c}\text { Non_Robust } \\
\text { Std. } \sim \mathrm{S}\end{array}$ & $\begin{array}{l}\text { Robust } \\
\text { Std. s }\end{array}$ & Coef. & $\begin{array}{c}\text { Non_Robust } \\
\text { Std. } \sim S\end{array}$ & $\begin{array}{l}\text { Robust } \\
\text { Std. } \sim \mathrm{s}\end{array}$ \\
\hline log Awards (t) & 0.364373 & $(0.061064)$ & $(0.068219)$ & 0.283972 & $(0.042585)$ & $(0.049156)$ & 0.316035 & $(0.039502)$ & $(0.050464)$ \\
\hline log Marketing (t) & 0.007589 & $(0.025289)$ & $(0.020475)$ & 0.067918 & $(0.018417)$ & $(0.019239)$ & 0.062159 & $(0.017976)$ & $(0.019892)$ \\
\hline log Graduates (t) & -0.009413 & $(0.003978)$ & $(0.002659)$ & 0.019759 & $(0.011429)$ & $(0.009053)$ & 0.004042 & $(0.007600)$ & $(0.008331)$ \\
\hline $\log$ Professors (t) & 0.32153 & $(0.087608)$ & $(0.089277)$ & 0.22021 & $(0.061164)$ & $(0.066665)$ & 0.257922 & $(0.056336)$ & $(0.062130)$ \\
\hline Log Population (t) & 0.120701 & $(0.014007)$ & $(0.015458)$ & 0.529917 & $(0.320226)$ & $(0.299665)$ & 0.114422 & $(0.034255)$ & $(0.044047)$ \\
\hline Trend & -0.020545 & $(0.007466)$ & $(0.007440)$ & -0.017785 & $(0.004531)$ & $(0.005328)$ & -0.018174 & $(0.003309)$ & $(0.004760)$ \\
\hline Constant & -3.692762 & $(0.54)$ & $(0.50)$ & -8.234195 & $(4.832424)$ & (4.125773) & -2.770998 & $(0.74)$ & $(0.79)$ \\
\hline U_Toronto & & & & (omitted) & & & & & \\
\hline Brock_U & & & & 1.180943 & $(0.82)$ & $(0.73)$ & & & \\
\hline Carleton_U & & & & 0.518569 & $(0.47)$ & $(0.41)$ & & & \\
\hline Lakehead_U & & & & 1.328184 & (1.19) & $(1.05)$ & & & \\
\hline Laurentian_U & & & & 1.25142 & (1.10) & $(0.97)$ & & & \\
\hline McMaster_U & & & & 0.54383 & $(0.64)$ & $(0.58)$ & & & \\
\hline Nipissing_U & & & & 2.225303 & $(1.37)$ & $(1.22)$ & & & \\
\hline OCAD_U & & & & -0.628861 & $(0.19)$ & $(0.33)$ & & & \\
\hline Queens_U & & & & 1.169395 & $(1.12)$ & $(1.02)$ & & & \\
\hline Ryerson_U & & & & 0.047335 & $(0.09)$ & $(0.15)$ & & & \\
\hline Trent_U & & & & 1.37877 & $(1.20)$ & $(1.06)$ & & & \\
\hline U_Guelph & & & & 1.594888 & (1.16) & (1.04) & & & \\
\hline UOIT_U & & & & 0.859067 & $(0.85)$ & $(0.73)$ & & & \\
\hline U_Ottawa & & & & 0.560473 & $(0.48)$ & $(0.42)$ & & & \\
\hline U_Waterloo & & & & 0.874322 & $(0.78)$ & $(0.70)$ & & & \\
\hline U_Windsor & & & & 1.099728 & $(0.88)$ & $(0.79)$ & & & \\
\hline Western_U & & & & 0.701734 & $(0.77)$ & $(0.71)$ & & & \\
\hline Wilfrid_U & & & & 1.012696 & $(0.76)$ & $(0.67)$ & & & \\
\hline York_U & & & & 0.142275 & $(0.05)$ & $(0.07)$ & & & \\
\hline No. of Obs. & 129 & & & 129 & & & 129 & & \\
\hline R-Squared & 0.95 & & & 0.997 & & & 0.94 & & \\
\hline
\end{tabular}

Note. The results from the above regressions were compared with Lagged models. The results are broadly similar. 


\section{Table 11.2.}

Robustness Checks of the Relationship between Universities Expenditure on Price and Non-

Price Competitive Variables (Unlagged Variables) and Total Number of Applicants

Table 11.2.1.

Pooled OLS for Unlagged Model: Applicants

Linear regression

$$
\begin{aligned}
& \text { Number of obs }=128 \\
& F(6, \quad 121)=216.90 \\
& \text { Prob }>F=0.0000 \\
& \text { R-squared }=0.8821 \\
& \text { Root MSE }=.3245
\end{aligned}
$$

\begin{tabular}{lcccccc}
\hline Log Applicants & Coef. & Robust Std. Err. & $\mathrm{t}$ & $\mathrm{P}\rangle|\mathrm{t}|$ & {$[95 \%$ Conf. } & Interval] \\
\hline $\log$ Award $(\mathrm{t})$ & 0.5258228 & 0.1145808 & 4.59 & 0.000 & 0.2989799 & 0.7526657 \\
$\log$ Marketing $(\mathrm{t})$ & 0.1855149 & 0.0387874 & 4.78 & 0.000 & 0.1087251 & 0.2623047 \\
$\log$ Graduates $(\mathrm{t})$ & -0.0088565 & 0.00529 & -1.67 & 0.097 & -0.0193294 & 0.0016164 \\
$\log$ Professors $(\mathrm{t})$ & -0.028374 & 0.1639008 & -0.17 & 0.863 & -0.3528589 & 0.2961109 \\
$\log$ Population $(\mathrm{t})$ & 0.1664611 & 0.0334709 & 4.97 & 0.000 & 0.1001966 & 0.2327257 \\
Trend & -0.0300841 & 0.0144059 & -2.09 & 0.039 & -0.0586045 & -0.0015638 \\
Constant & -3.502815 & 0.9755005 & -3.59 & 0.000 & -5.434075 & -1.571554 \\
\hline
\end{tabular}

Note. Variables are unlagged $(\mathrm{t})$.

Robust standard errors are reported in the table. 
Table 11.2.2.

Fixed Effect (LSDV) for Unlagged Model: Applicants

Linear regression

Number of obs $=128$

$\mathrm{F}(24,103)=3231.19$

Prob $>\mathrm{F}=0.0000$

R-squared $=0.9926$

Root MSE $=.0882$

\begin{tabular}{|c|c|c|c|c|c|c|}
\hline Log Applicants & Coef. & Robust Std. Err. & $\mathrm{t}$ & $\mathrm{P}>|\mathrm{t}|$ & [95\% Conf. & Interval] \\
\hline $\log$ Award (t) & 0.0949703 & 0.0749121 & 1.27 & 0.208 & -0.0536002 & 0.2435408 \\
\hline $\log$ Marketing (t) & 0.0309518 & 0.0234284 & 1.32 & 0.189 & -0.0155129 & 0.0774165 \\
\hline $\log$ Graduates (t) & 0.0438379 & 0.033463 & 1.31 & 0.193 & -0.022528 & 0.1102037 \\
\hline $\log$ Professors (t) & 0.0493655 & 0.0925822 & 0.53 & 0.595 & -0.1342494 & 0.2329805 \\
\hline $\log$ Population $(\mathrm{t})$ & 1.511946 & 0.499734 & 3.03 & 0.003 & 0.5208417 & 2.503051 \\
\hline Trend & -0.0104621 & 0.0072002 & -1.45 & 0.149 & -0.024742 & 0.0038178 \\
\hline Constant & -16.57448 & 7.443131 & -2.23 & 0.028 & -31.33617 & -1.812784 \\
\hline U_Toronto & (omitted) & & & & & \\
\hline Brock_U & 3.336225 & 1.264388 & 2.64 & 0.010 & 0.8286094 & 5.843841 \\
\hline Carleton_U & 1.757651 & 0.7268869 & 2.42 & 0.017 & 0.3160419 & 3.199259 \\
\hline Lakehead_U & 3.91982 & 1.836244 & 2.13 & 0.035 & 0.2780636 & 7.561577 \\
\hline Laurentian_U & 3.823921 & 1.690566 & 2.26 & 0.026 & 0.471082 & 7.176761 \\
\hline McMaster_U & 2.763198 & 0.9962427 & 2.77 & 0.007 & 0.7873851 & 4.73901 \\
\hline Nipissing_U & 5.727622 & 2.090431 & 2.74 & 0.007 & 1.581745 & 9.873498 \\
\hline OCAD_U & -2.239576 & 0.26021 & -8.61 & 0.000 & -2.755642 & -1.723511 \\
\hline Queens_U & 4.713705 & 1.747605 & 2.7 & 0.008 & 1.247742 & 8.179668 \\
\hline Ryerson_U & 0.1481282 & 0.1138073 & 1.3 & 0.196 & -0.0775817 & 0.373838 \\
\hline Trent_U & 4.409775 & 1.846509 & 2.39 & 0.019 & 0.7476591 & 8.07189 \\
\hline U_Guelph & 4.817042 & 1.786166 & 2.7 & 0.008 & 1.274603 & 8.359482 \\
\hline UOIT_U & 2.867647 & 1.308055 & 2.19 & 0.031 & 0.2734277 & 5.461866 \\
\hline U_Ottawa & 1.761733 & 0.7440697 & 2.37 & 0.020 & 0.2860458 & 3.237419 \\
\hline U_Waterloo & 3.351474 & 1.206866 & 2.78 & 0.007 & 0.95794 & 5.745008 \\
\hline U_Windsor & 3.186551 & 1.373441 & 2.32 & 0.022 & 0.4626538 & 5.910448 \\
\hline Western_U & 3.399172 & 1.205087 & 2.82 & 0.006 & 1.009167 & 5.789178 \\
\hline Wilfrid U & 3.171506 & 1.163989 & 2.72 & 0.008 & 0.8630082 & 5.480004 \\
\hline York_U & 0.1159606 & 0.0881901 & 1.31 & 0.191 & -0.0589437 & 0.290865 \\
\hline
\end{tabular}

Note. University of Toronto is the base.

Variables are unlagged $(\mathrm{t})$.

Robust standard errors are reported in the table. 


\section{Table 11.2.3.}

Random Effect for Unlagged Model: Applicants

Random-effects GLS regression

Group variable: University d

R-sq: within $=0.2129$

between $=0.8386$

overall $=0.8285$

corr(u_i, X) $=0$ (assumed)

(Std. Err. adjusted for 19 clusters in University_id) $\begin{array}{rr}\text { Number of obs }= & 128 \\ \text { Number of groups }= & 19 \\ & \\ \text { Obs per group: } \min = & 5 \\ \text { avg }= & 6.7 \\ \max = & 8\end{array}$

Wald chi2(6) $=91.61$

Prob $>$ chi2 $=0.0000$

\begin{tabular}{lcccccc}
\hline Log Applicants & Coef. & Robust Std. Err. & $\mathrm{z}$ & $\mathrm{P}>|\mathrm{z}|$ & [95\% Conf. & Interval] \\
\hline $\log$ Award (t) & 0.2564053 & 0.0881241 & 2.91 & 0.004 & 0.0836853 & 0.4291253 \\
$\log$ Marketing (t) & 0.043125 & 0.0292906 & 1.47 & 0.141 & -0.0142835 & 0.1005336 \\
$\log$ Graduates (t) & 0.030231 & 0.012885 & 2.35 & 0.019 & 0.0049769 & 0.0554851 \\
$\log$ Professors (t) & 0.1794788 & 0.1183442 & 1.52 & 0.129 & -0.0524716 & 0.4114293 \\
$\log$ Population (t) & 0.1459313 & 0.1135577 & 1.29 & 0.199 & -0.0766376 & 0.3685002 \\
Trend & -0.0185825 & 0.0093363 & -1.99 & 0.047 & -0.0368814 & -0.0002837 \\
Constant & -0.7930394 & 1.699852 & -0.47 & 0.641 & -4.124689 & 2.53861 \\
\hline sigma_u & 0.36491704 & \multicolumn{7}{c}{} & & \\
sigma_e & 0.0881994 & & & & \\
rho & 0.94480675 & (fraction of variance due to u_i) & & & \\
\hline
\end{tabular}

Note. Variables are unlagged $(\mathrm{t})$.

Robust standard errors are reported in the table.

Note. The results reported throughout the thesis arise from running panel data regression models with robust standard errors. Regression results are summarized in Table 11.2.4. 
Table 11.2.4.

Summary Results from Pooled OLS, Fixed (LSDV), and Random Effect Regressions with Robust

Standard Errors and without Robust Standard Errors for Unlagged Model: Applicants

\begin{tabular}{|c|c|c|c|c|c|c|c|c|c|}
\hline \multirow[b]{3}{*}{ Independent Variable } & \multicolumn{9}{|c|}{ Dependent Variable: Log Applicants } \\
\hline & \multicolumn{3}{|c|}{ Pooled OLS } & \multicolumn{3}{|c|}{ Fixed Effect LSDV } & \multicolumn{3}{|c|}{ RandomEffect } \\
\hline & Coef. & $\begin{array}{l}\text { Non_Robust } \\
\text { Std. } \sim \mathrm{S}\end{array}$ & $\begin{array}{l}\text { Robust } \\
\text { Std. } \sim \text { s }\end{array}$ & Coef. & $\begin{array}{l}\text { Non_Robust } \\
\text { Std. } \sim \mathrm{s}\end{array}$ & $\begin{array}{l}\text { Robust } \\
\text { Std. } \sim\end{array}$ & Coef. & $\begin{array}{l}\text { Non_Robust } \\
\text { Std. } \sim \mathrm{S}\end{array}$ & $\begin{array}{l}\text { Robust } \\
\text { Std. } \sim S\end{array}$ \\
\hline $\log$ Awards (t) & 0.525820 & $(0.119595)$ & $(0.114581)$ & 0.09497 & $(0.090192)$ & $(0.074912)$ & 0.256409 & $(0.084526)$ & $(0.088124)$ \\
\hline $\log$ Marketing $(\mathrm{t})$ & 0.185515 & $(0.049704)$ & $(0.038787)$ & 0.030951 & $(0.035637)$ & $(0.023428)$ & 0.043124 & $(0.036405)$ & $(0.029291)$ \\
\hline $\log$ Graduates (t) & -0.008856 & $(0.007308)$ & $(0.005290)$ & 0.043838 & $(0.022023)$ & $(0.033463)$ & 0.030231 & $(0.015230)$ & $(0.012885)$ \\
\hline $\log$ Professors (t) & -0.028370 & $(0.175475)$ & $(0.163901)$ & 0.049365 & $(0.117810)$ & $(0.092582)$ & 0.179475 & $(0.114980)$ & $(0.118344)$ \\
\hline Log Population (t) & 0.166461 & $(0.027132)$ & $(0.033471)$ & 1.512138 & $(0.616469)$ & $(0.499734)$ & 0.145933 & $(0.068397)$ & $(0.113558)$ \\
\hline Trend & -0.030084 & $(0.014606)$ & $(0.014406)$ & -0.010464 & $(0.008829)$ & $(0.007200)$ & -0.018582 & $(0.006630)$ & $(0.009336)$ \\
\hline Constant & -3.502838 & $(1.07)$ & $(0.98)$ & -16.577425 & $(9.286775)$ & (7.443131) & -0.793039 & (1.49) & $(1.70)$ \\
\hline U_Toronto & & & & (omitted) & & & & & \\
\hline Brock_U & & & & 3.33673 & $(1.57)$ & $(1.26)$ & & & \\
\hline Carleton_U & & & & 1.75794 & $(0.91)$ & $(0.73)$ & & & \\
\hline Lakehead_U & & & & 3.920546 & (2.28) & (1.84) & & & \\
\hline Laurentian_U & & & & 3.824598 & (2.11) & (1.69) & & & \\
\hline McMaster_U & & & & 2.763593 & (1.23) & $(1.00)$ & & & \\
\hline Nipissing_U & & & & 5.728471 & $(2.64)$ & $(2.09)$ & & & \\
\hline OCAD_U & & & & -2.23958 & $(0.40)$ & $(0.26)$ & & & \\
\hline Queens_U & & & & 4.714384 & (2.16) & $(1.75)$ & & & \\
\hline Ryerson_U & & & & 0.148127 & (0.18) & $(0.11)$ & & & \\
\hline Trent_U & & & & 4.410508 & (2.30) & $(1.85)$ & & & \\
\hline U_Guelph & & & & 4.817744 & $(2.22)$ & (1.79) & & & \\
\hline UOIT_U & & & & 2.868171 & (1.64) & $(1.31)$ & & & \\
\hline U_Ottawa & & & & 1.762023 & $(0.92)$ & $(0.74)$ & & & \\
\hline U_Waterloo & & & & 3.351944 & (1.49) & $(1.21)$ & & & \\
\hline U_Windsor & & & & 3.187093 & (1.70) & $(1.37)$ & & & \\
\hline Western_U & & & & 3.39964 & (1.49) & $(1.21)$ & & & \\
\hline Wiffrid_U & & & & 3.171976 & (1.46) & $(1.16)$ & & & \\
\hline York_U & & & & 0.115961 & $(0.09)$ & $(0.09)$ & & & \\
\hline No. of Obs. & 128 & & & 128 & & & 128 & & \\
\hline R-Squared & 0.88 & & & 0.99 & & & 0.83 & & \\
\hline
\end{tabular}

Note. Robust Standard Errors are in parentheses.

University of Toronto is the base.

Variables are unlagged $(\mathrm{t})$.

Note. The results from the above regressions were compared with Lagged models. The results are broadly similar. 
Table 11.3.

Robustness Checks of the Relationship between Universities Expenditure on Price and Non-

Price Competitive Variables (unlagged variables) and Persistence Ratio in Publicly Funded

Universities in Ontario

Table 11.3.1. Pooled OLS for Unlagged Model: Persistence Ratio

Number of obs $=127$
$F(6, \quad 120)=12.07$
Prob $>\mathrm{F}=0.0000$
R-squared $=0.2975$
Root MSE $=.25024$

\begin{tabular}{lcccccc}
\hline Log Persistence Ratio & Coef. & Robust Std. Err. & $\mathrm{t}$ & $\mathrm{P}>|\mathrm{t}|$ & {$[95 \%$ Conf. } & Interval] \\
\hline $\log$ Award $(\mathrm{t})$ & -0.1722042 & 0.0767069 & -2.24 & 0.027 & -0.3240785 & -0.02033 \\
$\log$ Marketing $(\mathrm{t})$ & -0.1852294 & 0.0316466 & -5.85 & 0.000 & -0.2478874 & -0.1225714 \\
$\log$ Graduates $(\mathrm{t})$ & -0.0011234 & 0.0048432 & -0.23 & 0.817 & -0.0107126 & 0.0084658 \\
$\log$ Professors $(\mathrm{t})$ & 0.3781261 & 0.1249508 & 3.03 & 0.003 & 0.1307323 & 0.6255199 \\
$\log$ Population $(\mathrm{t})$ & -0.0476394 & 0.0245307 & -1.94 & 0.054 & -0.0962085 & 0.0009297 \\
Trend & 0.0072042 & 0.0109205 & 0.66 & 0.511 & -0.0144176 & 0.028826 \\
Constant & -0.3596364 & 0.8056796 & -0.45 & 0.656 & -1.954826 & 1.235553 \\
\hline
\end{tabular}

Note. Variables are unlagged $(\mathrm{t})$.

Robust standard errors are reported in the table. 
Table 11.3.2.

Fixed Effect (LSDV) for Unlagged Model: Persistence Ratio

\begin{tabular}{|c|c|}
\hline Linear regression & $\begin{array}{l}\text { Number of obs }=127 \\
F(24,102)=226.03 \\
\text { Prob }>\mathrm{F}=0.0000 \\
\text { R-squared }=0.9105 \\
\text { Root MSE }=.09688\end{array}$ \\
\hline
\end{tabular}

\begin{tabular}{|c|c|c|c|c|c|c|}
\hline Log Persistence Ratio & Coef. & Robust Std. Err. & $\mathrm{t}$ & $\mathrm{P}>|\mathrm{t}|$ & [95\% Conf. & Interval] \\
\hline $\log$ Award (t) & 0.141335 & 0.0927648 & 1.52 & 0.131 & -0.0426636 & 0.3253336 \\
\hline log Marketing (t) & 0.0363266 & 0.0299274 & 1.21 & 0.228 & -0.0230344 & 0.0956875 \\
\hline $\log$ Graduates (t) & -0.0263841 & 0.0352918 & -0.75 & 0.456 & -0.0963852 & 0.043617 \\
\hline $\log$ Professors ( $t$ ) & 0.177205 & 0.121444 & 1.46 & 0.148 & -0.0636787 & 0.4180886 \\
\hline $\log$ Population (t) & -0.9353438 & 0.4819545 & -1.94 & 0.055 & -1.891298 & 0.0206106 \\
\hline Trend & -0.005638 & 0.0091091 & -0.62 & 0.537 & -0.0237058 & 0.0124297 \\
\hline Constant & 8.429899 & 6.951051 & 1.21 & 0.228 & -5.357477 & 22.21728 \\
\hline U_Toronto & (omitted) & & & & & \\
\hline Brock_U & -2.1454 & 1.162621 & -1.85 & 0.068 & -4.451453 & 0.1606535 \\
\hline Carleton_U & -1.234843 & 0.6719097 & -1.84 & 0.069 & -2.567573 & 0.0978867 \\
\hline Lakehead_U & -2.541683 & 1.709286 & -1.49 & 0.140 & -5.932043 & 0.8486769 \\
\hline Laurentian_U & -2.53481 & 1.566652 & -1.62 & 0.109 & -5.642257 & 0.5726379 \\
\hline McMaster_U & -2.179489 & 0.9331451 & -2.34 & 0.021 & -4.030378 & -0.3286005 \\
\hline Nipissing_U & -3.519443 & 1.866964 & -1.89 & 0.062 & -7.222556 & 0.1836708 \\
\hline OCAD_U & 1.393553 & 0.4961604 & 2.81 & 0.006 & 0.4094212 & 2.377685 \\
\hline Queens_U & -3.421734 & 1.656978 & -2.07 & 0.041 & -6.708343 & -0.1351261 \\
\hline Ryerson_U & -0.1878894 & 0.2210039 & -0.85 & 0.397 & -0.6262496 & 0.2504707 \\
\hline Trent_U & -2.977934 & 1.719481 & -1.73 & 0.086 & -6.388517 & 0.4326479 \\
\hline U_Guelph & -3.126078 & 1.682669 & -1.86 & 0.066 & -6.463644 & 0.2114871 \\
\hline UOIT_U & -2.079293 & 1.204748 & -1.73 & 0.087 & -4.468905 & 0.3103185 \\
\hline U_Ottawa & -1.17162 & 0.6962447 & -1.68 & 0.095 & -2.552618 & 0.2093778 \\
\hline U_Waterloo & -2.39529 & 1.14266 & -2.1 & 0.039 & -4.66175 & -0.1288306 \\
\hline U_Windsor & -2.048612 & 1.275939 & -1.61 & 0.111 & -4.579431 & 0.4822064 \\
\hline Western_U & -2.619801 & 1.139492 & -2.3 & 0.024 & -4.879979 & -0.3596236 \\
\hline Wilfrid_U & -2.165709 & 1.068498 & -2.03 & 0.045 & -4.28507 & -0.0463485 \\
\hline York_U & -0.0158625 & 0.1261585 & -0.13 & 0.9 & -0.2660972 & 0.2343723 \\
\hline
\end{tabular}

Note. University of Toronto is the base.

Variables are unlagged $(\mathrm{t})$.

Robust standard errors are reported in the table. 


\section{Table 11.3.3.}

Random Effect for Unlagged Model: Persistence Ratio

Random-effects GLS regression

Group variable: University $\sim$

R-sq: within $=0.0750$

between $=0.0662$

overall $=0.0491$

corr $\left(\mathrm{u} \_\mathrm{i}, \mathrm{X}\right)=0$ (assumed)

(Std. Err. adjusted for 19 clusters in University_id)

$$
\begin{aligned}
& \text { Number of obs }=127 \\
& \text { Number of groups }=19 \\
& \text { Obs per group: } \min =\quad 5 \\
& \text { avg }=\quad 6.7 \\
& \max =8 \\
& \text { Wald chi2(6) }=30.17 \\
& \text { Prob }>\text { chi } 2=0.0000
\end{aligned}
$$

\begin{tabular}{lcccccc}
\hline Log Persistence Ratio & Coef. & Robust Std. Err. & $\mathrm{z}$ & $\mathrm{P}>|\mathrm{z}|$ & {$[95 \%$ Conf. } & Interval] \\
\hline $\log$ Award $(\mathrm{t})$ & 0.001555 & 0.0980726 & 0.02 & 0.987 & -0.1906638 & 0.1937738 \\
$\log$ Marketing (t) & 0.0035107 & 0.0313188 & 0.11 & 0.911 & -0.057873 & 0.0648944 \\
$\log$ Graduates $(\mathrm{t})$ & -0.0218774 & 0.0078727 & -2.78 & 0.005 & -0.0373075 & -0.0064473 \\
$\log$ Professors $(\mathrm{t})$ & 0.0745729 & 0.1246543 & 0.6 & 0.55 & -0.169745 & 0.3188907 \\
$\log$ Population (t) & -0.0174958 & 0.0666248 & -0.26 & 0.793 & -0.1480779 & 0.1130863 \\
Trend & 0.0046892 & 0.0087814 & 0.53 & 0.593 & -0.0125221 & 0.0219004 \\
Constant & -0.95278 & 1.840112 & -0.52 & 0.605 & -4.559333 & 2.653773 \\
\hline sigma_u & 0.26153139 & & & & \\
sigma_e & 0.09687947 & & & & & \\
rho & 0.87933771 & (fraction of variance due to u_i) & & & \\
\hline
\end{tabular}

Note. Variables are unlagged $(\mathrm{t})$.

Robust standard errors are reported in the table. 


\section{Appendix I: Data Analysis for Each Individual University (Enrollees: Lagged Model)}

A modified Fixed Effect regression was conducted for each individual university. The results shown in each figure indicate which variables have stronger effects (denoted by positive additional effect) in the particular university relative to the baseline for all other universities and which variables have weaker effects (denoted by negative additional effects). Thus, the coefficients show the expected additional percentage changes in enrolment for a given university relative to the baseline for all universities stemming from a one percent change in its variables.

\section{Brock University}

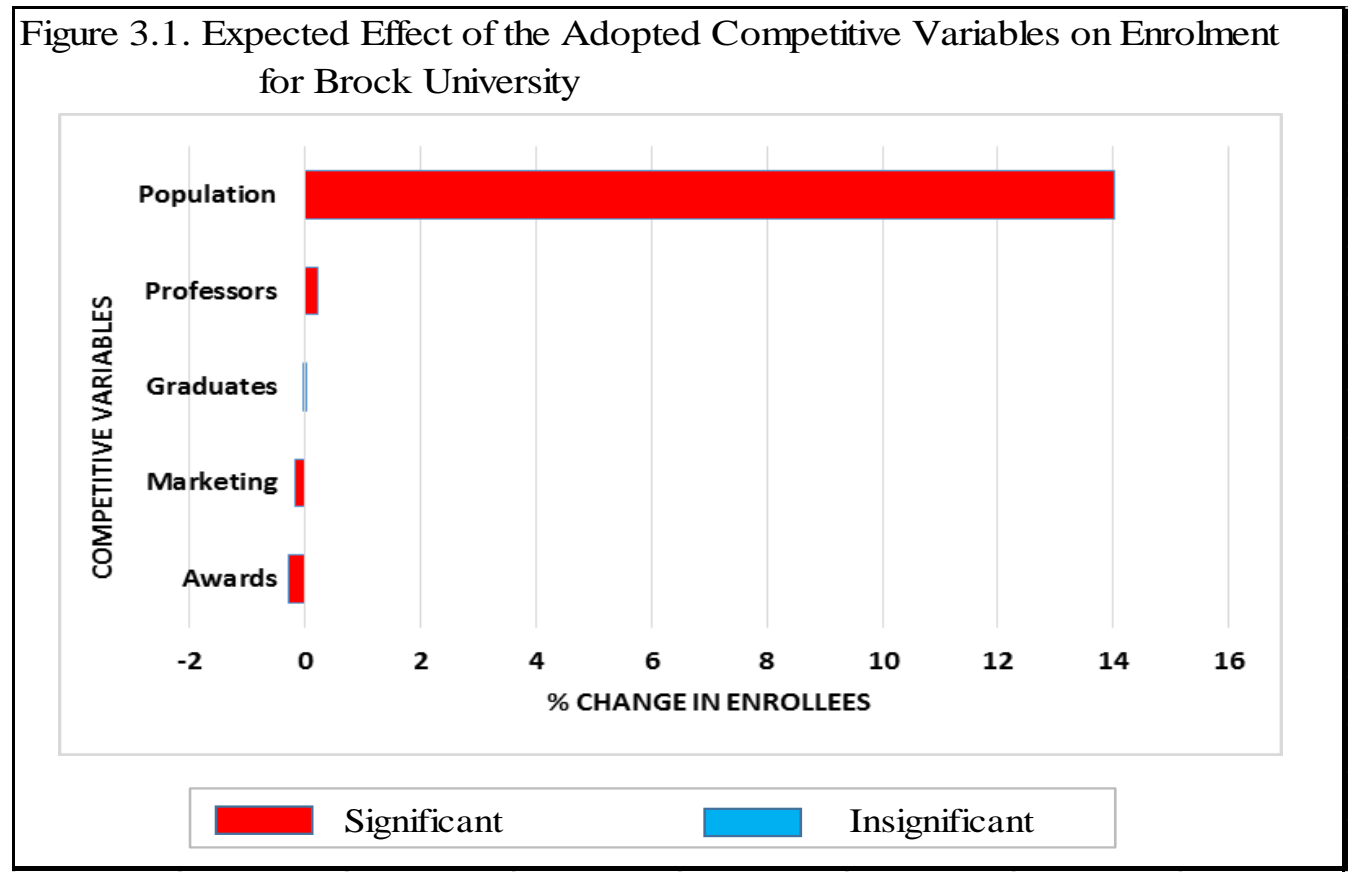

The result from Fixed Effects (a modified Fixed Effect regression) explains how enrollees respond to a one percent change in awards, marketing, graduates, professors, and population for Brock University. The regression result shows a strong relationship between enrolment and the adopted competitive variables (R-Squared=0.996). R-Squared indicates that approximately $99 \%$ of the change in enrolment can be explained by the change in awards, marketing, professors, and population. The result suggests that the responsiveness of enrolment 
with respect to awards, marketing, professors, and population is about $-0.30,-0.19,0.23$, and $14.03 \%$, respectively. These additional effect coefficients are statistically significant at 5, 5, 10, and $1 \%(\rho<.05 \rho<.05 \rho<.10, \& \rho<.01)$. Overall effects also estimate negative and positive significant signs and these are explained in Appendix E, Table 7.2.1.

The positive and significant additional effects suggest that professors and population have a larger effect on enrollees, while a negative and significant sign suggests that awards, and marketing have a smaller effect on enrolment. The larger effect suggests that a one percent increase in investing in faculty members (professors) is expected to produce a greater effect on enrolment by about $0.23 \%$. A one percent increase in population is expected to produce a larger effect on enrolment by about $14.03 \%$. A smaller effect suggests that a one percent increase in expenditure on awards and marketing is expected to produce a smaller effect on enrolment by about 0.30 and $0.19 \%$, respectively, for Brock University relative to all other Ontario universities.

However, the existence of significant responsiveness leads one to infer that the changes in population and in university expenditure on awards, marketing, and professors are likely to affect the total number of enrolled students for Brock University. Evaluating the effect of adopted competitive variables can shed light on the importance of resource allocation in order to enhance the competitiveness of publicly funded universities. Brock University might need these responsiveness estimates in order to determine the most effective competitive variables to make good managerial decisions in the short run, and to plan for its enrolment growth in the long run. 


\section{Carleton University}

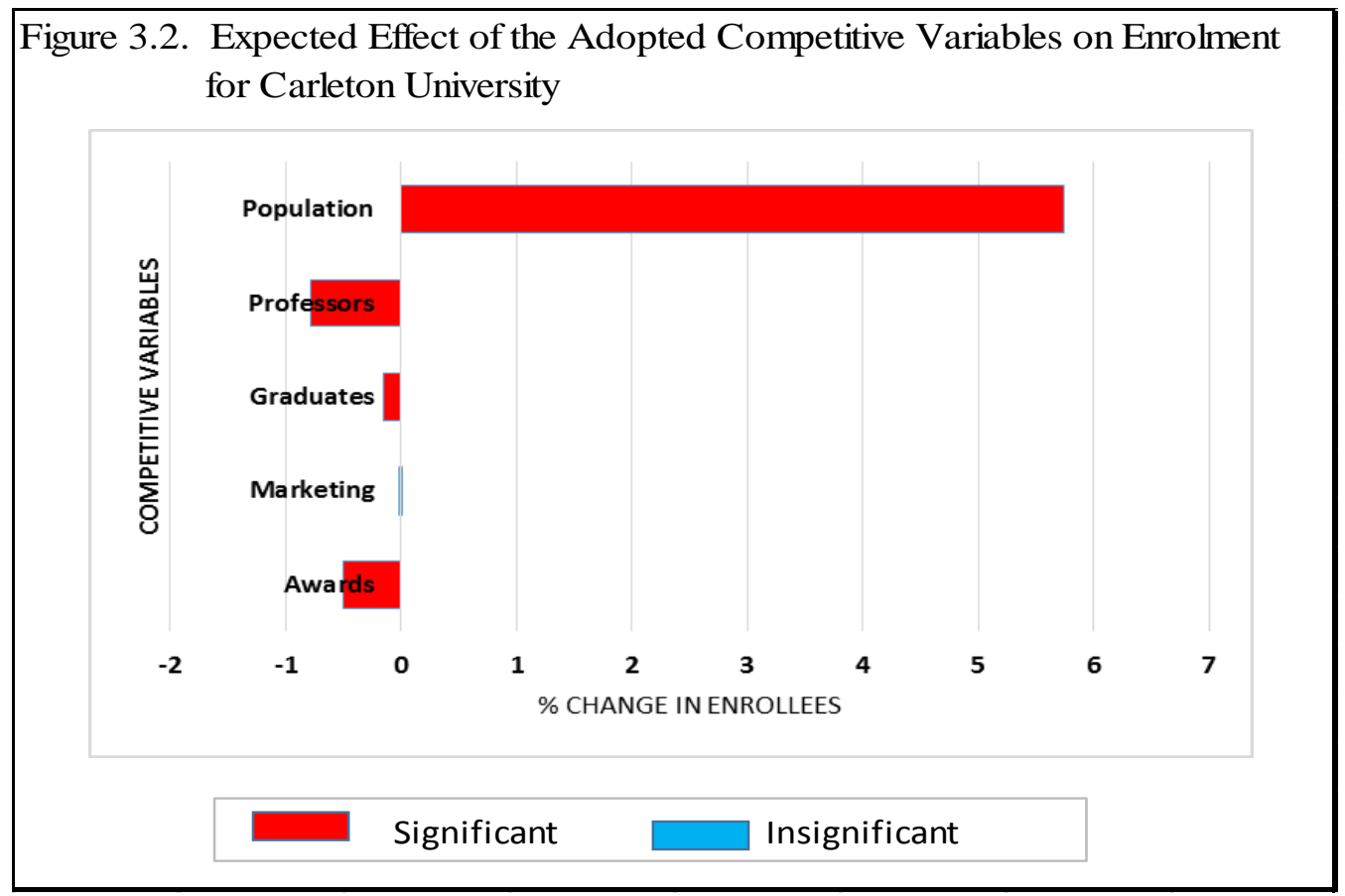

The result from Fixed Effects (a modified Fixed Effect regression) explains how

enrolment respond to a one percent change in awards, marketing, graduates, professors, and population for Carleton University. The regression result shows a strong relationship between enrolment and the adopted competitive variables (R-Squared=0.996). R-Squared indicates that approximately $99 \%$ of the change in enrolment can be explained by the change in awards, graduates, professors, and population. The result suggests that the responsiveness of enrolment with respect to awards, graduates, professors, and population is about $-0.50,-0.15,-0.78$, and $5.74 \%$, respectively. These additional effect coefficients are statistically significant at $1,5,10$, $1 \%(\rho<.01, \rho<.05, \rho<.10, \& \rho<.01)$. Overall effects also estimate negative and positive significant signs and these are explained in Appendix E, Table 7.2.1.

The positive and significant additional effects suggest that population has a larger effect on enrollees, while a negative and significant sign suggests that awards, graduates, and professors have a smaller effect on enrolment. The larger effect suggests that a one percent 
increase in population is expected to produce a greater effect on enrolment by about $5.74 \%$. A smaller effect suggests that a one percent increase in expenditure on awards, graduates, and professors is expected to produce a smaller effect on enrolment by about $0.50,0.15$, and $0.78 \%$, respectively, for Carleton University relative to all other Ontario universities.

However, the existence of significant responsiveness leads one to infer that the changes in awards, graduates, professors, and populations are likely to affect the total number of enrolled students for Carleton University. Evaluating the effect of adopted competitive variables can shed light on the importance of fund allocations. Fund allocations and the shift from variables with smaller effects to variables with greater effects can help publicly funded universities compete effectively and increase their market share. Carleton University might need these responsiveness estimates in order to determine the most effective competitive variables to make good managerial decisions in the short run, and to plan for its enrolment growth in the long run.

\section{Lakehead University}

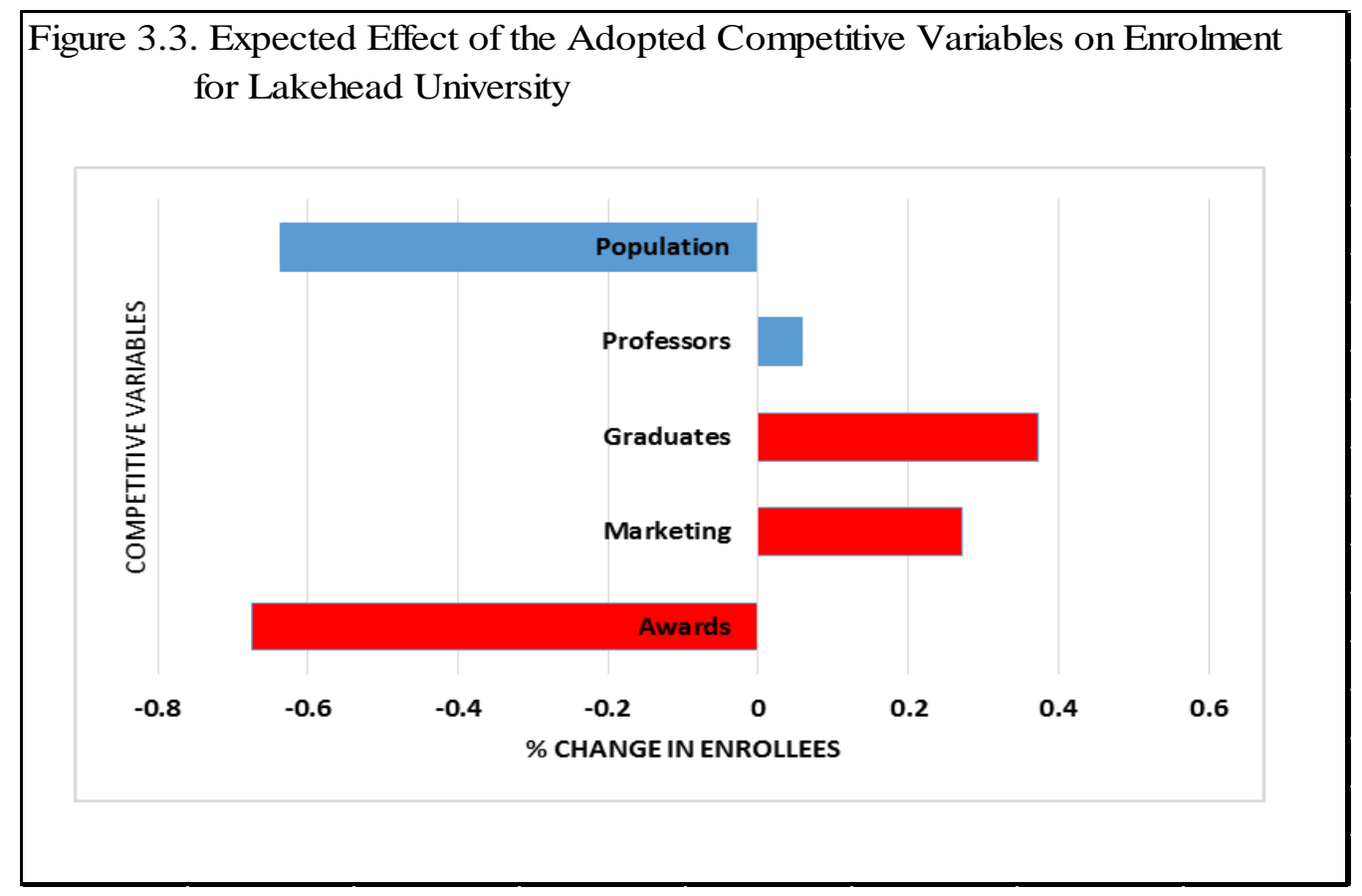


The result from Fixed Effects (a modified Fixed Effect regression) explains how enrolment respond to a one percent change in awards, marketing, graduates, professors, and population for Lakehead University. Regression result shows a strong relationship between enrolment and the adopted competitive variables $(\mathrm{R}-\mathrm{Squared}=0.99)$. R-Squared indicates that approximately $99 \%$ of the change in enrolment can be explained by the change in university expenditure on awards, marketing, and graduates. The result suggests that the responsiveness of enrolment with respect to awards, marketing, and graduates is about $-0.67,0.27$, and $0.37 \%$ respectively. These additional effect coefficients are statistically significant at $1 \%(\rho<.01)$. Overall effects also estimate negative and positive significant signs and they are explained in Appendix E, Table 7.2.1.

The positive and significant additional effects suggest that marketing and graduates have a larger effect on enrollees, while a negative and significant sign suggests that awards has a smaller effect on enrolment. A larger effect suggests that a one percent increase in expenditure on marketing and graduates is expected to produce a greater effect on enrolment by about 0.27 and $0.37 \%$, respectively. A smaller effect suggests that a one percent increase in expenditure on awards is expected to produce a smaller effect on enrolment by about $0.67 \%$ for Lakehead University relative to all other Ontario universities. However, the existence of significant responsiveness leads one to infer that the changes in university expenditure on awards, marketing, and graduates are likely to affect the total number of enrolled students for Lakehead University. Evaluating the effect of adopted competitive variables can shed light on the importance of fund allocations and the shift from variables with smaller effects to variables with greater effects. This can help publicly funded universities compete effectively and increase their market share. Lakehead University might need these responsiveness estimates in order to 
determine the most effective competitive variables to make good managerial decisions in the short run and to plan for its enrolment growth in the long run.

\section{Laurentian University}

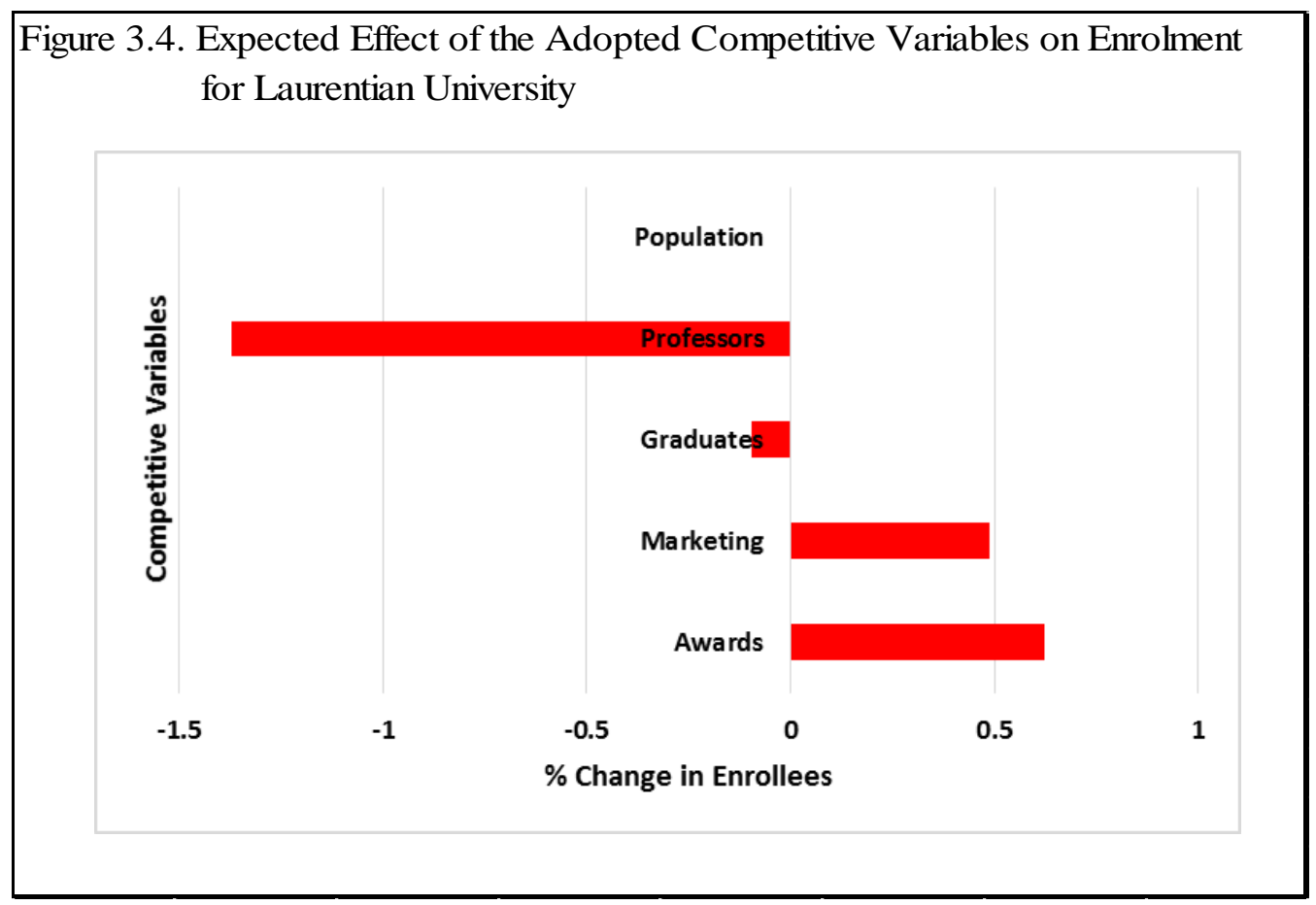

The result from Fixed Effects (a modified Fixed Effect regression) explains how

enrolment respond to a one percent change in awards, marketing, graduates, professors, and population for Laurentian University. The regression result shows a strong relationship between enrolment and the adopted competitive variables (R-Squared=0.996). R-Squared indicates that approximately $99 \%$ of the change in enrolment can be explained by the change in university expenditure on awards, marketing, graduates, and professors. The result suggests that the responsiveness of enrolment with respect to awards, marketing, graduates, and professors is about $0.62,0.49,-0.10$, and $-1.37 \%$, respectively. These additional effect coefficients are statistically significant at $1 \%(\rho<.01)$. Overall effects also estimate negative and positive significant signs and these are explained in Appendix E, Table 7.2.1. 
The positive and significant additional effects suggest that awards and marketing have a larger effect on enrolment, while a negative and significant sign suggests that graduates and professors have a smaller effect on enrollees. A larger effect suggests that a one percent increase expenditure on awards and marketing is expected to produce a greater effect on enrolment by about 0.62 and $0.49 \%$, respectively, for Laurentian University relative to all other Ontario universities. A smaller effect suggests that a one percent increase in expenditure on graduates and professors is expected to produce a smaller effect on enrolment by about 0.10 and $1.37 \%$, respectively, for Laurentian University relative to all other Ontario universities. However, the existence of significant responsiveness leads one to infer that the changes in university expenditure on awards, marketing, graduates, and professors are likely to affect the total number of enrolled students for Laurentian University. Laurentian University might need these responsiveness estimates in order to determine the most effective competitive variables to make good managerial decisions in the short run and to plan for its enrolment growth in the long run.

\section{McMaster University}

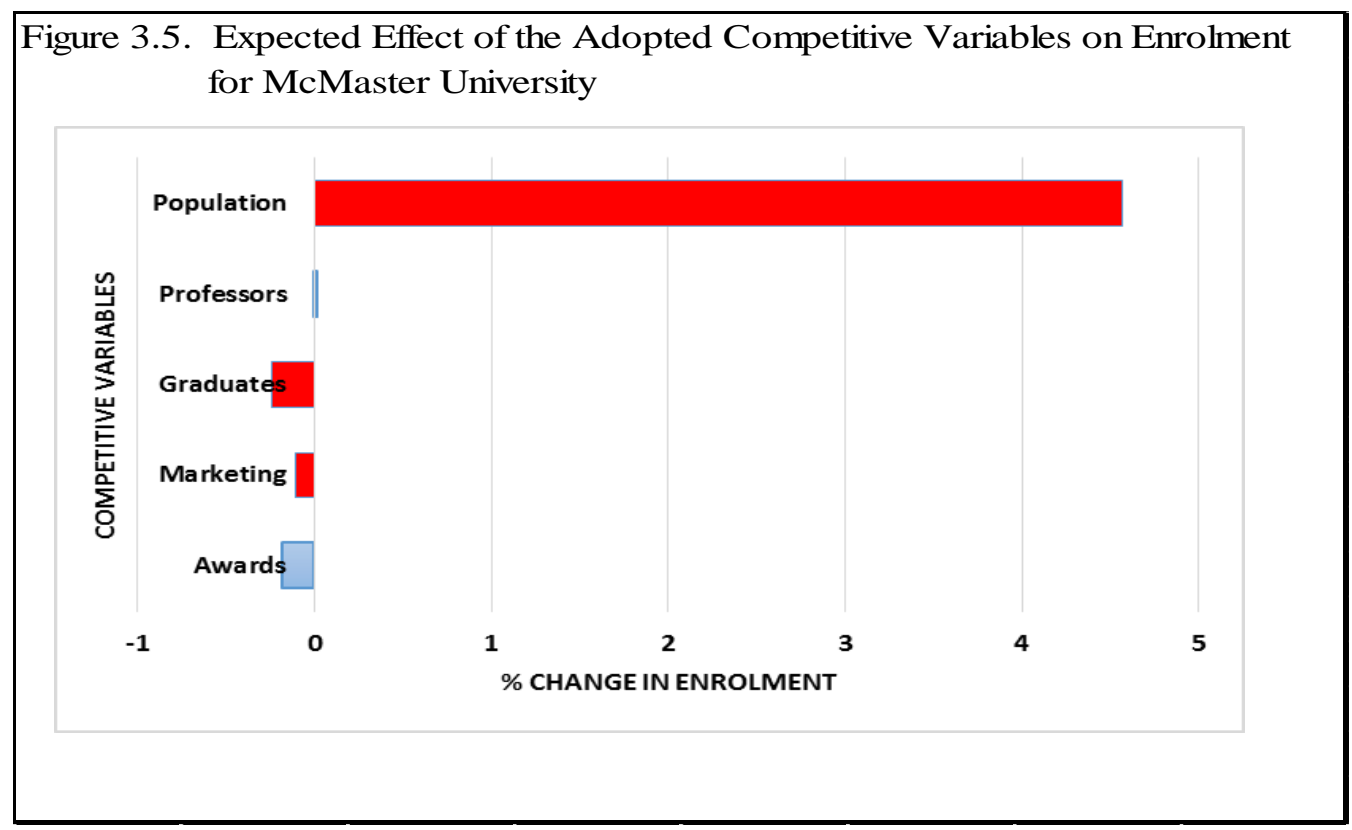


The result from Fixed Effects (a modified Fixed Effect regression) explains how enrolment respond to a one percent change in awards, marketing, graduates, professors, and population for McMaster University. The regression result shows a strong relationship between enrolment and the adopted competitive variables (R-Squared=0.99). R-Squared indicates that approximately $99 \%$ of the change in enrolment can be explained by the change in university expenditure on marketing and graduates, and by the change in population. The result suggests that the responsiveness of enrolment with respect to marketing, graduates, and population is about $-0.11,-0.24$, and $4.57 \%$, respectively. These additional effect coefficients are statistically significant at $1 \%(\rho<.01)$. Overall effects also estimate negative and positive significant signs and these are explained in Appendix E, Table 7.2.1.

The positive and significant additional effects suggest that population has a larger effect on enrollees, while a negative and significant sign suggests that marketing and graduates have a smaller effect on enrolment. A larger effect suggests that a one percent increase in population is expected to produce a greater effect on enrolment by about $4.57 \%$. A smaller effect suggests that a one percent increase in expenditure on marketing and graduates is expected to produce a smaller effect on enrolment by about 0.11 and $0.24 \%$, respectively, for McMaster University relative to all other Ontario universities. However, the existence of significant responsiveness leads one to infer that the changes in university expenditure on marketing and graduates, and the change in population are likely to affect the total number of enrolled students for McMaster University. Evaluating the effect of adopted competitive variables can shed light on the importance of resource allocation in order to enhance the competitiveness of publicly funded universities. Fund allocations and the shift from variables with smaller effects to variables with 
greater effects can help publicly funded university compete effectively and increase their market share.

\section{Nipissing University}

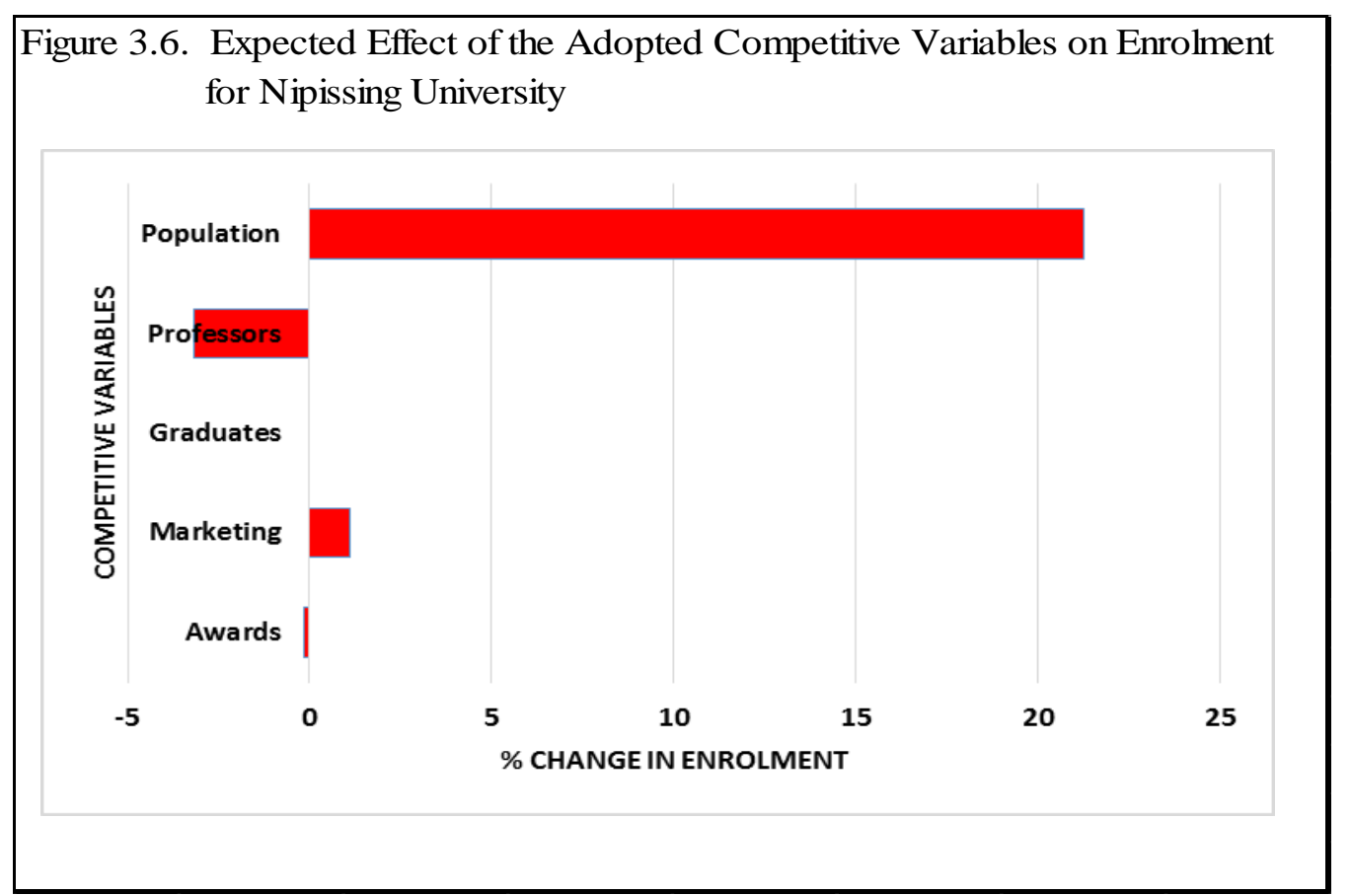

The result from Fixed Effects (a modified Fixed Effect regression) explains how

enrolment respond to a one percent change in awards, marketing, graduates, professors, and population for Nipissing University. The regression result shows a strong relationship between enrolment and the adopted competitive variables (R-Squared=0.996). R-Squared indicates that approximately $99 \%$ of the change in enrolment can be explained by the change in university expenditure on awards, marketing, and professors, and by the change in population. The result suggests that the responsiveness of enrolment with respect to awards, marketing, professors, and population is about $-0.16,1.10,-3.18$, and $21.27 \%$, respectively. These additional effect coefficients are statistically significant at $10,1,1$, and $1 \%$, respectively $(\rho<.10, \rho<.01, \rho<.01, \&$ $\rho<.01)$. Overall effects also estimate negative and positive significant signs and these are explained in Appendix E, Table 7.2.1. 
The positive and significant additional effects suggest that marketing and population have a larger effect on enrollees, while a negative and significant sign suggests that awards and professors have a smaller effect on enrollees. A larger effect suggests that a one percent increase in marketing and population is expected to produce a greater effect on enrolment by about 1.10 and $21.27 \%$, respectively, for Nipissing University relative to all other Ontario universities. A smaller effect suggests that a one percent increase in expenditure on awards and professors is expected to produce a smaller effect on enrolment by about 0.16 and $3.18 \%$, respectively, for Nipissing University relative to all other Ontario universities. However, the existence of significant responsiveness leads one to infer that the changes in university expenditure on awards, marketing, and professors, and also the change in population are likely to affect the total number of enrolled students for Nipissing University. Nipissing University might need these responsiveness estimates in order to determine the most effective competitive variables to make good managerial decisions in the short run and to plan for its enrolment growth in the long run.

\section{OCAD University}

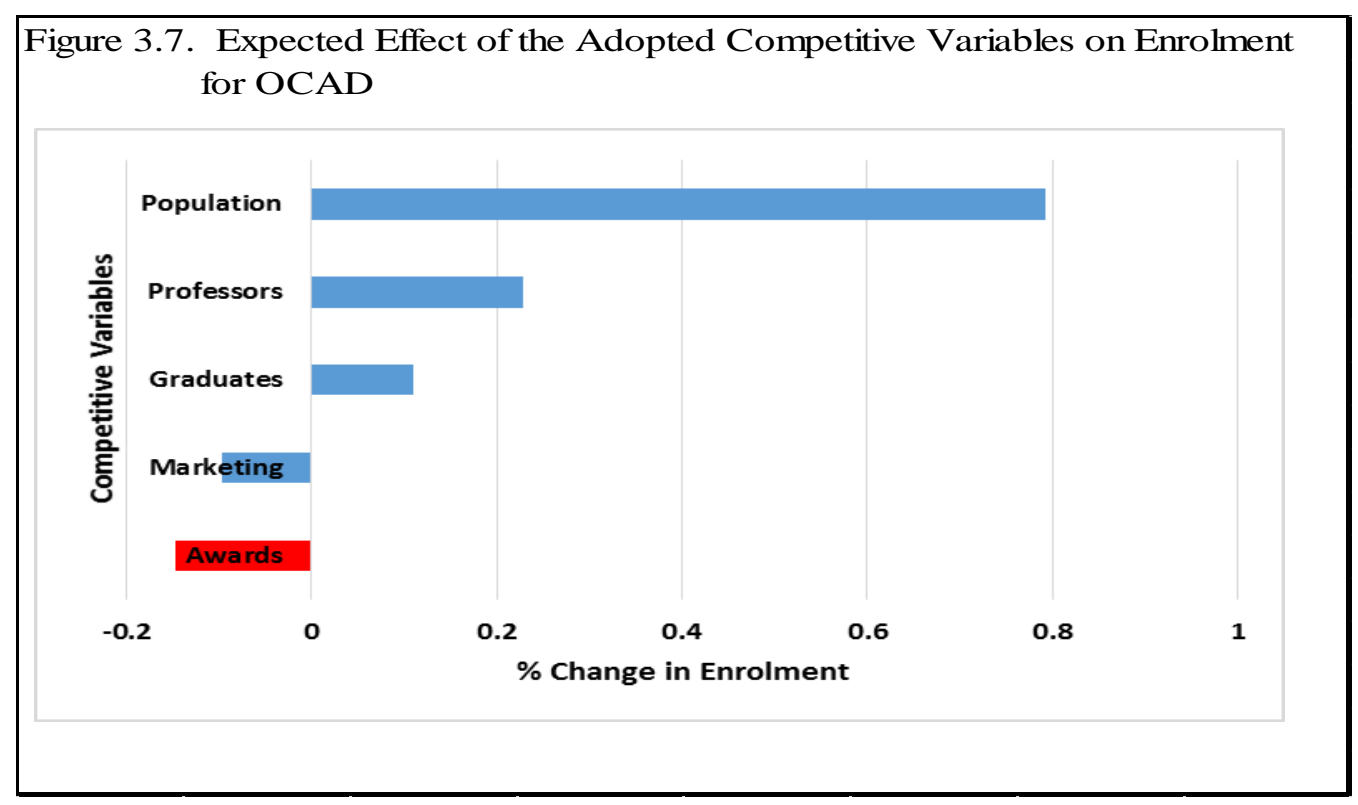


The result from Fixed Effects (a modified Fixed Effect regression) explains how enrolment respond to a one percent change in awards, marketing, graduates, professors, and population for OCAD. The regression result shows a strong relationship between enrolment and the adopted competitive variables $(\mathrm{R}-\mathrm{Squared}=0.996)$. R-Squared indicates that approximately $99 \%$ of the change in enrolment can be explained by the change in university expenditure on awards. The result suggests that the responsiveness of enrolment with respect to awards is about $-0.15 \%$. This additional effect coefficient is statistically significant at $10 \%(\rho<.10)$. Overall effects also estimate negative and positive significant signs and these are explained in Appendix E, Table 7.2.1.

The negative and significant sign suggests that a one percent increase in expenditure on awards has a smaller effect on enrolment for OCAD. A smaller effect suggests that a one percent increase in expenditure on awards is expected to produce a smaller effect on enrolment by about $0.15 \%$ for OCAD relative to all other Ontario universities. However, the existence of significant responsiveness leads one to infer that the changes in university expenditure on awards is likely to affect the total number of enrolled students for OCAD. A significant effect was not found for the competitive variables of marketing, graduates, professors, and population. This insignificance suggests that changes in university expenditure on marketing, graduates, professors, and the change in population are unlikely to affect enrolment for OCAD University. OCAD University might need these responsiveness estimates in order to determine the most effective competitive variables to make good managerial decisions in the short run and to plan for its enrolment growth in the long run. 


\section{Queen's University}

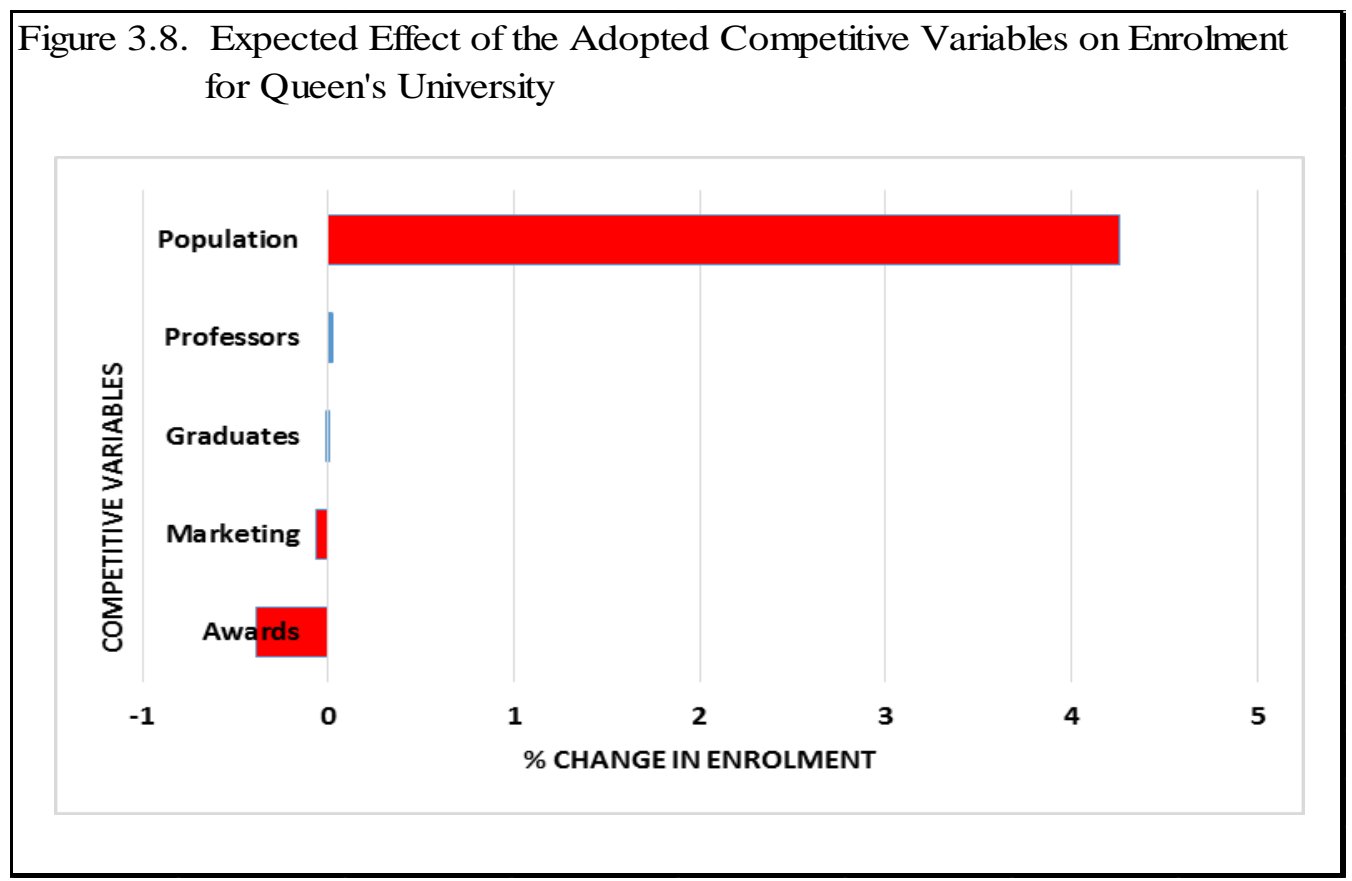

The result from Fixed Effects (a modified Fixed Effect regression) explains how

enrolment respond to a one percent change in awards, marketing, graduates, professors, and population for Queen's University. The regression result shows a strong relationship between enrolment and the adopted competitive variables (R-Squared=0.996). R-Squared indicates that approximately $99 \%$ of the change in enrolment can be explained by the change in university expenditure on awards and marketing, and by the change in population. The result suggests that the responsiveness of enrolment with respect to awards, marketing, and population is about $-0.38,-0.06$, and $4.26 \%$, respectively. These additional effect coefficients are statistically significant at $1 \%(\rho<.01)$. Overall effects also estimate negative and positive significant signs and these are explained in Appendix E, Table 7.2.1

The positive and significant additional effects suggest that population has a larger effect on enrollees, while a negative and significant sign suggests that awards and marketing have a smaller effect on enrollees. A larger effect suggests that a one percent increase in population is 
expected to produce a greater effect on enrolment by about $4.26 \%$. A smaller effect suggests that a one percent increase in expenditure on awards and marketing is expected to produce a smaller effect on enrolment by about 0.38 and $0.06 \%$, respectively, for Queen's University relative to all other Ontario universities. A significant effect was not found for university expenditure on graduates and professors. However, the existence of significant responsiveness leads one to infer that the changes in university expenditure on awards and marketing, and the change in population, are likely to affect the total number of enrolled students for Queen's University. Queen's University might need these responsiveness estimates in order to determine the most effective competitive variables to makes good managerial decisions in the short and in the long run.

\section{Ryerson University}

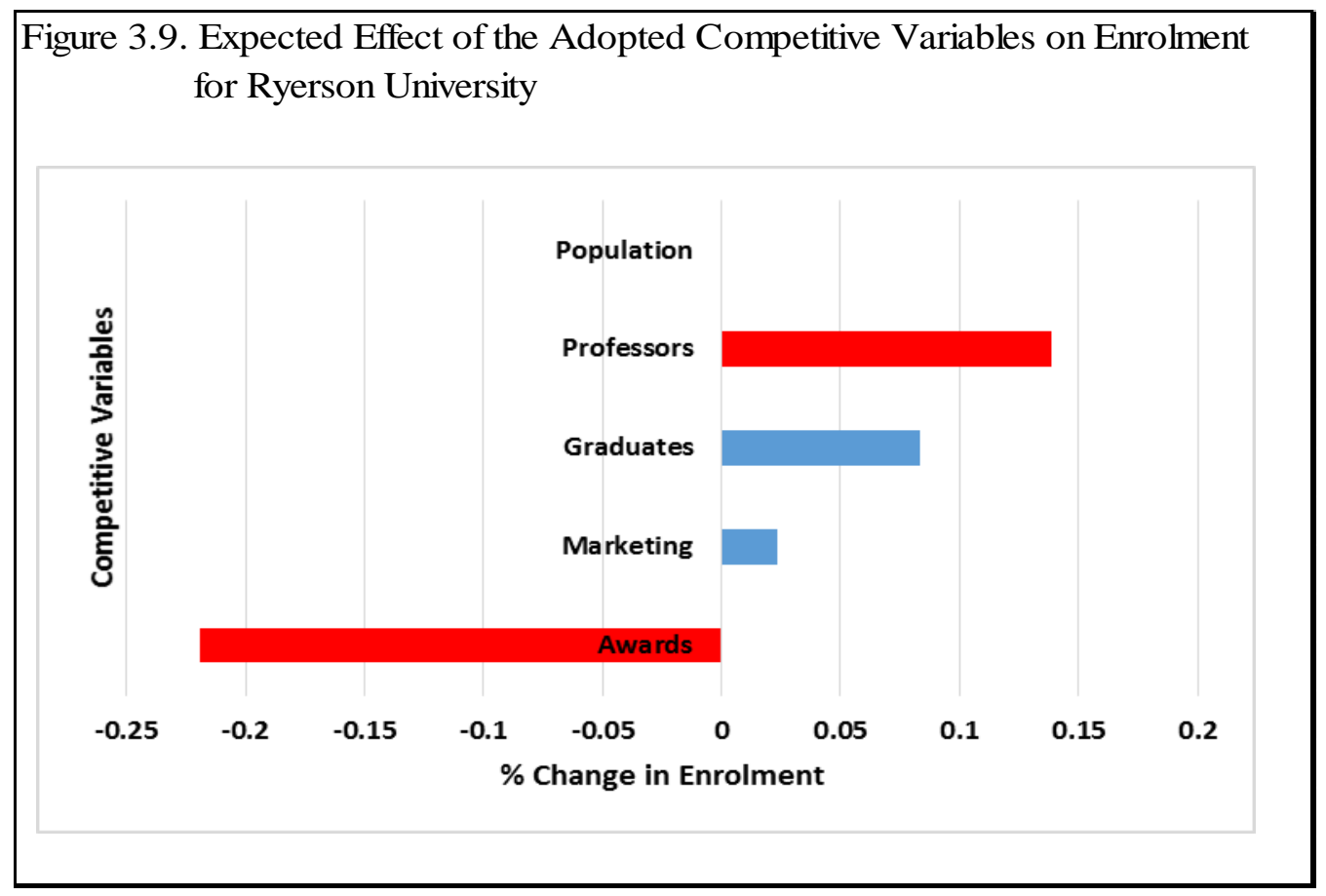

The result from Fixed Effects (a modified Fixed Effect regression) explains how enrollees respond to a one percent change in awards, marketing, graduates, professors, and population for Ryerson University. The regression result shows a strong relationship between 
enrolment and the adopted competitive variables (R-Squared=0.996). R-Squared indicates that approximately $99 \%$ of the change in enrolment can be explained by the change in university expenditure on awards and professors. The result suggests that the responsiveness of enrolment with respect to awards and professors is about -0.22 and $0.14 \%$, respectively. These additional effect coefficients are statistically significant at 1 and $10 \%(\rho<.01 \& \rho<.10)$. Overall effects also estimate negative and positive significant signs and these are explained in Appendix E, Table 7.2.1

The positive and significant additional effects suggest that professors has a larger effect on enrollees, while a negative and significant sign suggests that awards has a smaller effect on enrollees. A larger effect suggests that a one percent increase in investing in faculty members (professors) is expected to produce a greater effect on enrolment by about $0.14 \%$. A smaller effect suggests that a one percent increase in expenditure on awards is expected to produce a smaller effect on enrolment by about $0.22 \%$, respectively, for Ryerson University relative to all other Ontario universities. A significant effect was not found for university expenditure on marketing and graduates. However, the existence of significant responsiveness leads one to infer that the changes in university expenditure on awards and professors are likely to affect the total number of enrolled students for Ryerson University. 


\section{Trent University}

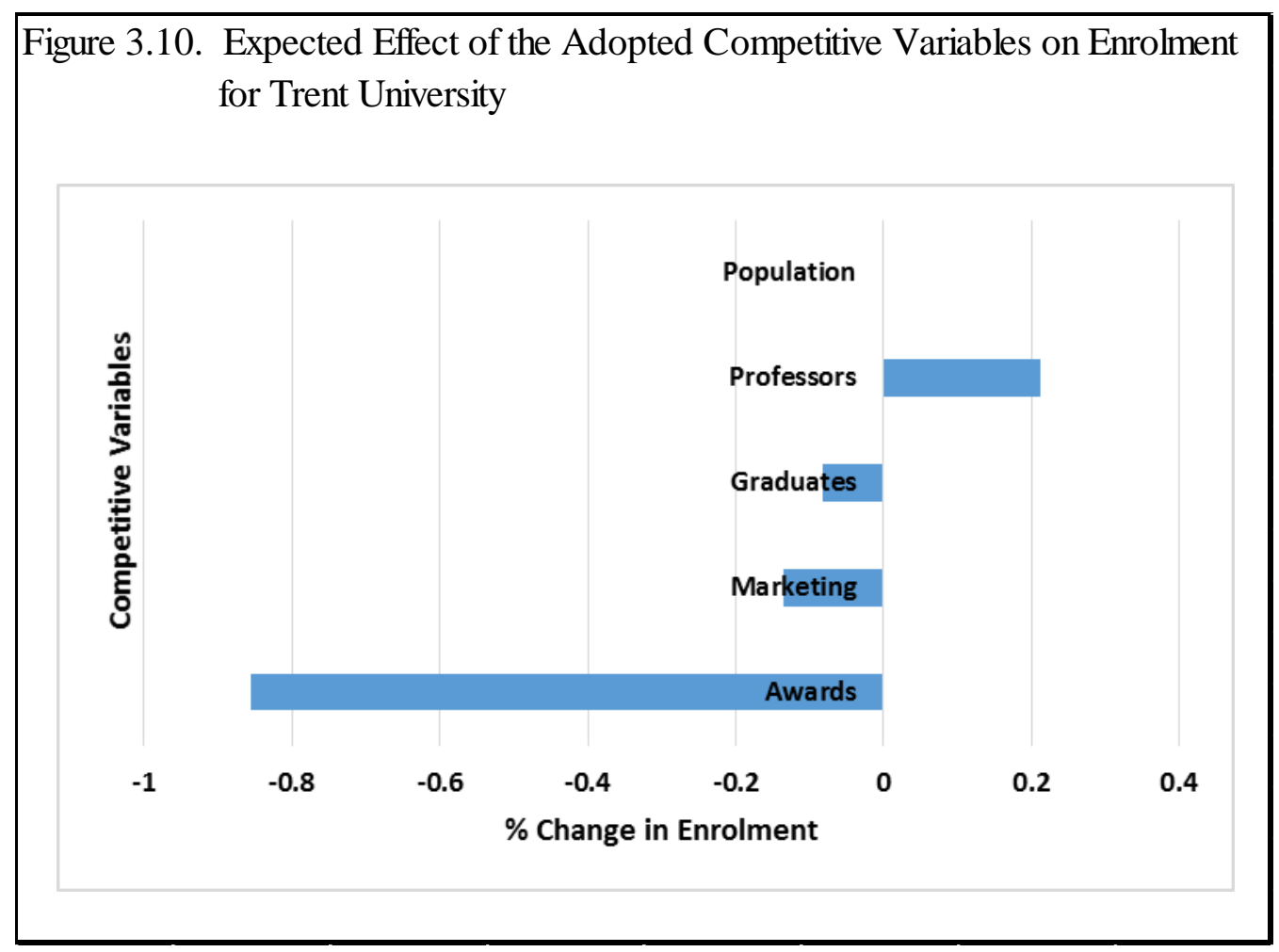

The result from Fixed Effects (a modified Fixed Effect regression) explains how

enrollees respond to a one percent change in awards, marketing, graduates, professors, and population for Trent University. A significant relation was not found for adopted competitive variables. This insignificance suggests that changes in university expenditure on awards, marketing, graduates, and professors are unlikely to affect total number of enrolled students for Trent University. These additional effect coefficients are statistically insignificant for Trent University. Overall effects also estimate insignificant relation and these are explained in Appendix E, Table 7.2.1. 


\section{University of Guelph}

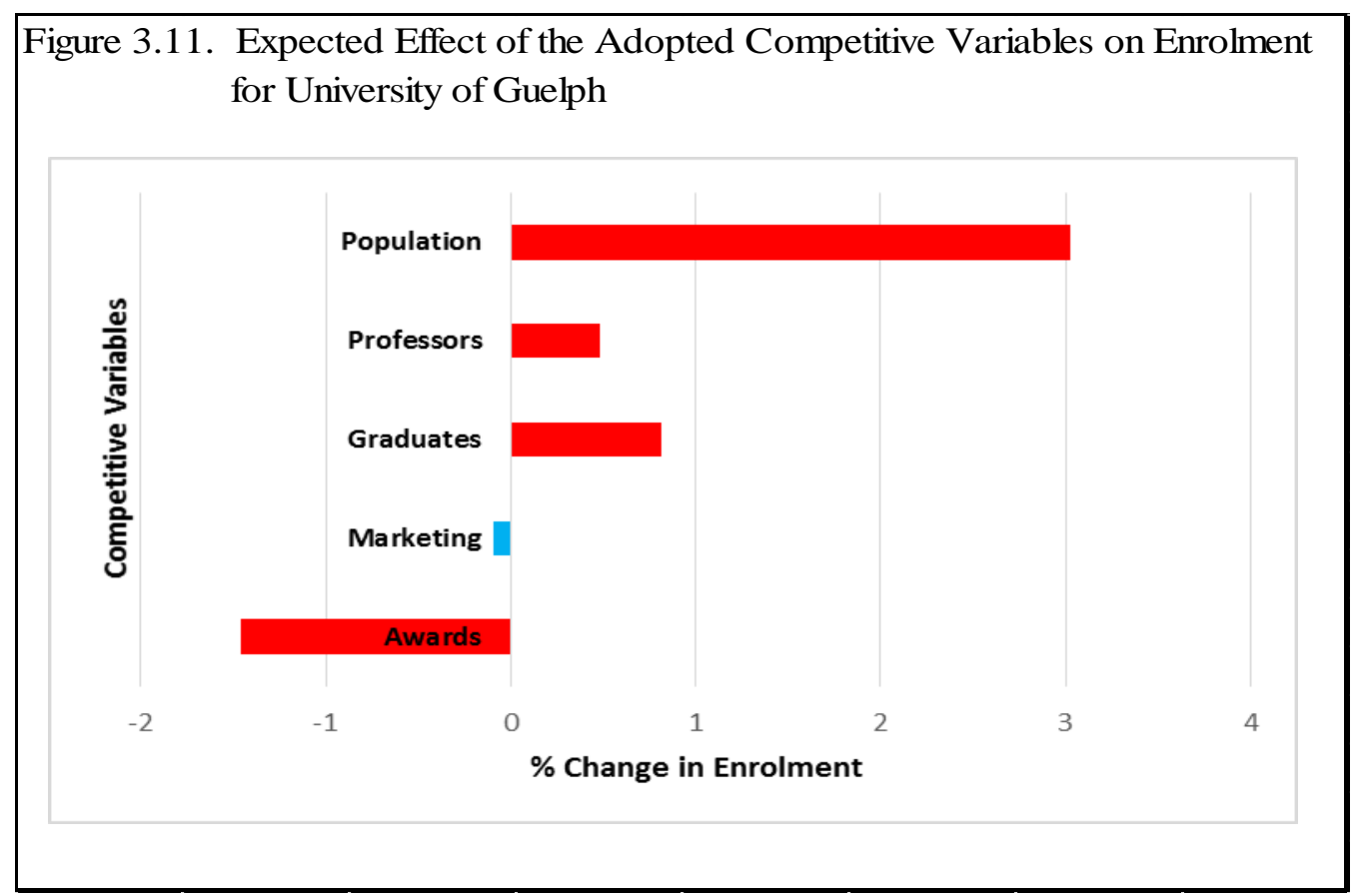

The result from Fixed Effects (a modified Fixed Effect regression) explains how enrolment respond to a one percent change in awards, marketing, graduates, professors, and population for University of Guelph. The regression result shows a strong relationship between enrolment and the adopted competitive variables (R-Squared=0.996). R-Squared indicates that approximately $99 \%$ of the change in enrolment can be explained by the change in university expenditure on awards, graduates, and professors, and by the change in population. The result suggests that the responsiveness of enrolment with respect to awards, graduates, professors, and population is about $-1.46,0.81,0.48$, and $3.03 \%$, respectively. These additional effect coefficients are statistically significant at $1,1,5$, and $5 \%(\rho<.01, \rho<.01, \rho<.05, \& \rho<.05)$. Overall effects also estimate negative and positive significant signs and these are explained in Appendix E, Table 7.2.1.

The positive and significant additional effects suggest that graduates, professors, and population have a larger effect on enrolment, while a negative and significant sign suggests that 
awards has a smaller effect on enrolment. A larger effect suggests that a one percent increase in expenditure on graduates and professors is expected to produce a greater effect on enrolment by about 0.81 and $0.48 \%$, respectively, for University of Guelph relative to all other Ontario universities. A one percent increase in population is expected to produce a greater effect on enrolment by about $3.03 \%$. A smaller effect suggests that a one percent increase in expenditure on awards is expected to produce a smaller effect on enrolment by about $1.46 \%$, for University of Guelph relative to all other Ontario universities. However, the existence of significant responsiveness leads one to infer that the changes in university expenditure on awards, graduates, and professors, and the changes in population are likely to affect the total number of enrolled students for University of Guelph.

\section{UOIT}

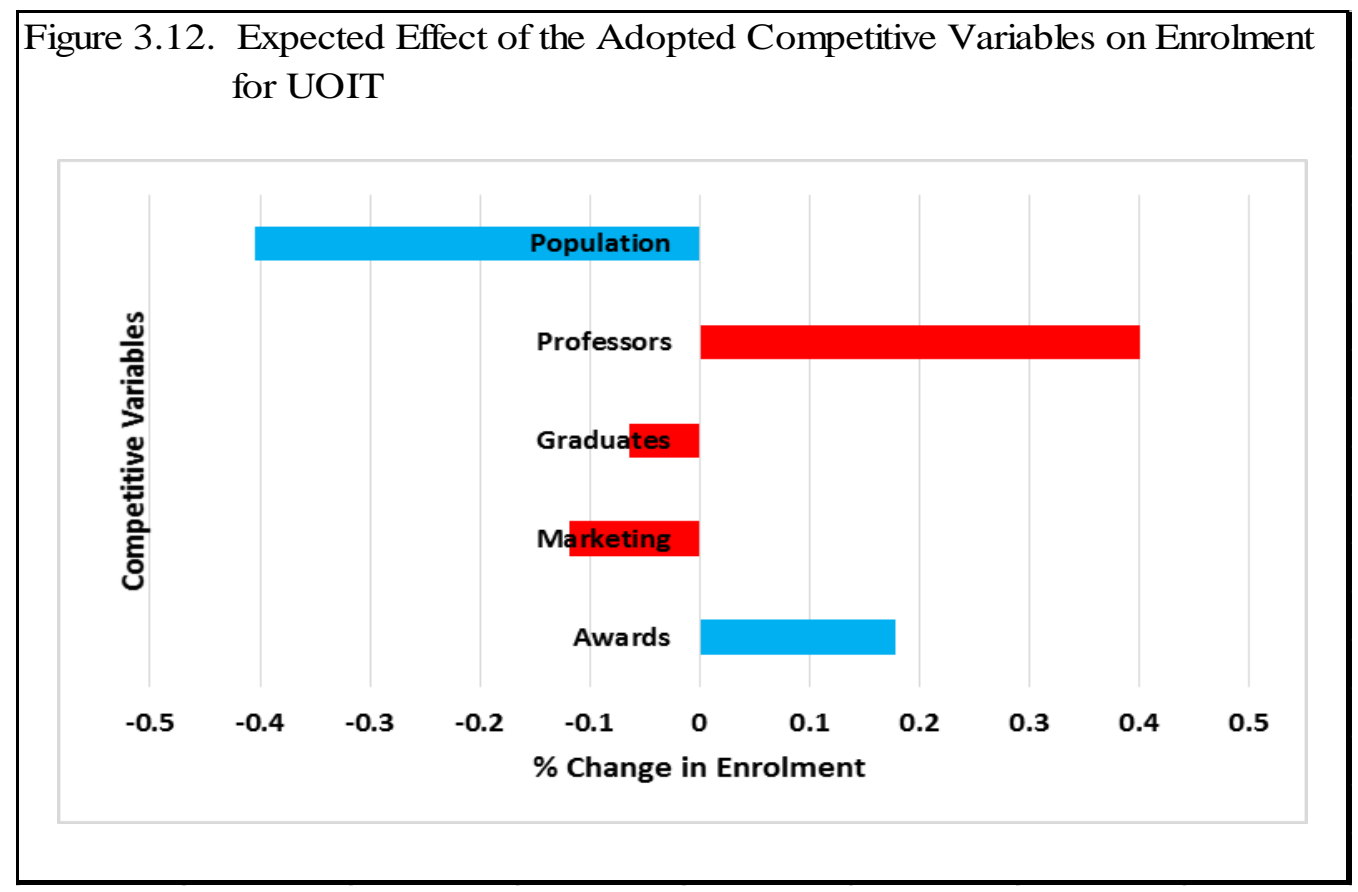

The result from Fixed Effects (a modified Fixed Effect regression) explains how enrollees respond to a one percent change in awards, marketing, graduates, professors, and population for UOIT. The regression result shows a strong relationship between enrolment and 
the adopted competitive variables $(\mathrm{R}-\mathrm{Squared}=0.997)$. R-Squared indicates that approximately $99 \%$ of the change in enrolment can be explained by the change in university expenditure on marketing, graduates, and professors. The result suggests that the responsiveness of enrolment with respect to marketing, graduates, and professors is about $-0.12,-0.06$, and $0.40 \%$, respectively. These additional effect coefficients are statistically significant at 5, 5, and $1 \%$ $(\rho<.05, \rho<.05, \& \rho<.01)$. Overall effects also estimate negative and positive significant signs, and these are explained in Appendix E, Table 7.2.1.

The positive and significant additional effects suggest that professors has a larger effect on enrolment, while a negative and significant sign suggests that marketing and graduates have a smaller effect on enrolment. A larger effect suggests that a one percent increase in investing in faculty members (professors) is expected to produce a greater effect on enrolment by about $0.40 \%$. A smaller effect suggests that a one percent increase in expenditure on marketing and graduates is expected to produce a smaller effect on enrolment by about 0.12 and $0.06 \%$, respectively, for OUIT relative to all other Ontario universities. However, the existence of significant responsiveness leads one to infer that the changes in university expenditure on awards, graduates, and professors are likely to affect the total number of enrolled students for UOIT. The other two variables were found to be insignificant. This insignificance suggests that changes in university expenditure on awards and in population are unlikely to affect total number of applications for admission for UOIT. 


\section{University of Ottawa}

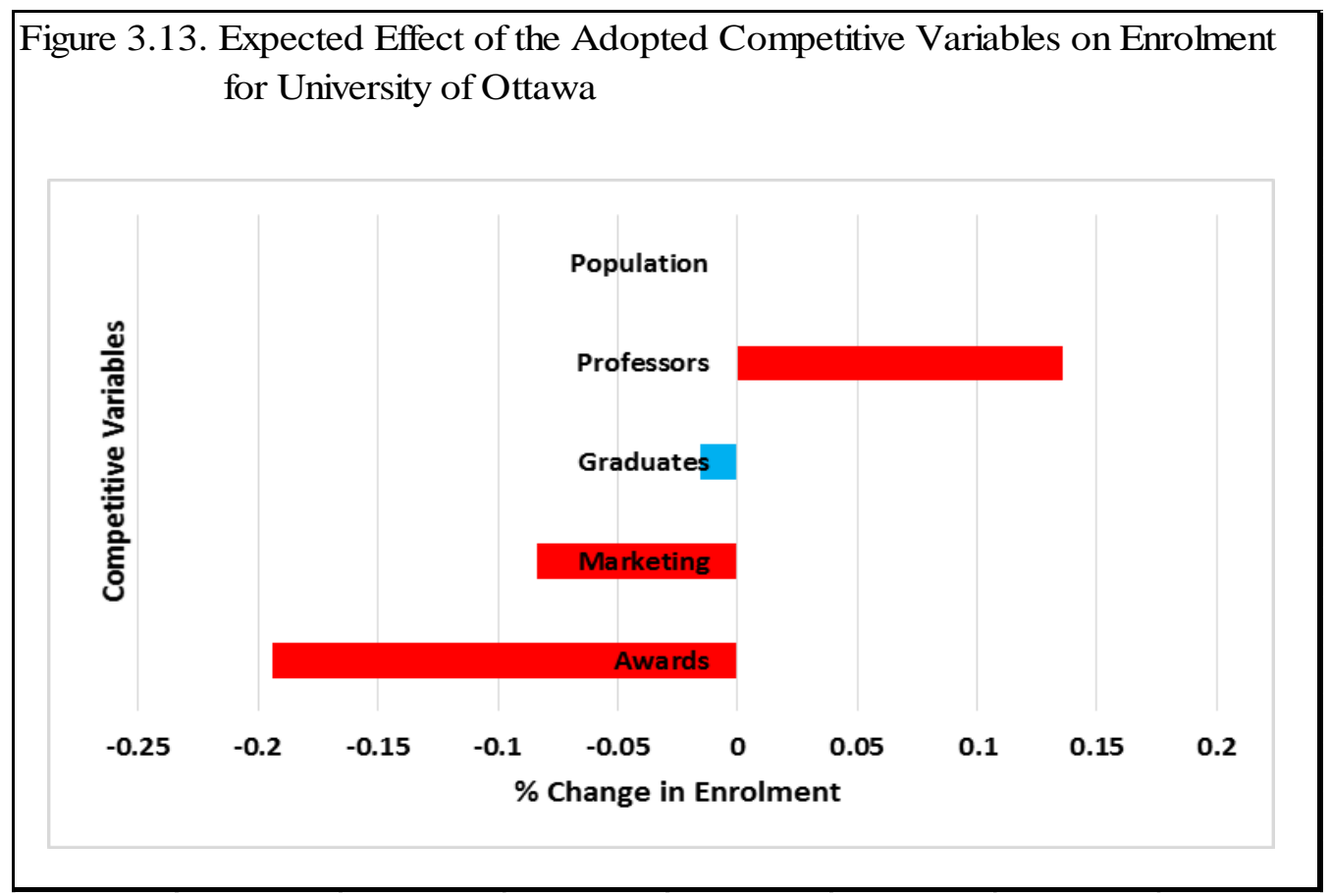

The result from Fixed Effects (a modified Fixed Effect regression) explains how

enrollees respond to a one percent change in awards, marketing, graduates, professors, and population for University of Ottawa. The regression result shows a strong relationship between enrolment and the adopted competitive variables (R-Squared=0.996). R-Squared indicates that approximately $99 \%$ of the change in enrolment can be explained by the change in university expenditure on awards, marketing, and professors. The result suggests that the responsiveness of enrolment with respect to awards, marketing, and professors is about $-0.19,-0.08$, and $0.14 \%$, respectively. These additional effect coefficients are statistically significant at 1, 1, and 5\% $(\rho<.01, \rho<.01, \& \rho<.05)$. Overall effects also estimate negative and positive significant signs, and these are explained in Appendix E, Table 7.2.1.

The positive and significant additional effects suggest that professors has a larger effect on enrollees, while a negative and significant sign suggests that awards and marketing have a smaller effect on enrollees. A one percent increase in expenditure on professors has a greater 
effect on enrolment by about $0.14 \%$, while a one percent increase in expenditure on awards and marketing has a smaller effect on enrolment by about 0.19 and $0.08 \%$, respectively, for University of Ottawa relative to all other Ontario universities. However, the existence of significant responsiveness leads one to infer that the changes in university expenditure on awards, marketing, and professors are likely to affect the total number of enrolled students for University of Ottawa. A significant effect was not found for the competitive variables of graduates and population. This insignificance suggests that changes in university expenditure on graduates and in population are unlikely to affect total number of enrolled students for University of Ottawa.

\section{University of Waterloo}

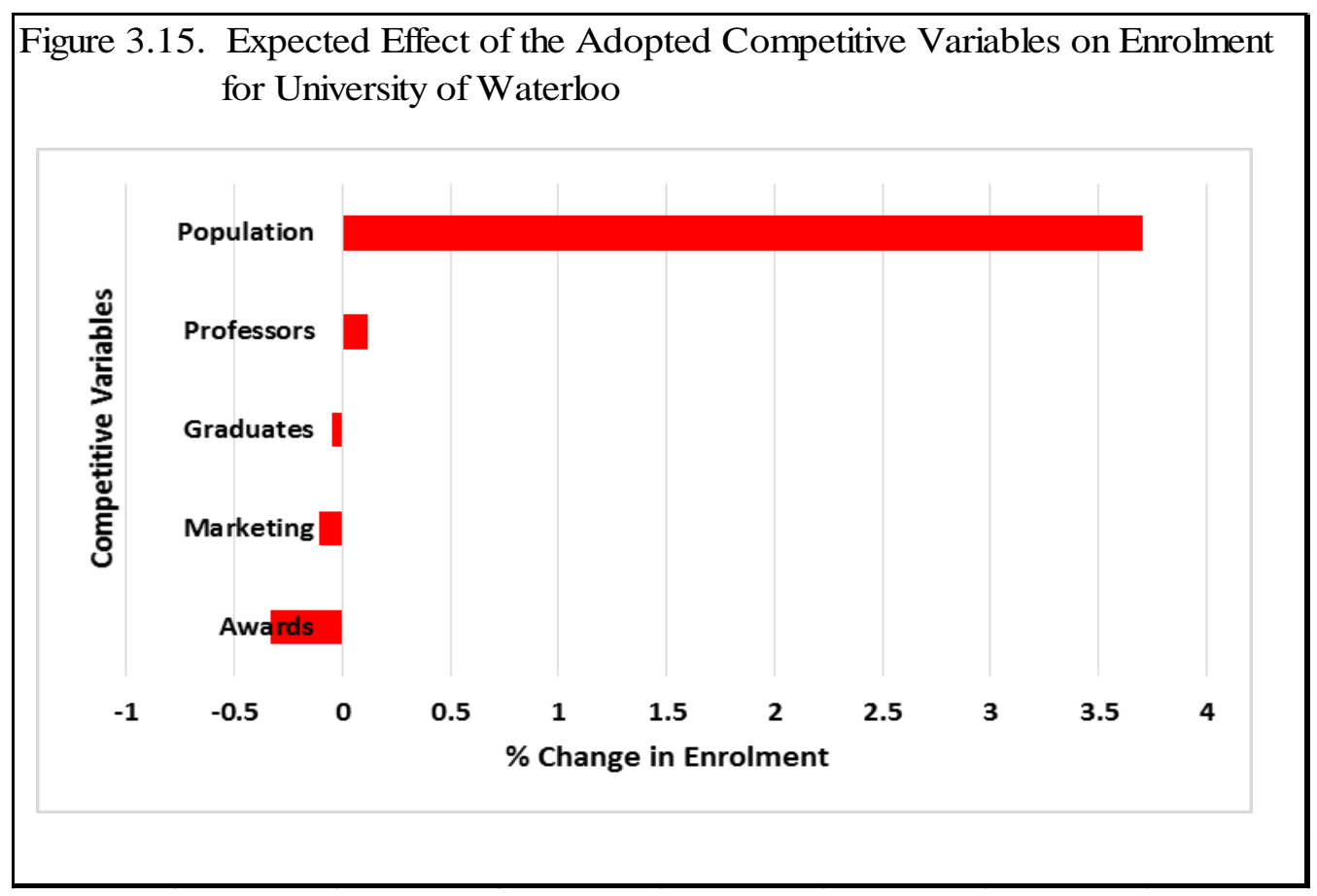

The result from Fixed Effects (a modified Fixed Effect regression) explains how enrollees respond to a one percent change in awards, marketing, graduates, professors, and population for University of Waterloo. The regression result shows a strong relationship between enrolment and the adopted competitive variables ( $\mathrm{R}$-Squared=0.99). R-Squared 
indicates that approximately $99 \%$ of the change in enrolment can be explained by the change in university expenditure on awards, marketing, graduates, and professors, and by the change in population. The result suggests that the responsiveness of enrolment with respect to awards, marketing, graduates, professors, and population is about $-0.33,-0.10,-0.05,0.12$, and $3.70 \%$, respectively. These additional effect coefficients are statistically significant at $1 \%(\rho<.01)$. Overall effects also estimate negative and positive significant signs and these are explained in Appendix E, Table 7.2.1.

The positive and significant additional effects suggest that professors and population have a larger effect on enrolment, while a negative and significant sign suggests that awards, marketing, and graduates have a smaller effect on enrolment. A larger effect suggests that a one percent increase in investing in faculty members (professors) is expected to produce a greater effect on enrolment by about $0.12 \%$ for University of Waterloo relative to all other Ontario universities. A one percent increase in population is expected to produce a greater effect on enrolment by about $3.70 \%$. A smaller effect suggests that a one percent increase in expenditure on awards, marketing, and graduates is expected to produce a smaller effect on enrolment by about $0.33,0.10$, and $0.05 \%$, respectively, for University of Waterloo relative to all other Ontario universities. However, the existence of significant responsiveness leads one to infer that the changes in population and in university expenditure on awards, marketing, graduates, and professors are likely to affect the total number of enrolled students for University of Waterloo. 


\section{University of Windsor}

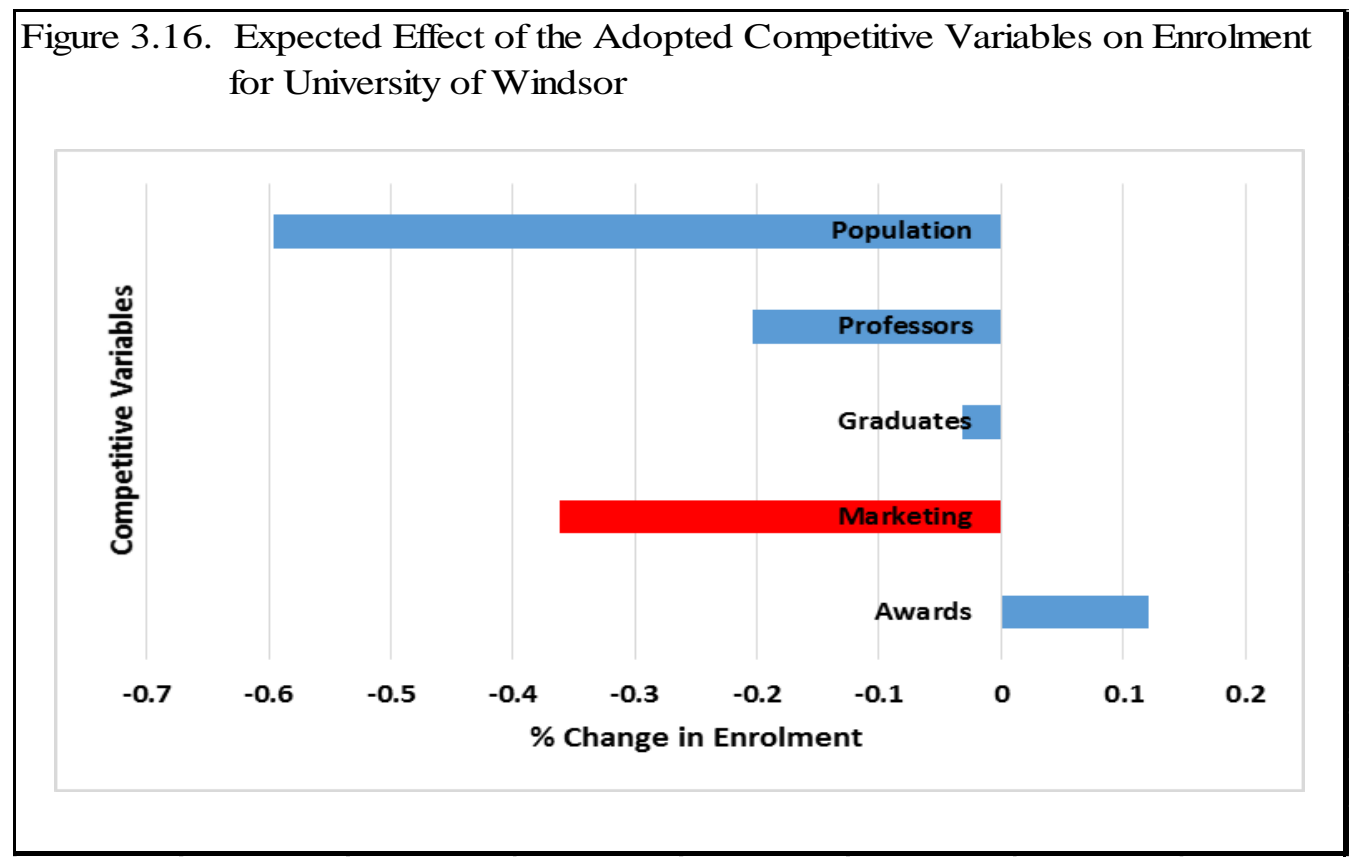

The result from Fixed Effects (a modified Fixed Effect regression) explains how

enrollees respond to a one percent change in awards, marketing, graduates, professors, and population for University of Windsor. R-Squared indicates that approximately $99 \%$ of the change in enrolment can be explained by the change in university expenditure on marketing. The result suggests that the responsiveness of enrolment with respect to marketing is about $-0.36 \%$. This additional effect coefficient is statistically significant at $1 \%(\rho<.01)$. Overall effects also estimate negative and positive significant signs and they are explained in Appendix E, Table 7.2.1.

The negative and significant sign suggests that marketing has a smaller effect on enrolment. A smaller effect suggests that a one percent increase in expenditure on marketing is expected to produce a smaller effect on enrolment by about $0.36 \%$ for University of Windsor relative to all other Ontario universities. A significant effect was not found for variables such as awards, graduates, professors, and population. However, the existence of significant 
responsiveness leads one to infer that the changes in university expenditure on marketing is likely to affect the total number of enrolled students for University of Windsor. University of Windsor might need these responsiveness estimates in order to determine the most effective competitive variables to makes good managerial decisions in the short run and to plan for its enrolment growth in the long run.

\section{Western University}

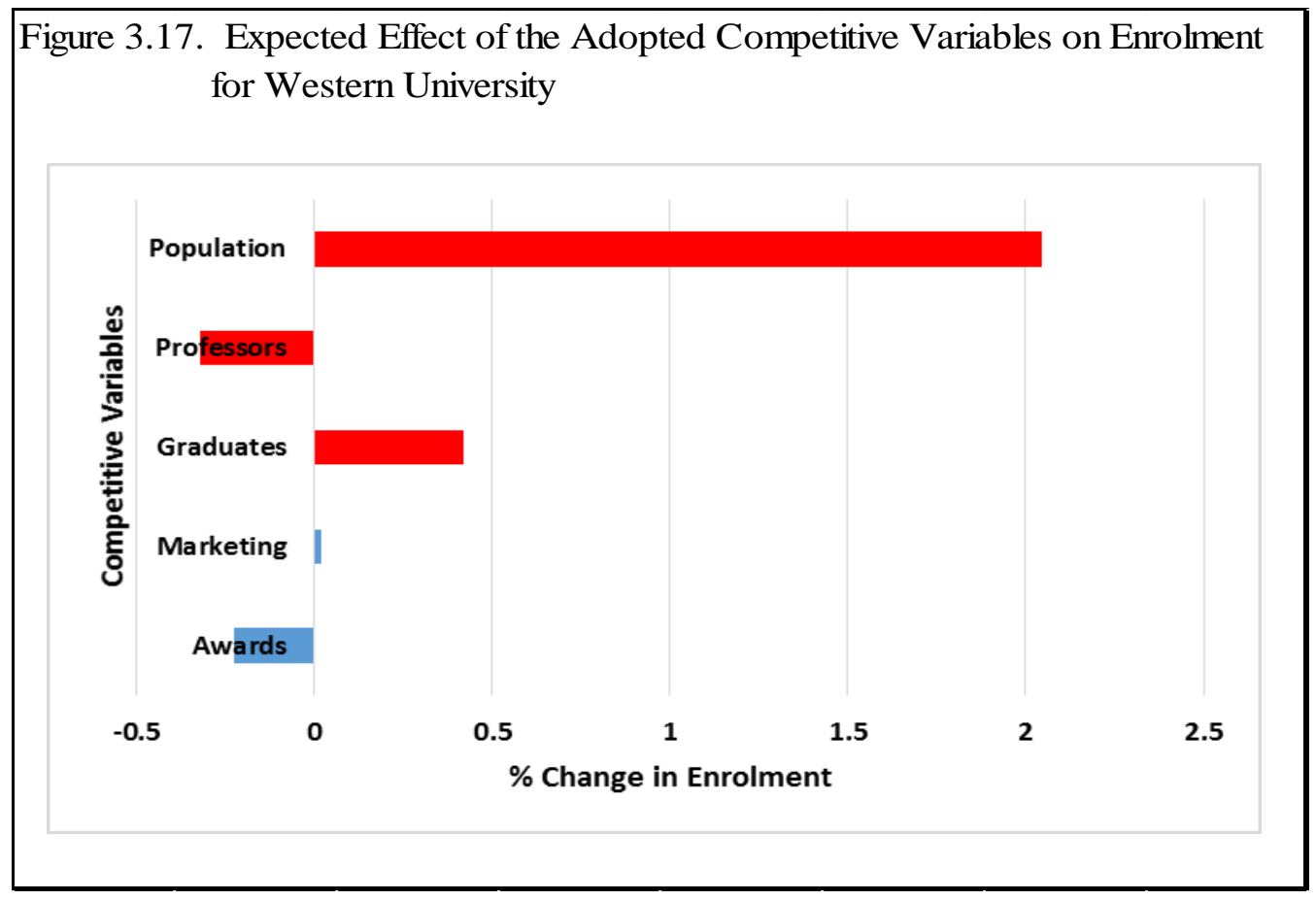

The result from Fixed Effects (a modified Fixed Effect regression) explains how

enrollees respond to a one percent change in awards, marketing, graduates, professors, and population for Western University. R-Squared indicates that approximately $99 \%$ of the change in enrolment can be explained by the change in university expenditure on graduates and professors, and by the change in population. The result suggests that the responsiveness of enrolment with respect to graduates, professors, and population is about $0.42,-0.32$, and $2.05 \%$, respectively. These additional effect coefficients are statistically significant at 5, 1, and 1\% 
$(\rho<.05, \rho<.01, \& \rho<.01)$. Overall effects also estimate negative and positive significant signs and these are explained in Appendix E, Table 7.2.1.

The positive and significant additional effects suggest that graduates and population have a larger effect on enrolment, while a negative and significant sign suggests that professors have a smaller effect on enrolment. A larger effect suggests that a one percent increase in graduates and population is expected to produce a greater effect on enrolment by about 0.42 and $2.05 \%$, respectively. A smaller effect suggests that a one percent increase in expenditure on professors is expected to produce a smaller effect on enrolment by about $0.32 \%$ for Western University relative to all other Ontario universities. A significant effect was not found for awards and marketing. However, the existence of significant responsiveness leads one to infer that the changes in university expenditure on graduates and professors, and the change in population, are likely to affect the total number of enrolled students for Western University. 


\section{Wilfrid Laurier University}

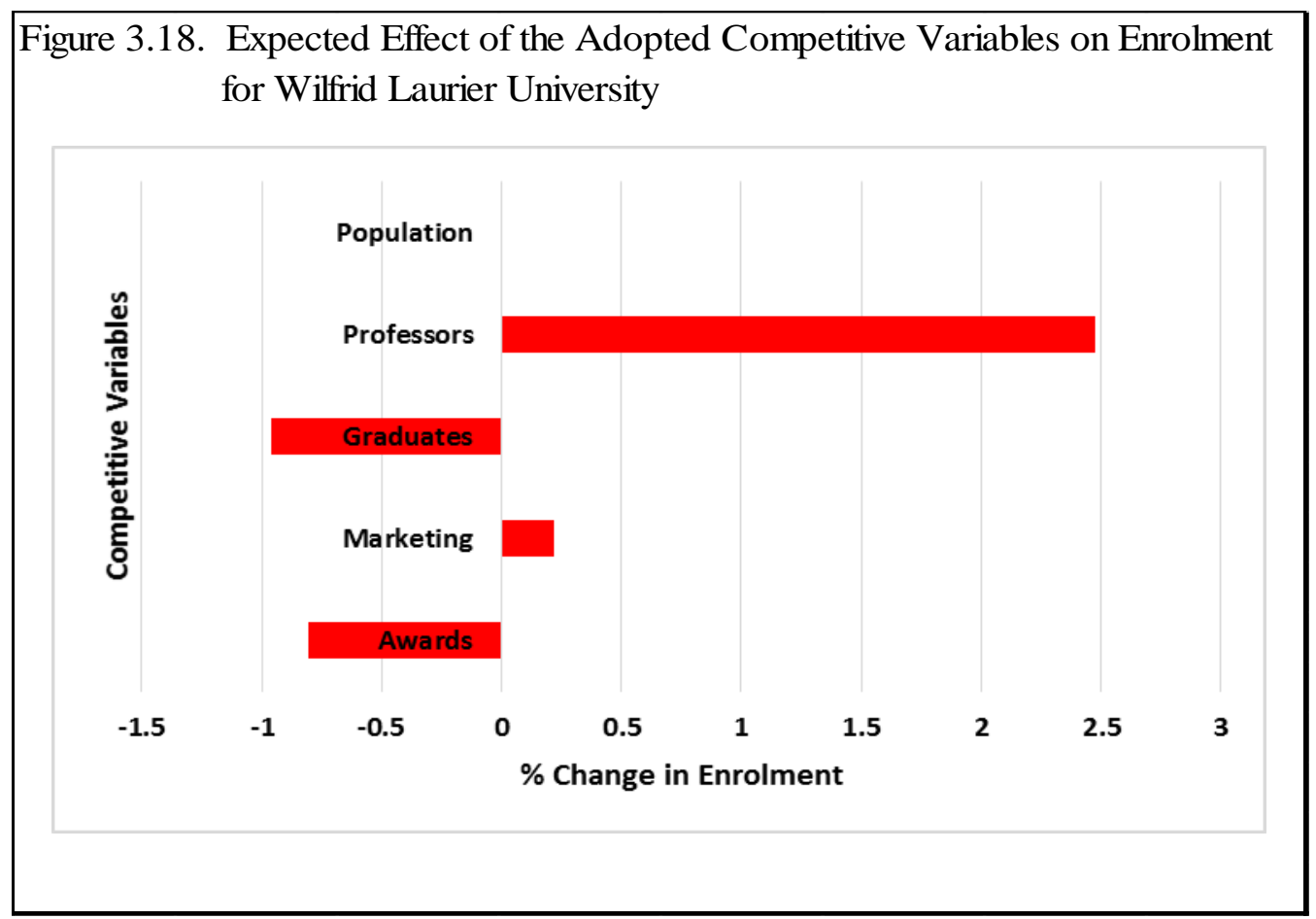

The result from Fixed Effects (a modified Fixed Effect regression) explains how

enrollees respond to a one percent change in awards, marketing, graduates, professors, and population for Wilfrid Laurier University. The regression result shows a strong relationship between enrolment and the adopted competitive variables (R-Squared=0.996). R-Squared indicates that approximately $99 \%$ of the change in enrolment can be explained by the change in university expenditure on awards, marketing, graduates, and professors. The result suggests that the responsiveness of enrolment with respect to awards, marketing, graduates, and professors is about $-0.80,0.22,-0.96$, and $2.48 \%$, respectively. These additional effect coefficients are statistically significant at $1 \%(\rho<.01)$. Overall effects also estimate negative and positive significant signs and these are explained in Appendix E, Table 7.2.

The positive and significant additional effects suggest that marketing and professors have a larger effect on enrolment, while a negative and significant sign suggests that awards and 
graduates have a smaller effect on enrolment. A larger effect suggests that a one percent increase in expenditure on marketing and professors is expected to produce a greater effect on enrolment by about 0.22 and $2.48 \%$, respectively. A smaller effect suggests that a one percent increase in expenditure on awards and graduates is expected to produce a smaller effect on enrolment by about 0.80 and $0.96 \%$, respectively, for Wilfrid Laurier University relative to all other Ontario universities. However, the existence of significant responsiveness leads one to infer that the changes in university expenditure on awards, marketing, graduates, and professors are likely to affect the total number of enrolled students for Wilfrid Laurier University.

\section{York University}

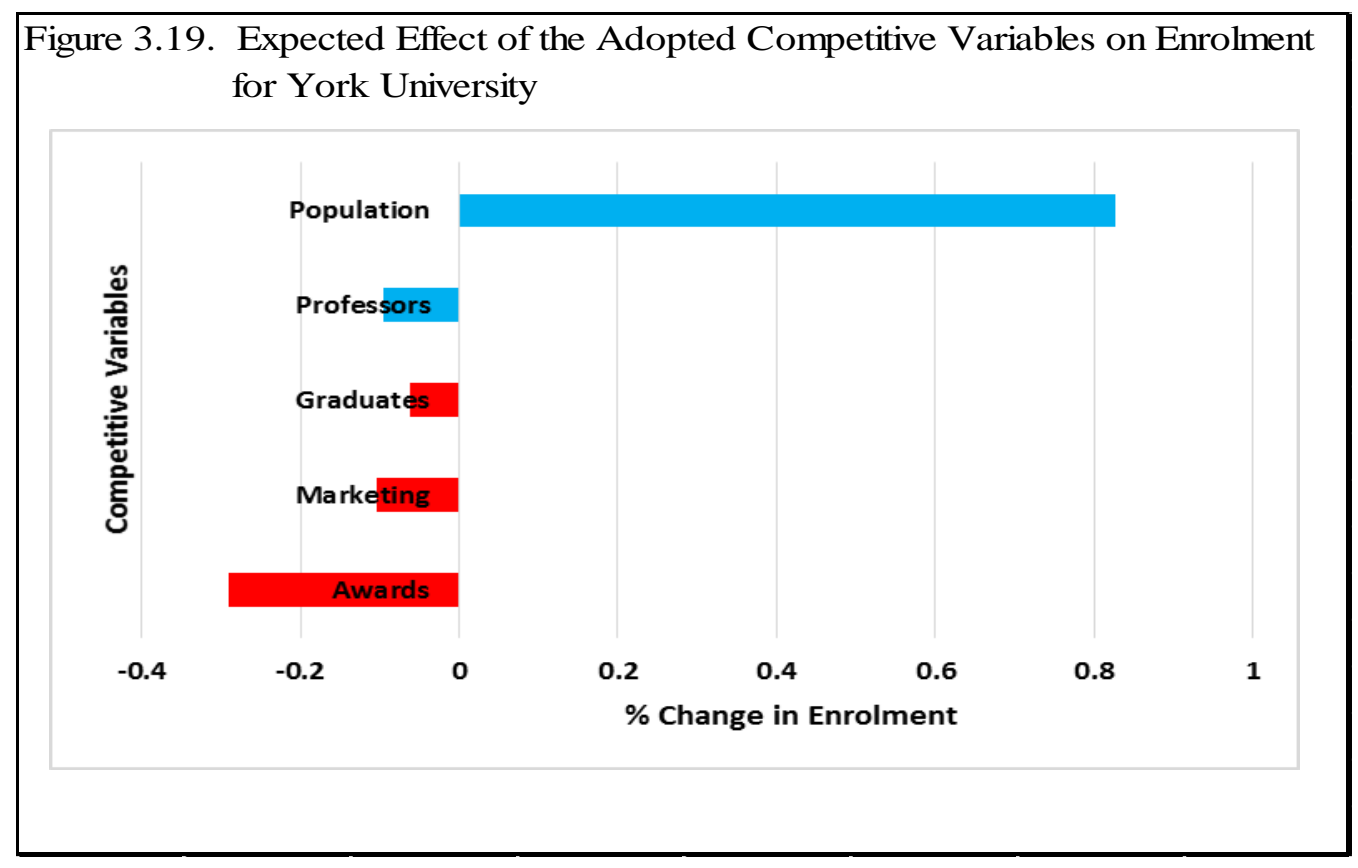

The result from Fixed Effects (a modified Fixed Effect regression) explains how enrollees respond to a one percent change in awards, marketing, graduates, professors, and population for York University. R-Squared indicates that approximately $99 \%$ of the change in enrolment can be explained by the change in university expenditure on awards, marketing, and graduates. The result suggests that the responsiveness of enrolment with respect to awards, 
marketing, and graduates is about $-0.29,-0.10$, and $-0.06 \%$, respectively. These additional effect coefficients are statistically significant at $1 \%(\rho<.01)$. Overall effects also estimate negative and positive significant signs and these are explained in Appendix E, Table 7.2.1.

The negative and significant sign suggests that awards, marketing, and graduates have a smaller effect on enrollees. A one percent increase in expenditure on awards, marketing, and graduates has a smaller effect on enrolment by about $0.29,0.10$, and $0.06 \%$, respectively, for York University relative to all other Ontario universities. A significant effect was not found for professors and population. However, the existence of significant responsiveness leads one to infer that the changes in university expenditure on awards, marketing, and graduates are likely to affect the total number of enrolled students for York University. 


\section{Appendix J: Data Analysis for Each Individual University (Applications: Lagged Model)}

A modified Fixed Effect regression was conducted for each individual university. The results shown in each figure indicate which variables have stronger effects (denoted by positive additional effects) in the particular university relative to the baseline for all other universities and which variables have weaker effects (denoted by negative additional effects). Thus, the coefficients show the expected additional percentage changes in applications for a given university relative to the baseline for all universities stemming from a one percent change in its variables.

\section{Brock University}

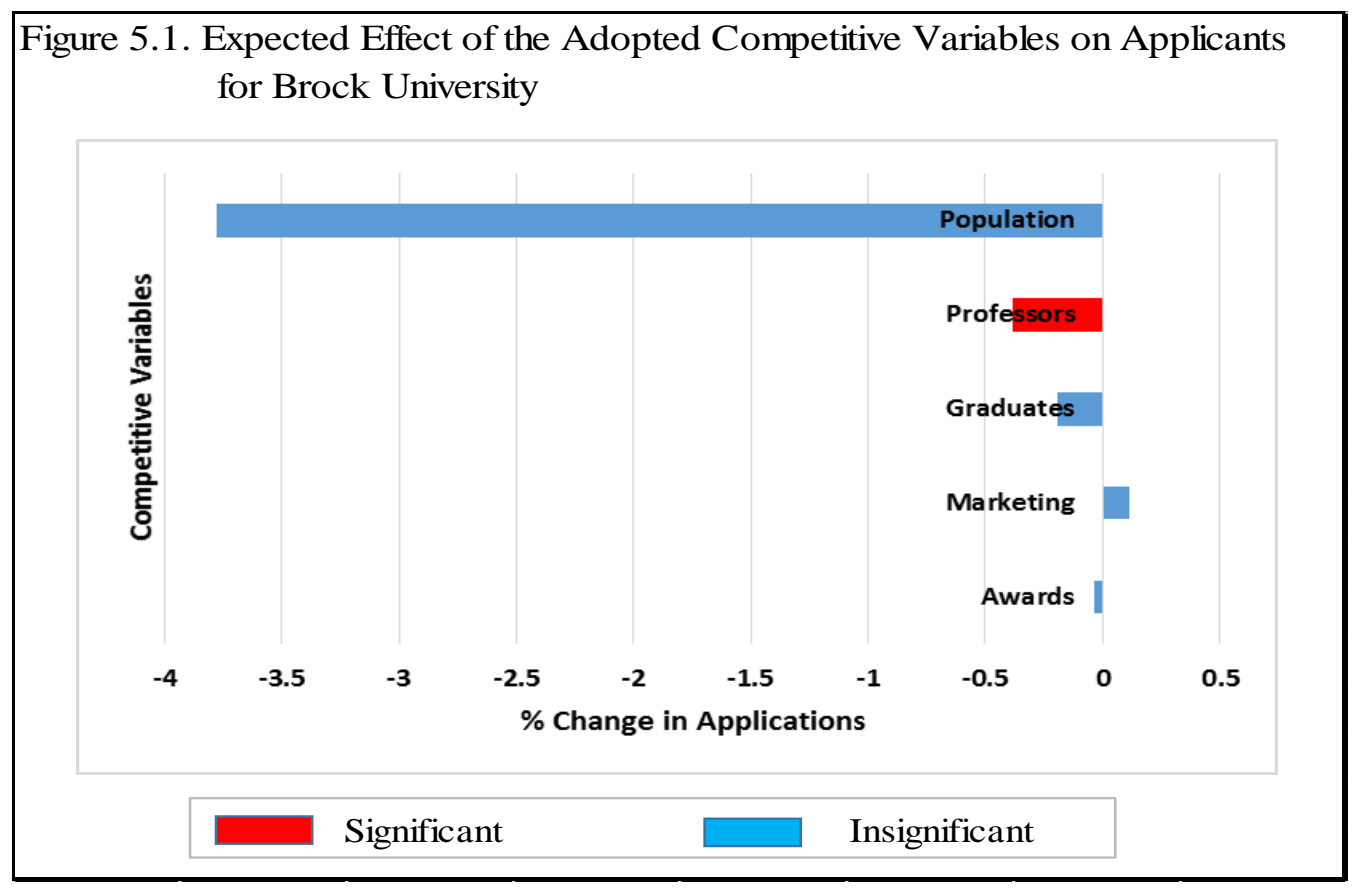

The result from Fixed Effects (a modified Fixed Effect regression) explains how the total number of applicants responds to a one percent change in awards, marketing, graduates, professors, and population for Brock University. R-Squared indicates that approximately $99 \%$ of the change in the total number of applicants can be explained by the change in university expenditure on professors. The result suggests that the responsiveness of applicants with respect to professors is about $-0.39 \%$, respectively. This additional effect coefficient is statistically 
significant at $10 \%(\rho<.10)$. Overall effects estimate negative and positive significant signs and these are explained in Appendix F, Table 8.2.1.

The negative and significant sign suggests that professors has a smaller effect on applicants. A one percent increase in expenditure on professors has a smaller effect on the total number of applicants by about $0.39 \%$ for Brock University relative to all other Ontario universities. A significant effect was not found for variables awards, marketing, graduates, and population. However, the existence of significant responsiveness leads one to infer that the changes in university expenditure on professors are likely to affect the total number of applicants for Brock University. Brock University might need these responsiveness estimates in order to determine the most effective competitive variables to make good managerial decisions in the short run and to plan for attracting more applicants in the long run.

\section{Carleton University}

Figure 5.2. Expected Effect of the Adopted Competitive Variables on Applicants for Carleton University

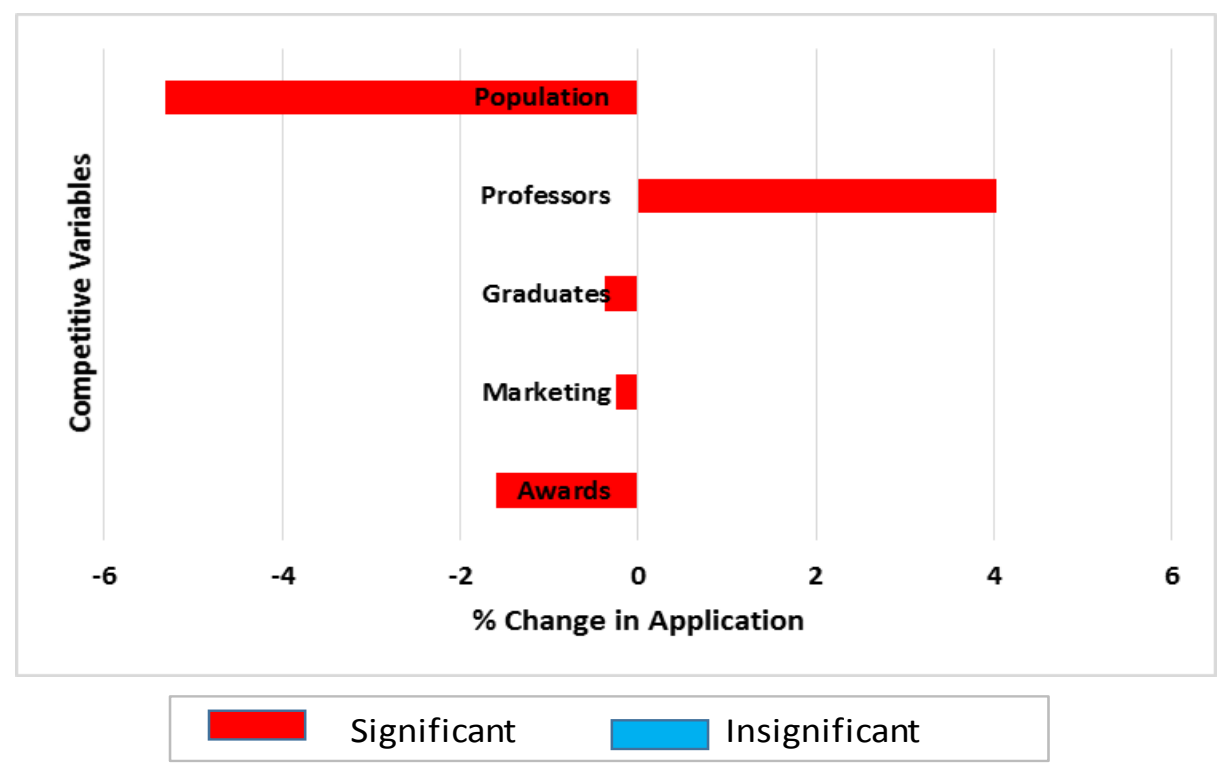


The result from Fixed Effects (a modified Fixed Effect regression) explains how the total number of applicants responds to a one percent change in awards, marketing, graduates, professors, and population for Carleton University. The regression result shows a strong relationship between the total number of applicants and the adopted competitive variables ( $\mathrm{R}$ Squared $=0.99$ ). R-Squared indicates that approximately $99 \%$ of the change in total number of applicants can be explained by the change in university expenditure on awards, marketing, graduates, and professors, and by the change in population. The result suggests that the responsiveness of applicants with respect to awards, marketing, graduates, professors, and population is about $-1.59,-0.25,-0.36,4.03$, and $-5.32 \%$, respectively. These additional effect coefficients are statistically significant at $1,1,5,1$, and $1 \%(\rho<.01, \rho<.01, \rho<.05, \rho<.01, \&$ $\rho<.01)$. Overall effects also estimate negative and positive significant signs and these are explained in Appendix F, Table 8.2.1.

The positive and significant additional effects suggest that professors has a larger effect on applicants, while a negative and significant sign suggests that awards, marketing, graduates, and population have a smaller effect on applicants. A larger effect suggests that a one percent increase in investing in faculty members (professors) is expected to produce a greater effect on total number of applicants by about $4.03 \%$. A smaller effect suggests that a one percent increase in awards, marketing, graduates, and population is expected to produce a smaller effect on the total number of applicants by about $1.59,0.25,0.36$, and $5.32 \%$, respectively, for Carleton University relative to all other Ontario universities. However, the existence of significant responsiveness leads one to infer that the changes in university expenditure on awards, marketing, graduates, professors, and the changes in population are likely to affect the total number of applicants for Carleton University. Carleton University might need these 
responsiveness estimates in order to determine the most effective competitive variables to make good managerial decisions in the short run and to plan for attracting more applicants in the long run.

\section{Lakehead University}

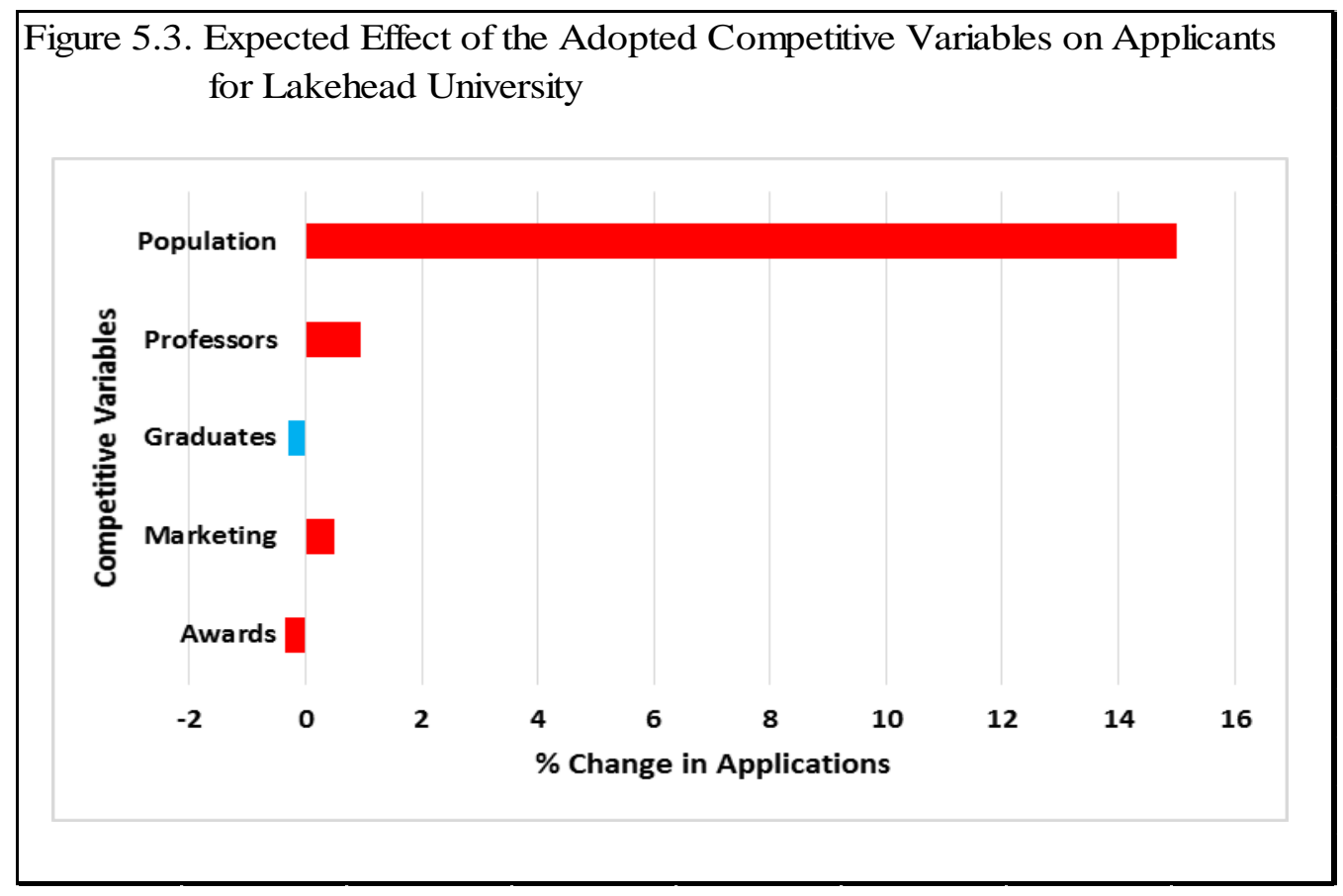

The result from Fixed Effects (a modified Fixed Effect regression) explains how the total number of applicants responds to a one percent change in awards, marketing, graduates, professors, and population for Lakehead University. The regression result shows a strong relationship between total number of applicants and the adopted competitive variables (RSquared=0.99). R-Squared indicates that approximately $99 \%$ of the change in total number of applicants can be explained by the change in awards, marketing, professors, and population. The result suggests that the responsiveness of applicants with respect to awards, marketing, professors, and population are about $-0.36,0.50,0.96$, and $15.01 \%$, respectively. These additional effect coefficients are statistically significant at $5,1,10$, and $1 \%(\rho<.05, \rho<.01, \rho<.10$, 
$\& \rho<.01)$. Overall effects also estimate negative and positive significant signs and these are explained in Appendix F, Table 8.2.1.

The positive and significant additional effects suggest that marketing, professors, and population have a larger effect on applicants, while a negative and significant sign suggests that awards has a smaller effect on applicants. A larger effect suggests that a one percent increase in marketing, professors, and population is expected to produce a greater effect on total number of applicants by about $0.50,0.96$, and $15.01 \%$, respectively. A smaller effect suggests that a one percent increase in expenditure on awards is expected to produce a smaller effect on total number of applicants by about $0.36 \%$ for Lakehead University relative to all other Ontario universities. However, the existence of significant responsiveness leads one to infer that the changes in university expenditure on awards, marketing, professors, and the changes in population are likely to affect the total number of applicants for Lakehead University. Lakehead University might need these responsiveness estimates in order to determine the most effective competitive variables to make good managerial decisions in the short run, and to plan for attracting more applicants in the long run.

\section{Laurentian University}

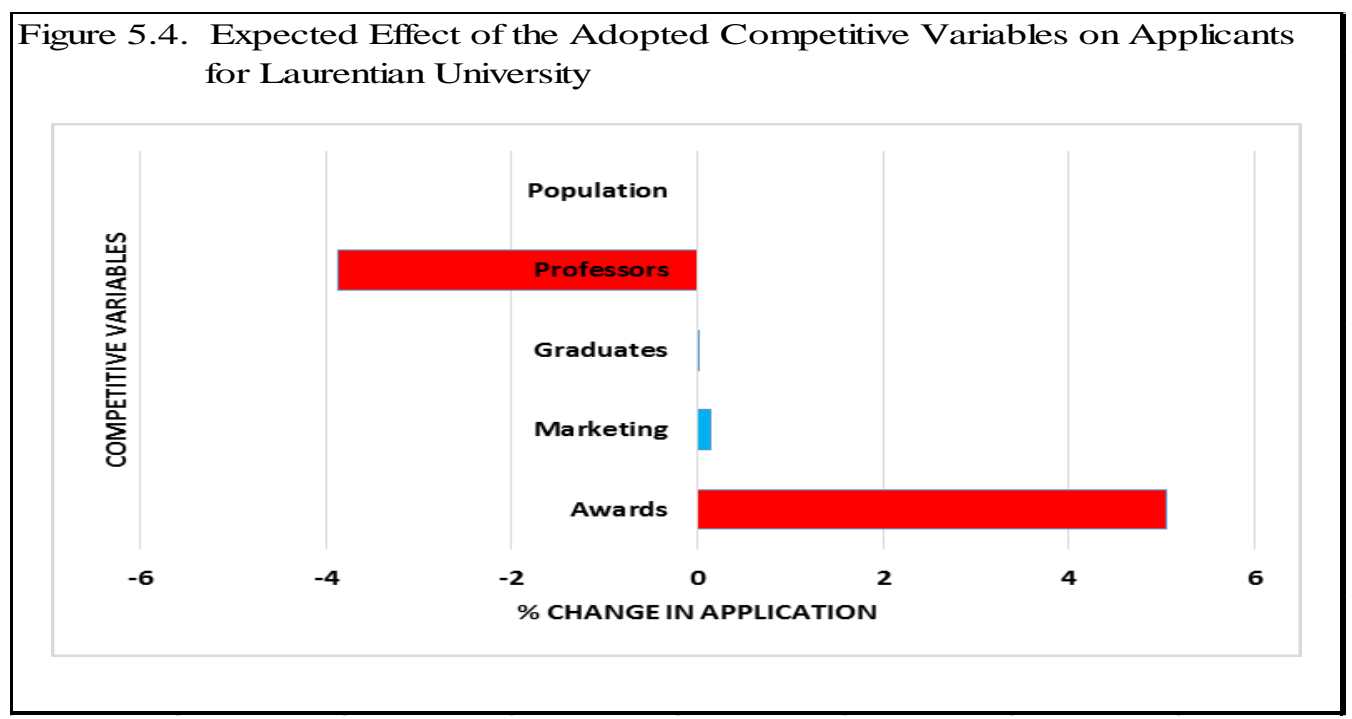


The result from Fixed Effects (a modified Fixed Effect regression) explains how the total number of applicants responds to a one percent change in awards, marketing, graduates, professors, and population for Laurentian University. R-Squared indicates that approximately $99 \%$ of the change in total number of applicants can be explained by the change in university expenditure on awards and professors. The result suggests that the responsiveness of applicants with respect to awards and professors is about 5.05 and $-3.87 \%$, respectively. These additional effect coefficients are statistically significant at $1 \%(\rho<.01)$. Overall effects also estimate negative and positive significant signs and they are explained in Appendix F, Table 8.2.1.

The positive and significant additional effects suggest that awards has a larger effect on applicants, while a negative and significant sign suggests that professors has a smaller effect on applicants. A larger effect suggests that a one percent increase in expenditure on awards is expected to produce a greater effect on total number of applicants by about 5.05\%. A smaller effect suggests that a one percent increase in expenditure on professors is expected to produce a smaller effect on total number of applicants by about $3.87 \%$ for Laurentian University relative to all other Ontario universities. A significant effect was not found for the variables of marketing and graduates. However, the existence of significant responsiveness leads one to infer that the changes in university expenditure on awards and professors are likely to affect the total number of applicants for Laurentian University. 


\section{McMaster University}

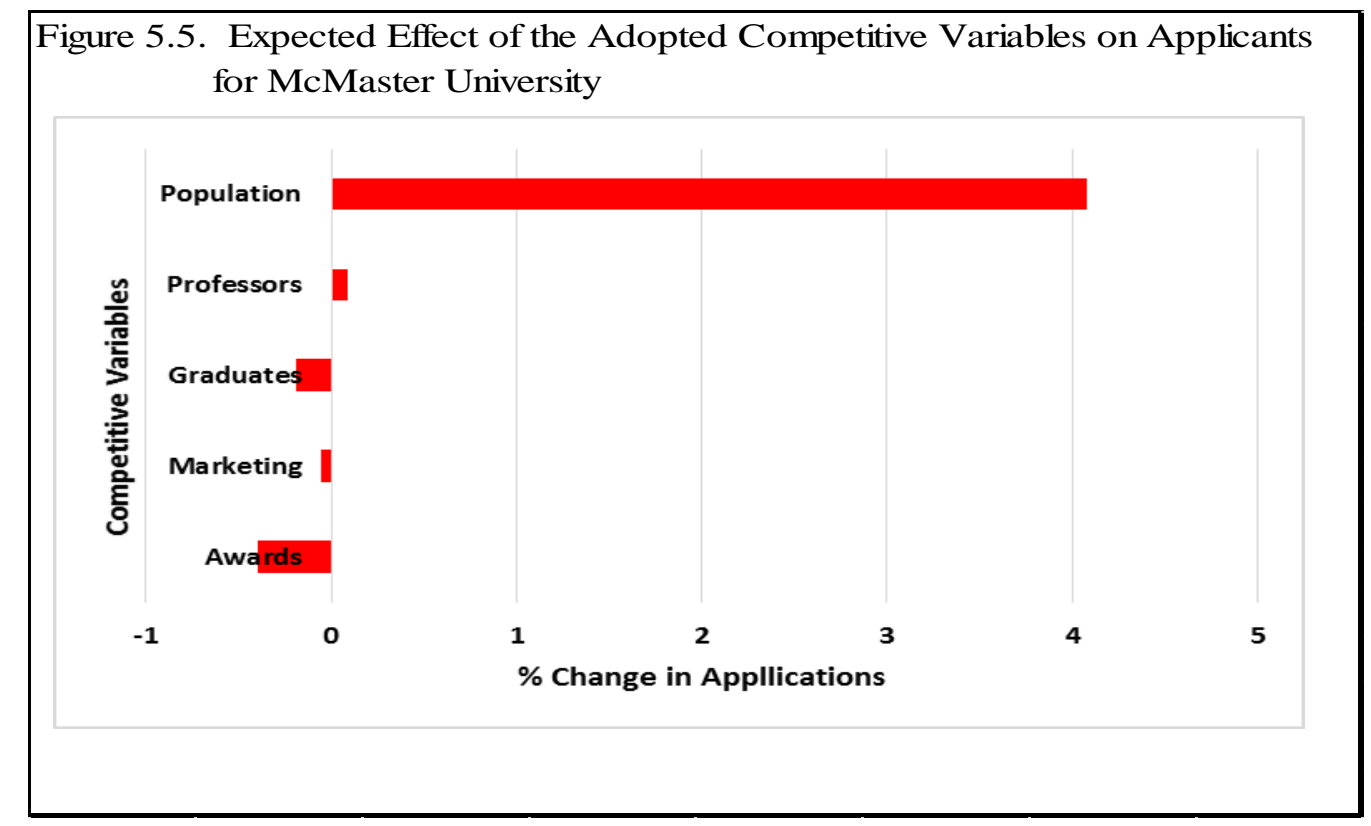

The result from Fixed Effects (a modified Fixed Effect regression) explains how the total number of applicants responds to a one percent change in awards, marketing, graduates, professors, and population for McMaster University. The regression result shows a strong relationship between total number of applicants and the adopted competitive variables (R-Squared=0.99). R-Squared indicates that approximately $99 \%$ of the change in total number of applicants can be explained by the change in population, and in university expenditure on awards, marketing, graduates, and professors. The result suggests that the responsiveness of applicants with respect to awards, marketing, graduates, professors, and population is about $-0.40,-0.06,-0.19,0.09$, and $4.08 \%$, respectively. These additional effect coefficients are statistically significant at $5,10,5,10$, and $1 \%(\rho<.05 \rho<.10 \rho<.05 \rho<.10)$. Overall effects also estimate negative and positive significant signs and these are explained in Appendix F, Table 8.2.1.

The positive and significant additional effects suggest that professors and population have a larger effect on applicants, while a negative and significant sign suggests that awards, 
marketing, and graduates have a smaller effect on applicants. A larger effect suggests that a one percent increase in professors and population is expected to produce a greater effect on total number of applicants by about 0.09 and $4.08 \%$, respectively. A smaller effect suggests that a one percent increase in expenditure on awards, marketing, and graduates is expected to produce a smaller effect on total number of applicants by about $0.40,0.06$, and $0.19 \%$, respectively, for McMaster University relative to all other Ontario universities. However, the existence of significant responsiveness leads one to infer that the changes in population and in university expenditure on awards, marketing, graduates, and professors are likely to affect the total number of applicants for McMaster University.

\section{Nipissing University}

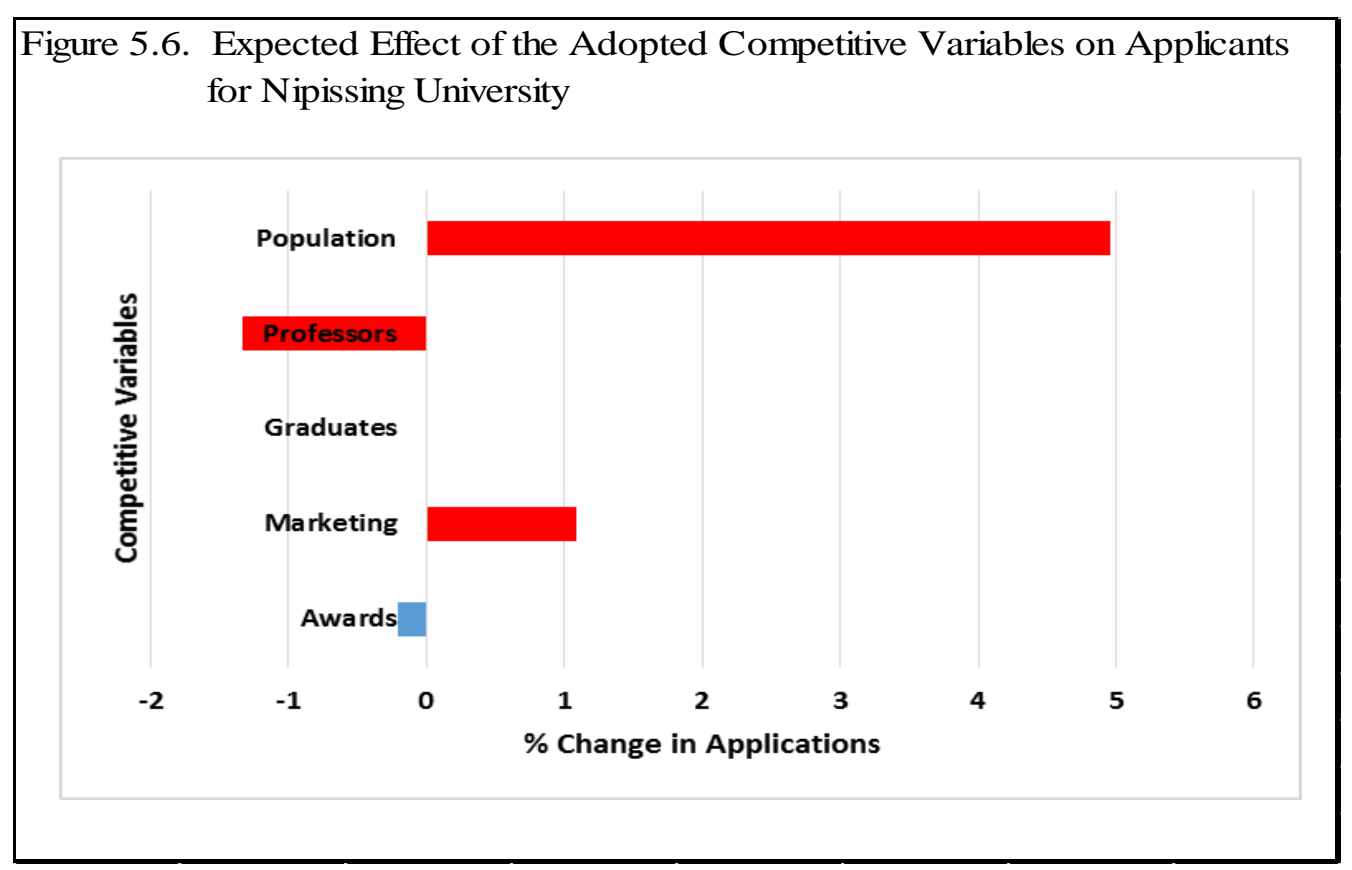

The result from Fixed Effects (a modified Fixed Effect regression) explains how the total number of applicants responds to a one percent change in awards, marketing, graduates, professors, and population for Nipissing University. Regression result shows a strong relationship between total number of applicants and the adopted competitive variables ( $R$ - 
Squared $=0.99$ ). R-Squared indicates that approximately $99 \%$ of the change in total number of applicants can be explained by the change in population, and by the change in university expenditure on marketing and professors. The result suggests that the responsiveness of applicants with respect to marketing, professors, and population is about $1.09,-1.34$, and $4.95 \%$, respectively. These additional effect coefficients are statistically significant at $1 \%(\rho<.01)$. Overall effects also estimate negative and positive significant signs and these are explained in Appendix F, Table 8.2.1.

The positive and significant additional effects suggest that marketing and population have a larger effect on applicants, while a negative and significant sign suggests that professors has a smaller effect on applicants. A larger effect suggests that a one percent increase in marketing and population is expected to produce a greater effect on total number of applicants by about 1.09 and $4.95 \%$, respectively. A smaller effect suggests that a one percent increase in expenditure on professors is expected to produce a smaller effect on total number of applicants by about $1.34 \%$ for Nipissing University relative to all other Ontario universities.

\section{OCAD University}

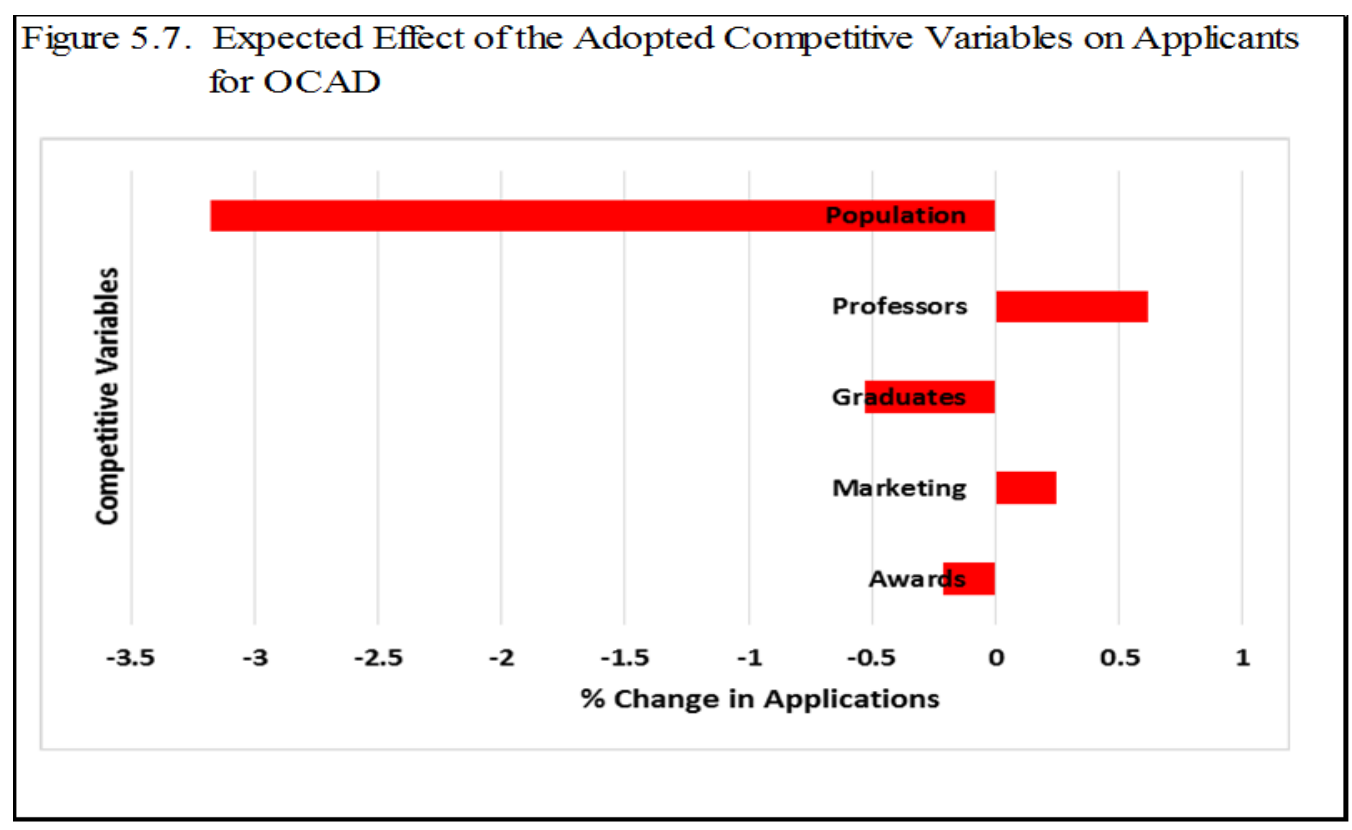


The result from Fixed Effects (a modified Fixed Effect regression) explains how the total number of applicants responds to a one percent change in awards, marketing, graduates, professors, and population for OCAD. The regression result shows a strong relationship between total number of applicants and the adopted competitive variables (R-Squared=0.99).

R-Squared indicates that approximately $99 \%$ of the change in total number of applicants can be explained by the change in population, and the change in university expenditure on awards, marketing, graduates, and professors. The result suggests that the responsiveness of applicants with respect to awards, marketing, graduates, professors, and population is about $-0.21,0.25$, $-0.53,0.61$, and $-3.18 \%$, respectively. These additional effect coefficients are statistically significant at $1,5,1,1$, and $5 \%(\rho<.01, \rho<.05, \rho<.01, \rho<.01, \& \rho<.05)$. Overall effects also estimate negative and positive significant signs and these are explained in Appendix F, Table 8.2.1.

The positive and significant additional effects suggest that marketing and professors have a larger effect on applicants, while a negative and significant sign suggests that awards, graduates, and population have a smaller effect on applicants. A larger effect suggests that a one percent increase in expenditure on marketing and professors is expected to produce a greater effect on total number of applicants by about 0.25 and $0.61 \%$, respectively. A smaller effect suggests that a one percent increase in expenditure on awards and graduates, and in population, is expected to produce a smaller effect on total number of applicants by about $0.21,0.53$, and $3.18 \%$, respectively, for OCAD relative to all other Ontario universities. 


\section{Queen's University}

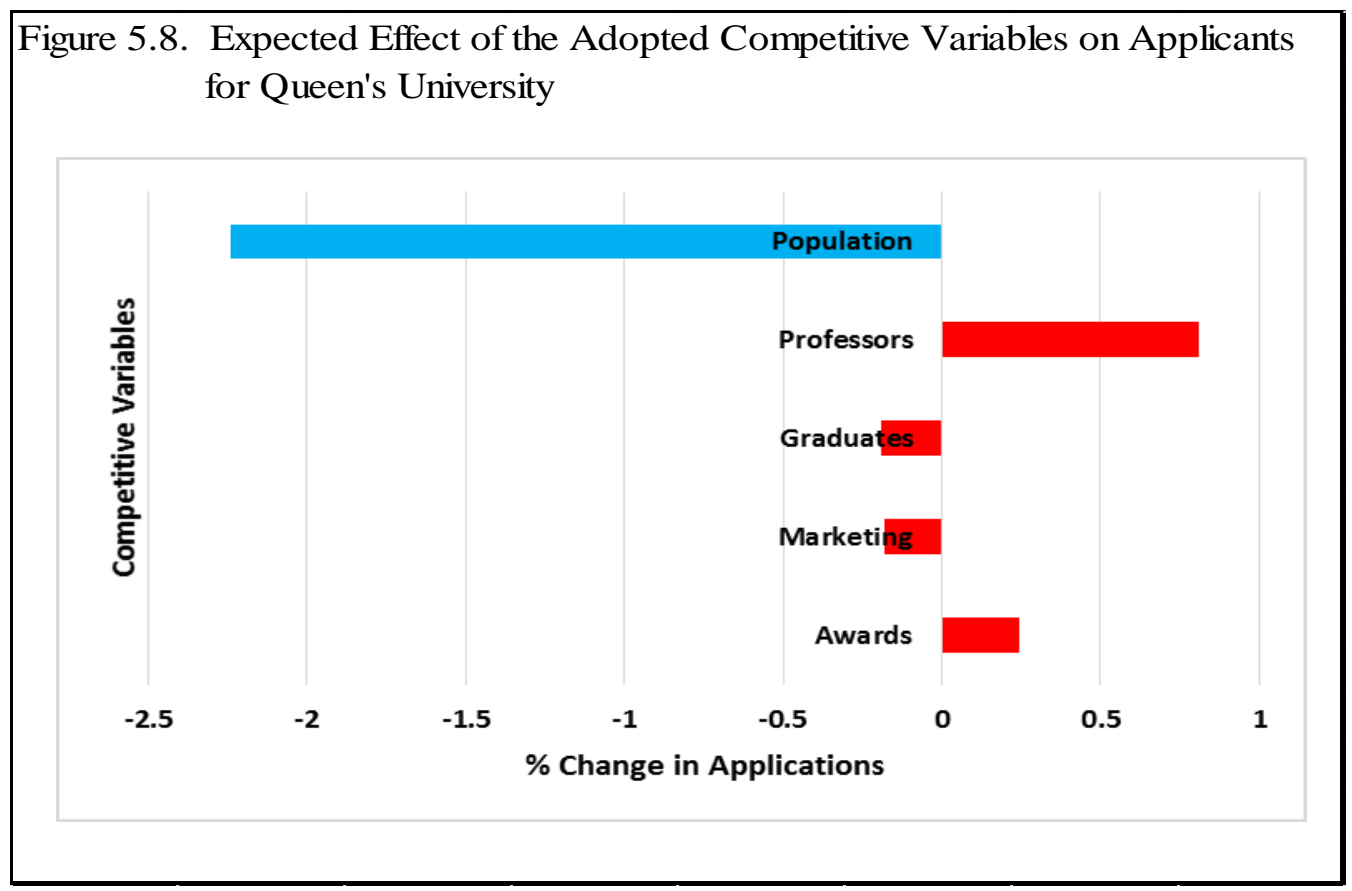

The result from Fixed Effects (a modified Fixed Effect regression) explains how the total number of applicants responds to a one percent change in awards, marketing, graduates, professors, and population for Queen's University. The regression result shows a strong relationship between total number of applicants and the adopted competitive variables (RSquared=0.99). R-Squared indicates that approximately $99 \%$ of the change in total number of applicants can be explained by the change in university expenditure on awards, marketing, graduates, and professors. The result suggests that the responsiveness of applicants with respect to awards, marketing, graduates, and professors is about $0.25,-0.18,-0.19$, and $0.81 \%$, respectively. These additional effect coefficients are statistically significant at $5,1,10$, and $1 \%$ $(\rho<.05, \rho<.01, \rho<.10, \& \rho<.01)$. Overall effects also estimate negative and positive significant signs and these are explained in Appendix F, Table 8.2.1.

The positive and significant additional effects suggest that awards and professors have a larger effect on applicants, while a negative and significant sign suggests that marketing and 
graduates have a smaller effect on applicants. A larger effect suggests that a one percent increase in expenditure on awards and professors is expected to produce a greater effect on total number of applicants by about 0.25 and $0.81 \%$, respectively, for Queen's University relative to all other Ontario universities. A smaller effect suggests that a one percent increase in expenditure on marketing and graduates is expected to produce a smaller effect on total number of applicants by about 0.18 and $0.19 \%$, respectively, for Queen's University relative to all other Ontario universities. A significant effect was not found for population. However, the existence of significant responsiveness leads one to infer that the changes in university expenditure on awards, marketing, graduates, and professors are likely to affect the total number of applicants for Queen's University.

\section{Ryerson University}

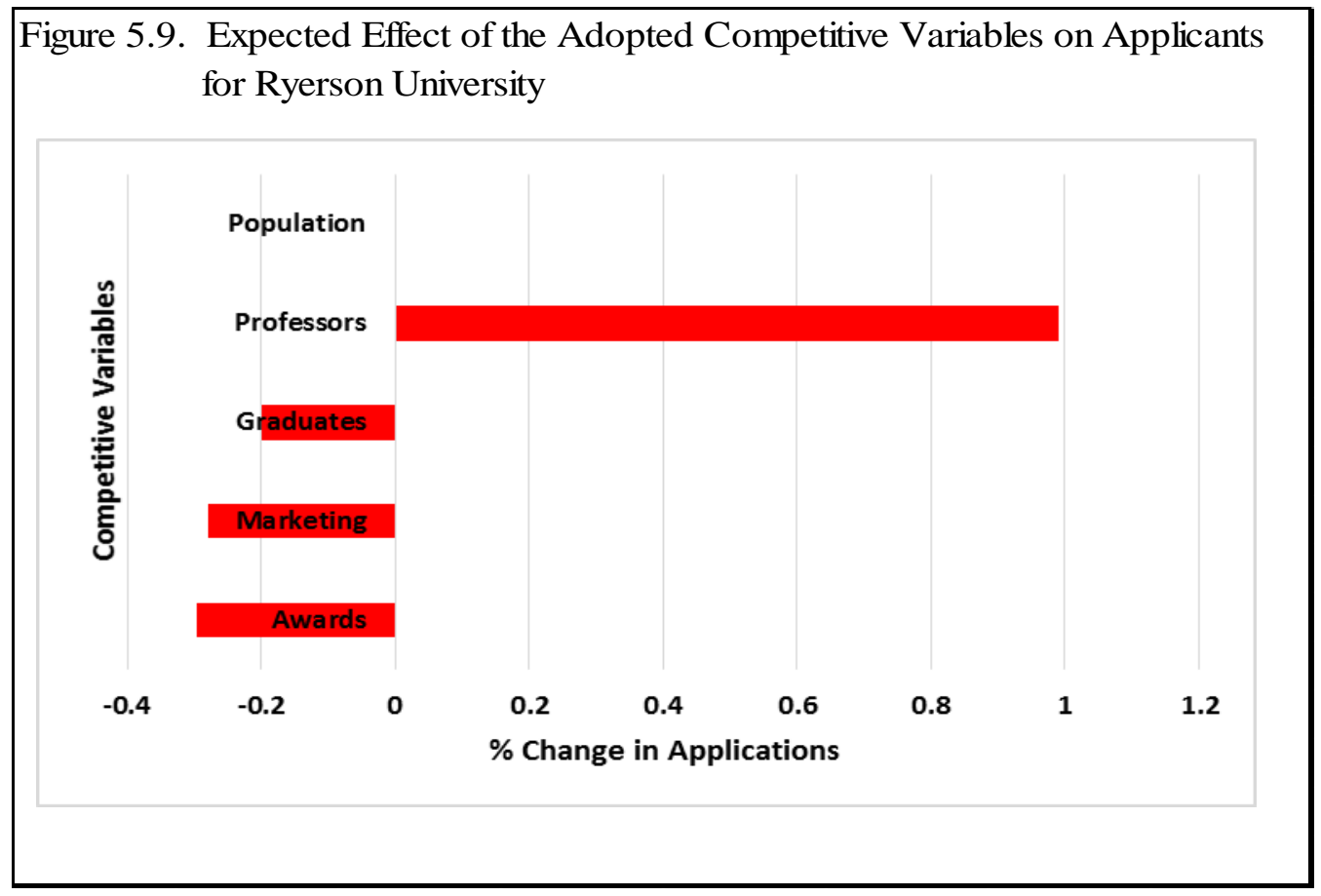

The result from Fixed Effects (a modified Fixed Effect regression) explains how the total number of applicants responds to a one percent change in awards, marketing, graduates, professors, and population for Ryerson University. The regression result shows a strong 
relationship between total number of applicants and the adopted competitive variables (RSquared=0.99). R-Squared indicates that approximately $99 \%$ of the change in total number of applicants can be explained by the change in university expenditure on awards, marketing, graduates, and professors. The result suggests that the responsiveness of applicants with respect to awards, marketing, graduates, and professors is about $-0.30,-0.28,-0.20$, and $0.99 \%$, respectively. These additional effect coefficients are statistically significant at 1, 1, 5, and 1\% $(\rho<.01, \rho<.01, \rho<.05, \& \rho<.01)$. Overall effects also estimate negative and positive significant signs and these are explained in Appendix F, Table 8.2.1.

The positive and significant additional effects suggest that professors has a larger effect on applicants, while a negative and significant sign suggests that awards, marketing, and graduates have a smaller effect on applicants. A larger effect suggests that a one percent increase in investing in faculty members (professors) is expected to produce a greater effect on total number of applicants by about $0.99 \%$. A smaller effect suggests that a one percent increase in expenditure on awards, marketing, and graduates is expected to produce a smaller effect on total number of applicants by about $-0.30,-0.28$, and $-0.20 \%$, respectively, for Ryerson University relative to all other Ontario universities. 


\section{Trent University}

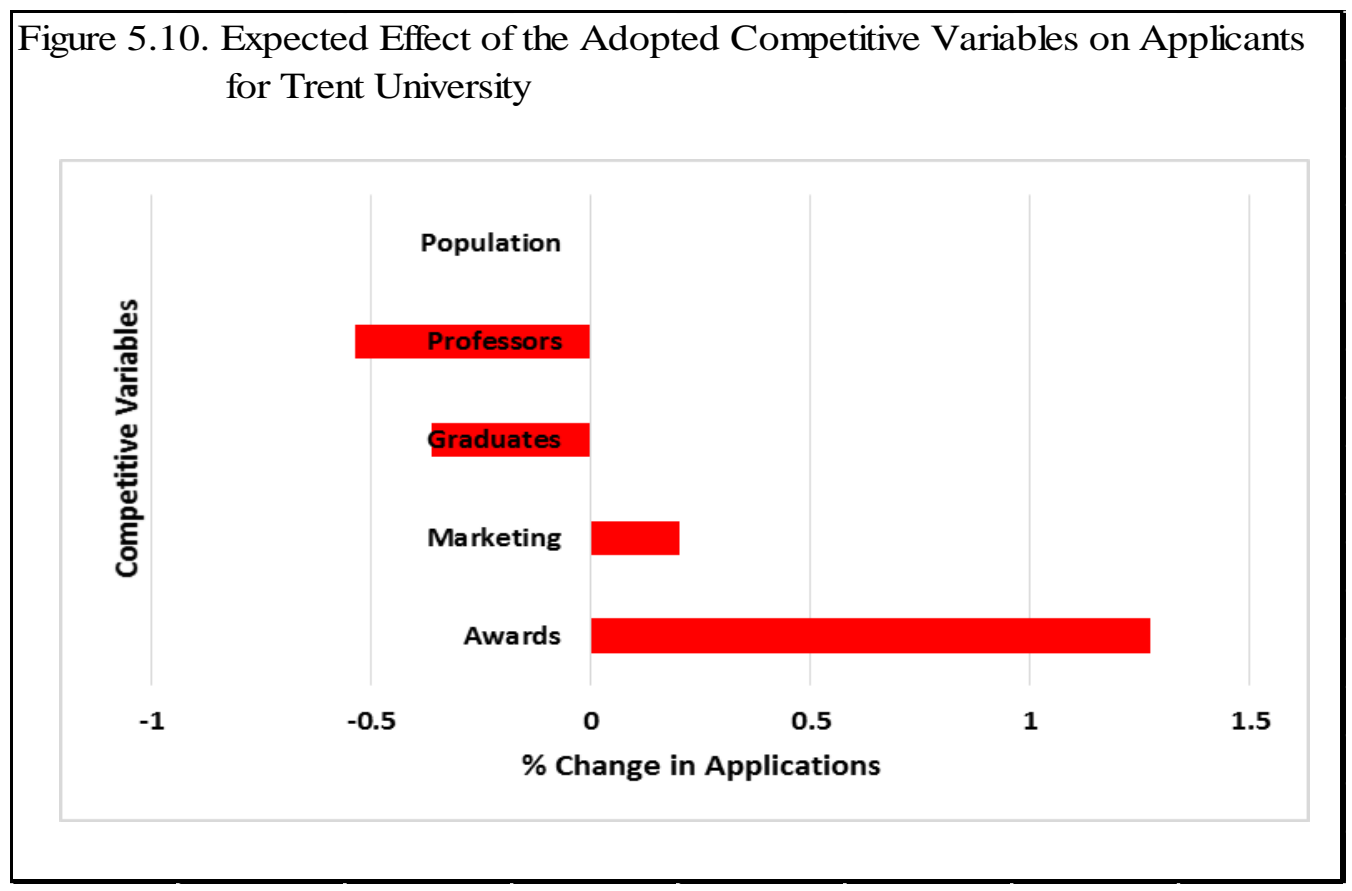

The result from Fixed Effects (a modified Fixed Effect regression) explains how the total number of applicants responds to a one percent change in awards, marketing, graduates, professors, and population for Trent University. The regression result shows a strong relationship between total number of applicants and the adopted competitive variables (RSquared $=0.99$ ). R-Squared indicates that approximately $99 \%$ of the change in total number of applicants can be explained by the change in university expenditure on awards, marketing, graduates, and professors. The result suggests that the responsiveness of applicants with respect to awards, marketing, graduates, and professors is about $1.27,0.20,-0.36$, and $-0.54 \%$, respectively. These additional effect coefficients are statistically significant at 1, 1, 5, and $1 \%$ $(\rho<.01, \rho<.01, \rho<.05, \& \rho<.01)$. Overall effects also estimate negative and positive significant signs and these are explained in Appendix F, Table 8.2.1.

The positive and significant additional effects suggest that awards and marketing have a larger effect on applicants, while a negative and significant sign suggests that graduates and 
professors have a smaller effect on applicants. A larger effect suggests that a one percent increase in expenditure on awards and marketing is expected to produce a greater effect on total number of applicants by about 1.27 and $0.20 \%$, respectively. A smaller effect suggests that a one percent increase in expenditure on graduates and professors is expected to produce a smaller effect on total number of applicants by about 0.36 and $0.54 \%$, respectively, for Trent University relative to all other Ontario universities.

\section{University of Guelph}

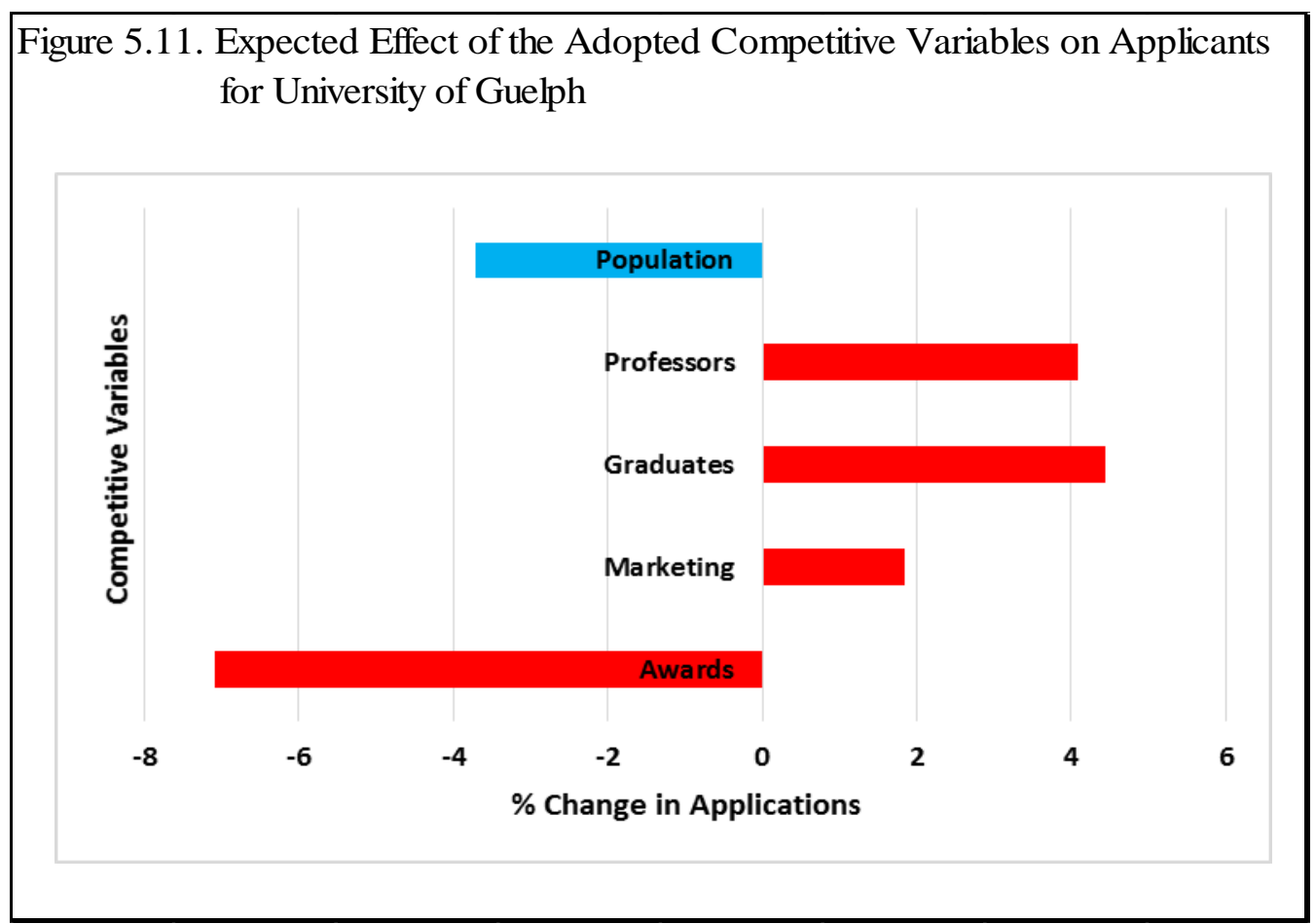

The result from Fixed Effects (a modified Fixed Effect regression) explains how the total number of applicants responds to a one percent change in awards, marketing, graduates, professors, and population for University of Guelph. The regression result shows a strong relationship between total number of applicants and the adopted competitive variables (RSquared $=0.99$ ). R-Squared indicates that approximately $99 \%$ of the change in total number of applicants can be explained by the change in university expenditure on awards, marketing, 
graduates, and professors. The result suggests that the responsiveness of applicants with respect to awards, marketing, graduates, and professors is about $-7.09,1.85,4.44$, and $4.09 \%$, respectively. These additional effect coefficients are statistically significant at $1 \%(\rho<.01)$. Overall effects also estimate negative and positive significant signs and these are explained in Appendix F, Table 8.2.1.

The positive and significant additional effects suggest that marketing, graduates, and professors have a larger effect on applicants, while a negative and significant sign suggests that awards has a smaller effect on applicants. A larger effect suggests that a one percent increase in expenditure on marketing, graduates, and professors is expected to produce a greater effect on total number of applicants by about $1.89,4.44$, and $4.09 \%$, respectively. A smaller effect suggests that a one percent increase in expenditure on awards is expected to produce a smaller effect on total number of applicants by about $7.09 \%$ for University of Guelph relative to all other Ontario universities. However, the existence of significant responsiveness leads one to infer that the changes in university expenditure on awards, marketing, graduates, and professors are likely to affect the total number of applicants for University of Guelph. University of Guelph might need these responsiveness estimates in order to determine the most effective competitive variables to make good managerial decisions in the short run, and to plan for attracting more applicants in the long run. 


\section{UOIT}

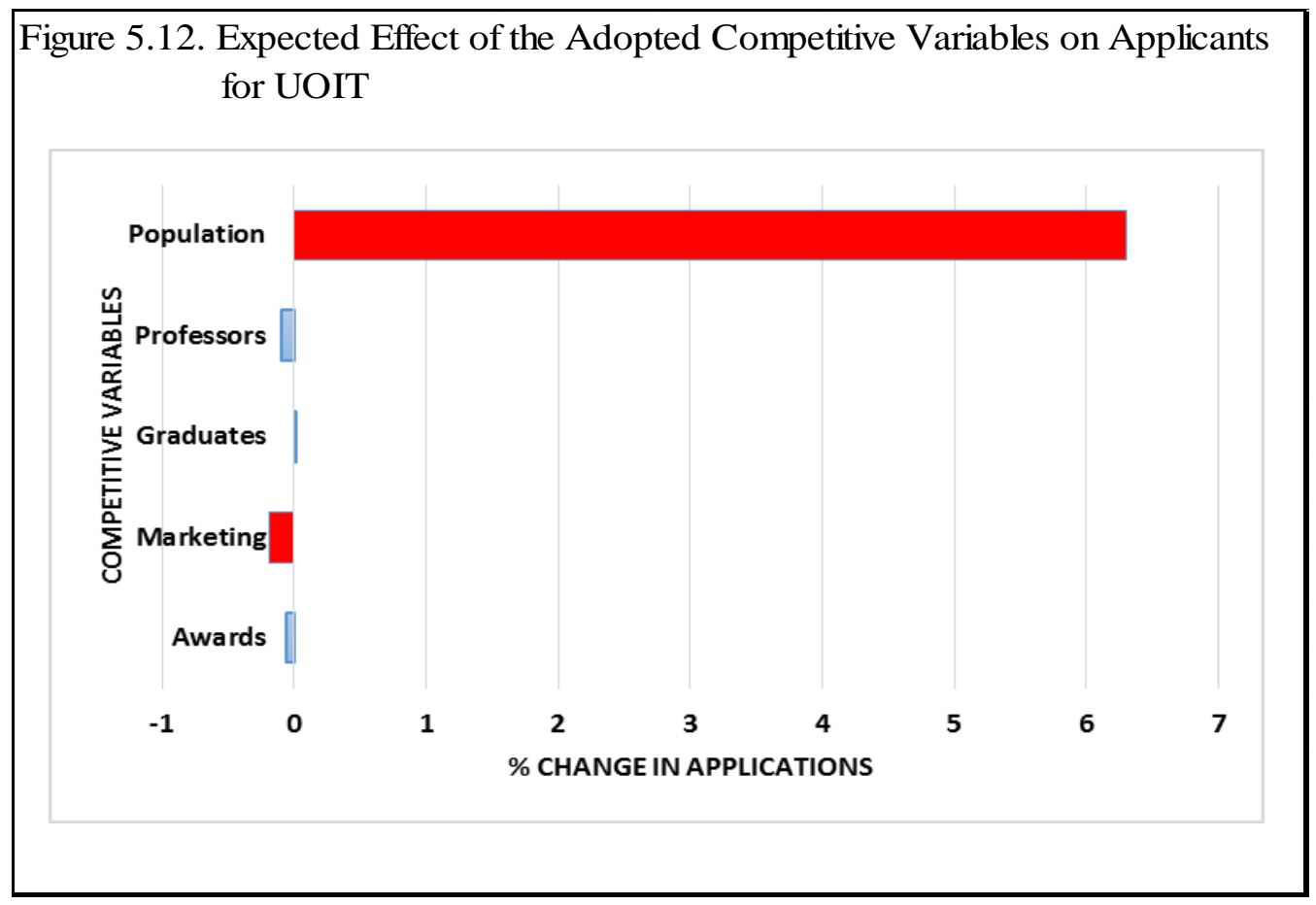

The result from Fixed Effects (a modified Fixed Effect regression) explains how the total number of applicants responds to a one percent change in awards, marketing, graduates, professors, and population for UOIT. R-Squared indicates that approximately $99 \%$ of the change in total number of applicants can be explained by the change in university expenditure on marketing, and by the change in population. The result suggests that the responsiveness of applicants with respect to marketing and population is about -0.19 , and $6.31 \%$, respectively. These additional effect coefficients are statistically significant at 1 and $5 \%(\rho<.01 \& \rho<.05)$. Overall effects also estimate negative and positive significant signs and these are explained in Appendix F, Table 8.2.1.

The positive and significant additional effects suggest that population has a larger effect on applicants, while a negative and significant sign suggests that marketing has a smaller effect on applicants. A one percent increase in population has a greater effect on applicants by about 
$6.31 \%$, while a one percent increase in expenditure on marketing has a smaller effect on applicants by about $0.19 \%$ for UOIT relative to all other Ontario universities. A significant effect was not found for the variables of awards, graduates, and professors. However, the existence of significant responsiveness leads one to infer that the changes in population and in university expenditure on marketing are likely to affect the total number of applicants for UOIT.

\section{University of Ottawa}

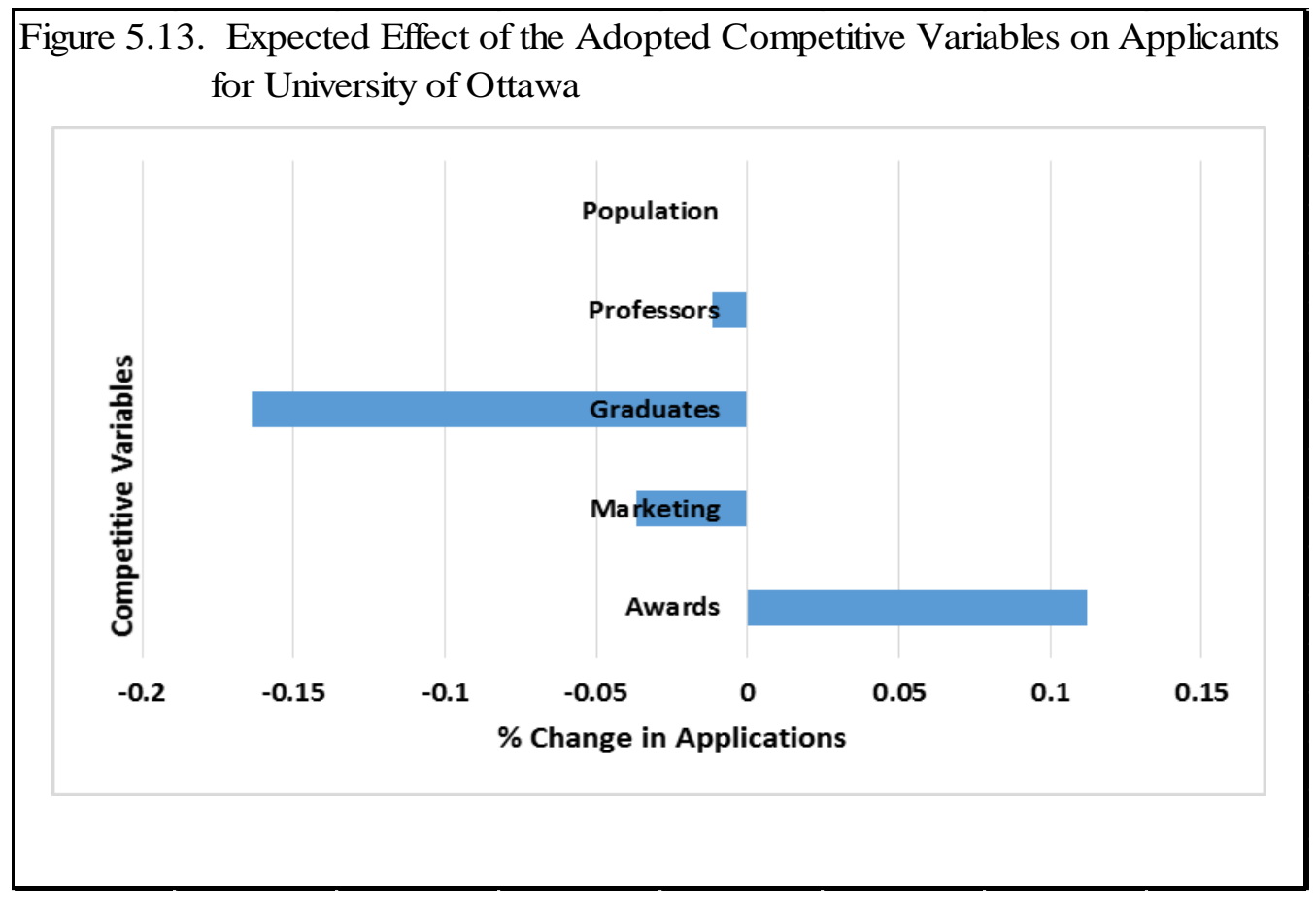

The result from Fixed Effects (a modified Fixed Effect regression) explains how the total number of applicants responds to a one percent change in awards, marketing, graduates, professors, and population for University of Ottawa. A significant relation was not found for adopted competitive variables. This insignificance suggests that changes in university expenditure on awards, marketing, graduates, and professors are unlikely to affect total number of applications for admission for University of Ottawa. These additional effect coefficients are 
statistically insignificant for University of Ottawa. Overall effects also estimate insignificant relation and these are explained in Appendix F, Table 8.2.1.

\section{University of Waterloo}

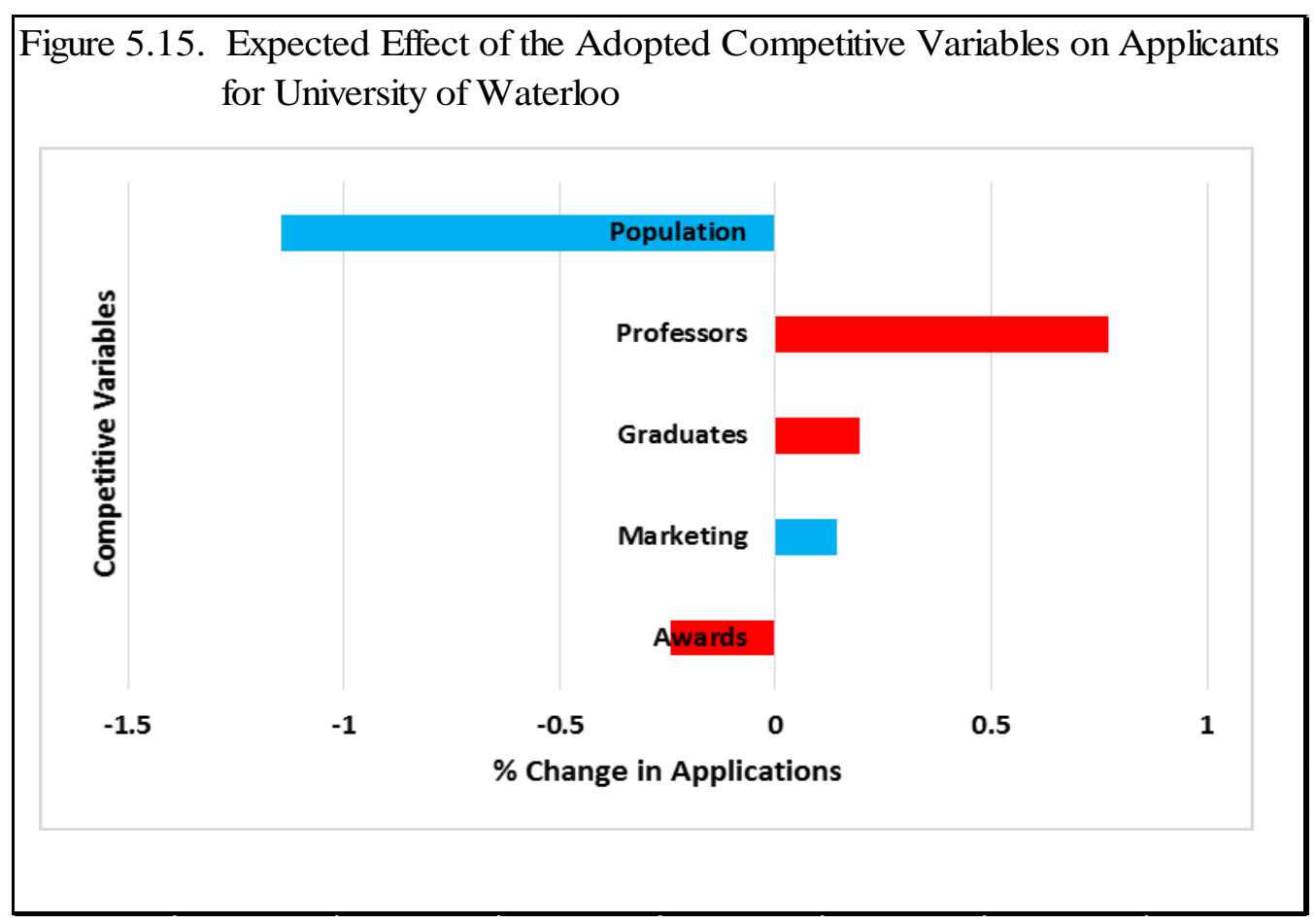

The result from Fixed Effects (a modified Fixed Effect regression) explains how the total number of applicants responds to a one percent change in awards, marketing, graduates, professors, and population for University of Waterloo. The regression result shows a strong relationship between the total number of applicants and the adopted competitive variables ( $\mathrm{R}$ Squared $=0.99$ ). R-Squared indicates that approximately $99 \%$ of the change in total number of applicants can be explained by the change in university expenditure on awards, graduates, and professors. The result suggests that the responsiveness of applicants with respect to awards, graduates, and professors is about $-0.24,0.20$, and $0.77 \%$, respectively. These additional effect coefficients are statistically significant at 1,5 , and $1 \%(\rho<.01, \rho<.05, \& \rho<.01)$. Overall effects 
also estimate negative and positive significant signs and these are explained in Appendix F, Table 8.2.1.

The positive and significant additional effects suggest that graduates and professors have a larger effect on applicants, while a negative and significant sign suggests that awards has a smaller effect on applicants. A one percent increase in expenditure on graduates and professors has a greater effect on applicants by about 0.20 and $0.77 \%$, respectively, while a one percent increase in expenditure on awards has a smaller effect on applicants by about $0.24 \%$ for University of Waterloo relative to all other Ontario universities. A significant effect was not found for the variables of marketing and population. However, the existence of significant responsiveness leads one to infer that the changes in university expenditure on awards, graduates, and professors are likely to affect the total number of applicants for University of Waterloo.

\section{University of Windsor}

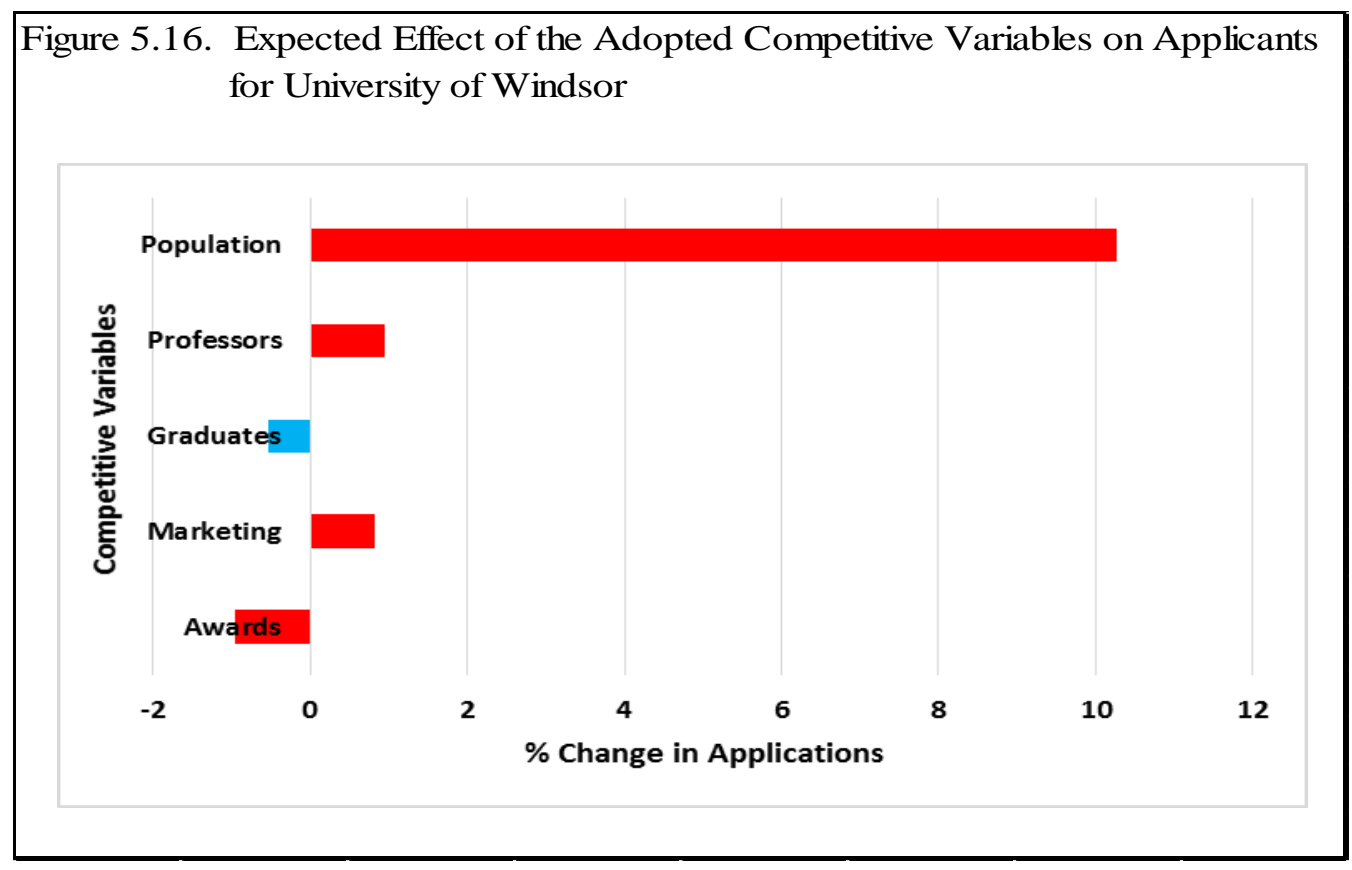


The result from Fixed Effects (a modified Fixed Effect regression) explains how the total number of applicants responds to a one percent change in awards, marketing, graduates, professors, and population for University of Windsor. The regression result shows a strong relationship between total number of applicants and the adopted competitive variables (R-Squared=0.99). R-Squared indicates that approximately $99 \%$ of the change in total number of applicants can be explained by the change in population, and in university expenditure on awards, marketing, and professors. The result suggests that the responsiveness of applicants with respect to awards, marketing, professors, and population is about $-0.97,0.82,0.96$, and $10.26 \%$, respectively. These additional effect coefficients are statistically significant at $1,1,5$, and $1 \%$ $(\rho<.01, \rho<.01, \rho<.05, \& \rho<.01)$. Overall effects also estimate negative and positive significant signs and these are explained in Appendix F, Table 8.2.1.

The positive and significant additional effects suggest that marketing, professors, and population have a larger effect on applicants, while a negative and significant sign suggests that awards has a smaller effect on applicants. A larger effect suggests that a one percent increase in expenditure on marketing and professors is expected to produce a greater effect on total number of applicants by about 0.82 and $0.96 \%$, respectively. A one percent increase in population has a greater effect on applicants by about $10.26 \%$. A smaller effect suggests that a one percent increase in expenditure on awards is expected to produce a smaller effect on total number of applicants by about $0.97 \%$ for University of Windsor relative to all other Ontario universities. A significant effect was not found for the variable of graduates. However, the existence of significant responsiveness leads one to infer that the changes in population, and in university expenditure on awards, marketing, and professors are likely to affect the total number of applicants for University of Windsor. 


\section{Western University}

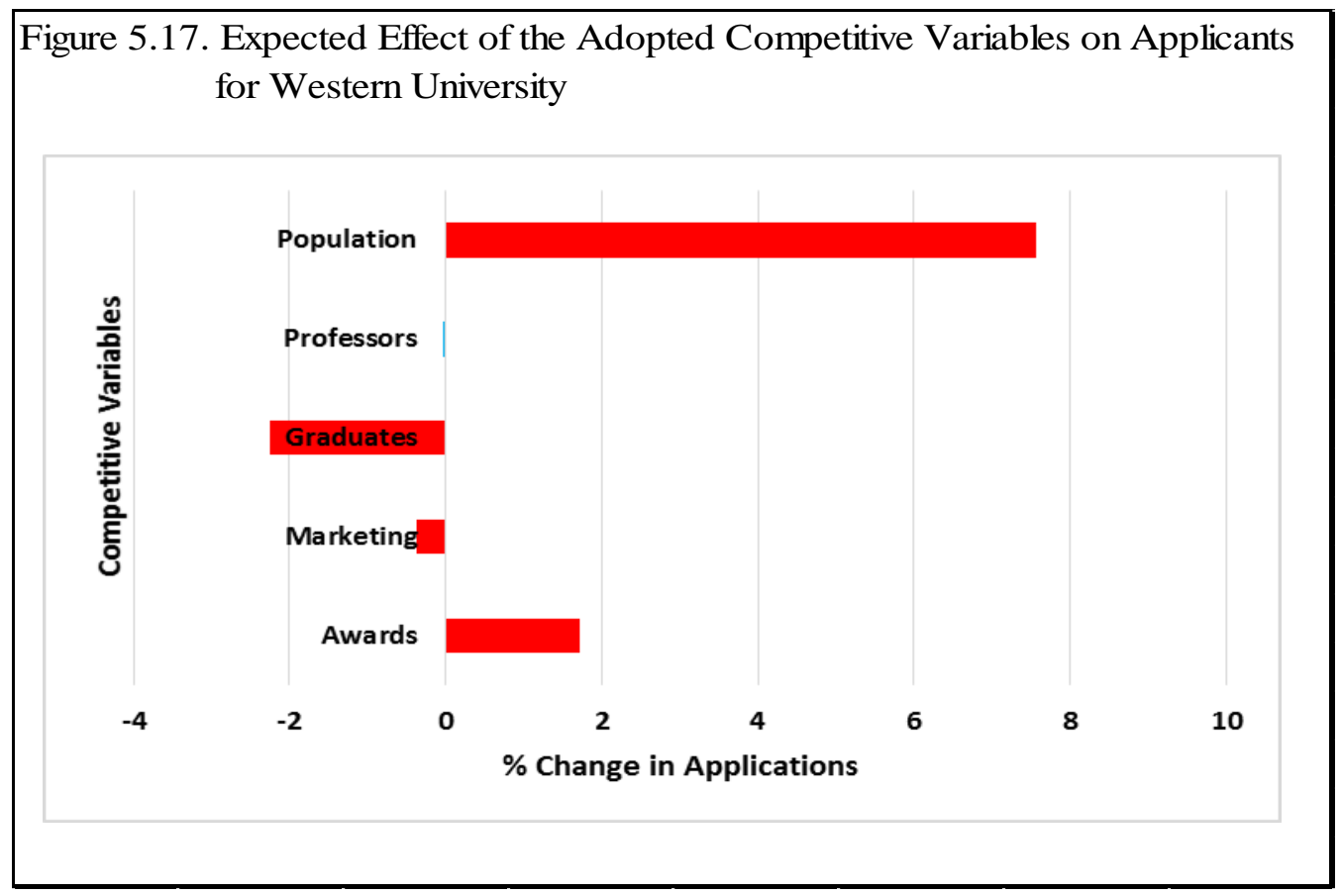

The result from Fixed Effects (a modified Fixed Effect regression) explains how the total number of applicants responds to a one percent change in awards, marketing, graduates, professors, and population for Western University. The regression result shows a strong relationship between total number of applicants and the adopted competitive variables (R-Squared=0.99). R-Squared indicates that approximately $99 \%$ of the change in total number of applicants can be explained by the change in population, and in university expenditure on awards, marketing, and graduates. The result suggests that the responsiveness of applicants with respect to awards, marketing, graduates, and population is about $1.71,-0.37,-2.25$, and $7.56 \%$, respectively. These additional effect coefficients are statistically significant at $1 \%(\rho<.01)$. Overall effects also estimate negative and positive significant signs and these are explained in Appendix F, Table 8.2.1.

The positive and significant additional effects suggest that awards and population have a larger effect on applicants, while a negative and significant sign suggests that marketing and 
graduates have a smaller effect on applicants. A larger effect suggests that a one percent increase in expenditure on awards is expected to produce a greater effect on total number of applicants by about $1.71 \%$. A one percent increase in population has a greater effect on applicants by about $7.56 \%$ for Western University relative to all other Ontario universities. A smaller effect suggests that a one percent increase in expenditure on marketing and graduates is expected to produce a smaller effect on total number of applicants by about 0.37 and $2.25 \%$, respectively, for Western University relative to all other Ontario universities. A significant effect was not found for the variable of professors. However, the existence of significant responsiveness leads one to infer that the changes in population, and in university expenditure on awards, marketing, and graduates are likely to affect the total number of applicants for Western University.

\section{Wilfrid Laurier University}

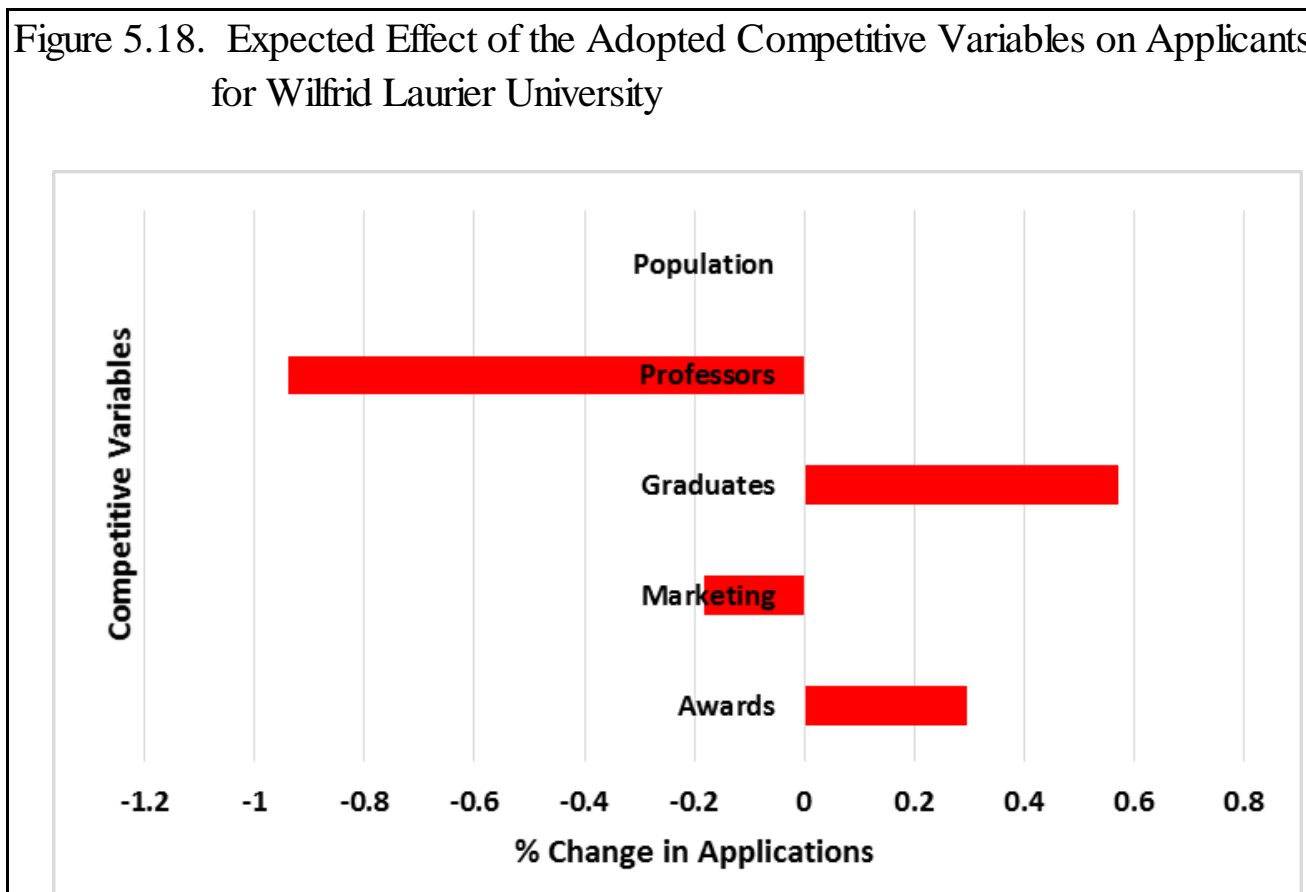


The result from Fixed Effects (a modified Fixed Effect regression) explains how the total number of applicants responds to a one percent change in awards, marketing, graduates, professors, and population for Wilfrid Laurier University. The regression result shows a strong relationship between total number of applicants and the adopted competitive variables ( $\mathrm{R}$ Squared $=0.99$ ). R-Squared indicates that approximately $99 \%$ of the change in total number of applicants can be explained by the change in university expenditure on awards, marketing, graduates, and professors. The result suggests that the responsiveness of applicants with respect to awards, marketing, graduates, and professors is about $0.30,-0.18,0.57$, and $-0.94 \%$, respectively. These additional effect coefficients are statistically significant at $1 \%(\rho<.01)$. Overall effects also estimate negative and positive significant signs and these are explained in Appendix F, Table 8.2.1.

The positive and significant additional effects suggest that awards and graduates have a larger effect on applicants, while a negative and significant sign suggests that marketing and professors have a smaller effect on applicants. A one percent increase in expenditure on awards and graduates has a greater effect on applicants by about 0.30 and $0.57 \%$, respectively, while a one percent increase in expenditure on marketing and professors has a smaller effect on applicants by about 0.18 and $0.94 \%$, respectively for Wilfrid Laurier University relative to all other Ontario universities. However, the existence of significant responsiveness leads one to infer that the changes in university expenditure on awards, marketing, graduates, and professors are likely to affect the total number of applicants for Wilfrid Laurier University. 


\section{York University}

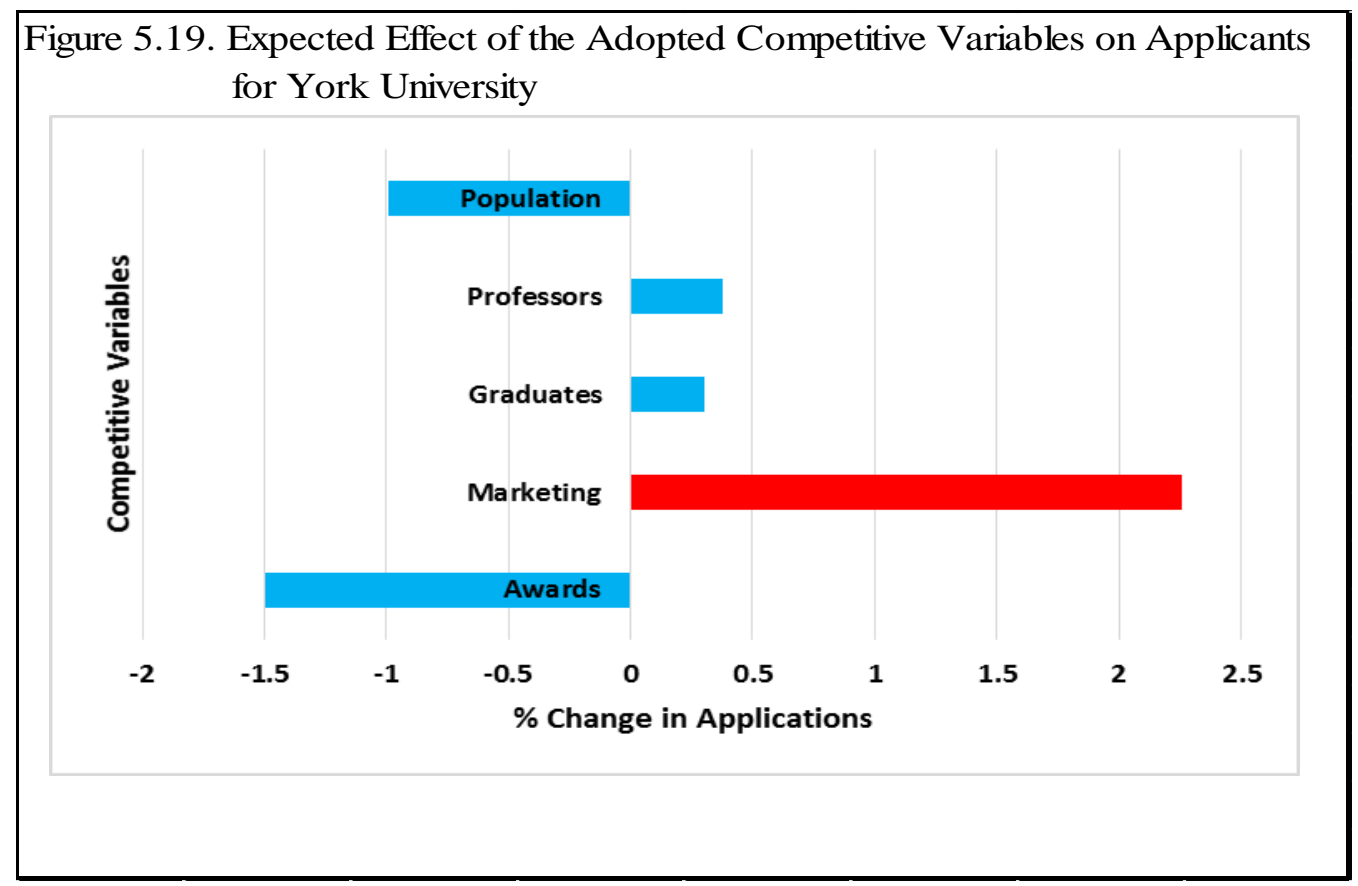

The result from Fixed Effects (a modified Fixed Effect regression) explains how the total number of applicants responds to a one percent change in awards, marketing, graduates, professors, and population for York University. R-Squared indicates that approximately $99 \%$ of the change in total number of applicants can be explained by the change in university expenditure on marketing. The result suggests that the responsiveness of applicants with respect to marketing is about $2.26 \%$, respectively. This additional effect coefficient is statistically significant at $10 \%(\rho<.10)$. Overall effects also estimate negative and positive significant signs and these are explained in Appendix F, Table 8.2.1.

The positive and significant additional effects suggest that marketing has a larger effect on applicants. A one percent increase in expenditure on marketing has a greater effect on applicants by about $2.26 \%$ for York University relative to all other Ontario universities. A significant effect was not found for the variables of awards, graduates, professors, and population. However, the existence of significant responsiveness leads one to infer that the 
changes in university expenditure on marketing is likely to affect the total number of applicants for York University. York University might need these responsiveness estimates in order to determine the most effective competitive variables to make good managerial decisions in the short run and to plan for attracting more applicants in the long run. 


\section{Appendix K: Data Analysis for Each Individual University (Persistence Ratio: Lagged Model)}

A modified Fixed Effect regression was conducted for each individual university. The results shown in each Figure indicate which variables have stronger effects (denoted by positive additional effects) in the particular university relative to the baseline for all other universities and which variables have weaker effects (denoted by negative additional effects). Thus, the coefficients show the expected additional percentage changes in persistence ratio for a given university relative to the baseline for all universities stemming from a one percent change in its variables.

\section{Brock University}

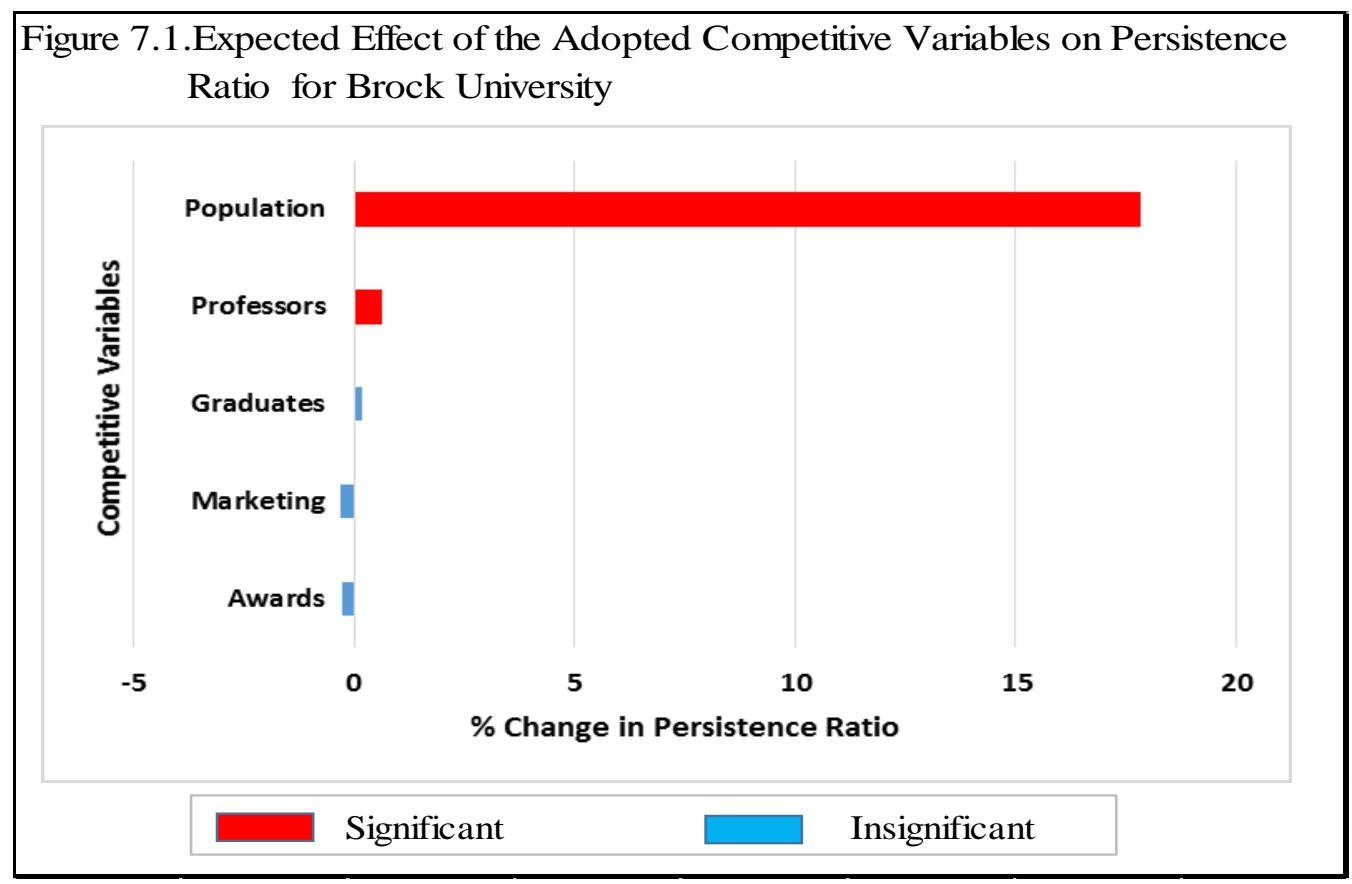

The result from Fixed Effects (a modified Fixed Effect regression) explains how persistence ratio responds to a one percent change in awards, marketing, graduates, professors, and population for Brock University. The regression result shows a strong relationship between persistence ratio and the adopted competitive variables $(\mathrm{R}$-Squared $=0.92)$. R-Squared indicates 
that approximately $92 \%$ of the change in persistence ratio can be explained by the change in university expenditure on professors and in the change in population. The result suggests that the responsiveness of persistence ratio with respect to professors and population is about 0.62 and $17.83 \%$, respectively. These additional effect coefficients are statistically significant at 5 and $10 \%(\rho<.05 \& \rho<.10)$. Overall effects also estimate negative and positive significant signs and these are explained in Appendix G, Table 9.2.1.

The positive and significant additional effects suggest that professors and population have a larger effect on persistence ratio. A larger effect suggests that a one percent increase in professors and population is expected to produce a greater effect on persistence ratio by about 0.62 and $17.83 \%$, respectively. A significant effect was not found for the variable of awards, marketing, and graduates. However, the existence of significant responsiveness leads one to infer that the changes in population, and in university expenditure on professors are likely to affect the persistence ratio for Brock University. However, Brock University might need these responsiveness estimates in order to determine the most effective competitive variables to make good managerial decisions in the short run and in the long run. 


\section{Carleton University}

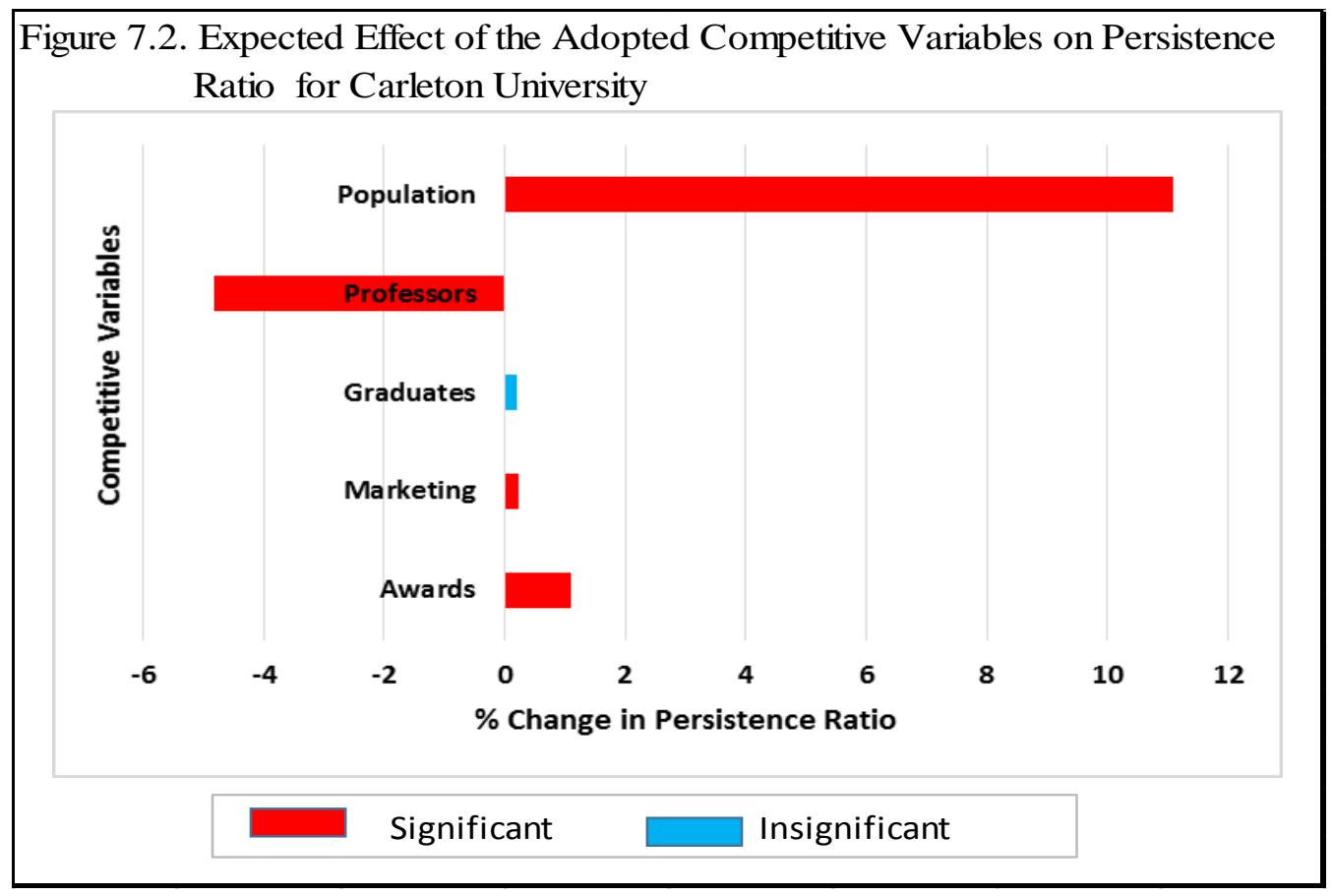

The result from Fixed Effects (a modified Fixed Effect regression) explains how persistence ratio responds to a one percent change in awards, marketing, graduates, professors, and population for Carleton University. The regression result shows a strong relationship between persistence ratio and the adopted competitive variables ( $\mathrm{R}$-Squared=0.92). R-Squared indicates that approximately $92 \%$ of the change in persistence ratio can be explained by the change in population, and in university expenditure on awards, marketing, and professors. The result suggests that the responsiveness of persistence ratio with respect to awards, marketing, professors, and population is about $1.09,0.24,-4.81$, and $11.09 \%$, respectively. These additional effect coefficients are statistically significant at $5,1,1$, and $1 \%(\rho<.05, \rho<.01, \rho<.01, \& \rho<.01)$. Overall effects also estimate negative and positive significant signs and these are explained in Appendix G, Table 9.2.1.

The positive and significant additional effects suggest that awards, marketing, and population have a larger effect on persistence ratio, while a negative and significant sign 
suggests that professors has a smaller effect on persistence ratio. A larger effect suggests that a one percent increase in awards, marketing, and population is expected to produce a greater effect on persistence ratio by about $1.09,0.24$, and $11.09 \%$, respectively. A smaller effect suggests that a one percent increase in expenditure on professors is expected to produce a smaller effect on persistence ratio by about $4.81 \%$ for Carleton University relative to all other Ontario universities. A significant effect was not found for the variable of graduates. However, the existence of significant responsiveness leads one to infer that the changes in population, and in university expenditure on awards, marketing, and professors are likely to affect the persistence ratio for Carleton University. Carleton University might need these responsiveness estimates in order to determine the most effective competitive variables to make good managerial decisions in the short run and in the long run.

\section{Lakehead University}

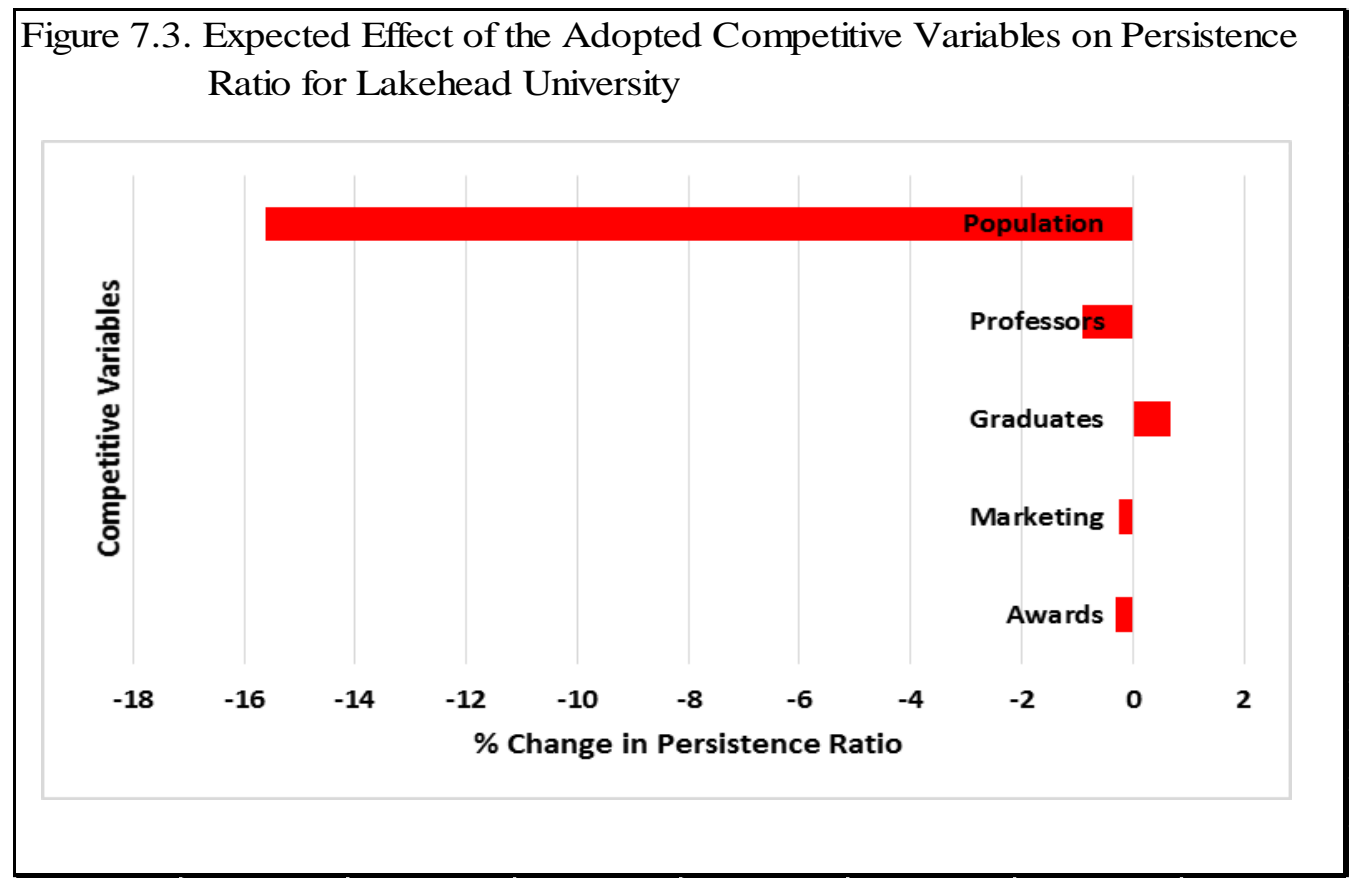

The result from Fixed Effects (a modified Fixed Effect regression) explains how persistence ratio responds to a one percent change in awards, marketing, graduates, professors, 
and population for Lakehead University. The regression result shows a strong relationship between persistence ratio and the adopted competitive variables (R-Squared=0.92). R-Squared indicates that approximately $92 \%$ of the change in persistence ratio can be explained by the change in population, and in university expenditure on awards, marketing, graduates, and professors. The result suggests that the responsiveness of persistence ratio with respect to awards, marketing, graduates, professors, and population is about $-0.32,-0.23,0.68,-0.90$, and $-15.63 \%$, respectively. These additional effect coefficients are statistically significant at $1,5,1$, 1 , and $1 \%(\rho<.01, \rho<.05, \rho<.01, \rho<.01, \& \rho<.01)$. Overall effects also estimate negative and positive significant signs and these are explained in Appendix G, Table 9.2.1.

The positive and significant additional effects suggest that graduates has a larger effect on persistence ratio, while a negative and significant sign suggests that awards, marketing, professors, and population have a smaller effect on persistence ratio. A one percent increase in expenditure on graduates has a greater effect on persistence ratio by about $0.68 \%$ for Lakehead University relative to all other Ontario universities. A smaller effect suggests that a one percent increase in expenditure on awards, marketing, and professors is expected to produce a smaller effect on persistence ratio by about $0.32,0.23$, and $0.90 \%$, respectively. A one percent increase in population has a smaller effect on persistence ratio by about $15.63 \%$ for Lakehead University relative to all other Ontario universities. However, the existence of significant responsiveness leads one to infer that the changes in population, and in university expenditure on awards, marketing, graduates, and professors are likely to affect the persistence ratio for Lakehead University. 


\section{Laurentian University}

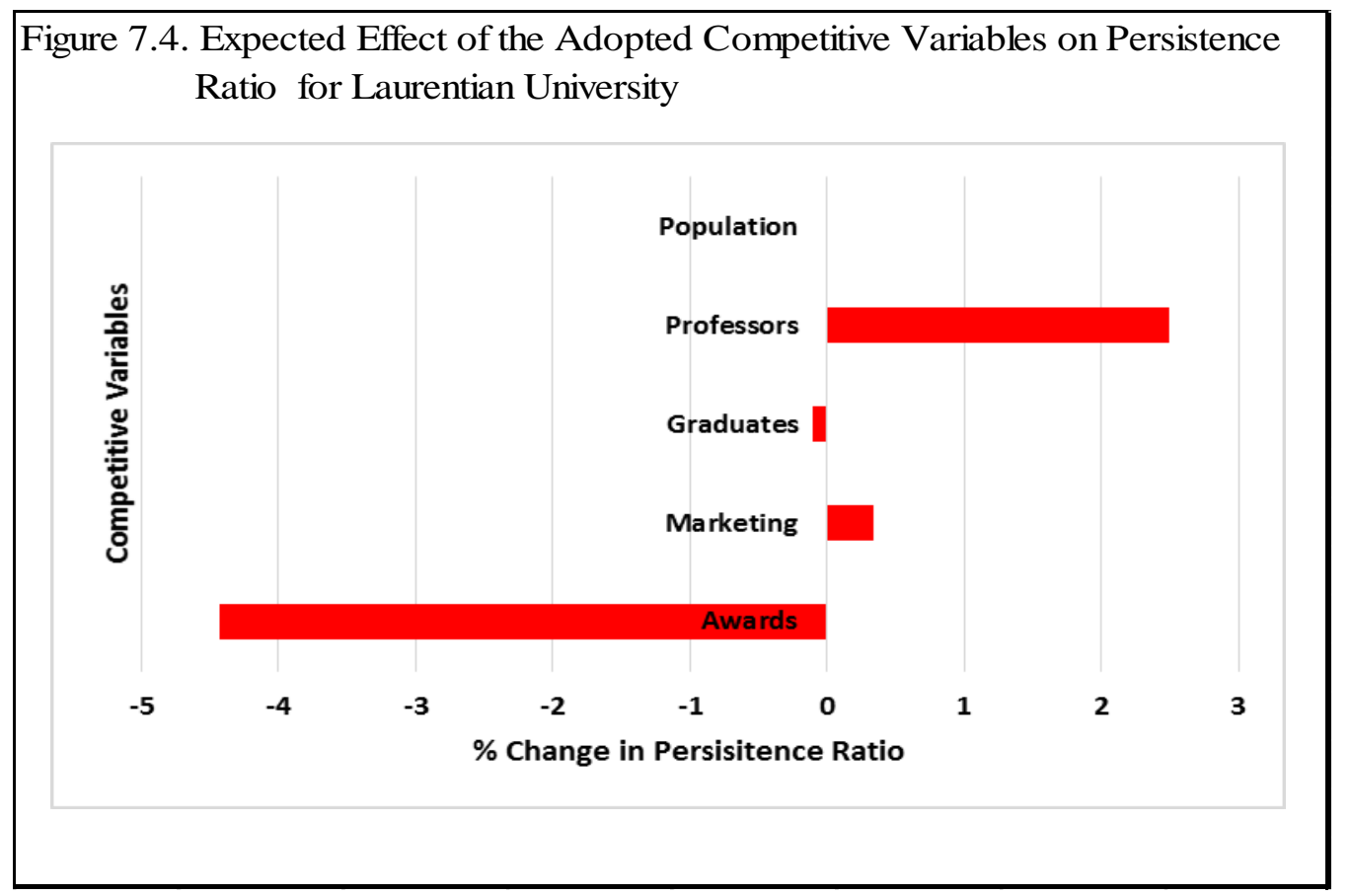

The result from Fixed Effects (a modified Fixed Effect regression) explains how

persistence ratio responds to a one percent change in awards, marketing, graduates, professors, and population for Laurentian University. The regression result shows a strong relationship between persistence ratio and the adopted competitive variables (R-Squared=0.93). R-Squared indicates that approximately $93 \%$ of the change in persistence ratio can be explained by the change in university expenditure on awards, marketing, graduates, and professors. The result suggests that the responsiveness of persistence ratio with respect to awards, marketing, graduates, and professors is about $-4.43,0.35,-0.10$, and $2.49 \%$, respectively. These additional effect coefficients are statistically significant at $1,5,1$, and $1 \%(\rho<.01, \rho<.05, \rho<.01, \& \rho<.01)$. Overall effects also estimate negative and positive significant signs and these are explained in Appendix G, Table 9.2.1.

The positive and significant additional effects suggest that marketing and professors have a larger effect on persistence ratio, while a negative and significant sign suggests that awards and 
graduates have a smaller effect on persistence ratio. A larger effect suggests that a one percent increase in expenditure on marketing and professors is expected to produce a greater effect on persistence ratio by about 0.35 and $2.49 \%$, respectively. A smaller effect suggests that a one percent increase in expenditure on awards and graduates is expected to produce a smaller effect on persistence ratio by about 4.43 and $0.10 \%$, respectively, for Laurentian University relative to all other Ontario universities. However, the existence of significant responsiveness leads one to infer that the changes in university expenditure on awards, marketing, graduates, and professors are likely to affect the persistence ratio for Laurentian University. Laurentian University might need these responsiveness estimates in order to determine the most effective competitive variables to make good managerial decisions in the short run and in the long run.

\section{McMaster University}

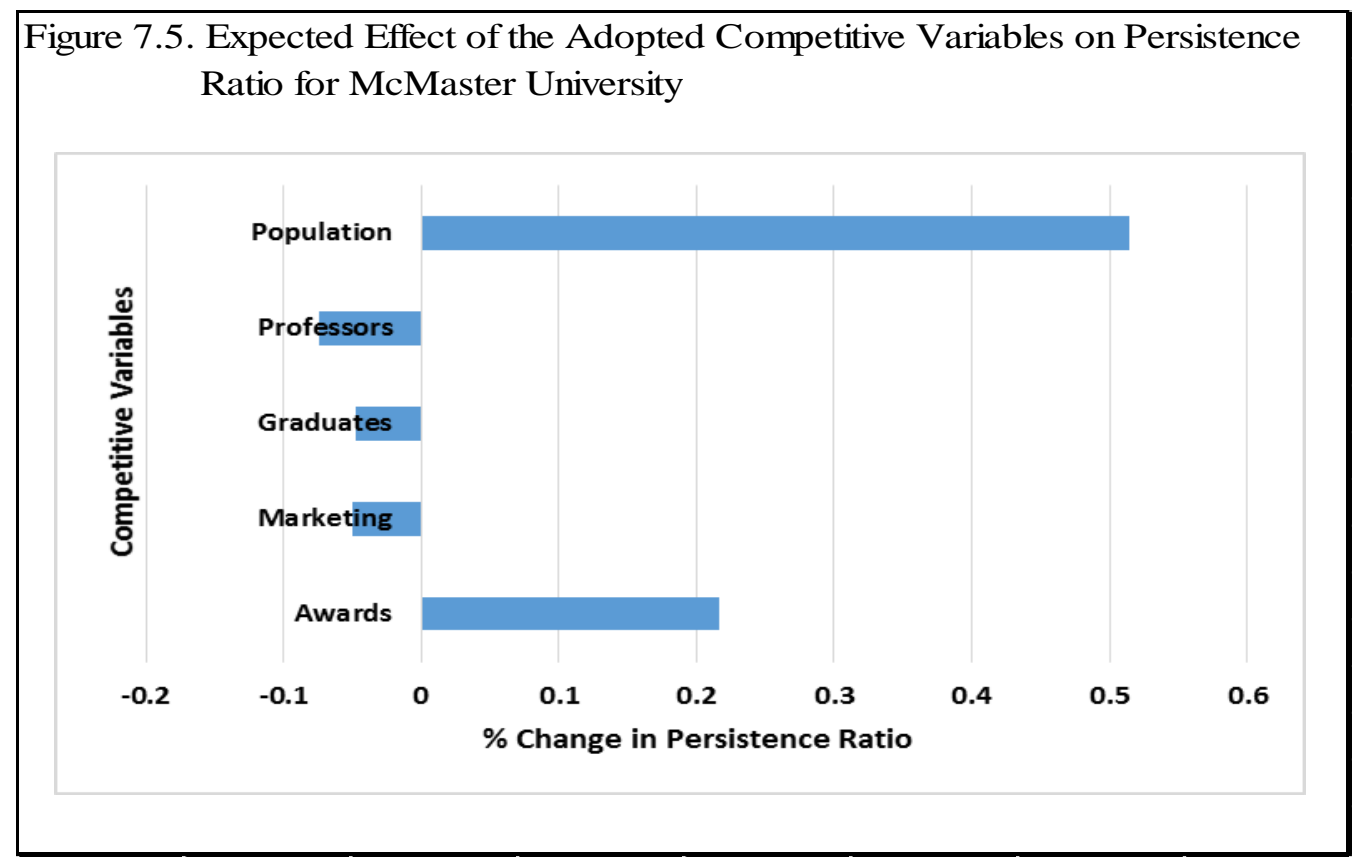

The result from Fixed Effects (a modified Fixed Effect regression) explains how persistence ratio responds to a one percent change in awards, marketing, graduates, professors, and population for McMaster University. A significant relation was not found for adopted 
competitive variables. This insignificance suggests that changes in population, and in university expenditure on awards, marketing, graduates, and professors are unlikely to affect persistence ratio for McMaster University. These additional effect coefficients are statistically insignificant for McMaster University. Overall effects estimate negative and positive significant signs and these are explained in Appendix G, Table 9.2.1.

\section{Nipissing University}

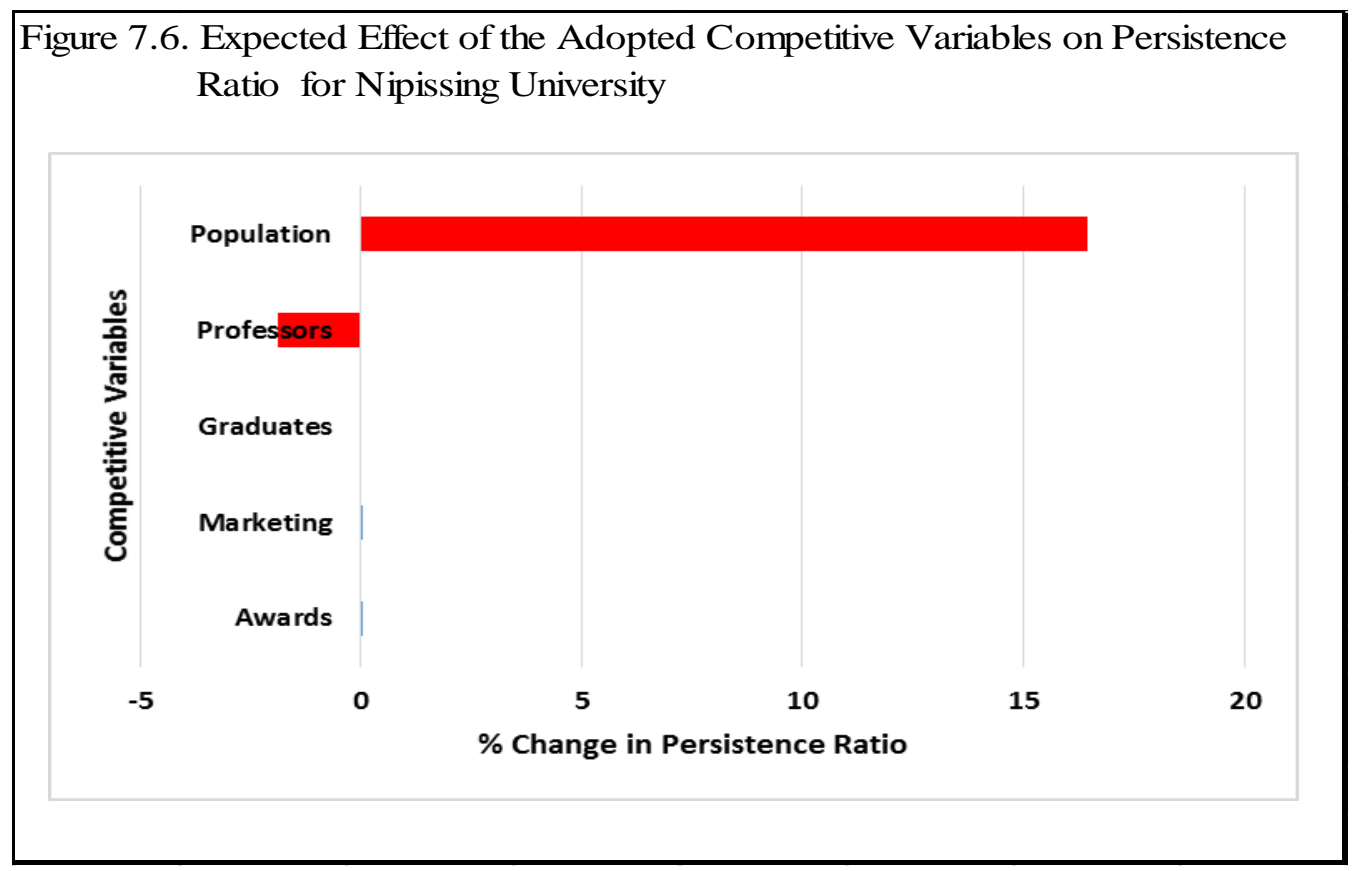

The result from Fixed Effects (a modified Fixed Effect regression) explains how persistence ratio responds to a one percent change in awards, marketing, graduates, professors, and population for Nipissing University. The regression result shows a strong relationship between persistence ratio and the adopted competitive variables (R-Squared=0.93). R-Squared indicates that approximately $93 \%$ of the change in persistence ratio can be explained by the change in population, and in university expenditure on professors. The result suggests that the responsiveness of persistence ratio with respect to professors and population is about -1.87 , and $16.46 \%$, respectively. These additional effect coefficients are statistically significant at $1 \%$ 
$(\rho<.01)$. Overall effects also estimate negative and positive significant signs and these are explained in Appendix G, Table 9.2.1.

The positive and significant additional effects suggest that population has a larger effect on persistence ratio, while a negative and significant sign suggests that professors has a smaller effect on persistence ratio. A larger effect suggests that a one percent increase in population is expected to produce a greater effect on persistence ratio by about $16.46 \%$. A smaller effect suggests that a one percent increase in expenditure on professors is expected to produce a smaller effect on persistence ratio by about $1.87 \%$ for Nipissing University relative to all other Ontario universities. However, the existence of significant responsiveness leads one to infer that the changes in population, and in university expenditure on professors are likely to affect the persistence ratio for Nipissing University.

\section{OCAD University}

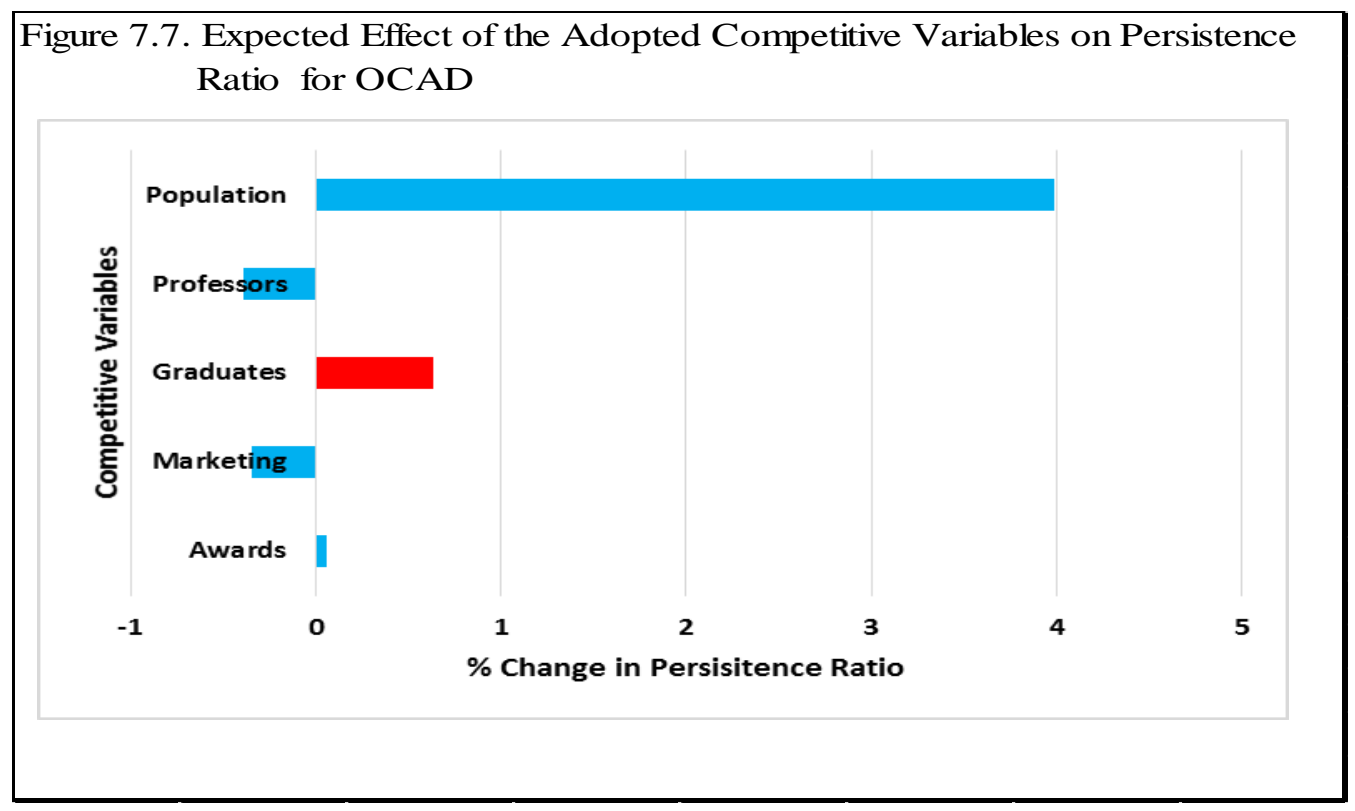

The result from Fixed Effects (a modified Fixed Effect regression) explains how persistence ratio responds to a one percent change in awards, marketing, graduates, professors, and population for OCAD. The regression result shows a strong relationship between 
persistence ratio and the adopted competitive variables ( $\mathrm{R}$-Squared $=0.92)$. R-Squared indicates that approximately $92 \%$ of the change in persistence ratio can be explained by the change in university expenditure on graduates. The result suggests that the responsiveness of persistence ratio with respect to graduates is about $0.64 \%$. This additional effect coefficient is statistically significant at $5 \%(\rho<.05)$. Overall effects also estimate negative and positive significant signs and these are explained in Appendix G, Table 9.2.1.

The positive and significant additional effects suggest that graduates has a larger effect on persistence ratio. A larger effect suggests that a one percent increase in expenditure on graduates is expected to produce a greater effect on persistence ratio by about $0.64 \%$ for OCAD University relative to all other Ontario universities.

\section{Queen's University}

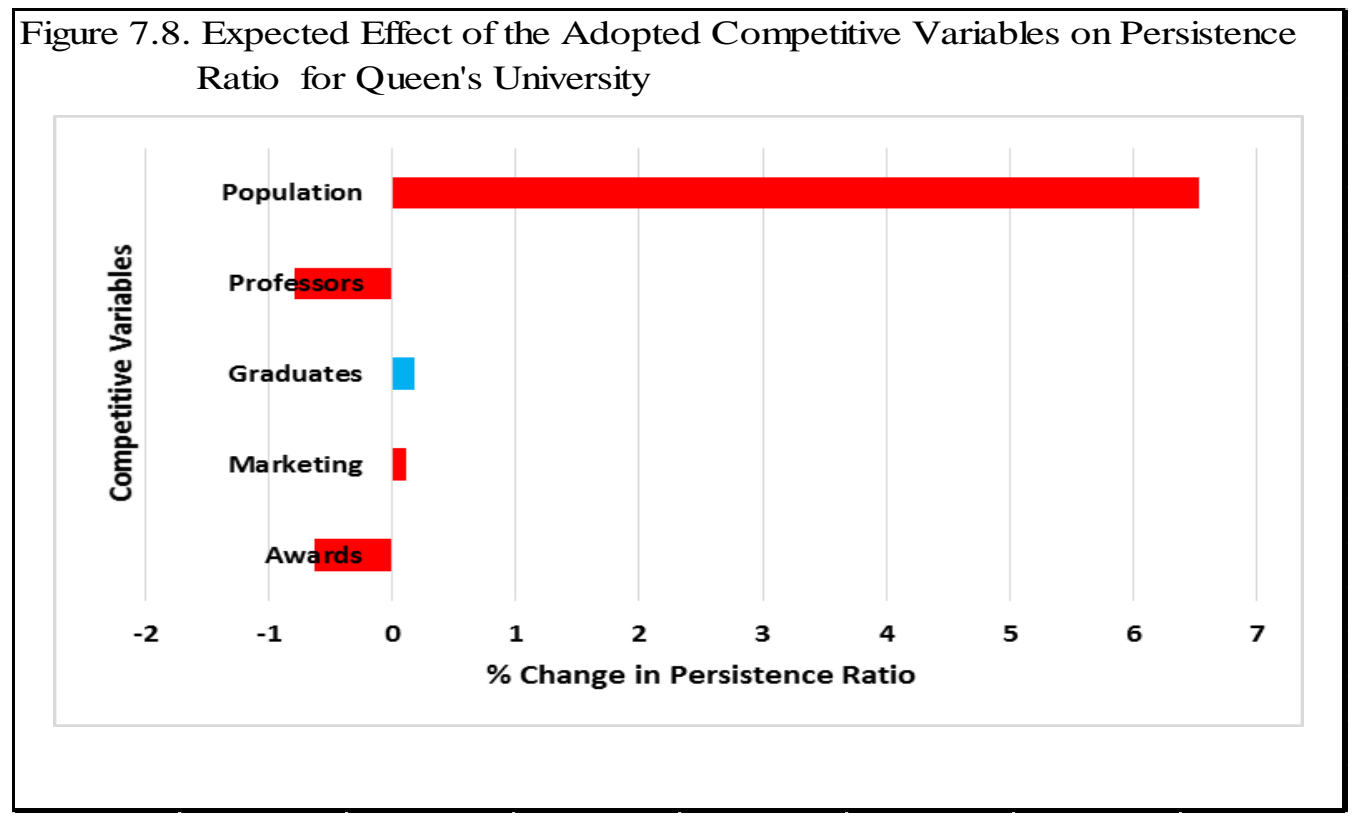

The result from Fixed Effects (a modified Fixed Effect regression) explains how persistence ratio responds to a one percent change in awards, marketing, graduates, professors, and population for Queen's University. The regression result shows a strong relationship between persistence ratio and the adopted competitive variables (R-Squared=0.92). R-Squared 
indicates that approximately $92 \%$ of the change in persistence ratio can be explained by the change in population and in university expenditure on awards, marketing, and professors. The result suggests that the responsiveness of persistence ratio with respect to awards, marketing, professors, and population is about $-0.63,0.12,-0.79$, and $6.53 \%$, respectively. These additional effect coefficients are statistically significant at $1,5,1$, and $1 \%(\rho<.01, \rho<.05, \rho<.01, \& \rho<.01)$. Overall effects also estimate negative and positive significant signs and these are explained in Appendix G, Table 9.2.1.

The positive and significant additional effects suggest that marketing and population have a larger effect on persistence ratio, while a negative and significant sign suggests that awards and professors have a smaller effect on persistence ratio. A larger effect suggests that a one percent increase in marketing and population is expected to produce a greater effect on persistence ratio by about 0.12 and $6.53 \%$, respectively. A smaller effect suggests that a one percent increase in expenditure on awards and professors is expected to produce a smaller effect on persistence ratio by about 0.63 and $0.79 \%$, respectively, for Queen's University relative to all other Ontario universities. A significant effect was not found for the variable of graduates. However, the existence of significant responsiveness leads one to infer that the changes in population, and in university expenditure on awards, marketing, and professors are likely to affect the persistence ratio for Queen's University. Queen's University might need these responsiveness estimates in order to determine the most effective competitive variables to make good managerial decisions in the short run and in the long run. 


\section{Ryerson University}

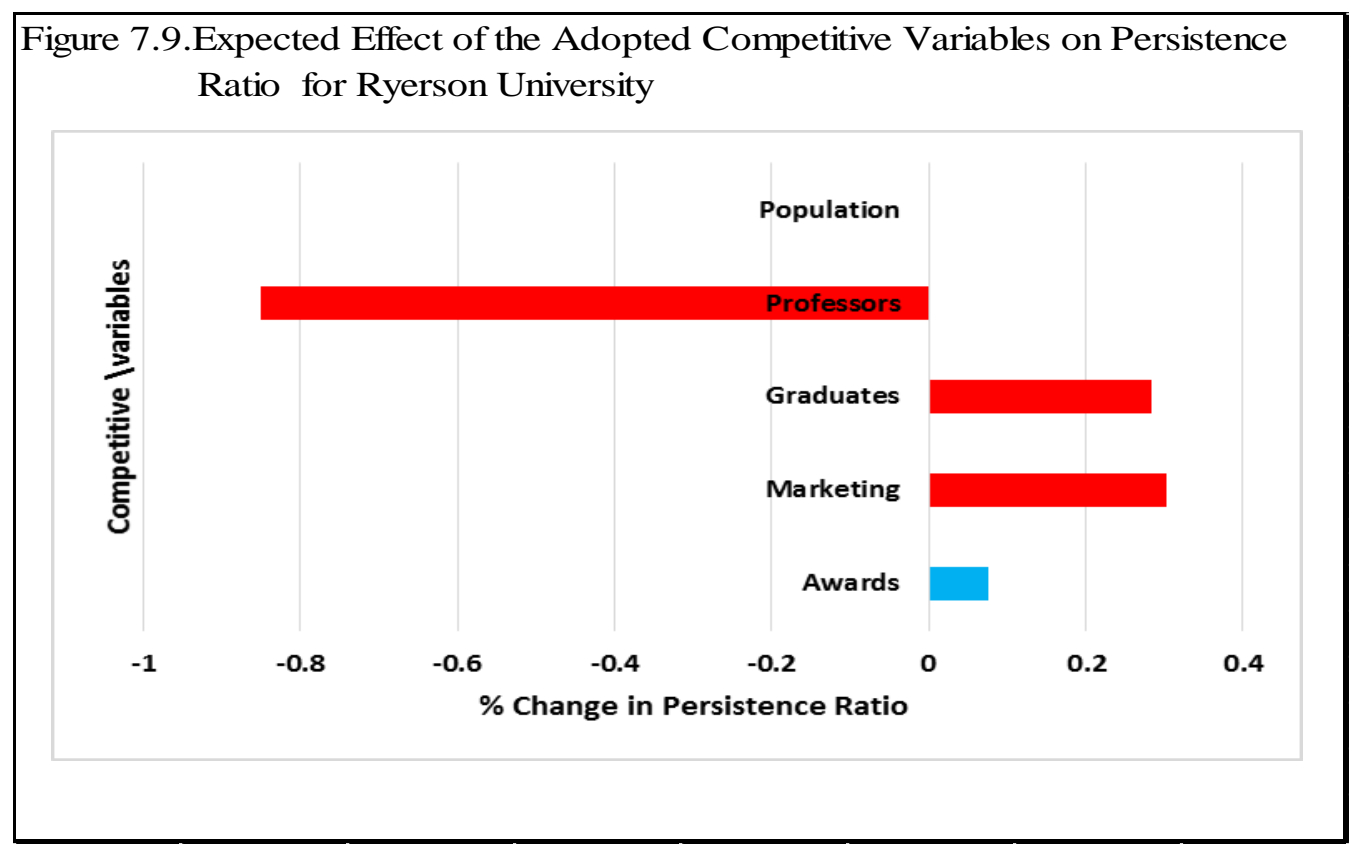

The result from Fixed Effects (a modified Fixed Effect regression) explains how persistence ratio responds to a one percent change in awards, marketing, graduates, professors, and population for Ryerson University. The regression result shows a strong relationship between persistence ratio and the adopted competitive variables ( $R$-Squared=0.92). R-Squared indicates that approximately $92 \%$ of the change in persistence ratio can be explained by the change in university expenditure on marketing, graduates, and professors. The result suggests that the responsiveness of persistence ratio with respect to marketing, graduates, and professors is about $0.30,0.28$, and $-0.85 \%$, respectively. These additional effect coefficients are statistically significant at $1 \%(\rho<.01)$. Overall effects also estimate negative and positive significant signs and these are explained in Appendix G, Table 9.2.1.

The positive and significant additional effects suggest that marketing and graduates have a larger effect on persistence ratio, while a negative and significant sign suggests that professors has a smaller effect on persistence ratio. A larger effect suggests that a one percent increase in 
expenditure on marketing and graduates is expected to produce a greater effect on persistence ratio by about 0.30 and $0.28 \%$. A smaller effect suggests that a one percent increase in expenditure on professors is expected to produce a smaller effect on persistence ratio by about $0.85 \%$ for Ryerson University relative to all other Ontario universities. A significant effect was not found for the variable of awards. However, the existence of significant responsiveness leads one to infer that the changes in university expenditure on marketing, graduates, and professors are likely to affect the persistence ratio for Ryerson University.

\section{Trent University}

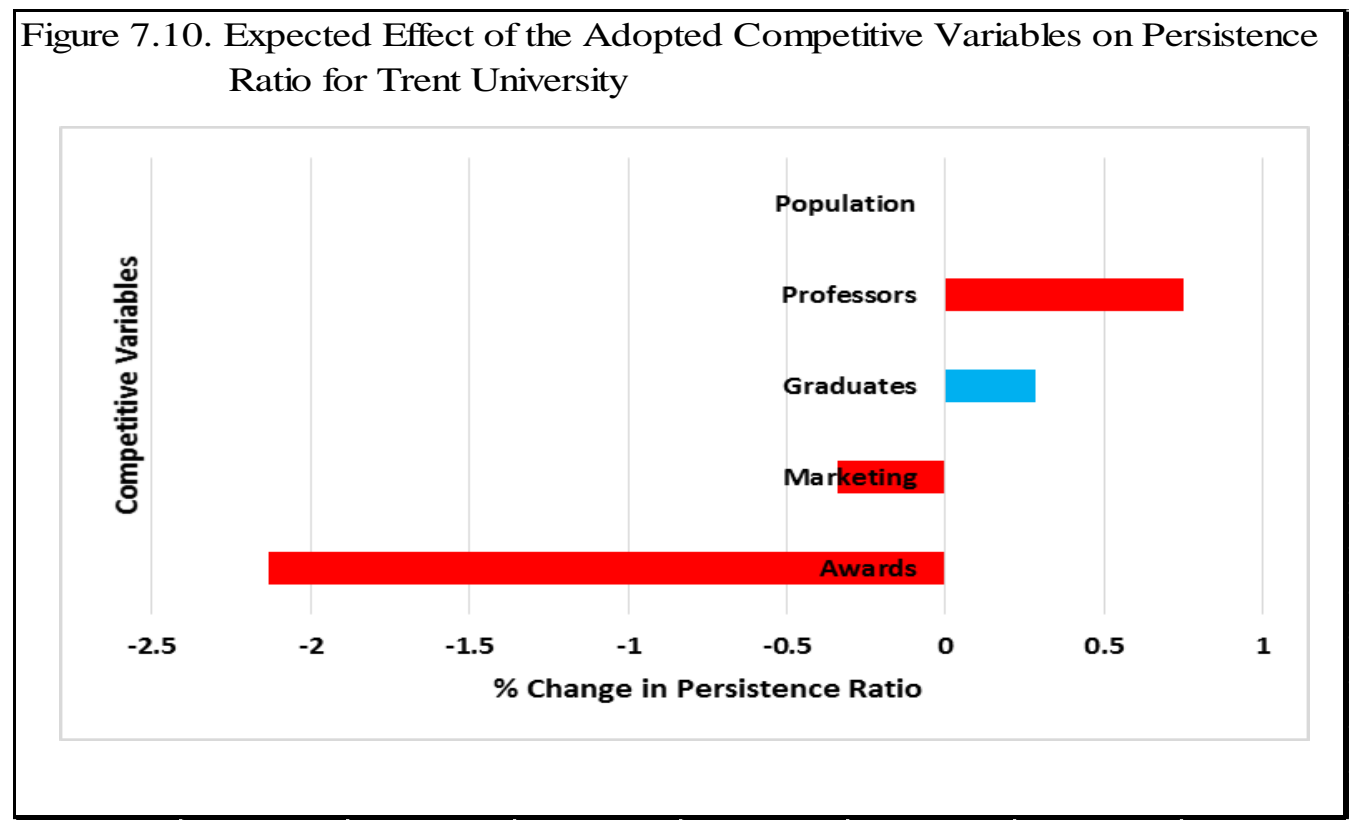

The result from Fixed Effects (a modified Fixed Effect regression) explains how persistence ratio responds to a one percent change in awards, marketing, graduates, professors, and population for Trent University. The regression result shows a strong relationship between persistence ratio and the adopted competitive variables (R-Squared $=0.93)$. R-Squared indicates that approximately $93 \%$ of the change in persistence ratio can be explained by the change in university expenditure on awards, marketing and professors. The result suggests that the responsiveness of persistence ratio with respect to awards, marketing, and professors is about 
$-2.13,-0.34$, and $0.75 \%$, respectively. These additional effect coefficients are statistically significant at 1,1 , and $5 \%(\rho<.01, \rho<.01, \& \rho<.05)$. Overall effects also estimate negative and positive significant signs and these are explained in Appendix G, Table 9.2.1.

The positive and significant additional effects suggest that professors has a larger effect on persistence ratio, while a negative and significant sign suggests that awards and marketing have a smaller effect on persistence ratio. A larger effect suggests that a one percent increase in investing in faculty members (professors) is expected to produce a greater effect on persistence ratio by about $0.75 \%$. A smaller effect suggests that a one percent increase in expenditure on awards and marketing is expected to produce a smaller effect on persistence ratio by about 2.13 and $0.34 \%$, respectively, for Trent University relative to all other Ontario universities. A significant effect was not found for the variable of graduates. However, the existence of significant responsiveness leads one to infer that the changes in university expenditure on awards, marketing, and professors are likely to affect the persistence ratio for Trent University

\section{University of Guelph}

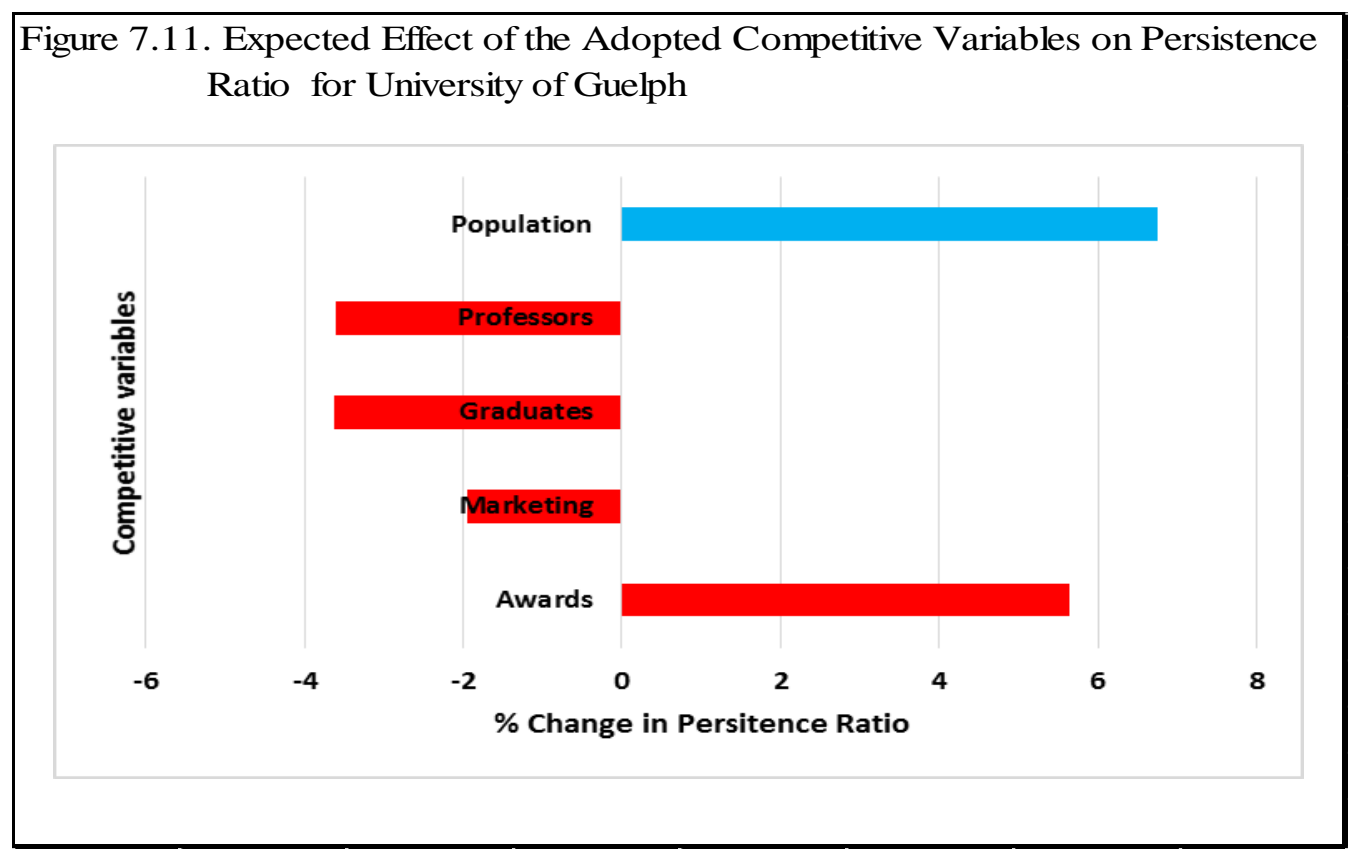


The result from Fixed Effects (a modified Fixed Effect regression) explains how persistence ratio responds to a one percent change in awards, marketing, graduates, professors, and population for University of Guelph. The regression result shows a strong relationship between persistence ratio and the adopted competitive variables (R-Squared=0.93). R-Squared indicates that approximately $93 \%$ of the change in persistence ratio can be explained by the change in university expenditure on awards, marketing, graduates, and professors. The result suggests that the responsiveness of persistence ratio with respect to awards, marketing, graduates, and professors is about $5.63,-1.94,-3.62$, and $-3.61 \%$, respectively. These additional effect coefficients are statistically significant at $1 \%(\rho<.01)$. Overall effects also estimate negative and positive significant signs and these are explained in Appendix G, Table 9.2.1.

The positive and significant additional effects suggest that awards has a larger effect on persistence ratio, while a negative and significant sign suggests that marketing, graduates, and professors have a smaller effect on persistence ratio. A larger effect suggests that a one percent increase in expenditure on awards is expected to produce a greater effect on persistence ratio by about $5.63 \%$. A smaller effect suggests that a one percent increase in expenditure on marketing, graduates, and professors is expected to produce a smaller effect on persistence ratio by about $1.94,3.62$, and $3.61 \%$, respectively, for University of Guelph relative to all other Ontario universities. However, the existence of significant responsiveness leads one to infer that the changes in university expenditure on awards, marketing, graduates, and professors are likely to affect the persistence ratio for University of Guelph. 


\section{UOIT}

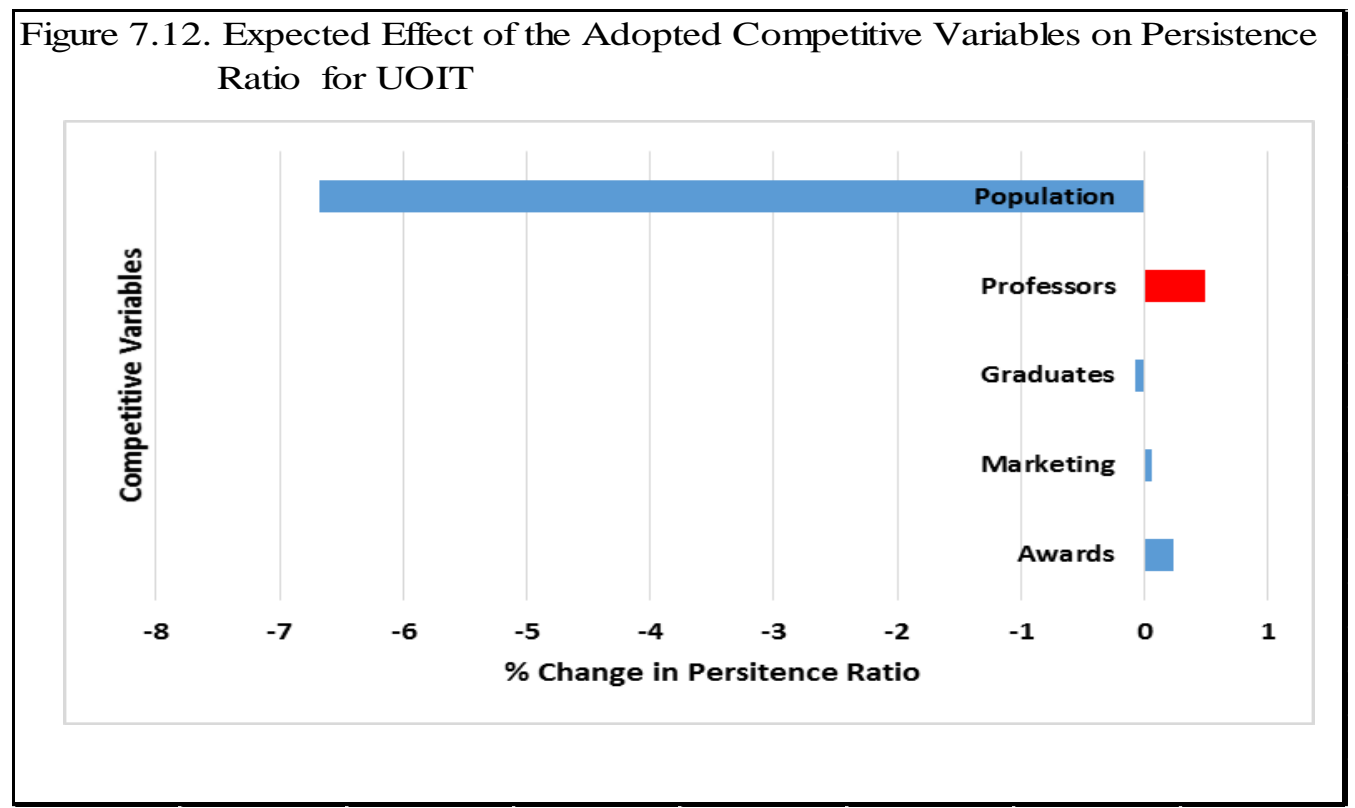

The result from Fixed Effects (a modified Fixed Effect regression) explains how persistence ratio responds to a one percent change in awards, marketing, graduates, professors, and populations for UOIT. The regression result shows a strong relationship between persistence ratio and the adopted competitive variables (R-Squared=0.93). R-Squared indicates that approximately $93 \%$ of the change in persistence ratio can be explained by the change in university expenditure on professors. The result suggests that the responsiveness of persistence ratio with respect to professors is about $0.49 \%$. This additional effect coefficient is statistically significant at $5 \%(\rho<.05)$. Overall effects also estimate negative and positive significant signs and these are explained in Appendix G, Table 9.2.1.

The positive and significant additional effects suggest that professors has a larger effect on persistence ratio. A larger effect suggests that a one percent increase in investing in faculty members (professors) is expected to produce a greater effect on persistence ratio by about $0.49 \%$ for UOIT relative to all other Ontario universities. A significant effect was not found for the variables of awards, marketing, graduates, and population. However, the existence of significant 
responsiveness leads one to infer that the changes in university expenditure on professors are likely to affect the persistence ratio for UOIT.

\section{University of Ottawa}

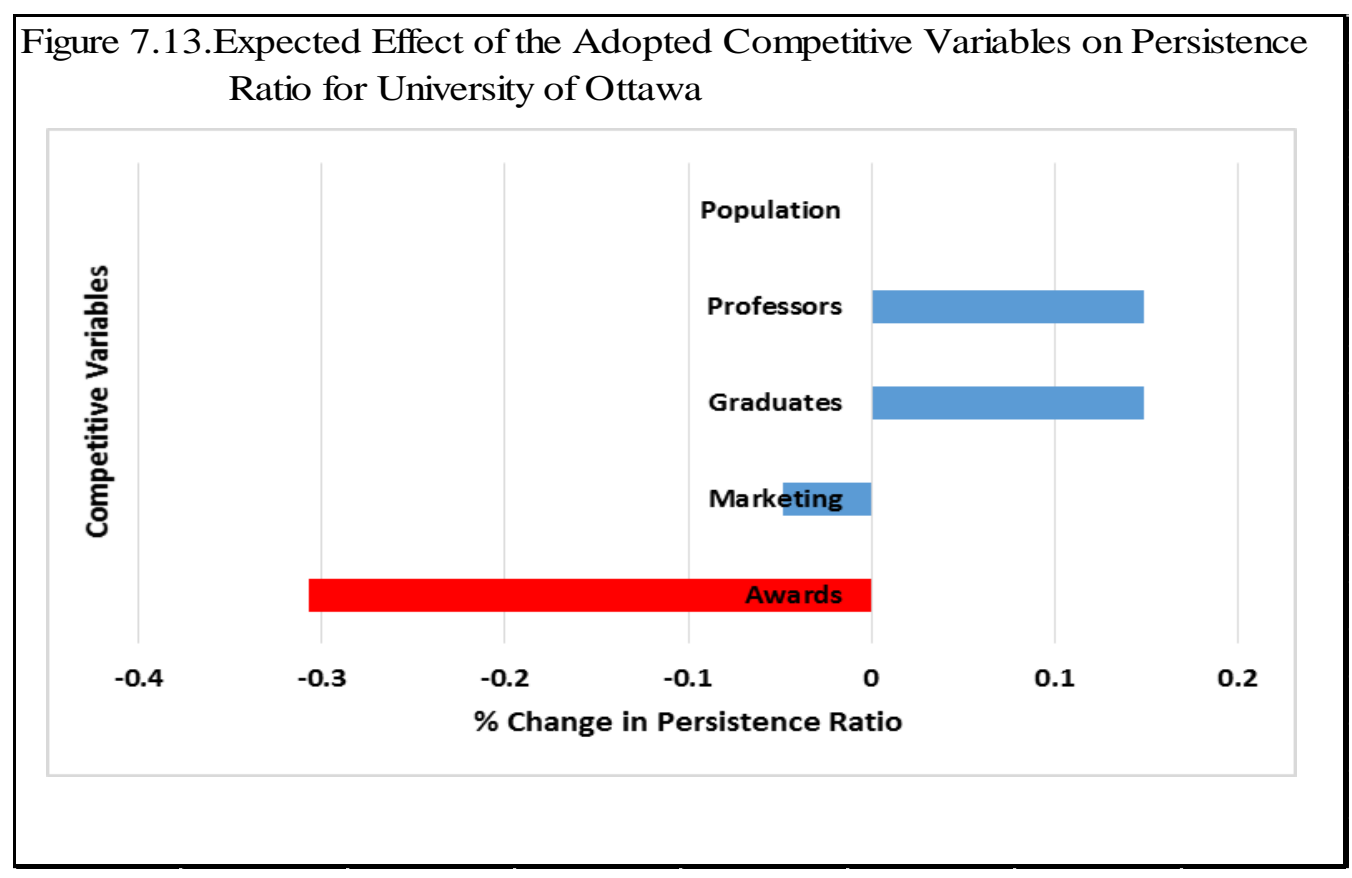

The result from Fixed Effects (a modified Fixed Effect regression) explains how

persistence ratio responds to a one percent change in awards, marketing, graduates, professors, and population for University of Ottawa. The regression result shows a strong relationship between persistence ratio and the adopted competitive variables (R-Squared=0.92). R-Squared indicates that approximately $92 \%$ of the change in persistence ratio can be explained by the change in university expenditure on awards. The result suggests that the responsiveness of persistence ratio with respect to awards is about $-0.31 \%$. This additional effect coefficient is statistically significant at $10 \%(\rho<.10)$. Overall effects also estimate negative and positive significant signs and these are explained in Appendix G, Table 9.2.1.

The negative and significant sign suggests that awards has a smaller effect on persistence ratio. A smaller effect suggests that a one percent increase in expenditure on awards is expected 
to produce a smaller effect on persistence ratio by about $0.31 \%$ for University of Ottawa relative to all other Ontario universities. A significant effect was not found for the variables of marketing, graduates, professors, and population. However, the existence of significant responsiveness leads one to infer that the changes in university expenditure on awards are likely to affect the persistence ratio for University of Ottawa.

\section{University of Waterloo}

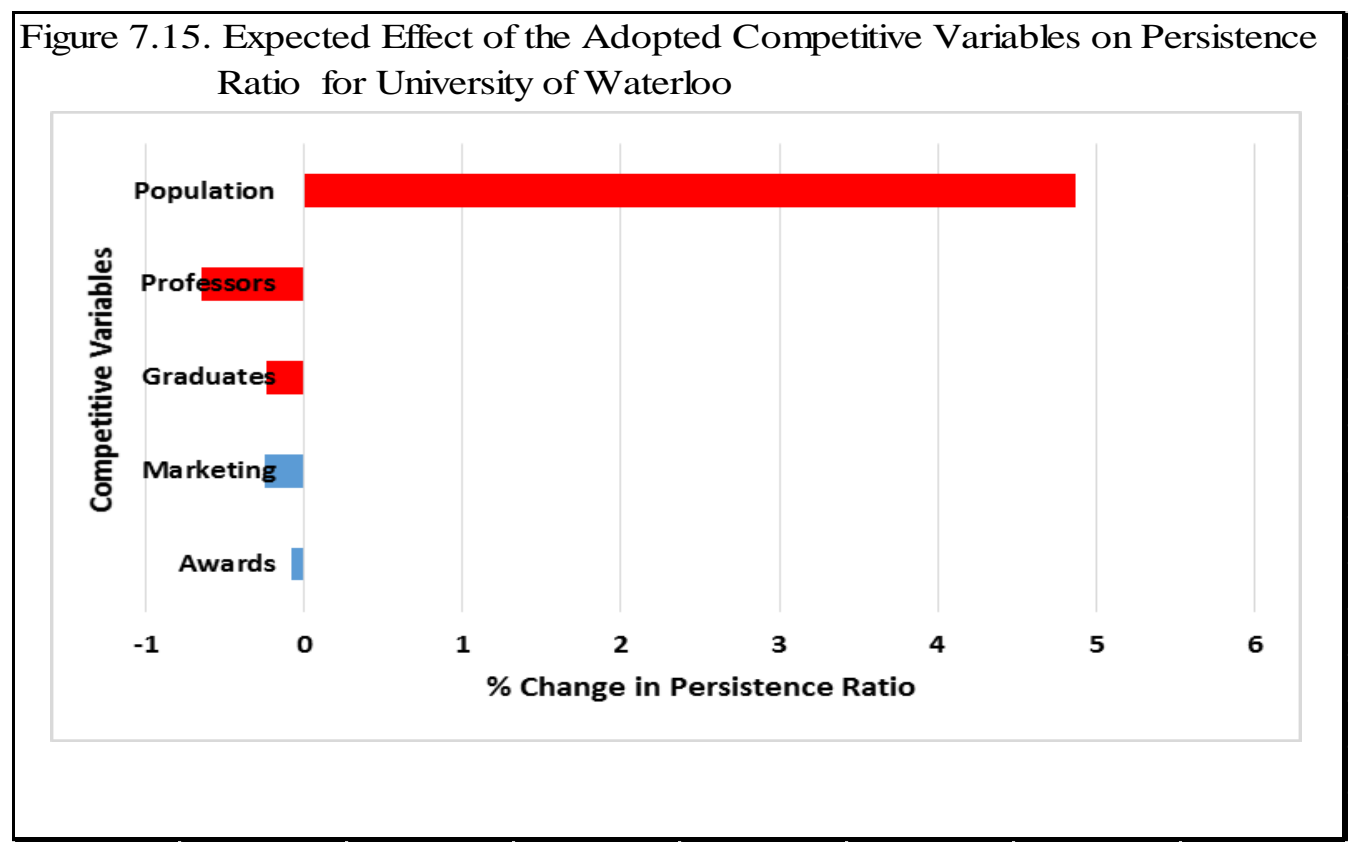

The result from Fixed Effects (a modified Fixed Effect regression) explains how persistence ratio responds to a one percent change in awards, marketing, graduates, professors, and population for University of Waterloo. The regression result shows a strong relationship between persistence ratio and the adopted competitive variables ( $\mathrm{R}$-Squared=0.93). R-Squared indicates that approximately $93 \%$ of the change in persistence ratio can be explained by the change in graduates, professors, and population. The result suggests that the responsiveness of persistence ratio with respect to graduates, professors, and population is about $-0.24,-0.65$ and $4.87 \%$, respectively. These additional effect coefficients are statistically significant at 5,1 , and 
$1 \%(\rho<.05, \rho<.01, \& \rho<.01)$. Overall effects also estimate negative and positive significant signs and these are explained in Appendix G, Table 9.2.1.

The positive and significant additional effects suggest that population has a larger effect on persistence ratio, while a negative and significant sign suggests that graduates and professors have a smaller effect on persistence ratio. A larger effect suggests that a one percent increase in population is expected to produce a greater effect on persistence ratio by about $4.87 \%$. A smaller effect suggests that a one percent increase in expenditure on graduates and professors is expected to produce a smaller effect on persistence ratio by 0.24 and $0.65 \%$, respectively, for University of Waterloo relative to all other Ontario universities. A significant effect was not found for the variables of awards and marketing. However, the existence of significant responsiveness leads one to infer that the changes in population, and in university expenditure on graduates and professors are likely to affect the persistence ratio for University of Waterloo.

\section{University of Windsor}

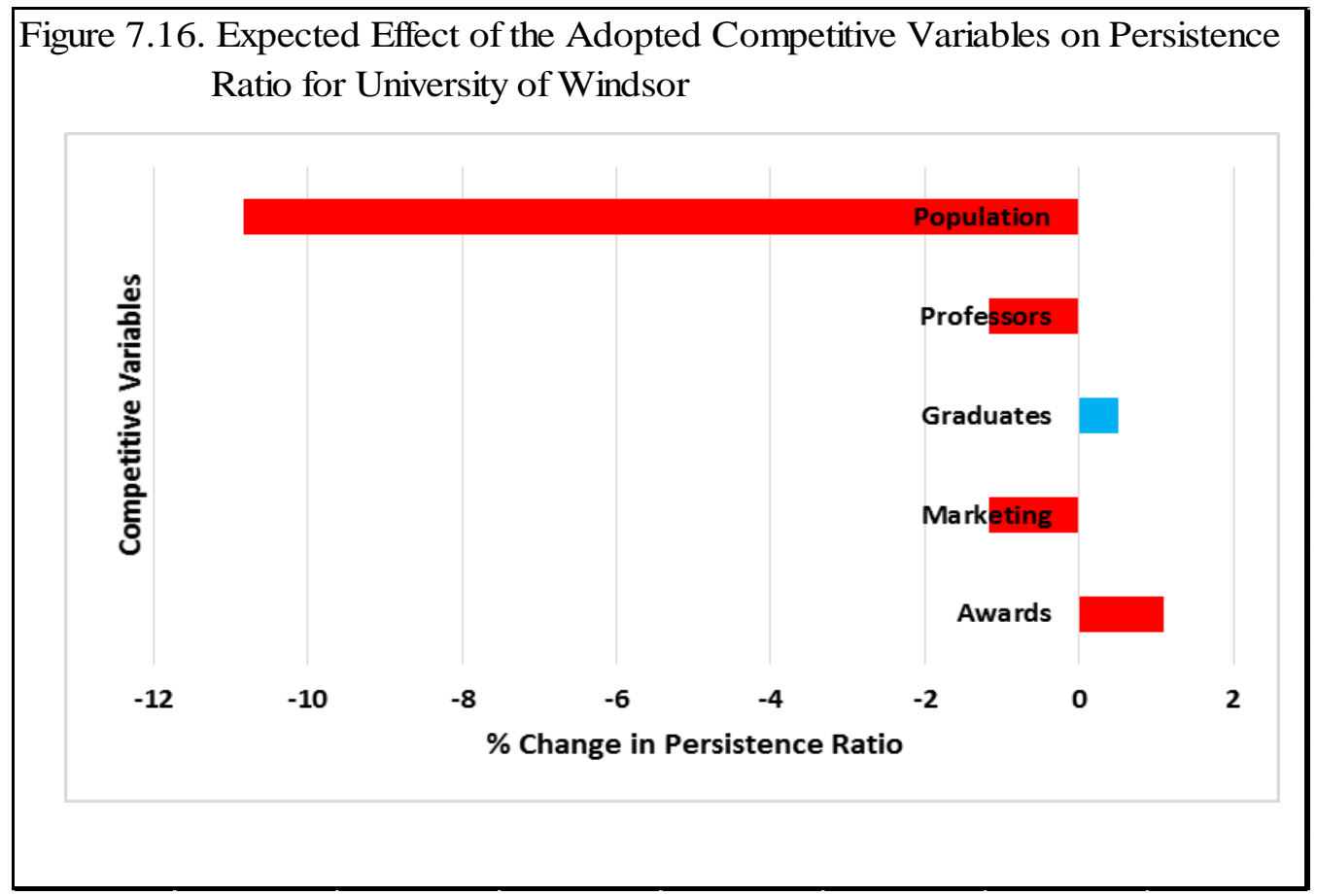


The result from Fixed Effects (a modified Fixed Effect regression) explains how persistence ratio responds to a one percent change in awards, marketing, graduates, professors, and population for University of Windsor. The regression result shows a strong relationship between persistence ratio and the adopted competitive variables (R-Squared=0.92). R-Squared indicates that approximately $92 \%$ of the change in persistence ratio can be explained by the change in population, and in university expenditure on awards, marketing, and professors. The result suggests that the responsiveness of persistence ratio with respect to awards, marketing, professors, and population is about $1.09,-1.18,-1.16$, and $-10.84 \%$, respectively. These additional effect coefficients are statistically significant at $1,1,5$, and $1 \%(\rho<.01, \rho<.01, \rho<.05$, $\& \rho<.01)$. Overall effects also estimate negative and positive significant signs and these are explained in Appendix G, Table 9.2.1.

The positive and significant additional effects suggest that awards has a larger effect on persistence ratio, while a negative and significant sign suggests that marketing, professors, and population have a smaller effect on persistence ratio. A larger effect suggests that a one percent increase in expenditure on awards is expected to produce a greater effect on persistence ratio by about $1.09 \%$. A smaller effect suggests that a one percent increase in marketing, professors, and population is expected to produce a smaller effect on persistence ratio by about $1.18,1.16$, and $10.84 \%$, respectively, for University of Windsor relative to all other Ontario universities. A significant effect was not found for the variable of graduates. However, the existence of significant responsiveness leads one to infer that the changes in population, and in university expenditure on awards, marketing, and professors are likely to affect the persistence ratio for University of Windsor. 


\section{Western University}

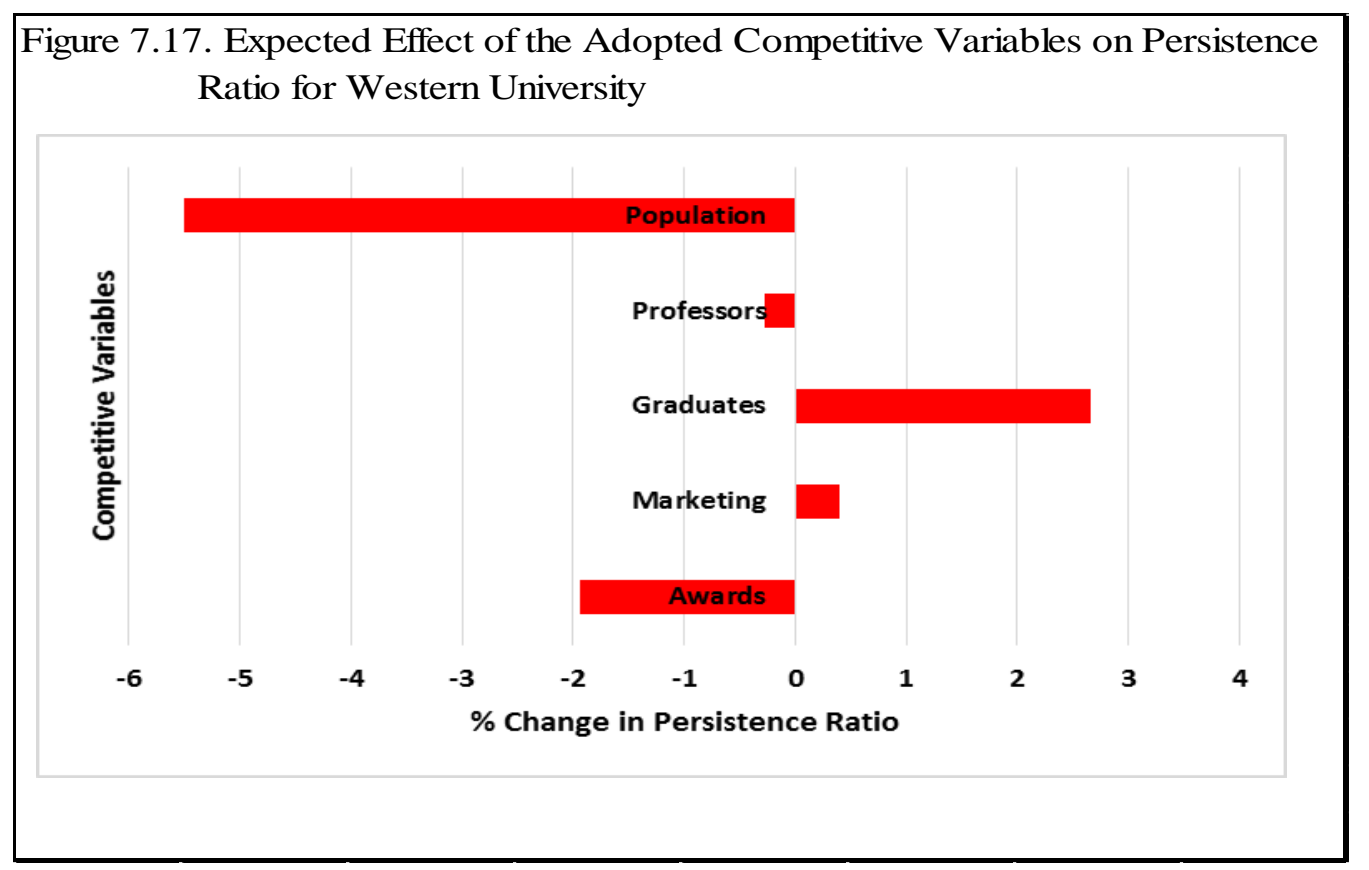

The result from Fixed Effects (a modified Fixed Effect regression) explains how persistence ratio responds to a one percent change in awards, marketing, graduates, professors, and population for Western University. The regression result shows a strong relationship between persistence ratio and the adopted competitive variables ( $\mathrm{R}$-Squared=0.93). R-Squared indicates that approximately $93 \%$ of the change in persistence ratio can be explained by the change in population, and in university expenditure on awards, marketing, graduates, and professors. The result suggests that the responsiveness of persistence ratio with respect to awards, marketing, graduates, professors, and population is about $-1.94,0.39,2.67,-0.28$, and $-5.50 \%$, respectively. These additional effect coefficients are statistically significant at $1 \%$ $(\rho<.01)$. Overall effects also estimate negative and positive significant signs and these are explained in Appendix G, Table 9.2.1.

The positive and significant additional effects suggest that marketing and graduates have a larger effect on persistence ratio, while a negative and significant sign suggests that awards, 
professors, and population have a smaller effect on persistence ratio. A larger effect suggests that a one percent increase in marketing and graduates is expected to produce a greater effect on persistence ratio by about 0.39 and $2.67 \%$, respectively. A smaller effect suggests that a one percent increase in awards, professors, and population is expected to produce a smaller effect on persistence ratio by about $1.94,0.28$, and $5.50 \%$, respectively, for Western University relative to all other Ontario universities. However, the existence of significant responsiveness leads one to infer that the changes in population, and in university expenditure on awards, marketing, graduates, and professors are likely to affect the persistence ratio for Western University.

\section{Wilfrid Laurier University}

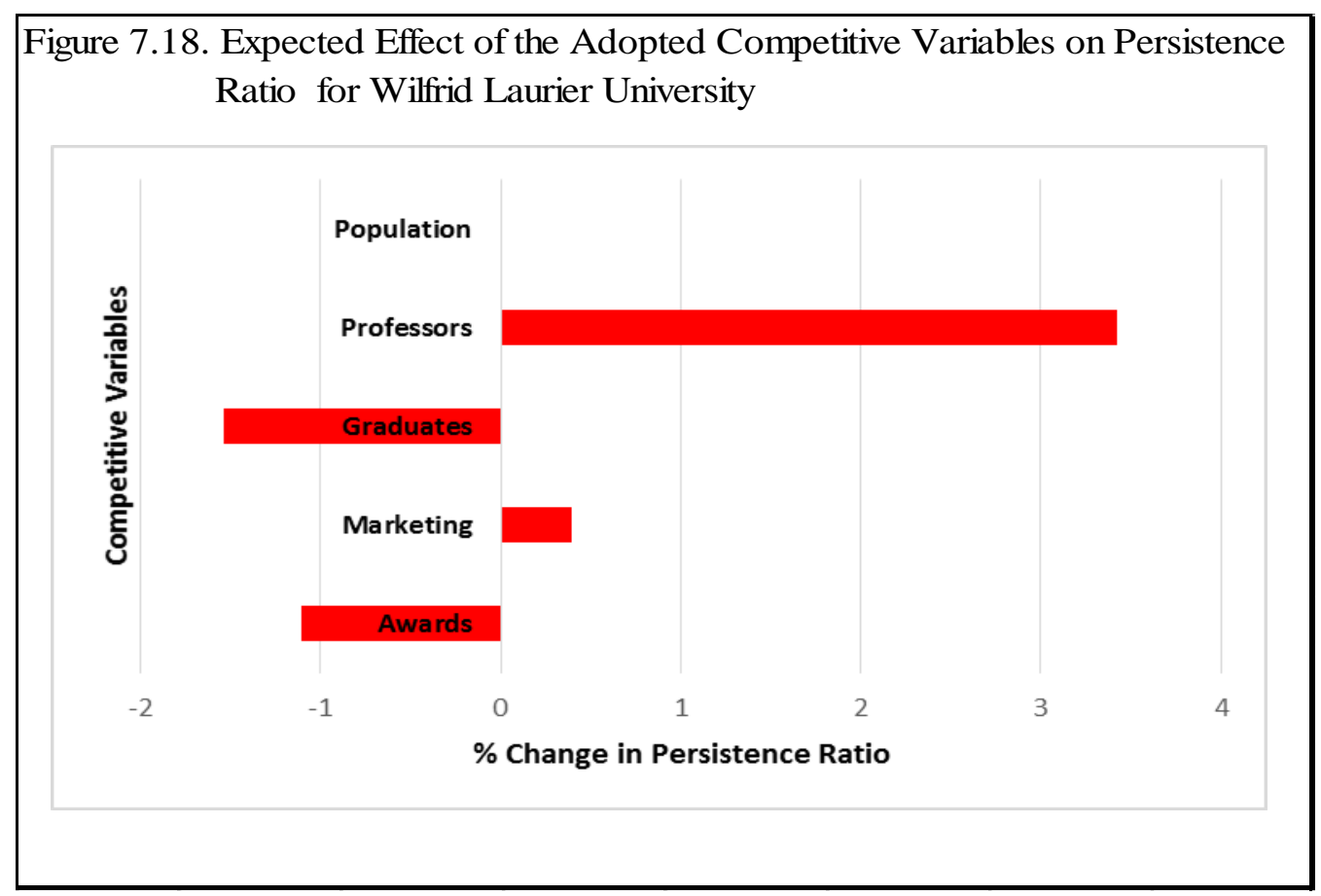

The result from Fixed Effects (a modified Fixed Effect regression) explains how persistence ratio responds to a one percent change in awards, marketing, graduates, professors, and population for Wilfrid Laurier University. The regression result shows a strong relationship between persistence ratio and the adopted competitive variables (R-Squared=0.92). R-Squared indicates that approximately $92 \%$ of the change in persistence ratio can be explained by the 
change in university expenditure on awards, marketing, graduates, and professors. The result suggests that the responsiveness of persistence ratio with respect to awards, marketing, graduates, and professors is about $-1.10,0.40,-1.54$, and $3.42 \%$, respectively. These additional effect coefficients are statistically significant at $1 \%(\rho<.01)$. Overall effects also estimate negative and positive significant signs and these are explained in Appendix G, Table 9.2.1.

The positive and significant additional effects suggest that marketing and professors have a larger effect on persistence ratio, while a negative and significant sign suggests that awards, and graduates have a smaller effect on persistence ratio. A larger effect suggests that a one percent increase in marketing and professors is expected to produce a greater effect on persistence ratio by about 0.40 and $3.42 \%$, respectively. A smaller effect suggests that a one percent increase in awards and graduates is expected to produce a smaller effect on persistence ratio by about 1.10 and $1.54 \%$, respectively, for Wilfrid Laurier University relative to all other Ontario universities. However, the existence of significant responsiveness leads one to infer that the changes in university expenditure on awards, marketing, graduates, and professors are likely to affect the persistence ratio for Wilfrid Laurier University. 


\section{York University}

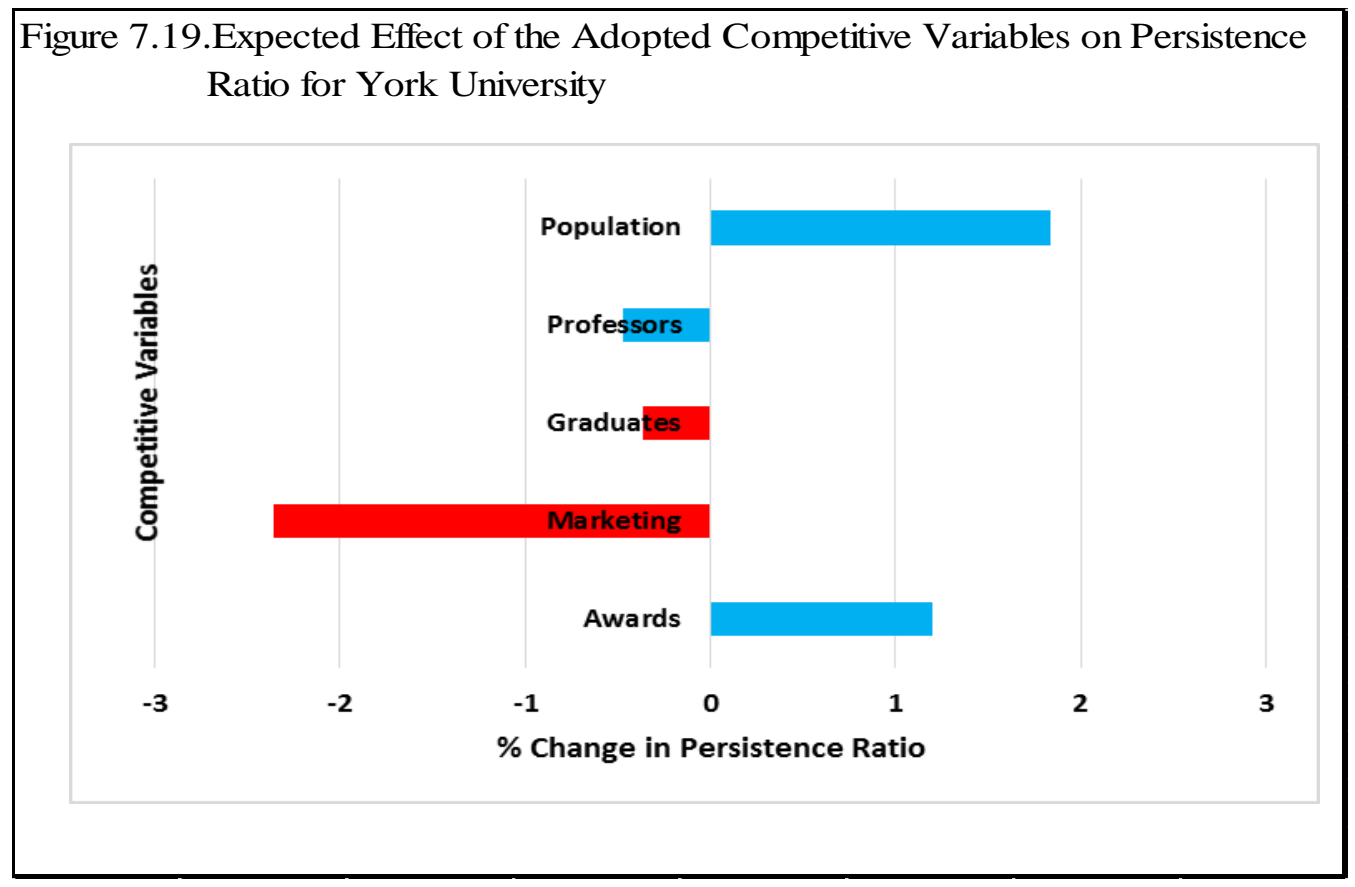

The result from Fixed Effects (a modified Fixed Effect regression) explains how persistence ratio responds to a one percent change in awards, marketing, graduates, professors, and population for York University. The regression result shows a strong relationship between persistence ratio and the adopted competitive variables $(\mathrm{R}$-Squared=0.92). $\mathrm{R}$-Squared indicates that approximately $92 \%$ of the change in persistence ratio can be explained by the change in university expenditure on marketing and graduates. The result suggests that the responsiveness of persistence ratio with respect to marketing and graduates is about -2.36 and $-0.36 \%$, respectively. These additional effect coefficients are statistically significant at $10 \%(\rho<.10)$. Overall effects also estimate negative and positive significant signs and these are explained in Appendix G, Table 9.2.1.

The negative and significant sign suggests that marketing and graduates have a smaller effect on persistence ratio. A smaller effect suggests that a one percent increase in expenditure on marketing and graduates is expected to produce a smaller effect on persistence ratio by about 
2.36 and $0.36 \%$, respectively, for York University relative to all other Ontario universities. A significant effect was not found for the variables of awards, professors, and population. However, the existence of significant responsiveness leads one to infer that the changes in university expenditure on marketing and graduates are likely to affect the persistence ratio for York University. 